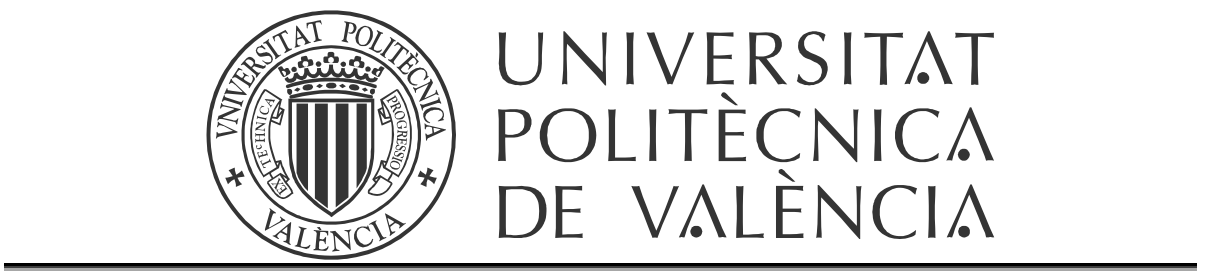

Instituto de Tecnologia de Materiales

Departamento de Ingeniería Mecánica y de Materiales

\title{
DESARROLLO DE PIEZAS POROSAS DE Ti6Al4V MEDIANTE TÉCNICAS PULVIMETALÚRGICAS
}

\section{Tesis Doctoral}

Presentada por:

Lucía Reig Cerdá

Directores:

Dr. D. Vicente Amigó Borrás

Dr. D. David Busquets Mataix

Valencia, Diciembre de 2009 



\section{AGRADECIMIENTOS}

Desearía expresar mi agradecimiento al Dr. Vicente Amigó Borrás, director de ésta Tesis Doctoral, quien me transmitió su entusiasmo por los materiales y la investigación.

Al Dr. David Busquets, codirector de la tesis y quien siempre me mostró su apoyo y colaboración de forma clara y eficiente.

A la empresa "Aleaciones de Metales Sinterizados S.A.", AMES, por permitirme realizar parte de la investigación en su centro Alme, ubicado en Sant Vicenç dels Horts.

Al "Centro de Estudios e Investigaciones Científicas de Guipúzcoa", CEIT, en San Sebastián, y muy especialmente a Paco Castro, Shandra, Guillen Iñigo, Corey y Will, quienes tan bien me acogieron durante mi corta estancia.

A mi inestimable compañero, José Luís Ortiz quien me ofreció su conocimiento y ayuda durante su estancia en la universidad, y cuya amistad y cooperación espero se mantenga a pesar de la distancia.

Como no, al servicio de microscopia de la universidad, donde Manolo, José Luis, Merche y Ali siempre estuvieron dispuestos a echar una mano en la investigación.

A todos mis compañeros, tanto a los del Departamento de Ingeniería Mecánica y de Materiales, con los que compartí tan buenos momentos, como a los de la Universidad Jaume I de Castellón, quienes siempre me apoyaron para que la presente tesis fuese una realidad.

A mi familia, por el cariño y la comprensión que me han ofrecido a lo largo de los años. A mis amigos, por los momentos y la confianza que compartimos. Y... muy especialmente, a ti Marc, por tu paciencia y apoyo constante y sincero. 



\section{RESUMEN}

Por su elevada biocompatibilidad, resistencia a la corrosión y resistencia específica, entre otras, el titanio es ampliamente utilizado en el campo de la biomedicina. No obstante, su rigidez resulta elevada en comparación con la del hueso cortical humano, lo que genera problemas por debilitamiento óseo. Por otra parte, pese a que se considera un material bioinerte, es necesario generar rugosidad superficial, con una porosidad y tamaño de poro adecuado para permitir el desarrollo óseo y reducir así el tiempo de recuperación del paciente. Además, la elevada reactividad del titanio dificulta su procesado, pues la reacción con elementos intersticiales deteriora en gran medida sus propiedades.

En la presente investigación se han desarrollado piezas porosas de la aleación Ti6Al4V, con una rigidez similar a la del hueso cortical humano y resistencia suficiente para permitir su uso como implante. Para ello se han empleado dos técnicas pulvimetalúrgicas distintas, como son la sinterización de microesferas y el método de espaciadores.

El estudio previo de reactividad realizado reveló una interacción máxima sobre gres y alúmina, y una reacción mínima sobre itria, lo que condujo a la obtención de las mejores propiedades mecánicas y menor fragilización.

Las piezas porosas de Ti6Al4V desarrolladas por sinterización de microesferas presentan una porosidad abierta e interconectada, con un tamaño de poro proporcional al tamaño de las microesferas. Presentan una rigidez inferior al $40 \%$ de la del material sólido, con unas propiedades mecánicas que aumentan con la temperatura y tiempo y evolucionan de forma inversa con el tamaño de la microesfera, siendo éste el parámetro de mayor influencia.

Por el contrario, las piezas obtenidas por el método de espaciadores presentan una porosidad cerrada y aislada. La rigidez de éstas oscila entre un 20 y $65 \%$ en relación a la del material sólido y, al igual que el resto de propiedades mecánicas, depende principalmente del contenido en 
bicarbonato. No obstante, resulta de gran importancia eliminar el espaciador inmediatamente tras la compactación, con el fin de minimizar el riesgo de reactividad por un contacto prolongado con éste.

Por otra parte, el estudio de la resistencia a la corrosión de las piezas obtenidas por la técnica de espaciadores ha puesto de manifiesto como la porosidad dificulta determinar con exactitud de la velocidad de corrosión. A pesar de ello, no se observan diferencias significativas entre las piezas desarrolladas y una de forja.

De igual modo, resulta complejo mejorar, mediante la aplicación de tratamientos térmicos, la resistencia a fatiga y las propiedades mecánicas de las piezas porosas. Aunque a nivel de laboratorio si se ha logrado un afino de la microestructura sin que se origine reactividad, en los hornos convencionales no es posible lograr un afino de la microestructura sin fragilización. 


\section{RESUM}

Per la seua elevada biocompatibilitat, resistència a la corrosió i resistència específica, entre d'altres, el titani és àmpliament utilitzat en el camp de la biomedicina. No obstant això, la seva rigidesa resulta elevada comparada amb la de l'os cortical humà, la qual cosa genera problemes per debilitament ossi. D'altra banda, malgrat que es considera un material bioinert, és necessari desenvolupar rugositat superficial, amb una porositat i mida de porus adequada per a permetre el desenvolupament ossi i reduir així el temps de recuperació del pacient. A més, l'elevada reactivitat del titani en dificulta el processament, ja que la reacció amb elements intersticials deteriora en gran manera les propietats que té.

En aquesta investigació s'han desenvolupat peces poroses de l'aliatge Ti6Al4V, amb una rigidesa similar a la de l'os cortical humà i resistència suficient per a permetre'n l'ús com a implant. Per a fer-ho s'han emprat dues tècniques pulvimetal-|úrgiques distintes, com són la sinterització de microesferes i el mètode d'espaiadors.

L'estudi previ de reactivitat mostra una interacció màxima sobre gres i alúmina, i una reacció mínima sobre ítria, cosa que va conduir a l'obtenció de les millors propietats mecàniques i menor fragilització.

Les peces poroses de Ti6Al4V desenvolupades per sinterització de microesferes presenten una porositat oberta i interconnectada, amb una grandària de porus proporcional a la grandària de les microesferes. Presenten una rigidesa inferior al $40 \%$ de la del material sòlid, amb unes propietats mecàniques que augmenten amb la temperatura $i$ el temps $i$ evolucionen de forma inversa amb la grandària de la microesfera, que és el paràmetre de major influència.

Per contra, les peces obtingudes pel mètode d'espaiadors presenten una porositat tancada i aïllada. La rigidesa d'aquestes oscil•la entre un 20 i 65\% en relació a la del material sòlid $\mathrm{i}$, igual que la resta de propietats mecàniques, depèn principalment del contingut en bicarbonat. No obstant 
això, resulta de gran importància eliminar l'espaiador immediatament després de la compactació, amb la finalitat de minimitzar el risc de reactivitat per un contacte perllongat amb aquest.

D'altra banda, l'estudi de la resistència a la corrosió de les peces obtingudes mitjançant la tècnica d'espaiadors ha posat de manifest com la porositat dificulta determinar amb exactitud la velocitat de corrosió. Tanmateix, no s'observen diferències significatives entre les peces desenvolupades i una de forja.

De la mateixa manera, resulta complex millorar, mitjançant l'aplicació de tractaments tèrmics, la resistència a fatiga i les propietats mecàniques de les peces poroses. Encara que al laboratori sí que s'ha assolit un afinament de la microestructura sense que s'origini reactivitat, en els forns convencionals no és possible assolir l'anomenat afinament sense fragilització. 


\section{ABSTRACT}

Titanium is widely used in biomedicine given its properties that include high biocompatibility, corrosion resistance and specific strength. However, its stiffness is too high in comparison to the human cortical bone where it causes difficulties with bone weakening. Although titanium is considered to be a bioinert material, it must have a superficial roughness with porosity and pore size so as to allow osseous development in order to reduce patient recovery time. In addition, its high reactivity makes manufacturing difficult since reaction with interstitial elements has a very negative effect on its properties.

In this study, porous specimens of the alloy Ti6Al4V were developed with a similar stiffness to that of the human cortical bone, and with enough strength to allow their use as an implant. To develop these pieces, two different powder metallurgy technologies have been used: the sintering of titanium beads and the space holder method.

A prior study of reactivity revealed a maximum interaction when sintering on stoneware ceramic and aluminium oxide, and a minimum reaction on yttria, which resulted in the best mechanical properties and less fragility.

Porous specimens developed by the sintering of Ti6Al4V beads have an open and interconnected porosity with a pore size proportional to the size of the microsphere beads. Their stiffness is less than $40 \%$ of the solid material, while their mechanical properties increase with temperature and time and change inversely with the size of the microspheres, which was the most influential parameter.

By contrast, specimens obtained by the space holder method present closed and isolated porosity. Its stiffness ranges from 20 to $65 \%$ of that of the solid material and, as other mechanical properties, it depends mainly on the content of spacer particles. However, removing the spacer particles immediately after compaction is of great importance to minimize the risk of reactivity caused by the prolonged contact with it. 
A study of corrosion resistance was performed on the specimens developed by the space holder method. This study revealed that it was difficult to accurately determine the rate of corrosion. However, no significant differences were observed between the developed pieces and a forged piece.

Similarly, improving the fatigue resistance and mechanical properties of porous pieces by heat treatment is very complex. While a refinement of the microstructure without incurring reactivity was observed in treatments applied in the laboratory, the structure could not be refined in conventional ovens without increasing fragility. 


\section{ÍNDICE}

SIMBOLOS Y ABREVIATURAS

1. INTRODUCCIÓN.

1.1. Antecedentes.................................................... 3

1.2. Justificación............................................................ 5

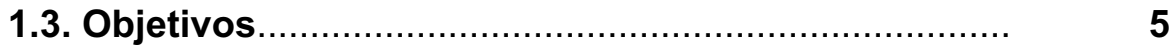

1.3.1. Objetivo General..................................................

1.3.2. Objetivos Particulares............................................... 6

1.4. Aportaciones De La Tesis....................................... 7

1.5. Limitaciones.......................................................... 8

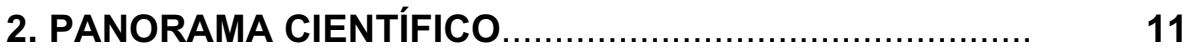

2.1. El Titanio y sus Aleaciones....................... 13

2.1.1. Titanio CP....................................... 16

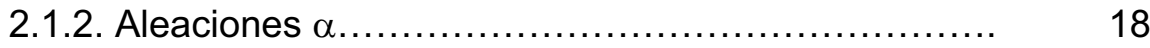

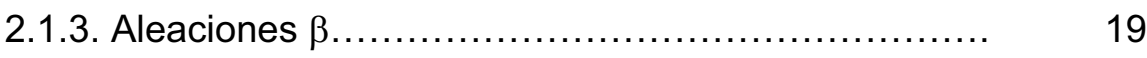

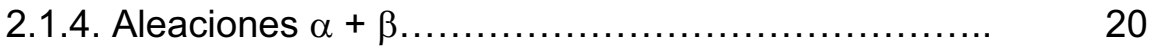

2.2. Métodos de obtención de polvo de titanio............. 22

2.2.1. Proceso De Electrodo Rotatorio De Plasma............ 23

2.2.2. Proceso De Hidruración - Deshidruración............. 25

2.3. Características exigibles a los implantes............. $\quad 26$

2.4. Materiales comúnmente utilizados como implantes. 31

2.5. Porosidad y tamaño de poro a desarrollar............ $\quad 40$

2.6. Propiedades mecánicas a obtener................... 43

2.7. Particularidades de los metales porosos............. 44 
2.8. Tratamientos térmicos aplicables sobre aleaciones de titanio

2.9. Métodos de modificación de la rigidez empleados en titanio

2.10. Tratamientos superficiales aplicables al titanio.....

3. PLANIFICACIÓN DE LA INVESTIGACIÓN

3.1. Estudios Previos.

3.2. Sinterización de Microesferas.

3.3. Método de Espaciadores

4.1. Material de partida ................................ 93

4.1.1. Descripción del material de partida................... 93

4.1.2. Caracterización del material de partida................ 95

4.1.2.1. Composición química y análisis granulométrico...

4.1.2.2. Fluidez, densidad aparente $\left(\rho_{a}\right)$ y densidad vibrada $\left(\rho_{\text {tap }}\right)$.

4.1.2.3. Preparación metalográfica.

4.1.2.4. Microscopia óptica (MO) y electrónica de barrido (MEB).

4.1.2.5. Microdureza

4.2. Obtención de piezas porosas por sinterización de microesferas y estudio de reactividad.

4.2.1. Desarrollo de piezas porosas por sinterización de microesferas.

4.3. Obtención de piezas porosas por el método de espaciadores.

4.3.1. Desarrollo de la investigación realizada.

4.3.2. Proceso de obtención de piezas porosas por el método de espaciadores 
4.4. Caracterización de la pieza porosa.

4.4.1. Caracterización microestructural..................... 126

4.4.1.1. Microscopia óptica (MO) y estereomicroscopia.... 126

4.4.1.2. Microscopia electrónica de barrido (MEB).......... 127

4.4.1.3. Microdureza....................................... 127

4.4.2. Densidad, porosidad y tamaño de poro................ 128

4.4.2.1. Densidad, y porosidad del sinterizado.............. 128

4.4.2.2. Tamaño de poro y tamaño de poro teórico......... 132

4.4.3. Dimensiones de los cuellos de unión.................. 132

4.4.4. Caracterización mecánica............................. 134

4.4.4.1. Resistencia a flexión.............................. 135

4.4.4.2. Resistencia a compresión......................... 137

4.4.4.3. Rigidez........................................ 139

4.4.5. Análisis de elementos............................... 141

4.4.5.1. Análisis de carbono............................... 141

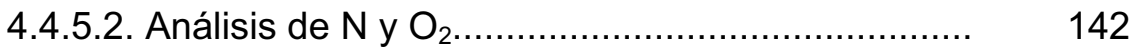

4.4.6. Tratamientos térmicos............................ 143

4.4.6.1. Tratamientos térmicos realizados en dilatómetro.. $\quad 144$

4.4.6.2. Tratamientos térmicos realizados en horno......... 145

4.4.7. Corrosión............................................... 147

5. RESULTADOS Y DISCUSIÓN ............................. 153

5.1. Introducción....................................... 155

5.2. Estudios Previos ................................. 155

5.2.1. Análisis de la reactividad con el molde................ 156

5.2.1.1 Reactividad con los moldes de gres................ $\quad 157$

5.2.1.2 Reactividad con los moldes de $\mathrm{Al}_{2} \mathrm{O}_{3} \ldots \ldots \ldots \ldots \ldots \ldots . . . . . . .182$

5.2.1.3 Reactividad con los moldes de circona............. 171

5.2.1.4 Reactividad con los moldes de $\mathrm{Y}_{2} \mathrm{O}_{3} \ldots \ldots \ldots \ldots \ldots \ldots . . . . . . . . .175$ 
5.2.1.5. Microdureza...................................

5.2.1.6 Discusión y conclusiones parciales de la reactividad del titanio con los distintos moldes

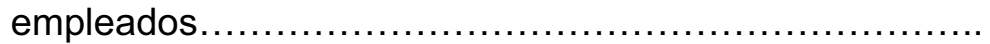

5.2.2. Pruebas previas realizadas por la tecnica de espaciadores.................................................

5.2.2.1 Porosidad y observaciones al proceso de obtención.

5.2.2.2 Resistencia a flexión y rigidez de las piezas porosas obtenidas.

5.3. Piezas porosas obtenidas por sinterización de microesferas.

5.3.1. Caracterización microestructural.

5.3.1.1. Microscopia óptica (MO), estereomicroscopía y microscopia electrónica de barrido (MEB).

5.3.2. Densidad, porosidad y tamaño de poro.

5.3.2.1. Tamaño de poro teórico.

5.3.2.2. Conclusiones parciales de la porosidad, densidad y tamaño de poro de la pieza porosa...

5.3.3. Dimensiones de los cuellos de unión

5.3.4. Caracterización mecánica. 209

5.3.4.1. Resistencia a flexión 209

5.3.4.2. Rigidez a flexión.

5.3.4.3 Discusión y conclusiones parciales de las propiedades mecánicas obtenidas por sinterización de microesferas.

5.3.5. Análisis de elementos

5.3.5.1. Análisis de carbono

5.3.5.2. Análisis de $\mathrm{N}_{\text {y }} \mathrm{O}_{2}$ 
5.3.6. Tratamientos Térmicos............................. $\quad 232$

5.3.6.1. Tratamientos térmicos realizados en dilatómetro.. $\quad 232$

5.3.6.1.1. Transformaciones dilatométricas en los ciclos

B y BT.

5.3.6.1.2. Transformaciones dilatométricas en los ciclos $\mathrm{S}$ y ST.

5.3.6.2. Tratamientos térmicos realizados en horno..........

5.3.6.2.1. Microestructura de las muestras tratadas térmicamente en horno...................................

5.3.6.2.2. Propiedades mecánicas de las muestras tratadas térmicamente en horno.

5.3.6.3. Conclusiones parciales de la aplicación de tratamientos térmicos.

\subsection{Piezas Porosas Obtenidas Por El Método De} Espaciadores

5.4.1. Observaciones al proceso de obtención.

5.4.2. Caracterización microestructural....................... 255

5.4.3. Densidad, porosidad y tamaño de poro................ 260

5.4.3.1. Densidad, porosidad y tamaño de poro............. 260

5.4.3.2. Conclusiones parciales de densidad, porosidad y tamaño de poro de las piezas porosas de ti64 realizadas por el método de espaciadores.

5.4.4. Caracterización mecánica.............................. 265

5.4.4.1. Influencia del tiempo de espera entre la compactación y la eliminación del espaciador...............

5.4.4.2. Resistencia a flexión de la las piezas porosas base de la investigación.

5.4.4.3. Resistencia a compresión.

5.4.4.4. Rigidez de las piezas porosas base de la presente investigación. 
5.4.4.5. Modelos matemáticos de correlación entre la densidad relativa y las propiedades mecánicas de las piezas porosas de ti64 obtenidas mediante el método de espaciadores

5.4.4.6. Conclusiones parciales de la caracterización mecánica de las piezas porosas de ti6al4v desarrolladas por el método de espaciadores

5.4.5. Análisis de elementos................................ 295

5.4.5.1. Análisis de carbono .............................. 296

5.4.5.2. Análisis de $\mathrm{Ny} \mathrm{O}_{2} \ldots \ldots \ldots \ldots \ldots \ldots \ldots \ldots \ldots \ldots \ldots . \ldots \ldots$

5.4.6. Corrosión.............................................. $\quad 299$

5.4.6.1. Resultados de corrosión y discusión............... 300

5.4.6.2. Conclusiones parciales de la corrosión en piezas obtenidas por el método de espaciadores.

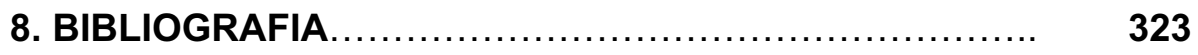

8.1. Bibliografía ..................................... $\quad 325$

8.2. Webs Consultadas........................................... $\quad 339$

\section{ANEXOS}

ANEXO 1. Microestructura de las piezas porosas desarrolladas por sinterización de microesferas y tras los tratamientos térmicos realizados.

ANEXO 2. Publicaciones derivadas de la presente tesis...... 


\section{SIMBOLOS Y ABREVIATURAS}

T Temperatura

$\mathrm{t} \quad$ tiempo

$\emptyset_{\mathrm{ME}} \quad$ Diámetro de microesfera promedio

P Presión de compactación

$\Delta \mathrm{G}_{\mathrm{f}}^{\circ} \quad$ Variación de la Energía Libre De Gibbs de formación

$\Delta \mathrm{H} \quad$ Variación de Entalpía

$\Delta S \quad$ Variación de Entropía

$\mathrm{HC} \quad$ Estructura Hexagonal Compacta

CCC Estructura cúbica centrada en caras

CC Estructura cúbica centrada en el cuerpo

TiCP Titanio comercialmente puro

Ti64 Aleación Ti6Al4V

$\mathrm{HDH} \quad$ Hidruración-Deshidruración

GA Atomización Gaseosa

PREP Proceso de Electrodo Rotatorio de Plasma

HA Hidroxiapatita

BUS "Broken-Up Structure"

TCP "Thermochemical processing"

DLF "Direct Laser Forming"

SPS "Spark Plasma Sintering"

PMMA Polimetilmetacrilato

MO Microscopia óptica

EDX Energías Dispersivas de Rayos $\mathrm{X}$

MEB Microscopía Electrónica de Barrido

GF Granulometría Fina

GM Granulometría Media 
GG Granulometría Gruesa

50M50G Mezcla al 50\% en volumen de las granulometrías media y gruesa

$\rho_{\mathrm{A}} \quad$ Densidad aparente del polvo

$\rho_{\text {TAP }} \quad$ Densidad vibrada del polvo

$\rho_{S} \quad$ Densidad teórica

$\rho_{\mathrm{r}} \quad$ Densidad relativa

$\rho^{*} \quad$ Densidad aparente del sinterizado,

$\rho_{\text {liq }} \quad$ Densidad del líquido

$\mathrm{V}_{\mathrm{A}} \quad$ Volumen aparente de la muestra

$V_{S} \quad$ Volumen real de la muestra

$\mathrm{P}_{\text {saturada }} \quad$ Peso de la muestra saturada

$\mathrm{P}_{\mathrm{BH}} \quad$ Peso en balanza hidrostática

$\rho_{\text {agua }} \quad$ Densidad del agua a la temperatura de inmersión

$\mathrm{M}_{\mathrm{A}} \quad$ Masa de la muestra en el aire sin parafina

$M_{B} \quad$ Masa de la muestra en el aire con parafina

$\mathrm{M}_{\mathrm{C}} \quad$ Masa de la muestra con parafina en el agua, tarada

$\% \mathrm{P}_{\mathrm{A}} \quad$ Porosidad interconectada de la muestra

$\nabla r / r_{0} \quad$ Contracción radial

$\nabla \mathrm{l} / \mathrm{I}_{0} \quad$ Contracción lineal

$\nabla \mathrm{V} / \mathrm{N}_{\mathrm{o}} \quad$ Contracción volumétrica

$\rho_{\text {parafina }} \quad$ Densidad de la parafina

$S_{\text {unión }} \quad$ Superficie de unión entre esferas contiguas

$S_{\text {esfera }} \quad$ Superficie de una esfera

$\varnothing_{\text {cuello }} \quad$ Diámetro del cuello de unión desarrollado.

$\varnothing_{\mathrm{ME}} \quad$ Diámetro de la microesfera de partida

$\sigma_{y} \quad$ Límite elástico

$\sigma_{\mathrm{yF}}{ }^{*} \quad$ Límite elástico a flexión del sinterizado 


$\begin{array}{ll}\sigma_{\mathrm{yFs}} & \text { Límite elástico a flexión del material sólido } \\ \sigma_{\mathrm{yc}}{ }^{*} & \text { Límite elástico a compresión del sinterizado } \\ \sigma_{\mathrm{yCs}} & \text { Límite elástico a compresión del material sólido } \\ \mathrm{F} & \text { Fuerza } \\ \mathrm{I} & \text { Distancia entre apoyos } \\ \mathrm{b} & \text { Ancho de la probeta } \\ \mathrm{h} & \text { Espesor de la probeta } \\ \mathrm{E} & \text { Módulo de Young, Rigidez } \\ \mathrm{I} & \text { Momento de inercia } \\ \mathrm{y} & \text { Flecha máxima } \\ \varepsilon & \text { Deformación } \\ \varepsilon_{0} & \text { Deformación unitaria } \\ \varepsilon_{\mathrm{y}} & \text { Deformación elástica } \\ \varepsilon_{\text {plástica }} & \text { Deformación plástica } \\ \Delta \mathrm{L} & \text { Variación de longitud } \\ \text { Lo } & \text { Longitud inicial }\end{array}$

$\mathrm{E}_{\mathrm{FP}} \quad$ Rigidez a flexión determinada mediante la pendiente de la curva

$\mathrm{E}_{\mathrm{FF}} \quad$ Rigidez a flexión determinada mediante aplicación de la fórmula

$\mathrm{E}_{\mathrm{C}} \quad$ Rigidez a compresión

ES Rigidez del sólido

E $\quad$ Rigidez del sólido obtenida mediante la pendiente de curva

E $\quad$ Rigidez del sólido obtenida mediante la fórmula de flexión

$E_{\text {r-PEND }} \quad$ Rigidez relativa obtenida mediante la pendiente de curva

$\mathrm{E}_{\mathrm{r}-\mathrm{FORM}} \quad$ Rigidez relativa obtenida mediante la fórmula de flexión

EIS Espectroscopia de Impedancia Electroquímica 


$\begin{array}{ll}\text { ENM } & \text { Ruido de Electroquímico } \\ \text { SCE } & \text { Electrodo de calomelanos } \\ R_{s o l} & \text { Resistencia del electrolito } \\ C_{d l} & \text { Capacitancia de la doble capa } \\ R_{c t} & \text { Resistencia a la transferencia de carga } \\ R_{n} & \text { Resistencia al ruido electroquímico } \\ I_{c o r r} & \text { Intensidad de corrosión } \\ E_{c o r r} & \text { Potencial de corrosión } \\ \text { EPN } & \text { Potencial de Ruido Electroquímico } \\ \text { ECN } & \text { Corriente de Ruido Electroquímico } \\ \text { TT } & \text { Tratamiento Térmico } \\ \text { IS 1 } & \text { Isoterma uno } \\ \text { IS } 2 & \text { Isoterma dos } \\ \text { IS 3 } & \text { Isoterma tres } \\ \text { EF1 } & \text { Enfriamiento uno }\end{array}$




\section{1 INTRODUCCIÓN}





\subsection{ANTECEDENTES.}

A pesar de que el titanio fue descubierto a finales del siglo XVIII, no fue hasta medidados del XX cuando empezó a utilizarse como biomaterial [Tarín 1999, Kostov 2006]. Su uso en este campo viene justificado por su excelente comportamiento en el cuerpo humano, pues es resistente a la corrosión, no tóxico, biológicamente compatible con huesos y tejidos y no induce la formación de tejido que impida el crecimiento del hueso alrededor del metal [Vallet 2000; Keating 2001]. Existen además otros aspectos que facilitan su interacción con el individuo, como son su ligereza, su excelente relación entre resistencia mecánica / densidad, reducidos calor específico y coeficiente de dilatación térmica, así como el cambio alotrópico que se produce entorno a los $882^{\circ} \mathrm{C}$, pues posibilita la obtención de diferentes tipos de microestructuras con una amplio abanico de propiedades [Baeslack 1993; ASM N4 1994; Asaoka 2003].

No obstante, su aspecto más significativo de cara tanto a la obtención de componentes, como a su características, es su gran reactividad. La rápida reacción de titanio con elementos como el oxígeno, nitrógeno, hidrógeno, hierro o carbono, así como el incremento exponencial de dicha reactividad a elevadas temperaturas provoca que se requieran técnicas de vacío para su procesado pues, de lo contrario, la difusión de elementos hacia su interior genera compuestos de gran fragilidad que deterioran las propiedades de la pieza [Garcia 2006; Baeslack 2003].

Por otra parte, pese a que de entre los materiales metálicos empleados como implante, las aleaciones base titanio presenten la mejor combinación de resistencia, ductilidad, módulo elástico y resistencia a la corrosión [Park 2001; Ratner 1996] su rigidez (110 GPa) [ASM N4 1994; Ryan 2006] todavía queda muy alejada en relación a la del hueso humano (10-30 GPa) [Ryan 2006; Asaoka 2003]. Ello impide que el hueso trabaje correctamente, por lo que no se regenera de forma adecuada, lo que conduce a su debilitamiento y aflojamiento (reabsorción ósea) [Freese 2001; Ysander 2001]. 
Cabe indicar además que, pese a que sus excelentes propiedades lo han conducido a ser empleado en muy diversas aplicaciones dentro de la biomedicina (sistemas de fijacion y osteosintesis, prótesis ortopédicas, implantes dentales, caracasas de marcapasos...) [biomet.es; lafitt-sa.com; Wehmöller 2004], es necesario desarrollar su aptitud para favorecer el crecimiento del hueso. En definitiva, para mejorar el comportamiento en servicio de los implantes permanentes, resulta fundamental generar una respuesta apropiada de los tejidos, lo que implica tanto no producir partículas tóxicas, como fomentar un apropiado crecimiento del hueso (osteointegración) [Ratner 1996; Vallet 2000]. En este sentido, pese a que el titanio se considera un material bioinerte (no genera partículas toxicas), es necesario incrementar su rugosidad superficial, así como tratar de generar un tamaño de poro tal que permita el desarrollo del hueso y, con ello, la rápida recuperación del paciente.

Con el fin de paliar estos inconvenientes, en los últimos años se han desarrollado un gran número de técnicas, tratando tanto de fomentar la osteointegración y reducir la rigidez del implante, como de mejorar la resistencia al desgaste [Rodriguez 1999]. Entre los primeros cabe destacar métodos como la sinterización de microesferas, la fabricación mediante espaciadores, sinterización por láser, etc. [Ryan 2006; Li 2002; Dewidar 2005; Oh I.H 2006; Rak 2006; Kotan 2007; Kohl 2007], mientras que otros como la implantación iónica, proyección por plasma, sinterización de bolas,... buscan mejorar la resistencia al desgaste e integración ósea mediante la modificación superficial [Rodriguez 1999].

Por tanto, a pesar de que las excelentes caracteristicas del titanio y sus aleaciones lo hacen idóneo para su uso en el cuerpo humano, determinadas propiedades como su elevada reactividad, rigidez en comparación con la del hueso y la reducida capacidad de osteointegración que presentan las piezas densas de este material, dificultan tanto su obtención como un adecuado comportamiento en servicio. Por ello, resulta necesario tanto desarrollar piezas de titanio menos rigidas y con características que permitan la osteointegración, 
como minimizar la reactividad durante su obtención, pues degradaría las características de la pieza obtenida.

\subsection{JUSTIFICACIÓN.}

Como se ha indicado, entre los materiales metálicos existentes capaces de desempeñar una función como biomaterial, las aleaciones base titanio presentan la mejor combinación de propiedades: resistencia específica, ductilidad, resistencia a la corrosión, módulo elástico y biocompatibilidad.

No obstante, su elevada reactividad dificulta la obtención de piezas de titanio, al tiempo que produce una merma significativa de sus propiedades mecánicas. Por otra parte, su rigidez resulta muy elevada en comparación con la del hueso humano, lo que conlleva problemas de debilitamiento del hueso y aflojamiento del implante por reabsorción ósea. Cabe indicar además que, pese a que el titanio se considera un material bioinerte, las piezas densas desarrolladas no facilitan la integración ósea, lo que incrementa el periodo de recuperación del paciente.

Por todo ello, resulta necesario desarrollar nuevos componentes de titanio porosos, menos rigidos, con propiedades mecánicas adecuadas, así como con una porosidad y tamaño de poro tales que permitan el crecimiento del hueso hacia su interior (osteointegración). En definitiva, desarrollar piezas porosas de titanio en ausencia de reactividad, y con unas características que faciliten la integración ósea, generando una respuesta apropiada de los tejidos al tiempo que minimizan los problemas de reabsorción.

\subsection{OBJETIVOS.}

\subsubsection{OBJETIVO GENERAL.}

El objetivo fundamental de la presente tesis es reducir la rigidez y mejorar la aptitud a la osteointegración del titanio mediante el desarrollo de piezas porosas de este material. 


\subsubsection{OBJETIVOS PARTICULARES.}

Con el fin de desarrollar las piezas de titanio descritas, se deberá alcanzar los siguientes objetivos específicos:

- Desarrollar piezas porosas de titanio mediante sinterización de microesferas, controlando los parámetros de proceso: Temperatura, tiempo y tamaño de microesfera.

- Desarrollar piezas porosas de titanio mediante el método de espaciadores, controlando los parámetros de proceso: tamaño y adición de espaciador, presión de compactación y temperatura y tiempo de sinterización.

- Analizar la reactividad del titanio con el molde utilizado para la sinterización y establecer el material idóneo a utilizar.

- Controlar la rigidez y aptitud para el desarrollo óseo de las piezas obtenidas por sinterización de microesferas mediante su relación con la porosidad y tamaño de poros.

- Establecer, para las piezas obtenidas por sinterización de microesferas, la relación entre las propiedades mecánicas y su porosidad y tamaño de poros.

- Controlar la rigidez de las piezas obtenidas por el método de espaciadores mediante su relación con la porosidad, morfología, tamaño y distribución de poros de las piezas desarrolladas.

- Relacionar, para las piezas desarrolladas por el método de espaciadores, sus propiedades mecánicas con la porosidad, morfología, tamaño y distribución de poros.

- Determinar, para ambos procesos, la combinación óptima de variables que proporciona la menor rigidez, mejores propiedades mecánicas y posibilidades de osteointegración.

- Analizar el efecto de tratamientos térmicos sobre la microestructura y propiedades mecánicas de las piezas porosas obtenidas. 


\subsection{APORTACIONES DE LA TESIS.}

La realización de la presente tesis supone las siguientes aportaciones:

- La puesta a punto de los procedimientos para desarrollar piezas porosas de titanio, tanto mediante sinterización de microesferas, como por el método de espaciadores.

- La determinación del material idóneo a utilizar como molde para evitar la reactividad de I titanio y la consecuente merma de propiedades mecánicas.

- El control sobre la rigidez y aptitud para la osteointegración de las piezas porosas de titanio desarrolladas por sinterización de microesferas en función de los parámetros de proceso (temperatura, tiempo y tamaño de microesferas) y de su relación con la densidad y tamaño de poro de las piezas desarrolladas.

- La combinación idónea de temperatura, tiempo y tamaño de microesfera que confiere la menor rigidez, mejores propiedades mecánicas y aptitud para la osteointegración a las piezas desarrolladas por sinterización de microesferas.

- El control de la rigidez de las piezas obtenidas por el método de espaciadores, en función de las variables de proceso (temperatura, tiempo presión de compactación, tamaño y porcentaje de espaciador) y de su relación con la porosidad, morfologia, tamaño y distribución de poros.

- La combinación idónea de tamaño y cantidad de espaciador, presión de compactación, temperatura y tiempo de sinterización; que confiere la menor rigidez y mejores propiedades mecánicas a las piezas desarrolladas por el método de espaciadores.

- La puesta a punto de una metodología para, mediante la aplicación de tratamientos térmicos, modificar la microestructura y mejorar determinadas propiedades de las piezas porosas desarrolladas. 


\subsection{LIMITACIONES.}

Como toda investigación, la presente tesis presenta ciertas llimitaciones, inherentes tanto a los procesos de obtención de las piezas porosas, como a los medios disponibles para llevarlas a cabo o la propia extensión. Al afrontar el siguiente estudio, nos encontramos con las siguinetes limitaciones:

De la obtención de piezas porosas de titanio mediante sinterización de microesferas:

- Lograr una elevada porosidad de las piezas porosas obtenidas, pues por su morfologia y ausencia de rugosidad superficial, las microesferas se ordenan en el molde de forma regular.

- Alcanzar un tamaño de poro grande con propiedades mecánicas elevadas, pues cuanto mayor sea el primero, menor será el número de puntos de contacto entre microesferas, lo que provocará que las propiedades mecánicas desarrolladas sean menores.

De la obtención de piezas porosas de titanio mediante el método de espaciadores:

- Encontrar una amplia gama de agentes espaciadores, pues la elevada reactividad del titanio provoca que pocos materiales puedan ser eliminados de forma eficiente sin contaminarlo durante la sinterización.

- Existe un limite máximo de porosidad a obtener, determinado por el colapso de las paredes de las celdas al exceder un contenido determinado de espaciador. Este contenido máximo probablemente se ve reducido por la baja presión de compactación que es necesario aplicar para no aplastar las partículas de espaciador, pues induce una menor cohesion a las partículas de titanio que conforman las paredes de las celdas.

- Es muy probable que los poros permanezcan aislados para reducidas cantidades de espaciador $y$, aunque se produzca cierta conexión para adiciones mayores, es posible que el tamaño de la apertura entre ellos resulte reducido. 


\section{En general:}

- Es necesario simplificar la forma de las piezas obtenidas, pues en la sinterización de microesferas estas son vertidas en el molde por gravedad y no existe cohesión, mientras que en la técnica de espaciadores se emplean reducidas presiones de compactación, lo que ocasionaría un relleno deficiente del molde y gran heterogeneidad.

- Ambos procesos deben realizarse en vacío, por lo que no es posible aplicar elevadas velocidades de enfriamiento. 



\section{2 PANORAMA CIENTÍFICO}





\subsection{EL TITANIO Y SUS ALEACIONES.}

Desde mediados del siglo $\mathrm{XX}$, cuando empezó a utilizarse por primera vez el titanio con fines biomédicos, hasta la actualidad, las aplicaciones dentro de este campo han ido en aumento [Leyens 2003, Kostov 2006]. El excelente comportamiento del material en el cuerpo humano está justificado fundamentalmente por su biocompatibilidad con huesos y tejidos, siendo una material que no induce a la formación de tejidos que impidan el crecimiento del hueso alrededor del metal [Keating 2001, Vallet 2000]. Por otra parte, aspectos como su resistencia a la corrosión, ligereza, relación resistencia mecánica / densidad o reducidos calor específico y coeficiente de dilatación térmica (tabla 2.1), favorecen la adaptación del titanio al cuerpo humano.

Tabla 2.1. Propiedades físicas del Titanio [Tarín 1999].

\begin{tabular}{|l|c|}
\hline Estructura cristalina & $\begin{array}{c}\alpha(\mathrm{HCP}) \text { a } \mathrm{T}<882^{\circ} \mathrm{C} \\
\beta(\mathrm{BCC}) \text { a T>882 }\end{array}$ \\
\hline Densidad & $\begin{array}{c}\text { fase } \alpha\left(20^{\circ} \mathrm{C}\right): 4,51 \mathrm{~g} \mathrm{~cm}^{-3} \\
\text { fase } \beta\left(885^{\circ} \mathrm{C}\right): 4,35 \mathrm{~g} \mathrm{~cm}^{-3}\end{array}$ \\
\hline Capacidad calorífica & $523 \mathrm{~J} / \mathrm{Kg}^{\circ} \mathrm{C}$ \\
\hline Conductividad térmica & $17 \mathrm{~W} / \mathrm{m}^{\circ} \mathrm{C}$ \\
\hline Coefic. Expansión térmica $\left(20^{\circ} \mathrm{C}\right)$ & $8,41 \times 10^{-6} /{ }^{\circ} \mathrm{C}$ \\
\hline Conductividad eléctrica (relativa al $\mathrm{Cu})$ & 0,031 \\
\hline
\end{tabular}

Las propiedades mecánicas del titanio dependen fundamentalmente de su pureza. Así, el titanio comercialmente puro posee reducida resistencia, aunque ésta puede incrementarse con la adición de aleantes, a costa de reducir su plasticidad. A esta aptitud debe sumarse la posibilidad de realizar tratamientos térmicos con transformación total o parcial y su endurecimiento por acritud [Baeslack 1993, ASM N4 1994].

No obstante, el titanio es un metal caro, pues reacciona muy rápidamente con el oxígeno, nitrógeno, hidrógeno, hierro y carbono, lo que dificulta su extracción y procesado. Dado que a elevadas temperaturas dicha reactividad aumenta exponencialmente, se requieren técnicas de vacío para su procesado, pues contenidos muy reducidos de elementos de aleación, 
especialmente los intersticiales, modifican en gran medida sus propiedades [Baeslack 1993, Tarín 1999]. Además de la reactividad con los elementos presentes en la atmósfera del horno, cabría destacar la interacción con los diferentes materiales empleados como molde (gres, alúmina, itria y circona en la presente investigación), determinada fundamentalmente por la variación de la energía libre de Gibbs $\left(\Delta \mathrm{G}_{\mathrm{f}}^{\circ}=\Delta \mathrm{H}-\mathrm{T} \Delta \mathrm{S}\right)$ de los respectivos óxidos. Cuanto más negativo este valor, mayor la estabilidad del óxido formado.

En relación a sus características, cabe señalar que el titanio es el único metal ligero que presenta dimorfismo, ya que en estado puro su estructura hexagonal compacta $(\mathrm{HC}$, fase $\alpha)$ presenta una transformación alotrópica a $882^{\circ} \mathrm{C}$, pasando a una microestructura cúbica centrada en el cuerpo (CC, fase $\beta$ ) [Tarín 1999]. Así, las aleaciones de titanio se pueden clasificar en 4 grupos fundamentales en función de la microestructura que presentan a temperatura ambiente: TiCP, aleaciones tipo $\alpha$, aleaciones tipo $\beta$ y aleaciones $\alpha+\beta$ [ASM N2 1990].

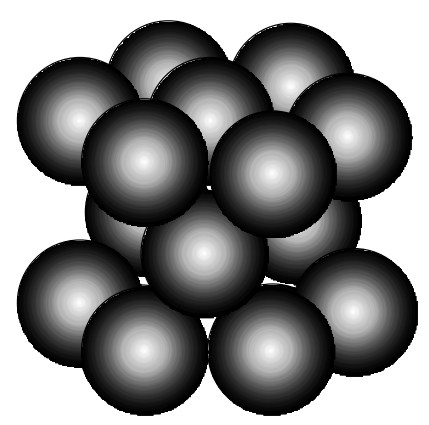

a

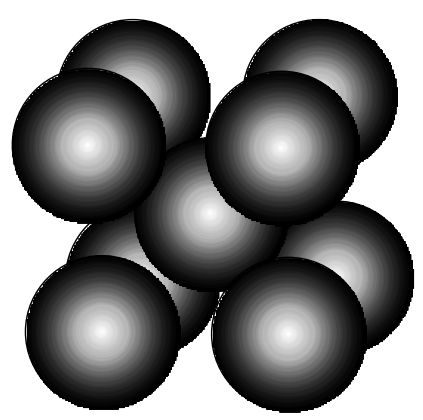

b

Fig. 2.1. Estructuras del titanio: a) $\alpha-H C$; b) $\beta$ - CC.

En equilibrio, la estructura beta es inestable a temperaturas inferiores a $882^{\circ} \mathrm{C}$, descomponiéndose de nuevo en fase a al enfriar por debajo de la temperatura de transición. Si los elementos aleantes presentan una red cristalina hexagonal (isomorfa del titanio $\alpha$ ), ensancharán la región $\alpha$, incrementando la temperatura a la cual la fase $\alpha$ es estable, figura 2.2. Entre 
ellos se encuentran el oxígeno, carbono, aluminio y nitrógeno [Reig 2005, Amigó 2003a].

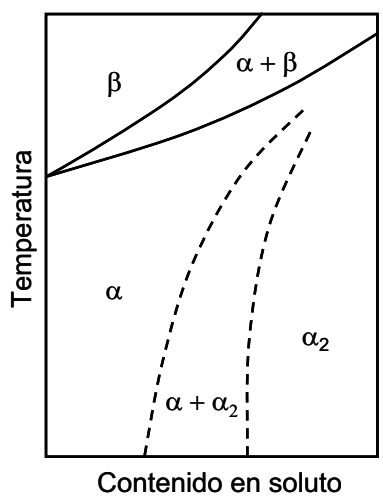

Fig. 2.2. Diagrama de equilibrio del titanio con un elemento $\alpha$-estabilizante.

$\mathrm{Si}$, por el contrario los elementos estabilizan la fase $\beta$ permiten que sea estable a temperaturas menores de la temperatura de $\beta$-transus, figura 2.3. Destacan como aleantes $\beta$ el vanadio, cromo, hierro, molibdeno y tántalo [Leyens 2003, Tarín 1999].

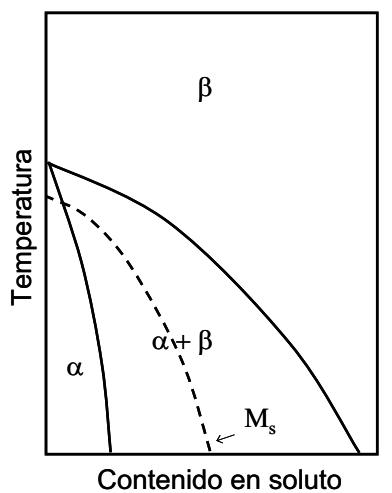

Fig. 2.3. Diagrama de equilibrio del titanio con un elemento $\beta$-estabilizante.

Otro grupo de aleantes que estabilizan la fase $\beta$ son los que forman sistemas eutectoides con el titanio, reduciendo la temperatura a la que se produce la transformación eutectoide y produciendo, por tanto, estructura bifásica a temperatura ambiente, figura 2.4. Entre estos aleantes destacan el hierro, el manganeso, el cromo, el cobalto, el níquel, el cobre y el silicio [ASM N4 1994, Tarín 1999]. 


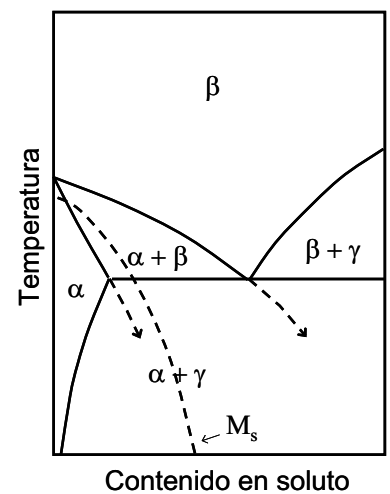

Fig. 2.4. Diagrama de equilibrio del titanio con un elemento $\beta$-eutectoide.

En definitiva el titanio y sus aleaciones se pueden clasificar en cuatro grupos, en función del tipo de fase que presenta la estructura de la aleación a temperatura ambiente [Amigó 2003a].

\subsubsection{TITANIO CP.}

El titanio comercialmente puro se clasifica dentro del grupo de las aleaciones $\alpha$. Tal como se ha indicado, es el grupo con menor dureza y resistencia mecánica, pero máxima ductilidad, soldabilidad y resistencia a la corrosión por lo que, en el campo de la biomedicina se emplean en aplicaciones tan diversas como implantes dentales, alambres y placas para fracturas óseas [Rack 2006, Beljavin 2004, Leyens 2003]

La normativa de la American Society for Testing and Materials (ASTM) clasifica el titanio $C P$ en cuatro grados, definidos por la concentración presente de otros elementos, tabla 2.2.

Tabla 2.2. Clasificación del Titanio según la norma ASTM F67 [ASTM F67].

\begin{tabular}{|l|c|c|c|c|c|c|}
\hline & \multicolumn{7}{|c|}{ COMPOSICIÓN (wt \%) } \\
\cline { 2 - 7 } & $\mathbf{N}$ & $\mathbf{C}$ & $\mathbf{O}$ & $\boldsymbol{F e}$ & $\boldsymbol{H}$ & $\boldsymbol{T i}$ \\
\hline GRADO 1 & 0,03 & 0,10 & 0,18 & 0,20 & 0,0125 & Bal. \\
\hline GRADO 2 & 0,03 & 0,10 & 0,25 & 0,30 & 0,0125 & Bal. \\
\hline GRADO 3 & 0,05 & 0,10 & 0,35 & 0,30 & 0,0125 & Bal. \\
\hline GRADO 4 & 0,05 & 0,10 & 0,40 & 0,50 & 0,0125 & Bal. \\
\hline
\end{tabular}


A mayor concentración de elementos químicos, las propiedades mecánicas de resistencia y límite elástico aumentan, a la vez que disminuye el alargamiento [Tarín 1999, Amigo 2003a], tabla 2.3 y figura 2.5 .

Tabla 2.3. Propiedades del Titanio CP [Tarín 1999, Amigo 2003a].

\begin{tabular}{|c|c|c|c|}
\hline & $\begin{array}{c}\text { Resistencia a la } \\
\text { tracción, MPa }\end{array}$ & $\begin{array}{c}\text { Limite elástico, } \\
\text { MPa }\end{array}$ & Elongación, \% \\
\hline Titanio Puro & 256 & 106 & 72 \\
\hline 1 & 240 & 170 & 24 \\
\hline 2 & 345 & 275 & 20 \\
\hline 3 & 450 & 380 & 18 \\
\hline 4 & 550 & 483 & 15 \\
\hline
\end{tabular}

Los datos aportados en la tabla pueden observarse en el siguiente gráfico:

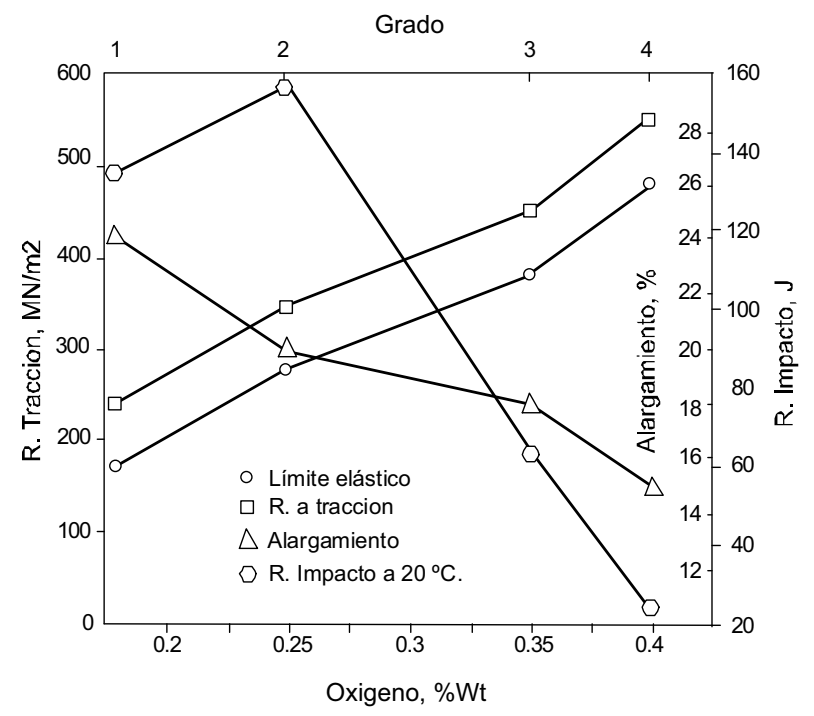

Fig. 2.5. Propiedades mecánicas del TiCP, grados 1 - 4 [Tarín 1999]. 


\subsubsection{ALEACIONES $\alpha$.}

En las aleaciones de titanio $\alpha$ el efecto de los aleantes usados es generalmente el de producir un aumento de la temperatura $\beta$-transus, generando una estructura hexagonal (tipo $\alpha$ ) a temperatura ambiente. De los elementos estabilizadores de la fase a los más interesantes industrialmente y los más empleados son el aluminio y el estaño [Tarín 1999, Amigó 2003a]. Habitualmente estas aleaciones contienen un 5\% de aluminio y $2,5 \%$ de estaño; caracterizándose por su buena soldabilidad y resistencia a la corrosión. A temperatura ambiente poseen menor resistencia que las $\alpha / \beta$, aunque son bastante dúctiles y conformables para tratarse de una estructura hexagonal $(\mathrm{HC})$ y presentan buen comportamiento a fluencia. Dentro del campo de la biomedicina se usan en aplicaciones similares al Ti CP [Leyens 2003].

Pese a que también estabilizan la fase $\alpha$ el carbono, nitrógeno e hidrógeno, en general se tiende a eliminarlos, pues son perjudiciales [Tarín 1999, Amigó 2003a]. Concretamente, la presencia de hidrógeno provoca la formación de hidruros, los cuales favorecen la fragilidad y alteran enormemente el comportamiento mecánico, sobre todo a fatiga [Wang 1998]. Tal como se observa en la figura 2.6, el efecto ejercido por un mismo contenido en hidrógeno depende de cada aleación:

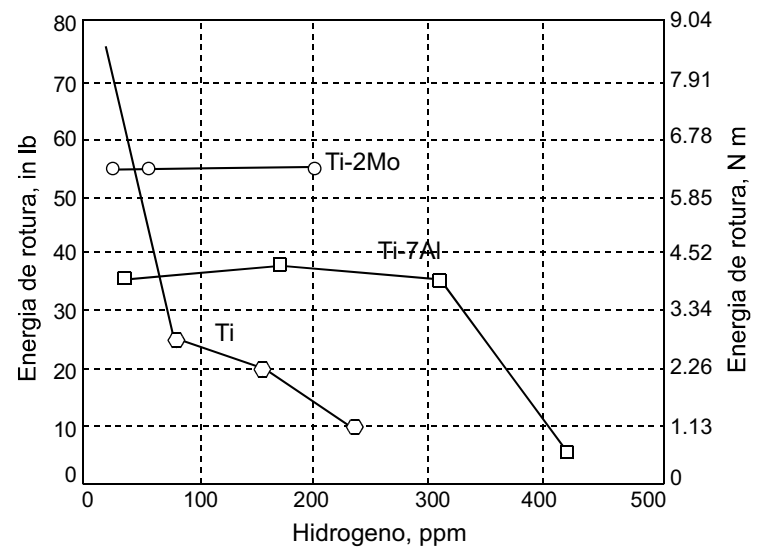

Fig. 2.6. Efecto del hidrógeno en la R. Impacto. Pequeñas adiciones de Al y Mo aumentan la resistencia a temperatura ambiente mientras que el titanio no aleado sufre una fragilización severa [Tarín 1999]. 
En este sentido cabe hacer referencia a diversas fracturas sufridas por implantes dentales de titanio, cuyo estudio concluyó que las aleaciones de titanio en ambientes biológicos son susceptibles de absorber hidrógeno, lo que provoca su fragilización y rotura prematura [Yokohama 2002].
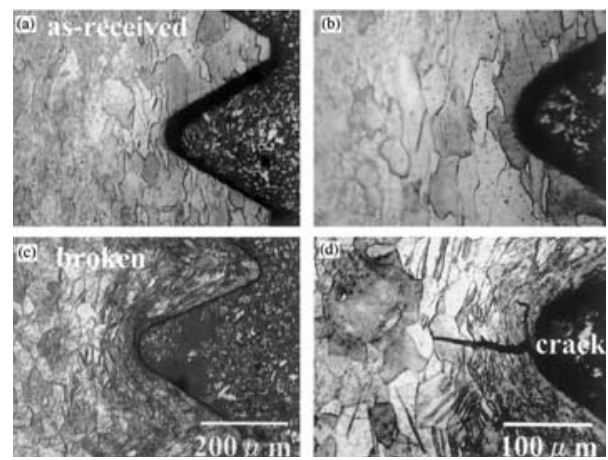

Fig. 2.7. Microestructura de un tornillo de titanio de un implante dental. a y b) Estado recepción, c y d) Tuerca rota [Yokohama 2002].

\subsubsection{ALEACIONES $\beta$.}

En éste tipo de aleaciones, el elevado contenido en elementos estabilizadores de la fase $\beta(\mathrm{Cr}, \mathrm{V}, \mathrm{Mo} \ldots)$ impide que se produzca una transformación completa desde el estado beta, estabilizando dicha fase a temperatura ambiente [Eisenbarth 2004, Tarín 1999, Leyens 2003, Amigo 2003a]. A pesar de ello, la mayoría de estas aleaciones contienen pequeñas cantidades de estabilizadores de la fase a con el fin de permitir el endurecimiento por precipitación de segundas fases, incrementando con ello sus propiedades mecánicas, resistencia al desgaste y tenacidad [Tarín 1999].

Este tipo de aleaciones se caracteriza por poseer buena tenacidad a la fractura y elevada resistencia a tracción aunque, por otra parte, presentan transformación dúctil - frágil, por lo que no deben emplearse a bajas temperaturas [Leyens 2003, Kuroda 1998]. 
Desde el punto de vista de la biocompatiblidad y su aplicación como implante, cabe destacar que, en general, las aleaciones tipo $\beta$ presentan menor módulo elástico que las anteriores, siendo considerados la mayoría de elementos estabilizadores de la fase $\beta$ (molibdeno, niobio y tántalo) muy biocompatibles, incluso más que los estabilizantes de la fase a como el aluminio o estaño. Ello ha conducido a la realización de diversos estudios con la finalidad de obtener aleaciones de reducido módulo, facilitando con ello la osteointegración [Kuroda 2005, Eisenbarth 2004, Nomura 2005]. Por otra parte, dado que la posible toxicidad podría dañar sensiblemente el cuerpo humano, además de las propiedades mecánicas, numerosos estudios han evaluado su biocompatibilidad, determinando otros aspectos como la resistencia a la corrosión o la facilidad de regeneración de células sobre el implante [Eisenbarth 2004, Ibris 2002, Rondelli 1996, Simon 2005, Kujala 2004, Oh I.H. 2007].

\subsubsection{ALEACIONES $\alpha+\beta$.}

La combinación de las fases $\alpha$ y $\beta$ aporta buenas características mecánicas y elevada plasticidad, lo que convierte este grupo de aleaciones de titanio en el de mayor interés industrial [Leyens 2003, timet.com]. La aleación Ti6Al4V, empleada en el presente estudio se clasifica dentro de este grupo y es muy ampliamente utilizada en el campo de los biomateriales [Amigó 2003a, timet.com, biomet.es, lafitt-sa.com].

Las aleaciones $\alpha / \beta$ se han desarrollado debido a la mala forjabilidad de las tipo $\alpha$, su reducida resistencia en frío y fragilidad cuando se intenta incrementar su resistencia adicionando elementos de aleación. Todas ellas contienen elementos estabilizadores de la fase $\beta$ que posibilitan la realización de tratamientos térmicos y elementos estabilizadores de la fase a que mejoran las características mecánicas, en especial a alta temperatura [Hardie 1999].

En el campo de los biomateriales las aleaciones de Titanio más empleadas corresponden a los 4 grados de TiCP así como la Ti6Al4V (IMI 318), a la 
que se dedica la mitad de la producción del titanio metal [timet.com, biomet.es, lafitt-sa.com]. La aleación Ti6Al4V se caracteriza fundamentalmente por sus buenas resistencia, soldabilidad, forjabilidad y excelente comportamiento a fatiga, presentando por el contrario mal comportamiento a temperaturas superiores a los $400{ }^{\circ} \mathrm{C}$. Pueden encontrarse hasta doce variantes de la misma, incluidas las ELI y super ELI, con menores contenidos en elementos intersticiales [ASM N2 1990].

A pesar de la buena combinación de propiedades que presenta este grupo de aleaciones, determinados autores [Kuroda 2005, Eisenbarth 2004] han apuntado sobre la toxicidad de determinados elementos como el $\mathrm{Al}$ o $\mathrm{V}$ (estabilizadores de las fases $\alpha$ y $\beta$ respectivamente). Ello ha conducido a la realización de diversos estudios que tratan de desarrollar aleaciones de titanio libres de éstos, fundamentalmente de tipo $\beta$ pues, como se ha comentado, permiten obtener un menor módulo elástico, manteniendo unas propiedades mecánicas y alargamiento similares, lo que mejora el comportamiento junto al hueso [Kuroda 2005, Eisenbarth 2004, Nomura 2005].

A modo de síntesis, la figura 2.8 resume la evolución de diversas propiedades en función del tipo de estructura, $\alpha \circ \beta$. Tal como se ha indicado, las aleaciones tipo $\alpha+\beta$ poseen propiedades intermedias, lo que les confiere gran interés industrial. 
Estabilizantes

fase $\alpha .(\mathrm{Al}, \mathrm{N}, \ldots)$
Estabilizantes fase

ß. (Fe, V, Mn,...)

$\uparrow$ estabilizantes $\alpha$ estabiliza la fase $\alpha$

$\uparrow$ estabilizantes $\beta$ estabiliza la fase $\beta$

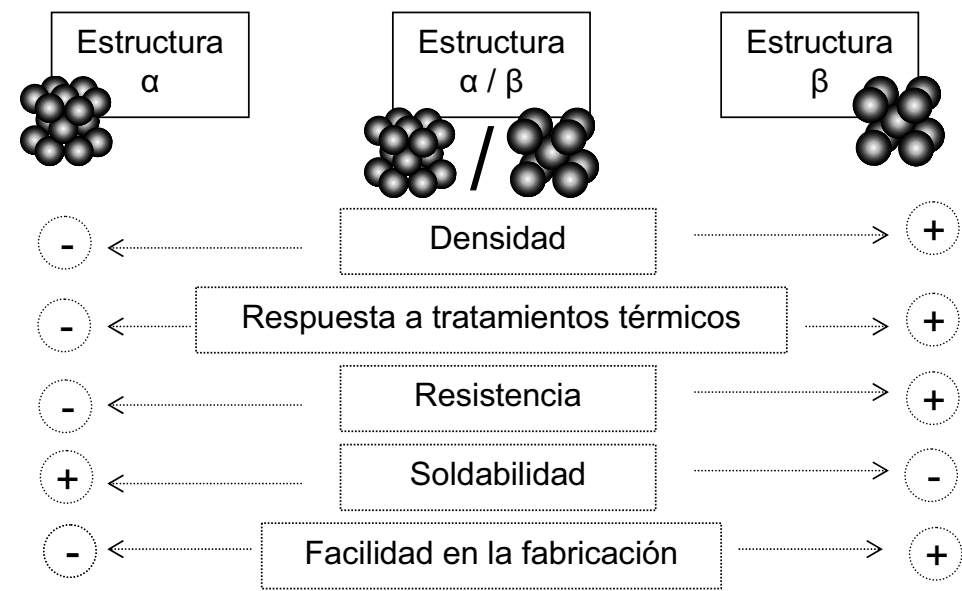

Fig. 2.8. Efecto de los elementos de aleación en la microestructura de las es de titanio [Baeslack 1993].

\subsection{MÉTODOS DE OBTENCIÓN DE POLVO DE TITANIO.}

Las características del titanio anteriormente comentadas, fundamentalmente su elevada reactividad, provocan que su polvo no pueda obtenerse por cualquier procedimiento, sino tan sólo a través de algunos procesos específicos como reducción química, hidruración / deshidruración (HDH), atomización gaseosa (GA), electrodo rotatorio de plasma (PREP) o aleación mecánica [ASM N7 1993, Upadhayaya 1997]. De entre ellos, el material de partida utilizado para la sinterización de microesferas es elaborado mediante el método PREP [Wosche 1995, German 1994], mientras que los polvos de TiCP y Ti6Al4V empleados para el conformado de piezas mediante el método de espaciadores es manufacturado mediante $\mathrm{HDH}$. 


\subsubsection{PROCESO DE ELECTRODO ROTATORIO DE PLASMA.}

El proceso de "electrodo rotatorio de plasma (PREP)" es la técnica de atomización centrífuga más comúnmente empleada a nivel industrial para metales reactivos o fuertemente aleados. Una variante de éste es el método REP, donde en lugar de emplearse plasma se usa un cátodo de tungsteno, aunque éste se utiliza en menor medida que el anterior, pues produce mayor nivel de contaminación en los polvos [Isonishi 1989, German 1994, Upadhayaya 1997].

En el PREP, se confecciona un electrodo consumible con la composición deseada, que posteriormente es sometido a rotación mediante un motor externo que lo hace girar a velocidades del orden de $15.000 \mathrm{rpm}$. Frente a la barra se coloca un soplete de plasma $(\mathrm{He})$, cuya focalización del haz provoca una fusión localizada en superficie. La fuerza centrífuga provocada por la propia rotación de la barra provoca la expulsión del metal fundido en forma de spray, solidificando durante la caída en forma de partículas esféricas, figura 2.9. Puesto que el proceso se realiza en atmósfera controlada (gas inerte, He) y no existe contacto con ningún otro material, se obtiene un polvo de gran pureza [German 1994, Wosche 1995].

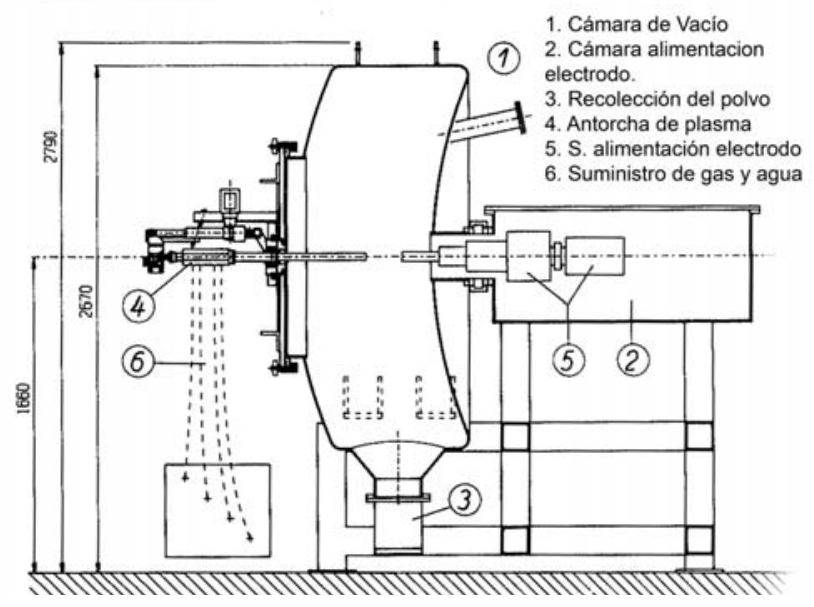

Fig. 2.9. Diagrama de una planta de producción de polvo mediante PREP [Wosche 1995]. 
Tal como se observa en el siguiente esquema, el material fundido forma una fina película que rodea el electrodo y, debido a la fuerza centrífuga y tensión superficial, se forman protuberancias y ligamentos que van abandonando el sustrato, figura 2.10. Durante la caída estas primeras partículas longitudinales se van transformando en esferas.

El tamaño de partícula final se sitúa habitualmente entre 100 y $300 \mu \mathrm{m}$, pudiendo reducirse al aumentar la velocidad de rotación, reducir el ratio de fusión o incrementar el tamaño del ánodo [Wosche 1995, ASM N7 1993].

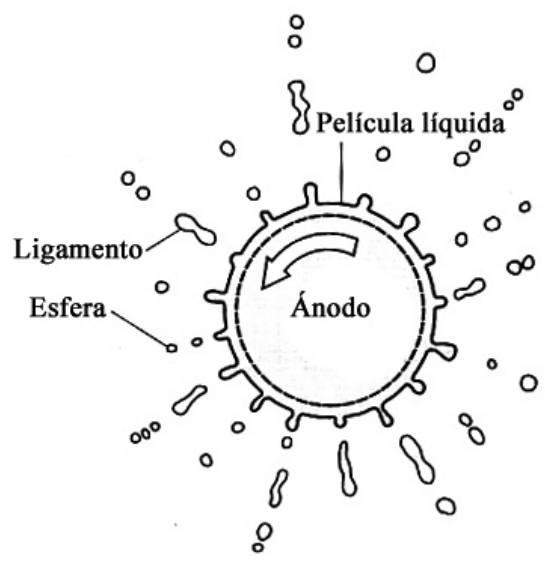

Fig. 2.10. Formación de partículas esféricas en el ánodo consumible sometido a rotación [German 1994].

Comparado con otros métodos como el de proceso de hidruración deshidruración $(\mathrm{HDH})$, el PREP obtiene partículas más esféricas, figura 2.11 a y $b$, que permiten mayor fluidez y densidad de empaquetamiento (65\% de la $\rho_{\text {teórica }}$ aprox.) [ASM N7 1993, Upadhayaya 1997]. Por el contrario, la morfología del polvo obtenido por PREP impide obtener piezas en verde mediante técnicas convencionales de prensado, por lo que durante el conformado mediante sinterización de microesferas, el llenado del molde deberá realizarse por gravedad [Upadhayaya 1997]. 


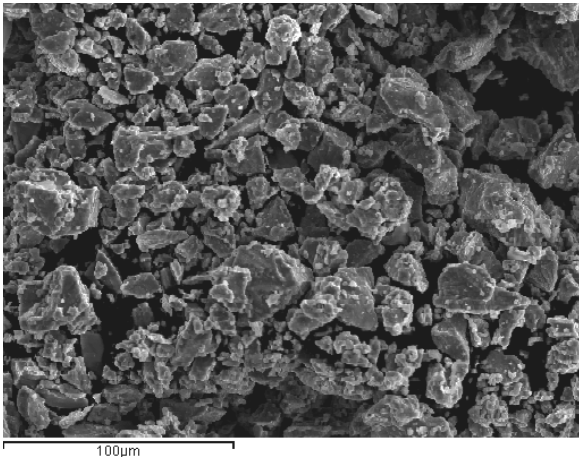

a

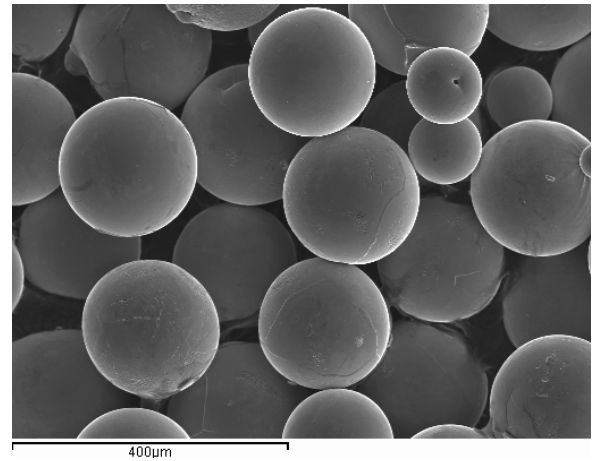

b

Fig. 2.11. Micrografías SEM de polvo de Ti6AI4V obtenido por: a) HDH; b) PREP.

Los principales beneficios que aporta el PREP frente a otros procesos de obtención son la limpieza de polvo, morfología esférica, tamaño uniforme de partícula y ausencia de materia contaminante procedente de un crisol; no obstante, su ratio de producción es reducido y los costes de equipamiento y procesado son elevados lo que encarece los polvos obtenidos [German 1994, Schatt 1997].

\subsubsection{PROCESO DE HIDRURACIÓN - DESHIDRURACIÓN.}

Frente al PREP, el proceso de hidruración-deshidruración, $\mathrm{HDH}$, se fundamenta en la adición de hidrógeno al titanio y sus aleaciones, habitualmente dúctiles, con el fin de fragilizarlas y posibilitar su disgregación. La hidrogenación se realiza mediante calentamiento en atmósfera de hidrógeno, tras lo cual el material es fácilmente reducido a polvo para finalmente deshidrogenarlo mediante calentamiento en vacío.

La temperatura mínima de hidruración depende de la aleación concreta, situándose para el titanio $\mathrm{CP}$ alrededor de los $400^{\circ} \mathrm{C}$, con 0,007 $\mathrm{MPa}$ de presión de hidrógeno [Boyer 1994].

Comparado con el polvo esférico obtenido por PREP, mediante HDH se obtiene un polvo de morfología final similar al obtenido por reducción química (métodos Kroll o Hunter), figura 2.12. La irregularidad de sus 
partículas provoca que la fluidez y densidad de empaquetamiento resulten reducidas aunque, por el contrario, permiten manipular las piezas en verde para su posterior sinterización.

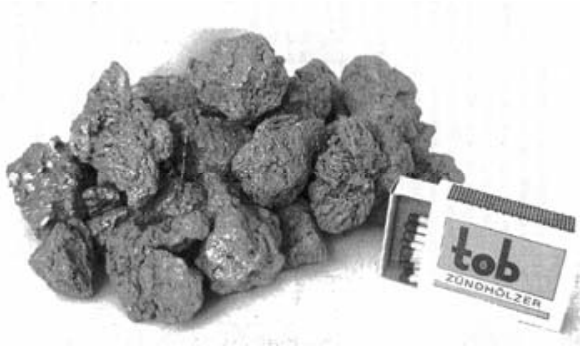

a

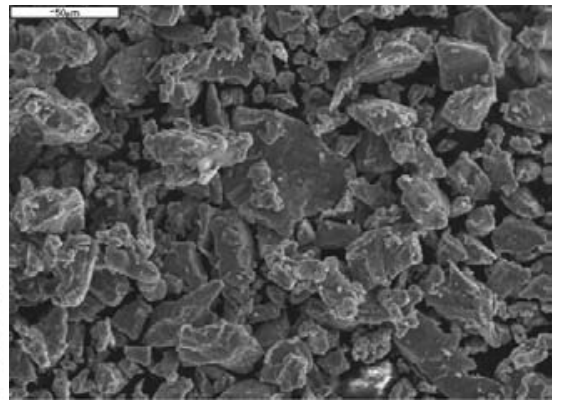

b

Fig. 2.12. Morfología irregular de polvos obtenidos por: a) Reducción química [Leyens 2003]; b) HDH, Micrografía SEM TiCP3.

Tal como se ha indicado anteriormente, mediante HDH se obtiene un polvo de menor pureza comparado con el obtenido mediante PREP [Lutjëring 2007].

Por otra parte, ambos procesos requieren de equipamiento sofisticado con un elevado grado de infraestructura, por lo que no seria viable que una empresa destinada al conformado de polvos fabricase su propio material de partida mediante HDH o PREP.

\subsection{CARACTERISTICAS EXIGIBLES A LOS IMPLANTES.}

Una vez obtenido y caracterizado el material de partida, debe procesarse con el fin de obtener una pieza cuyas características permitan su uso como implante. Para ello, resulta fundamental conocer las exigencias a las que se verá sometido, pues condicionan las características necesarias para su adecuado comportamiento. Así, un material implantado en el cuerpo humano suele estar sometido a exigencias muy elevadas [Oh 2003b, Li C.F. 2005], por lo que su durabilidad depende de varios factores. Algunos de estos condicionantes son responsabilidad del fabricante, otros, como la técnica de implantación, dependen del cirujano, aunque el éxito final 
depende también de características propias del paciente, como su condición médica, la respuesta biológica y fisiológica, su conducta en relación al aumento de peso, el transporte de cargas pesadas o adoptar un alto nivel de actividad física [UNE-EN ISO 21534, UNE-EN ISO 14602].

La gran diversidad de factores intervinientes provocan que en el diseño de un implante deban ser tenidos en cuenta diversos aspectos [UNE-EN ISO 14630, UNE-EN ISO 21534], tales como:

- Seguridad biológica. No generar reacciones dañinas al interaccionar con el cuerpo humano [Vallet 2000, Oh 2003a].

- Biofuncionalidad. Los biomateriales son compuestos inorgánicos diseñados para sustituir, en parte o totalmente, una función del cuerpo humano en condiciones aceptables de seguridad, economía y condiciones estéticas y fisiológicas, por lo que el diseño y propiedades deben adecuarse a cada uso concreto [Heimann 2002, Wehmoller 2004].

- Respuesta apropiada de los tejidos. La integración de un elemento ajeno al cuerpo humano, genera reacciones (fisiológicas y biológicas), principalmente en la interfaz entre el elemento implantado y los tejidos anexos, por lo que la compatibilidad del implante con los tejidos y los fluidos del cuerpo resulta de vital importancia para su eficiencia y durabilidad [Freese 2001, Ysander 2001]. En este sentido, resulta tan importante fomentar un apropiado crecimiento del hueso en los implantes permanentes (osteointegración), como no generar partículas tóxicas.

- Propiedades mecánicas. Además de la resistencia necesaria para soportar las cargas a las que se verá sometido el implante, con el fin de regenerar un hueso sano y fuerte, es necesario estimular los osteoblastos (células de producción de hueso nuevo) mediante la transmisión eficiente de esfuerzos en la intercara entre el implante y el hueso [Simske 1997, Vallet 2000]. Para ello, resulta fundamental 
que la rigidez del implante sea lo más semejante posible a la del hueso, lo que constituye el principal objetivo de la presente tesis, pues si éste no se regenera, se producirá su debilitamiento y aflojamiento [Comín 1999, Oh 2003b, Li J.P. 2006].

- Resistencia a la fatiga. A diferencia del hueso, que se remodela mediante la aplicación de esfuerzos, los implantes generalmente fracasan a fatiga [Comín 1999]. Por ello, además de la resistencia ante cargas estáticas, en el tratamiento de fracturas óseas resulta de gran importancia la resistencia a fatiga.

- Resistencia a la corrosión. Sólo los metales más nobles, como el oro y algunos del grupo del platino, o los más pasivos, como el titanio $y$ el cromo, tienen alguna posibilidad de mantener un ritmo de corrosión lo suficientemente bajo como para ser considerados como alternativas aceptables [Comín 1999]. La inoxidabilidad de un metal se produce por pasivación de su superficie, esto es, por formación de una fina película superficial de óxido que resulte adherente, compacta y dificulte los fenómenos de difusión de oxígeno a través de ella, disminuyendo así la velocidad de progresión de la corrosión [Freese 2001, ASM N13 1992]. Por ello, en implantes metálicos, la importancia de la liberación de los productos de corrosión a los tejidos biológicos resulta de vital importancia [Blackwood 2000, Ibris 2002].

- El desgaste de las superficies articulantes. Los fenómenos de desgaste en implantes tienen lugar en situaciones en las que exista un movimiento relativo de deslizamiento entre dos componentes en contacto, lo que ocurre fundamentalmente en prótesis articulares, tendones y ligamentos. Los efectos que produce resultan adversos no sólo por la pérdida de material, sino también por la liberación de pequeñas partículas al organismo, que normalmente provocan reacciones y conducen necesariamente a un recambio del implante [Comín 1999]. 
- La durabilidad de los recubrimientos y tratamientos superficiales. La aplicación de recubrimientos y tratamientos superficiales puede realizarse tanto con el objetivo de proporcionar una superficie biocompatible o bioreactiva a una superficie bioinerte [Simske 1997, Kupp 2002, Heimann 2002, Gaona 2007] como con el fin de mejorar la resistencia al desgaste [Venugopalan 2000, Garcia 2003, Gil 2007 b].

- Facilidad de procesado. Como se ha anticipado, la elevada reactividad del titanio dificulta su extracción y procesado, por lo que se requieren técnicas de vacío para minimizar la contaminación de la pieza obtenida y obtener unas propiedades adecuadas a la aplicación final.

- Disponibilidad. La fabricación de componentes para aplicaciones biomédicas debe realizarse a un precio asequible, con el fin de mantener un stock adecuado que permita intervenir quirúrgicamente al paciente de urgencia en caso de necesidad.

La mayoría de estos factores que condicionan el diseño del implante se engloban dentro de un único concepto: "biocompatibilidad", entendiendo como tal la habilidad del componente para permanecer en una situación específica con una buena respuesta por parte del huésped [Heimann 2002, Kujala 2004]. Dentro de este concepto, pueden definirse distintas categorías de materiales en función de la interacción entre el implante y el tejido humano [Heimann 2002]. Así, puede distinguirse entre materiales:

- Incompatibles: aquellos que generan sustancias tóxicas pudiendo provocar desde simples alergias, hasta la no asimilación por parte del individuo.

- Biocompatible: Aquellos que generan sustancias pero en concentraciones no tóxicas. 
- Bioinertes: Aquellos que no generan partículas toxicas. Generalmente la interfase entre el implante y el material únicamente es capaz de transmitir esfuerzos de compresión ("bony on-growth").

- Bioactivos: Aquellos, como los fosfatos de calcio, que presentan una interacción positiva con los tejidos circundantes, formándose una unión química en la interfase entre ambos. Además de los esfuerzos de compresión, en cierta manera son capaces de transmitir esfuerzos de tracción y cortante ("bony in-growth") a través de la interfase entre ambos.

Mientras que materiales como los aceros inoxidables se consideran biocompatibles, autores como Heimann et al. [Heimann 2002], consideran el titanio como un material bioinerte. No obstante, según Simske [Simske 1997] se ha demostrado cierta liberación de iones bajo condiciones que probablemente se repetirían in vivo.

En definitiva, para hacer frente a los factores anteriormente descritos, y cumplir adecuadamente su función, en biomateriales metálicos como el titanio, resultan de gran relevancia clínica características como:

- Resistencia mecánica suficiente [Zardiackas 2001].

- Un módulo elástico lo más parecido posible al del hueso [Ryan 2006, Nomura 2005, Niinomi 2008].

- Adecuada resistencia para soportar cargas cíclicas (fatiga) [Magnissalis 2003, Gil 2007 b].

- Porosidad y tamaño de poro tales que faciliten la osteointegración [Kupp 2002, Dewidar 2005, Köhl 2007].

- Ausencia de reacciones de tejido adversas [Ratner 1996, Vallet 2000].

- Elevada resistencia a la corrosión y al desgaste, con el fin de evitar la formación de iones y partículas y, en caso de que se formaran, que fuesen reabsorbibles o, por lo menos, no tóxicas [Rodríguez 1999, Ibris 2002, Kamachi 2003]. 
La presente investigación se enmarca en el contexto descrito, siendo su principal objetivo generar, mediante el desarrollo de porosidad, piezas de titanio menos rígidas, con unas propiedades mecánicas adecuadas y aptitud para la osteointegración, sin generar reacciones adversas, y con capacidad para mantener sus características en el tiempo.

\subsection{MATERIALES COMÚNMENTE UTILIZADOS COMO IMPLANTES.}

El abanico de materiales capaces de hacer frente a las exigencias anteriormente comentadas resulta verdaderamente amplio, pudiendo utilizar tanto polímeros, como materiales cerámicos o metálicos. No obstante, la idoneidad de unos u otros depende de la aplicación concreta.

Así, el uso de materiales metálicos en el cuerpo humano no avanzó hasta la Guerra Civil Americana, aunque las agujas y alambres de hierro, oro, plata y platino empleados fracasaron por infección. Con el desarrollo de nuevas aleaciones metálicas a principios del siglo $\mathrm{XX}$ y el conocimiento de los modos de fallo de los implantes, se realizaron continuas mejoras. Así, se empezaron a utilizar las aleaciones de titanio, Cr-Co y $\mathrm{Fe}-\mathrm{Cr}-\mathrm{Ni}$ (acero inoxidable) para la fabricación de implantes ortopédicos y dentales, lo que vino impulsado tanto por sus buenas propiedades mecánicas como por su excelente resistencia a la corrosión en comparación con los materiales empleados hasta el momento [Comín 1999, Leyens 2003].

De entre los materiales existentes, los metales y cerámicas son principalmente empleados para implantes que soportan cargas moderadas y altas, mientras que los elastómeros y plásticos se suelen utilizar para sustituir tejidos blandos e implantes en contacto con la sangre [Comín 1999]. De igual modo, materiales como polímeros reabsorbibles y determinadas pastas cerámicas deben utilizarse a corto plazo o en aplicaciones que no soporten cargas, pues previsiblemente sus propiedades mecánicas decrecen con el tiempo al ser implantados [Zardiackas 2001]. 
En relación a los materiales cerámicos, los más comúnmente utilizados como biomateriales son la alúmina, circona estabilizada con itria y fosfatos de calcio, principalmente la hidroxiapatita (HA) [Heimann 2002]. Las cerámicas se han empleado habitualmente tanto en superficies articulantes (como la cabeza femoral) donde presentan buena resistencia al desgaste, como en forma de recubrimientos, para mejorar la osteointegración [www.laffit.es, Popa 2005, Bansiddhi 2008].

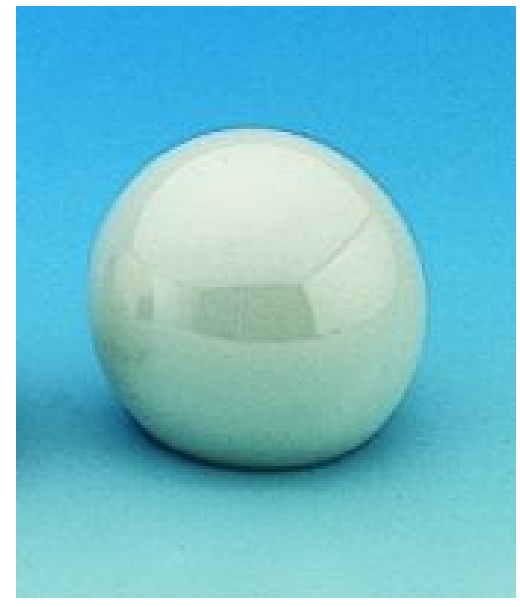

a

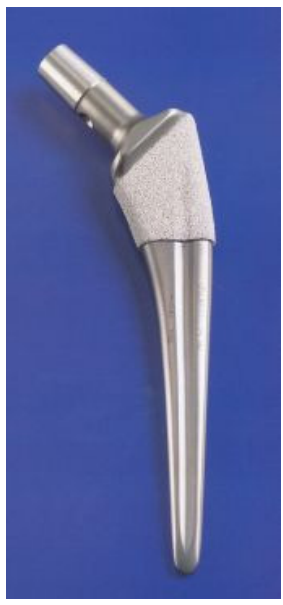

b

Fig. 2.13. a) Cabeza femoral cerámica; b) Vástago con recubrimiento de microesferas e HA [www. lafitt.es].

En relación a los materiales metálicos en general, es bien conocido que los metales se deterioran por corrosión en medios biológicos, pues los estados de oxidación de los metales resultan más estables (menor energía libre) que los estados puros [ASM N13 1992].

Tal como se ha indicado, dichos procesos de corrosión generan problemas de debilitación del implante y reacciones adversas frente a los productos de corrosión. Por ello, el número de biomateriales metálicos con alguna posibilidad de mantener un ritmo de corrosión lo suficientemente bajo como para ser considerados como alternativas aceptables se reduce a materiales nobles (como el oro y algunos del grupo del platino), o pasivables (como el titanio y el cromo) [Comín 1999]. Este último grupo basa su resistencia a la 
oxidación en la formación de una fina película superficial de óxido que resulte adherente y compacta, para dificultar los fenómenos de difusión de oxígeno a través de ella y reducir así la velocidad de progresión de la corrosión [Delplancke 1982, Gil 2002, Van Gils 2004].

Por ello, desde el desarrollo de los materiales metálicos y su utilización como implantes, los materiales metálicos más comúnmente empleados en el campo de la biomedicina han sido los aceros inoxidables austeníticos y aleaciones cobalto-cromo o base titanio [Kamachi 2003].

El uso de los aceros inoxidables ha venido justificado por su facilidad de fabricación y economía, además de facilitar la adaptación al hueso (permite cierta modificación de forma) en el curso de la operación [Kamachi 2003]. Como acero inoxidable para implantes se utiliza la aleación AISI 316L, compuesta por hasta un $2 \%$ de $\mathrm{Mn}, 2-4 \%$ de Mo, $12-14 \%$ de Ni y $17-20 \%$ de $\mathrm{Cr}$, con menos del $1 \%$ de Si, S, P, C y entre un 59-66 de Fe como elemento principal de la aleación. El $\mathrm{Ni}$ es el encargado de proporcionar la resistencia a la corrosión, debido a que estabiliza la fase austenítica. No obstante, estudios electroquímicos realizados sobre medios corrosivos (solución Hank, sangre y solución salina), han demostrado que la resistencia a corrosión del acero inoxidable es notablemente inferior a la de las aleaciones de titanio y de cobalto [Comín 1999, Kamachi 2003], lo que supone tanto una razón para su uso temporal, como una inconveniencia a la hora de crear espumas de acero inoxidable o recubrir estos implantes con materiales porosos, pues aumentaría la relación área superficial / volumen [Simske 1997].

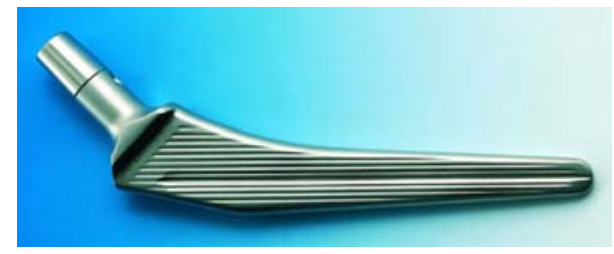

Fig. 2.14. Vástago cementado de acero inoxidable [www.lafitt.es]. 
El otro grupo de aleaciones metálicas, las de Cr-Co-Mo (Vitallium) presentan mejor resistencia a la corrosión, aunque son menos biocompatibles que las base titanio [Smallman 1999]. Las aleaciones de cromo-cobalto empleadas para la fabricación de implantes reciben diversos nombres comerciales como Stellite $^{R}$, Vitallium ${ }^{R} \circ$ Vinertia $^{R}$. Sus propiedades mecánicas son superiores a las de los aceros inoxidables, con una resistencia a fatiga y a corrosión excelentes. El mayor inconveniente de estas aleaciones reside en el elevado coste de los procesos de fabricación [Comín 1999].

Frente al acero inoxidable y las aleaciones de cobalto-cromo, el titanio aporta una mejora de propiedades, como elevada resistencia especifica y a fatiga, un módulo elástico más semejante al del hueso humano [Esen 2007, Gil 2007 b], véase tabla 2.4, así como una excelente resistencia a la corrosión al contacto tanto con el hueso como con los fluidos del cuerpo humano [Smalmann 1962, Freese 2001, Blackwood 2000, Ibris 2002].

Tabla 2.4. Propiedades mecánicas de las aleaciones metálicas habitualmente empleadas en la fabricación de implantes quirúrgicos [Adaptado de Comín 1999].

\begin{tabular}{|c|c|c|c|c|}
\hline Aleación & $\sigma_{y}, \mathrm{MPa}$ & $\sigma_{\mathrm{R}}, \mathrm{MPa}$ & $A, \%$ & $\mathrm{E}, \mathrm{GPa}$ \\
\hline \multicolumn{5}{|c|}{ Aceros inoxidables } \\
\hline $18 \mathrm{Cr}-8 \mathrm{Ni}$, recocido & $200-300$ & $540-700$ & $50-65$ & 200 \\
\hline $18 \mathrm{Cr}-10 \mathrm{Ni}$, recoc. & $200-250$ & $540-620$ & $55-60$ & 200 \\
\hline 316 , recocido & $240-300$ & $600-700$ & $35-55$ & 200 \\
\hline 316 , acritud & $700-800$ & 1000 & $7-10$ & 200 \\
\hline \multicolumn{5}{|c|}{ Aleaciones Cr-Co-Mo } \\
\hline Moldeo & 450 & 655 & 8 & 200 \\
\hline Forja, recocido & 380 & 900 & 60 & 230 \\
\hline Forja, acritud & 1050 & 1540 & 9 & 230 \\
\hline \multicolumn{5}{|c|}{ Aleaciones de $\mathrm{Ti}$} \\
\hline TiCP3 & 380 & 500 & 18 & 105 \\
\hline TiCP4 & 485 & 550 & 15 & 105 \\
\hline Ti6Al4V & 830 & 896 & 10 & 110 \\
\hline
\end{tabular}


Pese a que, tal como se ha indicado, las dificultades de extracción y procesado del titanio y sus aleaciones, provocan que su coste sea elevado (doble que el acero inoxidable), en el campo de la biomedicina los costos están justificados si realmente el implante aporta una mejora en la calidad de vida del paciente. Por otra parte, el efecto se compensa por su densidad $\left(4,5 \mathrm{~g} / \mathrm{cm}^{3}\right)$, relativamente baja en comparación con el acero $\left(7,9 \mathrm{~g} / \mathrm{cm}^{3}\right)$ y las aleaciones de Cr-Co de moldeo y forja $\left(8,3\right.$ y $9,2 \mathrm{~g} / \mathrm{cm}^{3}$, respectivamente), lo que le confiere mayor resistencia específica [Comín 1999].

Por otra parte, pese a que no puede considerarse completamente bioinerte, pues se ha demostrado cierta liberación de iones bajo condiciones que probablemente se repetirían in vivo [Simske 1997], es el metal más habitualmente empleado para el desarrollo de implantes y recubrimientos porosos, figura 2.15, [www.biomet.co.uk, www.stryker.com].

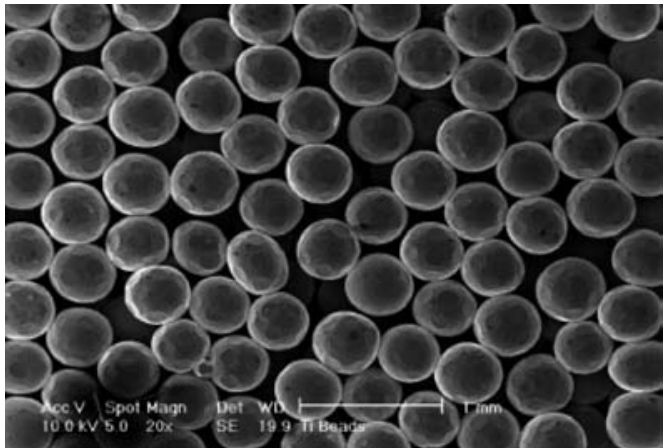

a

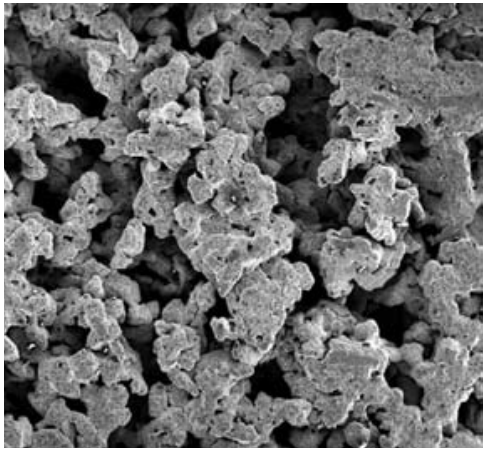

b

Fig. 2.15. Recubrimientos porosos de titanio: a) Microesferas [Frenkel 2004]; b) Regenerex [Lombardi 2007].

Otra de las ventajas que aportan las aleaciones de titanio es que no absorben completamente la radiación, por tanto, cuando el espesor del componente no es excesivamente elevado, permiten realizar un cierto seguimiento del proceso post-operatorio sin necesidad de acceder directamente a la zona afectada, figura 2.16 [Ellingsen 2006]. 


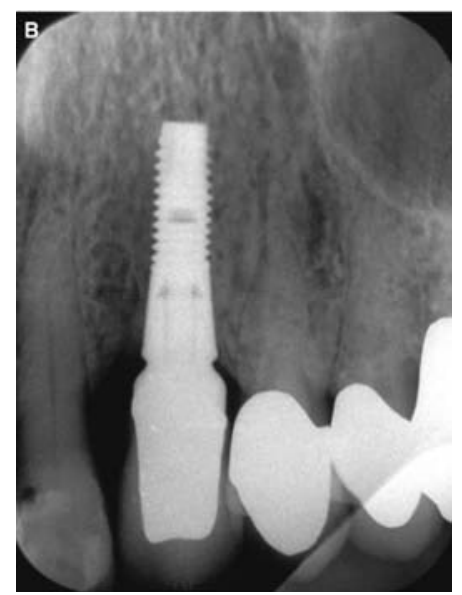

Fig. 2.16. Transparencia a la radiación de las aleaciones de titanio [Ellingsen 2006].

La tabla 2.5 refleja las propiedades mecánicas de gran parte de aleaciones de titanio empleadas en biomedicina. Tal como se ha descrito, las aleaciones tipo a presentan la menor resistencia y máxima ductilidad, mientras que las $\beta$ y $\alpha / \beta$ presentan rangos de propiedades más amplios, función de la microestructura generada tras el proceso de fabricación y tratamiento térmico aplicado [ASM N3 1997, Amigó 2003b, Niinomi 2008]. Tal como se observa, se han desarrollado aleaciones tipo $\beta$, libres de componentes tóxicos y de menor rigidez, lo que facilita la adecuación del trabajo junto al hueso.

Entre ellas, la aleación Ti6Al4V es una de las más empleadas en biomedicina, especialmente en aplicaciones ortopédicas y de osteosíntesis [Garcia 2003]. Las aleaciones de Ti64 empleadas para la fabricación de implantes reciben diversos nombres comerciales en función del fabricante (Tivanium $^{\mathrm{R}}$, Tivaloy $^{\mathrm{R}}$, Tikrutan $^{\mathrm{R}}$ ).

Además de los materiales descritos, cabe hacer referencia a otros ampliamente utilizados en la actualidad, como son las aleaciones de níqueltitanio (NiTi) y las espumas de tántalo. 
Tabla 2.5. Propiedades mecánicas de aleaciones de titanio empleadas en aplicaciones biomédicas [Amigó 2003a; ASM N3 1997, Leyens 2003, Kuroda 2005, Schuch 2007, Niinomi 2008].

\begin{tabular}{|c|c|c|c|c|c|}
\hline \multicolumn{6}{|c|}{ Aleaciones de Ti empleadas en aplicaciones biomédicas } \\
\hline Aleación & Tipo & $\mathrm{E}, \mathrm{GPa}$ & $\sigma_{\mathrm{R}}, \mathrm{MPa}$ & $\sigma_{Y}, \mathrm{MPa}$ & $A, \%$ \\
\hline Ti puro & $\alpha$ & $\mathrm{n} / \mathrm{a}$ & 256 & 106 & 72 \\
\hline TiCP, grado 1 & $\alpha$ & 102 & 240 & 170 & 24 \\
\hline TiCP, grado 2 & $\alpha$ & 103 & 345 & 275 & 20 \\
\hline TiCP, grado 3 & $\alpha$ & 105 & 450 & 380 & 18 \\
\hline TiCP, grado 4 & $\alpha$ & 105 & 550 & 483 & 15 \\
\hline Ti6Al4V (ELI) & $\alpha / \beta$ & $110-113$ & 860 & 795 & 10 \\
\hline Ti6Al4V & $\alpha / \beta$ & $110-113$ & 930 & 860 & 10 \\
\hline Ti5Al2,5V & $\alpha / \beta$ & - & 690 & 586 & 15 \\
\hline Ti5Al2,5Fe & $\alpha / \beta$ & 110 & 1033 & 914 & \\
\hline Ti6Al7Nb & $\alpha / \beta$ & 105 & 862 & 793 & 10 \\
\hline Ti13Nb13Zr & $\beta$ & $75-79$ & 1030 & 900 & 15 \\
\hline Ti12Mo6Zr2Fe & $\beta$ & $74-85$ & 1000 & 965 & 15 \\
\hline Ti15Mo & $\beta$ & 78 & 793 & 655 & 22 \\
\hline Ti16Nb10Hf & $\beta$ & - & 486 & 276 & 16 \\
\hline $\mathrm{Ti} 15 \mathrm{Mo} 2,8 \mathrm{Nb} 0,2 \mathrm{Si}$ & $\beta$ & - & 793 & 655 & 22 \\
\hline Ti15Mo5Zr3Al & $\beta$ & $75-113$ & $882-1312$ & $870-1284$ & \\
\hline Ti30Nb & $\beta$ & 42 & 700 & 500 & 20 \\
\hline Ti35Zr10Nb & $\beta$ & - & 897 & 621 & 16 \\
\hline Ti29Nb13Ta4,6Zr & $\beta$ & 60 & - & - & - \\
\hline Ti35Nb7Zr5Ta & $\beta$ & 55 & 590 & 530 & 20 \\
\hline Ti30Ta & $\beta$ & 58 & 740 & 590 & 28 \\
\hline $55 \mathrm{Ti} 8 \mathrm{Ni}$ & Intermetálico & & 1034 & 345 & 20 \\
\hline
\end{tabular}


Las aleaciones $\mathrm{Ni}-\mathrm{Ti}$ se emplean fundamentalmente por sus propiedades de memoria de forma y superelasticidad. El primer efecto consiste en que el material con estructura martensítica puede deformarse plásticamente por debajo de la temperatura de inicio de retransformación a austenita, pudiendo recobrar su forma inicial con un simple calentamiento a temperatura superior a la de fin de retransformación. El comportamiento superelástico se caracteriza por la posibilidad de obtener grandes deformaciones elásticas debidas a la aparición de placas martensíticas inducidas por tensión y a la reorientación de dichas placas. En las aleaciones $\mathrm{Ni}$ - $\mathrm{Ti}$ pueden alcanzarse recuperaciones superelásticas superiores al $10 \%$ de la deformación, en contraste con los biomateriales metálicos convencionales, en los que el campo elástico es normalmente inferior al 0,5\% de la deformación [Es-Souni 2002, Kujala 2004, Barrabes 2008]. Por ello, habitualmente las aleaciones $\mathrm{Ni}-\mathrm{Ti}$ se utilizan en la fabricación de alambres de ortodoncia, figura 2.17.

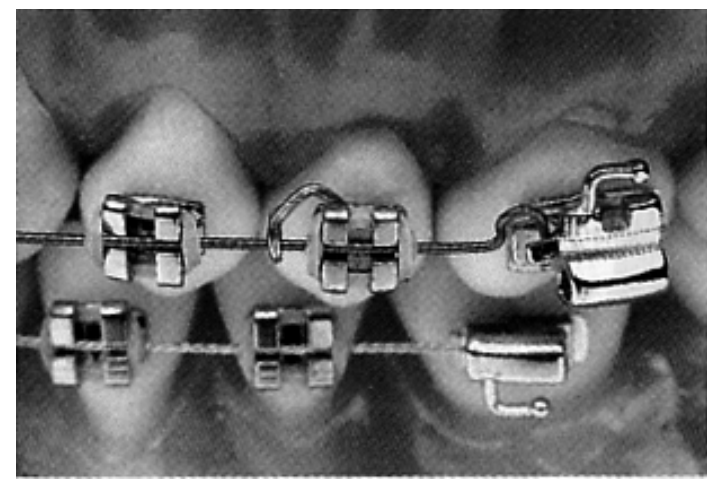

Fig. 2.17. Alambres de ortodoncia realizados con Ni-Ti [Leyens 2003].

El tántalo, por el contrario, se caracteriza principalmente por ser un metal con una metalurgia extractiva muy compleja. Resiste a la corrosión por mecanismos de pasivación similares a los del titanio y posee unas propiedades mecánicas semejantes a las del acero inoxidable pero con una densidad mucho mayor $\left(16,6 \mathrm{~g} / \mathrm{cm}^{3}\right)$ [Comín 1999, Gil 2007 b]. 
Con el fin de aproximarse a las propiedades del hueso, se fabrica en forma de espumas, figura 2.18, [Levine 2006]. Así, existen espumas de tántalo comerciales (Hedrocel [www.zimmer.com]) desarrolladas mediante un proceso de infiltración química en fase vapor (CVI), precipitando tántalo en una retícula de carbón vítreo. Estas espumas tienen entre un $75-85 \%$ de porosidad, siendo esta interconectada, con una resistencia a compresión de $60 \mathrm{MPa}$ y a flexión de aproximadamente $110 \mathrm{MPa}$. Determinados resultados clínicos han demostrado que dichas espumas facilitan el desarrollo óseo y que su resistencia a compresión es suficiente para soportar cargas fisiológicas en determinadas aplicaciones, tales como el cotilo acetabular. A pesar de ello, su principal inconveniente es la reducida ductilidad en comparación con los materiales metálicos habitualmente utilizados como implantes [Zardiackas 2001, Sevilla 2007].

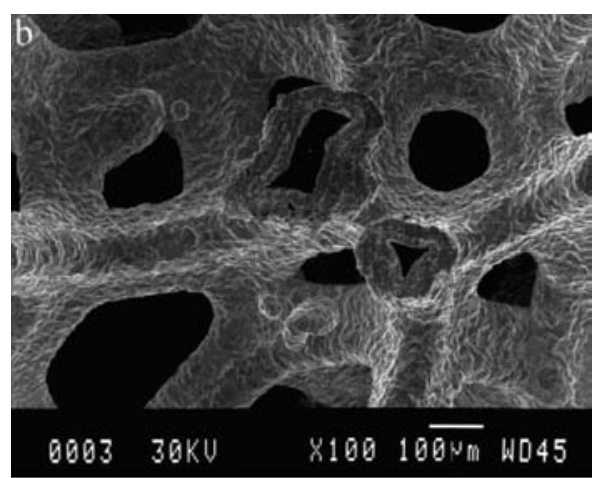

Fig. 2.18. Espuma de tántalo [Zardiackas 2001]

Como conclusión, cabe indicar que, de entre los materiales existentes, los polímeros se utilizan habitualmente en sustitución de tejidos blandos, mientras que las cerámicas suelen utilizarse en superficies articulantes 0 como recubrimiento para fomentar el desarrollo del hueso. Entre los materiales metálicos, las aleaciones base titanio presentan la mejor combinación de propiedades de cara a un uso como implante. No obstante, poseen reducida resistencia al desgaste y, aunque su rigidez es inferior a la del resto de materiales metálicos utilizados, todavía resulta elevada en 
comparación con la del hueso humano. Dichos inconvenientes han propiciado el desarrollo de numerosas investigaciones con el fin tanto de incrementar la resistencia al rozamiento [Sakamoto 2006, Xuanyong 2004, Rodríguez 1999, Smallmann 1962], como de reducir su rigidez [Niinomi 2008, Rack 2006, Schuch 2007, Cirincione 2002, Kujala 2003, Nomura 2005, Li J.P. 2006].

Pese a que la presente investigación se centrará fundamentalmente en el desarrollo de piezas porosas de titanio menos rígidas, resistentes y con una porosidad y tamaño de poro adecuados para permitir el crecimiento óseo; se analizarán las diferentes técnicas utilizables para incrementar las propiedades tribológicas del material, tratando así de conocer posibilidades de mejora de las piezas porosas obtenidas en la presente tesis.

\subsection{POROSIDAD Y TAMAÑO DE PORO A DESARROLLAR.}

Tal como se ha indicado, de entre los materiales metálicos utilizables como implantes, las aleaciones de titanio presentan la mejor combinación de propiedades. No obstante, su rigidez resulta muy elevada en comparación con la del hueso humano, lo que conlleva problemas de debilitamiento óseo y aflojamiento del implante [Simske 1997, Vallet 2000]. Por otra parte, la creación de rugosidad superficial, o porosidad interconectada adecuadas facilitan el desarrollo del hueso y, con ello, la rápida recuperación del paciente [Kupp 2002, Gaona 2007].

Por tanto, uno de los principales parámetros a observar en los implantes desarrollados será su porosidad. Por una parte, el desarrollo de una estructura porosa permitirá reducir la rigidez del implante mientras que, para permitir el crecimiento de los tejidos óseos dicha porosidad deberá ser interconectada y poseer un tamaño de poro suficiente [Wen 2002b, Oh 2003a, Dewidar 2005, Köhl 2007].

Según diversos autores la porosidad óptima para permitir el crecimiento de los tejidos óseos se sitúa entre el 20 y 80\% [Oh 2003a, Bansiddhi 2008]. 
Pese a que no existe unanimidad en relación al tamaño de poro idóneo que permita la adhesión y crecimiento de los osteoblastos, diversos autores lo sitúan entre 100 y $\mathbf{5 0 0 ~ \mu m ~ [ S i m s k e ~ 1 9 9 7 , ~ W e n ~ 2 0 0 2 b , ~ K u p p ~ 2 0 0 2 , ~ D e w i d a r ~}$ 2005, Takemoto 2006, Bansiddhi 2008], tal que permita desarrollar los conductos sanguíneos por una parte $(\approx 450 \mu \mathrm{m})$, y las células del hueso por otra $(\approx 100 \mu \mathrm{m})$ [Bram 2005].

En el caso de las piezas porosas desarrolladas por sinterización de microesferas, este tamaño de poro podría asemejarse al de una ordenación cristalina. Así, pese a que todas las partículas no poseerán el mismo tamaño, sino que existirá una distribución granulométrica, y la ordenación de éstas no será perfecta, la porosidad total, número de microesferas en contacto y tamaño de poro, dependerán de su ordenación en el espacio. Por tanto, en cierta medida pueden adoptarse los parámetros de las redes cristalinas teóricas recogidos en la tabla 2.6 para predecir estas propiedades sobre las piezas porosas desarrolladas. Concretamente, la tabla recoge, para las ordenaciones cúbica centrad en caras (CCC), cúbica centrada en cuerpo (CC) y hexagonal compacta $(\mathrm{HC})$, el factor de empaquetamiento (factor de ocupación del espacio), tamaño de poro en función del tamaño de la microesfera de partida e índice de coordinación ( $n^{\circ}$ de átomos en contacto con otro).

Tal como se observa, las ordenaciones CCC y $\mathrm{HC}$ resultan las menos porosas, coincidiendo en ellas el tamaño de los huecos, que resulta distinto, e inferior en relación al tamaño de la microesfera, en la ordenación cúbica centrada en cuerpo (CC). En este sentido, al representar el tamaño de poro teórico para las distintas ordenaciones cristalinas, en función del tamaño medio de la esfera, figura 2.19, se observa como, para lograr el tamaño de poro crítico establecido (entre 100 y $500 \mu \mathrm{m}$ ), las esferas deberían tener, en el mejor de los supuestos (hueco octaédrico en $\mathrm{CCC}$ o HC) un diámetro superior a 250 micras. 
Tabla 2.6. Parámetros de las estructuras cristalinas CCC, CC y HC. O Disolvente; oátomos insertados [Schatt 1997, Pero-Sanz 2000, Asbhy 2005].

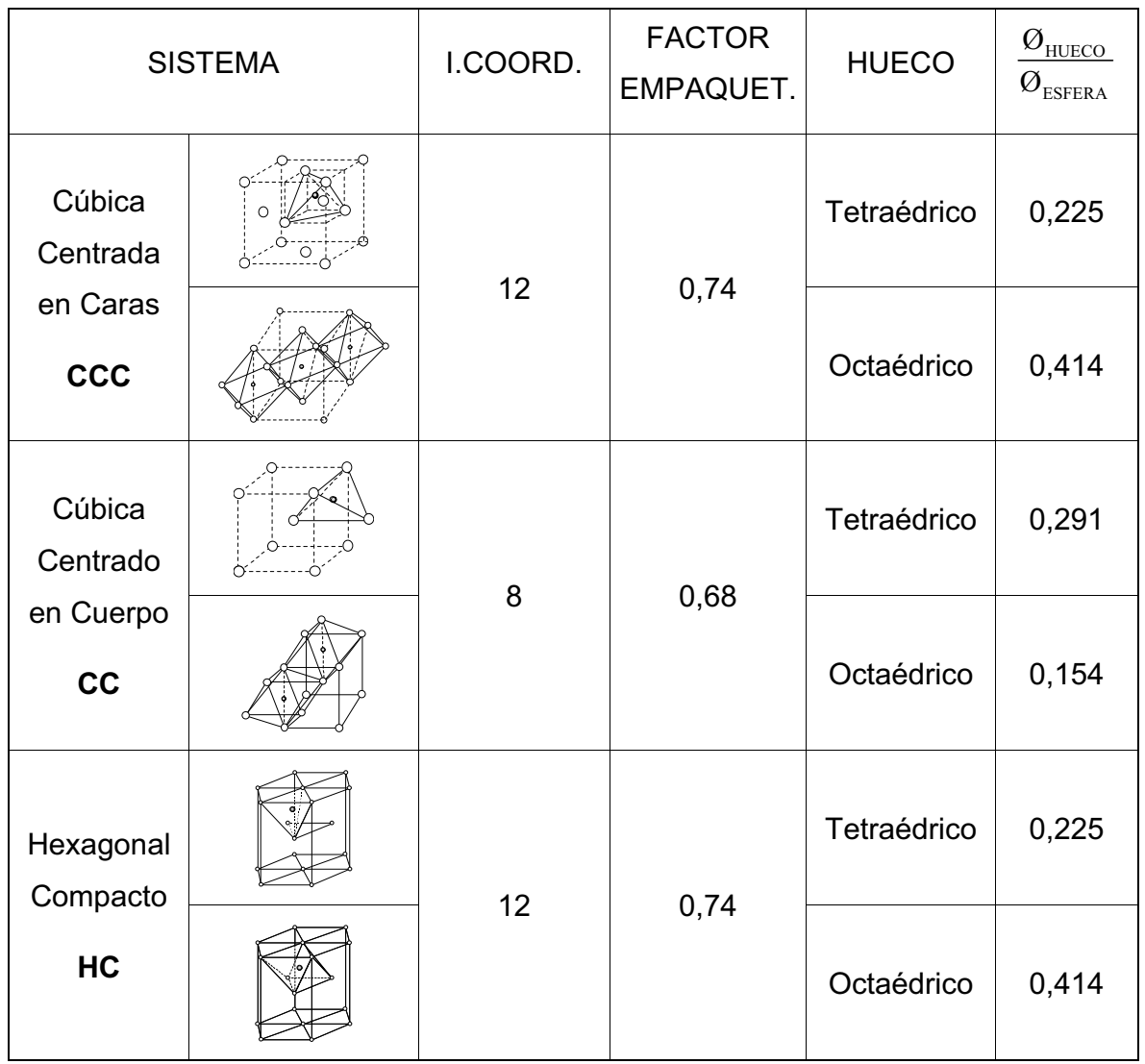

Tamaño poro según ordenación cristalina

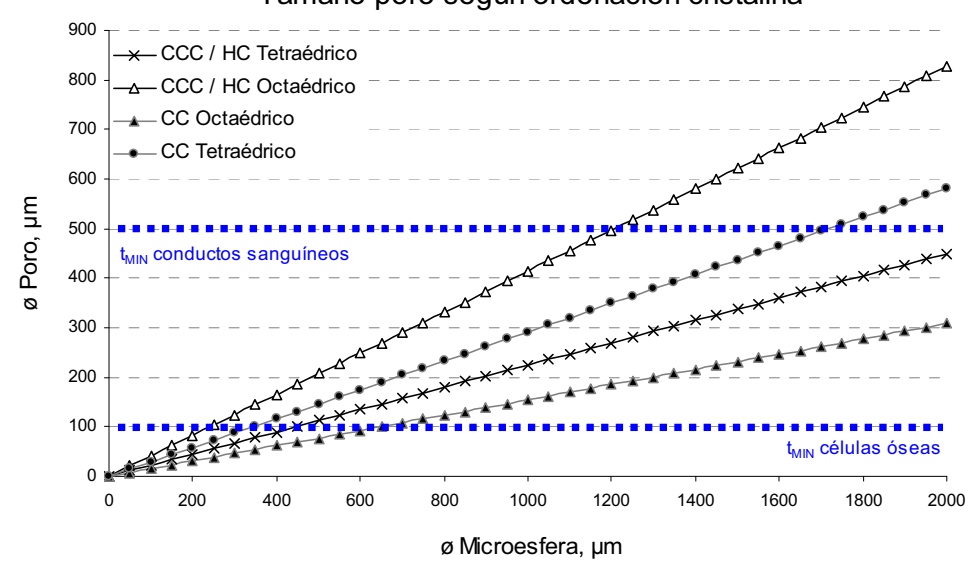

Fig. 2.19. Evolución del tamaño de poro teórico para distintas ordenaciones cristalinas en función del tamaño de la esfera. 


\subsection{PROPIEDADES MECÁNICAS A OBTENER.}

Tal como se ha indicado, el objetivo de la presente tesis es desarrollar piezas de titanio menos rígidas y con aptitud para la osteointegración mediante el desarrollo de porosidad. Como se ha visto, para permitir el desarrollo del hueso es necesario generar una porosidad interconectada y con un tamaño de poro mínimo de $100 \mu \mathrm{m}$. No obstante, para cumplir adecuadamente su función, el implante debe presentar unas propiedades mecánicas mínimas, que se verán mermadas con el desarrollo de porosidad. Por tanto, deberemos buscar un compromiso entre el grado de porosidad, tamaño de poro, rigidez y propiedades mecánicas obtenidas.

En relación a la resistencia a obtener, cabe indicar que el tejido óseo presenta un comportamiento anisótropo, con una resistencia y rigidez máximas en el sentido longitudinal. Por otra parte, la resistencia ósea resulta máxima a compresión, siendo inferior a tracción y flexión [Comín 1999, Heimann 2002]. La tabla 2.7 [adaptada de Comín 1999, Wen 2002 a, Heimann 2002, Asaoka 2003] recoge el módulo de Young, límite elástico a compresión, y tensión de rotura a tracción y compresión de diferentes huesos del cuerpo humano. Pese a que no se incluye en la tabla, la resistencia a flexión del hueso cortical oscila entorno a 100 MPa [Heimann 2002].

Tabla 2.7. Propiedades mecánicas de diferentes huesos del cuerpo humano.

\begin{tabular}{|c|c|c|c|c|c|}
\hline \multirow{2}{*}{ Tipo de hueso } & \multirow{2}{*}{ Hueso } & \multirow{2}{*}{$\mathrm{E}, \mathrm{GPa}$} & \multirow{2}{*}{$\sigma_{Y C}, \mathrm{MPa}$} & \multicolumn{2}{|c|}{$\sigma_{\mathrm{R}}, \mathrm{MPa}$} \\
\hline & & & & Compresión & Tracción \\
\hline \multirow{4}{*}{ CORTICAL } & Fémur & $12-27,4$ & 121 & $167-206$ & $133-134,5$ \\
\hline & Tibia & $14-18,1$ & 140 & $130-201$ & 156 \\
\hline & Radio & $12-18,6$ & 149 & $114-200$ & - \\
\hline & Húmero & 17,2 & 130 & 132 & - \\
\hline \multirow{2}{*}{ ESPONJOSO } & $\begin{array}{l}\text { Cabeza } \\
\text { Femoral }\end{array}$ & 2,9 & - & 68 & - \\
\hline & Vertebras & $0,23-1,5$ & $3,1-3,7$ & $4,1-10$ & - \\
\hline
\end{tabular}


Por tanto, las piezas porosas desarrolladas en la presente tesis deberán tener una rigidez entorno a $10-30 \mathrm{GPa}$, una porosidad mínima del $20 \%$ con un tamaño de poro superior a $100 \mu \mathrm{m}$, así como una resistencia a flexión y a compresión de, como mínimo, 100 y 200 MPa respectivamente. Además de estas propiedades, en las que se centrará la presente investigación, otros aspectos de vital importancia de cara al comportamiento en servicio de la pieza porosa, como son su resistencia a fatiga, a la corrosión o su aptitud ante el desarrollo de células óseas, serán estudiados por otros grupos de investigación.

\subsection{PARTICULARIDADES DE LOS METALES POROSOS.}

Como se ha venido indicando en los apartados previos, las piezas porosas desarrolladas deberán hacer frente a unas determinadas exigencias. Con el fin de analizar las propiedades de espumas y piezas porosas metálicas y poder preveer el comportamiento del material, cabe atender a los parámetros que determinan en mayor medida sus propiedades, como son:

- Propiedades intrínsecas del material sólido que conforma las paredes de las celdas ("bulk material").

- Densidad relativa.

- Tipo de estructura celular: abierta o cerrada.

- Cuando la porosidad es cerrada, la fracción de material sólido contenido en las paredes entre macroporos.

- Inhomogeneidades en la distribución del material.

- Tamaño y distribución de tamaños de las celdas.

- Forma y anisotropía de las celdas.

- Conectividad entre macroporos.

- Defectos, como la rotura de paredes de celda.

Entre todas ellas, la característica más importante es la densidad relativa $\left(\rho^{*} / \rho_{s}\right)$, es decir, la densidad de la pieza porosa comparada con la del metal denso. En general se consideran espumas metálicas las piezas porosas con una densidad relativa inferior a 0,3 , mientras que cuando se supera este 
valor, se habla de metales porosos, pero no de espumas como tal [Gibson 1999, Degischer 2002].

La densidad relativa es de gran utilidad para describir el material a nivel "macro". No obstante, otros aspectos como la forma y distribución de los poros (denominada estructura geométrica o arquitectura), anisotropía, rugosidad, curvatura de las celdillas... resultan también de gran interés, pues influyen sobre propiedades como la rigidez o resistencia de la pieza, al tiempo que pueden conllevar densidades no homogéneas a lo largo de ésta, lo que va en detrimento de las características de la pieza obtenida.

En este sentido, cabe indicar que la influencia de los distintos parámetros depende de la propiedad en cuestión pues, mientras que características como la estructura cristalina o la temperatura de fusión no varían con la densidad, otras como la rigidez y resistencia mecánica si se modifican, viéndose además afectadas por la morfología y distribución de los poros en el material [Degischer 2002].

Por otra parte, diversos modelos relacionan las propiedades de las espumas con las características de la pieza porosa, siendo el más conocido de ellos el obtenido por Gibson-Asbhy [Asbhy 2000]. Los autores proponen un modelo de correlación para espumas de célula abierta con densidad relativa inferior a 0,2, según el cual algunas propiedades físicas y mecánicas siguen la ley expresada en la ecuación (2.1):

$$
A\left(\rho_{r}\right)=A_{0} \times \rho_{r}^{n}
$$

Donde $\rho_{r}$ es la densidad relativa y $A_{0}$ y $n$ son parámetros del material y dependen de diversos factores, como la influencia de una membrana exterior densa, o la dirección de espumación.

Para espumas de mayor densidad la extensión o compresión de las aristas de las celdillas modifican su curvatura, por lo que, al variar el mecanismo de deformación, es de esperar una desviación respecto al modelo propuesto [Degischer 2002]. 
Otros factores determinantes del comportamiento de la espuma son la microestructura y características del metal base, pues determinan su comportamiento, distinguiéndose entre espumas elastoméricas, elastoplásticas y frágiles. A compresión estas tres tipologías muestran un comportamiento similar, pero motivado por distintas razones, de forma que las espumas elásticas presentan una deformación más 0 menos recuperable, mientras que en espumas plásticas y frágiles la deformación no se recupera. Así, mientras que las espumas elásticas rompen por deformación elástica de las paredes de las celdillas, en espumas frágiles se produce la rotura de las paredes de celda.

Cabe indicar además que espumas metálicas de densidad relativa inferior a 0,2 , siempre exhiben un plateau (deformación a tensión constante) tras un comportamiento elástico. Dado que, en general, el comportamiento a compresión de las espumas metálicas es dúctil, presentan una primera región elástica (no tan claramente establecida como en el material sólido), seguida de un endurecimiento (inducido además por la redistribución de regiones deformadas), un plateau y densificación final.

La estructura porosa de estos materiales origina concentraciones de tensiones en determinados puntos, con lo que el material plastifica y se produce cierta deformación no reversible en el tramo aparentemente elástico. Por ello, resulta más apropiado hablar de rigidez de la estructura celular, en lugar de módulo de Young [Banhart 2001, Degisher 2002]. En consecuencia, el análisis de la pendiente de la curva tensión - deformación permite comparar la rigidez de los materiales desarrollados, pero no su modulo de Young como tal. Por ello, diversos autores han utilizado métodos de ultrasonidos para determinar el módulo elástico. Mediante estos procedimientos se aplica una deformación muy reducida sobre la espuma, y se obtienen resultados significativamente mas elevados que los determinados a tracción o a compresión [Inoue 1984, Panakkal 1997, Zhu 2007]. 
Como se ha indicado, otra de las características de gran importancia de cara a la durabilidad de un implante es su vida a fatiga. En este sentido, cabe indicar que las ventajas que aportan los implantes porosos pueden verse mitigadas por la reducción de resistencia a fatiga que originan los propios poros [Simske 1997]. La superficie irregular de los poros, así como su reducido radio de curvatura actúan como concentradores de tensiones ante las cargas cíclicas que debe soportar el implante durante su vida útil, provocando que en determinadas áreas el material plastifique y se inicie una grieta. Estudios realizados han demostrado que implantes de Ti64 con recubrimientos porosos presentan un tercio de la resistencia a fatiga respecto al metal sin recubrir, lo que es debido a la concentración de tensiones en regiones especificas del implante. No obstante, el problema puede reducirse modificando la geometría de la interfase entre ambos [Simske 1997, Kupp 2002].

Un último aspecto a destacar seria la dispersión de resultados en materiales porosos, pues resulta mayor que en productos densos [Banhart 1998]. Ello es debido a diversas causas, como una distribución de densidad generalmente no homogénea, la existencia de microdefectos, como grietas en paredes de las celdillas o la formación de macroporos de dimensiones superiores a la media y su posición dentro de la pieza porosa, pues cuanto más próximo a la superficie, resulta más perjudicial, al no poder compensarse el efecto con material circundante. Por ello, otro aspecto de importancia de cara a la calidad de las piezas desarrolladas, es la reproducibilidad de propiedades, manteniendo unas tolerancias geométricas determinadas y homogeneidad en sus características más relevantes de cara a su puesta en servicio [Degisher 2002].

En definitiva, existen distintos parámetros que condicionan las propiedades de las espumas metálicas, siendo los más influyentes su densidad relativa y arquitectura celular. Por otra parte, debido a la estructura no homogénea de las espuma metálicas, es de esperar que los esfuerzos se localicen al aplicar tensión, produciéndose cierta plastificación en el tramo 
aparentemente elástico. Por ello, al determinar la rigidez mediante la pendiente de la curva tensión-deformación, resulta más apropiado hablar de rigidez en lugar de módulo de Young.

\subsection{TRATAMIENTOS TÉRMICOS APLICABLES SOBRE ALEACIONES DE TITANIO.}

Como se ha visto, mediante el desarrollo de porosidad se pretende reducir la rigidez del implante $\mathrm{y}$, si el tamaño de poro y nivel de porosidad alcanzada lo permiten, facilitar la integración ósea. No obstante, el desarrollo de porosidad también implica la merma de determinadas propiedades, como la resistencia mecánica y a fatiga. Por ello, los tratamientos térmicos se aplicarán con el fin de optimizar las propiedades de la pieza porosa obtenida mediante la modificación de su microestructura [Baeslack 1993, Rodríguez 2001, Amigó 2003b].

Tal como se ha visto, en las aleaciones de titanio, uno de los aspectos de mayor importancia a considerar es la reactividad de este material. Así, el empleo de atmósferas como aire o agua para la aplicación de los tratamientos térmicos provoca la reacción de los gases presentes $(\mathrm{O}, \mathrm{N}, \mathrm{H})$ con la superficie del metal, conformando una capa frágil denominada $\alpha$ case, figura 2.20, que necesariamente debe ser eliminada de la pieza antes de su puesta en servicio. Pese a que esta capa puede eliminarse por mecanizado, ello puede ocasionar un desgaste excesivo del utillaje empleado para ello, por lo que en ocasiones conviene utilizar medios químicos [ASM N4 1994]. Por otra parte, en piezas porosas dicha capa se originaria a lo largo de toda la pieza y no únicamente en superficie, por lo que su completa eliminación resulta todavía más compleja. 


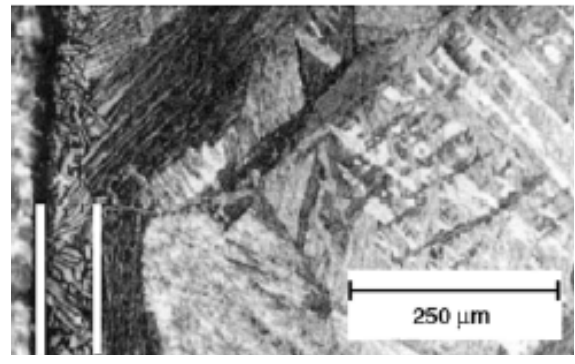

a

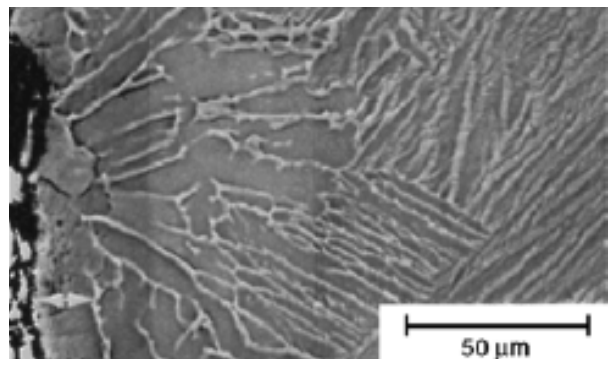

b

Fig. 2.20. "Alpha case": a) $\alpha$-case desarrollada en la superficie de una pieza de titanio obtenida por colada en arena; b) Detalle [ASM N9 2004]

Por tanto, dado que de cara a una aplicación como implante resulta de vital importancia evitar la contaminación de la pieza con el fin de evitar su fragilización, los tratamientos térmicos realizados sobre piezas porosas de titanio deben llevarse a cabo en vacío o bajo atmósfera inerte.

Por otro lado, conviene recalcar que, previo a la realización de cualquier tratamiento térmico las piezas de titanio deben estar completamente limpias, para lo cual se eliminarán los posibles restos de grasas, pinturas, aceites... pues la elevada reactividad del titanio a elevadas temperaturas puede conducir a su absorción, incrementando su fragilización y susceptibilidad a la corrosión bajo tensión.

Cabe indicar además que la aplicación de tratamientos térmicos resulta más compleja sobre espumas que en material denso [Banhart 2001]. Ello es debido a la convergencia de diversos factores entre los que cabe destacar la densidad no homogénea de la pieza porosa y su menor conductividad térmica, lo que reduce la velocidad de temple. A ello cabe sumar además la reducida conductividad térmica de las aleaciones de titanio, lo que dificulta la realización de estos tratamientos, pues retrasa la consecución de una temperatura homogénea en la pieza.

La respuesta del titanio a los tratamientos térmicos depende fundamentalmente de su composición química y velocidad de enfriamiento desde fase $\beta$ [Tarín 1995, Gil 2001, Beliavin 2004]. Dado que las aleaciones 
tipo $\alpha / \beta$ poseen ambas fases a temperatura ambiente, resultan las más comunes y versátiles, pues permiten modificar la composición y distribución de fases mediante la aplicación de tratamientos térmicos o termomecánicos [ASM N4 1994].

En el enfriamiento, la fase $\alpha$ empieza a formarse después de la temperatura de transición $\beta\left(1000+/-20^{\circ} \mathrm{C}\right.$ para el Ti64 [ASM N4 1994]). Si el enfriamiento es lento, la fase $\beta$ empieza a descomponer por un proceso de difusión (nucleación y crecimiento), conformándose una estructura denominada Widmanstätten, producto de la precipitación en forma de laminillas de la fase $\alpha$ dentro de la matriz $\beta$, figura 2.21. Cuanto menor la velocidad de enfriamiento, mayor la longitud y espesor de los granos [Tarín 1999, Rodríguez 1999, ASM N4 1994]. La aleación Ti64 enfriada lentamente puede contener hasta un $90 \% \mathrm{v}$ de fase $\alpha$ [ASM N9 2004].

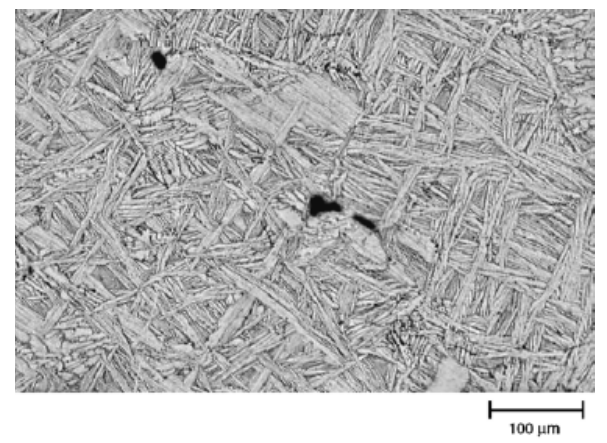

Fig. 2.21. Microestructura tipo Widmanstätten de la aleación Ti-6Al-4V enfriada lentamente desde fase $\beta$ [ASM N9 2004].

A mayor velocidad de enfriamiento, más finas resultan las láminas resultantes, hasta el punto que un temple rápido provoca una transformación martensítica de la fase $\beta$, figura 2.22. En este caso la descomposición de la fase $\beta$ se produce en ausencia de difusión y se genera una microestructura muy fina [Gil 2001, ASM N4 1994]. Pese a que la fuerte distorsión originada en la red cristalina provoca un endurecimiento e incremento de resistencia del material, éste es moderado en comparación con el acero [Beliavin 2004]. 


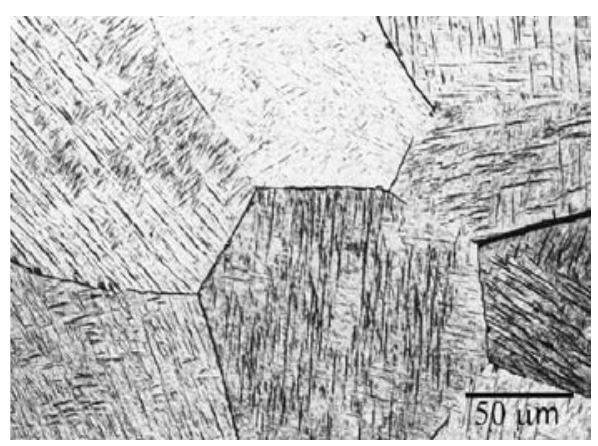

Fig. 2.22. Microestructuras martensítica de la aleación Ti6Al4V [Rodríguez 1999].

La martensita es una fase $\alpha$ sobresaturada generada por transformación sin difusión desde la fase $\beta$. En función de la composición química y las condiciones de temple puede formarse una martensita tipo $\alpha$, de estructura HC o tipo $\alpha "$, de estructura ortorrómbica. Así, en el caso concreto de la aleación Ti6Al4V, al templar desde temperaturas superiores a $900{ }^{\circ} \mathrm{C}$ se forma martensita tipo $\alpha^{\prime}$, mientras que a temperaturas inferiores (750 a 900 ${ }^{\circ} \mathrm{C}$ ) la microestructura resultante puede ser una mezcla de $\alpha^{\prime}+\alpha$ ", [Leyens 2003, ASM N9 2004].

La martensita tipo $\alpha$ ' tiene morfología acicular, con una ordenación cristalina y parámetros de red similares a la fase $\alpha$ HC [Gil 2001]. Por el contrario, la martensita ortorrómbica, tipo $\alpha$ ", es bastante blanda y dúctil y suele generarse con contenidos en vanadio del orden del $10 \% \mathrm{Wt}$. Mientras que la $\alpha$ " puede formarse tanto por enfriamiento rápido como por aplicación de tensión (deformación de la fase $\beta$ metaestable), $\alpha$ '́nicamente puede obtenerse por temple [Tarín 1995. ASM N9 2004].

En relación al desarrollo de microestructuras con fase $\beta$ retenida 0 metaestable ( $\beta$ ') a temperatura ambiente, cabe indicar que ello únicamente es posible en aleaciones tipo $\beta$ o $\alpha+\beta$ con suficiente cantidad de elementos estabilizadores de dicha fase. A medida que crece el contenido en aleantes $\beta$, se obtiene por temple una mezcla de martensita y fase $\beta$ ' metaestable, hasta el punto de que, cuando se alcanzan contenidos en $\beta$ suficientemente 
elevados la única fase obtenida es $\beta$ ' metaestable, pues no llega a iniciarse transformación martensítica [Tarín 1999, Rodríguez 1999].

Por otra parte, es importante señalar la reducida templabilidad de las aleaciones de titanio, tanto menor cuanto menor es el contenido de elementos estabilizadores de la fase $\beta$. A medida que el contenido en aleantes $\beta$ aumenta, la velocidad de temple puede reducirse, figura 2.23, con lo que éste puede llevarse a cabo en medios menos agresivos. Por tanto, en aleaciones tipo $\beta$ o con un contenido relativamente elevado de estabilizantes $\beta$, así como en piezas de reducida sección el enfriamiento al aire $o$ en ventiladores puede ser suficiente, lo que se prefiere frente a medios más agresivos de enfriamiento, pues la distorsión producida es menor. No obstante, debe apuntarse que, si el enfriamiento es demasiado lento, la fase $\beta$ difunde, originándose pérdidas apreciables de resistencia y plasticidad.

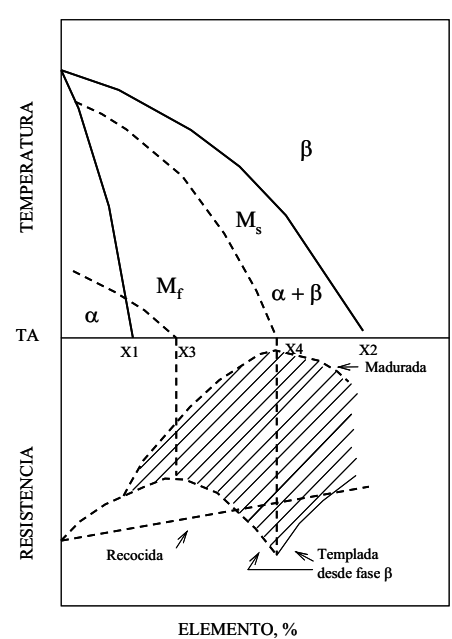

Fig. 2.23. Diagrama esquemático para tratamientos térmicos de aleaciones de titanio y resistencias obtenibles [Tarín 1999].

Generalmente, tras el tratamiento de temple las aleaciones de titanio son recalentadas a temperaturas entre 425 y $600{ }^{\circ} \mathrm{C}$, generándose la descomposición de la fase $\beta$ sobresaturada que había quedado retenida en 
el temple (proceso denominado maduración), o provocando la descomposición de la martensita en $\alpha+\beta$ (revenido), lo que mejora la resistencia de la aleación [ASM N4 1994, Tarín 1995, Gil 1996]. Dicha precipitación se produce por un proceso de nucleación y crecimiento controlado por difusión, por lo que el nivel de descomposición depende de la temperatura y tiempo, siendo este último menor a medida que aumenta la temperatura. Así, a temperaturas superiores al fin de la transformación martensítica $\left(\approx 800^{\circ} \mathrm{C}\right.$ ) la descomposición es total, produciendo una alta saturación de la matriz, lo que genera los valores más elevados de dureza.

Comparando las durezas de temple con las conseguidas tras la maduración se observa que los mayores incrementos de dureza se producen para las máximas cantidades de fase $\beta$ metaestable retenida pues, a pesar de que la martensita sí incrementa su dureza, lo hace en un grado muy inferior. No obstante, la maduración de la fase $\beta$ retenida puede ocasionar la formación de una fase intermedia omega $(\omega)$ finamente dispersa y muy frágil, lo que resultaría inaceptable de cara a las propiedades del producto final. Por ello, debe evitarse su formación mediante calentamientos a temperaturas superiores a $500{ }^{\circ} \mathrm{C}$, durante un tiempo suficiente para completar la transformación de la fase $\omega$ a fase $\alpha$. No obstante, ésta fase frágil no suele formarse en aleaciones con un contenido en aluminio superior al $3 \%$.

De forma práctica, para obtener una buena resistencia con adecuada ductilidad en aleaciones tipo $\alpha+\beta$, debe solubilizarse generalmente a temperatura elevada dentro de la región $\alpha+\beta$, entre 25 y $85^{\circ} \mathrm{C}$ por debajo de la temperatura de transición de la aleación. Por el contrario, cuando se desea incrementar la tenacidad a la fractura o la resistencia a la corrosión bajo tensión, la solubilización debe realizarse desde fase $\beta$, aunque ello implique pérdida de ductilidad. En este sentido, cabe indicar que la pérdida de propiedades, especialmente la ductilidad, resultan difícilmente recuperables con tratamientos posteriores [ASM N4 1994]. 
Además de las microestructuras lamelares descritas hasta el momento, la aplicación de otros tratamientos termomecánicos permite obtener estructuras tipo equiaxiales o bimodales (mixtas entre ambas). Mientras que las estructuras equiaxiales se obtienen por procesos de recristalización, por lo que requieren una deformación en frío previa, las aciculares únicamente puede obtenerse mediante tratamientos térmicos (temple y recocido) [Hagiwara 1998], lo que hace más interesantes a éstos últimos de cara a su aplicación a las piezas porosas desarrolladas. Por otra parte, las microestructuras bimodales (granos $\alpha$ aislados en una matriz $\beta$ transformada) pueden obtenerse con un recocido a $950^{\circ} \mathrm{C}$, seguido de un temple en agua o enfriamiento al aire y un envejecido a $600{ }^{\circ} \mathrm{C}$ [Rodríguez 1999].

En las aleaciones $\alpha+\beta$ la estructura equiaxial está conformada por granos equiaxiales embebidos en una matriz de $\alpha+\beta$ con una morfología característica tipo cesta generada durante el enfriamiento desde fase $\beta$, figura 2.24. Esta estructura, conocida como "mill-annealed", depende mucho del trabajado previo del material y su grado de acritud y presenta una buena combinación de resistencia, tenacidad, ductilidad y resistencia a la fatiga [Rodríguez 1999].

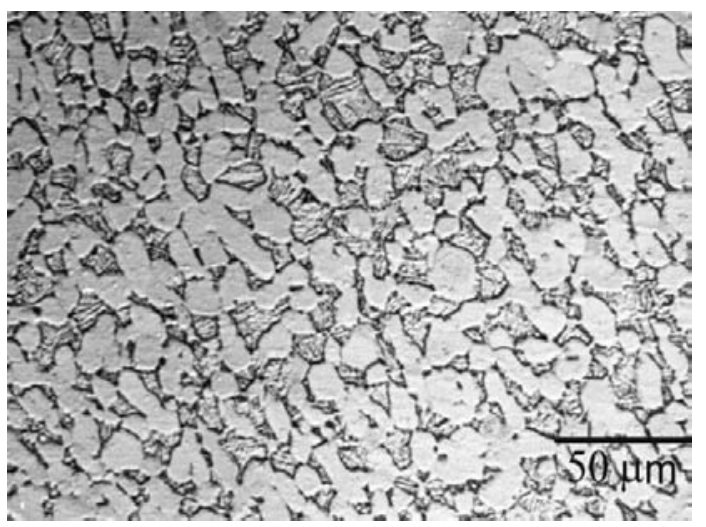

Fig. 2.24. Microestructura mill - annealed del Ti6Al4V [Rodríguez 1999]. 
A modo de síntesis, la tabla 2.8 recoge los tratamientos térmicos habitualmente empleados en aleaciones tipo $\alpha+\beta$ y las microestructuras resultantes.

Tabla 2.8. Tratamientos térmicos habituales de las aleaciones de titanio tipo $\alpha+\beta$ [ASM N4 1994].

\begin{tabular}{|c|c|c|}
\hline DESIGNACIÓN & CICLO TÉRMICO & MICROESTRUCTURA \\
\hline Recocido Dúplex & $\begin{array}{l}\text { Solución a } 50-75^{\circ} \mathrm{C}< \\
\text { Transición } \beta \text {, enfriamiento } \\
\text { en aire y envejecido a } \\
540-675^{\circ} \mathrm{C} \text { de } 2-8 \mathrm{~h} .\end{array}$ & $\begin{array}{l}\alpha \text { Primaria con regiones } \\
\alpha-\beta \text { tipo Widmanstätten }\end{array}$ \\
\hline Solución y envejecido & $\begin{array}{l}\text { Solución a } 40< \\
\text { Transición } \beta \text {, temple en } \\
\text { agua y envejecido a } 535- \\
675^{\circ} \mathrm{C} \text { de } 2-8 \mathrm{~h} \text {. }\end{array}$ & $\begin{array}{l}\alpha \text { Primaria con una } \\
\text { mezcla de } \alpha^{\prime} \text { o mezcla de } \\
\alpha-\beta \text {. }\end{array}$ \\
\hline Recocido $\beta$ & $\begin{array}{l}\text { Solución a } 15^{\circ} \mathrm{C}> \\
\text { Transición } \beta \text {, enfriamiento } \\
\text { en aire y estabilización a } \\
650-760^{\circ} \mathrm{C} \text { durante } 2 \mathrm{~h} \text {. }\end{array}$ & $\begin{array}{l}\text { Widmanstätten, formada } \\
\text { por colonias de } \alpha-\beta \text {. }\end{array}$ \\
\hline Temple $\beta$ & $\begin{array}{l}\text { Solución a } 15^{\circ} \mathrm{C}> \\
\text { Transición } \beta \text {, temple en } \\
\text { agua y estabilización a } \\
650-760^{\circ} \mathrm{C} \text { durante } 2 \mathrm{~h} \text {. }\end{array}$ & $\alpha^{\prime}$ de temple \\
\hline $\begin{array}{l}\text { Recocido de } \\
\text { recristalización }\end{array}$ & $\begin{array}{l}924^{\circ} \mathrm{C} \text { durante } 4 \mathrm{~h} \text {, } \\
\text { enfriamiento a } 50^{\circ} \mathrm{C} / \mathrm{h} \\
\text { hasta } 760^{\circ} \mathrm{C} \text { y } \\
\text { enfriamiento en aire }\end{array}$ & $\begin{array}{l}\alpha \text { equiaxial } \operatorname{con} \beta \text { en } \\
\text { borde de grano. }\end{array}$ \\
\hline
\end{tabular}

En relación a las propiedades que aporta cada una de las microestructuras descritas, cabe indicar que, en general, microestructuras finas incrementan tanto la resistencia como la ductilidad, además de retrasar la nucleación de grietas, mientras que tamaños de grano más groseros ofrecen mayor 
resistencia al creep y al crecimiento de grieta por fatiga [Leyens 2003, ASM N9 2004].

Por otra parte, en comparación con microestructuras laminares, las equiaxiales son dúctiles y presentan mayor resistencia a la iniciación de grietas por fatiga, mientras que las laminares son más tenaces y más resistentes al creep y a la propagación de grietas por fatiga [Hagiwara 1998, Rodríguez 2001, Gil 2001]. La elevada tenacidad de la microestructura laminar es debida a la facilidad de desviar la grieta entre las diferentes láminas [Leyens 2003, Kupp 2002].

Además de los tratamientos descritos, existen otros específicos que se aplican sobre determinadas aleaciones con el fin de mejorar algunas propiedades concretas, como la tenacidad a la fractura o la resistencia a fatiga. Entre ellos, uno de los empleados con mayor éxito en la aleación Ti6Al4V, ha sido el denominado "Broken-Up Structure" (BUS), con el que se obtiene una microestructura conformada por fase $\alpha$ de reducido tamaño embebida en una matriz $\beta$, figura 2.25, [Amigo 2003b, ASM N9 2004].

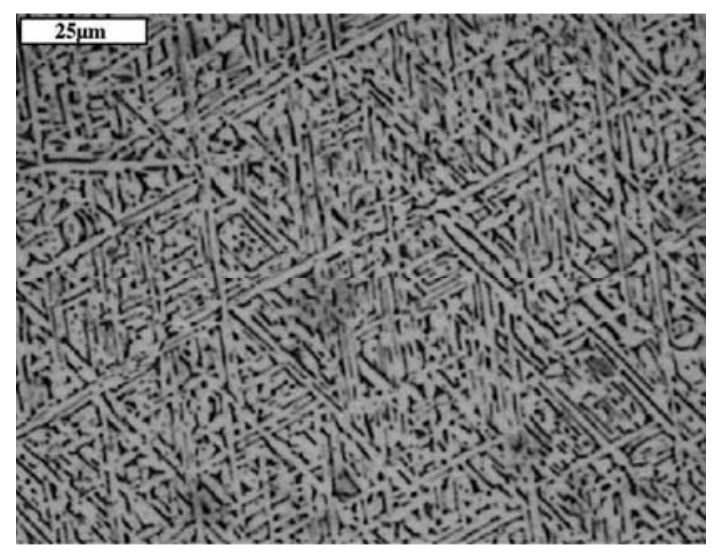

Fig. 2.25. Microestructura "broken-up" de un implante sobre el que se ha realizado el tratamiento BUS [Amigo 2003b]. 
La tabla 2.9 recoge algunos tratamientos específicos aplicables sobre la aleación Ti6Al4V, empleada en la presente investigación.

Tabla 2.9. Tratamientos térmicos aplicables sobre la aleación Ti6Al4V [Adaptada de ASM N4 1994, Amigo 2003b, ASM N9 2004].

\begin{tabular}{|c|c|c|c|c|}
\hline Etapa & $\begin{array}{l}\text { Solución y } \\
\text { envejecido }\end{array}$ & $\begin{array}{c}\text { Recocido } \\
\text { Recristalización }\end{array}$ & Recocido Beta & BUS \\
\hline SOLUCION & $\begin{array}{c}955^{\circ} \mathrm{C} \\
1 \mathrm{~h}\end{array}$ & $\begin{array}{c}925-950^{\circ} \mathrm{C} \\
\geq 4 h\end{array}$ & $\begin{array}{c}1010-1040^{\circ} \mathrm{C} \\
5-60 \mathrm{~min} .\end{array}$ & $\begin{array}{l}\approx 1025^{\circ} \mathrm{C} \\
30 \mathrm{~min} .\end{array}$ \\
\hline ENFRIAM. 1 & $\begin{array}{c}\text { Temple en } \\
\qquad \mathrm{H}_{2} \mathrm{O}\end{array}$ & $\begin{array}{c}\text { En horno hasta } \\
760^{\circ} \mathrm{C} \\
\text { a } 56^{\circ} \mathrm{C} / \mathrm{h} \text { Max. }\end{array}$ & $\begin{array}{l}\text { En aire hasta } \\
650^{\circ} \mathrm{C} \text { a } 85 \\
{ }^{\circ} \mathrm{C} / \mathrm{min} .\end{array}$ & Temple en ar. \\
\hline ENVEJECIDO & $\begin{array}{c}705^{\circ} \mathrm{C} \\
2 \mathrm{~h}\end{array}$ & $\begin{array}{l}\text { Enfriamiento } \\
\text { hasta } 480^{\circ} \mathrm{C} \text { a } \\
370{ }^{\circ} \mathrm{C} / \mathrm{h} \mathrm{min} .\end{array}$ & $\begin{array}{c}730-790^{\circ} \mathrm{C} \\
2 \mathrm{~h}\end{array}$ & $\begin{array}{l}850^{\circ} \mathrm{C} \\
2-8 \mathrm{~h}\end{array}$ \\
\hline ENFRIAM. 2 & Aire & Aire & Aire & Enfriamiento \\
\hline Propiedades & $\begin{array}{l}\uparrow \text { "notch } \\
\text { strength" } \\
\uparrow \text { Tenacidad } \\
\uparrow \text { R. Creep } \\
\approx \text { R. mecánica }\end{array}$ & $\begin{array}{l}\uparrow \text { Tenacidad a } \\
\text { la fractura } \\
\uparrow \mathrm{R} \text {. A la } \\
\text { propagación de } \\
\text { grietas por } \\
\text { fatiga } \\
\downarrow \text { R.mecanica } \\
\text { ligeramente }\end{array}$ & $\begin{array}{l}\uparrow \text { Tenacidad a } \\
\text { la fractura } \\
\uparrow \mathrm{R} \text {. Fatiga a } \\
\text { altos ciclos } \\
\uparrow \mathrm{R} . \text { Corrosión } \\
\text { bajo tensión }\end{array}$ & $\begin{array}{l}\uparrow \text { Dureza } \\
\uparrow \text { R. Fatiga } \\
\uparrow \text { R. mecánica }\end{array}$ \\
\hline
\end{tabular}

Con el fin de afinar la microestructura del titanio sin necesidad de aplicar deformación, otros tratamientos empleados son los termoquímicos ("thermochemical processing", TCP). El TCP emplea hidrógeno como elemento temporal de aleación, siendo eliminado al final del proceso mediante un recocido en vacío. Resulta especialmente útil para las porosas obtenidas por vía pulvimetalúrgica, donde la aproximación a la forma final de la pieza hace que generalmente no se aplique deformación [Froes 1990]. La figura 2.26 muestra la microestructura de una pieza de Ti-6Al-4V obtenida por pulvimetalúrgica sobre la que se ha aplicado un tratamiento de este tipo. 


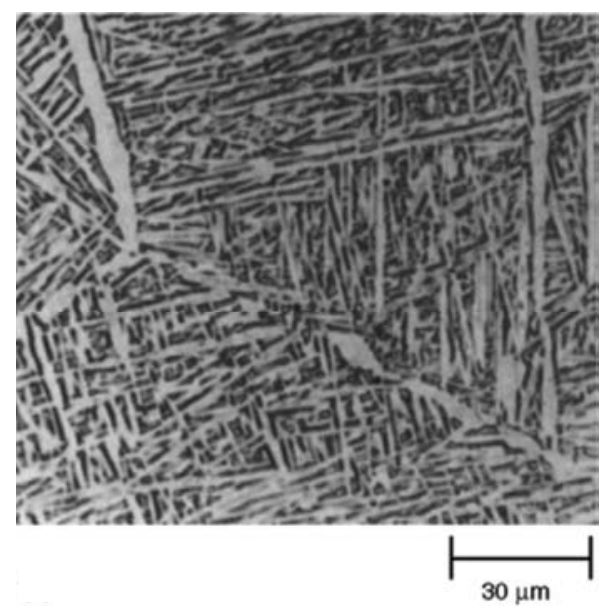

Fig. 2.26. Afino de la estructura empleando hidrógeno como elemento temporal de aleación [ASM N9 2004].

Pese a que la presente tesis se centrará fundamentalmente en reducir la rigidez de las piezas de titanio y fomentar su osteointegración para mejorar el trabajo junto al hueso, es bien sabido que también son necesarias otras propiedades como una resistencia mecánica y a fatiga suficientes para su uso en servicio. Por ello, se aplicarán tratamientos térmicos sobre las piezas porosas desarrolladas, tratando de mejorar las mencionadas características mediante la modificación de su microestructura.

\subsection{MÉTODOS DE MODIFICACIÓN DE LA RIGIDEZ EMPLEADOS EN TITANIO.}

Pese a que en la presente tesis la rigidez y aptitud para la osteointegración tratarán de alcanzarse mediante el desarrollo de porosidad, existen otras técnicas para lograr ambos aspectos, bien simultáneamente o por separado. Concretamente el presente apartado se centra en aquellos métodos destinados principalmente a reducir la rigidez, mientras que las técnicas empleadas para incrementar la aptitud a la osteointegración se analizarán en el apartado siguiente. 
Por una parte, el uso de implantes metálicos para la fijación de fracturas óseas permite a los pacientes utilizar su extremidad en un tiempo más corto, facilitando su retorno a la actividad diaria y el restablecimiento de los fragmentos fracturados. Además, dicha fijación impide el denominado "síndrome de la fractura", consistente en la pérdida de movimiento articular, rigidez, y debilidad muscular que derivarían de una inmovilización prolongada [Comín 1999]. No obstante y tal como se ha visto, uno de los aspectos más perjudiciales que presenta la fijación se produce cuando el hueso fracturado se fija rígidamente, lo que puede alterar la remodelación de la fractura y provocar la reabsorción del tejido óseo adyacente debido a la diferencia entre la rigidez del hueso y la del implante [Oh 2003a, Li H. 2005, Ryan 2006]. En definitiva, cuando el hueso no se ve sometido a las tensiones habituales, se genera una pérdida local de masa ósea, aumentando la posibilidad de refractura al extraer la placa [Comín 1999, Nomura 2005, Niinomi 2008]. Este problema se puede evitar utilizando placas menos rígidas.

Entre los diversos métodos existentes para reducir la rigidez del material, uno de ellos consiste en modificar los elementos de aleación, incrementando el contenido de aleantes tipo $\beta$ [Kuroda 2005, Nomura 2005, Schuh 2007]. Mediante esta metodología se han desarrollado nuevas aleaciones de titanio menos rígidas, como la Ti-12Mo-6Zr-2Fe (TMZF), Ti15Mo-5Zr-3Al; Ti-15Zr-4Nb-2Ta-0,2Pd, Ti-15Sn-4Nb-2Ta-0,2Pd, Ti-13Nb$13 \mathrm{Zr}$ alcanzando valores tan reducidos como los 55GPa que presenta la aleación Ti35Nb5Ta7Zr, bastante similar a los del hueso cortical (10-40 GPa) [Wen 2002 a]. A pesar de la evidente mejora, cabe remarcar que el módulo elástico de estas aleaciones de titanio todavía resulta superior al del hueso humano, especialmente el esponjoso.

Por ello, otro de los métodos aplicado con la finalidad de rebajar la rigidez es fabricar espumas, componentes cuya rugosidad superficial facilita además el crecimiento óseo, proporcionando mayor superficie de anclaje y fijación, lo que mejora la transmisión de esfuerzos entre el implante y el 
hueso [Oh 2003a, Esen 2007]. En este campo han sido numerosos los estudios realizados [Nomura 2005, Wen 2001, Cirincione 2002, Asaoka 2003, Oh 2002, Kujala 2003, Thieme 2001, Li J.P. 2004], tratando tanto de recubrir el material sólido, como de crear un implante poroso en su totalidad.

Los procesos existentes para el desarrollo de espumas metálicas son diversos, pudiendo partir del metal tanto en estado sólido (en forma de polvo o fibras), como líquido o gaseoso. Por otra parte, las espumas pueden clasificarse en función de la tipología y distribución de poros, pudiendo ser de poro cerrado, donde cada celda está completamente rodeada por una fina membrana, o abierto, en las que cada celda individual está interconectada, permitiendo a los tejidos infiltrarse en la espuma y anclar mecánicamente en ella [Gibson 1999].

La tabla 2.10 recoge los principales métodos de fabricación de materiales metálicos celulares, (piezas porosas en su totalidad, sin incluir recubrimientos porosos), según tipo y distribución de poros. Pese a que en la creación de piezas porosas de titanio se emplean varios de los métodos expuestos, debido a su elevada temperatura de fusión y reactividad con los gases atmosféricos y con los materiales empleados como molde, la espumación en fase sólida mediante técnicas pulvimerlúrgicas resulta más prometedora en comparación con el espumado en fase líquida [Degischer 2002, Esen 2007, Bansiddi 2008].

Por ello, mientras que métodos como la síntesis reactiva apenas han sido investigados, la viabilidad de otros procesos, como la técnica de HIP con gas atrapado [Degischer 2002], la sinterización de microesferas [Cirincione 2002, Thieme 2001], o el método de espaciadores [Bram 2005, Laptev 2004] si ha sido demostrada. 
Tabla 2.10. Métodos de fabricación de espumas metálicas según tipo y distribución de poros [Adaptado de Kupp 2002, Ryan 2006, Esen 2007].

\begin{tabular}{|c|c|c|}
\hline Tipo poro & Distribución poro & Método fabricación espuma \\
\hline \multirow[t]{2}{*}{ Célula Cerrada } & Distribución poro aleatoria & $\begin{array}{l}\text { - Inyección de gas en el metal fundido. } \\
\text { - Descomposición de agentes espumantes. } \\
\text { - HIP con expansión de gas atrapado. }\end{array}$ \\
\hline & Distribución poro gradual & - Spray Plasma. \\
\hline \multirow[t]{3}{*}{ Célula Abierta } & No Homogénea & $\begin{array}{l}\text { - Sinterización de polvos. } \\
\text { - Sinterización de microesferas. } \\
\text { - Sinterización de fibras. } \\
\text { - Método de espaciadores. } \\
\text { - Réplica. } \\
\text { - Síntesis reactiva (SHS). } \\
\text { - Spray Plasma. } \\
\text { - Sinterización por plasma (SPS). }\end{array}$ \\
\hline & Homogénea & $\begin{array}{l}\text { - Fusión de alambres orientados. } \\
\text { - Deposición en fase vapor. } \\
\text { - Electrodeposición. } \\
\text { - Ordenamiento de fibras ferromagnéticas. } \\
\text { - Prototipado rápido. }\end{array}$ \\
\hline & Graduado funcional & $\begin{array}{l}\text { - Prototipado rápido. } \\
\text { - Compactación por descarga eléctrica. }\end{array}$ \\
\hline
\end{tabular}

Por una parte, los procesos basados en métodos de deposición, como el empleado para conformar la espuma de la figura 2.27, necesitan movilizar el metal para transportarlo hasta un sustrato poroso [Degischer 2002, Kupp 2002, Li 2004, Li 2006]. Estos métodos requieren de un tratamiento químico o térmico para eliminar la estructura sobre la que se deposita el metal por lo que, pese a que permiten obtener espumas de célula abierta, la elevada reactivad del titanio hace compleja su utilización. 


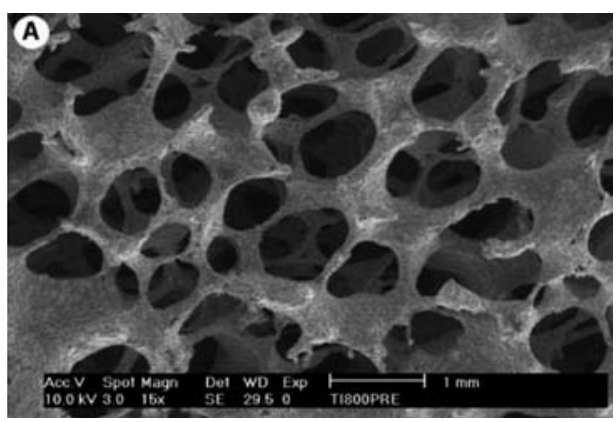

Fig. 2.27. Espuma de titanio desarrollada por réplica sobre un sustrato polimérico [Li 2006].

De forma similar, determinados autores han empleado técnicas de prototipado rápido para desarrollar moldes porosos sobre los que depositan una suspensión de titanio con ligantes [López-Heredia 2006, Ryan 2008]. Posteriormente, los elementos ajenos al titanio son eliminados por temperatura y la pieza porosa resultante es sinterizada. Otros autores, como Jia Ping et al. [Jia-Ping 2006] han empleado esta técnica para desarrollar redes bidimensionales como la de la figura 2.28.a, generada mediante la deposición de una suspensión de titanio en forma de fibras, cuya sucesión a 0 y $90^{\circ}$ genera una malla porosa tridimensional. De forma similar, autores como Hollander [Hollander 2006] emplean el láser para crear piezas porosas de Ti64 por sinterización de polvos en atmósfera de Ar lo que se conoce como "Direct Laser Forming" (DLF), figura 2.9.2 b.

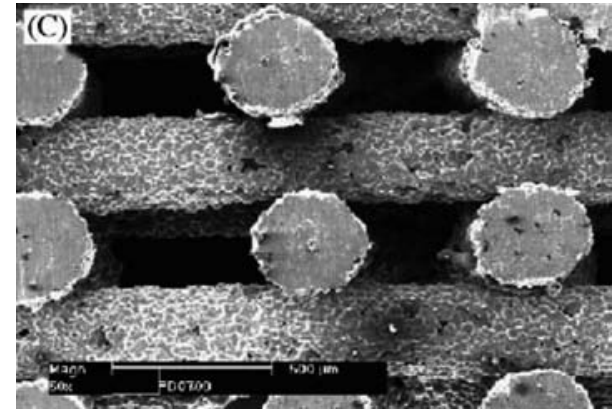

a

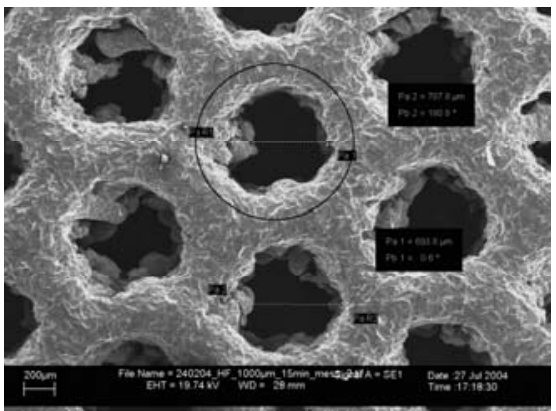

b

Fig. 2.28. Espumas de Ti64 desarrollada por: Prototipado rápido [Jia-Ping 2006]; b) Sinterización por láser (DLF) [Hollander 2006]. 
La principal ventaja de la técnica de prototipado rápido es que permite obtener piezas con elevada porosidad interconectada, permitiendo alta reproducibilidad de resultados. No obstante, al igual que las técnicas de deposición anteriormente descritas, el empleo de elementos ajenos al titanio, como ligantes y dispersantes favorece la contaminación de la pieza porosa desarrollada.

Por ello, tal como se ha indicado, la reactividad del titanio ha propiciado el empleo mayoritario de metodologías basadas en procesos pulvimetalúrgicos, que utilizan técnicas diversas como la aplicación de temperatura y tiempo, plasma o descarga eléctrica, para llevar a cabo la sinterización.

Entre dichas técnicas, la síntesis reactiva utiliza fenómenos especiales de sinterización. Esta metodología se ha empleado especialmente en sistemas intermetálicos como el Ti-Al cuyos polvos elementales, al ser procesados bajo determinadas condiciones, sufren una hinchazón, lo que permite generar un componente poroso [Degischer 2002, Bansiddhi 2008].

Existen otros procedimientos, como el empleado para desarrollar la espuma de la figura 2.29, en los que se encapsula polvo de titanio en presencia de $\mathrm{Ar}$, y se somete a un proceso de prensado isostático en caliente (HIP), figura 2.9.3. Posteriormente, se aplican elevadas temperaturas sobre la pieza compactada y los microporos de Ar a alta presión expanden mediante deformación por creep del material circundante. Si el proceso de expansión es llevado a cabo bajo condiciones térmicas cíclicas entorno a la temperatura de transformación alotrópica de las fases $\alpha$ a del titanio, la deformación es controlada por superplasticidad en lugar de creep, lo que permite incrementar la velocidad de espumado y la porosidad total [Murray 2003]. Este proceso permite obtener piezas con porosidades de hasta el 40\%, y poros aislados de entre 10-100 micras de diámetro [Degischer 2002, Bansiddhi 2008] y se ha empleado habitualmente para desarrollar piezas sándwich, conformadas por una piel densa y un alma porosa. 


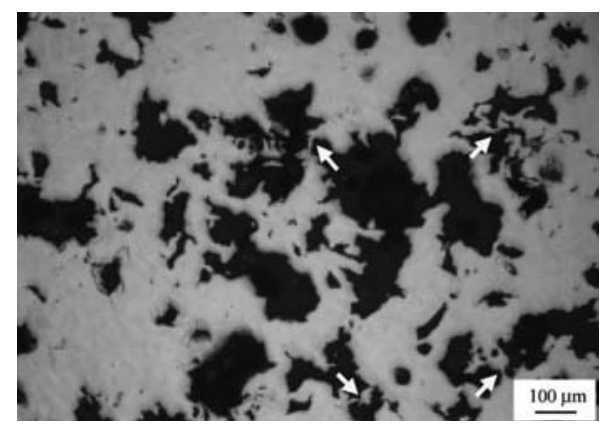

Fig. 2.29. MO de una pieza porosa de titanio obtenida mediante HIP y gas atrapado [Murray 2003].

Otros autores como Beljavin et al. [Beljavin 2004] han desarrollado piezas porosas de titanio mediante presinterización y sinterización de microesferas, en atmósfera protectora y utilizando descargas eléctricas para ello. La principal ventaja que aporta el método es que no se necesita introducir elementos adicionales ajenos al titanio, con lo que se reduce la posible contaminación. Por otra parte, debido a la reducida duración del tratamiento (cientos de veces menor respecto a la sinterización en vacío), se reduce muchísimo el engrosamiento de grano.

De forma similar, otros autores [Oh 2003] han desarrollado piezas porosas de titanio mediante sinterización por plasma ("Spark Plasma Sintering", SPS), alcanzando porosidades entre el 5,1 y $39,2 \%$.

En otras técnicas más convencionales, como la sinterización de microesferas, figura 2.30.a, o el método de espaciadores, figura 2.9.4.b, la sinterización es llevada a cabo en hornos, bajo la aplicación de un ciclo térmico. Pese a que ambas técnicas permiten crear espumas de poro abierto, con una distribución no uniforme de éstos, la primera se utiliza tanto para recubrir materiales densos como para fabricar piezas totalmente porosas; mientras que la segunda únicamente se emplea para conformar materiales totalmente porosos. 


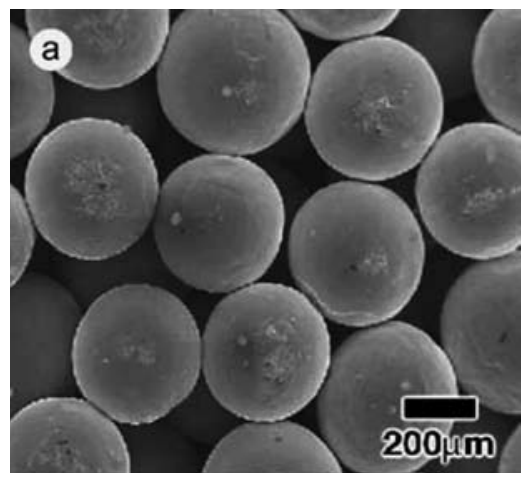

a

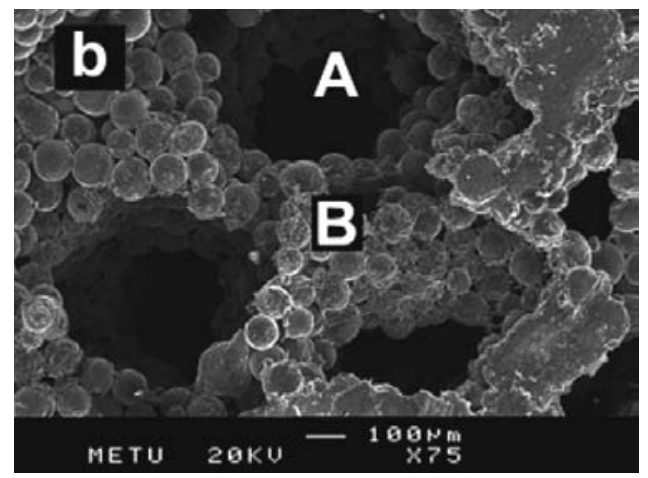

b

Fig. 2.30. Piezas porosas de titanio obtenidas por: a) Sinterización de microesferas [Oh 2003 a] y métodos de espaciadores [Esen 2007].

La sinterización de microesferas [Cirincione 2002, Thieme 2001] es una técnica sencilla en la que las propiedades finales dependen fundamentalmente de la granulometría de las microesferas empleadas y el ciclo de sinterización al que se someten. La distribución granulométrica del material de partida determina el tamaño de poro y grado de porosidad resultantes. Una variante de esta técnica consiste en la sinterización de microesferas huecas, generadas mediante técnicas de deposición química sobre sustratos. Posteriormente se aplica temperatura para eliminar el ligante y el sustrato y finalmente las microesferas huecas son sinterizadas para crear piezas porosas de reducida densidad [Kupp 2002].

Frente a la sinterización de microesferas, la técnica de espaciadores permite fabricar componentes con mayor nivel de porosidad. El proceso se inicia con la mezcla del titanio con el agente que funcionará como espaciador, seguido de una compactación a presiones bajas [Bram 2000]. Posteriormente el espaciador es eliminado a baja temperatura y, finalmente, la pieza es sinterizada a elevada temperatura, lo que le confiere las propiedades finales.

Como espaciador se han utilizado materiales tan diversos como urea, bicarbonato de amonio, magnesio, cloruro sódico, sacarosa, PMMA...[Bram 2005, Dewidar 2005, Kotan 2007, Esen 2007], con diferentes condiciones 
de eliminación para cada uno de ellos. Así, mientras que agentes como la sacarosa o el cloruro sódico se disuelven en agua, otros como el PMMA, la urea o el bicarbonato de amonio, desaparecen por temperatura [Kotan 2007, Wen 2002 b].

Según diversos autores [Bram 2005, Esen 2007], el método de espaciadores es una de las formas más fáciles de obtener piezas porosas de titanio, cuyo control de la forma, tamaño y cantidad de poros viene determinado por la geometría, dimensión y volumen de espaciador. No obstante, su principal dificultad es la necesidad de eliminar grandes cantidades de espaciador sin contaminar la pieza porosa final [Esen 2007, Kohl 2007]. Por otra parte, a pesar de que con porosidades elevadas existe cierta conexión entre los poros, ésta puede resultar de reducido tamaño, con lo que podría inhibirse el crecimiento óseo [Bansiddhi 2008].

En definitiva, de entre los diferentes métodos empleados para reducir la rigidez del implante, en la presente investigación las piezas porosas de titanio se desarrollarán mediante sinterización de microesferas y el método de espaciadores, pues resultan técnicas relativamente sencillas y posibles de aplicar con los medios actualmente disponibles. Con el uso de estas técnicas se pretende desarrollar piezas de titanio menos rígidas, con unas propiedades mecánicas adecuadas, y porosidad y tamaño de poro tales que faciliten su osteointegración, todo ello con el fin último de adecuar el comportamiento en servicio y reducir los problemas por reabsorción ósea.

\subsection{TRATAMIENTOS SUPERFICIALES APLICABLES AL TITANIO.}

Tal como se ha indicado en el apartado anterior, además de las técnicas empleadas con el fin de reducir la rigidez, existen otras que tratan fundamentalmente de mejorar la aptitud frente a la osteointegración. Pese a que, de entre los diversos tratamientos existentes nos centraremos únicamente en aquellos destinados a acelerar la osteointegración y mejorar el anclaje mecánico entre el hueso y el implante, se hará mención a 66 
aquellos aplicados con el fin de minimizar la velocidad de corrosión o incrementar la resistencia al desgaste [Rodríguez 1999, Kupp 2002, Bansiddhi 2008, Guehennec 2008].

A pesar de todo, es de vital importancia señalar que únicamente se exponen para su conocimiento pues, pese a que supondrán posibilidades de mejora de las piezas porosas desarrolladas, no se van a aplicar en la presente investigación.

Como se indicó en apartados previos, las prótesis de titanio encuentran su mayor problema en las superficies articulantes y los efectos derivados de la fricción entre las superficies de los materiales en contacto [Comín 1999, Gil 2002, Kamachi 2003]. Dichos problemas son principalmente el desgaste, la corrosión y las consecuencias que de ellos se derivan, como la presencia de terceras partículas, toxicidad,... [Rodríguez 1999, Blackwood 2000]. Este proceso todavía puede agravarse más si va acompañado de corrosión, pues los iones metálicos formados podrían entrar en contacto con los tejidos adyacentes y ser distribuidos a otros órganos a través de fluidos orgánicos [Ibris 2002, Kamachi 2003, Olmedo 2005].

Dentro de este campo, los tratamientos superficiales destinados principalmente a modificar las propiedades tribológicas del titanio pueden clasificarse en tratamientos de deposición en fase vapor, de conversión termoquímica y galvanoplastia [Rodríguez 1999, Venugopalan 2000, Bansiddhi 2008]. De forma esquemática, la tabla 2.11 recoge las principales ventajas e inconvenientes de cada uno de ellos. 
Tabla 2.11.Ventajas y limitaciones de tratamientos superficiales aplicables al titanio para mejorar sus propiedades tribológicas.

\begin{tabular}{|c|c|c|}
\hline \multicolumn{3}{|c|}{ Ventajas y limitaciones de los tratamientos superficiales para aleaciones de titanio } \\
\hline Tratamiento & Ventajas & Limitaciones \\
\hline \multicolumn{3}{|c|}{ Deposición física } \\
\hline $\begin{array}{l}\text { Implantación } \\
\text { iónica }\end{array}$ & $\begin{array}{c}\text { Proceso de baja temperatura, interfase gradual, } \\
\text { mantiene forma. }\end{array}$ & $\begin{array}{c}\text { Zona de modificación superficial poco profunda, } \\
\text { elevado coste. }\end{array}$ \\
\hline Spray plasma & $\begin{array}{c}\text { Deposición rápida, amplia zona de modificación } \\
\text { superficial, su porosidad puede retener } \\
\text { lubricante, reducido coste. }\end{array}$ & $\begin{array}{l}\text { Acabado superficial grosero, requiere capa de } \\
\text { adherencia, interfase abrupta, difícil de } \\
\text { controlar la composición de la cobertura. }\end{array}$ \\
\hline Evaporación & $\begin{array}{l}\text { Amplio rango de materiales disponibles, } \\
\text { composiciones adaptables, coberturas de } \\
\text { elevada pureza, reducido coste. }\end{array}$ & Películas delgadas, interfase abrupta. \\
\hline Sputtering & $\begin{array}{l}\text { Proceso de baja temperatura, apto para cubrir } \\
\text { en capas, composición adaptable. }\end{array}$ & Películas delgadas, interfase abrupta. \\
\hline \multicolumn{3}{|l|}{ Termoquímicos } \\
\hline $\begin{array}{l}\text { Nitruración, } \\
\text { carburación, } \\
\text { boruración }\end{array}$ & $\begin{array}{l}\text { Interfase gradual, transformación del substrato, } \\
\text { amplia zona de modificación superficial. }\end{array}$ & $\begin{array}{c}\text { Potencial riesgo de fragilización por hidrógeno, } \\
\text { la elevada temperatura puede distorsionar los } \\
\text { componentes y reducir sus propiedades, } \\
\text { acabado superficial grosero. }\end{array}$ \\
\hline Galvanoplastia & Reducido coste. & $\begin{array}{l}\text { Potencial riesgo de fragilización por hidrógeno, } \\
\text { interfase abrupta. }\end{array}$ \\
\hline
\end{tabular}

Entre los tratamientos anteriormente indicados una diferencia fundamental es su temperatura de aplicación, pues mientras que procesos como la implantación iónica se realizan a temperaturas cercanas a la ambiente, la nitruración por plasma o los procesos de carburación requieren temperaturas superiores a $900{ }^{\circ} \mathrm{C}$, lo que implica mayor modificación microestructural [Dahotre 1999].

Por otra parte, técnicas como la implantación iónica, el sputtering, la deposición por plasma o procesos de evaporación [Hu 1988, Rembges 1993, Stern 1996, Dahotre 1999, Rodríguez 1999, Mändl 2000, Liu 2004], poseen el denominador común de acelerar, mediante el empleo de un potencial eléctrico o el uso de temperatura, iones de nitrógeno, boro, carbono u oxígeno hacia el substrato sobre el que se van a depositar. Por tanto, en aquellas piezas que presenten una porosidad abierta, como las desarrolladas por sinterización de microesferas, los recubrimientos 
resultarán más difíciles de aplicar, ocasionando mayor heterogeneidad en la capa superficial desarrollada.

Por el contrario, los tratamientos termoquímicos, como la nitruración, carburación y boruración consisten en la incorporación de los elementos intersticiales mencionados por difusión en medio gaseoso [Rodríguez 1999, Venugopalan 2000, Rodríguez 2001, Liu 2004], lo que facilitaría la formación del recubrimiento sobre piezas con porosidad abierta frente a las técnicas de proyección. A pesar de ello, cabe indicar que el tratamiento del titanio mediante procesos termoquímicos ha tenido una aplicación limitada, pues la formación de compuestos con el oxígeno y la incorporación de hidrógeno a la estructura del titanio fragilizan la pieza. No obstante, dado que los elementos contaminantes proceden de las impurezas del medio gaseoso empleado, se ha demostrado que mediante el pretratamiento de las piezas de titanio a recubrir y el uso de gases de muy alta pureza, el proceso podría ser útil incluso a tiempos y temperaturas relativamente reducidos.

Entre los tratamientos destinados a mejorar las propiedades tribológicas del titanio cabe mencionar además la galvanoplastia, técnica de recubrimiento que engloba tres tratamientos distintos: la electrodeposición, el electroless y las coberturas por conversión química. Mientras que la primera se basa en el recubrimiento por deposición electrolítica en baños, en el electroless la deposición se logra sin electricidad, por reducción catalítica de iones metálicos. Finalmente, los tratamientos de conversión química, se basan en la reacción entre la superficie del substrato y el medio que lo rodea [Stern 1996].

Lo más significativo de cara a las piezas porosas desarrolladas en la presente tesis, reside en que todas ellas presentan dificultad en su aplicación sobre aleaciones de titanio, pues los óxidos superficiales formados impiden que se genere una buena adhesión con el substrato, por lo que resulta fundamental una adecuada preparación de la superficie [Dahotre 1999, Paunovic 2006]. Por tanto, resultará un tratamiento poco 
aconsejable para las piezas porosas desarrolladas por sinterización de microesferas, pues su porosidad abierta implicará una elevada superficie específica. No obstante, podría ser una técnica empleable para mejorar el comportamiento tribológico de piezas desarrolladas por el método de espaciadores, cuya reducción de rigidez mejoraría su adaptación junto al hueso.

Mención aparte cabría hacer del anodizado del titanio y sus aleaciones, técnica que también se enmarcaría dentro de los tratamientos de conversión química. La anodización del titanio mejora la resistencia al desgaste, en ausencia de cargas elevadas, mediante el desarrollo de capas de $\mathrm{TiO}_{2}$ de hasta $100 \mathrm{~nm}$ de espesor. Variando el voltaje aplicado pueden conseguirse un amplio abanico de colores [ASM N4 1994, Van-Gils 2004].

Como se ha indicado, existen otra técnicas que, en lugar de tratar de mejorar el comportamiento tribológico del implante, persiguen tanto facilitar el crecimiento óseo y la fijación, como generar resistencia a cortante e integridad mecánica para garantizar la estabilidad de éste a largo plazo [Pilliar 1998, Kupp 2002, Gil 2007 b].

En este campo, cabria diferenciar entre métodos que generan únicamente rugosidad superficial en la pieza, y aquellos, como la sinterización de polvos o fibras, en los que además de rugosidad, se crea una superficie porosa [Aparicio 2003, Amigo 2003b, Sakamoto 2006, Gil 2007 a]. Así, el "shot blasting", enmarcado en el primer grupo, es uno de los tratamientos superficiales mas empleados para generar rugosidad superficial en implantes dentales, pues además de facilitar el crecimiento óseo, aumenta la vida a fatiga debido a la formación de una capa superficial sometida a esfuerzos residuales de compresión [Gil 2007 b, Guehennec 2008].

Otras técnicas, como la proyección térmica o proyección plasma (proyección de material sobre un substrato), se encontrarían a caballo entre ambas, pues generan un recubrimiento más o menos compacto, figura 2.31, en función de los parámetros del proceso seleccionados (material, modo y 
velocidad de aporte) [Dahotre 1999, Liu 2004, Fernandez 2005, Bolelli 2006, Gaona 2007]. Debe indicarse que resultaría una técnica de difícil aplicación para las piezas porosas de titanio desarrolladas, pues las elevadas temperaturas que se alcanzan hacen necesario realizar el proceso bajo atmósfera controlada.

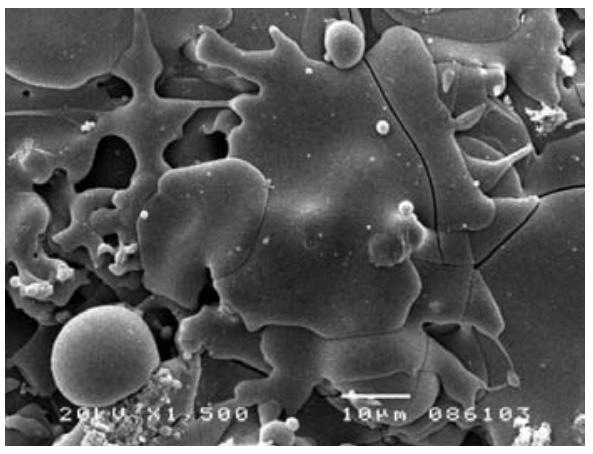

a

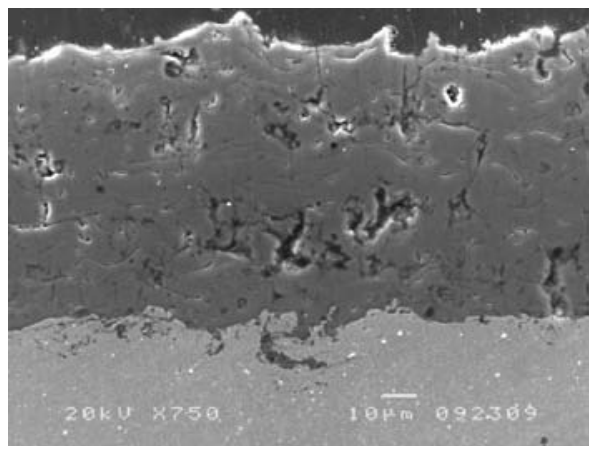

b

Fig. 2.31. Recubrimiento de HA obtenido mediante proyección térmica por plasma: a) Superficie libre; b) Sección transversal [Fernandez 2005].

Frente a los métodos descritos hasta el momento, mediante sinterización de polvos o microesferas sobre un substrato metálico se han desarrollado superficies con porosidad interconectada [Lafitt, Biomet, Amigo 2003b, Dewidar 2007]. Pese a que estas técnicas encuentran su principal inconveniente en el engrosamiento de la microestructura del metal base y la concentración de tensiones que se origina en la unión del recubrimiento al núcleo, dicha problemática puede mitigarse con la posterior aplicación de tratamientos térmicos [Comín 1999, Amigó 2003]. Además, los estudios realizados por Simmons et al. [Simmons 1998] demostraron que la fijación del implante y el crecimiento óseo era de 5 a 10 veces mejor sobre superficies con porosidad interconectada desarrolladas por sinterización que sobre recubrimientos realizados por spray plasma [Simske 1997]. Ello era debido a la mejor transferencia de esfuerzos entre el hueso y el implante y, por tanto la estabilidad de este [Kupp 2002]. 
Para el desarrollo de porosidad superficial se han empleado tanto materiales metálicos como cerámicos y poliméricos. Si bien es de esperar que en los recubrimientos metálicos se produzca mayor relegación de iones por corrosión al contacto con los fluidos corporales [Kupp 2002], las espumas cerámicas y poliméricas presentan generalmente reducidas propiedades mecánicas, por lo que pueden romper ante la aplicación de un esfuerzo repentino [Wen 2002 b].

Entre ellos, el recubrimiento con biocerámicas, como hidroxiapatita (HA), el bioglass, o el ceralbone aportan la ventaja de promover la formación de hueso (osteogénesis) [Breme 1995, Tsui 1998, Spoerke 2005, Gaona 2007]. Debido a similitudes químicas y estructurales, el más empleado de los tres a lo largo de las últimas décadas ha sido la HA. Esta cerámica se comporta de forma similar a la apatita encontrada en el cuerpo, favoreciendo el crecimiento óseo, por lo que ha sido catalogada como una cerámica osteointegrante y osteoconductora [Simske 1997, Flautre 2001, Frenkel 2004]. La adherencia entre ésta y el hueso es más fuerte que la del hueso con la capa de óxido nanométrica que recubre el titanio. Por ello, los recubrimientos de HA aportan diversas ventajas, como facilitar el crecimiento óseo, reducir el tiempo de recuperación del paciente, generar una intercara más fuerte entre el implante y el hueso, lo que permite transmitir esfuerzos de tracción y cortante; y minimizar el riesgo de liberación de iones de titanio, lo que podría generar ciertos problemas de citotoxicidad [Heimann 2002, Asaoka 2003, Xuanyong 2004].

No obstante, las técnicas de recubrimiento de HA, como la ablación iónica o el spray plasma, conllevan problemas por las altas temperaturas generadas $\left(>1100^{\circ} \mathrm{C}\right.$ ), pues modifican la microestructura del metal base, al tiempo que producen la descomposición de la HA en otras fases, con distintos niveles de bioactividad y solubilidad en los fluidos corporales [Gaona 2007]. Ello ha propiciado el desarrollo de nuevas técnicas de deposición, basadas en un procedimiento similar al del crecimiento natural del hueso en el cuerpo 
humano. El procedimiento es conocido como "método biomimético" y se realiza a temperatura inferior a $100{ }^{\circ} \mathrm{C}$, mediante la inmersión del implante en una solución con concentraciones iónicas similares a las de los fluidos corporales [Gaona 2007, Zhang 2009]. Las ventajas respecto a los métodos de aplicación anteriormente descritos son significativas, pues permite recubrir geometrías complejas sin degradar el substrato al tiempo que posibilita la incorporación de moléculas biológicas (proteínas, colágeno) que mejoran la osteoinduccion y el anclaje del implante. Por otra parte, es simple y económico [Gaona 2007].

En relación a la aplicación de estas técnicas sobre piezas porosas, un estudio realizado por Simske et al. [Simske 1997], revela que el crecimiento óseo se ve mas favorecido al aplicar estos tratamientos sobre piezas porosas en relación al material denso. Por otra parte, según dicho trabajo, el efecto beneficioso aportado por el recubrimiento de HA se produce en los primeros meses tras la implantación, de forma que permite que el hueso soporte cargas fisiológicas en un plazo de tiempo más corto en relación al implante poroso sin recubrir. No obstante, a largo plazo el crecimiento óseo resulta igual en ambos.

Finalmente, cabe indicar que, además de los recubrimientos realizados con biocerámicas, a nivel comercial, se están empleando diversos recubrimientos porosos realizados tanto en tántalo, como el "Trabecular

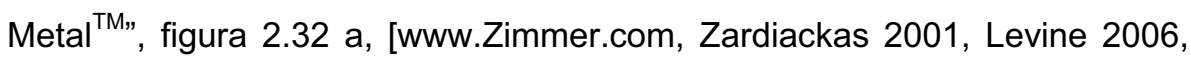
Levine 2008], como en titanio y sus aleaciones, como el "Regenerex" ${ }^{\mathrm{TM}}$, [www.biomet.co.uk], el Tritanium, figura 2.32 b, [www.stryker.com, Frenkel 2004] o el "Biofoam ${ }^{\mathrm{TM}}$ Titanium" [www.wmt.com]. 

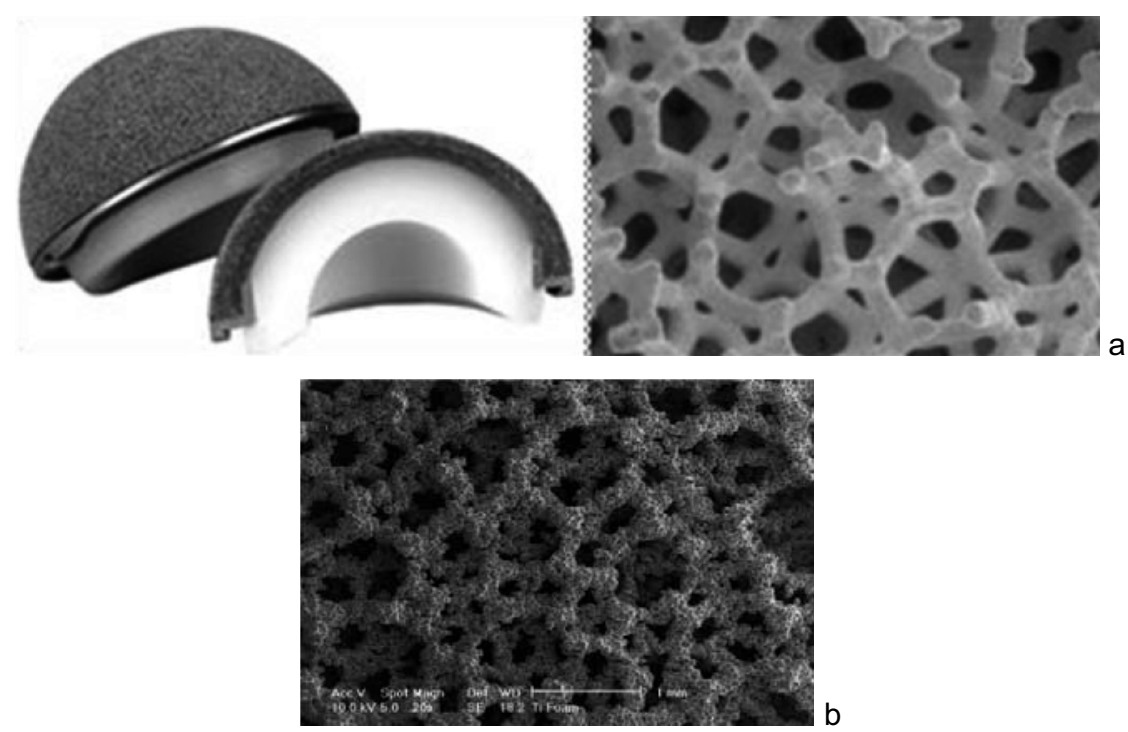

Fig. 2.32. Recubrimientos porosos comerciales realizados sobre prótesis de titanio: a) Micrografía SEM y recubrimiento del cotilo acetabular con "Trabecular Metal" [Levine 2008]; b) Micrografía SEM del "Tritanium" [Frenkel 2004].

Un estudio comparativo entre cupones sólidos de Ti6Al4V recubiertos con tritanium, sinterización de microesferas y ambos recubiertos a su vez con hidroxiapatita, concluye que la penetración ósea resulta mayor en el recubrimiento de tritanium en relación al obtenido por sinterización de microesferas, lo que se debe a su mayor porosidad. Por otra parte, la HA mejora la adhesión entre el hueso generado y las microesferas, aunque no aumentan la penetración, pues es necesario un tamaño de poro mínimo para permitir el desarrollo óseo [Frenkel 2004].

Como conclusión, son diversos los posibles tratamientos superficiales aplicables al titanio, algunos con el objetivo de mejorar su resistencia al desgaste y otros de incrementar su aptitud a la osteointegración. A pesar de que todos ellos suponen posibilidades de mejora para las piezas porosas desarrolladas en la presente tesis, cabe destacar que, en general, resultarán más difíciles de aplicar que en una pieza densa, especialmente cuando la porosidad es abierta e interconectada, pues es más heterogénea y posee mayor superficie específica. 
Tal como se ha visto a lo largo del presente capítulo, las excelentes propiedades del titanio lo convierten en un material idóneo para ser empleado como implante. No obstante, un aspecto de vital importancia de cara a su procesado es la reactividad, tanto con los elementos presentes en la atmósfera del horno, como con los materiales utilizados como molde. Por otra parte, en su interacción con el individuo presenta determinados inconvenientes, como son su reducida resistencia al desgaste o la excesiva rigidez en comparación con la del hueso humano, que conlleva problemas de debilitamiento por reabsorción ósea. Resulta necesario además fomentar el crecimiento del hueso, tratando de lograr una mejor adherencia y la rápida recuperación del paciente.

De todo ello se desprende la necesidad tanto de desarrollar piezas de titanio menos rígidas, como de fomentar su osteointegración. Dichas propiedades tratarán de mejorarse mediante el desarrollo de porosidad, empleando para ello las técnicas pulvimetalúrgicas de sinterización de microesferas y el método de espaciadores, por ser relativamente sencillas y aplicables con los medios actualmente disponibles. Finalmente, dado que el incremento de porosidad va en detrimento de otras propiedades, como la resistencia mecánica o a fatiga, tratarán de mejorarse mediante la aplicación de tratamientos térmicos sobre la pieza porosa obtenida. 

3

\section{PLANIFICACIÓN DE LA INVESTIGACIÓN}





\section{PLANIFICACIÓN DE LA INVESTIGACION.}

Como se ha indicado, el objetivo general de la presente tesis es controlar la rigidez y aptitud para la osteointegración de piezas de titanio mediante el desarrollo de porosidad. Asimismo, las piezas desarrolladas deberán tener unas propiedades mecánicas tales que permitan su implantación y uso en servicio.

Dada la amplitud del estudio y el abanico de propiedades a estudiar, el análisis de otras características de gran interés para la aplicación, como son la resistencia a fatiga, la liberación de iones o la resistencia a la corrosión, será llevado a cabo por otros grupos de investigación como el de Biomateriales de la U. Politécnica de Cataluña o el dirigido por José L. Ortiz en el Tecnológico de Monterrey, Méjico.

Tal como se ha indicado, de entre los posibles métodos utilizables para desarrollar piezas porosas de titanio, se emplearán técnicas de espumado en fase sólida, pues poseen menores problemas de reactividad respecto al espumado en fase líquida o técnicas de deposición. Entre las primeras, se adoptará la sinterización de microesferas y el método de espaciadores por tratarse de técnicas relativamente sencillas y posibles de obtener con los métodos actualmente disponibles.

En relación a los materiales, se empleará titanio comercialmente puro y la aleación Ti6Al4V como material base, pues son los más utilizados en aplicaciones ortopédicas y de osteosíntesis. Entre los posibles agentes utilizados como espaciador, se optará por aquellos que pueden desaparecer por temperatura, como la urea y el bicarbonato, pues la descomposición en agua podría incrementar los problemas de reactividad y absorción de elementos intersticiales. Concretamente, la investigación se centrará principalmente en el uso de bicarbonato de amonio como agente espaciador, pues se ha utilizado con éxito en trabajos previos desarrollados por otros autores [Laptev 2005, Bram 2006]. 
Tras la obtención de las piezas porosas por ambos métodos, se analizará el efecto de diferentes tratamientos térmicos sobre la microestructura y propiedades mecánicas de las piezas obtenidas, tratando con ello de optimizar la resistencia a fatiga de las piezas desarrolladas.

Dado que el número de variables existente en la técnica de espaciadores resulta amplio (temperatura, tiempo, presión, fracción granulométrica y tamaño de espaciador), se realizarán unas pruebas previas con el fin de determinar la viabilidad de obtener piezas porosas por ésta técnica, así como establecer el rango para las distintas variables de proceso.

Por otra parte, puesto que la reactividad del titanio condiciona enormemente las propiedades de la pieza final, se realizará un estudio previo para evaluar la reacción del titanio con diferentes tipos de moldes utilizados para la sinterización.

\subsection{ESTUDIOS PREVIOS.}

Tal como se ha indicado, con el fin de determinar el material idóneo a utilizar como molde para minimizar la reactividad y la consecuente merma de propiedades, previo al desarrollo de las piezas se estudiará la reactividad del titanio en diferentes moldes y para distintas condiciones de sinterización.

Concretamente el estudio se llevará a cabo sobre gres, alúmina, itria y circona. El primero de ellos se selecciona por su facilidad de conformado y consolidación con los medios actualmente disponibles, lo que permitirá realizar distintas morfologías así como iniciar la investigación en cuanto estén disponibles las microesferas para llevar a cabo el proceso. En segundo lugar, se sinterizará sobre alúmina, por tratarse de una cerámica de gran estabilidad. El tercer material a utilizar como sustrato serán recubrimientos de itria sobre moldes de alúmina, pues determinados estudios apuntan sobre la estabilidad de este material al contacto con el titanio [Wang 1998, Kim 2002, García 2006, Smeacetto 2006]. Finalmente se sinterizará sobre moldes de circona, pues se ha empleado de forma satisfactoria para la sinterización de titanio [Esteban 2008]. 
El esquema adjunto muestra como se llevará a cabo el estudio de reactividad en función del molde:

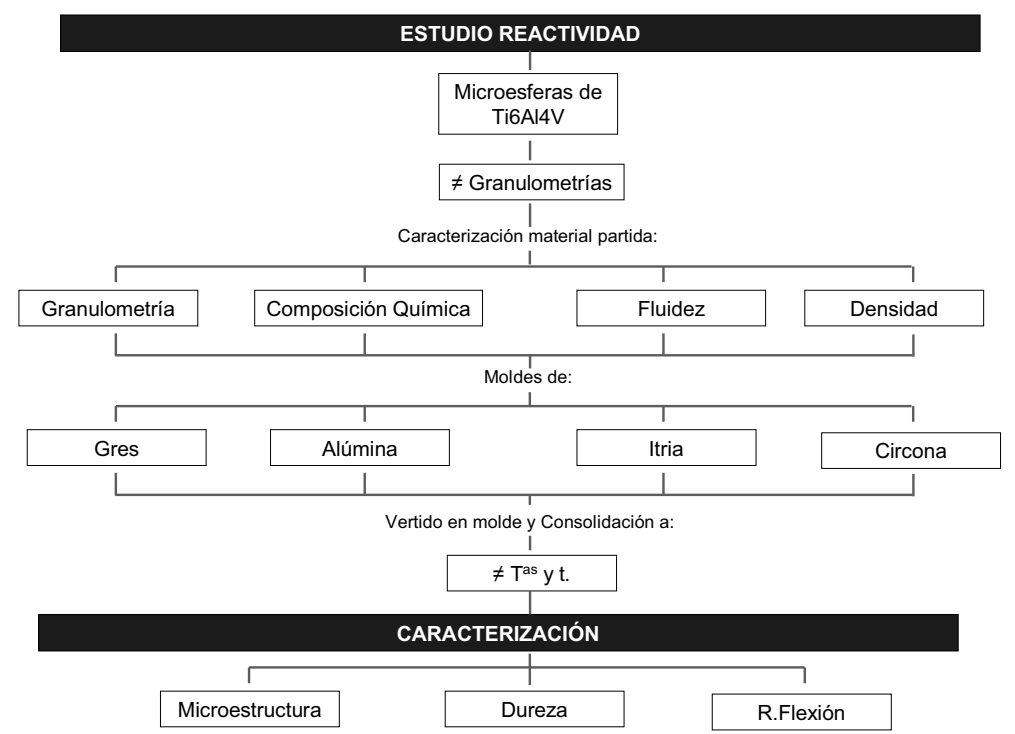

Fig. 3.1. Planificación del estudio de reactividad en función del molde utilizado para distintas condiciones de proceso.

Concretamente éste se realizará únicamente sobre piezas obtenidas mediante sinterización de microesferas, pues existen menos variables de proceso, con lo que resulta más fácil analizar la influencia del molde. Para la realización del estudio se emplearán únicamente microesferas de la aleación Ti6Al4V, por ser la más ampliamente utilizada. Por otra parte, se variará tanto el tamaño de las microesferas, como la temperatura y tiempo de sinterización, lo que permitirá analizar tanto el efecto de la superficie específica como del incremento del tiempo y temperatura para los diferentes moldes empleados.

Previo a la consolidación de las piezas porosas, se caracterizará el material de partida, determinando su composición química y análisis granulométrico. Asimismo, se evaluará la fluidez y densidad aparente y vibrada de las microesferas vertidas en el molde, con el fin de compararla posteriormente con la presentada por los polvos obtenidos por $\mathrm{HDH}$. 
Tras su caracterización, las microesferas serán vertidas en los diferentes moldes por gravedad, aplicando posteriormente una vibración, bien por medios manuales o mecánicos. Las dimensiones de las piezas dependerán del tipo de molde, aunque deberán permitir en todos los casos la obtención de probetas para su ensayo a flexión, y tratará de mantenerse constante su espesor.

Posteriormente las piezas serán consolidadas en vacío, tratando así de eliminar la reactividad del titanio con elementos presentes en la atmósfera del horno. De acuerdo con estudios previos realizados, en los que se sinterizó titanio de menor tamaño de partícula [Amigó 2007], la temperatura mínima de sinterización será de $1300^{\circ} \mathrm{C}$, con un tiempo superior a 1 hora.

Una vez obtenidas las piezas, se extraerán muestras para su caracterización. Para ello, de cada pieza obtenida con distintos parámetros de proceso ( $T$, t y tamaño de microesfera), se cortarán piezas para su estudio microestructural y ensayo de flexión a tres puntos, según norma ISO 3325:2000, ensayo que se utilizará además para evaluar la rigidez de las piezas obtenidas. Sobre las primeras se determinará además la microdureza, diferenciando entre las zonas de contacto con el molde y con la atmósfera del horno.

Mediante la comparación, para los distintos moldes empleados y parámetros de proceso, de la resistencia a flexión, el estudio microestructural, análisis EDX y determinación de microdureza, se establecerá el material idóneo a utilizar como molde, aquel sobre el cual la reactividad resulta mínima y, por tanto, confiere las mejores propiedades a igualdad del resto de variables.

Asimismo, las piezas sinterizadas sobre los distintos moldes se aprovecharán para caracterizarlas mediante metodologías distintas y poder comparar los resultados obtenidos.

Tal como se ha indicado, se realizará otro estudio previo, relacionado con el método de espaciadores y cuyo objetivo es acotar los parámetros de proceso y la combinación de variables a aplicar. Estas pruebas previas se desarrollarán tal como muestra el esquema adjunto: 


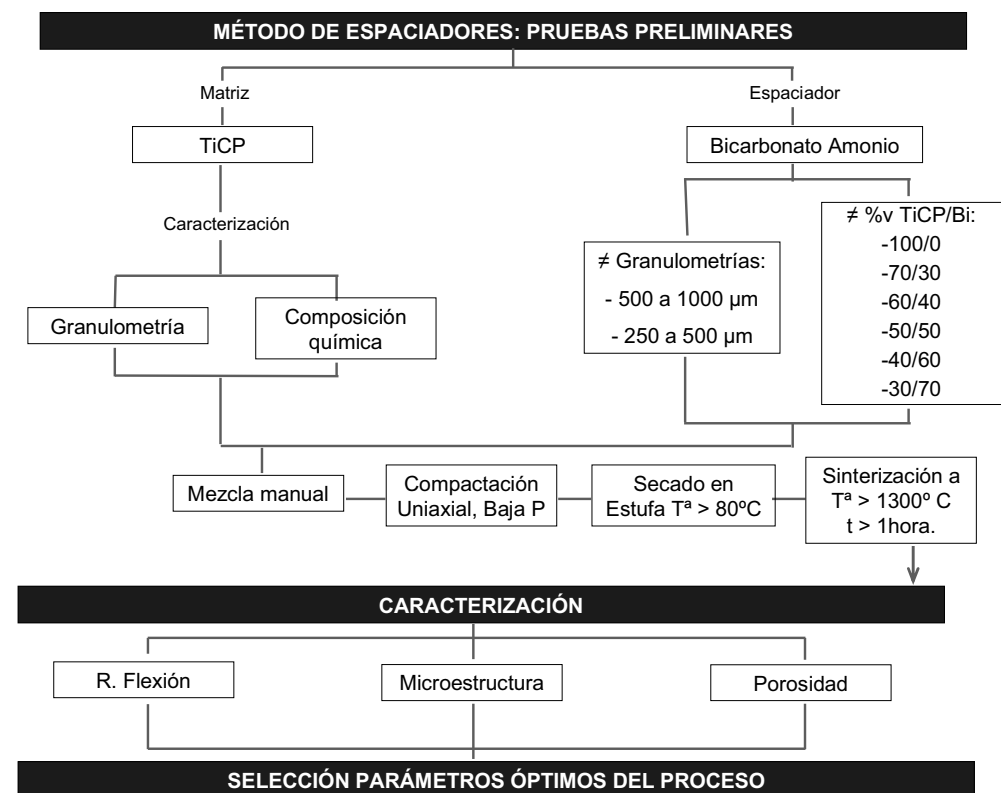

Fig. 3.2. Planificación de las pruebas preliminares a realizar por el método de espaciadores.

Concretamente en las pruebas previas se empleará polvo de TiCP como material base y bicarbonato de amonio como espaciador. Con el objetivo común de reducir la rigidez e incrementar la aptitud de la pieza al desarrollo óseo, y dado que el tamaño de poro idóneo para permitir el crecimiento de los osteoblastos oscila entre 100 y $500 \mu \mathrm{m}$ [Simske 1997, Kupp 2002, Takemoto 2006a], el polvo de bicarbonato de amonio se triturará manualmente, y se tamizará posteriormente para separar entre las fracciones granulométricas de 500 a 1000, 250 a 500 e inferior a $250 \mu \mathrm{m}$. Para la realización de estas pruebas previas se empleará únicamente las fracciones superiores.

De igual modo, dado que según diversos autores, la porosidad óptima para permitir el crecimiento de los tejidos óseos se sitúa entre el 20 y $80 \%$ (Oh 2003, Bansiddhi 2008], se establece un porcentaje volumétrico de espaciador entre el 30 y $70 \% \mathrm{v}$, variando en incrementos del $10 \% \mathrm{v}$. No obstante, también se consolidarán piezas sin espaciador con el fin de estimar el efecto de éste sobre el material base. Puesto que se trata de pruebas preliminares, y la cantidad de muestras no resulta excesiva, las mezclas se realizarán de modo manual. 
De acuerdo con los datos obtenidos de bibliografía [Wen 2001] y con el fin de evitar el aplastamiento de las partículas de bicarbonato, se aplicarán presiones de compactación bajas, pero que permitan a su vez la consolidación de los polvos y manipulación de las piezas hasta su sinterización. Por ello, se compactará a 100 y $200 \mathrm{MPa}$. De nuevo, debido al relativamente reducido numero de piezas a compactar, el proceso se llevará a cabo en una prensa manual, obteniendo compactos cilíndricos de aproximadamente $5 \mathrm{~mm}$. de altura y cuyas dimensiones permitan realizar su posterior caracterización.

Tras el conformado de la pieza, el bicarbonato de amonio será eliminado en estufa a $80^{\circ} \mathrm{C}$ durante un tiempo superior a 14 horas [Bram 2005]. Finalmente, con el fin de reducir las variables de estudio, todas las probetas se consolidarán bajo un mismo ciclo Temperatura - tiempo. Así, la sinterización se realizará a $1300{ }^{\circ} \mathrm{C}$ durante $2 \mathrm{~h}$, temperatura y tiempo empleados en investigaciones previas para un tamaño de partícula similar al del material empleado como matriz [Amigo 2007]. Como se ha mencionado anteriormente, con el objeto de minimizar la reactividad del titanio, el proceso se llevará a cabo en vacío.

Finalmente, puesto que estas pruebas preliminares se realizarán simultáneamente al estudio de reactividad, se emplearán moldes de gres para llevar a cabo la sinterización.

La tabla 3.1. recoge las variables de estudio seleccionadas:

Tabla 3.1. Variables del estudio seleccionadas para el desarrollo de las pruebas previas realizadas mediante el método de espaciadores.

\begin{tabular}{|c|c|}
\hline Fracción granulométrica de espaciador, $\mu \mathrm{m}$ & 250 a 500,500 a 1000 \\
\hline Porcentaje volumétrico, \%TiCP-\%Bic, \% & $\begin{array}{c}100-0,70-30,60-40,50-50 \\
40-60,30-70\end{array}$ \\
\hline Presión de compactación, MPa & 100,200 \\
\hline Temperatura de sinterización, ${ }^{\circ} \mathrm{C}$ & 1300 \\
\hline Tiempo de sinterización, $\mathrm{h}$ & 2 \\
\hline
\end{tabular}


Tal como se ha indicado en el esquema anterior, una vez obtenidas las piezas se procederá a su caracterización. Para ello, de las piezas porosas desarrolladas se extraerán probetas de flexión, que posteriormente se utilizarán para obtener la porosidad por el método de Arquímedes. El resto de la probeta se empleará para estudiar su microestructura.

La determinación de la resistencia y rigidez obtenidas mediante el ensayo de flexión a tres puntos (norma ISO 3325:2000) y su correlación con la porosidad y evolución microestructural, permitirá establecer si el rango de variables establecido es adecuado o conviene modificarlo, así como evaluar si las propiedades obtenidas resultan adecuadas de cara a un uso como implante.

\subsection{SINTERIZACIÓN DE MICROESFERAS.}

Para el desarrollo de piezas porosas mediante sinterización de microesferas se empleará la aleación Ti6Al4V como material base. Dada la influencia del tamaño de éstas sobre la dimensión del poro resultante, se emplearán tres fracciones granulométricas así como una mezcla entre dos de ellas, cuyo objetivo es aumentar el índice de coordinación y, por tanto, la resistencia mecánica a obtener. La fracción concreta a utilizar dependerá de la disponibilidad por parte de los distintos fabricantes aunque, con el objeto de estudiar la aptitud a la osteointegración y su relación con las propiedades mecánicas y rigidez de las piezas obtenidas, se tratará de obtener tamaños bien diferenciados que permitan determinar claramente la influencia sobre el resto de parámetros de proceso (T y t de sinterización).

Tras el estudio previo de reactividad, se decidió sinterizar las microesferas sobre moldes recubiertos con itria, pues fueron los que menor reactividad y mejores propiedades proporcionaron a igualdad de parámetros de proceso. El proceso se desarrollará tal como se ha indicado al planificar el estudio de reactividad, aunque modificando el rango de ciclos a sinterizar y la caracterización de la pieza obtenida, figura 3.3. 


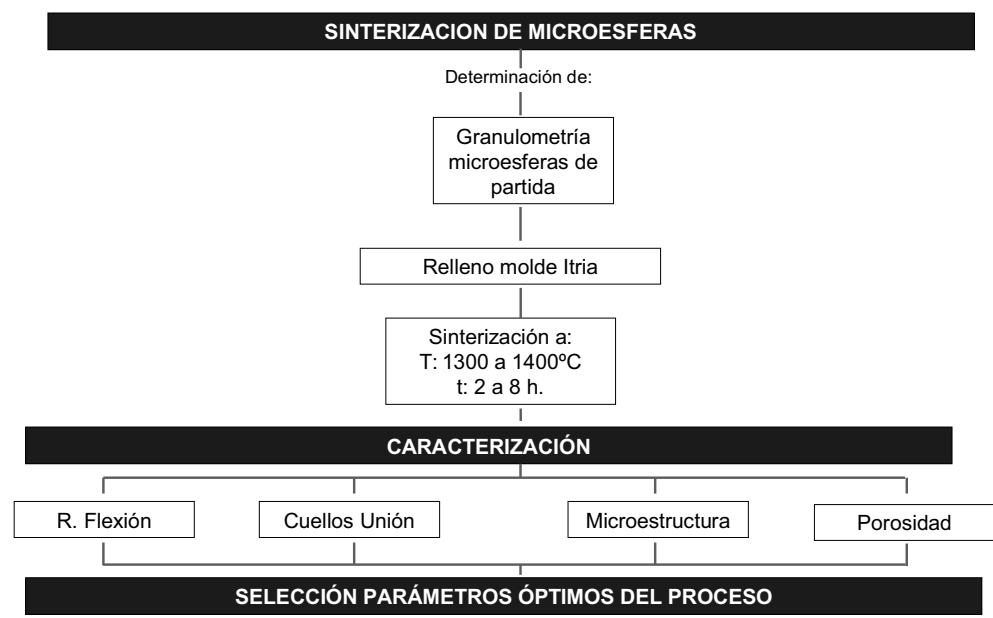

Fig. 3.3. Planificación del desarrollo de componentes porosos de Ti6Al4V mediante sinterización de microesferas.

Partiendo de estudios y pruebas previas realizadas con microesferas de TiCP3, se establece una temperatura mínima para la sinterización de $1300^{\circ} \mathrm{C}$, que se incrementará hasta los $1400^{\circ} \mathrm{C}$. De igual modo, dado que el tamaño de las microesferas es superior al de los polvos empleados habitualmente en procesos pulvimetalúrgicos, se incrementará el tiempo de sinterización desde 2 hasta 8 horas.

Una vez obtenidas las piezas porosas, se cortarán para proceder a su caracterización. Así, de cada pieza obtenida con parámetros de proceso distintos ( $T, t$, tamaño microesfera), se extraerán muestras tanto para estudiar su microestructura, como determinar su rigidez y resistencia mecánica a flexión. Finalmente, se determinarán las dimensiones de los cuellos de unión y la porosidad.

La resistencia a flexión y rigidez se determinarán mediante el ensayo de flexión a tres puntos, según norma ISO 3325:2000 (ASTM E290-97a), mientras que el estudio microestructural y de las dimensiones de los cuellos de unión desarrollados se llevará a cabo mediante microscopia óptica y electrónica de barrido. Mientras que la primera se determina con el fin tanto de comparar la resistencia mecánica como la variación de rigidez en función de los parámetros 
de proceso y analizar si resultan adecuadas de cara a una aplicación como implante, el análisis microestructural se realizará para correlacionar la variación de las propiedades obtenidas con las modificaciones microestructurales ocasionadas durante el proceso de obtención. Finalmente, se determinará la evolución del tamaño de los cuellos de unión desarrollados, con el fin de establecer una relación con la rigidez, propiedades mecánicas y tamaño de poro de las piezas obtenidas.

Por otra parte, la porosidad de la pieza obtenida se determinará tanto mediante análisis de imagen como por el método de Arquímedes, según norma ASTM B328. La determinación mediante ambos métodos permitirá, por una parte, comparar los resultados obtenidos y, por otra, establecer diferencias entre la porosidad abierta y cerrada, de gran importancia de cara al desarrollo óseo.

\subsection{MÉTODO DE ESPACIADORES.}

Al igual que en las piezas porosas desarrolladas por sinterización de microesferas y a diferencia de las pruebas preliminares realizadas por el método de espaciadores, el desarrollo de la investigación de piezas porosas realizadas por éste último método se realizará con polvo de Ti6Al4V como matriz.

Tras los estudios previos realizados se concretó el rango de variables a estudiar. Así, se establece una temperatura media de $1300^{\circ} \mathrm{C}$, con un rango de variación de $+/-25^{\circ} \mathrm{C}$ respecto a ésta. De igual modo, se adopta un tiempo medio de 120 minutos (2 horas), que se llevará al doble y a la mitad (1 y 4 horas) con el fin de analizar la influencia sobre las propiedades obtenidas. Asimismo, se ampliarán las presiones de compactación aplicadas en las pruebas preliminares, y se compactará también a $300 \mathrm{MPa}$. Dado que se prevé una distribución más homogénea de las partículas de espaciador cuanto menores son éstas, y con el fin de analizar fundamentalmente la rigidez, se incluirá otra fracción granulométrica de menor tamaño, concretamente de 125 a $250 \mu \mathrm{m}$. Finalmente, con el fin de reducir la cantidad de variables, se establece una variación de la adición de espaciador entre el mismo rango, pero con 
variaciones del $15 \%$ v en lugar del $10 \%$ v adoptado en las pruebas previas. Dado que de la combinación de variables resulta un número elevado de probetas, se establece una selección intermedia de cada combinación, figura 3.4 .

\begin{tabular}{cccc}
\hline $\mathbf{T}^{\mathbf{a}},{ }^{\mathbf{}} \mathbf{C}$ & \multicolumn{3}{l}{$\mathbf{t}, \mathbf{h}$} \\
\hline 1275 & 1 & 2 & 4 \\
\hline 1300 & 1 & 2 & 4 \\
\hline 1325 & 1 & 2 & 4 \\
\hline
\end{tabular}

\begin{tabular}{cccc}
\hline Fracción, $\mu \mathrm{m}$ & \multicolumn{3}{c}{ Presión, MPa } \\
\hline $125-250$ & 100 & 200 & 300 \\
\hline $250-500$ & 100 & 200 & 300 \\
\hline $500-1000$ & 100 & 200 & 300 \\
\hline
\end{tabular}

b)

\begin{tabular}{c|ccccc}
\hline Fracción, $\mu \mathrm{m}$ & \multicolumn{5}{c}{ Porcentaje espaciador, \%v } \\
\hline $125-250$ & 70 & 55 & 40 & 25 & 0 \\
\hline $250-500$ & 70 & 55 & 40 & 25 & 0 \\
\hline $500-1000$ & 70 & 55 & 40 & 25 & 0 \\
\hline
\end{tabular}

Fig. 3.4. Variables a estudiar seleccionadas sombreadas en gris: a) Temperatura tiempo; b) Tamaño espaciador - Presión de compactación; c) Tamaño - Adición de espaciador.

Con todo ello, los parámetros del proceso a estudiar se recogen en la tabla 3.2.

Tabla 3.2. Variables del estudio seleccionadas para el desarrollo de piezas porosas de Ti6Al4V fabricadas mediante el método de espaciadores.

\begin{tabular}{|c|c|}
\hline Fracción granulométrica de espaciador, $\mu \mathrm{m}$ & 125 a 250, 250 a 500, 500 a 1000 \\
\hline Porcentaje volumétrico, \%Ti64-\%Bic, \% & $100-0,75-25,60-40,45-55,30-70$ \\
\hline Presión de compactación, MPa & 100,200 y 300 \\
\hline${\text { Temperatura de sinterización, }{ }^{\circ} \mathrm{C}}^{\text {Tiempo de sinterización, } \mathbf{h}}$ & 1275,1300 y 1325 \\
\hline & 1,2 y 4 \\
\hline
\end{tabular}


El siguiente esquema resume el proceso por el que se llevará a cabo la investigación:

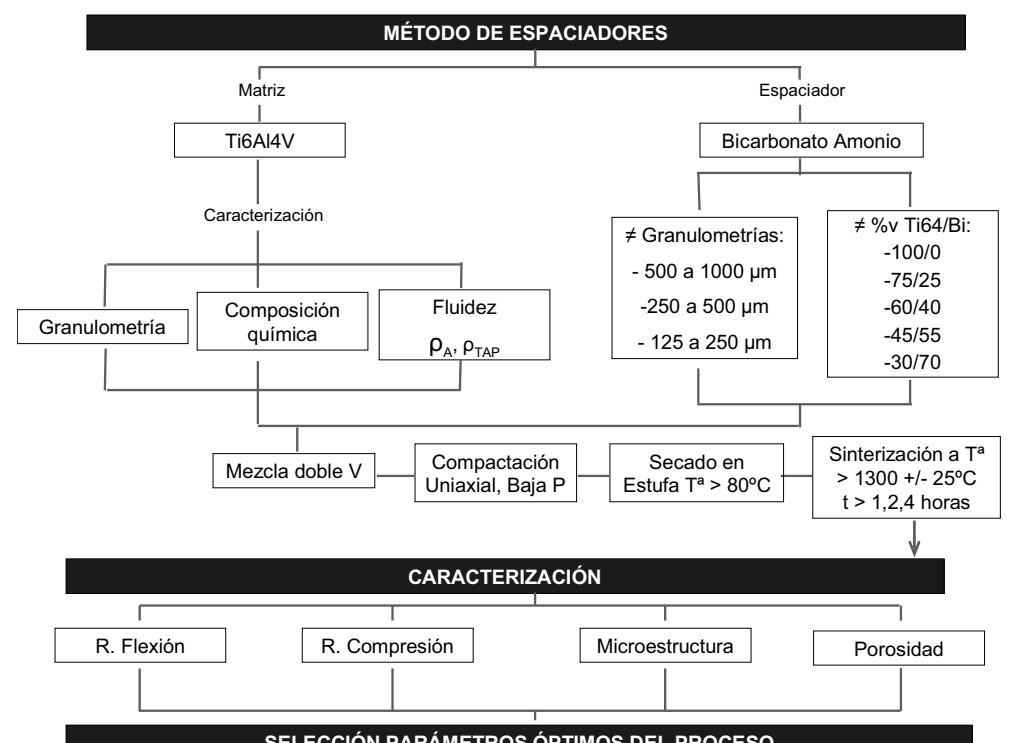

Fig. 3.5. Planificación del desarrollo de componentes porosos de Ti6Al4V mediante el método de espaciadores.

Al igual que se procedió en las pruebas preliminares, previo al desarrollo de las piezas se caracterizará el polvo de Ti6Al4V, determinando su granulometría, composición química, fluidez y densidad aparente y vibrada. Posteriormente se realizarán las correspondientes mezclas y, dado que no se observó una distribución homogénea del espaciador en las pruebas preliminares, en este caso se realizarán en un mezclador de doble V. Posteriormente se conformarán probetas de flexión y compresión, aplicando presiones de 100, 200 y 300 MPa y se determinará su masa y dimensiones, con el fin de determinar la pérdida de peso y contracción de la pieza a lo largo del proceso de obtención. Para asemejar más el proceso a la práctica industrial, la compactación se llevará a en una prensa automática, en la empresa "Aleaciones de Metales Sinterizados S.A.", AMES. No obstante, la preparación del material de partida así como los procesos de secado y sinterización se realizarán en la UPV. 
Una vez conformadas las piezas, los compactos serán introducidos en estufa con el fin de eliminar el bicarbonato de amonio y, posteriormente, volverá a determinarse la masa y dimensiones. Finalmente las piezas será consolidadas mediante sinterización a temperaturas entre 1275 y $1325^{\circ} \mathrm{C}$ y tiempos entre 1 y 4 horas.

Una vez obtenidas las piezas bajo las diferentes condiciones descritas, se procederá a su caracterización. Para ello, se determinará la densidad (porosidad), y se ensayarán a flexión a tres puntos (según norma ISO 3325:2000, ASTM E290-97a) y a compresión (según norma ASTM E9 89 a). Se analizará además la microestructura, tamaño, morfología y distribución de poros de las muestras obtenidas. Dada la forma regular de las probetas, en este caso la porosidad se determinará mediante la determinación de las dimensiones y masa de las muestras. Finalmente, se relacionará la porosidad, tamaño y morfología de los poros originados tanto con la rigidez y propiedades mecánicas, como con la aptitud para el desarrollo óseo. 
4 DESARROLLO EXPERIMENTAL 



\section{DESARROLLO EXPERIMENTAL.}

Dada la elevada reactividad del titanio y su influencia sobre las propiedades de la pieza obtenida, previo al desarrollo de la investigación se realizó un estudio con el fin de determinar el material idóneo a utilizar como molde. Por otra parte, se realizó otro estudio preliminar para acotar el rango de las variables relativas a la obtención de piezas porosas mediante el método de espaciadores.

Tras caracterizar el material de partida, se realizaron los estudios previos descritos. Una vez determinado el material idóneo a emplear como molde y acotadas las variables a emplear en el método de espaciadores, se desarrollaron las piezas porosas base de la presente investigación. Finalmente se procedió a su caracterización y estudio de las propiedades obtenidas.

Debido a las diferencias inherentes a los dos procesos de fabricación de piezas porosas de titanio empleados en la presente tesis, se presentaran los resultados por separado. Es decir, se estudiará para cada proceso el efecto que la porosidad, morfología y distribución de los poros ejercen sobre la rigidez, propiedades mecánicas y posibilidades de osteointegración, y se realizará una comparativa final de las características de las piezas obtenidas mediante ambos métodos.

\subsection{MATERIAL DE PARTIDA.}

\subsubsection{DESCRIPCIÓN DEL MATERIAL DE PARTIDA.}

Para llevar a cabo el estudio de reactividad de las microesferas con los distintos moldes utilizados, así como el desarrollo de piezas porosas de titanio menos rígidas y con mayor grado de osteointegración, se adquirieron microesferas tanto de Titanio comercialmente puro de grado 3 (TiCP3), como de la aleación Ti6Al4V (comúnmente conocida como Ti64). Concretamente, se compraron dos granulometrías distintas del TiCP3, que denominamos como "grano fino" (GF) y "grano grueso" (GG); y tres 
granulometrías diferentes de aleación Ti64, que identificamos como "grano fino" (GF), "grano medio" (GM) y "grano grueso" (GG) a lo largo del presente trabajo. Todas ellas fueron fabricadas mediante el proceso de electrodo rotatorio de plasma (PREP), y suministradas por PHELLY MATERIALS (USA.) Inc.

Pese a que la presente investigación se centró en el desarrollo de piezas porosas de Ti64, la caracterización de microesferas y piezas porosas de TiCP3 se empleó a nivel comparativo. Además de las tres granulometrías empleadas, se realizó una mezcla al $50 \%$ en volumen de las granulometrías media y gruesa, tratando de incrementar con ello el índice de coordinación $\mathrm{y}$, en consecuencia, las propiedades mecánicas de la pieza porosa obtenida.

Para desarrollar piezas porosas mediante la técnica de espaciadores, se empleó como matriz polvo tanto de TiCP3 como de Ti64, ambos fabricados mediante HDH por Se-Jong Materials. Como espaciador se utilizó tanto bicarbonato de amonio, $\mathrm{NH}_{4} \mathrm{HCO}_{3}$, el cual fue suministrado por Scharlau Chemie, como urea, $\mathrm{CO}\left(\mathrm{NH}_{2}\right) 2$, suministrada por Panreac Química S.A.U. La siguiente tabla resume los materiales empleados en cada etapa de la investigación.

Tabla 4.1. Materiales empleados en las diferentes etapas de la investigación.

\begin{tabular}{|c|c|c|c|}
\hline \multirow{4}{*}{$\begin{array}{l}\text { Técnica de } \\
\text { Sinterización de } \\
\text { Microesferas }\end{array}$} & ETAPA & \multicolumn{2}{|c|}{ MATERIAL BASE } \\
\hline & $\begin{array}{l}\text { Comparación con } \\
\text { Microesf. Ti64 }\end{array}$ & \multicolumn{2}{|c|}{ TiCP3 (PREP) } \\
\hline & Estudio Reactividad & \multicolumn{2}{|c|}{ Ti6Al4V (PREP) } \\
\hline & Investigación & \multicolumn{2}{|c|}{ Ti6Al4V (PREP) } \\
\hline \multirow{4}{*}{$\begin{array}{l}\text { Técnica de } \\
\text { Espaciadores }\end{array}$} & ETAPA & MATRIZ & ESPACIADOR \\
\hline & Previo & TiCP3 (HDH) & $\begin{array}{c}\text { Bicarbonato } \\
\text { Amonio }\end{array}$ \\
\hline & Investigación & Ti6Al4V (HDH) & $\begin{array}{c}\text { Bicarbonato } \\
\text { Amonio }\end{array}$ \\
\hline & Prueba Final & Ti6Al4V (HDH) & Urea \\
\hline
\end{tabular}


El bicarbonato de amonio descompone en aire a temperatura próxima a $60^{\circ} \mathrm{C}$, según la reacción (4.1.1) [Bram 2005], dando lugar a poros de gran tamaño.

$$
\left(\mathrm{NH}_{4}\right) \mathrm{HCO}_{3} \longrightarrow \mathrm{NH}_{3}+\mathrm{CO}_{2}+\mathrm{H}_{2} \mathrm{O}
$$

Por otra parte, la urea descompone a temperatura próxima a $150^{\circ} \mathrm{C}$, según la reacción (4.1.2), dando lugar a poros de gran tamaño.

$$
2\left(\mathrm{NH}_{2}-\mathrm{CO}-\mathrm{NH}_{2}\right) \stackrel{150-180^{\circ} \mathrm{C}}{\longrightarrow} \mathrm{NH}_{2}-\mathrm{CO}-\mathrm{NH}-\mathrm{CO}-\mathrm{NH}_{2}+\mathrm{NH}_{3}
$$

\subsubsection{CARACTERIZACIÓN DEL MATERIAL DE PARTIDA.}

Previo al desarrollo de las piezas porosas, se caracterizó el material de partida. Así, la composición química y el análisis granulométrico de los diferentes polvos fueron facilitados por sus fabricantes. Por otra parte la caracterización se completó mediante la determinación de su fluidez, densidad aparente $\left(\rho_{\mathrm{A}}\right)$ y vibrada ( $\left.\rho_{\text {TAP }}\right)$, así como de su estudio microestructural. Para completar el estudio de reactividad, se determinó la microdureza de las microesferas de partida.

A continuación se describe la metodología empleada.

\subsubsection{Composición química y análisis granulométrico.}

La composición química y el análisis granulométrico (según ASTM B214), tanto para las microesferas de TiCP3 como de la aleación Ti64, pueden consultarse en las tablas 4.2 y 4.3 y figuras 4.1 y 4.2 . Tal como se ha indicado, los análisis fueron realizados por el fabricante (PHELLY MATERIALS Inc.).

Tabla 4.2. Composición química de las microesferas de TiCP3 de granulometría fina y gruesa.

ANÁLISIS QUÍMICO, \%Wt

\begin{tabular}{|l|c|c|c|c|c|c|}
\hline Elemento & $\mathrm{Fe}$ & $\mathrm{C}$ & $\mathrm{O}$ & $\mathrm{N}$ & $\mathrm{H}$ & $\mathrm{Ti}$ \\
\hline ASTM F1580-07 & 0,50 & 0,10 & 0,40 & 0,05 & 0,05 & Balance \\
\hline Resultados TiCP, GF & 0,056 & $<0,005$ & 0,08 & 0,002 & 0,005 & Balance \\
\hline Resultados TiCP, GG & 0,200 & 0,011 & 0,150 & 0,005 & 0,003 & Balance \\
\hline
\end{tabular}


Tabla 4.3. Composición química de las microesferas de Ti64 de granulometrías fina, media y gruesa.

ANÁLISIS QUÍMICO, \%Wt

\begin{tabular}{|l|c|c|c|c|c|c|c|c|c|c|}
\hline Elemento & $\mathrm{Al}$ & $\mathrm{V}$ & $\mathrm{O}$ & $\mathrm{Fe}$ & $\mathrm{C}$ & $\mathrm{H}$ & $\mathrm{N}$ & $\mathrm{Cu}$ & $\mathrm{Sn}$ & $\mathrm{Ti}$ \\
\hline ASTM F1580-07 & $5,5-6,75$ & $3,5-4,5$ & 0,20 & 0,30 & 0,08 & 0,015 & 0,05 & 0,10 & 0,10 & Balance \\
\hline Resultados Ti64, GF & 6,45 & 4,15 & 0,12 & 0,13 & 0,041 & 0,004 & 0,029 & $<0,05$ & $<0,05$ & Balance \\
\hline Resultados Ti64, GM & 6,73 & 4,05 & 0,11 & 0,21 & 0,016 & 0,004 & 0,026 & $<0,10$ & $<0,10$ & Balance \\
\hline Resultados Ti64, GG & 6,15 & 4,18 & 0,076 & 0,072 & 0,016 & 0,002 & 0,006 & $<0,01$ & $<0,01$ & Balance \\
\hline
\end{tabular}

Tal como se observa, todas ellas cumplen con las especificaciones de la norma ASTM F1580-07.

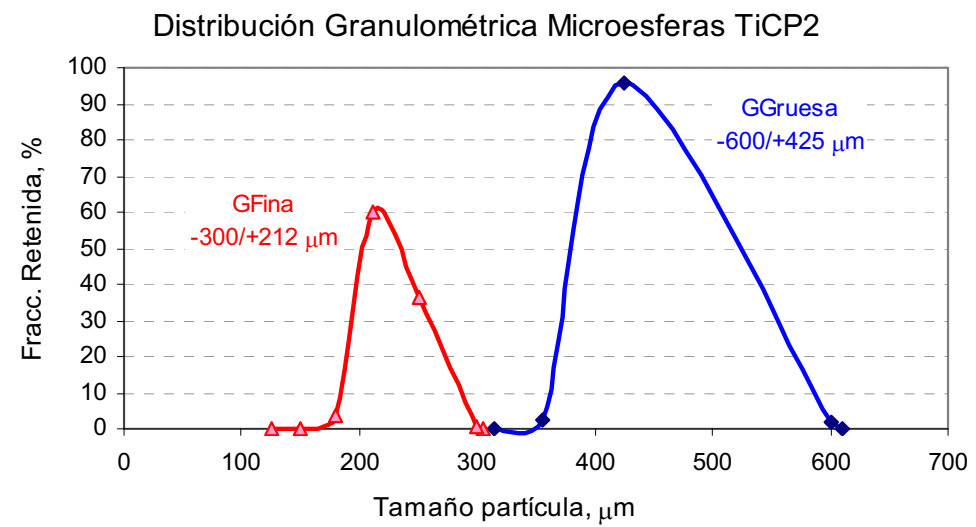

Fig. 4.1. Distribución granulométrica microesferas TiCP3. Fracciones fina y gruesa.

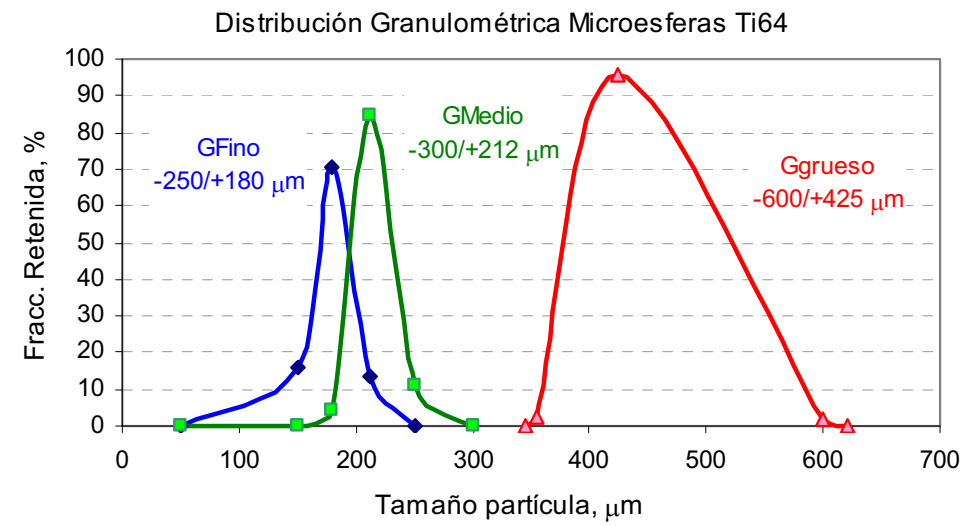

Fig. 4.2. Distribución granulométrica microesferas Ti64. Fracciones fina, media y gruesa. 
Frente a las microesferas, los polvos de TiCP3 y Ti6Al4V obtenidos por $\mathrm{HDH}$ fueron suministrados por Se-Jong Materials y poseían un tamaño inferior a 325 mesh $(<45 \mu \mathrm{m})$. La composición química, según análisis realizado por el fabricante, puede consultarse en las tablas 4.4 y 4.5 , respectivamente.

Tabla 4.4. Composición química del polvo de TiCP3 suministrado por Se-Jong Materials.

ANÁLISIS QUíMICO, \%Wt
\begin{tabular}{|l|c|c|c|c|c|c|c|c|c|}
\hline Elemento & $\mathrm{N}$ & $\mathrm{H}$ & $\mathrm{Fe}$ & $\mathrm{Si}$ & $\mathrm{C}$ & $\mathrm{Mg}$ & $\mathrm{Mn}$ & $\mathrm{O}$ & $\mathrm{Ti}$ \\
\hline ASTM F1580-07 & 0,05 & 0,05 & 0,50 & 0,04 & 0,10 & - & - & 0,40 & Balance \\
\hline Resultados TiCP, HDH & $0,04-0,08$ & $0,4-0,5$ & 0,04 & 0,04 & 0,017 & 0,02 & 0,003 & 0,30 & Balance \\
\hline
\end{tabular}

Tabla. 4.5. Composición química del polvo Ti6Al4V suministrado por Se-Jong Materials.

ANÁLISIS QUÍMICO, \%Wt
\begin{tabular}{|l|c|c|c|c|c|c|c|}
\hline Elemento & $\mathrm{Al}$ & $\mathrm{V}$ & $\mathrm{O}$ & $\mathrm{Fe}$ & $\mathrm{H}$ & $\mathrm{N}$ & $\mathrm{Ti}$ \\
\hline ASTM F1580-07 & $5,5-6,75$ & $3,5-4,5$ & 0,20 & 0,30 & 0,015 & 0,05 & Balance \\
\hline Resultados Ti64, HDH & 6,63 & 4,57 & Max. 0,55 & 0,03 & Max. 0,3 & Max. 0,5 & 88,86 \\
\hline
\end{tabular}

La figura 4.3 recoge la distribución granulométrica de los polvos de Ti6Al4V $\mathrm{HDH}$ empleados en el desarrollo de la investigación mediante la técnica de espaciadores.

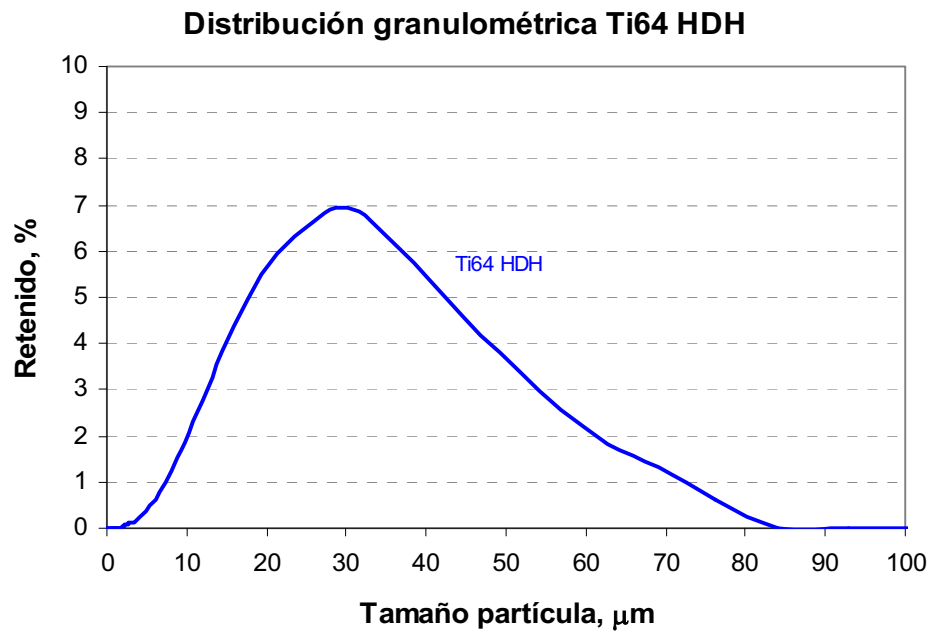

Fig. 4.3. Análisis granulométrico del polvo Ti6Al4V suministrado por Se-Jong Materials. 


\subsubsection{Fluidez, densidad aparente $\left(\rho_{\mathrm{A}}\right)$ y densidad vibrada ( $\left.\rho_{\text {TAP }}\right)$.}

Tras la recepción de los polvos, se determinó la fluidez de los diferentes tamaños de microesferas, de la mezcla de fracciones granulométricas, así como del polvo de Ti64 obtenido por $\mathrm{HDH}$. El ensayo se realizó según norma ASTM B213-97, con un flujómetro Hall de AcuPowder Internacional, figura 4.4 a y b. Para ello, se midió el tiempo que tardaron $50 \mathrm{~g}$. de polvo en fluir a través de un orificio de $2.54 \mathrm{~mm}$ de obertura.

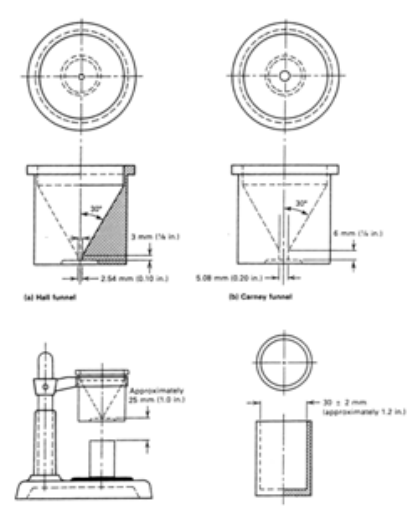

a

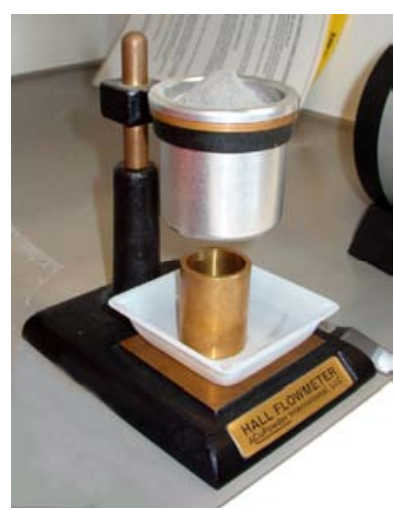

b

Fig. 4.4.a) Esquema del Flujómetro Hall y embudo Carney; b) Flujómetro hall.

La densidad aparente $\left(\rho_{A}\right)$ y vibrada $\left(\rho_{\text {TAP }}\right)$ de los polvos se determinó según la norma ASTM B213-97, mientras que para la densidad teórica, $\rho_{S}$, se adoptaron los valores de $4,5 \mathrm{~g} / \mathrm{cm}^{3}$ para el TiCP y $4,42 \mathrm{~g} / \mathrm{cm}^{3}$ para el Ti64 [ASM N4 1994, Matweb.com].

La densidad aparente de las microesferas de partida, $\rho_{\mathrm{A}}$, representa la masa por unidad de volumen cuando las microesferas son simplemente vertidas en el molde, mientras que la vibrada, $\rho_{\text {TAP }}$, define dicha relación tras aplicar una determinada vibración [German 1994, Upadhyaya. 1997]. Cabe hacer referencia además a la densidad teórica, $\rho_{S}$, de los materiales empleados, como si los polvos se fundieran en una masa sólida sin dejar poros entre ellos. 
Finalmente, la densidad relativa, $\left(\rho_{r}=\frac{\rho^{*}}{\rho_{S}}\right)$, relaciona la densidad de la pieza porosa obtenida, $\rho^{*}$, con la densidad del sólido, $\rho_{s}$.

En el caso de las microesferas, figura 4.5, los valores de densidad aparente, $\rho_{\mathrm{A}}$, y vibrada, $\rho_{\mathrm{TAP}}$, muestran gran similitud $\left(2,76 \pm 0,15 \mathrm{~g} / \mathrm{cm}^{3}\right)$, tanto entre las distintas granulometrías, como dentro de cada fracción. Ello es debido a la morfología esférica y regular de las partículas (véase apartado 4.1.2.4), pues provoca que éstas fluyan muy bien y se ordenen fácilmente en el molde [Shatt 1997, Reig 2005].

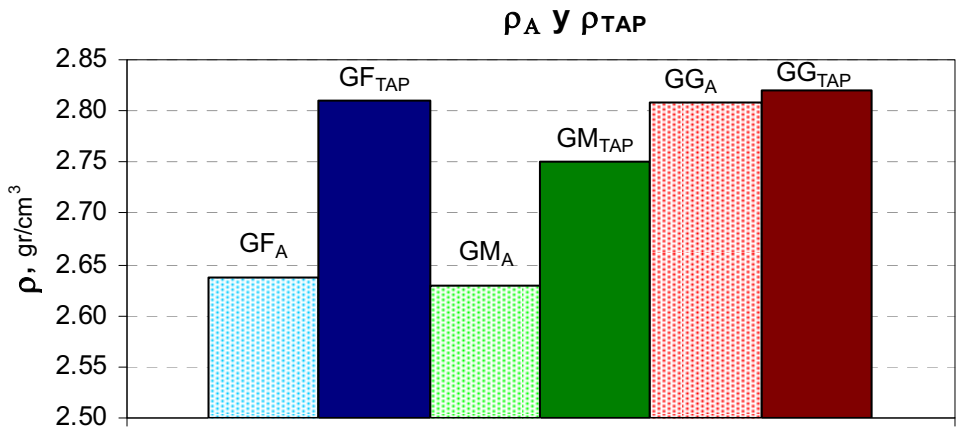

Fig. 4.5. $\rho_{\text {A }}$ У $\rho_{\text {TAP }}$ de las microesferas de Ti64 de granulometría fina (GF), media (GM) y gruesa (GG).

Tal como se observa, las granulometrías fina (GF) y media (GM) presentan valores de $\rho_{\mathrm{A}}$ muy similares, mientras que en la granulometría gruesa resulta superior. Esto es debido a su menor superficie específica, pues implica menor rozamiento entre éstas, lo que facilita el ordenamiento de las microesferas. A pesar de ello, al vibrar las microesferas se consiguen valores de $\rho_{\text {TAP }}$ muy similares en todos los casos, lo que indica que se reduce el volumen de huecos y, por tanto, aumenta el número de contactos entre partículas. Es de interés observar como, tras una ligera vibración de las partículas, la densidad aumenta en todos los casos hasta valores próximos a $2,8 \mathrm{~g} / \mathrm{cm}^{3}\left(\rho_{\mathrm{r}}=0,63\right)$. 
De acuerdo con Herrmann et al. [Herrmann 2002], si todas las esferas fuesen del mismo tamaño, el máximo empaquetamiento alcanzable correspondería a la de una estructura $\mathrm{CCC} \circ \mathrm{HC}$, es decir 0,74 (véase apartado 2.5). No obstante, al mezclar diferentes tamaños de partícula (distribución granulométrica) y aplicar vibración, la densidad resultante (densidad de empaquetado aleatoria), debería resultar superior a 0,64 [Herrmann 2002]. Los resultados de nuestros ensayos deportan una $\rho_{r}$ entorno a 0,63 , que únicamente es superior al combinar microesferas de granulometría media y gruesa (50M50G, $\rho_{\mathrm{r}} \approx 0,66$ ), lo que se debe a que las microesferas de menor tamaño rellenan los huecos dejados por las más groseras.

Por otra parte, tal como era de esperar, el mayor incremento de densidad se produce al vibrar las microesferas más finas, pues poseen mayor superficie específica $y$, por tanto, mayor rozamiento, lo que implica menor densificación durante el simple relleno por gravedad del molde.

Cabe indicar que, pese a que el aumento entre $\rho_{A}$ y $\rho_{\text {TAP }}$ parece reducido, podría implicar un considerable incremento de resistencia mecánica, pues aumenta el número de puntos de contacto entre microesferas y con ello, el de cuellos de unión generados durante la sinterización [German 1994, Upadhayaya 1997].

Por otra parte, para una misma $\rho_{\text {TAP }}$, resulta determinante considerar la superficie específica de cada fracción granulométrica (mayor cuanto menor el tamaño de la microesfera) [German 2005, Reig 2005], pues a igualdad de parámetros del proceso, implica mayor energía disponible para desarrollar nexos de unión entre microesferas, responsables de las propiedades mecánicas de la pieza porosa.

Para el polvo de Ti64 obtenido mediante $\mathrm{HDH}$, se obtuvieron unas densidades del polvo sensiblemente inferiores, con una $\rho_{A}$ de $1,46 \mathrm{~g} / \mathrm{cm}^{3}$ y $\rho_{\text {TAP }}$ de $1,80 \mathrm{~g} / \mathrm{cm}^{3}$. El menor valor en relación a los obtenidos para las microesferas, donde tanto $\rho_{A}$ como $\rho_{\text {TAP }}$ oscilaban entre $2,76 \pm 0,15 \mathrm{~g} / \mathrm{cm}^{3}$, 
se debe al mayor rozamiento entre las partículas del polvo $\mathrm{HDH}$, tanto por su menor tamaño (mayor superficie específica), como por su mayor rugosidad [ASM N7 1993, German 1994, Schatt 1997]. Ello justifica además el incremento de densidad que se produce entre las partículas cuando se aplica una vibración en relación a cuando estas son simplemente vertidas en el molde.

La fluidez es otro parámetro importante en la fabricación de componentes por vía pulvimetalúrgica, pues influye tanto en el tiempo como en la uniformidad de llenado, condicionantes ambos del rendimiento de la producción [Molera 1977]. En el desarrollo de piezas porosas mediante sinterización de microesferas un llenado homogéneo y con gran número de contactos entre partículas resultará fundamental para lograr unas propiedades mecánicas adecuadas.

Tal como se observa en la figura 4.6, la fluidez desciende ligeramente al incrementar el tamaño de partícula, lo que puede deberse a una mayor interacción entre éstas, lo que dificulta su ordenación.

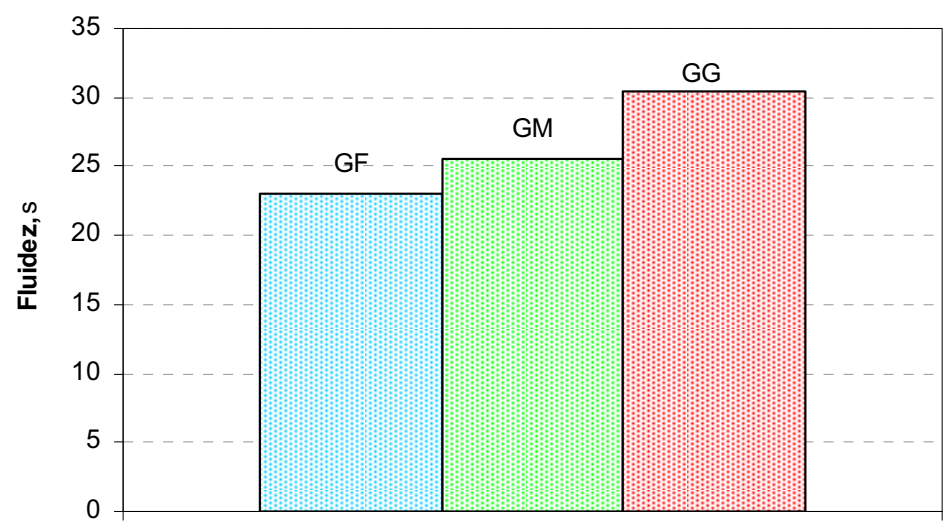

Fig. 4.6. Fluidez, (s/50g.) de las microesferas de Ti64 de GF, GM y GG.

A diferencia de las microesferas, el polvo de Ti64 HDH no fluyó en el flujómetro Hall ( $\varnothing=2,54 \mathrm{~mm}$, ASTM B213-97) ni en el embudo Carney $(\varnothing=$ $5,08 \mathrm{~mm}$, ASTM B417). 


\subsubsection{Preparación metalográfica.}

En el caso de las microesferas, se prepararon para su observación microesferas de las granulometrías fina y gruesa, tanto de TiCP3 como de la aleación Ti64. Entre los polvos utilizados para el desarrollo de piezas porosas por el método de espaciadores, se prepararon para su observación al microscopio óptico únicamente polvos de Ti64 obtenidos por HDH.

Para proceder a su preparación metalográfica, éstos se mezclaron con una pequeña cantidad de resina transparente polimetilmetacrilato (PMMA), que posteriormente se introdujo en un cilindro de aluminio $(5 \mathrm{~mm}$ de diámetro aprox.). Éste se introdujo en una embutidora Struers LaboPress-3, figura 4.7a, para obtener, por polimerización en caliente de resina PMMA, cilindros de $25 \mathrm{~mm}$ de diámetro y $10 \mathrm{~mm}$ de altura aproximada, figura $4.7 \mathrm{~b}$.

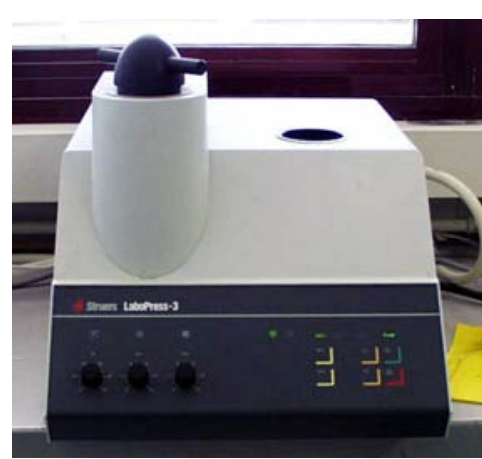

a

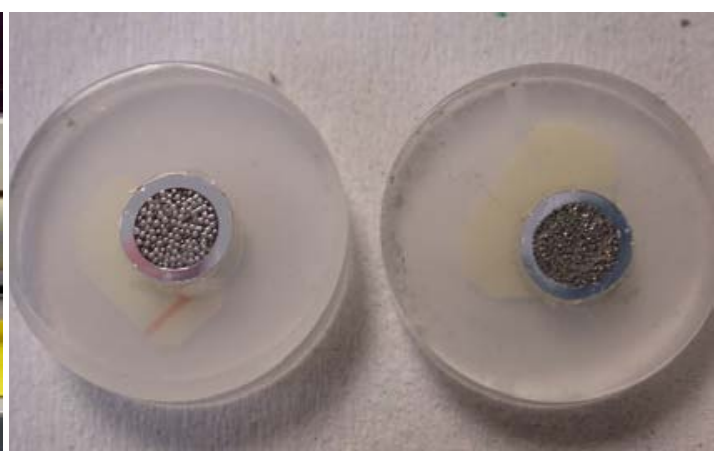

b

Fig. 4.7. a) Embutidora Struers LaboPress-3; b) Muestras embutidas de las microesferas suministradas por Phelly Materials.

El desbaste de las muestras se realizó en una desbastadora/pulidora de discos giratorios, marca Struers LaboPol-21, figura 4.8, con papeles abrasivos de SiC de 500, 1000 y 4000 grid. Para el pulido se empleó pasta de diamante de 3 y $1 \mu \mathrm{m}$, mientras que el acabado final se realizó en un solución de sílice coloidal (Mastermet de 0,06 $\mu \mathrm{m}$ diluida en $20 \%$ peróxido de oxigeno, $\mathrm{H}_{2} \mathrm{O}_{2}$ ). En las etapas de desbaste la limpieza se realizó con agua, mientras que durante el pulido en diamante se empleó una solución jabonosa. En ambos casos la probeta se introduce posteriormente en alcohol etílico, secándola finalmente en aire caliente. 
Tras esta preparación, determinadas probetas fueron atacadas durante 15 segundos con reactivo Kroll ( $\mathrm{HF} 3 \mathrm{ml}, \mathrm{HNO}_{3} 6 \mathrm{ml}, \mathrm{H}_{2} \mathrm{O} 100 \mathrm{ml}$ ), con el fin de revelar la microestructura existente.

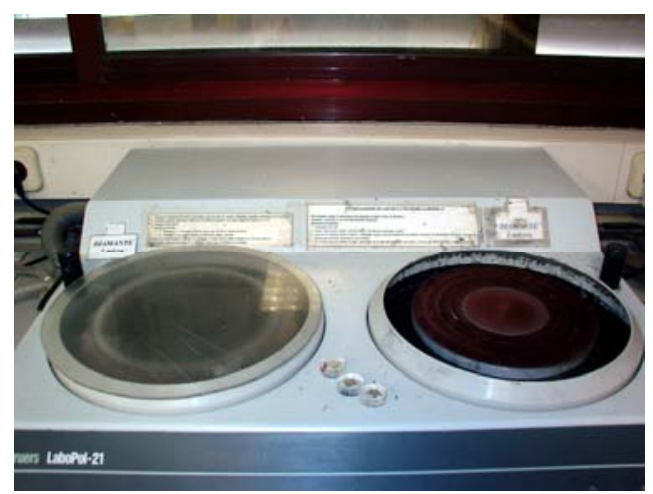

Fig. 4.8. Desbastadora/pulidora de discos giratorios, Struers LaboPol-21.

Las muestras preparadas fueron observadas mediante microscopía óptica y electrónica de barrido (MO y MEB).

4.1.2.4. Microscopia óptica (MO) y electrónica de barrido (MEB).

El estudio metalográfico se llevó a cabo en un microscopio metalográfico Nikon Microphot FX como el de la figura 4.9.

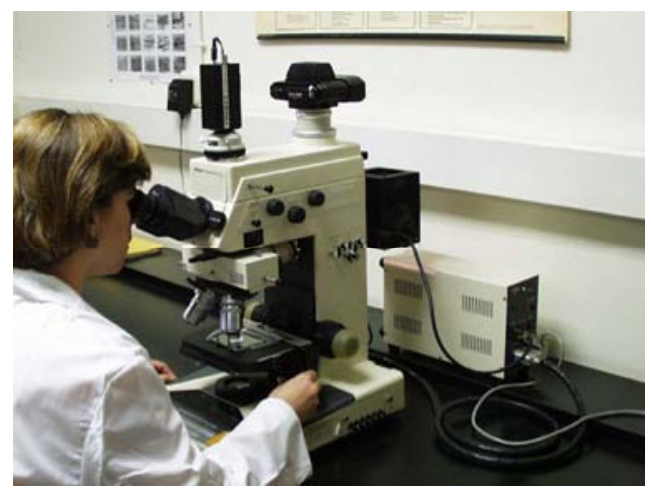

Fig. 4.9. Microscopio Metalográfico Nikon Microphot FX.

El análisis de la morfología y topografía superficial, así como la homogeneidad química de los polvos en su estado de recepción, se llevó a 
cabo en un microscopio electrónico de barrido JEOL JSM6300, figura 4.10, equipado con un detector para energías dispersivas de rayos $\mathrm{X}$ modelo 6508, de Oxford Instruments Ltda. con una resolución, a 5,9 KeV, de 137 $\mathrm{eV}$. Las condiciones normales de trabajo fueron de $20 \mathrm{KV}$ y $15 \mathrm{~mm}$ de distancia de trabajo, necesarias para la realización del análisis EDX.

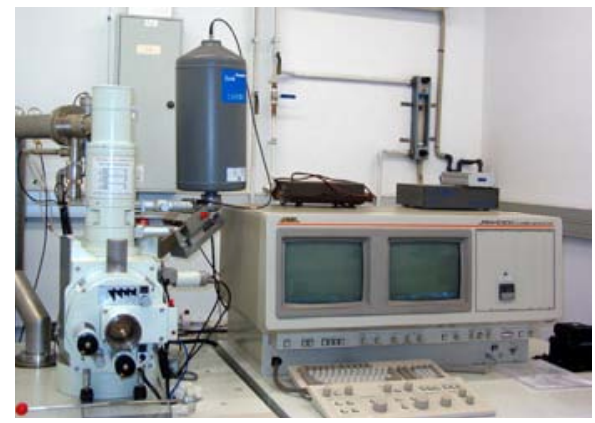

Fig. 4.10. Microscopio Electrónico de Barrido JEOL JSM6300.

En el caso de las microesferas, las micrografías obtenidas mediante microscopia óptica, tanto para TiCP3 como para Ti64, revelan una fina microestructura de laminillas de fase $\alpha$ y $\beta$ alternadas, producto del enfriamiento rápido generado durante su fabricación por PREP [German 1994, ASM N4 1994]. Ello provoca además que las microesferas de menor tamaño presenten una microestructura más fina respecto a las de mayor diámetro, figura 4.11 .

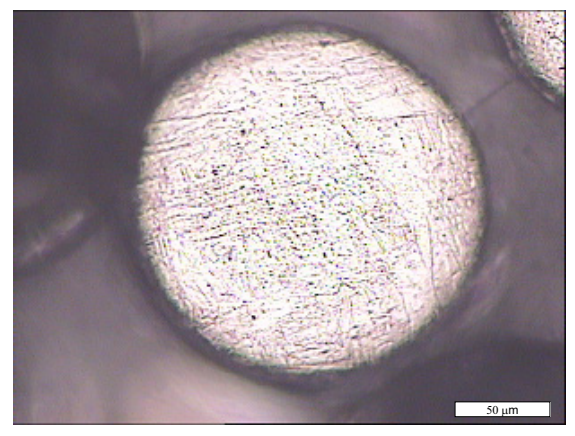

a

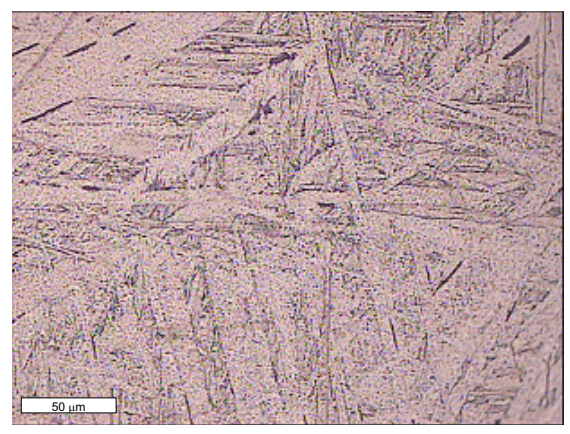

b

Fig. 4.11. Microestructura de microesferas de TiCP3, ataque Kroll: a) GF, b) GG.

Del mismo modo, comparado con el TiCP3, las laminillas que conforman la microestructura del Ti64 son más finas, figuras 4.11 y 4.12 , lo que es debido 104 
a la presencia de los elementos de aleación, pues dificultan el movimiento de átomos [Tarín 1999, Callister 2005].

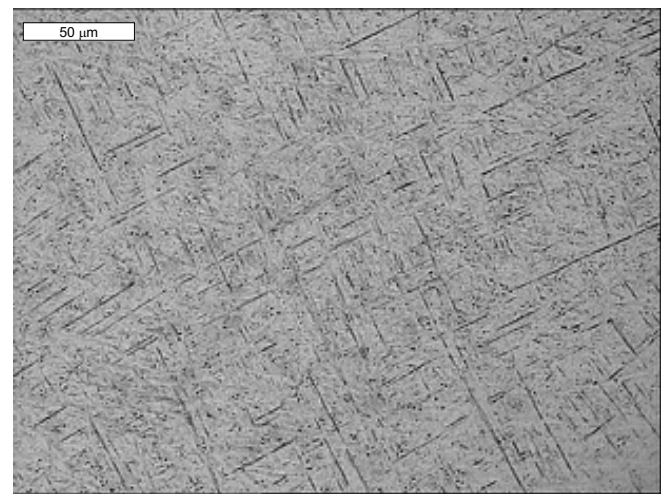

Fig. 4.12. Micrografía microesfera Ti64, GG. Ataque Kroll.

Por otra parte, las imágenes adquiridas en el MEB denotan tanto la morfología esférica de las partículas como el tamaño de los granos que las conforman. En algunas de ellas, se manifiestan en superficie las dendritas propias del proceso de solidificación, figura 4.13.

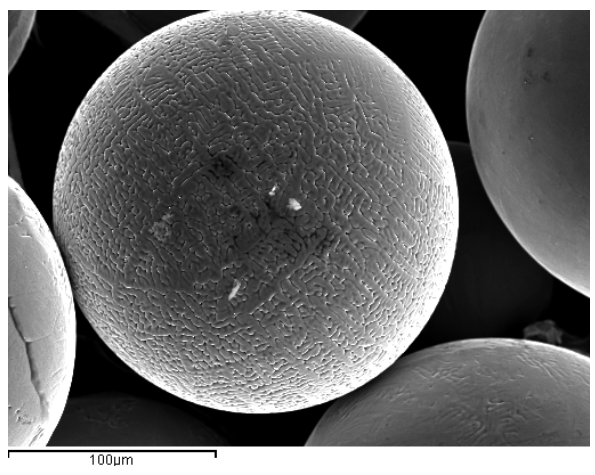

a

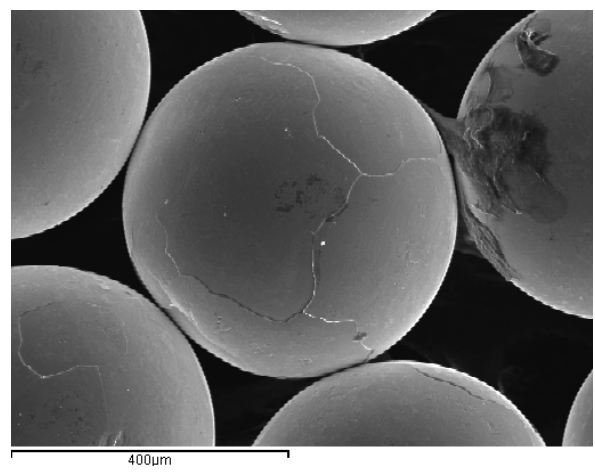

b

Fig. 4.13. Micrografías obtenidas por MEB de microesferas de Ti64: a) GF, b) GG.

A diferencia del tamaño y morfología presentada por las microesferas, el polvo de Ti64 obtenido mediante $\mathrm{HDH}$ presentaba un reducido tamaño de las partícula así como morfología irregular, figuras 4.14 y 4.15 . 

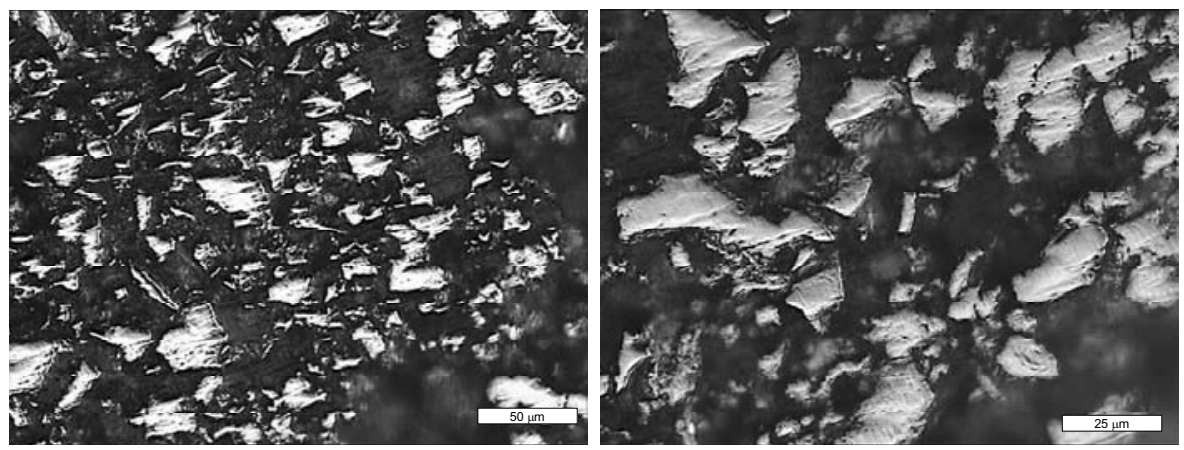

Fig. 4.14. Micrografías MO de polvo Ti64 $\mathrm{HDH}$.
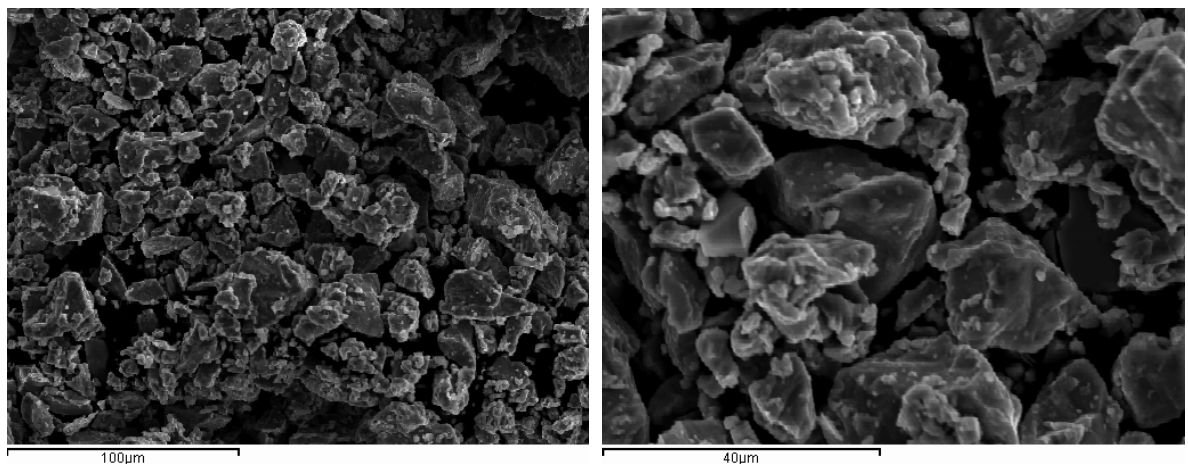

Fig. 4.15. Micrografías MEB de polvo Ti64 HDH.

De igual modo, el polvo de TiCP3 HDH así como el de bicarbonato de amonio empleado como espaciador en la mayor parte del desarrollo mediante ésta técnica, presentaban morfología irregular, figura 4.16.

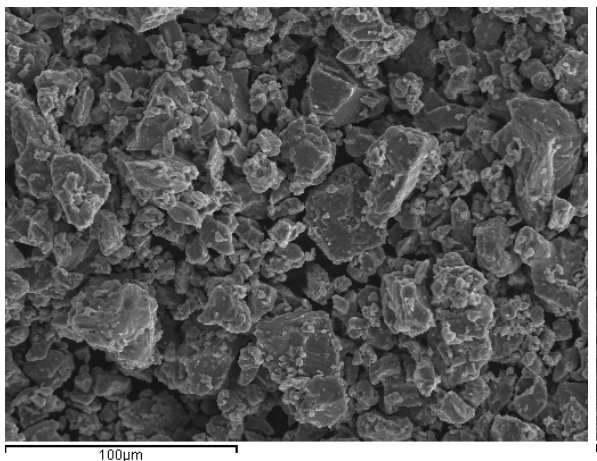

a

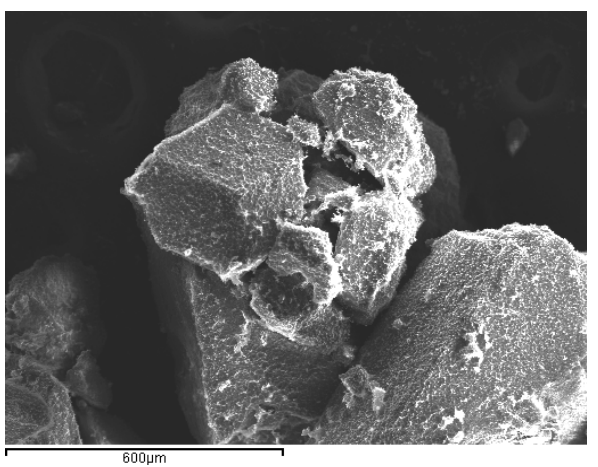

b

Fig.4.16. a) TiCP3 HDH; b) Bicarbonato de amonio fracción 500 a $1000 \mu \mathrm{m}$. 


\subsubsection{Microdureza.}

La microdureza se determinó únicamente sobre microesferas, tanto de las de partida (TiCP3 y Ti64), como de las sinterizadas, con el fin de evaluar la posible contaminación y, por tanto, reacción con el molde empleado. Para ello se empleó un microdurómetro Matsuzawa MHT2, con una carga de $25 \mathrm{~g}$ durante $15 \mathrm{~s}$, figura 4.17 .

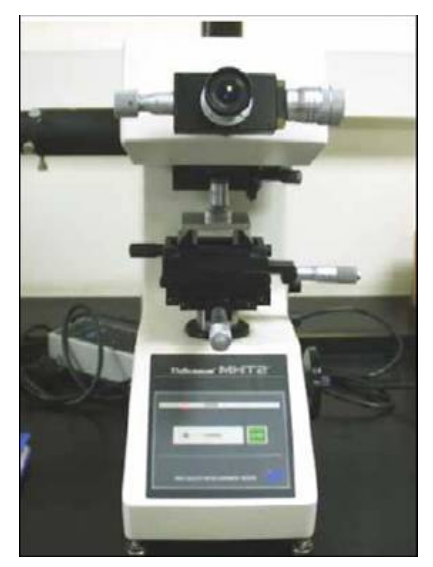

Fig. 4.17. Microdurómetro Matsuzawa MHT2.

Las determinaciones se realizaron sobre muestras previamente embutidas y desbastadas con lija de hasta 1000 grid. Se empleó una carga reducida con el fin de minimizar el área afectada y no romper los cuellos de unión entre microesferas. Dadas las reducidas dimensiones de las huellas generadas, las medidas de sus diagonales se determinaron a partir de la micrografía a x800 y empleando el software de análisis de imagen VISILOG.

La dureza Vickers HV0,025 se determinó según la fórmula:

$$
H V=1854 \cdot\left(\frac{F}{d^{2}}\right)
$$

Donde:

$\mathrm{F}=25 \mathrm{~g}$

$\mathrm{d}$ = diámetro medio de la huella, $\mu \mathrm{m}$. 
Tal como se observa en la figura 4.18, las microesferas de la aleación Ti64 presentan mayor dureza respecto a las de TiCP3, lo que se debe tanto al endurecimiento provocado por los elementos de aleación [Baeslack 1993, Amigó 2003a, Callister 2005], como al hecho de que presentan una microestructura más fina, véase apartado anterior 4.1.2.3.

Asimismo, al comparar la dureza entre las dos granulometrías de una misma aleación, se observa como en el TiCP3 apenas existe diferencia, mientras que las microesferas de la aleación Ti64 si presentan mayor dureza cuando el grano es fino. Ello es debido a su mayor superficie específica, pues incrementa la velocidad de enfriamiento, provocando una mayor sobresaturación de la matriz [Wosche 1995, Amigo 2001].

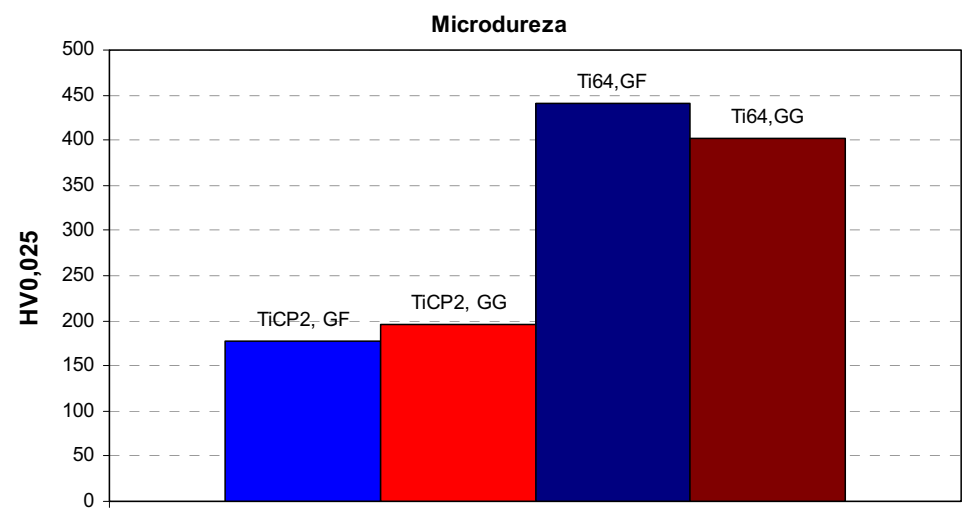

Fig. 4.18. Microdureza de las microesferas de TiCP3 y Ti64 en estado de recepción. 


\subsection{OBTENCIÓN DE PIEZAS POROSAS POR SINTERIZACIÓN DE MICROESFERAS Y ESTUDIO DE REACTIVIDAD.}

\subsubsection{DESARROLLO DE PIEZAS POROSAS POR SINTERIZACIÓN DE MICROESFERAS.}

Tras adquirir y caracterizar el material de partida, se llevó a cabo el estudio de reactividad. Dado que este se realizó sobre piezas porosas obtenidas por sinterización de microesferas, se describe en el presente apartado como se llevó a cabo el desarrollo de estas piezas.

El desarrollo de piezas porosas por sinterización de microesferas se realizó de acuerdo con el proceso recogido en el siguiente esquema:

\section{SINTERIZACION DE MICROESFERAS}

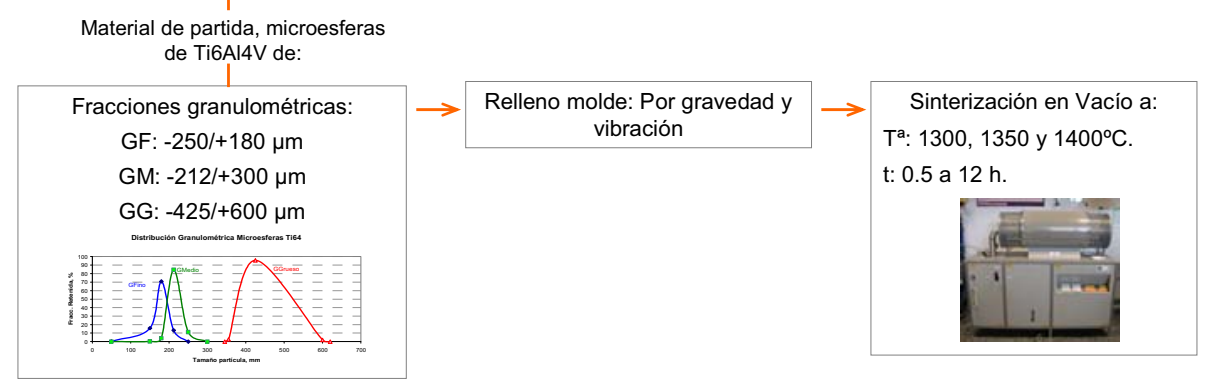

Fig. 4.19. Proceso de obtención de piezas porosas de Ti6Al4V realizadas mediante sinterización de microesferas.

Tal como se ha indicado, se seleccionaron tres fracciones granulométricas distintas (Fina, Media y Gruesa), y una mezcla al $50 \%$ v de las granulometrías media y gruesa. Las microesferas fueron vertidas en el molde por gravedad, siendo sometidas posteriormente a una ligera vibración manual con el fin de incrementar la densidad en verde y el número de contactos entre ellas. Posteriormente fueron sinterizadas en horno Carbolite de vacío modelo HVT 15/75/450, figura 4.20a, bajo un vacío de $10^{-4}$ a $10^{-5}$ 
mbar, a temperaturas comprendidas entre 1300 y $1400^{\circ} \mathrm{C}$, durante tiempos de 0,5 hasta 12 horas, según el ciclo térmico indicado en la figura 4.20b.

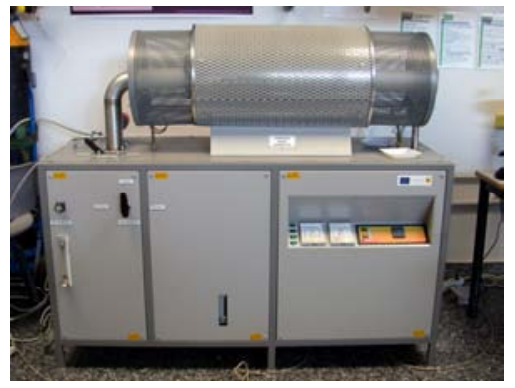

a

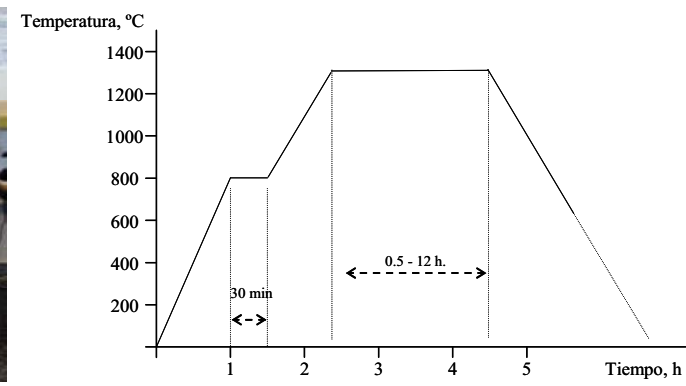

b

Fig. 4.20. a) Horno Carbolite de vacío; b) Ciclo térmico de sinterización.

Para llevar a cabo el estudio de reactividad, se sinterizaron probetas rectangulares sobre cuatro tipos de moldes distintos: gres, alúmina, itria y circona. Posteriormente se extrajeron muestras de cada pieza sinterizada para ensayar a flexión.

Para realizar los moldes de gres, éste se mezcló con chamota de $4 \mathrm{~mm}$ con el fin de minimizar la contracción de la cerámica. Para su sinterización, las microesferas se depositaron directamente sobre los moldes, figura 4.21 , que fueron introducidos en el horno sin ningún soporte intermedio.

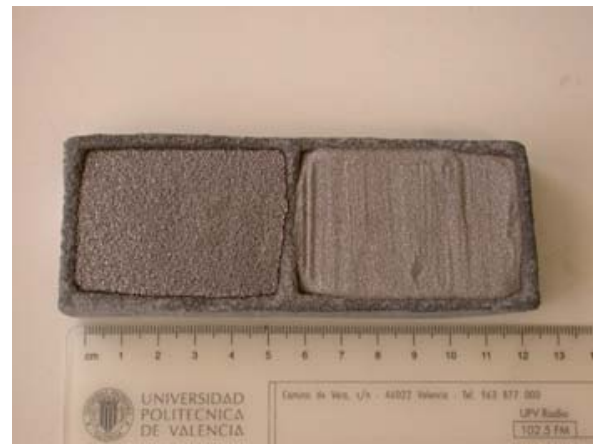

a

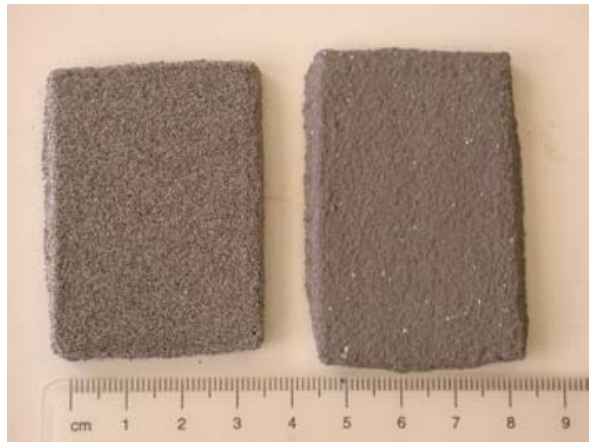

$\mathrm{b}$

Fig. 4.21. Sinterización en moldes de gres. a) Dentro del molde; b) Piezas desmoldadas tras su extracción. 
Los moldes de alúmina fueron suministrados por Keratec Advanced Materials S.A., figura 4.22a, y su uso permitió optimizar la carga del horno (de 6 hasta 12 probetas de $25 \times 35 \mathrm{~mm}^{2}$ ). Dada la contaminación observada tras cada ciclo de sinterización, se procedió a su limpieza mediante chorro de arena con una arenadora Eco Plus de Dentalfarm con sistema Wafis de filtración integrado, figura $4.22 \mathrm{~b}$. Se realizó una primera limpieza con corindón de $500 \mu \mathrm{m}$, entre 4 y 5 Bares de presión, y posteriormente un microchorreado con polvo de $\mathrm{Al}_{2} \mathrm{O}_{3}$ de $95 \mu \mathrm{m}$ entre 2 y 3 Bares de presión.

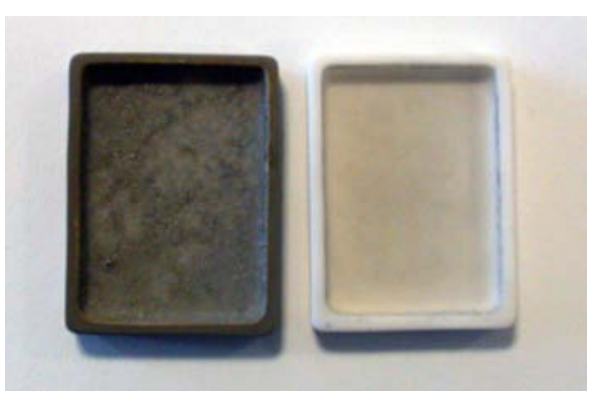

a

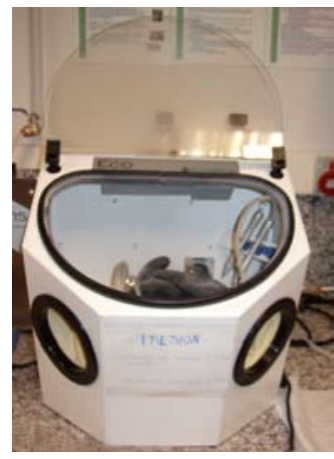

b

Fig. 4.22. a) Moldes de $\mathrm{Al}_{2} \mathrm{O}_{3}$ : Izquiera, tras la sinterización; derecha, tras limpiar con chorro de arena; b) Arenadora Eco Plus de Dentalfarm.

Para el recubrimiento con itria se emplearon moldes de alúmina como base. El polvo de itria fue suministrado por CymitQuimica y, para su deposición, se introdujeron en estufa los soportes de alúmina, a temperatura de $80^{\circ} \mathrm{C}$, posteriormente fueron recubiertos con polvo de itria disuelto en una suspensión acuosa y finalmente se introdujeron de nuevo en estufa a temperatura de $110^{\circ} \mathrm{C}$ para proceder al secado de la itria. Dicho recubrimiento fue eliminado y aplicado de nuevo tras cada ciclo de sinterización.

La última tipología de moldes empleados fueron de circona, suministrados también por Keratec Advanced Materials S.A. Estos poseían la misma forma que los de alúmina, aunque con unas dimensiones algo menores. 
Dado que la menor reactividad se obtuvo en las piezas sinterizadas sobre itria, se amplió el número de ciclos desarrollados sobre este tipo de molde, realizando en este caso un estudio más profundo de las propiedades de las piezas obtenidas. La tabla 4.6 recoge los ciclos térmicos realizados, en función del molde, granulometría y ciclo térmico empleado.

Tablas 4.6. Muestras rectangulares de Ti64 poroso obtenidas en función de los ciclos térmicos, tipo de molde y granulometría: $G=$ Granulometría; $F=F i n a ;$ M=Media; G=Gruesa; 50M50G = 50\%v Media + 50\%v Gruesa.

Sinterización en GRES.

\begin{tabular}{|c|c|c|c|c|}
\hline $\mathrm{T}^{\mathrm{a}} / \mathrm{t}$ & 1 & 2 & 4 & 8 \\
\hline 1300 & & & & $\mathrm{GF} / \mathrm{GG}$ \\
\hline 1400 & $\mathrm{GF} / \mathrm{GG}$ & $\mathrm{GF} / \mathrm{GG}$ & $\mathrm{GF} / \mathrm{GG}$ & $\mathrm{GF} / \mathrm{GG}$ \\
\hline
\end{tabular}

a)

Sinterización en ALÚMINA

\begin{tabular}{|c|c|c|c|c|}
\hline $\mathrm{T}^{\mathrm{a}} / \mathrm{t}$ & 2 & 3 & 4 & 8 \\
\hline 1300 & & & $\begin{array}{c}\text { GF / GM / GG / } \\
50 M 50 \mathrm{G}\end{array}$ & $\begin{array}{c}\text { GF / GM / GG / } \\
50 \mathrm{M} 50 \mathrm{G}\end{array}$ \\
\hline 1350 & $\mathrm{GF/GG}$ & $\mathrm{GF/GG}$ & $\mathrm{GF/GG}$ & $\mathrm{GF/GG}$ \\
\hline 1400 & GF/GG & & & \\
b)
\end{tabular}

Sinterización en ITRIA.

\begin{tabular}{|c|c|c|c|c|c|c|}
\hline $\mathrm{T} / \mathrm{t}$ & 0,5 & 2 & 3 & 4 & 8 & 12 \\
\hline 1300 & $\mathrm{GF} / \mathrm{GM} / \mathrm{GG}$ & $\begin{array}{c}\mathrm{GF} / \mathrm{GM} / \mathrm{GG} / \\
50 \mathrm{M} 50 \mathrm{G}\end{array}$ & $\begin{array}{c}\mathrm{GF} / \mathrm{GM} / \mathrm{GG} / \\
50 \mathrm{M} 50 \mathrm{G}\end{array}$ & $\mathrm{GF} / \mathrm{GM} / \mathrm{GG}$ & $\begin{array}{c}\mathrm{GF} / \mathrm{GM} / \mathrm{GG} / \\
50 \mathrm{M} 50 \mathrm{G}\end{array}$ \\
\hline 1350 & $\begin{array}{c}\mathrm{GF} / \mathrm{GM} / \mathrm{GG} / \\
50 \mathrm{M} 50 \mathrm{G}\end{array}$ & $\begin{array}{c}\mathrm{GF} / \mathrm{GM} / \mathrm{GG} / \\
50 \mathrm{M} 50 \mathrm{G}\end{array}$ & $\begin{array}{c}\mathrm{GF} / \mathrm{GM} / \mathrm{GG} / \\
50 \mathrm{M} 50 \mathrm{G}\end{array}$ & $\begin{array}{c}\mathrm{GF} / \mathrm{GM} / \mathrm{GG} / \\
50 \mathrm{M} 50 \mathrm{G}\end{array}$ & $\begin{array}{c}\mathrm{GF} / \mathrm{GM} / \mathrm{GG} / \\
50 \mathrm{M} 50 \mathrm{G}\end{array}$ & $\begin{array}{c}\mathrm{GF} / \mathrm{GM} / \mathrm{GG} / \\
50 \mathrm{M} 50 \mathrm{G}\end{array}$ \\
\hline 1400 & $\begin{array}{c}\mathrm{GF} / \mathrm{GM} / \mathrm{GG} / \\
50 \mathrm{M} 50 \mathrm{G}\end{array}$ & $\begin{array}{c}\mathrm{GF} / \mathrm{GM} / \mathrm{GG} / \\
50 \mathrm{M} 50 \mathrm{G}\end{array}$ & & $\begin{array}{c}\mathrm{GF} / \mathrm{GM} / \mathrm{GG} / \\
50 \mathrm{M} 50 \mathrm{G}\end{array}$ & $\begin{array}{c}\mathrm{GF} / \mathrm{GM} / \mathrm{GG} / \\
50 \mathrm{M} 50 \mathrm{G}\end{array}$ & \\
$\mathrm{C}$
\end{tabular}


Sinterización en CIRCONA.

\begin{tabular}{|c|c|c|c|}
\hline$T^{\mathrm{a} / \mathrm{t}}$ & 2 & 4 & 8 \\
\hline 1300 & $\mathrm{GF}, \mathrm{GM}, \mathrm{GG}$ & $\mathrm{GF}, \mathrm{GM}, \mathrm{GG}$ & $\mathrm{GF}, \mathrm{GM}, \mathrm{GG}$ \\
\hline 1350 & $\mathrm{GF}, \mathrm{GM}, \mathrm{GG}$ & $\mathrm{GF}, \mathrm{GM}, \mathrm{GG}$ & $\mathrm{GF}, \mathrm{GM}, \mathrm{GG}$ \\
\hline 1400 & $\mathrm{GF}, \mathrm{GM}, \mathrm{GG}$ & $\mathrm{GF}, \mathrm{GM}, \mathrm{GG}$ & \\
\hline
\end{tabular}

d)

Tras obtener las piezas porosas, se procedió a su caracterización. Dado que gran parte de las técnicas empleadas en la caracterización de las piezas porosas obtenidas son comunes tanto al estudio de reactividad, como al desarrollo de las piezas porosas por ambos métodos, su descripción se realizará en el apartado 4.4. No obstante, con el fin de clarificar el proceso, en el siguiente apartado se identifican tanto las técnicas empleadas para estudiar la reactividad con el molde, como las utilizadas para analizar las propiedades de las piezas obtenidas sobre moldes de itria.

El esquema 4.23, recoge la caracterización realizada para llevar a cabo el estudio de reactividad, mientras la el 4.24 , las técnicas empleadas para analizar las propiedades de las piezas sinterizadas sobre itria. Tal como se observa, la reactividad se estudió mediante la observación microestructural por microscopia óptica y electrónica, así como con análisis mediante EDX y de la resistencia obtenida a flexión.

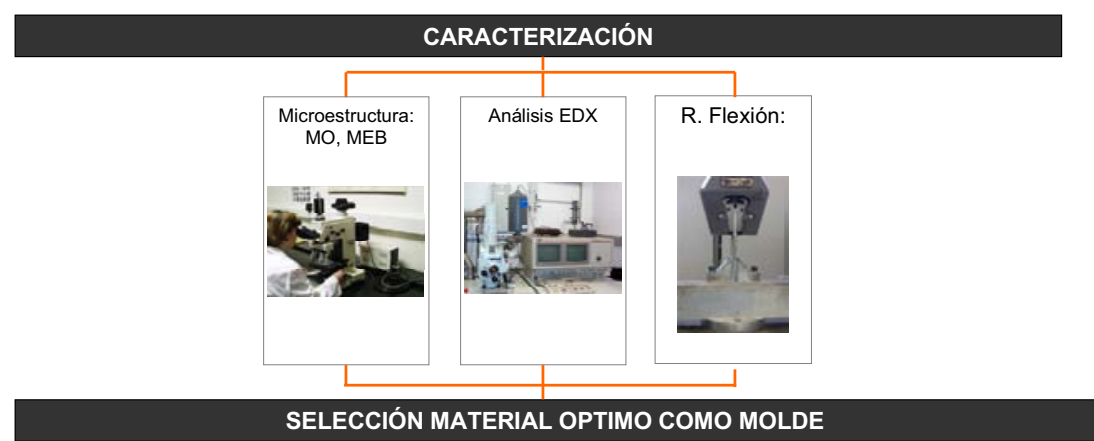

Fig. 4.23. Caracterización realizada para el estudio de reactividad en función del molde utilizado. 
En las piezas sinterizadas sobre itria, el estudió se completó con el análisis de la rigidez en función de los parámetros de proceso, así como las posibilidades de osteointegración sobre la pieza porosa en función de las características de los poros, y el desarrollo de los cuellos de unión generados durante la sinterización. Finalmente, se realizó un análisis de elementos para su comparación tanto con las microesferas de partida, como con las piezas obtenidas por el método de espaciadores.

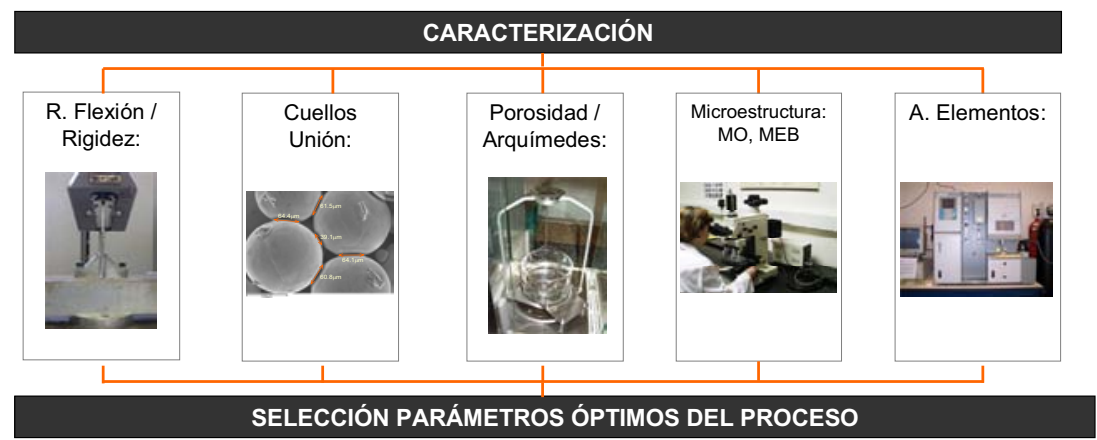

Fig. 4.24. Caracterización realizada para optimizar las propiedades de las piezas porosas desarrolladas por sinterización de microesferas.

Cabe recordar que, con el fin de comparar los resultados obtenidos mediante métodos de caracterización distintos, determinadas piezas desarrolladas para el estudio de reactividad se aprovecharon para determinar mediante análisis de imagen la porosidad y dimensiones de los cuellos de unión desarrollados.

Tras la obtención y caracterización de estas últimas piezas, se aplicaron tratamientos térmicos con el fin de modificar su microestructura y mejorar con ello sus propiedades mecánicas. El proceso mediante el cual se llevaron a cabo se describe en el apartado 4.4. 


\subsection{OBTENCIÓN DE PIEZAS POROSAS POR EL MÉTODO DE ESPACIADORES.}

\subsubsection{DESARROLLO DE LA INVESTIGACIÓN REALIZADA.}

Tras caracterizar el material de partida, se realizaron las pruebas preliminares para desarrollar piezas porosas de titanio mediante la técnica de espaciadores, lo que permitió concretar el rango de parámetros a analizar: porcentaje de espaciador, presión de compactación, temperatura de secado, temperatura y tiempo de sinterización.

Como muestra el esquema adjunto, figura 4.25 , se seleccionaron dos fracciones granulométricas distintas adicionadas a la matriz en diferentes porcentajes volumétricos. Las mezclas se compactaron a dos presiones distintas $y$, tras evaporar el espaciador, todas las muestras se sinterizaron bajo un mismo ciclo térmico. Finalmente las piezas porosas obtenidas fueron ensayadas a flexión con el fin de determinar su resistencia y variación de rigidez, y se estudió su microestructura y porosidad. El procedimiento mediante el cual se llevó a cabo la caracterización se describe en el apartado 4.4 .

Tras los resultados obtenidos en las pruebas previas descritas, se desarrollaron las probetas base de la presente investigación. Tal como se observa al comparar las figuras 4.25 y 4.26 , se siguió el mismo proceso, pero empleando polvo de Ti6Al4V como matriz y bicarbonato de amonio como espaciador. Además, se ampliaron tanto las fracciones granulométricas como las presiones de compactación a emplear, así como el rango de temperaturas y tiempos de sinterización. De igual modo, se modificaron ligeramente las cantidades de espaciador a adicionar respecto a las pruebas previas. 


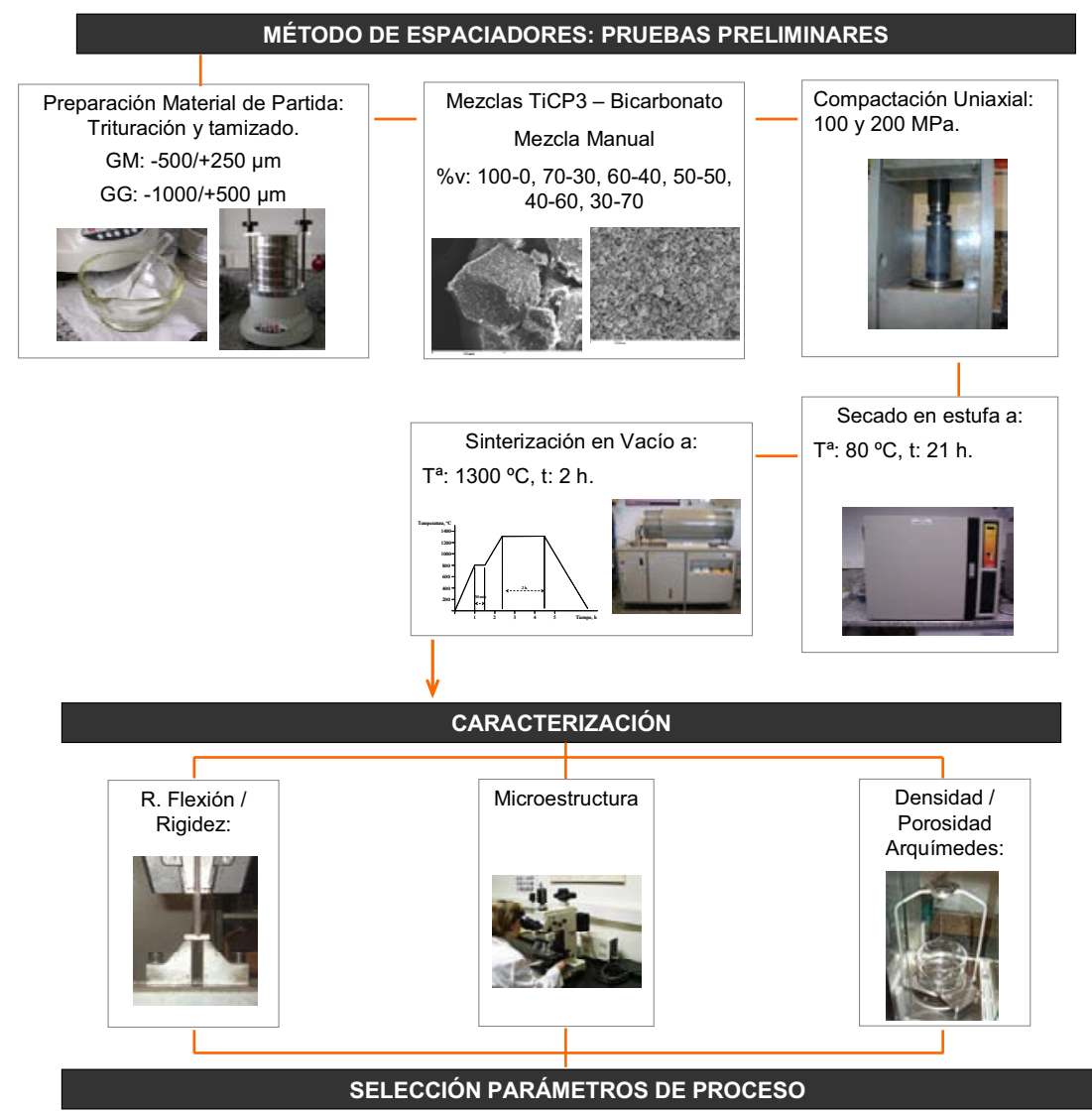

Fig. 4.25. Desarrollo de piezas porosas de TiCP3 mediante el método de espaciadores. Pruebas Preliminares.

Por otra parte, la caracterización mecánica realizada en las pruebas preliminares, se completó mediante el estudio de la resistencia a compresión y la obtención de la rigidez de las piezas también ante este tipo de esfuerzo. Estas propiedades se correlacionaron con la porosidad y microestructura de las piezas obtenidas. Finalmente, dado que se observó la rotura frágil de determinadas probetas, se determinó la posible contaminación de determinadas piezas porosas mediante el análisis de elementos ( $\mathrm{C}, \mathrm{N}, \mathrm{O})$. Tal como se ha indicado, la descripción de estos procesos se realizará en el apartado 4.4 . 


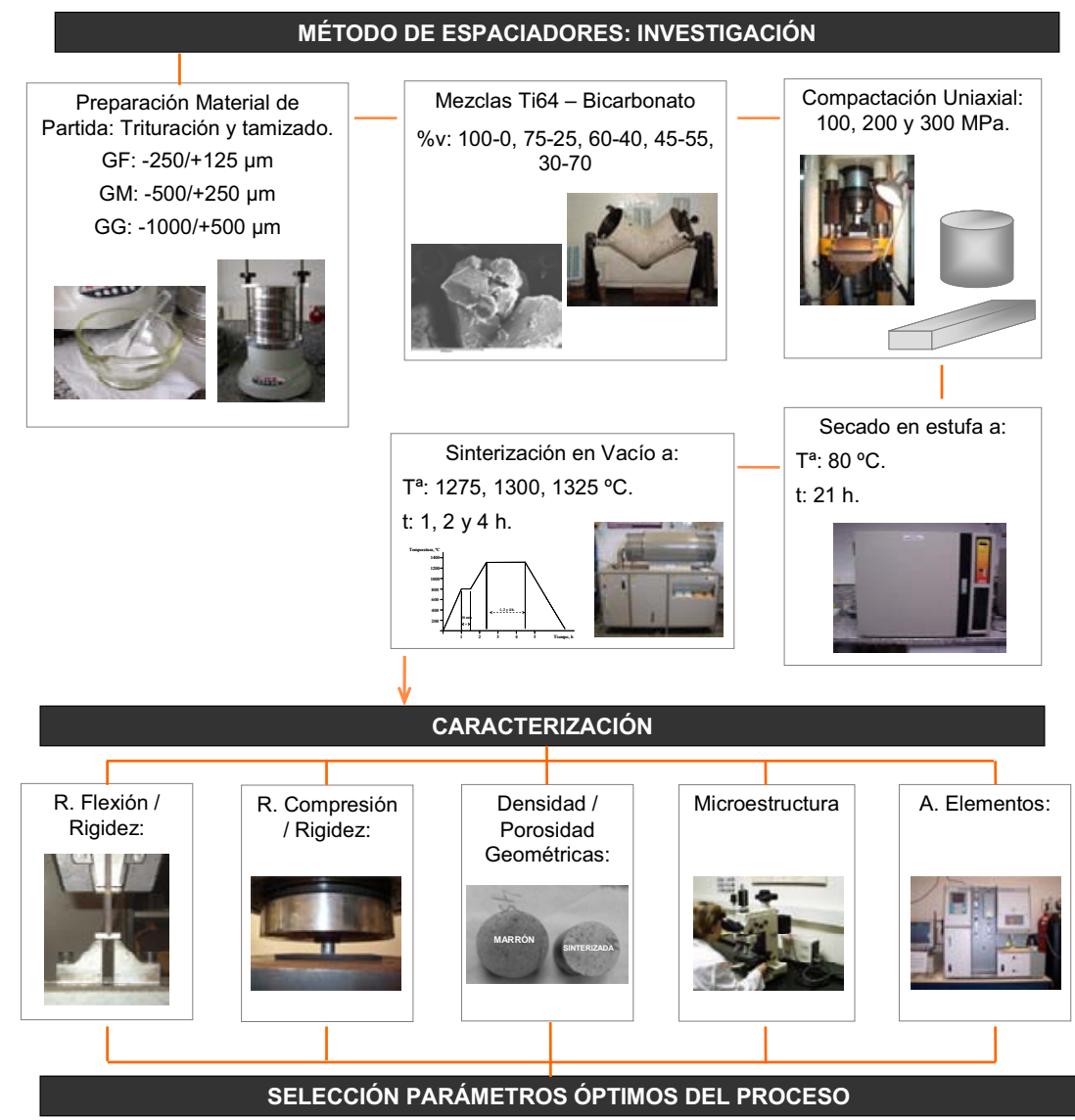

Fig. 4.26. Desarrollo de piezas porosas de Ti6Al4V mediante el método de espaciadores.

Como se ha indicado en la planificación, con el fin de simular el proceso industrial, las probetas fueron compactadas en la empresa "Aleaciones de Metales Sinterizados S.A.", AMES, mientras que el resto del proceso se llevó a cabo en la UPV.

Las tabla 4.7 recoge las probetas realizadas, producto de la combinación de variables anteriormente descrita. Para cada combinación de parámetros del proceso se obtuvieron cinco probetas de flexión $\left(32 \cdot 12 \cdot 6 \mathrm{~mm}^{3}\right)$ y 3 de compresión $(\phi=25 \mathrm{~mm}, \mathrm{~h}=25 \mathrm{~mm})$. 
Tabla 4.7. Muestras de Ti64 poroso a obtener con las distintas fracciones granulométricas de bicarbonato de amonio.

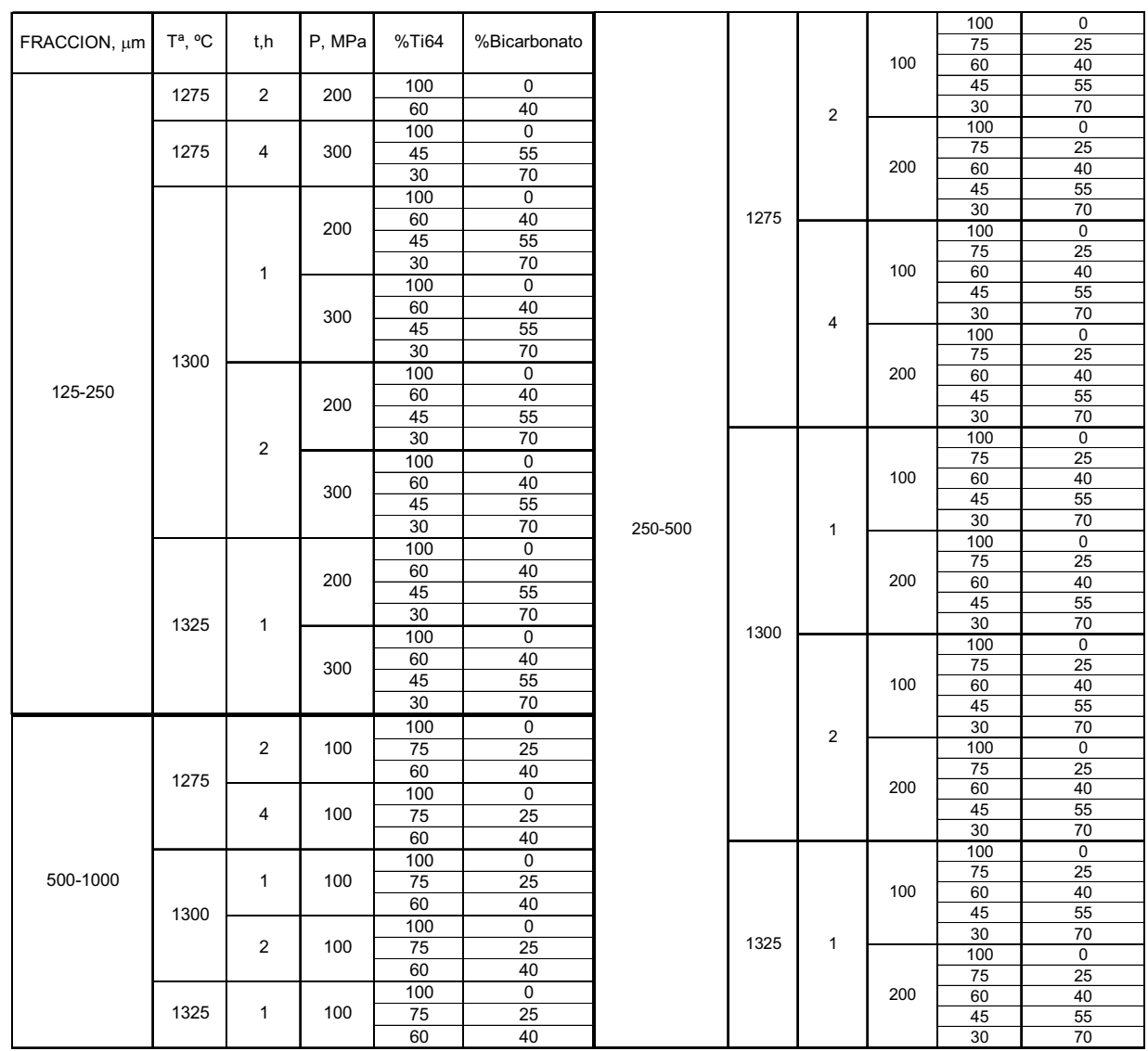

Por último, la investigación se completó mediante la realización de unas pruebas finales en las que el bicarbonato de amonio empleado como espaciador fue sustituido por urea. Para su realización se empleó el mismo proceso descrito, modificando únicamente el sistema de eliminación del espaciador. La descripción del proceso de desarrollo de las piezas se realiza en los siguientes apartados. 


\subsubsection{PROCESO DE OBTENCIÓN DE PIEZAS POROSAS POR EL MÉTODO DE ESPACIADORES.}

Las piezas porosas para el estudio preliminar fueron desarrolladas en la Universidad Politécnica de Valencia (UPV), según el proceso anteriormente descrito.

Tras triturar el polvo de bicarbonato en un mortero de vidrio, figura 4.27a, se separó en dos fracciones granulométricas (500 a $1000 \mu \mathrm{m}$ y de 250 a 500 $\mu \mathrm{m})$, empleando para ello una tamizadora Filtra FTL-0200, figura 4.27b.

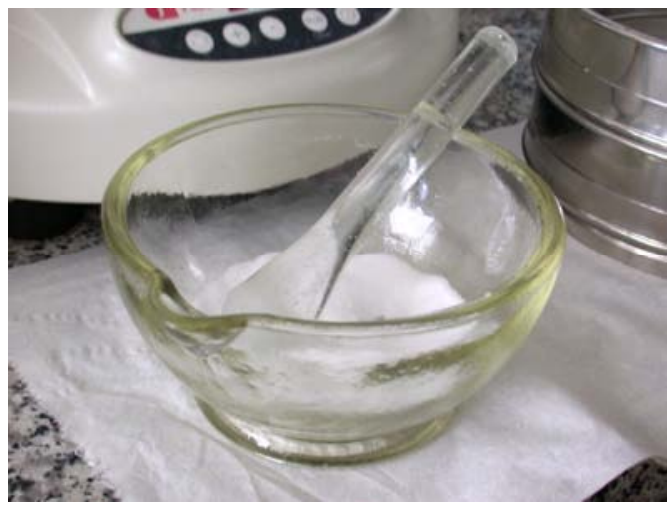

a

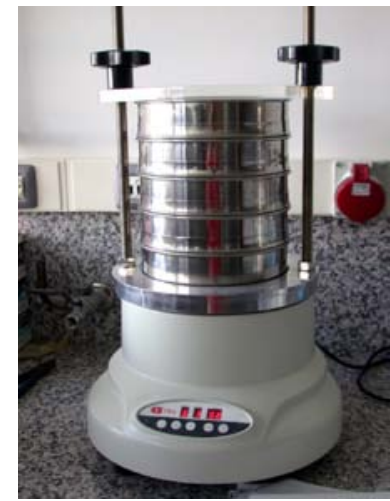

b

Fig. 4.27. a) Mortero de vidrio; b) Tamizadora Filtra FTL-0200.

Posteriormente se mezclaron manualmente los polvos, con porcentajes volumétricos $(\% \mathrm{v})$ TiCP3/Espaciador, para ambas fracciones granulométricas, de: 100/0, 70/30, 60/40, 50/50, 40/60 y 30/70. Cada una de ellas fue compactada en una prensa manual con matriz cilíndrica de $25 \mathrm{~mm}$ de diámetro, a presiones de 100 y $200 \mathrm{MPa}$, para obtener compactos de 5 $\mathrm{mm}$ de altura, figuras 4.28 y $4.29 \mathrm{~b}$. 


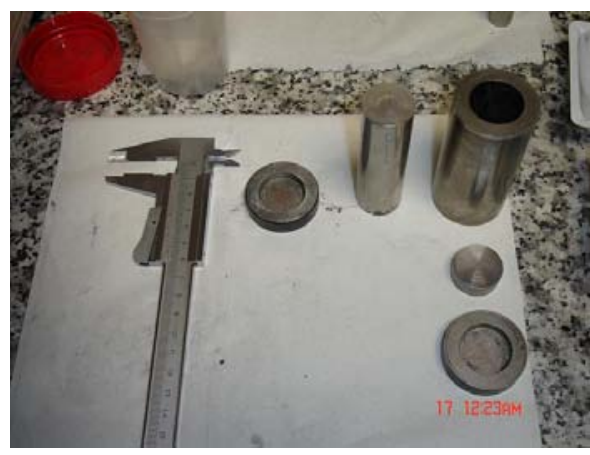

a

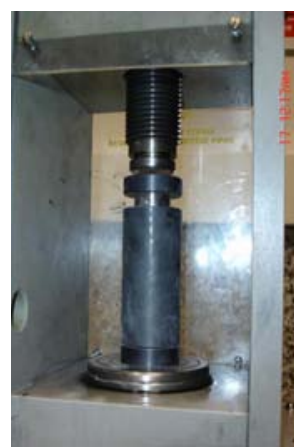

$\mathrm{b}$

Fig. 4.28. Útiles empleados en la compactación de TiCP3 con $\mathrm{NH}_{4} \mathrm{HCO}_{3}$ : a) Matriz; b) Prensa.

Las piezas en verde fueron introducidas en una estufa LHT5/60 (200) de temperatura máxima $500{ }^{\circ} \mathrm{C}$ de Carbolite, a temperatura de $80^{\circ} \mathrm{C}$, durante 21 horas, con el fin de eliminar el espaciador, figura 4.29 .

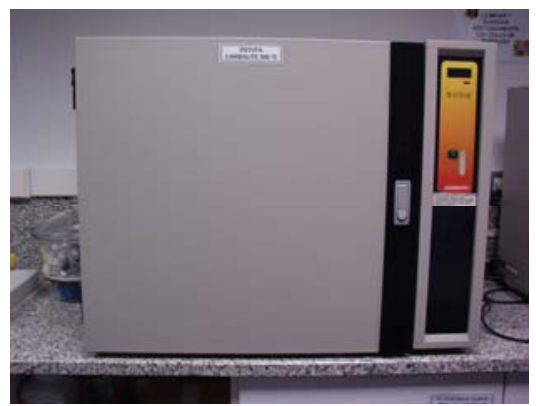

a

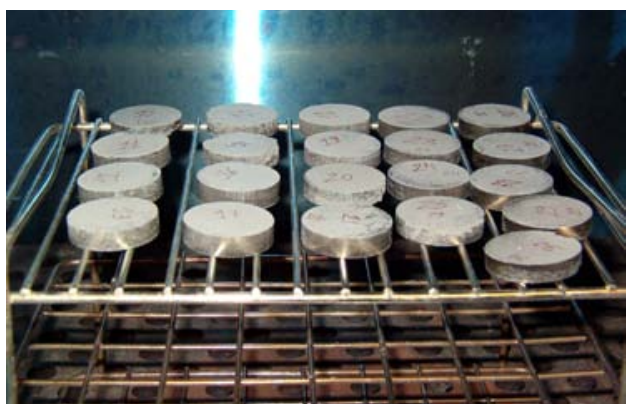

b

Fig. 4.29. a) Estufa Carbolite; b) Compactos en verde de TiCP3 / bicarbonato de amonio.

Tras el secado, las piezas fueron sinterizadas en vacío a $1300{ }^{\circ} \mathrm{C}$ durante $2 \mathrm{~h}$, empleando el horno y según ciclo térmico descritos en el apartado 4.2.1. Dado que estas pruebas previas se realizaron simultáneamente al estudio de reactividad, la sinterización se realizó sobre crisoles planos de gres, por ser los primeros en utilizar y los únicos disponibles en ese momento. Sobre éstos se depositó una delgada capa de alúmina en polvo, figura 4.30 . 


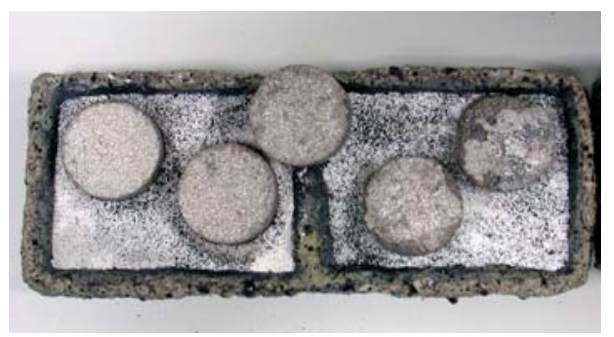

Fig. 4.30. Sinterización de TiCP3 poroso sobre crisol de gres.

Por el contrario, las piezas base del presente estudio fueron sinterizadas sobre moldes recubiertos de itria. Para su desarrollo se empleó polvo de Ti64 obtenido por HDH y bicarbonato como espaciador. Al igual que en las pruebas previas, las fracciones más groseras de espaciador se trituraron manualmente con un mortero de vidrio. Posteriormente el bicarbonato se tamizó, separando una fracción más respecto a las pruebas previas: 500$1000 \mu \mathrm{m}, 250-500 \mu \mathrm{m}, 125-250 \mu \mathrm{m}$ y menos de $125 \mu \mathrm{m}$.

Una vez caracterizado el material de partida, se realizaron la mezclas de Ti6Al4V / $\mathrm{NH}_{4} \mathrm{HCO}_{3}$ según la planificación anteriormente descrita. A diferencia de las pruebas previas, las mezclas se realizaron en un mezclador en $\mathrm{V}$, figura 4.31, durante un tiempo de 20 minutos, a velocidad de 38 rpm (3.98 Rad./s). Para ello previamente fueron introducidas en botes de plástico de $3 \mathrm{Kg}$. de capacidad.

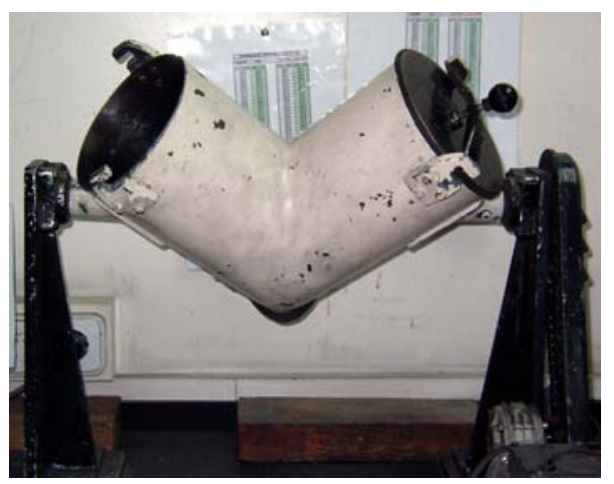

Fig. 4.31. Mezclador en V. 
Tras el mezclado, los polvos fueron compactados en una prensa uniaxial hidráulica de $100 \mathrm{Tn}$ fabricada por AMES, figura 4.32. Se aplicó una velocidad de pistón de $700 \mathrm{~mm} / \mathrm{min}$ hasta contactar con el polvo, y de 3000 $\mathrm{N} / \mathrm{seg}$ una vez en contacto con éste. Únicamente se empleó lubricación en las probetas de compresión sin espaciador (100\% Ti64). Para ello, se lubricaron las paredes de la matriz con estearato de zinc, sin lubricar en ningún caso internamente el polvo, con el fin de evitar la contaminación del titanio.

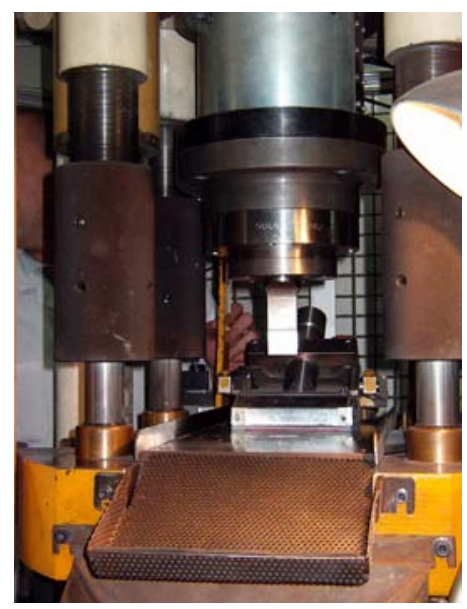

a

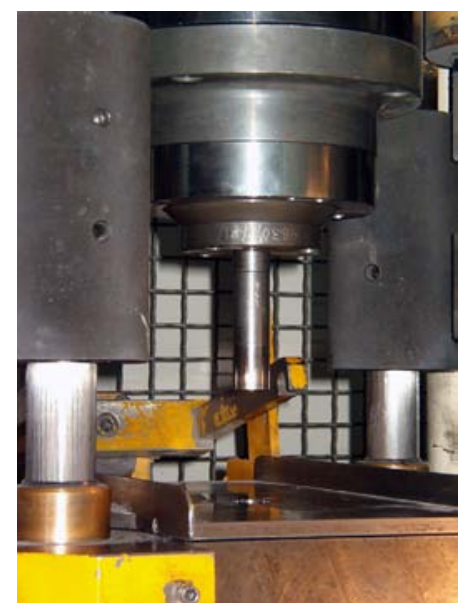

b

Fig. 4.32. Prensa uniaxial hidráulica fabricada por AMES; a) Matriz para muestras de flexión; b) Matriz para muestras de compresión.

Los compactos fueron introducidos en estufa Carbolite a temperatura de $80^{\circ} \mathrm{C}$, durante 21 h., con el fin de eliminar el espaciador. Dado que determinadas piezas se degradaron durante la eliminación del espaciador 0 al manipularlas posteriormente para su sinterización, figura 4.33a, la eliminación del bicarbonato se realizó directamente sobre el soporte en el que posteriormente serian sinterizadas, figura $4.33 \mathrm{~b}$. 


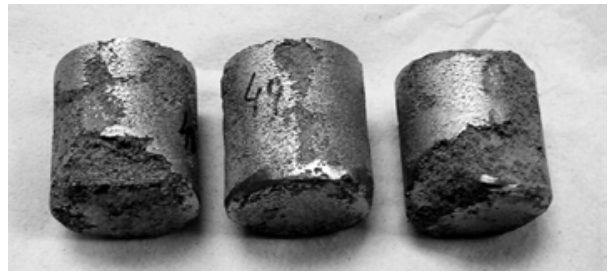

a

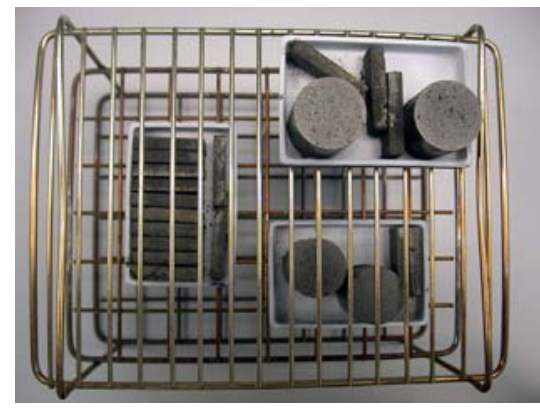

b

Fig. 4.33. a) Muestras degradadas durante su manipulación en verde; b) Secado de las probetas sobre molde de itria.

Finalmente las muestras fueron sinterizadas en vacío, siguiendo el proceso descrito en las pruebas preliminares y según los ciclos térmicos anteriormente indicados, tabla 4.7.

Puesto que, tras el estudio de reactividad con los moldes, se concluyó que las mejores propiedades se obtenían al emplear itria como sustrato, se emplearon moldes recubiertos de éste material como soporte para la sinterización de las piezas.

En relación al proceso de obtención, cabe señalar que, dado que se compactó un elevado número de muestras en la empresa "Aleaciones de metales sinterizados S.A." (AMES), mientras que el espaciador fue eliminado en la UPV, donde se realizó la sinterización; hubo muestras que contuvieron el bicarbonato de amonio durante un largo periodo de tiempo, incluso superior a dos meses.

Con el fin de determinar la influencia del tiempo transcurrido entre la compactación y la eliminación del espaciador, se distingue en los resultados entre aquellas muestras en las que el $\mathrm{NH}_{4} \mathrm{HCO}_{3}$ fue eliminado como máximo dos semanas después de la compactación (propiedades mecánicas en negro) y las que lo contuvieron durante un espacio de tiempo mayor (propiedades mecánicas en rojo).

Finalmente, con el fin de analizar la variación de rigidez, propiedades mecánicas y posibilidades de osteointegración en función del material 
utilizado como espaciador, se realizaron determinadas pruebas sustituyendo el bicarbonato de amonio por urea.

Concretamente, los parámetros de estudio seleccionados fueron:

Tabla 4.8. Variables del estudio seleccionadas para el desarrollo de piezas porosas de Ti6Al4V fabricadas mediante el método de espaciadores (urea).

\begin{tabular}{|c|c|}
\hline Fracción granulométrica de espaciador, $\mu \mathrm{m}$ & $\begin{array}{c}125 \text { a } 250, \quad 250 \text { a } 500 \\
500 \text { a } 1000\end{array}$ \\
\hline Porcentaje volumétrico, Ti64-Urea, \% & $100-0,75-25,60-40,45-55$ \\
\hline Presión de compactación, MPa & 200 y 300 \\
\hline Temperatura de sinterización, ${ }^{\circ} \mathrm{C}$ & 1300 \\
\hline Tiempo de sinterización, $\mathbf{h}$ & 2 \\
\hline
\end{tabular}

Dado que el estudio se realizó fundamentalmente para la comparación de estas piezas con las obtenidas al emplear bicarbonato de amonio como espaciador, se consolidaron únicamente bajo un mismo ciclo térmico, reduciendo el rango de presiones de compactación y adición de espaciador.

En la tabla 4.9 se resumen las probetas realizadas para cada tamaño de espaciador, resultantes de la combinación de variables anteriormente descrita. Para cada combinación de parámetros del proceso se obtuvieron cinco probetas de flexión $\left(32 \cdot 12 \cdot 6 \mathrm{~mm}^{3}\right)$ y 3 de compresión $(\phi=25 \mathrm{~mm}, \mathrm{~h}=$ $25 \mathrm{~mm})$. 
Tabla 4.9. Muestras de Ti64 poroso a obtener empleando urea como espaciador.

\begin{tabular}{|c|c|c|c|c|c|}
\hline FRACCION, $\mu \mathrm{m}$ & $\mathrm{T}^{\mathrm{a}},{ }^{\circ} \mathrm{C}$ & $t, h$ & $\mathrm{P}, \mathrm{MPa}$ & \%Ti64 & \%Urea \\
\hline \multirow{8}{*}{$125-250$} & \multirow{8}{*}{1300} & \multirow{8}{*}{2} & \multirow{4}{*}{200} & 100 & 0 \\
\hline & & & & 75 & 25 \\
\hline & & & & 60 & 40 \\
\hline & & & & 45 & 55 \\
\hline & & & \multirow{4}{*}{300} & 100 & 0 \\
\hline & & & & 75 & 25 \\
\hline & & & & 60 & 40 \\
\hline & & & & 45 & 55 \\
\hline \multirow{8}{*}{$250-500$} & \multirow{8}{*}{1300} & \multirow{8}{*}{2} & \multirow{4}{*}{200} & 100 & 0 \\
\hline & & & & 75 & 25 \\
\hline & & & & 60 & 40 \\
\hline & & & & 45 & 55 \\
\hline & & & \multirow{4}{*}{300} & 100 & 0 \\
\hline & & & & 75 & 25 \\
\hline & & & & 60 & 40 \\
\hline & & & & 45 & 55 \\
\hline \multirow{8}{*}{$500-1000$} & \multirow{8}{*}{1300} & \multirow{8}{*}{2} & \multirow{4}{*}{200} & 100 & 0 \\
\hline & & & & 75 & 25 \\
\hline & & & & 60 & 40 \\
\hline & & & & 45 & 55 \\
\hline & & & \multirow{4}{*}{300} & 100 & 0 \\
\hline & & & & 75 & 25 \\
\hline & & & & 60 & 40 \\
\hline & & & & 45 & 55 \\
\hline
\end{tabular}

De igual modo, se trituraron manualmente las fracciones más groseras con un mortero de vidrio y posteriormente se tamizó, separando en las mismas fracciones empleadas con el bicarbonato de amonio (500-1000 $\mu \mathrm{m}, 250-500$ $\mu \mathrm{m}, \quad 125-250 \mu \mathrm{m}$ y menos de $125 \mu \mathrm{m})$. El proceso de mezcla y compactación de las piezas porosas realizadas con urea como espaciador fue el mismo que el utilizado para las piezas realizadas con bicarbonato. Así, las mezclas se realizaron en un mezclador en $\mathrm{V}$ y los polvos fueron compactados en la prensa uniaxial hidráulica anteriormente descrita.

Por el contrario, la eliminación de la urea se realizó en una mufla a temperatura de $200-220^{\circ} \mathrm{C}$, durante $4 \mathrm{~h}$., y bajo un vacío de $4 \cdot 10^{-1} \mathrm{mbar}$. Tras el secado, las muestras fueron sinterizadas según procedimiento descrito para las pruebas preliminares. 


\subsection{CARACTERIZACIÓN DE LA PIEZA POROSA.}

En los apartados previos se ha descrito el proceso mediante el cual se ha desarrollado la presente tesis. Por una parte, se ha indicado el desarrollo de los estudios previos, tanto de la reactividad con los diferentes molde empleados, como de las pruebas previas realizadas con el método de espaciadores. Por otra parte, se han descrito los procesos de obtención de las piezas porosas de titanio desarrolladas por ambos métodos, microesferas y espaciadores, así como la caracterización del material de partida necesario para su obtención. En todos los casos se han señalado las técnicas aplicadas para la caracterización de las piezas obtenidas, indicando que, dado que algunas de ellas se repiten en determinados procesos, se procedería a su descripción en el presente apartado.

\subsubsection{CARACTERIZACIÓN MICROESTRUCTURAL.}

4.4.1.1. Microscopia óptica (MO) y estereomicroscopia.

La observación de las muestras a menores aumentos se realizó en una lupa estereoscópica Nikon SMZ800, figura 4.34a. Posteriormente las muestras fueron observadas en el microscopio Nikon Microphot FX descrito en el apartado 4.1.2.4. Para su preparación, las muestras fueron cortadas en la cortadora de precisión Struers Accutom-5, figura 4.34b, y preparadas metalográficamente tal como se describió en el apartado 4.1.2.3.

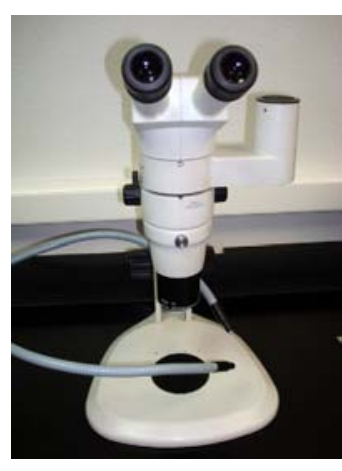

a

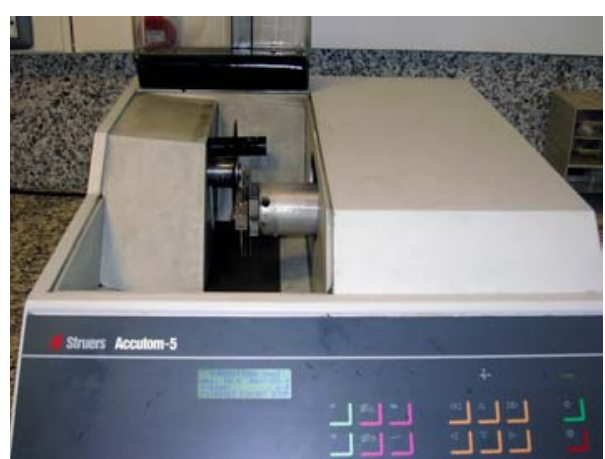

b

Fig. 4.34. a) Lupa estereoscópica Nikon SMZ800; b) Cortadora de precisión Struers Accutom-5. 
Se analizaron muestras obtenidas tanto por sinterización de microesferas, como mediante el método de espaciadores. En el primer caso, las muestras fueron extraídas de probetas de flexión (posteriormente a su rotura), y se diferenció entre zonas de contacto con el molde y con la atmósfera del horno.

En las piezas obtenidas por el método de espaciadores, se observaron al microscopio óptico tanto muestras de las pruebas preliminares, como piezas porosas base de la investigación. Asimismo, se prepararon tanto muestras sin espaciador (100\% Ti64), como con diferentes adiciones, para las tres fracciones granulométricas estudiadas y las diferentes presiones de compactación. Las probetas se extrajeron de probetas de flexión (zona de rotura y zonas alejadas de la tensión); y de compresión, observando en este caso tanto probetas sin ensayar, como muestras con comportamientos frágil y dúctil.

\subsubsection{Microscopia electrónica de barrido (MEB).}

El estudio mediante microscopia electrónica se llevó a cabo en el microscopio electrónico de barrido JEOL JSM6300 descrito en el apartado 4.1.2.4. Se analizaron mediante microscopia electrónica muestras observadas previamente en el microscopio óptico, así como las zonas de contacto de las probetas con el molde y con la atmósfera del horno, y la rotura de las piezas, donde se analizaron las dimensiones de los cuellos de unión desarrollados por las microesferas.

\subsubsection{Microdureza.}

La microdureza de las piezas porosas obtenidas mediante sinterización de microesferas se determinó siguiendo la metodología descrita en el apartado 4.1.2.5. Se adquirieron medidas tanto a lo largo de los cuellos de unión desarrollados en la sinterización, como en las zonas de contacto con el molde y con la atmósfera del horno. 


\subsubsection{DENSIDAD, POROSIDAD Y TAMAÑO DE PORO.}

\subsubsection{Densidad, y porosidad del sinterizado.}

Para la determinación de la densidad y porosidad de las piezas desarrolladas, se emplearon tres metodologías distintas: según norma ASTM B328, según dimensiones geométricas de la pieza y/o mediante análisis de imagen. El empleo de uno u otro método se justifica tanto por la comparación de los datos obtenidos según metodología empleada, como por las características de las piezas obtenidas mediante cada proceso, pues las piezas desarrolladas por el método de espaciadores presentaban una piel exterior densificada, con una porosidad no accesible desde el exterior.

Tras obtener la densidad aparente del sinterizado, $\rho^{*}$, se determinó la densidad relativa, $\left(\rho_{r}=\frac{\rho^{*}}{\rho_{S}}\right)$, de las piezas porosas desarrolladas, adoptando como densidad del sólido, $\rho_{\mathrm{S}}, 4,5 \mathrm{~g} / \mathrm{cm}^{3}$ para el TiCP3 y 4,42 $\mathrm{g} / \mathrm{cm}^{3}$ para el Ti64 [ASM N4 1994, Matweb.com]. La densidad relativa se relaciona con la porosidad absoluta de la pieza según las ecuaciones (4.2) y (4.3):

$$
\begin{aligned}
& \text { COMPACIDAD }=\rho_{r}=\rho^{*} / \rho_{S} \\
& \text { POROSIDAD }=1-\text { COMPACIDAD }=1-\rho^{*} / \rho_{S}
\end{aligned}
$$

Dado que las muestras obtenidas mediante sinterización de microesferas presentaban porosidad abierta con una superficie irregular, su densidad $(\rho *)$ y porosidad interconectada se determinaron según norma ASTM B328 (UNE EN ISO 2738:1999). El estudio se realizó para cada fracción granulométrica, sobre diferentes ciclos de sinterización.

En las muestras sinterizadas en moldes de gres, la porosidad determinada según norma ASTM B328 se comparó con la obtenida mediante análisis de imagen. 
De igual modo, la porosidad de las pruebas preliminares realizadas mediante el método de espaciadores se determinó según norma ASTM B328 sobre probetas previamente ensayadas a flexión. Éstas fueron previamente desbastadas para abrir su porosidad.

Por el contrario, puesto que en las pruebas previas se observó que los poros permanecían aislados casi en la totalidad de los casos, y dada la geometría regular $\left(\approx 13.32 .6 \mathrm{~mm}^{3}\right)$ de las probetas base de la presente investigación, su densidad aparente, contracción y porosidad total se realizaron mediante la toma directa de su masa y dimensiones.

\section{Determinación según norma ASTM B328.}

Tras determinar la masa de las muestras en aire y sin lubricante, $M_{A}$, éstas fueron sumergidas en parafina fundida a $90{ }^{\circ} \mathrm{C}$ durante 2 horas y luego limpiadas con un paño humedecido y enfriadas a temperatura ambiente. A continuación, las muestras con el lubricante se pesaron en aire, $M_{B}, y$ sumergidas en agua, $\mathrm{M}_{\mathrm{C}}$, utilizando para ello una balanza electrónica KERN 770 con $0,1 \mathrm{mg}$ de precisión y el instrumental para determinación del peso en agua Sartorius YDK01, figura 4.35 a y b.

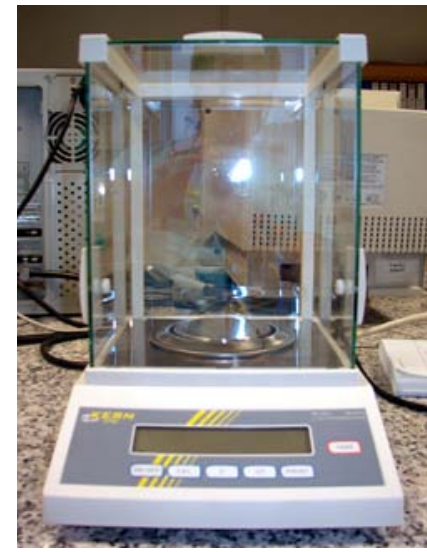

a

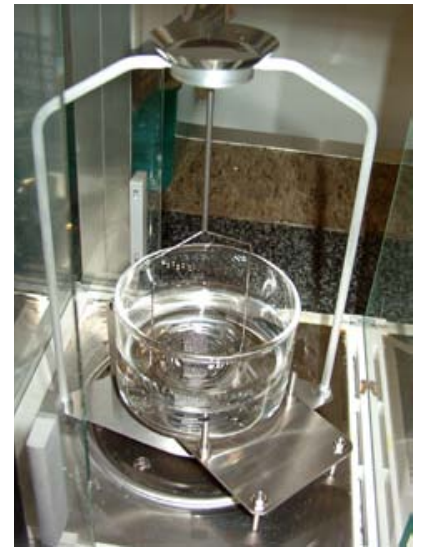

b

Fig. 4.35. a). Balanza electrónica de precisión KERN 770; b) Instrumental para determinación del peso en agua. 
El método se basa en el principio de Arquímedes, según el cual al sumergir una muestra en agua ésta recibe un empuje hacia arriba igual al peso del volumen de líquido que desaloja:

$$
\text { Empuje }=\rho_{\text {liq }} \cdot V_{A}=P_{\text {saturada }}-P_{B H}
$$

Dado que la porosidad interconectada quedó sellada con parafina, mediante la densidad del líquido y el peso en balanza hidrostática, se determinó el volumen aparente de la muestra, $V_{A}$, incluidos poros abiertos y cerrados. Con él se obtuvo la densidad aparente de las muestras:

$$
\rho^{*}=\left(M_{A} \cdot \rho_{\text {agua }}\right) /\left(M_{B}-M_{C}\right)
$$

Donde:

$\rho^{*}=$ densidad aparente, en $\mathrm{g} / \mathrm{cm}^{3}$

$\rho_{\text {agua }}=$ densidad del agua a la temperatura de inmersión, en $\mathrm{g} / \mathrm{cm}^{3}$.

$\mathrm{M}_{\mathrm{A}}=$ masa de la muestra en el aire sin parafina, en $\mathrm{g}$.

$M_{B}=$ masa de la muestra en el aire con parafina, en $\mathrm{g}$.

$M_{C}=$ masa de la muestra con parafina en el agua, tarada, en $\mathrm{g}$.

Puesto que la $\rho_{\text {agua }}$ depende de la temperatura, se midió esta durante la realización del ensayo, y se relacionó con su densidad por medio de la tabla I de la norma ASTM B328.

De forma similar se calculó la porosidad interconectada (abierta), determinada por la expresión:

$$
\% P_{A}=\left[\left(M_{B}-M_{A}\right) \cdot \rho_{\text {agua }} \cdot 100\right] /\left[\left(M_{B}-M_{C}\right) \cdot \rho_{\text {parafina }}\right]
$$

Donde:

$\% \mathrm{P}_{\mathrm{A}}=$ Porosidad interconectada de la muestra.

$\rho_{\text {parafina }}=0,92$ para la parafina utilizada. 
Mediante diferencia entre el volumen aparente, $\mathrm{V}_{\mathrm{A}}$, y real, $\mathrm{V}_{\mathrm{S}}$ (del sólido, como si no existiesen poros), se obtuvo el volumen total de poros de cada probeta, h. La relación entre éste y el volumen aparente de la pieza permitió determinar su porosidad total:

$$
\% \mathrm{P}=\left(\mathrm{V}_{\mathrm{A}}-\mathrm{V}_{\mathrm{S}}\right) / \mathrm{V}_{\mathrm{A}}
$$

Donde:

$\mathrm{V}_{\mathrm{A}}-\mathrm{V}_{\mathrm{S}}=\mathrm{h}=$ Volumen total de huecos, $\mathrm{cm}^{3}$.

$\% \mathrm{P}=$ Porosidad total de la muestra.

\section{Determinación según masa y dimensiones de la muestra.}

Para su determinación, se pesaron y midieron las probetas, tanto en verde (previo a la eliminación del espaciador), como tras su sinterización. Con el fin de no degradar las muestras durante su manipulación, no se adquirieron dichos datos una vez eliminado el espaciador, pues muchas de ellas presentaban insuficiente resistencia.

\section{Determinación mediante análisis de imagen.}

Los resultados obtenidos mediante los procedimientos descritos (norma ASTM B328 y toma de masa y dimensiones), se compararon con los obtenidos por análisis de imagen. La técnica se empleó sobre probetas realizadas tanto por sinterización de microesferas como por el método de espaciadores.

Para ello, se adquirieron micrografías de muestras sinterizadas embutidas y preparadas metalográficamente y, figura 4.36a. Con el software VISILOG se binarizaron, figura $4.36 \mathrm{~b}$, y se determinó la porosidad sobre un promedio de tres medidas, tomadas sobre tres micrografías distintas de cada muestra. En el caso de microesferas, con el fin de que la cantidad de éstas fuese similar, se adquirieron micrografías a 30x para la granulometría más grosera y a 50x para la más fina. 


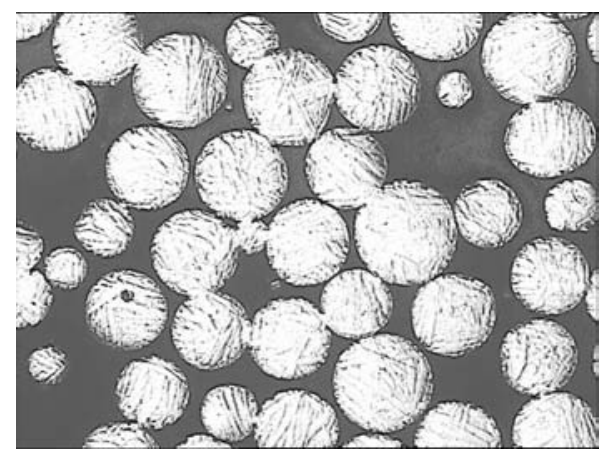

a

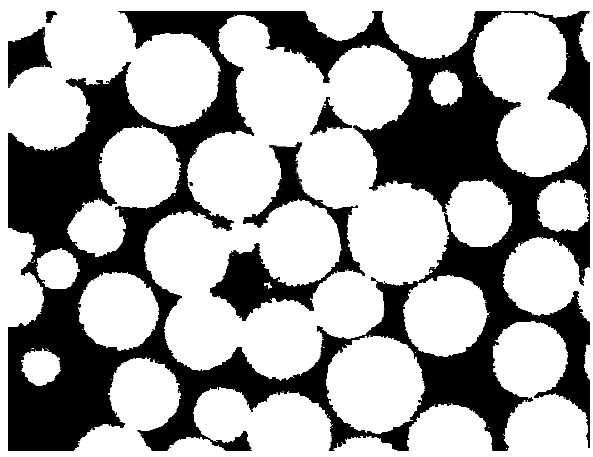

b

Fig. 4.36. Micrografía de una probeta de GF sinterizada a $1300^{\circ} \mathrm{C}$ durante $8 \mathrm{~h}$ : a) Lupa x50; b) Binarizada.

\subsubsection{Tamaño de poro y tamaño de poro teórico.}

El tamaño de poro de las piezas porosas obtenidas mediante el método de espaciadores, se determinó mediante análisis de imagen, siguiendo la metodología descrita en el apartado anterior.

Por el contrario, dado que en las muestras obtenidas mediante sinterización de microesferas la porosidad es interconectada, resulta difícil e impreciso determinar el tamaño de poro mediante el mismo método (pues en una micrografía bidimensional las microesferas son cortadas a distintas alturas) [Shatt 1997]. Por ello, se relacionó el tamaño de poro teórico en función de distintas ordenaciones cristalinas, con el obtenido experimentalmente por el grupo de investigación en biomateriales de la UPC.

\subsubsection{DIMENSIONES DE LOS CUELLOS DE UNIÓN.}

Las dimensiones de los cuellos de unión se determinaron tanto sobre micrografías tridimensionales (3D) adquiridas en el MEB, figura 4.37, como sobre bidimensionales, obtenidas en el microscopio metalográfico, figura 4.36. Mientras que en el primer caso la medida se determinó con el software propio del microscopio (INCA Instruments Ltda.), en el segundo se utilizó el software VISILOG. 


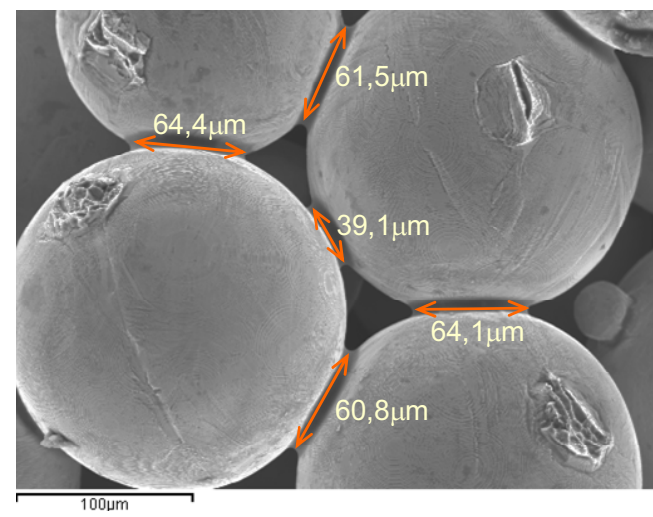

Fig. 4.37. Micrografía MEB con la determinación de las dimensiones de los cuellos de unión desarrollados durante la sinterización.

Dado que el estudio por ambos métodos se realizó únicamente a nivel comparativo, las medidas por los dos procedimientos sólo se adquirieron sobre piezas obtenidas mediante sinterización de microesferas sobre moldes de gres, mientras que en el resto de piezas se realizaron directamente sobre micrografías 3D (promedio de 30 medidas).

Con el fin de analizar la influencia del tamaño de las microesferas de partida, sobre los cuellos de unión desarrollados durante la sinterización y, por tanto, sobre la rigidez y propiedades mecánicas obtenidas, tras determinar la dimensión media de los cuellos de unión desarrollados para los distintos ciclos de sinterización y granulometrías, se estableció una relación entre la superficie de unión generada en la sinterización y la superficie específica promedio de cada granulometría $\left(\mathrm{S}_{\text {unión }} / \mathrm{S}_{\text {esfera }}\right)$. Para determinar el número de puntos de unión teórico por cada microesfera, se partió tanto de los resultados de porosidad y tamaño de poro, véase apartado 5.3.3, como del hecho de que todas las microesferas no poseen el mismo tamaño (distribución granulométrica), por lo que la ordenación nunca será perfecta (siempre existirán vacantes). Así, se consideró un empaquetamiento de microesferas no compacto (estructura cúbica centrada en cuerpo, índice coordinación = 8) [Callister 2005, Ashby 2005]. 
El diámetro del cuello de unión promedio se asemejó al de un círculo, que representaba la superficie de unión con la esfera contigua $\left(\pi \cdot r_{\text {cuello }}{ }^{2}\right)$. Finalmente, con el fin de normalizar la superficie de unión desarrollada respecto al tamaño medio de cada fracción granulométrica, se repercutió el área de unión calculada $\left(8 \cdot \pi \cdot r_{\text {cuello }}{ }^{2}\right)$ respecto a la superficie de una esfera $\left(4 \cdot \pi \cdot r_{\text {esf }}{ }^{2}\right)$, tomando para ello el diámetro promedio de cada granulometría.

\subsubsection{CARACTERIZACIÓN MECÁNICA.}

En las piezas desarrolladas por sinterización de microesferas, se determinó tanto la resistencia a flexión como la rigidez, mientras que en las obtenidas por el método de espaciadores el estudio fue completado con ensayos de compresión.

Tras someter las piezas a los correspondientes ensayos, se representaron las curvas $\sigma-\varepsilon$, y se determinó sobre ellas el límite elástico y la rigidez promedio de cada grupo de probetas con los mismos parámetros de proceso, es decir "fracción granulométrica, temperatura, tiempo de sinterización" en el caso de las microesferas, y "fracción granulométrica, porcentaje espaciador, ciclo de sinterización y presión de compactación" para las obtenidas mediante la técnica de espaciadores.

Tras el análisis de resultados se obtuvieron modelos matemáticos de correlación entre las variables de proceso y la rigidez y resistencia mecánica de las piezas porosas obtenidas. Para la obtención de los modelos en las piezas desarrolladas por el método de espaciadores, se eliminaron los resultados de las muestras con una fuerte degradación, que generalmente correspondían a muestras con adiciones de bicarbonato superiores al $25 \%$. Asimismo, para estas probetas los modelos matemáticos se obtuvieron promediando los datos de densidades y rigidez en función únicamente de la adición de bicarbonato de amonio, independientemente del tamaño de espaciador, Temperatura - tiempo y presión de compactación aplicada. 


\subsubsection{Resistencia a Flexión.}

La resistencia y rigidez a flexión se determinó mediante el ensayo de flexión a 3 puntos, según norma ISO 3325:2000 (ASTM E290-97a), en la máquina universal de ensayos Instron 4204, figura 4.38, con una velocidad de cruceta de $0,5 \mathrm{~mm} / \mathrm{seg}$.
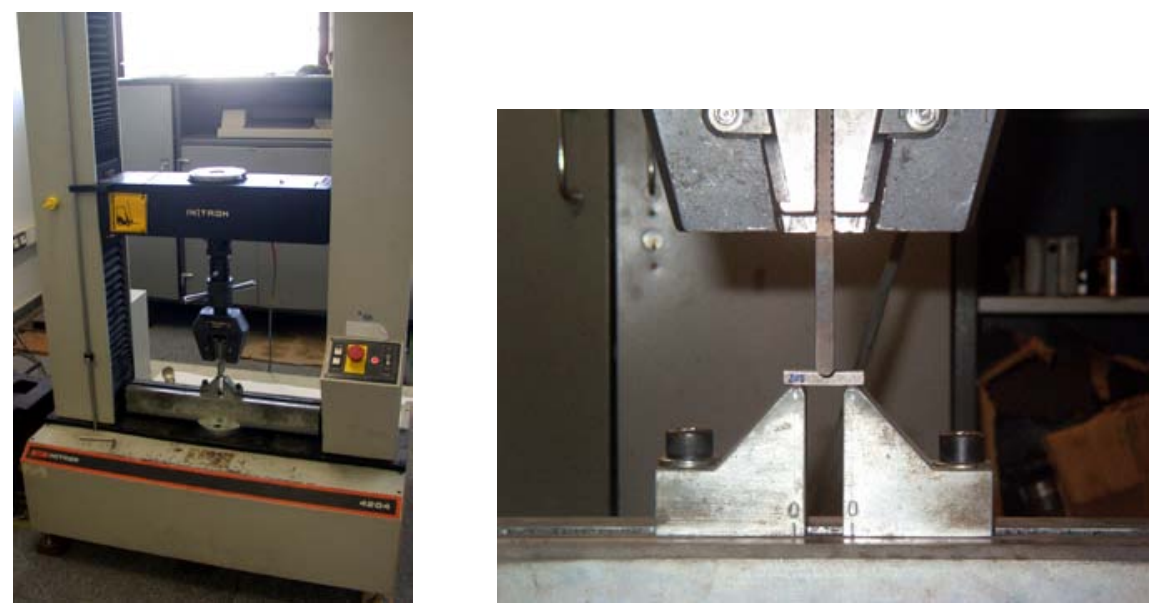

Fig. 4.38. Prensa Universal de Ensayos INSTRON 4204.

La resistencia a flexión se obtuvo según la fórmula:

$$
\sigma_{\mathrm{Y}}=\frac{(3 F I)}{\left(2 b h^{2}\right)}
$$

Donde:

$F$, es la fuerza en Newtons

I, es la distancia entre apoyos en $\mathrm{mm}$

b, es el ancho de la probeta en $\mathrm{mm}$

$\mathrm{h}$, es el espesor de la probeta, $\mathrm{mm}$

En las piezas porosas obtenidas por sinterización de microesferas, las probetas de flexión se obtuvieron mediante el corte de las piezas rectangulares obtenidas a dimensiones de aproximadamente $12 \mathrm{~mm}$ de ancho, con espesor y longitud en función del molde empleado (Struers Accutom-5, véase figura 4.34b. Así, las piezas sinterizadas en moldes de 
gres tenían una longitud de aproximadamente $30 \mathrm{~mm}$ y espesor entre $4,5 \mathrm{y}$ $5,3 \mathrm{~mm}$, mientras que en las sinterizadas en moldes de alúmina e itria la longitud fue de aproximadamente $25 \mathrm{~mm}$, con espesor comprendido entre 3,3 y $4,5 \mathrm{~mm}$.

Para el estudio de reactividad con los distintos moldes, las piezas sinterizadas sobre gres y alúmina se ensayaron con la cara de contacto con el molde dispuesta tanto en la zona traccionada como comprimida. Dado que la situación más desfavorable siempre se producía al someter el contacto con el molde a tracción, es decir, esta cara dispuesta hacia abajo, en el resto de probetas (sinterizadas sobre itria y circona), se mantuvo esta disposición.

De forma similar, en las pruebas preliminares realizadas por el método de espaciadores, las probetas de flexión se obtuvieron mediante corte de las piezas porosas sinterizadas, a dimensiones de aproximadamente $10 \mathrm{~mm}$ de ancho, 21,1 de longitud y entre 4 y $6 \mathrm{~mm}$ de espesor, figura 4.39 .

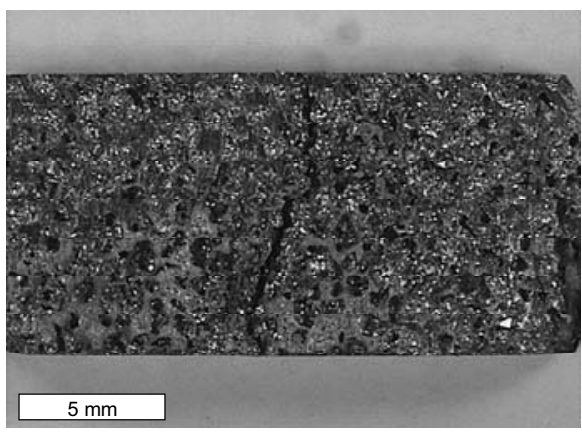

a

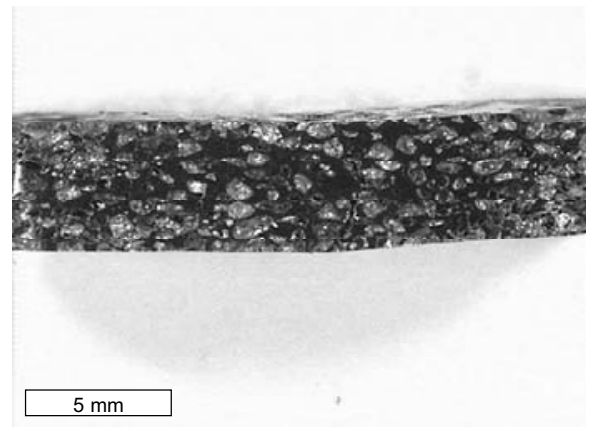

b

Figura 4.39. Micrografía superior y lateral de una probeta de flexión con 40TiCP3 / $60 \mathrm{NH}_{4} \mathrm{HCO}_{3}$, compactada a $300 \mathrm{MPa}$.

Por el contrario, las probetas de flexión base de la investigación realizadas por la técnica de espaciadores no fueron manipuladas tras su sinterización, pues fueron compactadas en la matriz de flexión indicada en la norma ISO 3325:2000 (ASTM E290-97a), con unas dimensiones en verde de 13.32.6 $\mathrm{mm}^{3}$ aprox. 
Tal como se ha explicado en el desarrollo experimental, dada la influencia del tiempo transcurrido entre compactación y evaporación / sinterización, en los resultados se distingue entre las probetas sinterizadas hasta un máximo de dos semanas tras la compactación (tanda A) y las sinterizadas entre dos semanas y dos meses después de su compactación (tanda B), indicando además el grado de degradación observado. Las probetas que no poseen indicación pertenecen a la tanda $A$, mientras que aquellas cuyas propiedades mecánicas se marcan en rojo en los correspondientes gráficos y tablas de resultados, pertenecen a la $\mathrm{B}$. Además, la diferencia se ha matizado también para las muestras con $100 \%$ Ti64, pues podrían de igual forma haber absorbido $\mathrm{Ne} \mathrm{H}_{2}$, con lo que sufrirían fragilización.

\subsubsection{Resistencia a Compresión.}

Los ensayos de compresión se realizaron únicamente sobre las muestras de Ti6Al4V obtenidas mediante el método de espaciadores en las que se empleó bicarbonato de amonio como tal. Estas probetas fueron compactadas en AMES empleando para ello la matriz indicada en la norma ASTM E9 89 a, con lo que se obtuvieron probetas de $25,5 \mathrm{~mm}$ de $\varnothing$ y entorno a $27 \mathrm{~mm}$ de altura, figura 4.40 .

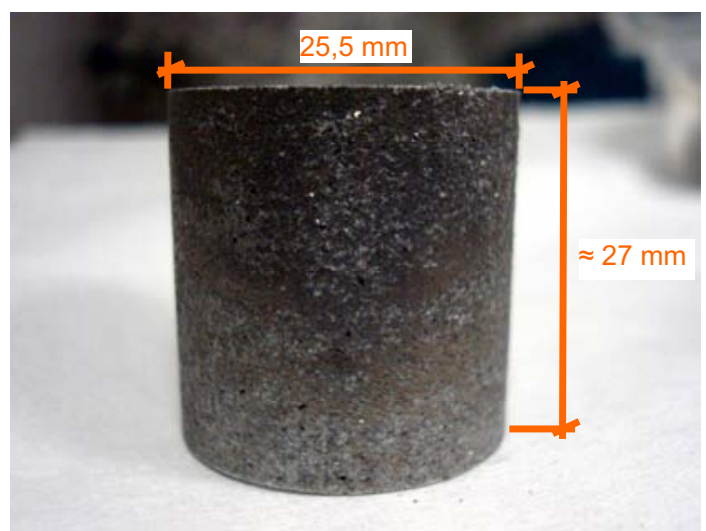

Fig. 4.40. Probeta de compresión realizada mediante el método de espaciadores, previo a su secado. 
Las piezas más porosas (menos de 45\% Ti64) se ensayaron en una máquina universal de ensayos Instron 4204, figura 4.41a, mientras que las más resistentes se ensayaron en una Instron modelo A1340-1006, de hasta $600 \mathrm{KN}$ de carga estática y $500 \mathrm{KN}$ de carga dinámica, figura 4.41b.

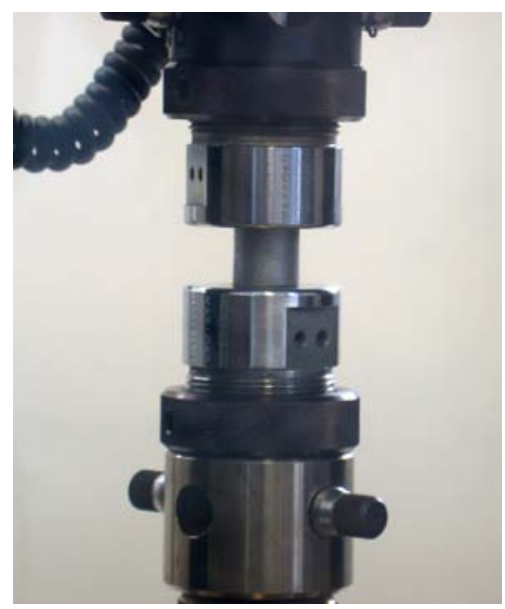

a

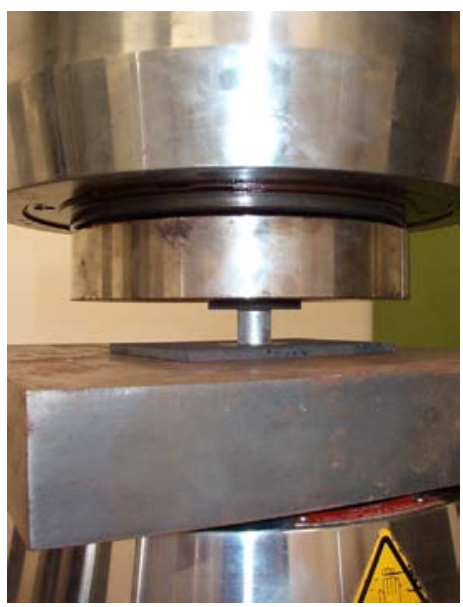

b

Fig. 4.41. Equipos para el ensayo a compresión de las piezas porosas de Ti64: a) Instron 4204; b) Instron A1340-1006.

El ensayo en la Instron 4204 se realizó a una velocidad de cruceta 0,2 $\mathrm{mm} / \mathrm{min}$ y hasta una extensión máxima de $3 \mathrm{~mm}$. Por el contrario, las probetas de espaciadores con mayor contenido en titanio se ensayaron en la Instron A1340-1006, con una velocidad de carga de 0,5 mm/min hasta una deformación relativa de $7 \mathrm{~mm}$, y descarga a $10 \mathrm{~mm} / \mathrm{min}$. Algunas de las muestras con 45\% Ti64 se ensayaron también en la Instron A1340-1006, con el fin de comparar resultados.

Tras el ensayo de compresión, se midieron de nuevo las probetas para determinar su deformación elástica y plástica y se representaron las curvas tensión $(\sigma)$ - deformación unitaria, $\varepsilon_{0}=\Delta \mathrm{L} / \mathrm{Lo}$, de las diferentes muestras ensayadas. Tal como se observa en la figura 4.42, entre los 40 y $100 \mathrm{MPa}$ se produce una deformación inherente al equipo de ensayo que es recuperada en la descarga. Sobre las curvas se determinó, una vez corregido el efecto de la máquina, la rigidez E2 (pendiente de la curva $\sigma-\varepsilon_{0}$ ), 138 
el límite elástico a compresión $\left(\sigma_{y}\right.$, intersección de las pendientes del tramo elástico y plástico) y la deformación en este punto, $\varepsilon_{y}$, Fig. 4.42 .

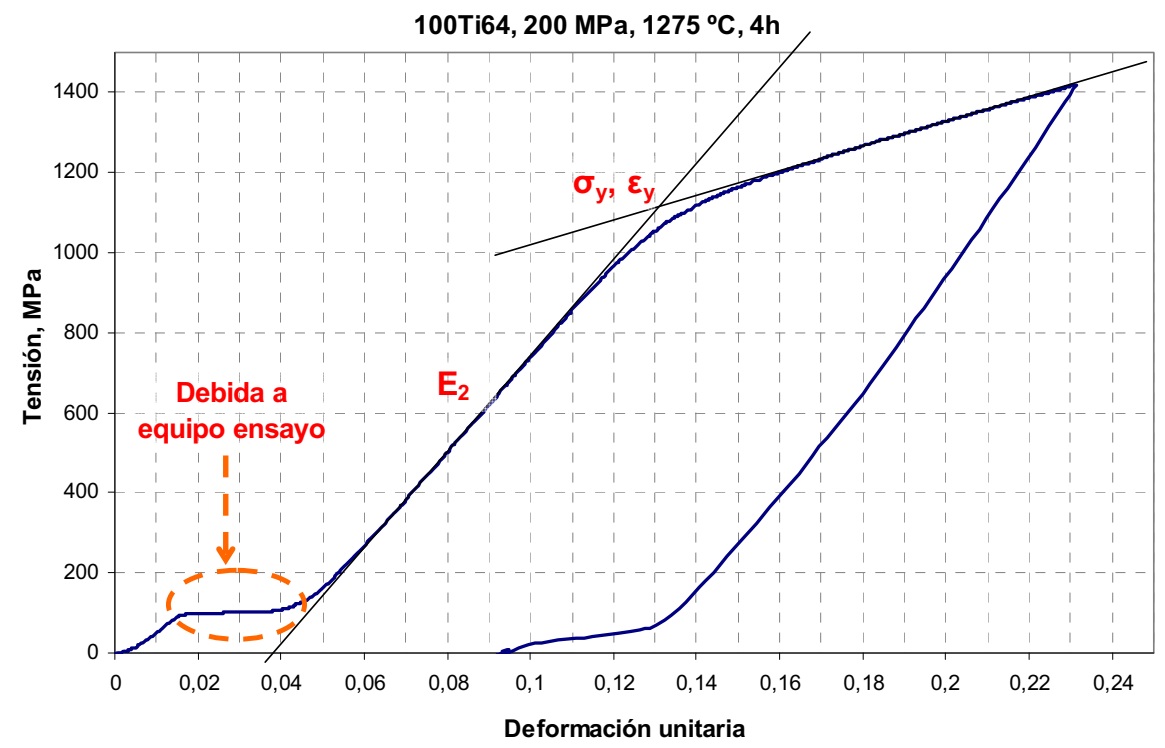

Fig. 4.42. Curva tensión - deformación" de una probeta de compresión 100\% Ti64.

\subsubsection{Rigidez.}

Cabe recordar que, como se indicó en el panorama científico, en metales porosos se produce cierta plastificación en el tramo aparentemente elástico, por lo que la ley de Hook no resulta aplicable [Schatt 1997]. Por ello, en adelante nos referiremos a rigidez en lugar de módulo elástico.

Como se ha venido indicando y debido a que la evolución de este parámetro resulta de vital importancia en la presente investigación, la rigidez se determinó tanto a flexión como a compresión. En el primer caso ésta se evaluó tanto mediante la determinación de la pendiente de la curva $\left(\mathrm{E}_{\mathrm{FP}}\right)$, como por la fórmula que relaciona el módulo de Young con la flecha máxima $\left(E_{F F}\right)$; mientras que en el segundo caso $\left(E_{C}\right)$, únicamente mediante la pendiente de la curva tensión - deformación unitaria. 
El módulo elástico a flexión $\left(\mathrm{E}_{\mathrm{FF}}\right)$ para una viga biapoyada cargada en su centro depende de la flecha en este punto y del momento de inercia de la probeta (rectangular), según la relación (4.9) [Schatt 1997]:

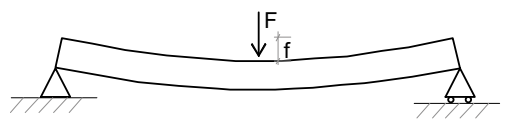

$$
y_{\max }=\frac{\left(F \cdot l^{3}\right)}{(48 \cdot E \cdot I)}
$$

Donde:

$\mathrm{F}=$ Fuerza, $\mathrm{N}$

$\mathrm{I}=$ distancia entre apoyos, $\mathrm{mm}$

$\mathrm{E}=$ Módulo de Young, MPa

$\mathrm{I}=$ Momento de inercia, $\mathrm{mm}^{4}$

Para la probeta de flexión, con sección rectangular, el momento de inercia depende de su base y altura:

$$
I=\left(\frac{b \cdot h^{3}}{12}\right)
$$

Donde:

$\mathrm{b}=$ ancho de la probeta, $\mathrm{mm}$

$\mathrm{h}=$ espesor de la probeta, $\mathrm{mm}$

Sustituyendo en la fórmula anterior y despejando, obtenemos el módulo de Young a flexión, para una probeta de sección rectangular, de ancho b y espesor $h$, fórmula (4.11):

$$
E=\frac{\left(F \cdot l^{3}\right)}{\left(4 \cdot y_{\max } \cdot b \cdot h^{3}\right)}
$$

Una vez obtenidos los valores descritos y con el fin de determinar la rigidez a flexión, se representaron curvas tensión $\left(\sigma_{F}\right)$ - deformación unitaria $\left(\varepsilon_{0}\right)$ y módulo a flexión según fórmula $\left(\mathrm{E}_{\mathrm{FF}}\right)$ - deformación unitaria $\left(\varepsilon_{0}\right)$. Sobre las primeras la rigidez fue evaluada mediante la determinación de la pendiente, mientras que sobre las segundas en el punto donde estabilizaba el valor de $\mathrm{E}_{\mathrm{FF}}$. 
Sobre los valores adquiridos se determinó la rigidez relativa $\left(E_{r}=E^{*} / E_{S}\right)$. Se adoptó como rigidez del sólido $\left(E_{S}\right)$ la de las piezas sin espaciador, diferenciando entre la rigidez obtenida mediante los diferentes métodos aplicados (pendiente de la curva $\sigma-\varepsilon_{0}$ y fórmula de flexión). Para las microesferas se determinó el promedio de todas las muestras de Ti64 sin espaciador, mientras que en las probetas de espaciadores se determinó el promedio para cada presión de compactación (Es de piezas sin espaciador a 100,200 y $300 \mathrm{MPa})$.

\subsubsection{ANÁLISIS DE ELEMENTOS.}

Para completar el análisis de las piezas sinterizadas sobre itria y evaluar la posible contaminación con el molde o elementos presentes en la atmósfera del horno, se analizó el contenido en elementos intersticiales ( $\mathrm{C}, \mathrm{N}$ y $\mathrm{O})$ de piezas porosas obtenidas por ambos métodos. Dichos análisis fueron realizados en el "Centro de Estudios e Investigaciones Científicas de Guipúzcoa", CEIT, en San Sebastián.

Para su preparación, las muestras fueron cortadas en una Acutton 5 , a las dimensiones necesarias, limpiadas en primer lugar con acetona, después con alcohol, y posteriormente secadas en aire caliente. Dada la porosidad de las piezas y para evitar errores de medida las muestras se secaron en estufa a temperatura de $80^{\circ} \mathrm{C}$, durante 18 horas.

\subsubsection{Análisis de carbono.}

Los análisis de Carbono se realizaron en un equipo CS200 de Leco, figura 4.43, empleando para ello el método de ensayo acero 0.2 ( $0,2 \%$ C máx.).

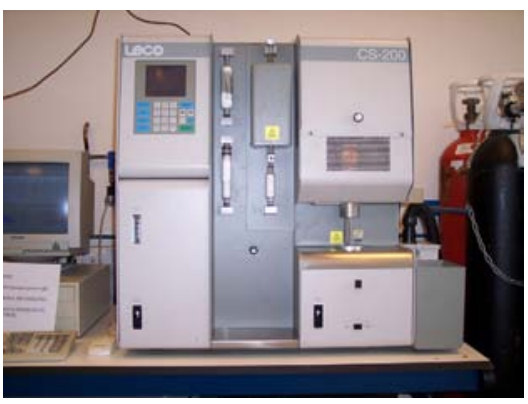

Fig. 4.43. Analizador elemental de C y S, modelo CS200 de Leco. 
Para la realización del ensayo se depositaron las muestras (masa máxima de $1 \mathrm{~g}$ ) en el crisol y se añadió el fundente (Lecocel II + Iron Chip acelerador), figura 4.44 .

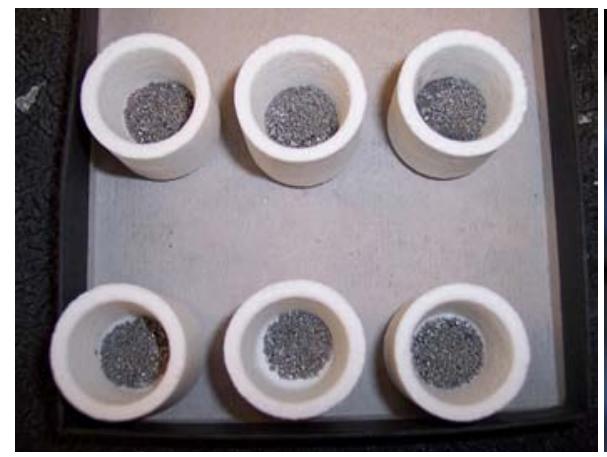

a

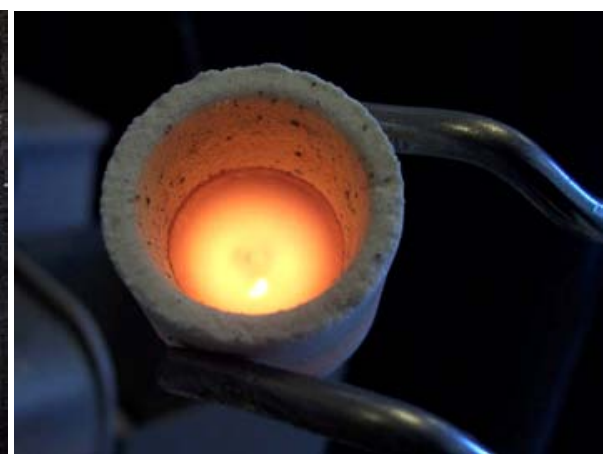

b

Fig. 4.44. Crisol utilizado para el análisis de $\mathrm{C}$ y S: a) Previo al ensayo, muestras con fundente; b) Tras la realización del análisis, muestra fundida.

Con el fin de corregir posteriormente el $\mathrm{C}$ de las muestras ensayadas, se determinó el contenido en $C$ del fundente utilizado, según la fórmula (4.12):

$$
\% \mathrm{C}_{\text {muestra }}-\% \mathrm{C}_{\text {fundente }} \cdot(1 \mathrm{~g} / \text { masa muestra })
$$

\subsubsection{Análisis de $\mathrm{N}$ y $\mathrm{O}$.}

Los análisis de Nitrógeno y Oxígeno se realizaron en un equipo TC400 de Leco, figura 4.45.

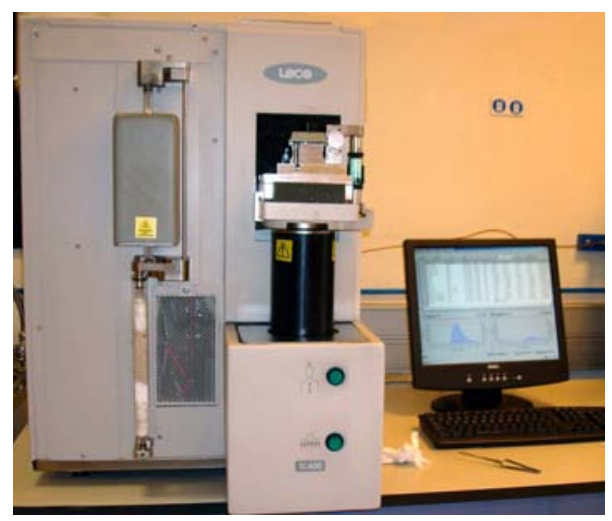

Fig. 4.45. Analizador elemental de N y O, modelo TC400 de Leco. 
Tras estabilizar el gas (30 minutos), purgar y calibrar el equipo, se introdujo la muestra (masa máxima de $1 \mathrm{~g}$ ) en el fundente, figura 4.46a y se depositó en la zona de carga. El gas empleado durante el análisis fue $\mathrm{He}$, a un caudal de $450 \mathrm{~cm}^{3} / \mathrm{m}$ y se aplicó una intensidad de 1000 A para fundir las muestras. Los crisoles utilizados fueron de carbono, figura 4.46b, previamente limpiados por el equipo con un flujo de $\mathrm{He}$ a $6000 \mathrm{~cm}^{3} / \mathrm{m}$. Tras la realización de cada medida, se limpiaron los electrodos con el fin de garantizar una intensidad adecuada.

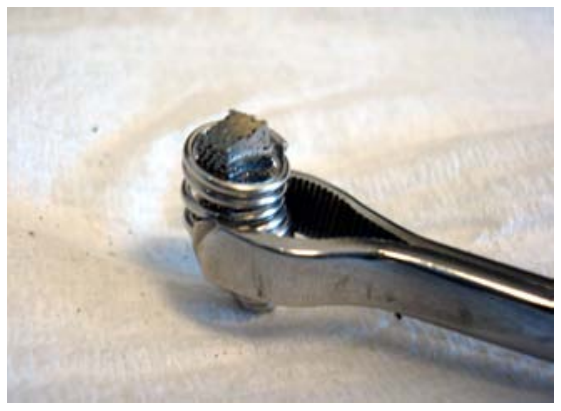

a

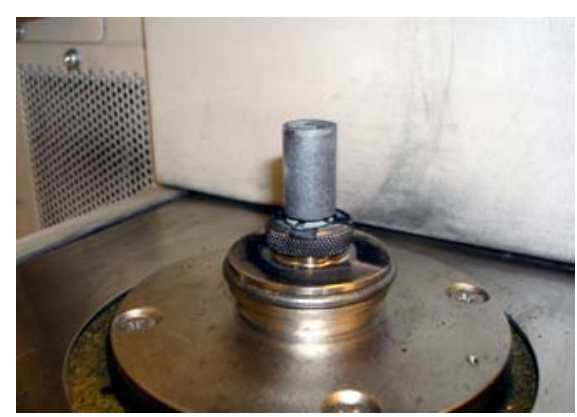

b

Fig. 4.46. a) Muestra introducida en el fundente; b) Colocación del crisol de grafito.

\subsubsection{TRATAMIENTOS TÉRMICOS.}

Tras la obtención de las piezas porosas se realizaron tratamientos térmicos con el fin de modificar la microestructura y optimizar determinadas propiedades de las piezas desarrolladas. Al igual que el análisis de elementos, los tratamientos térmicos fueron realizados en el CEIT.

Dado que se trataba de poner a punto el procedimiento de aplicación de tratamientos térmicos sobre muestras de titanio, y analizar la variación microestructural, éstos únicamente se realizaron sobre piezas porosas obtenidas mediante sinterización de microesferas.

Debido a la elevada reactividad del titanio, los tratamientos térmicos se realizaron bajo atmósfera controlada (argón o vacío). Además de los tratamientos realizados en horno, se aplicaron otros en dilatómetro, pues permitió obtener un vacío mayor, así como aplicar velocidades de enfriamiento más elevadas. 


\subsubsection{Tratamientos térmicos realizados en dilatómetro.}

Se realizaron cuatro ciclos térmicos distintos en un dilatómetro de la marca Bähr modelo Dil 805A, figura 4.47a. Estos tratamientos fueron realizados sobre diferentes muestras de una misma pieza porosa obtenida por sinterización de microesferas de granulometría media $(-300 /+212 \mu \mathrm{m})$ a $1350^{\circ} \mathrm{C}$ durante 2 horas. Para ello se prepararon muestras rectangulares, de longitud $L=9 \mathrm{~mm}$ y sección cuadrada de lado aproximadamente $\mathrm{I}=3,84$ $\mathrm{mm}$. Las muestras fueron conectadas a los electrodos por medio de dos puntos de soldadura, figura $4.47 \mathrm{~b}$.

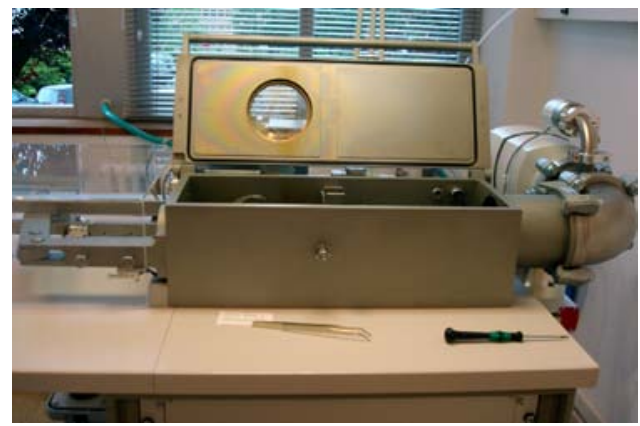

a

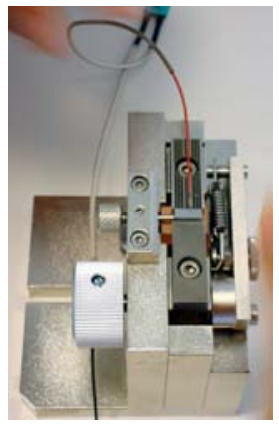

b

Fig. 4.47. a) Dilatómetro; b) Soldadura de los electrodos a la pieza.

Se simularon los dos ciclos térmicos que posteriormente serian realizados en horno ( $B$ y $S$ ), figura 4.48, y otros dos incrementando únicamente la velocidad del primer enfriamiento (BT y ST) de 3 a $50{ }^{\circ} \mathrm{C} / \mathrm{min}$. Estos tratamientos fueron adoptados de estudios previos realizados por el grupo de investigación, según los cuales la aplicación de los tratamientos denominados STA y BUS mejora la vida a fatiga de la pieza [Amigó 2003b].

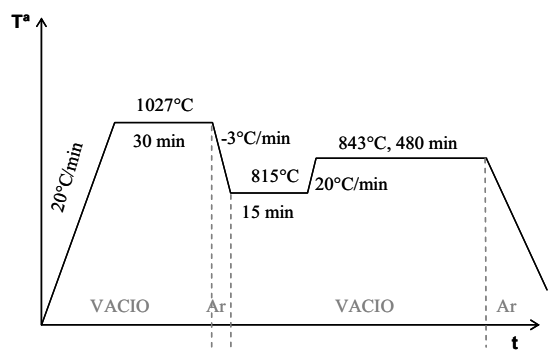

a

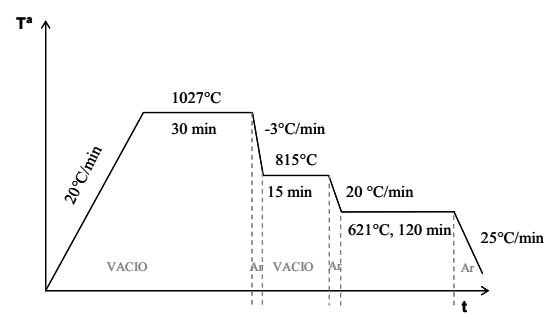

b

Fig. 4.48. Tratamientos térmicos aplicados en el dilatómetro: a) B; b) S. 
Las rampas de calentamiento y el mantenimiento de temperatura se realizaron bajo un vacío de $5 \cdot 10^{-5}$ mbares, mientras que los enfriamientos se realizaron en Ar. El calentamiento se realizó por inducción.

\subsubsection{Tratamientos térmicos realizados en horno.}

En horno se realizaron los dos tipos distintos de tratamientos térmicos, B y $\mathrm{S}$ anteriormente descritos, aunque modificando determinados tiempos de permanencia y rampas de calentamiento o enfriamiento con el fin de posibilitar su realización y garantizar la homogeneidad de temperaturas en las piezas a tratar. Se realizaron cuatro ciclos térmicos, los dos primeros en tubo de acero, y los últimos en tubo de alúmina. La figura 4.49 recoge los ciclos realmente registrados en tubo de alúmina, para los tratamientos tipo $B$ y tipo $S$ respectivamente.
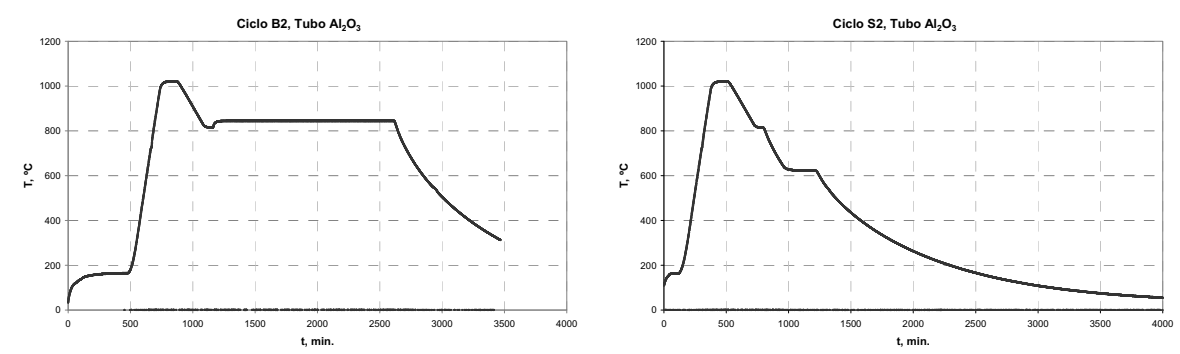

a

Fig. 4.49. Curva real de los ciclos térmicos realizados en horno empleando tubo de $\mathrm{Al}_{2} \mathrm{O}_{3}$. Tratamientos tipo: a) $\mathrm{B}$; b) $\mathrm{S}$.

Los tratamientos térmicos se aplicaron sobre muestras de diferentes granulometrías, sinterizadas a diferentes temperaturas y tiempos. Se realizaron tanto sobre muestras de reducidas dimensiones, como sobre probetas de flexión. La tabla 4.10 recoge la relación de piezas que fueron sometidas a tratamiento térmico, diferenciando entre la granulometría y ciclo térmico según el cual se conformó la pieza porosa de partida; si se trataba de una probeta para ensayar posteriormente a flexión (flexión), o únicamente para su estudio microestructural (Micro); así como el ciclo térmico al que fueron sometidas. 
Tabla 4.10. Piezas sometidas a tratamiento térmico.

\begin{tabular}{|c|c|c|c|c|c|c|c|}
\hline Granulom. & $\mathbf{T}^{\mathrm{a}},{ }^{\circ} \mathbf{C}$ & $\mathbf{t}$, horas & TIPO & $\begin{array}{c}\text { B1, Tubo } \\
\text { Acero (C1) }\end{array}$ & $\begin{array}{c}\text { S1, Tubo } \\
\text { Acero (C2) }\end{array}$ & $\begin{array}{c}\text { B2, Tubo } \\
\text { Alúmina (C3) }\end{array}$ & $\begin{array}{c}\text { S2, Tubo } \\
\text { Alúmina (C4) }\end{array}$ \\
\hline GF & 1300 & 8 & Micro & - & 1 & 1 & - \\
\hline GG & 1300 & 8 & Micro & - & 1 & 1 & - \\
\hline GG & 1300 & 12 & Micro & - & 1 & 1 & - \\
\hline GF & 1300 & 12 & Micro & - & 1 & 1 & - \\
\hline GF & 1350 & 2 & Flexión & 4 & 1 & 1 & 4 \\
\hline GM & 1350 & 2 & Flexión & - & 3 & 5 & 1 \\
\hline GG & 1350 & 2 & Flexión & 1 & 1 & 1 & 4 \\
\hline GF & 1350 & 4 & Micro & - & 1 & 1 & - \\
\hline GG & 1350 & 4 & Micro & - & 1 & 1 & - \\
\hline GF & 1350 & 8 & Micro & 1 & - & - & 1 \\
\hline GG & 1350 & 8 & Micro & 1 & - & - & 1 \\
\hline GF & 1350 & 12 & Micro & - & 1 & 1 & - \\
\hline GG & 1350 & 12 & Micro & - & 1 & 1 & - \\
\hline GF & 1400 & 4 & Micro & - & - & 1 & 1 \\
\hline GG & 1400 & 4 & Micro & 1 & - & - & 1 \\
\hline GF & 1400 & 8 & Micro & 1 & - & - & 1 \\
\hline GG & 1400 & 8 & Micro & 1 & - & - & 1 \\
\hline
\end{tabular}

Tal como se ha indicado, los dos primeros tratamientos térmicos se realizaron en un tubo de acero, cuya limpieza se realizó con hidrógeno, a $1240{ }^{\circ} \mathrm{C}$, durante 1 hora. El registro de temperaturas se realizó empleando un termopar tipo K con una pastilla de acero en la punta, figura 4.50.

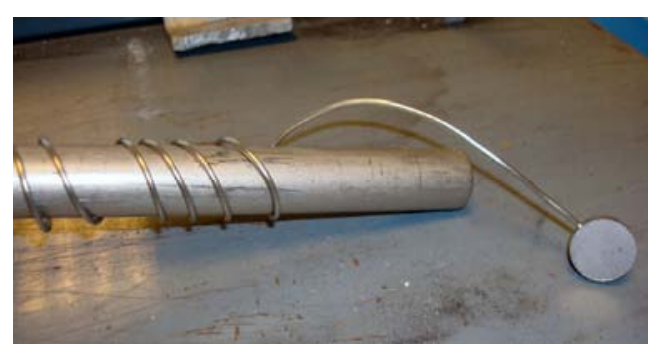

a

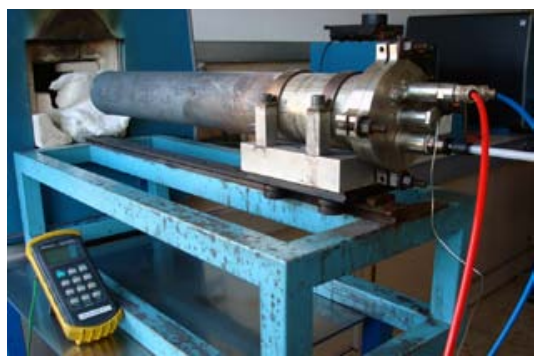

b

Fig. 4.50. a) Termopar tipo K; b) Tubo de acero empleado en los tratamientos térmicos 1 y 2 .

El primer tratamiento térmico realizado fue el B1 indicado anteriormente y se empleó como soporte una bandeja rectangular de $\mathrm{Al}_{2} \mathrm{O}_{3}$ de $94 \cdot 40 \mathrm{~mm}^{2}$ sobre la que se depositó un lecho de polvo de itria disuelto en alcohol. Tras introducir las piezas en el horno, se creó una atmósfera de argón ( $\mathrm{Ar}$ ) y posteriormente se inició el vacío, hasta alcanzar un nivel superior a $10^{-4}$ mbar, a partir del cual se inició el ciclo térmico. 
Dado que tras la realización del primer ciclo se observó una contaminación más severa al contacto con la $\mathrm{Y}_{2} \mathrm{O}_{3}$, se sustituyó ésta por una placa de Ti6Al4V. Así, el segundo tratamiento térmico, S1, se realizó siguiendo el procedimiento descrito para el ciclo 1, modificando el ciclo térmico a aplicar y el soporte base de las piezas (itria por Ti64). Por otra parte, previo al inicio del ciclo, se estabilizó el sistema a $150^{\circ} \mathrm{C}$ durante 30 minutos con el fin de eliminar la posible humedad residual.

Dado que durante el segundo ciclo también se produjo oxidación, para el tercer y cuarto ciclos se optó por sustituir el tubo de acero por un tubo de $\mathrm{Al}_{2} \mathrm{O}_{3}$. Por otra parte, se controló el nivel de $\mathrm{O}_{2}$ haciendo pasar la salida del tubo por un medidor.

Para su realización, tras generar una atmósfera de $\mathrm{Ar}$, se elevó la temperatura hasta $150{ }^{\circ} \mathrm{C}$ y se sustituyó el $\operatorname{Ar}$ por $\mathrm{H}_{2}$ (la cantidad de $\mathrm{O}_{2}$ en el tubo descendió hasta $0,01 \%, \log \mathrm{PO}_{2}=-27,01$ bares). Tras estabilizar la presión parcial de $\mathrm{O}_{2}$, se dejó pasar un flujo de $\mathrm{H}_{2}$ (10 minutos) y finalmente se inició el vacío $\left(<10^{-4} \mathrm{mbar}\right)$.

Concretamente, el tercer ciclo térmico programado fue del tipo $B$ (B2), mientras que el cuarto fue del tipo $S$, (S2). Entre la realización de ambos, se limpió la lanza de sujeción del termopar y, dado que se observó de nuevo reactividad entre las piezas y el soporte base, la chapa de titanio se envolvió con alambre de acero con el fin de facilitar el contacto de las muestras con la atmósfera del horno también por su parte inferior.

\subsubsection{CORROSIÓN.}

Tal como se ha indicado, dada la amplitud del estudio, determinadas propiedades de interés merecen ser investigadas por otros grupos. Así, el estudio de corrosión fue realizado bajo la dirección del Doctor José Luis Ortiz Rosales, en el Instituto Tecnológico y de Estudios Superiores de Monterrey, ubicado en el Campus de Querétano, México. 
La investigación se realizó sobre piezas porosas desarrolladas por el método de espaciadores, con porcentajes Ti64-Bicarbonato de 100-0 y 45$55 \% \mathrm{v}$, sobre muestras compactadas a 100 y $200 \mathrm{MPa}$ y sinterizadas a $1275^{\circ} \mathrm{C}$ durante 2 y 4 horas, y a $1325^{\circ} \mathrm{C}$ durante $1 \mathrm{~h}$. Las pruebas se realizaron también sobre Ti64 de forja para comparación.

El estudio se realizó mediante el desarrollo de curvas potenciodinámicas o voltamperometrías, Espectroscopía de Impedancia Electroquímica (EIS), y pruebas de Ruido de Electroquímico (ENM).

El trazado de las curvas intensidad de corriente "i" versus potencial " $E$ ", permitió relacionar la resistencia a la polarización con la velocidad de corrosión, pues ambas resultan inversamente proporcionales.

Por otra parte, la EIS permitió determinar las resistencias existentes en la celda electroquímica por separado, es decir, la resistencia del electrolito y la resistencia del material en lugar de determinar una resistencia total (métodos DC). Se determinó además la capacitancia producida por la separación de cargas en la superficie de la muestra. Los datos se representaron en un Diagrama de Nyquist, el cual muestra los puntos de medición a diferentes frecuencias graficando la componente real (proporcional a la resistencia, $\mathrm{Rp}$ ) y la componente imaginaria (proporcional a la capacitancia). Dicho diagrama permitió obtener los valores de los componentes del circuito equivalente, el cual simula un metal bajo el efecto de la corrosión, figura 4.51 , donde $R_{\text {sol, }}$ se refiere a la resistencia que presenta el electrolito, $C_{d l}$, representa la capacitancia de doble capa y $R_{c t}$, es la resistencia a la transferencia de carga, siendo esta última la variable a analizar, ya que es inversamente proporcional a la velocidad de corrosión.

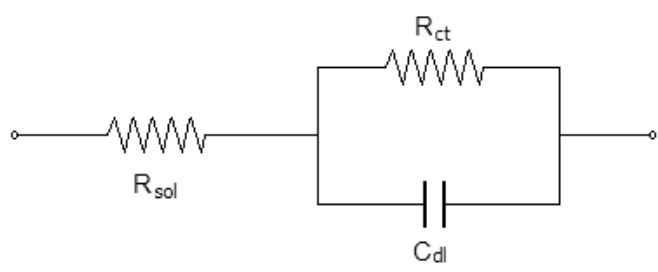

Fig. 4.51. Circuito eléctrico equivalente para un metal bajo corrosión. 
En la técnica de ruido electroquímico se midió el Potencial de Ruido Electroquímico (EPN, fluctuaciones de voltaje entre dos electrodos), la Corriente de Ruido Electroquímico (ECN, fluctuaciones de corriente entre los electrodos), y la resistencia al ruido electroquímico. Frente a las anteriores, mediante esta técnica se examinó el sistema en su comportamiento natural, sin aplicar ninguna perturbación.

Para controlar la superficie de cada muestra expuesta al electrolito, la porosidad abierta fue sellada con parafina, mediante la inmersión de cada pieza en parafina fundida a una temperatura de $90^{\circ} \mathrm{C}$ durante 2 horas, de acuerdo a la norma ASTM B328. Tras extraer las muestras del baño y solidificar la parafina, se desbastó cada probeta con papel abrasivo de SiC 400 y se pulió con lija grado 600 para finalmente desengrasar con acetona. Estas últimas operaciones, pulido y desengrase, se realizaron previo a la realización de cada ensayo.

Como electrolito se utilizó en todas las pruebas electroquímicas una solución Ringer, la cual simula un fluido corporal humano [González 1999, Kuphasuk 2001]. Esta solución se preparó disolviendo 8,6 $\mathrm{g} \mathrm{NaCl}, 0,3 \mathrm{~g}$ $\mathrm{KCl}, 0,33 \mathrm{~g} \mathrm{CaCl}_{2}$ en $1000 \mathrm{ml}$ de agua destilada, con un $\mathrm{pH}$ aproximadamente neutro $(\mathrm{pH} \approx 7)$. Para simular la temperatura promedio del cuerpo humano, ésta se mantuvo a $37 \pm 1^{\circ} \mathrm{C}$, empleando para ello un dispositivo aislado calentado por una lámpara incandescente, el cual fue controlado manualmente con la ayuda de un termómetro, figura 4.52 .

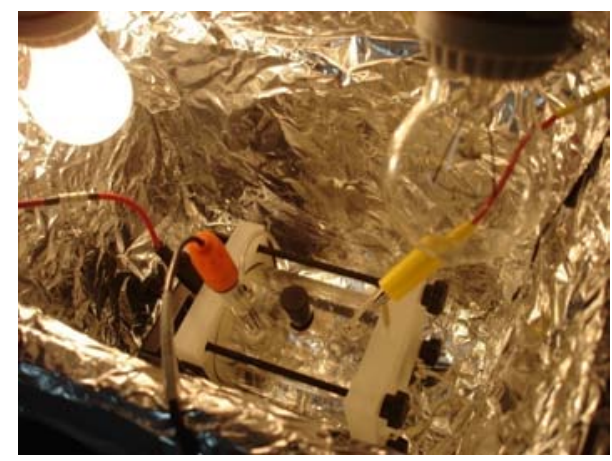

Fig. 4.52. Dispositivo para mantener a $37^{\circ} \mathrm{C}$ el electrolito. 
Las pruebas electroquímicas se realizaron utilizando un potenciostato/galvanostato ACM Instruments, Gill AC, figura 4.53a y una celda plana Princeton Applied Researh, modelo K0235, figura 4.53b para las pruebas potenciodinámicas e impedancia.

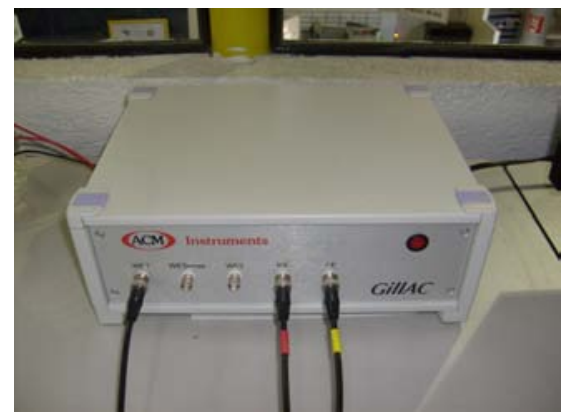

a

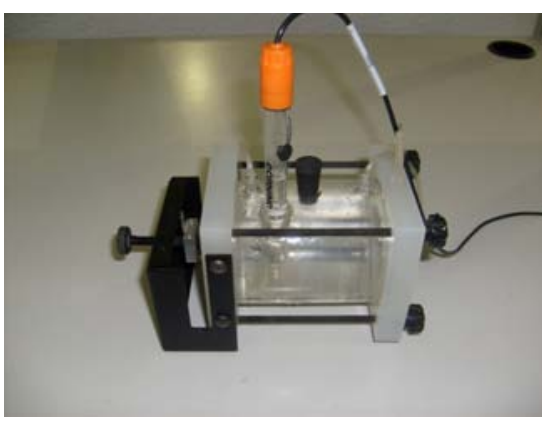

b

Fig. 4.53. a) Potenciostato/Galvanostato Gill AC; b) Celda plana PAR K0235.

Los ensayos de ruido electroquímico se realizaron en un vaso de precipitados, donde se sumergieron los dos electrodos de trabajo y un electrodo de referencia de calomelanos (SCE) en el electrolito previamente desaireado, a una temperatura de $37 \pm 1^{\circ} \mathrm{C}$, figura $4.54 a$. Para la realización de este ensayo, los electrodos de trabajo fueron encapsulados mediante una resina epóxica con la finalidad de exponer una superficie concreta al electrolito, figura $4.54 \mathrm{~b}$.

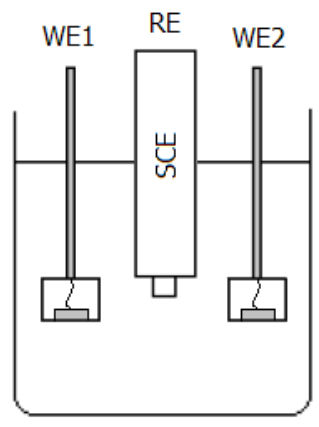

a

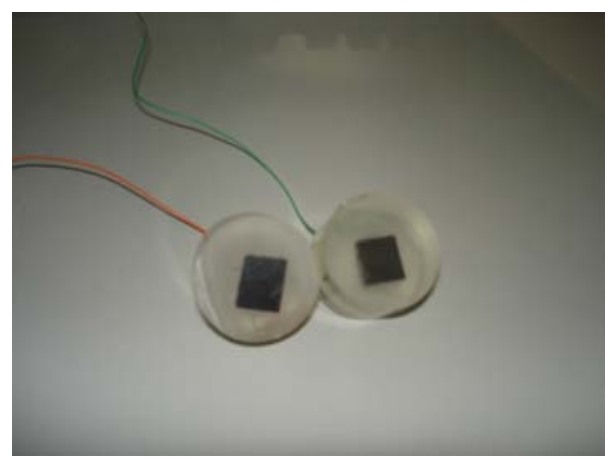

b

Fig. 4.54. Ruido electroquímico: a) Configuración de celda; b) Electrodos de trabajo. 
Las voltamperometrías se obtuvieron realizando un barrido de potencial de 200 a $800 \mathrm{mV}$, pues se encontró el potencial de estabilización entre los 150 y $250 \mathrm{mV}$. Para la EIS se aplicó un voltaje alterno con una amplitud de 10 $\mathrm{mV}$, realizando un barrido desde los $10.000 \mathrm{~Hz}$ hasta una frecuencia de 10 $\mathrm{mHz}(0,01 \mathrm{~Hz})$. 

5

RESULTADOS Y DISCUSIÓN 



\subsection{INTRODUCCIÓN.}

Se analizarán en primer lugar los resultados de las pruebas preliminares realizadas, tanto del estudio de reactividad como del estudio preliminar realizado por el método de espaciadores. Posteriormente, con el fin de exponer los resultados con la mayor claridad posible, se presentarán según el método de obtención de las piezas porosas desarrolladas. Es decir, se discutirán las características de las piezas porosas obtenidas por sinterización de microesferas sobre itria $y$, por otra los resultados de las piezas porosas obtenidas por el método de espaciadores. En este caso, se discutirán simultáneamente las propiedades de las piezas porosas base de la investigación así como de las pruebas finales.

\subsection{ESTUDIOS PREVIOS.}

Dada la elevada reactividad del titanio y su influencia sobre las propiedades de las piezas porosas obtenidas, fue necesario realizar un estudio previo de la reactividad del titanio con diferentes moldes y para distintas condiciones de sinterización. El estudio se realizó sobre moldes de gres, alúmina, itria y circona. La elección del primero vino condicionada por su facilidad de conformado y consolidación con los medios disponibles, lo que habría permitido conformar morfologías diversas; los moldes de alúmina se emplearon por su gran estabilidad. Por otra parte, se emplearon moldes de circona, así como recubrimientos de itria sobre moldes de alúmina, pues determinados estudios hacían referencia a su empleo de forma satisfactoria para el conformado de titanio [Wang 1998, Kim 2002, García 2006, Smeacetto 2006, Esteban 2008].

El estudio de reactividad se llevó a cabo sobre piezas porosas de Ti64 obtenidas mediante sinterización de microesferas, por existir menos variables de proceso, lo que permitió analizar más fácilmente la influencia del molde. Sobre ellas se analizó la microestructura, microdureza y resistencia a flexión. 
Por otra parte, se realizó otro estudio preliminar con el fin de evaluar las posibilidades de obtención de piezas porosas de titanio mediante la técnica de espaciadores, así como acotar las variables de proceso. En estas pruebas se empleó polvo de TiCP3 como material base y bicarbonato de amonio como espaciador, empleando para éste último dos fracciones granulométricas, de 500 a 1000 y 250 a $500 \mu \mathrm{m}$. Se estableció un porcentaje volumétrico de espaciador entre el 30 y $70 \% \mathrm{v}$, con incrementos del $10 \% \mathrm{v}$, aunque también se consolidaron piezas sin espaciador para estimar el efecto de éste sobre el material base. Las mezclas y la compactación, de 100 a $200 \mathrm{MPa}$, se realizaron de forma manual. Posteriormente se eliminó el bicarbonato y se sinterizó, véase apartado 3.1.

Para analizar el efecto de las variables de proceso, así como las posibilidades de conformado, se analizó su microestructura, y se determinó la porosidad, resistencia a flexión y rigidez.

\subsubsection{ANÁLISIS DE LA REACTIVIDAD CON EL MOLDE.}

Para estudiar la reactividad del titanio con los diferentes moldes, se extrajeron muestras de las piezas porosas obtenidas, y se estudió su microestructura y resistencia a flexión. Por otra parte, se determinó la microdureza, diferenciando entre las zonas de contacto con el molde y con la atmósfera del horno.

Los análisis realizados permitieron observar como la contaminación del titanio afectaba considerablemente a las propiedades mecánicas de las piezas obtenidas. Así, mientras que al sinterizar en moldes de gres la reactividad quedaba patente a simple vista, al emplear moldes de alúmina las piezas quedaban adheridas al molde, observándose además una merma importante de las propiedades mecánicas finales. A igualdad de parámetros de proceso (tamaño microesferas, temperatura y tiempo de sinterización), las mejores propiedades mecánicas se obtuvieron al emplear itria como soporte. 


\subsubsection{Reactividad con los moldes de gres.}

Tal como se ha indicado, al sinterizar sobre gres la reactividad podía observarse a fácilmente. Así, mediante la lupa estereoscópica, figura 5.1, se manifiestan diferencias entre las zonas de contacto con el molde y con la atmósfera del horno, presentando un aspecto más mate la primera.

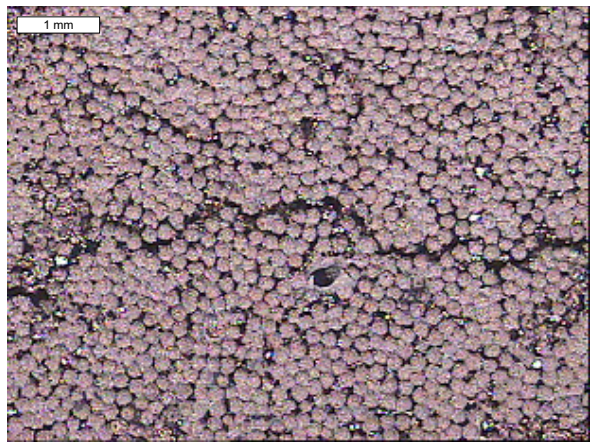

a

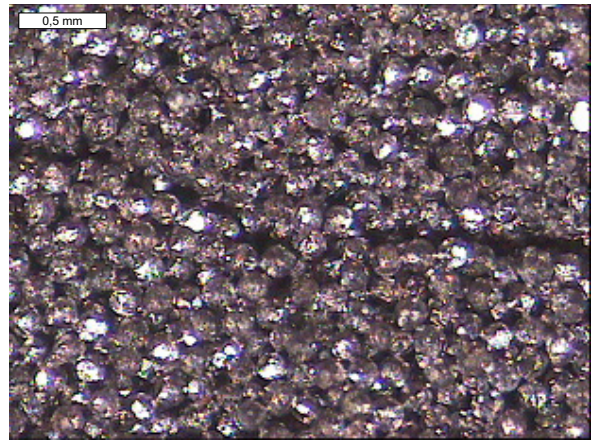

b

Fig. 5.1. Micrografía Ti64 GF sinterizado a $1300^{\circ} \mathrm{C}$, 8 h en molde de gres: a) Contacto con el molde; b) Contacto con atmósfera del horno.

La observación a mayores aumentos reveló una contaminación bastante severa en el contacto entre las microesferas y los moldes de gres. Ésta afectaba a más de una microesfera, figura 5.2.

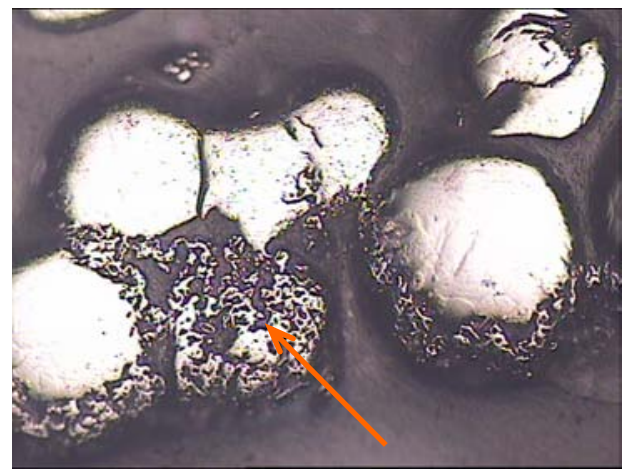

Fig. 5.2. Micrografías MO de microesferas en contacto directo con el molde, sinterizadas en molde de gres a $1400^{\circ} \mathrm{C}$ durante $8 \mathrm{~h}$. 
Mediante EDX se corroboró la presencia de elementos típicos de las arcillas [Valiente 2005], tales como $\mathrm{Si}$, $\mathrm{Na}$ e incluso algunas trazas de Fe, figura 5.3.

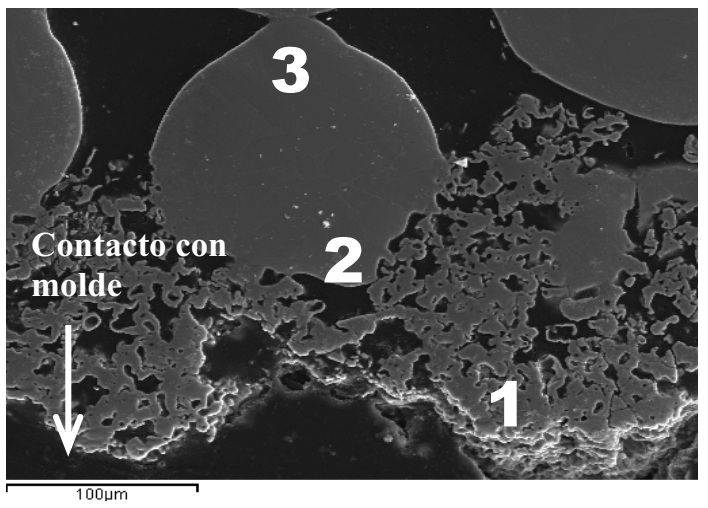

\begin{tabular}{|c|c|c|c|c|c|c|c|c|c|}
\cline { 2 - 9 } \multicolumn{2}{c|}{} & $\mathrm{Na}$ & $\mathrm{Si}$ & $\mathrm{Fe}$ & $\mathrm{Ca}$ & $\mathrm{O}$ & $\mathrm{Al}$ & $\mathrm{V}$ & $\mathrm{Ti}$ \\
\hline \multirow{2}{*}{ ESPEC. 1 } & $\% \mathrm{Wt}$ & 3,38 & 21,98 & 0,52 & - & 5,60 & 0,306 & 1,05 & 67,15 \\
\cline { 2 - 10 } & $\%$ Át & 5,50 & 29,33 & 0,34 & - & 13,12 & 0,428 & 0,77 & 50,51 \\
\hline \multirow{2}{*}{ ESPEC. 2} & $\% \mathrm{Wt}$ & - & 2,62 & 0,34 & 0,18 & - & 5,95 & 3,35 & 87,56 \\
\cline { 2 - 10 } & $\%$ Át & - & 4,15 & 0,29 & 0,20 & - & 9,43 & 2,92 & 83,01 \\
\hline \multirow{2}{*}{ ESPEC. 3 } & $\% \mathrm{Wt}$ & - & 1,20 & 0,88 & - & - & 6,40 & 4,40 & 87,12 \\
\cline { 2 - 10 } & $\%$ Át & - & 1,93 & 0,71 & - & - & 10,72 & 3,91 & 82,75 \\
\hline
\end{tabular}

Fig. 5.3. Micrografía MEB de microesferas de Ti64 sinterizadas en moldes de gres a $1400^{\circ} \mathrm{C}, 2 \mathrm{~h}$. Tabla: Análisis EDX en tres zonas diferentes de la muestra.

Tal como se observa en la tabla, cuanto más cerca del molde, mayor contenidos en $\mathrm{Si}$, e incluso aparecen otros elementos típicos de las cerámicas, tales como el $\mathrm{Ca}$ o el $\mathrm{Na}$. Pese a que al final de la segunda microesfera ya se han recuperado los contenidos en $\mathrm{Al}$ y $\mathrm{V}$ del material base, todavía se detectan cantidades de Si y Fe suficientes para modificar las propiedades mecánicas del componente fabricado. En el corte transversal se observa la formación de eutécticos en las zonas de contacto con el molde de gres, figura 5.4a, lo que provocó la fusión del material en determinadas zonas en contacto con el molde, figura 5.4b. 


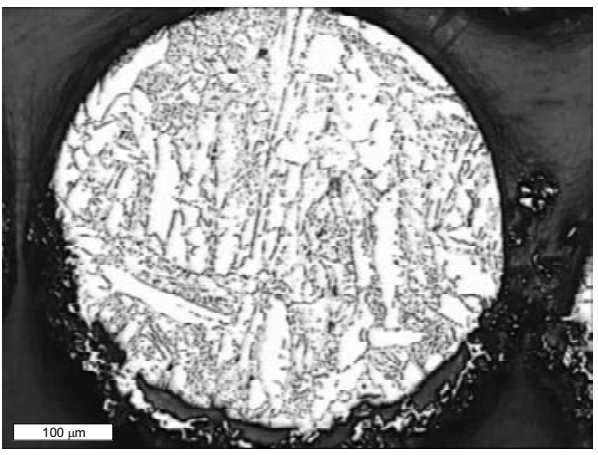

a

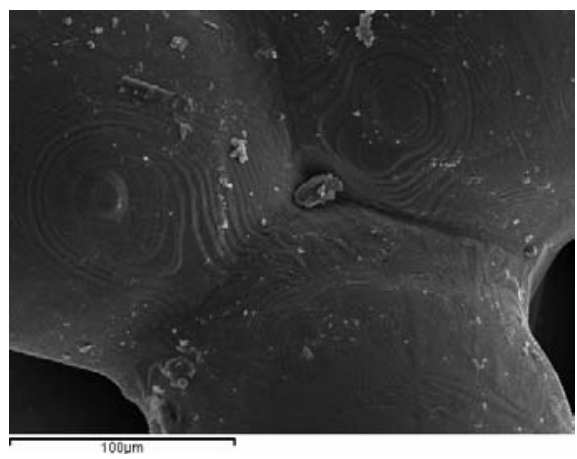

b

Fig. 5.4. Micrografías de microesferas en contacto con el molde de gres sinterizadas a $1400^{\circ} \mathrm{C}$ : a) MO Corte transversal, GG sint. h; b) MEB Vista frontal, GF sint. $2 \mathrm{~h}$.

Mientras que el $\mathrm{Na}$ resulta completamente insoluble en el titanio [ASM N3 1997], para contenidos en Si del orden de los obtenidos al contacto con el molde $(20-30 \% \mathrm{Wt})$, y a las temperaturas alcanzadas durante la sinterización $\left(1300\right.$ y $\left.1400^{\circ} \mathrm{C}\right)$, coexiste la fase líquida con la formación del intermetálico $\mathrm{Ti}_{5} \mathrm{Si}_{3}$, figura 5.5. Pese a que el comportamiento se modifica por la presencia de otros elementos ( $\mathrm{Na}, \mathrm{Al}, \mathrm{V}, \mathrm{Fe} \ldots)$, durante el enfriamiento se forma un eutéctico de $\mathrm{Ti}(\beta)$ y $\mathrm{Ti}_{5} \mathrm{Si}_{3}$. Al continuar con el enfriamiento lento en horno, se origina una transformación peritectoide, transformando la fase $\mathrm{Ti}_{5} \mathrm{Si}_{3}$ en $\mathrm{Ti}_{3} \mathrm{Si}$. Finalmente, por debajo de la temperatura de transición $\beta\left(\approx 865^{\circ} \mathrm{C}\right)$, se producirá la transformación alotrópica de la fase $\beta$ a fase $\alpha$. 


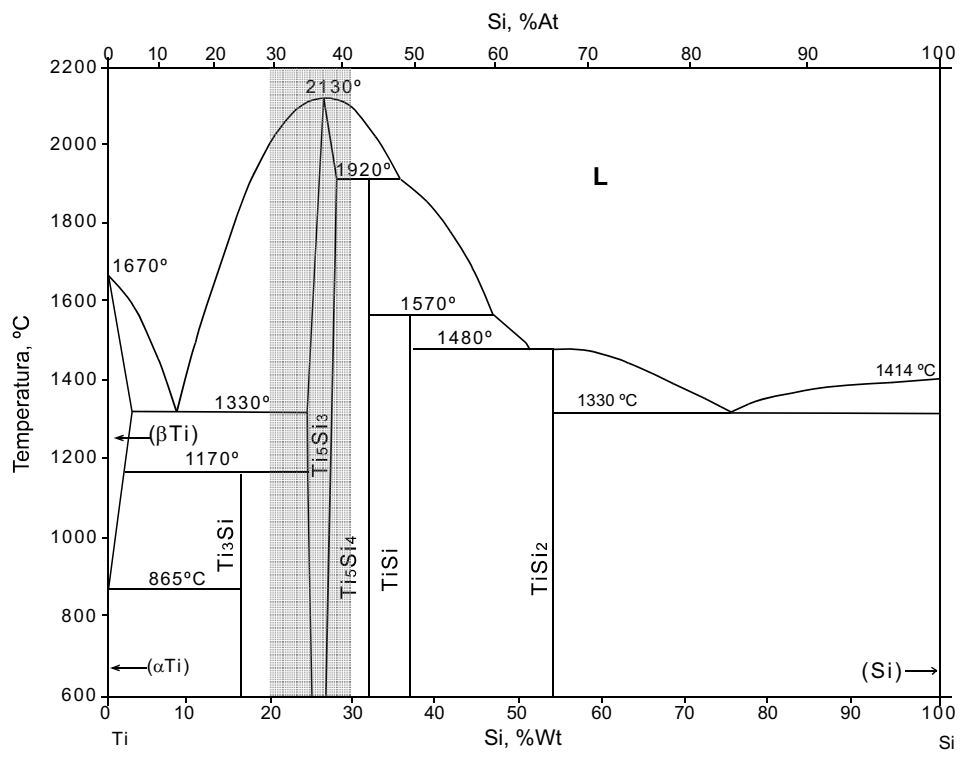

Fig. 5.5. Diagrama de fases Ti-Si [ASM N3 1997].

Por otra parte, pese a que existe una diferencia evidente entre la zona de contacto con el molde y la de la atmósfera del horno, figura 5.6, todavía en ésta última los análisis EDX denotan contaminación del titanio.

En relación a las propiedades mecánicas, como era de esperar, las resistencia resulta superior cuanto más finas las microesferas (140 MPa en GF frente a $35 \mathrm{MPa}$ en $\mathrm{GG}$ ), figura 5.7, lo que es debido a su mayor superficie específica y, por tanto, mayor desarrollo de los cuellos de unión, [German 1994, Shatt 1997]. Por otra parte, la reactividad origina grandes diferencias en función de la orientación de la probeta durante el ensayo (zona de contacto con el molde colocada en el área traccionada, MB, o comprimida, MA). Este último efecto resulta mucho más notable en la granulometría fina, lo que es debido a su mayor superficie específica [Upadhayaya 1997]. 


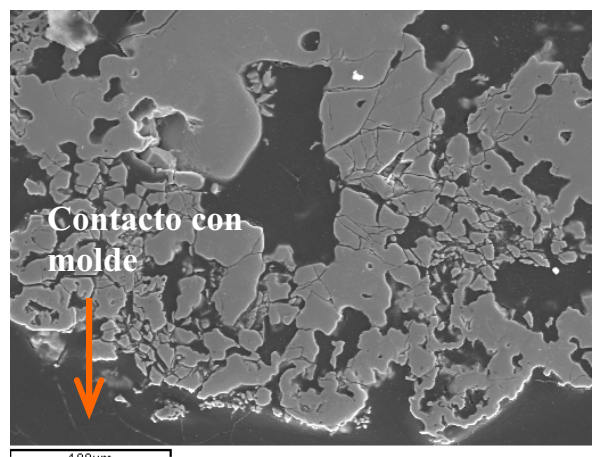

a

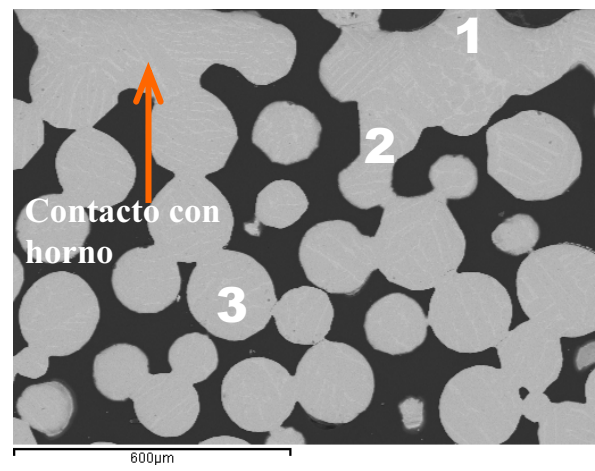

b

\begin{tabular}{|l|c|c|c|c|c|c|}
\cline { 3 - 7 } \multicolumn{2}{c|}{} & Si & Fe & Al & V & Ti \\
\hline \multirow{2}{*}{ ESPEC. 1} & $\% \mathrm{Wt}$ & 1,14 & 0,50 & 2,62 & 3,44 & 92,30 \\
\cline { 2 - 7 } & $\%$ Át & 1,90 & 0,42 & 4,57 & 3,18 & 90,03 \\
\hline \multirow{2}{*}{ ESPEC. 2} & $\% \mathrm{Wt}$ & 0,67 & 0,70 & 3,73 & 4,80 & 90,05 \\
\cline { 2 - 7 } & $\%$ Át & 1,12 & 0,58 & 6,22 & 4,41 & 87,68 \\
\hline \multirow{2}{*}{ ESPEC. 3 } & $\% \mathrm{Wt}$ & - & 0,30 & 5,80 & 3,89 & 89,98 \\
\cline { 2 - 7 } & $\%$ Át & - & 0,25 & 9,20 & 3,57 & 86,99 \\
\hline
\end{tabular}

Fig. 5.6. Micrografías MEB de microesferas de Ti64 sinterizadas en moldes de gres a $1400^{\circ} \mathrm{C}, 2 \mathrm{~h}$. Zonas de: a) Contacto con el molde; b) Contacto con la atmósfera del horno. Tabla: Análisis EDX en tres zonas diferentes de la muestra $b$

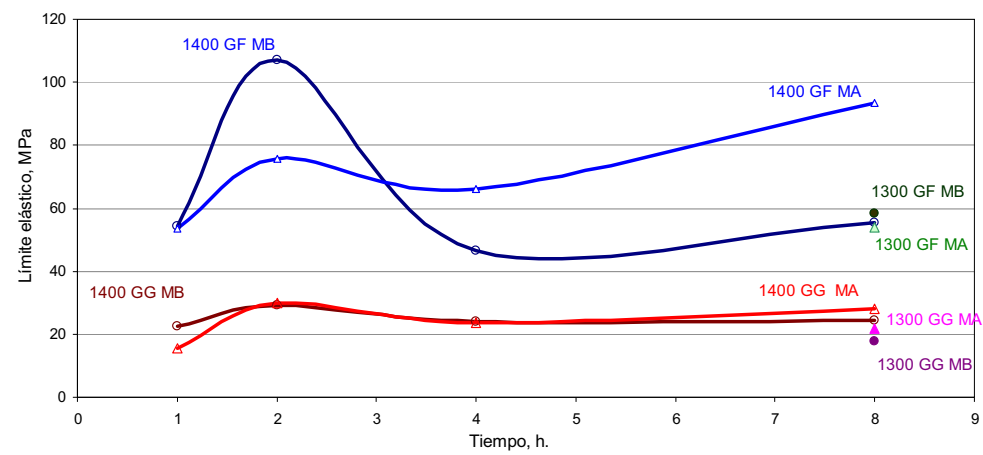

Fig. 5.7. R. Flexión microesferas Ti64 sinterizadas en gres a 1300 y $1400^{\circ} \mathrm{C}$ entre 1 y 8h. MB: contacto molde bajo; MA: contacto molde arriba. 
Por tanto, las propiedades mecánicas que se ven fuertemente afectadas por la reactividad con el molde. Por ello, pese a que la $S_{\text {unión }} / S_{\text {esfera }}$ resulta máxima para tiempos de $4 \mathrm{~h}$, lo que coincide con la máxima compacidad obtenida, véase apartados 5.3.3.1 y 5.3.2.1 respectivamente, no se corresponde con la máxima resistencia mecánica.

Tal como se observa, la máxima resistencia se obtiene para tiempos de hasta 2 horas, reduciéndose para tiempos superiores. Pese a que no se ha estudiado la contaminación a diferentes tiempos, probablemente el efecto es debido a que a tiempos cortos (hasta 2 horas) se produce un ligero endurecimiento con mejora de propiedades mecánicas; mientras que tiempos mayores ya implican fragilización, acompañada de una merma de resistencia. Lógicamente, estos resultados se acentúan cuando las muestras son ensayadas con la parte de contacto con el molde en la zona traccionada, mientras que al someter esta zona a compresión se observa cierto incremento de las propiedades mecánicas con la temperatura y tiempo de sinterización.

\subsubsection{Reactividad con los moldes de $\mathrm{Al}_{2} \mathrm{O}_{3}$.}

Al observar mediante estereoscopía las piezas sinterizadas sobre alúmina, figura 5.8, la zona de contacto con la atmósfera del horno parecía presentar mayor degradación aunque, tal como se verá, ésta resultó mayor al contacto con el molde.

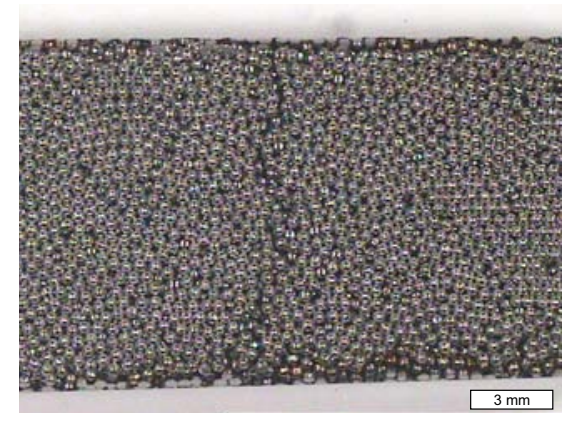

a

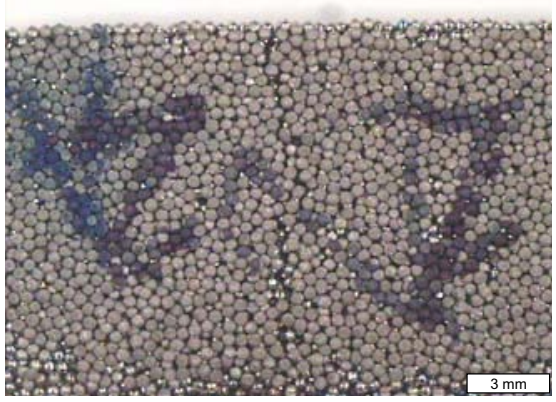

b

Fig. 5.8. Micrografía Ti64 GG sinterizado a $1400{ }^{\circ} \mathrm{C}, 2 \mathrm{~h}$ en molde de $\mathrm{Al}_{2} \mathrm{O}_{3}$ : a) Contacto con el molde; b) Contacto con atmósfera del horno. 
Posteriormente se emplearon también bandejas de alúmina como soporte. A pesar de la gran estabilidad de la $\mathrm{Al}_{2} \mathrm{O}_{3}$, se observó una fuerte reactividad con el molde, que quedaba patente simplemente al comparar a mayores aumentos las zonas de contacto con el molde y con la atmósfera del horno, figura 5.9 .

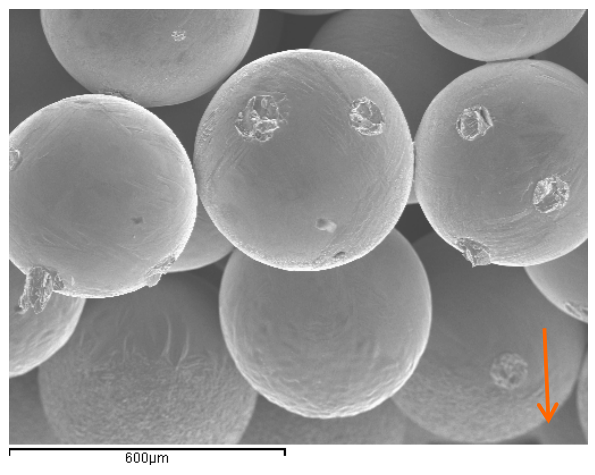

a

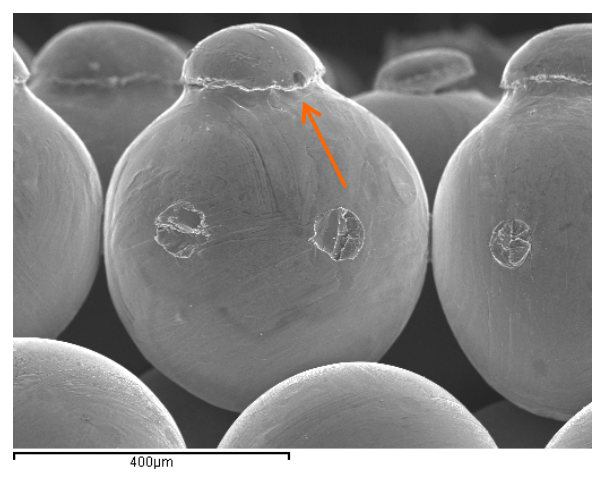

b

Fig. 5.9. Micrografías MEB de microesferas de Ti64 sinterizadas en moldes de alúmina $1350^{\circ} \mathrm{C}$; a) 4 horas, Zona de contacto con el horno; b) 2 horas, zona de contacto con el molde.

Tal como se observa en las figuras 5.10 y 5.11 , además del cambio morfológico, en la zona de contacto con el molde aumenta sustancialmente el contenido en aluminio. Cabe indicar además que, a diferencia de las piezas sinterizadas en molde de gres, no se detectan elementos ajenos a la aleación Ti6Al4V.

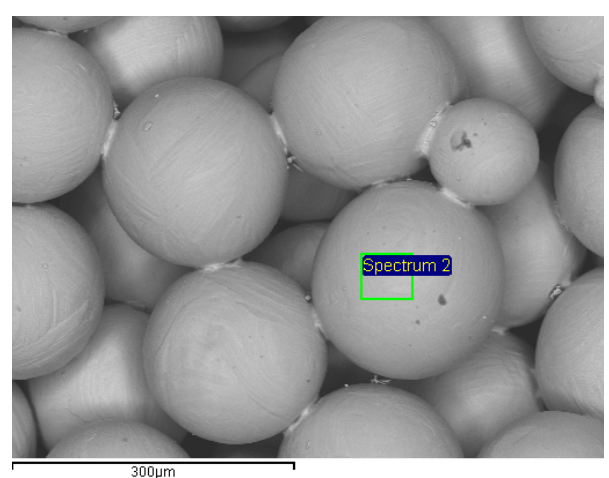

a

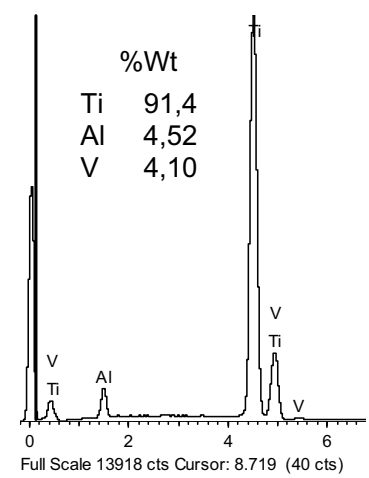

b

Fig. 5.10. Microesferas de Ti64, GF sinterizadas a $1350^{\circ} \mathrm{C}, 2 \mathrm{~h}$ en moldes de $\mathrm{Al}_{2} \mathrm{O}_{3}$. a) Zona de contacto con la atmósfera del horno; b) Espectro del análisis EDX. 


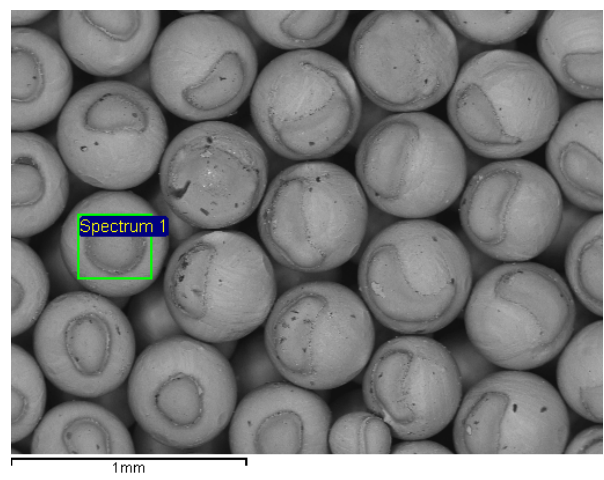

a

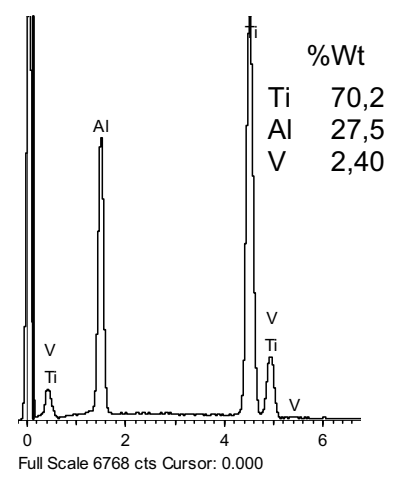

$\mathrm{b}$

Fig. 5.11. Microesferas de Ti64, GG sinterizadas a $1350^{\circ} \mathrm{C}$ durante $2 \mathrm{~h}$ en moldes de $\mathrm{Al}_{2} \mathrm{O}_{3}$. a) Zona de contacto con el molde cerámico; b) Espectro del análisis EDX.

Por otra parte, al observar piezas porosas sinterizadas a igual temperatura, pero tiempos mayores, se observa un inicio de fusión en la zona de contacto con la atmósfera del horno. Dicho cambio de forma viene acompañado de cierto incremento en la cantidad de aluminio, figura 5.12.

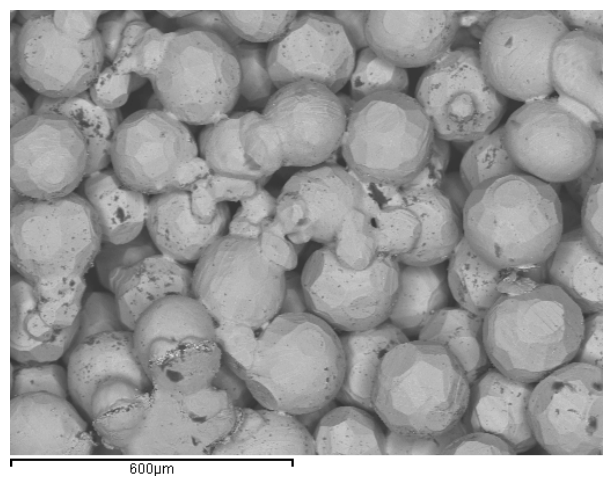

a

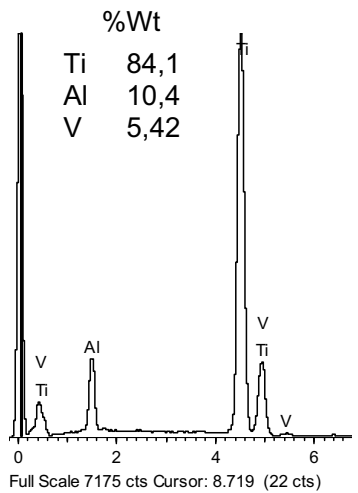

$\mathrm{b}$

Fig. 5.12. Microesferas de Ti64, GF sinterizadas a $1350^{\circ} \mathrm{C}$, $8 \mathrm{~h}$ en moldes de $\mathrm{Al}_{2} \mathrm{O}_{3}$. a) Zona de contacto con la atmósfera del horno; b) Espectro de un análisis EDX general.

Este efecto se ve acentuado en la zona de contacto con el molde cerámico, donde se produce una mayor poligonalización de las microesferas, resultando el contenido en Al mayor en relación a la zona de contacto con la atmósfera del horno, figura 5.13. 

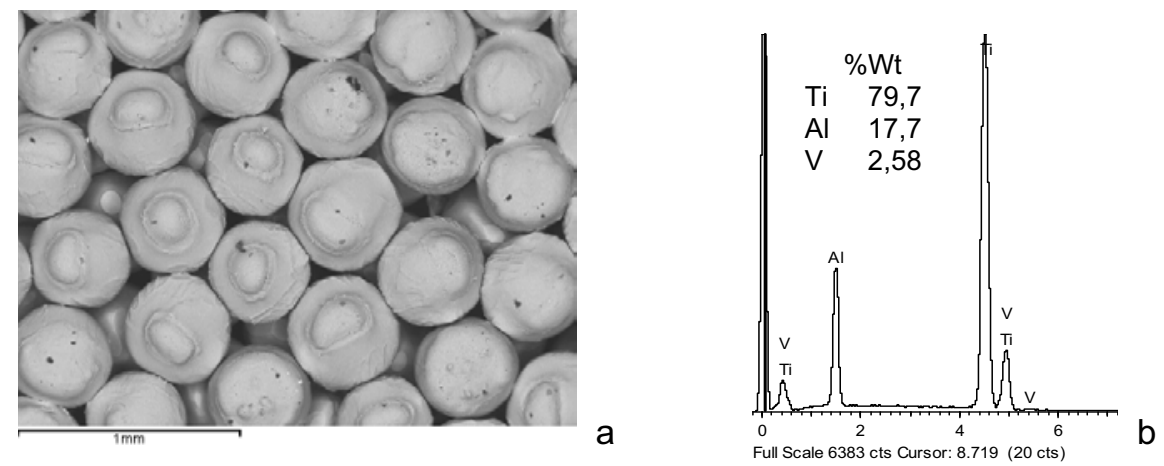

Fig. 5.13. Microesferas de Ti64, GG sinterizadas a $1350^{\circ} \mathrm{C}$ durante $8 \mathrm{~h}$ en moldes de $\mathrm{Al}_{2} \mathrm{O}_{3}$. a) Zona de contacto con el molde; b) Espectro de un análisis EDX general.

Además de las diferencias descritas, cabe indicar que, en el contacto con el molde cerámico, se observan determinadas zonas planas en las que parece que, pese a existir contacto con otras microesferas, no se han formado cuellos de unión, figura 5.14. Probablemente ello es debido a que la energía necesaria para su desarrollo se invierte en las reacciones desarrolladas con la $\mathrm{Al}_{2} \mathrm{O}_{3}$ y la formación de compuestos intermetálicos [Kostov 2006, Smeacetto 2006].

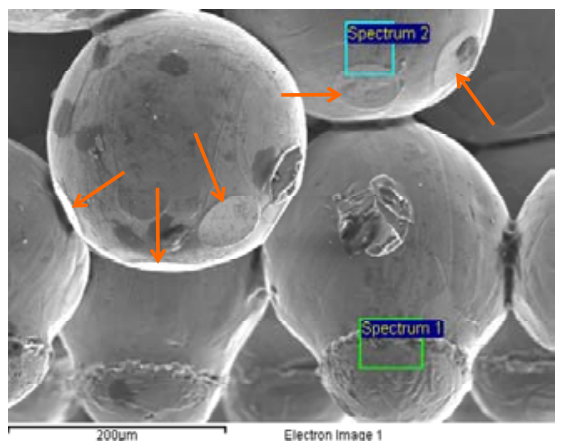

\begin{tabular}{|c|l|c|c|c|}
\cline { 2 - 5 } \multicolumn{2}{c|}{} & Al & V & Ti \\
\hline \multirow{2}{*}{ ESPEC. 1 } & $\% \mathrm{Wt}$ & 19,25 & 2,95 & 77,80 \\
\cline { 2 - 5 } & $\%$ Át & 29,78 & 2,42 & 67,80 \\
\hline \multirow{2}{*}{ ESPEC. 2 } & $\% \mathrm{Wt}$ & 4,98 & 4,18 & 90,85 \\
\cline { 2 - 5 } & $\%$ Át & 8,53 & 3,79 & 87,68 \\
\hline
\end{tabular}

Fig. 5.14. Microesferas de Ti64 50M50G sinterizadas a $1300^{\circ} \mathrm{C}$, $4 \mathrm{~h}$ en moldes de $\mathrm{Al}_{2} \mathrm{O}_{3}$. Micrografía MEB y análisis EDX de la zona de contacto con el molde.

Se analizaron además mediante EDX los moldes de $\mathrm{Al}_{2} \mathrm{O}_{3}$ tras la sinterización, lo que confirmó la presencia de elementos ligeros, como el Al y $\mathrm{O}_{2}$, figura 5.15, en las zonas oscuras (también oscuras en retrodispersados, BSE) mientras que en las zonas doradas (claras en BSE), espectro 2, aumenta la presencia de elementos ajenos al molde y 
adquiridos, por tanto, por reacción con las microesferas, $\mathrm{Ti}$ y $\mathrm{V}$. La observación de diferentes moldes empleados confirmó una mayor reactividad con la temperatura y tiempo de sinterización, pues se distinguía una mayor heterogeneidad en los moldes utilizados.

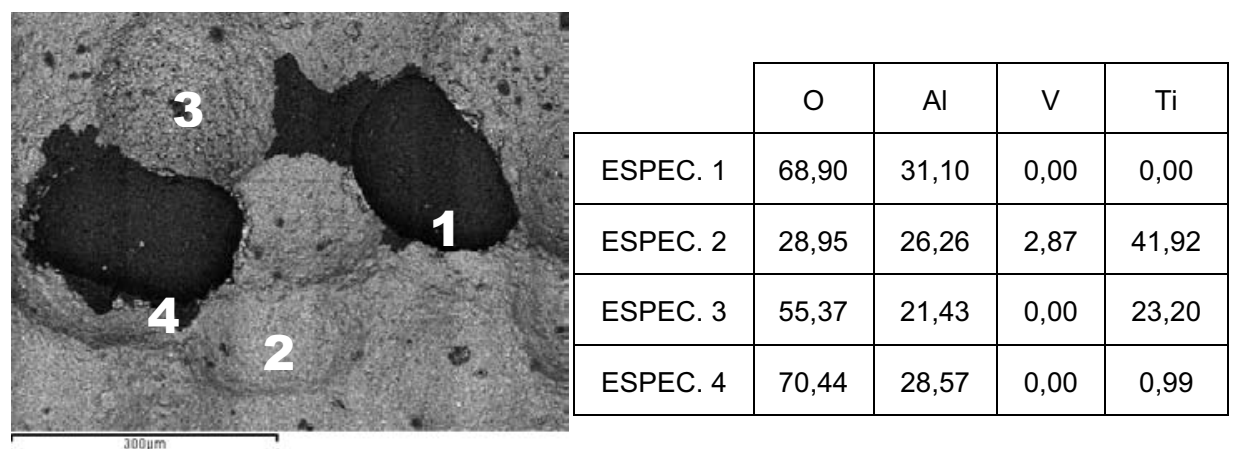

Fig. 5.15. Micrografía de electrones retrodispersados y análisis EDX, en \%Át., de diferentes áreas de un molde de $\mathrm{Al}_{2} \mathrm{O}_{3}$ tras la sinterización de microesferas.

Finalmente, se observó la rotura de las microesferas en contacto con el molde cerámico, figura 5.16, con un contenido en Al mayor al contacto directo con la $\mathrm{Al}_{2} \mathrm{O}_{3}$, figura 5.17.

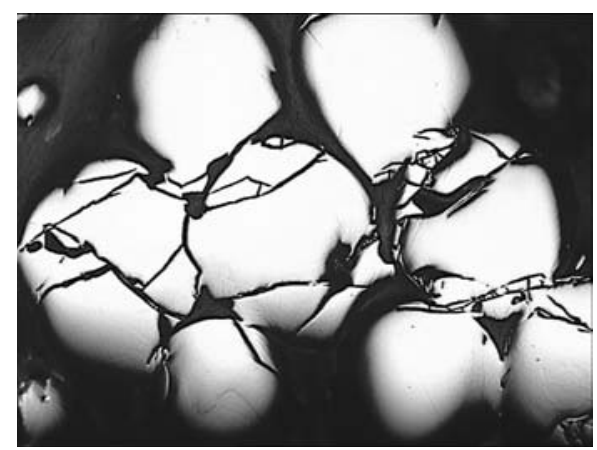

Fig. 5.16. Micrografías $\mathrm{MO}$ de microesferas en contacto con el molde de $\mathrm{Al}_{2} \mathrm{O}_{3}$, sinterizadas a $1350^{\circ} \mathrm{C}, 8 \mathrm{~h}$. 


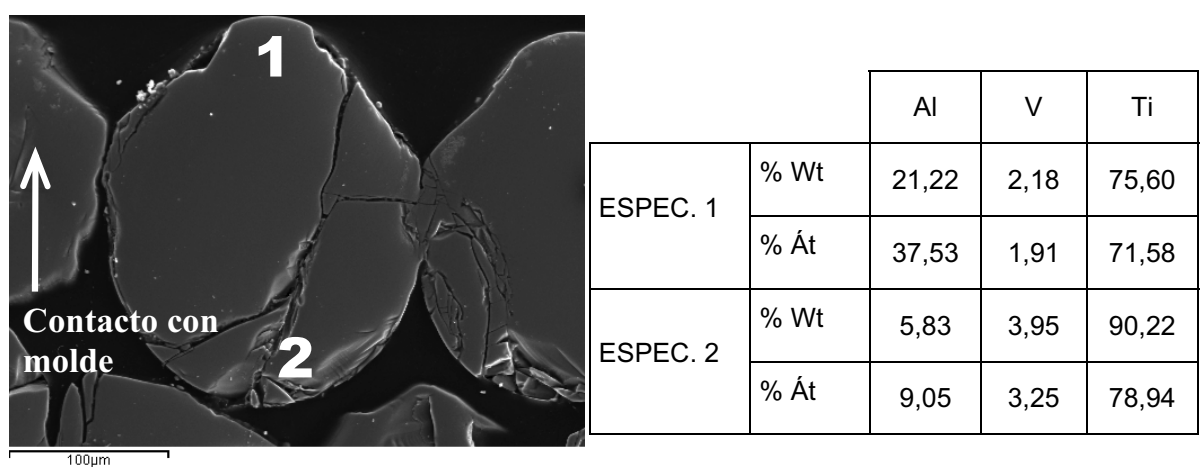

Fig. 5.17. Microesferas de Ti64 sinterizadas en moldes de $\mathrm{Al}_{2} \mathrm{O}_{3}$ a $1400^{\circ} \mathrm{C}, 2 \mathrm{~h}$. Micrografía MEB y análisis EDX de la zona de contacto con el molde.

Según los resultados obtenidos y de acuerdo con observaciones previas realizadas por diversos autores [Kostov 2006, Smeacetto 2006], durante la sinterización el titanio esta reduciendo a la alúmina del molde para formar óxidos $\left(\mathrm{TiO}, \mathrm{Ti}_{2} \mathrm{O}_{3}, \mathrm{TiO}_{2}\right)$ según la reacción [Smeacetto 2006]:

$$
\begin{aligned}
& \frac{2}{3} \mathrm{Al}_{2} \mathrm{O}_{3} \rightarrow \frac{4}{3} \mathrm{Al}+3 \mathrm{O}_{2} \\
& \mathrm{xTi}+\frac{\mathrm{y}}{2} \mathrm{O}_{2} \rightarrow \mathrm{Ti}_{x} \mathrm{O}_{y}
\end{aligned}
$$

Por tanto, tras la reducción de la alúmina del molde por parte del titanio, queda aluminio libre que difunde hacia el interior de las microesferas produciendo su endurecimiento y consecuente fragilización, figura 5.16. Los análisis EDX confirman estas hipótesis, pues al contacto con el molde de alúmina se produce un enriquecimiento de Al superior al $20 \% \mathrm{Wt}$, figura 5.17.

Pese a que la presencia del vanadio modificará ligeramente las transformaciones esperadas según el diagrama Ti-Al, contenidos de aluminio del orden de los obtenidos ( $\approx 37 \%$ Át.) implican la formación de compuestos duros del tipo $\mathrm{Ti}_{3} \mathrm{Al}$ y $\mathrm{TiAl}$, figura 5.18, que justificarían la rotura frágil observada. 


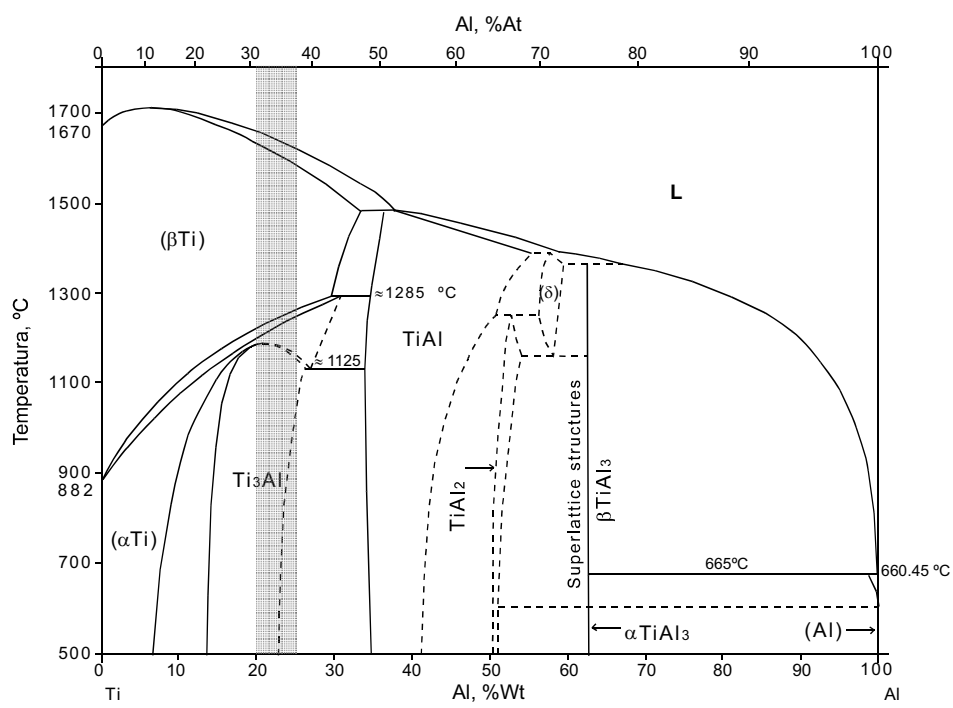

Fig. 5.18. Diagrama de fases Ti-Al [ASM N3 1997].

El diagrama ternario Ti-Al-V a diferentes temperaturas pone de manifiesto como, para el porcentaje de elementos obtenido ( $\approx 22 \mathrm{Al}, 2 \mathrm{~V}, 76 \mathrm{Ti} \% \mathrm{Wt})$, a elevada temperatura la aleación se encuentra prácticamente en fase $\beta$ mientras que, cuando esta desciende se forman compuestos duros del tipo TiAl y $\mathrm{Ti}_{3} \mathrm{Al}$ en las zonas de contacto con el molde, figura 5.19.

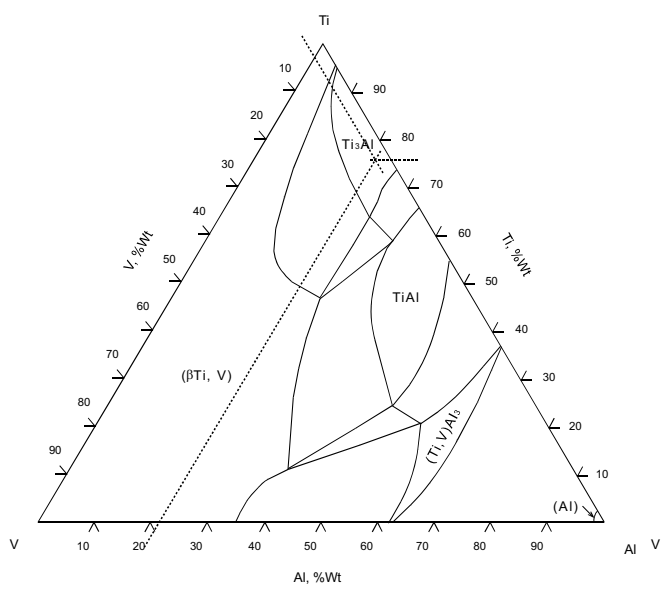

a

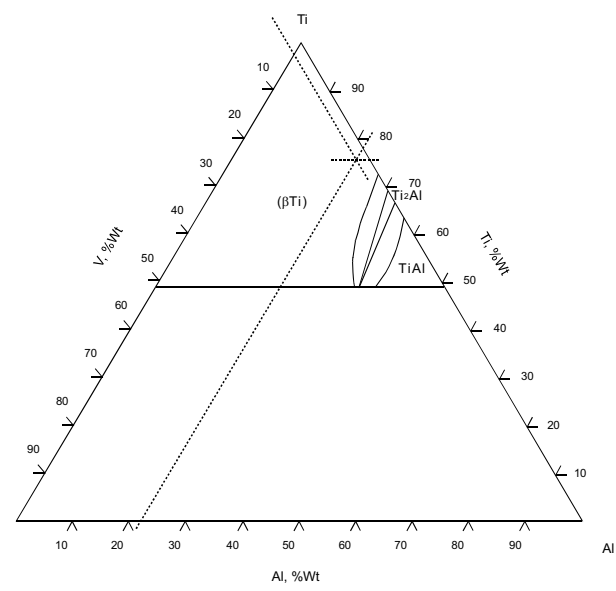

b

Fig. 5.19. Diagrama de fases ternario Ti-Al-V. Isotermas a: a) $980^{\circ} \mathrm{C}$; b) $1400^{\circ} \mathrm{C}$ [ASM N3 1997]. 
En cuando a la resistencia a flexión, al contrario que ocurría en las piezas obtenidas en moldes de gres, la reacción con la alúmina provoca que, para un mismo tiempo de sinterización, las propiedades mecánicas disminuyan a medida que aumenta la temperatura de sinterización, figura 5.20 .

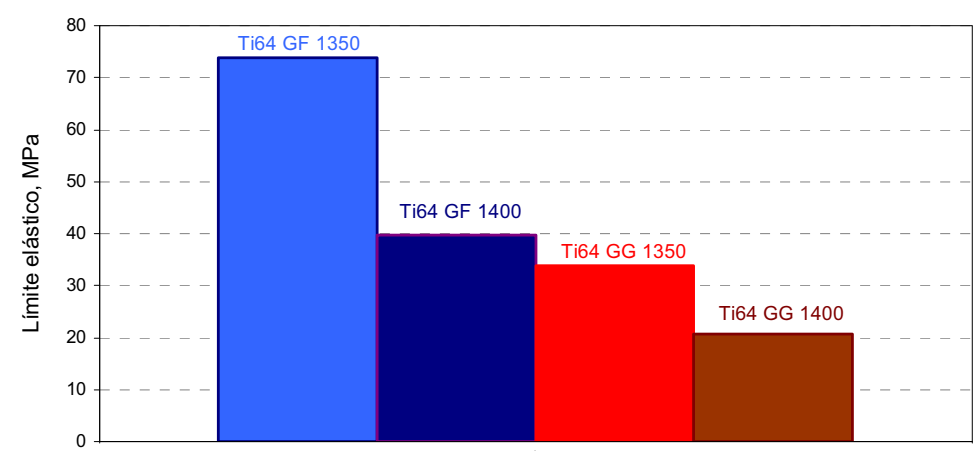

Fig. 5.20. R. Flexión microesferas sinterizadas en alúmina a 1400 y $1350{ }^{\circ} \mathrm{C}, 2$ horas.

Concretamente, a 2 horas el límite elástico obtenido para la granulometría fina a temperatura de $1350^{\circ} \mathrm{C}$ es del orden de 2 veces el obtenido a 1400 ${ }^{\circ} \mathrm{C}\left(\frac{\sigma_{\mathrm{y}}\left(1350^{\circ} \mathrm{C}\right)}{\sigma_{\mathrm{y}}\left(1400^{\circ} \mathrm{C}\right)} \approx 2\right)$; mientras que en la granulometría más grosera la relación es de aproximadamente de 1,6.

En relación al resto de parámetros, la resistencia obtenida sigue la misma tendencia que en las piezas sinterizadas en moldes de gres, pues resulta superior cuanto más finas son las microesferas (debido a su mayor superficie específica), y se obtiene el máximo para tiempos cortos, a partir del cual varía poco, figura 5.21. Cabe destacar que a mayor temperatura, el tiempo al que se obtiene la resistencia máxima es menor. 


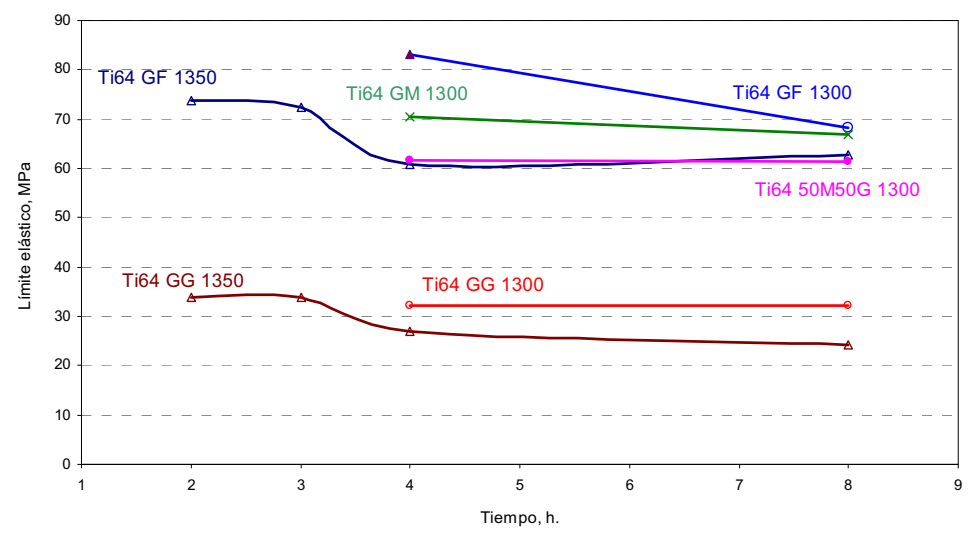

Fig. 5.21. R. Flexión de microesferas sinterizadas en moldes de $\mathrm{Al}_{2} \mathrm{O}_{3}$ a 1300 y 1350 ${ }^{\circ} \mathrm{C}$.

Tal como se observa, la temperatura resulta mucho más determinante que el tiempo de sinterización, observándose mayor variación de las propiedades resistentes cuanto más finas son las microesferas, lo que se debe a su mayor superficie específica [Leander 2002, German 1989].

Al comparar las propiedades obtenidas en moldes de gres y alúmina, se observa mayor variación en los primeros, siendo la diferencia mucho más notable cuanto más finas las microesferas. Para un mismo ciclo térmico $\left(1400{ }^{\circ} \mathrm{C}, 2 \mathrm{~h}\right)$, las propiedades mecánicas obtenidas resultan superiores sinterizando en moldes de gres, figura 5.22. No obstante, a menor temperatura $\left(1350^{\circ} \mathrm{C}\right)$ la resistencia obtenida en moldes de alúmina aumenta, provocando que las propiedades mecánicas de las piezas sinterizadas en ambos tipos de moldes, gres y alúmina, resulten comparables. 


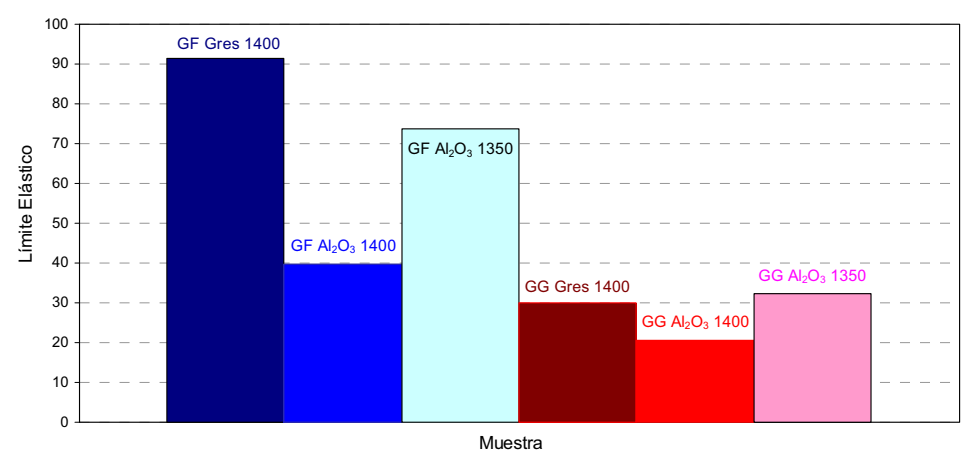

Fig. 5.22. Resistencia a flexión de las microesferas de Ti64 de GF y GG, sinterizadas en gres y $\mathrm{Al}_{2} \mathrm{O}_{3}$, a 1350 y $1400^{\circ} \mathrm{C}, 2 \mathrm{~h}$.

\subsubsection{Reactividad con los moldes de circona.}

La reactividad con los moldes de circona $\left(\mathrm{ZrO}_{2}\right)$ depende fundamentalmente de la temperatura y tiempo de sinterización. Así, a $1300^{\circ} \mathrm{C}$ y tiempos cortos (2h), se observa una rotura dúctil, similar a la mostradas por las sinterizadas en itria, véase apartado 5.3.1.1. No obstante, al aumentar el tiempo de sinterización de 2 a 8 horas, aumenta la fragilidad, especialmente en la zona de contacto con el molde cerámico, figura 5.23.

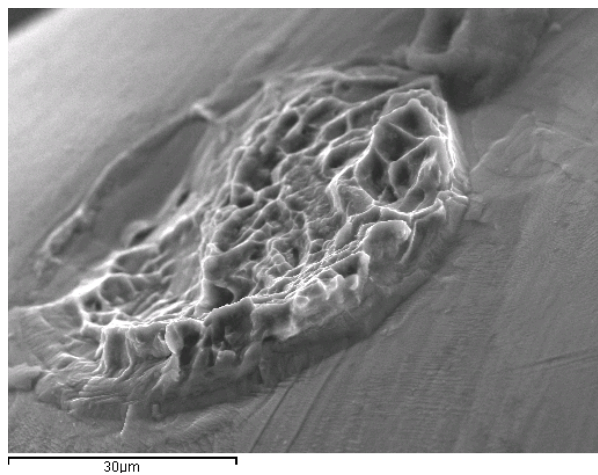

a

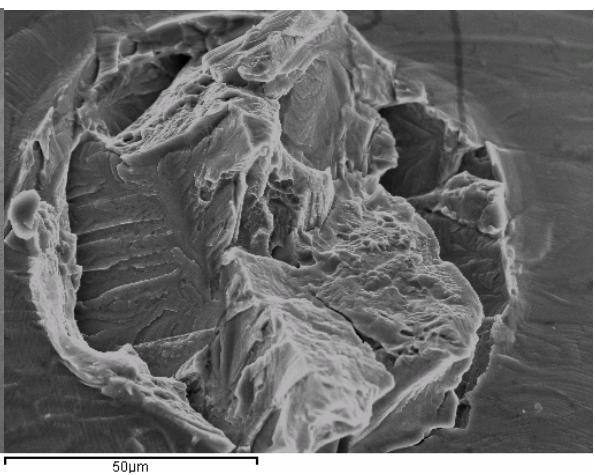

b

Fig. 5.23. Microesferas de Ti64 GG sinterizadas en molde de circona: a) $1300^{\circ} \mathrm{C}, 2 \mathrm{~h}$; b) $1400^{\circ} \mathrm{C}, 8 \mathrm{~h}$. 
Por otra parte, en las muestras sinterizadas a tiempos largos (8 horas) y/o mayor temperatura $\left(1400{ }^{\circ} \mathrm{C}\right)$, se observa variación en la morfología superficial de las microesferas, figura 5.24. Este efecto se produce casi en la totalidad de las microesferas en contacto con el molde.

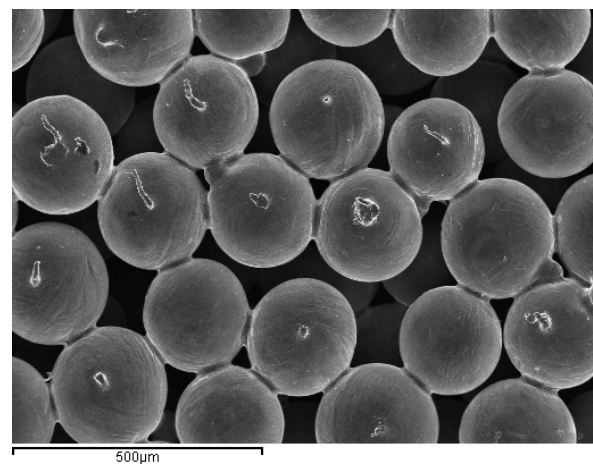

a

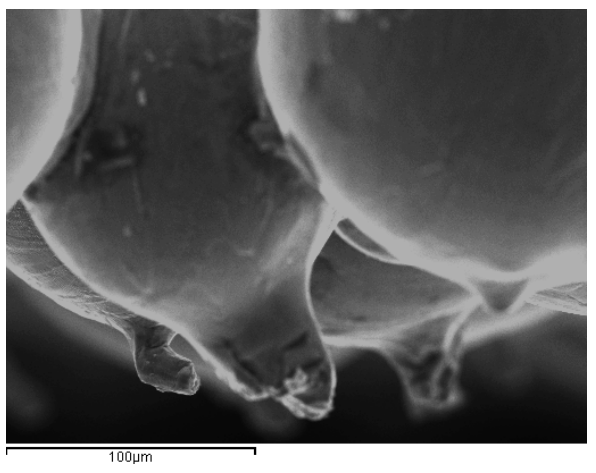

b

Fig. 5.24. Microesferas de Ti64, GF, sinterizadas en moldes de circona a $1400{ }^{\circ} \mathrm{C}$, durante $8 \mathrm{~h}$, zona molde: a) Vista frontal; b) Vista lateral.

Pese a que los análisis realizados no revelan presencia de elementos ajenos a la aleación Ti64, las muestras que manifiestan dicha deformación presentan una rotura frágil, figura 5.25 .

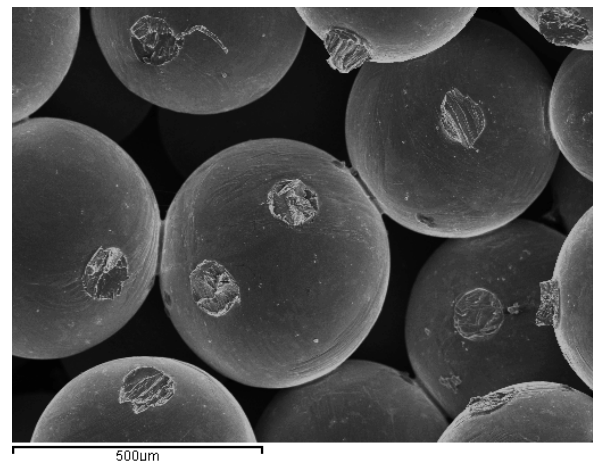

a

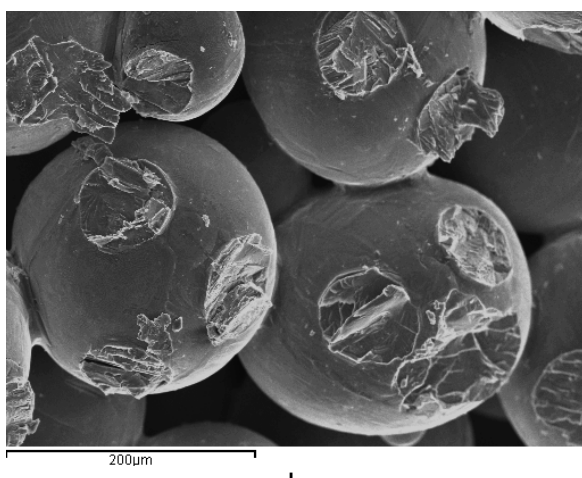

b

Fig. 5.25. Microesferas de Ti64, GF, sinterizadas en moldes de circona a $1400^{\circ} \mathrm{C}$, durante 8h; a) GG; b) GF.

Cabe indicar que, debido a la ligereza, la presencia de elementos intersticiales como el $\mathrm{O}_{2}$ resulta difícil de detectar mediante EDX. A pesar de ello, a nivel comparativo los análisis si revelaron cierto incremento en 
oxígeno en la zona de reacción $(0,42 \% A ́ t)$ en relación a las muestras que no presentaban tal modificación ( $0,2 \%$ Át) lo que, en el caso del titanio, modificaría en gran medida sus propiedades, véase apartado 2.1.1 [Baeslack 1993, Tarín 1999].

Por tanto, pese a que convendría concretar la absorción de oxígeno mediante análisis de elementos, a diferencia de los moldes de alúmina, al sinterizar sobre $\mathrm{ZrO}_{2}$ la fragilización no viene determinada por la formación de compuestos intermetálicos, sino por la absorción de elementos intersticiales como el $\mathrm{O}_{2}$.

Estos resultados son corroborados por Smeacetto et al. [Smeacetto 2007], cuyos estudios demuestran que al colar titanio sobre moldes de $\mathrm{ZrO}_{2}$ se produce la denominada " $\alpha$-case", figura 5.26, que fragiliza enormemente el material.

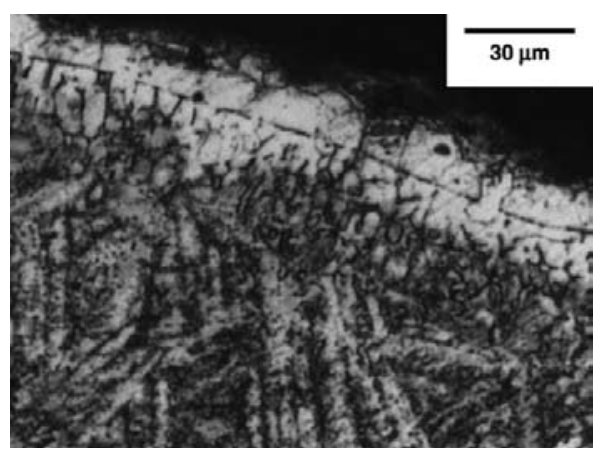

Fig. 5.26. "a-case" formada durante la colada de TiCP en moldes de $\mathrm{ZrO}_{2}$ [Tomado de Smeacetto 2007].

A pesar de todo, las propiedades de las piezas sinterizadas en estos moldes resultaron superiores a las obtenidas sobre alúmina, figuras 5.27 y 5.28 . Resulta destacable el comportamiento homogéneo de las muestras sinterizadas en circona pues, a excepción de la resistencia anormalmente elevada de las piezas sinterizadas a $1350^{\circ} \mathrm{C}$ durante $4 \mathrm{~h}$, se produce un incremento de resistencia con el tiempo de sinterización. 


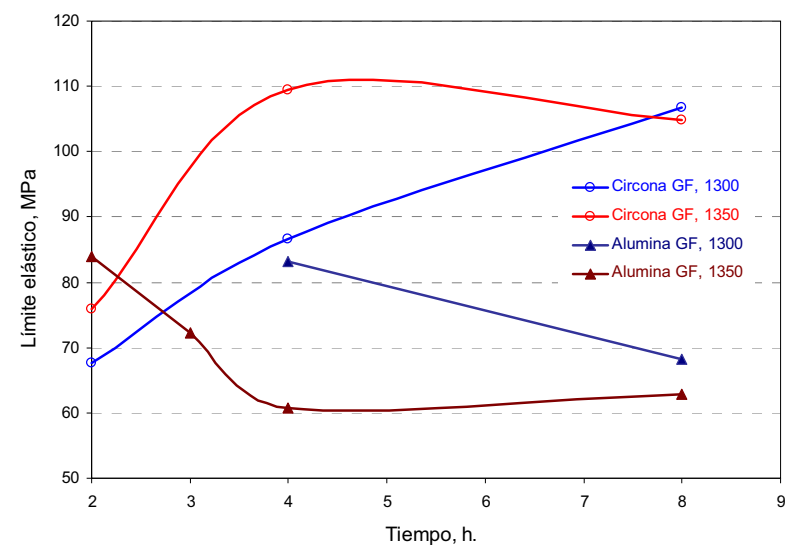

Fig. 5.27. R. Flexión de piezas porosas obtenidas con microesferas GF, sinterizadas en moldes de alúmina y circona.

Si bien para tiempos cortos, $2 \mathrm{~h}$, la resistencia llega a ser incluso superior al emplear moldes de alúmina, la tendencia se invierte rápidamente. Así, para ciclos de 8 horas la resistencia obtenida en moldes de circona resulta casi el doble respecto a la desarrollada en alúmina.

Esta misma tendencia se observa en las microesferas más groseras. En este caso se observa como la resistencia desarrollada al emplear moldes de alúmina no aumenta a partir de 4 horas, mientras que en los moldes de circona ésta si se sigue desarrollando, figura 5.28 .

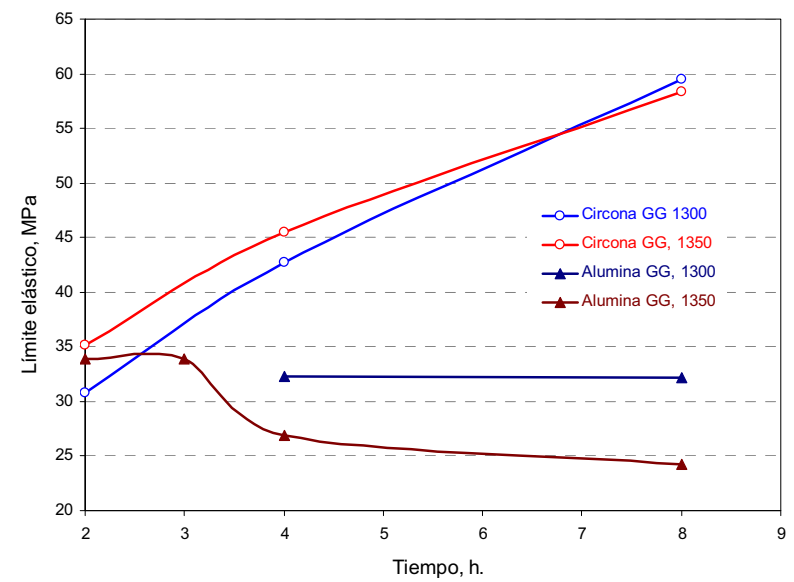

Fig. 5.28. R. Flexión de piezas porosas obtenidas con microesferas GG, sinterizadas en moldes de alúmina y circona. 
No obstante, tal como se verá en el apartado 5.3.4, estas propiedades resultan inferiores en relación a las piezas sinterizadas sobre itria.

\subsubsection{Reactividad con los moldes de $\mathrm{Y}_{2} \mathrm{O}_{3}$.}

La mayoría de las piezas sinterizadas en moldes recubiertos de itria presentan morfología esférica al contacto con el molde, figura 5.29a, no observándose las modificaciones detectadas al sinterizar en gres, alúmina o circona. Pese a ello, en determinadas piezas quedan algunas zonas con restos del recubrimiento de itria, lo que conlleva la formación de zonas planas, figura 5.29b, igual que sucedía al emplear moldes de alúmina, figura 5.14 , lo que podría influir sobre las propiedades mecánicas de la pieza porosa.

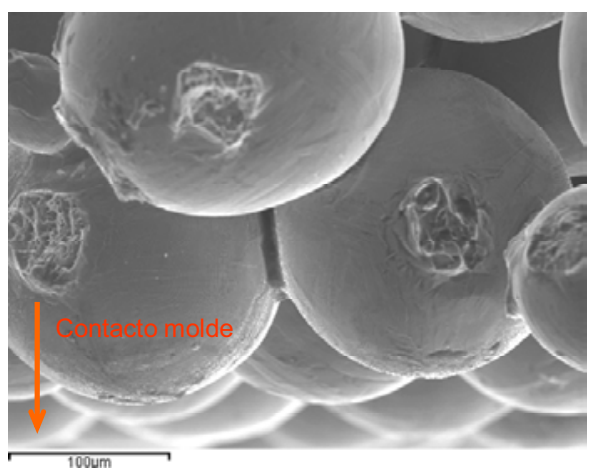

a

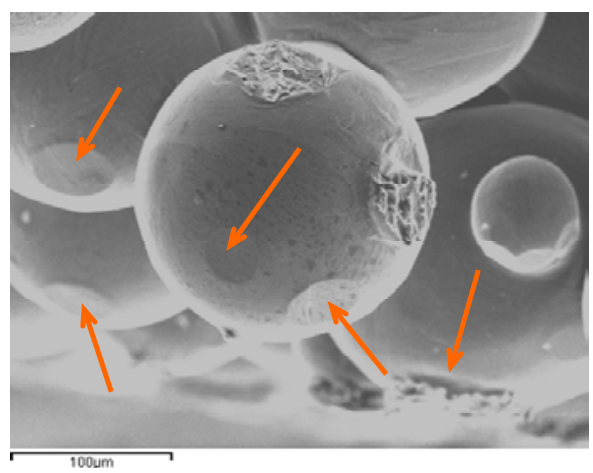

$\mathrm{b}$

Fig. 5.29. Micrografía MEB de microesferas de Ti64 GF sinterizadas en molde recubierto de $\mathrm{Y}_{2} \mathrm{O}_{3}$, a $1350{ }^{\circ} \mathrm{C}, 8$ horas. a) Sin restos de recubrimiento b) Con restos de recubrimiento.

A pesar de ello, al tratarse únicamente de un recubrimiento, y no de un molde cerámico como tal, en ocasiones, especialmente para temperaturas elevadas $\left(1400^{\circ} \mathrm{C}\right)$ y tiempos largos (> 8 horas), se observó cierto pegado de la itria a la pieza sinterizada, manifestándose como una adherencia de ésta hacia el interior de la pieza, figura 5.30. 


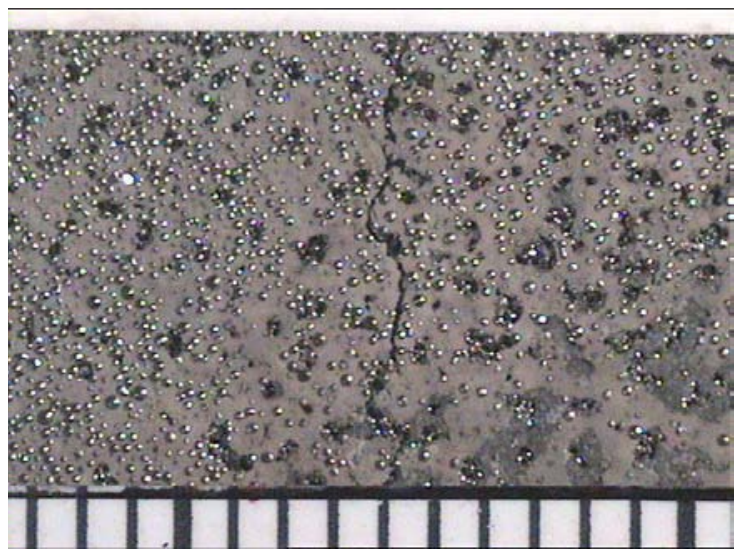

Fig. 5.30. Estereomicroscopía de la rotura a flexión de una pieza de Ti64, 50M50G obtenida por sinterización de microesferas en moldes recubiertos de $\mathrm{Y}_{2} \mathrm{O}_{3}$, a 1350 ${ }^{\circ} \mathrm{C}, 8 \mathrm{~h}$.

En definitiva, al incrementar la duración del ciclo o elevar la temperatura, el riesgo de atravesar la capa de itria y reaccionar con la alúmina del molde aumenta. En ocasiones se trata de una simple adherencia de la itria, figura 5.31, que no modifica la composición ni afecta a las propiedades mecánicas del sinterizado. En otras piezas, las microesferas llegan a reaccionar con la alúmina subyacente, figura 5.32 , lo que provoca pérdidas de hasta el $50 \%$ de la resistencia a flexión.

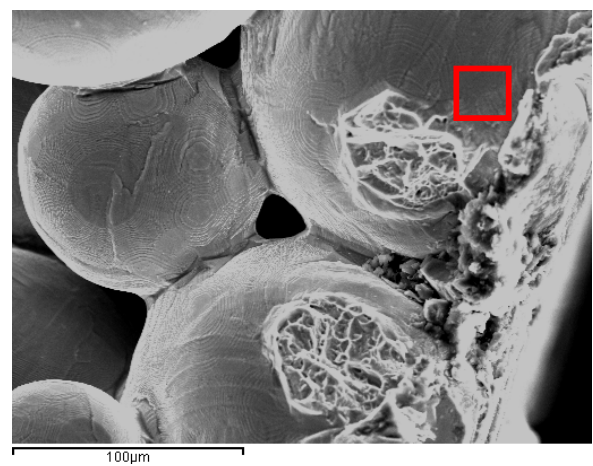

\begin{tabular}{|c|l|c|c|c|}
\cline { 2 - 5 } \multicolumn{2}{c|}{} & Al & V & Ti \\
\hline \multirow{2}{*}{ ESPEC. 1} & $\% \mathrm{Wt}$ & 6,76 & 4,08 & 89,20 \\
\cline { 2 - 5 } & $\%$ Át & 11,43 & 3,65 & 84,94 \\
\hline
\end{tabular}

Fig. 5.31. Zona de contacto con el molde de microesferas sinterizadas en molde recubierto de itria, a $1350^{\circ} \mathrm{C}$ durante 8 horas. Granulometría fina. a) Micrografía; b) Análisis EDX. 


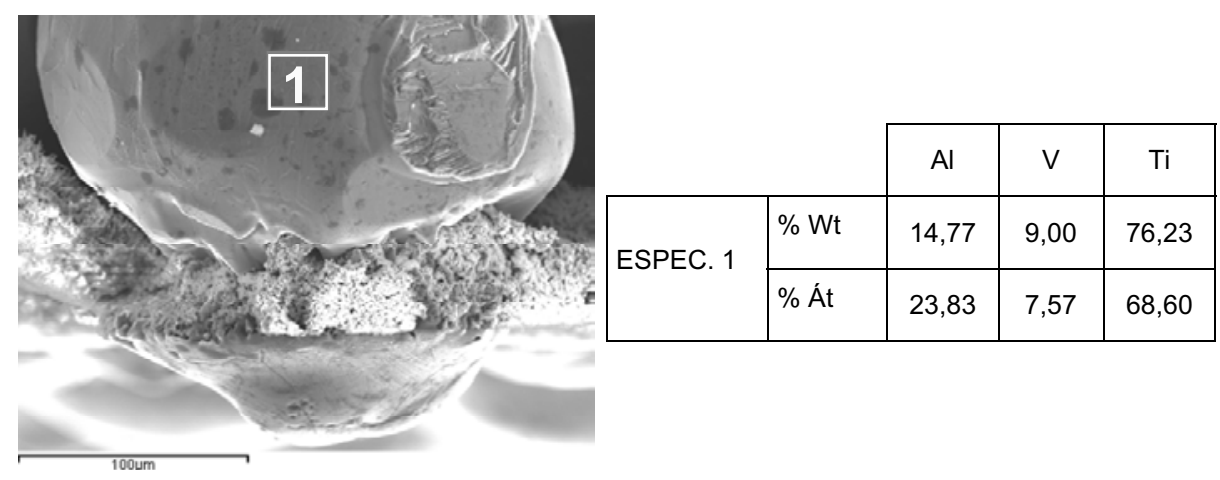

Fig. 5.32. Microesferas de Ti64 50M50G sinterizadas en molde recubierto de $\mathrm{Y}_{2} \mathrm{O}_{3}$, a $1400{ }^{\circ} \mathrm{C}, 8$ horas. Micrografía MEB y análisis EDX de la zona de contacto con el molde.

Dado que las propiedades mecánicas de las piezas sinterizadas sobre itria se estudiaron con mayor amplitud, los resultados se expondrán en la caracterización de las piezas porosas obtenidas (véase apartado 5.3), junto al estudio de otras propiedades como su rigidez y porosidad.

\subsubsection{Microdureza.}

El análisis de microdureza resultó coherente con los resultados previos obtenidos. Así, al sinterizar sobre gres se observa como, pese a que a 1300 ${ }^{\circ} \mathrm{C}$ se produce un aumento de dureza entre microesferas no sinterizadas y sinterizadas, el incremento es mucho más notable al incrementar $100^{\circ} \mathrm{C}$ más la temperatura, figura 5.33, lo que corrobora el hecho de que la reactividad del titanio es exponencial con la temperatura [Tarín 1999, Leyens 2003]. 


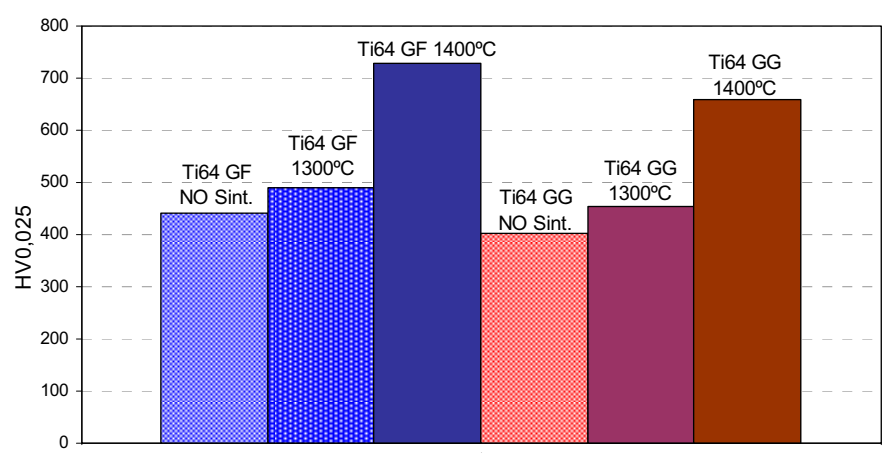

Fig. 5.33. Microdureza microesferas Ti64, de partida y en contacto con el molde de gres, sinterizadas durante 8 horas, a 1300 y $1400^{\circ} \mathrm{C}$.

En concordancia con el análisis microestructural y EDX realizado, se observa un endurecimiento máximo al sinterizar en moldes de alúmina, mientras que el recubrimiento de itria produce incluso un ablandamiento de éstas, figura 5.34. Este último fenómeno viene justificado tanto por la ausencia de reacción con la itria, como por el enfriamiento lento (recocido) que se produce en el horno de vacío que, tal como se verá en el apartado 5.3.1.1, provoca un engrosamiento del grano con la consecuente reducción de dureza [ASM N4 1994, Callister 2005].

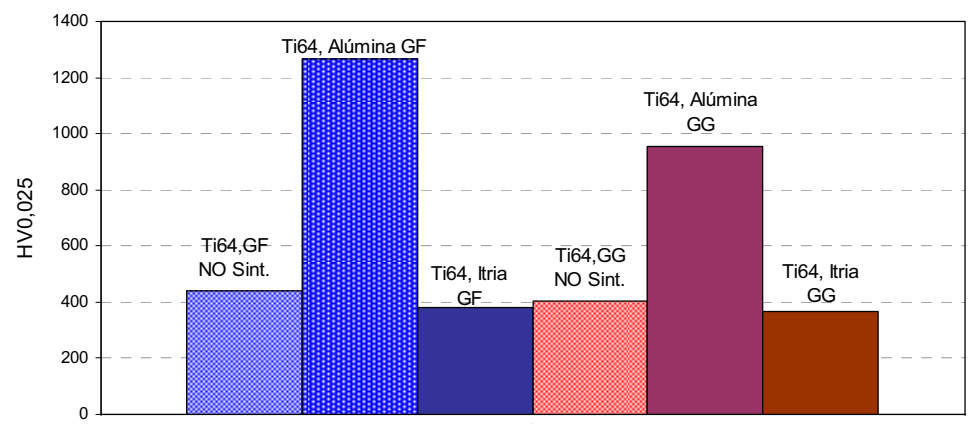

Fig. 5.34. Microdureza microesferas Ti64, de partida y en contacto con el molde. Sinterizadas en itria y alúmina a $1350^{\circ} \mathrm{C}, 8$ horas.

Por otra parte, pese a que al sinterizar en moldes de alúmina se observó una notable diferencia entre las microesferas de contacto con el molde y las del centro de la sección, se produce todavía cierto endurecimiento de estas últimas en relación al material de partida, figura 5.35. 


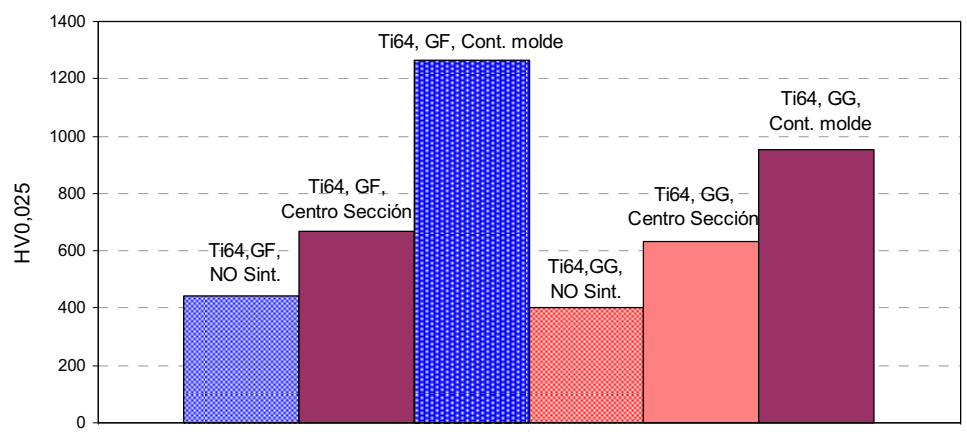

Fig. 5.35. Microdureza microesferas Ti64, de partida, en el centro de la sección y al contacto con el molde de alúmina, sinterizadas $1350^{\circ} \mathrm{C}, 8$ horas.

Como conclusión, estos resultados corroboran el análisis de la contaminación con los distintos moldes empleados y son acordes con las propiedades mecánicas de las piezas porosas obtenidas, pues el endurecimiento generado es producto de la reactividad del titanio con cada uno de los moldes utilizados, lo que provoca su fragilización y la consecuente pérdida de propiedades mecánicas.

5.2.1.6 Discusión y conclusiones parciales de la reactividad del titanio con los distintos moldes empleados.

Los resultados obtenidos ponen de manifiesto una contaminación severa al contacto con los moldes de gres y alúmina, siendo ésta menor en los moldes de circona y casi inexistente cuando se recubren con itria.

Mientras que en las piezas sinterizadas en moldes de gres se observa un incremento de elementos típicos de las arcillas, como $\mathrm{Si}$, además de la fusión parcial de las esferas en contacto con el molde; al sinterizar en moldes de $\mathrm{Al}_{2} \mathrm{O}_{3}$ las microesferas incrementan notablemente el contenido en $\mathrm{Al}$, al tiempo que sufren cierta modificación de su morfología esférica inicial y reducción del número de cuellos de unión formados entre ellas.

Según distintos estudios realizados [Wang 1998, Kim 2002, García 2006, Smeacetto 2006, Kostov 2006], la reactividad entre el titanio y el material que conforma el molde depende, entre otros, de la energía libre estándar de 
formación de éste último a cada temperatura, $\left(\Delta \mathrm{G}_{\mathrm{f}}^{\circ}\right)$. Así, según Kostov et al. [Kostov 2006], a temperaturas de 1300 a $1400{ }^{\circ} \mathrm{C}$, la variación de la energía libre de Gibbs de diferentes moldes cerámicos da un valor mínimo (máxima estabilidad) para la itria, seguida de la alúmina y la circona, siendo los óxidos de calcio y silicio, típicamente presentes en las arcillas, los menos estables, figura 5.36 [Kim 2002, Kostov 2006]. Por otra parte, cabe remarcar que este valor resulta menos negativo $\mathrm{y}$, por tanto denota menor estabilidad de los óxidos y mayor estabilidad del elemento puro [Muñoz 2005], a medida que aumenta la temperatura de sinterización.

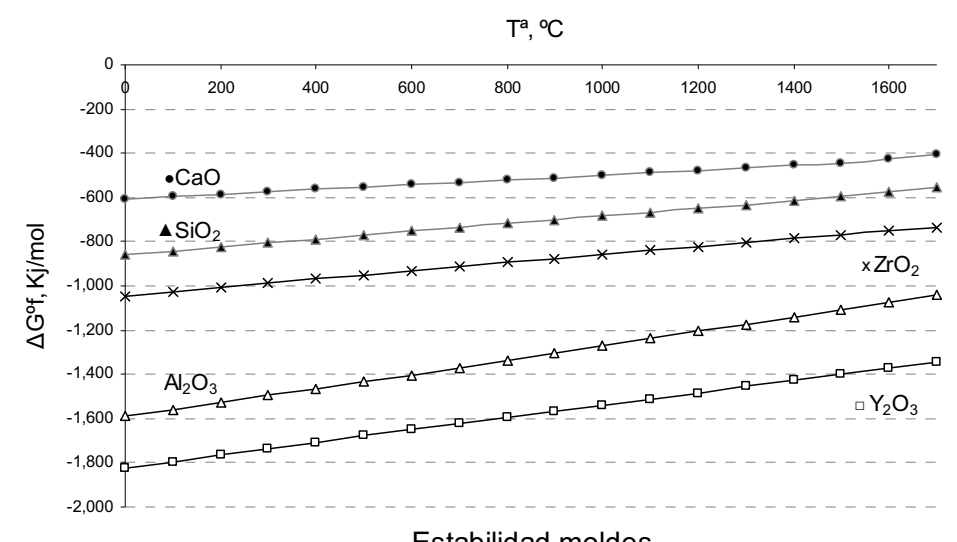

Fig. 5.36. Energía estándar de formación de distintos óxidos empleables como molde cerámico [Adaptado de Kostov 2006].

Por otra parte, la estabilidad del molde al contacto con el titanio depende de la energía libre de formación de sus respectivos óxidos, cuya evolución con la temperatura se recoge en la figura 5.37 para el titanio y los distintos materiales empleados como molde en la presente investigación. 


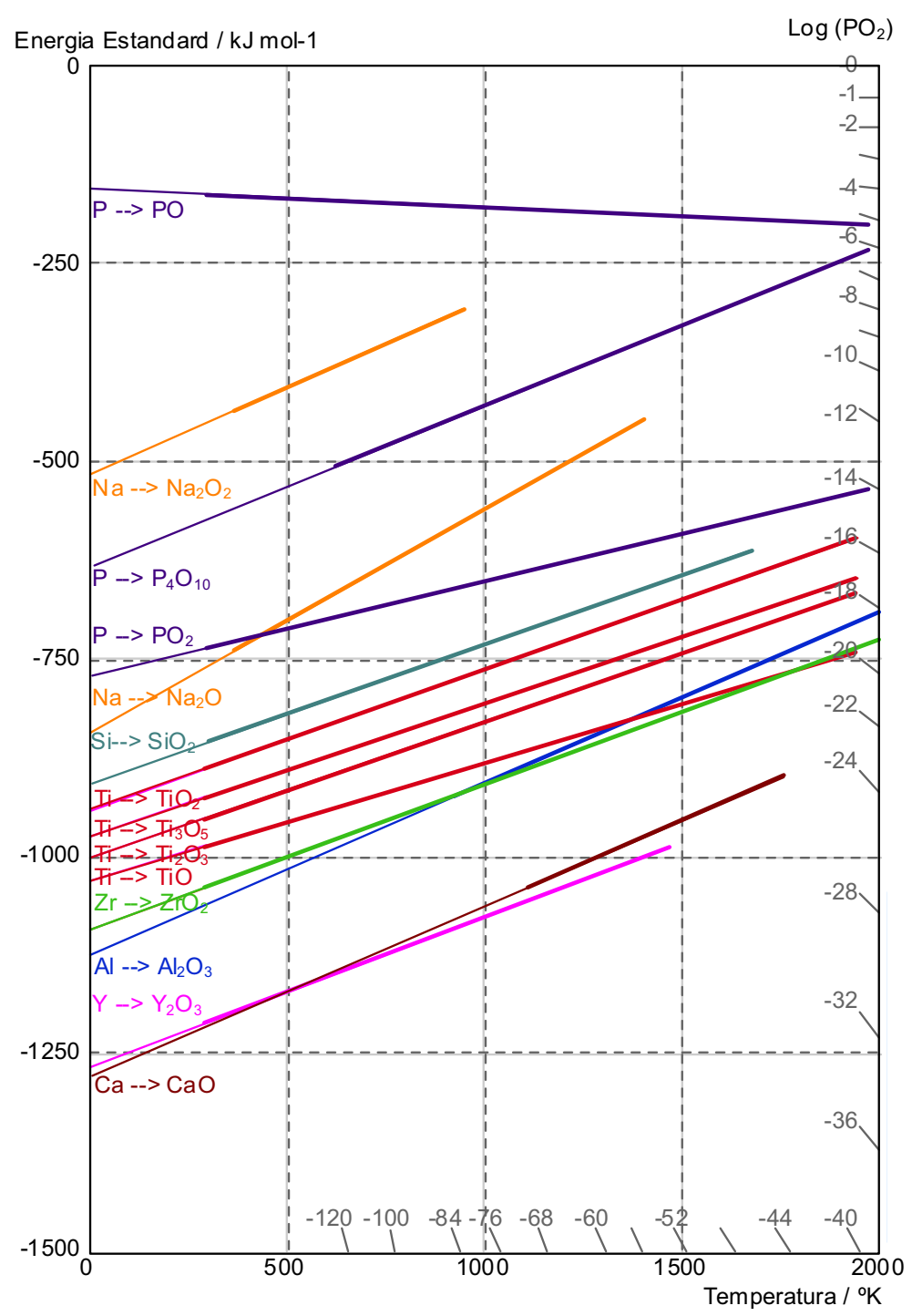

Fig. 5.37. Diagrama de Ellingham variación de la energía libre de óxidos de titanio y óxidos que componen los moldes utilizados. $\mathrm{T}\left({ }^{\circ} \mathrm{C}\right)=\mathrm{T}\left({ }^{\circ} \mathrm{K}\right)-273$. [Adaptado de "Interactive Ellingham diagram" de la Universidad de Cambridge].

Tal como se observa, según estos datos la circona presenta una estabilidad similar a la alúmina y, pese que ambas líneas se entrecruzan con la del titanio, en el caso de la $\mathrm{ZrO}_{2}$ esto ocurre a temperatura más elevada (entorno a $1220^{\circ} \mathrm{C}$ frente a los 1100 de la $\mathrm{Al}_{2} \mathrm{O}_{3}$ ). Por otro lado, los óxidos de $\mathrm{Si}, \mathrm{P}$ y $\mathrm{Na}$ resultan muy inestables en comparación con los de titanio, 
mientras que la itria presenta la máxima estabilidad, situándose por debajo de los óxidos de titanio para cualquier temperatura de sinterización. Es de gran interés señalar las diferencias en relación al $\mathrm{CaO}$, pues mientras Kostov y colaboradores [Kostov 2006] lo apuntaban como el material más inestable, según el diagrama de la universidad de Cambridge presentaría una estabilidad similar a la itria.

Asimismo, el gráfico corrobora la mayor reactividad observada con la temperatura, pues cuanto mayor resulta ésta, menor el valor absoluto de la energía libre de los distintos óxidos y, por tanto, menor estabilidad del molde utilizado [Muñoz 2005].

Estas observaciones son corroboradas por diversos autores, como Kim et al. [Kim 2002], según los cuales los moldes cerámicos de $\mathrm{ZrO}_{2}, \mathrm{Al}_{2} \mathrm{O}_{3}$ y $\mathrm{CaO}$ deberían presentar una estabilidad suficiente para ser empleados en la sinterización de titanio. De igual modo, otros autores [Wang 1998, Kostov 2006] coinciden en que materiales típicamente empleados para la fabricación de moldes como el $\mathrm{SiO}_{2}$ o el $\mathrm{P}_{2} \mathrm{O}_{5}$, serian inestables para el titanio, pues son fácilmente reducidos por éste para formar óxidos [Wang 1998].

A pesar de todo, resulta de vital importancia destacar como la estabilidad del molde no depende únicamente del material y temperatura, sino que también resulta fundamental la composición de la aleación y la solubilidad de los elementos metálicos que conforman la cerámica en el titanio [Kostov 2006, Smeacetto 2006]. Resulta necesario indicar que los cálculos termodinámicos empleados para la representación de los diagramas de Ellingham asumen la existencia del metal en estado puro, por lo que sería necesario considerar el efecto de los elementos aleantes, pues modifican la energía libre del metal [Cambridge]. No obstante, estos diagramas sirven como referencia.

El estudio termodinámico realizado por Kostov [Kostov 2006] muestra las estimaciones realizadas para el caso concreto de la aleación Ti6Al4V. Los 
resultados, figura 5.38, indican la variación de energía libre de la reacción, $\Delta G r$, de forma que valores positivos significan que el óxido permanecerá estable y, por tanto, no se disolverá al contacto con la aleación.

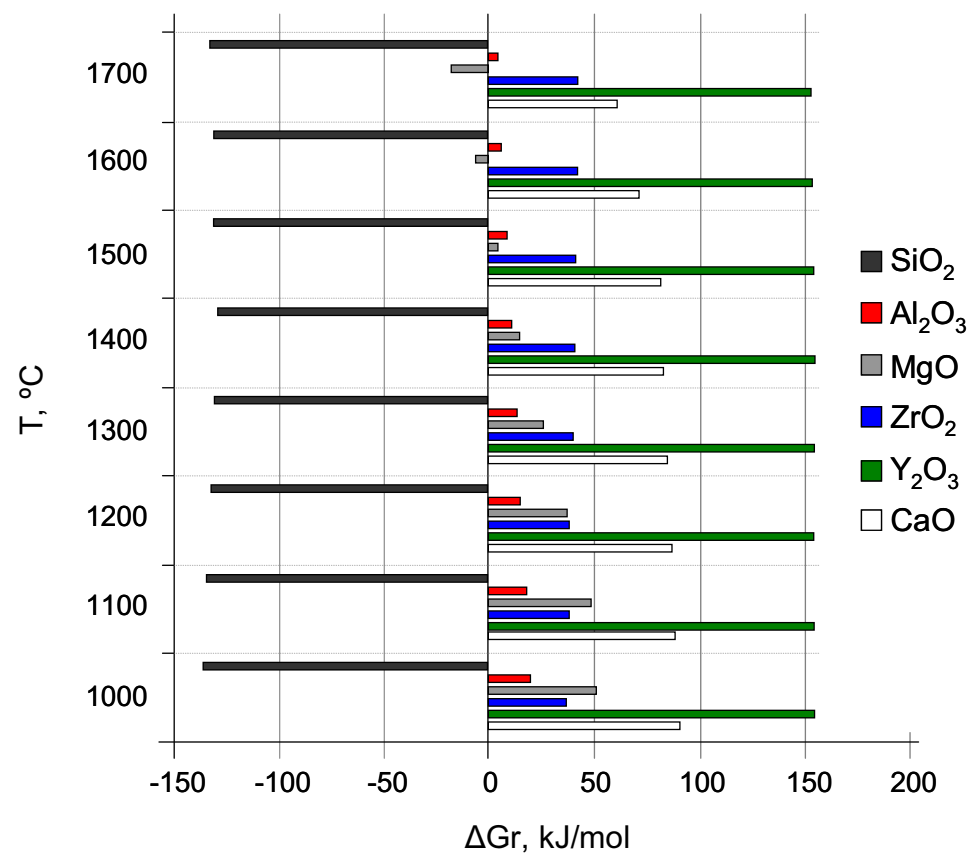

Fig. 5.38. Estimación de la $\Delta \mathrm{Gr}$ para diferentes cerámicas en contacto con Ti6Al4V.

Por tanto, al contacto con la aleación de Ti6Al4V la alúmina presenta mayor inestabilidad de la que cabria esperar según su energía de formación $\left(\Delta \mathrm{G}_{\mathrm{f}}^{\circ}\right)$, figura 5.37, siendo más inestable a medida que aumenta la temperatura. Dado que la itria se empleó como un mero recubrimiento, ello justifica el hecho de que a temperaturas elevadas las microesferas traspasen la capa de itria para reaccionar con la alúmina del molde. En este sentido, existen estudios [Smeacetto 2006, Smeacetto 2007] en los que, mediante el recubrimiento tanto del crisol como del molde cerámico con una barbotina de itria, se minimizó la reactivad de forma muy considerable y con mayor eficiencia y estabilidad respecto a la simple deposición con pincel empleada en nuestra investigación. 
Por otra parte, según Kostov [Kostov 2006], al contacto con la aleación Ti6Al4V el $\mathrm{CaO}$ presenta una estabilidad muy superior, que se asemeja más a la prevista según el diagrama Ellingham de la Universidad de Cambridge. Así, el $\mathrm{CaO}$ presentaría una estabilidad similar a la itria, por lo que su empleo podría ser objeto de una futura investigación.

Como conclusión, en la sinterización de microesferas de Ti6Al4V la máxima estabilidad se ha obtenido al recubrir los moldes con itria, mientras que la circona presenta menor reactividad en comparación con el molde de alúmina. Por tanto, mientras que la sinterización en moldes de gres y $\mathrm{Al}_{2} \mathrm{O}_{3}$ resulta del todo desaconsejable, pues en ambos casos las microesferas reaccionan de forma considerable, los moldes de circona podrían emplearse únicamente a temperaturas bajas $\left(1300^{\circ} \mathrm{C}\right)$ y tiempos cortos $(2 \mathrm{~h})$, pues en ciclos mayores se produce cierta reactividad con rotura frágil de algunas piezas. No obstante, dada la importancia de la reactividad sobre las propiedades de las piezas porosas obtenidas, convendría optimizar el recubrimiento de itria y dotarlo de mayor estabilidad.

\subsubsection{PRUEBAS PREVIAS REALIZADAS POR LA TECNICA DE ESPACIADORES.}

\subsubsection{Porosidad y observaciones al proceso de obtención.}

A lo largo del proceso de obtención de piezas porosas de titanio por la técnica de espaciadores, se observó como, tras eliminar el espaciador en estufa, las piezas con un $70 \%$ v de espaciador sufrían un considerable desmoronamiento en sus bordes.

Cabe remarcar que, dado que el presente estudio preliminar se realizó simultáneamente con el análisis de reactividad, las piezas fueron sinterizadas sobre moldes de gres lo que, tal como se ha visto (apartado 5.2.1) ocasionó contaminación. Por ello, para el desarrollo de posteriores piezas mediante la técnica de espaciadores se emplearon moldes recubiertos de itria. 
Independientemente de la reactividad, la observación al microscopio de las pruebas previas realizadas denotó la presencia tanto de poros de gran tamaño, producto de la evaporación del espaciador, como de microporos, producto del proceso pulvimetalúrgico [Bram 2005]. Cabe remarcar el efecto concentrador de tensiones ejercido por los poros que, por una parte, implica una distribución de tensiones no uniforme y, por otra, provoca una mayor variabilidad de los resultados, pues los poros se distribuyen de forma aleatoria. La concentración de tensiones en determinados puntos implica plastificación en zonas concretas, por lo que la ley de Hook no resulta aplicable en compuestos porosos [Schatt 1997, Asbhy 2000, Degischer 2002].

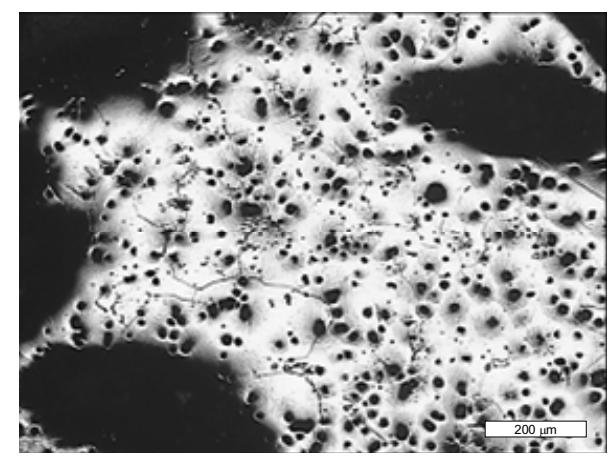

Fig. 5.39. Micrografía MO de una probeta de TiCP3 con $50 \%$ v de bicarbonato de amonio compactada a $200 \mathrm{MPa}$ y sinterizada a $1300^{\circ} \mathrm{C}$ durante $2 \mathrm{~h}$. Fracción 500 a $1000 \mu \mathrm{m}$.

Tal como se observa en la figura 5.40, mientras que determinadas muestras presentan una distribución homogénea de macroporos, en otras se produce coalescencia y segregación, de forma que aparecen aglomeraciones de poros dejados por las partículas de espaciador. Ello podría ser debido tanto a la gran diferencia de densidad entre el bicarbonato $\left(1.5 \mathrm{~g} / \mathrm{cm}^{3}\right)$ y el polvo de TiCP3 $\left(4.5 \mathrm{~g} / \mathrm{cm}^{3}\right.$ ), como a los diferentes tamaños de partícula (TiCP3 $<45 \mu \mathrm{m}$; espaciador $>250 \mu \mathrm{m}$ ).

Cabe señalar además la geometría irregular y rugosidad presentada por los macroporos, figura 5.40 , pues también generarán una mayor pérdida de resistencia para reducidas adiciones de espaciador [Degischer 2002]. Por 
otra parte, los macroporos permanecen en su mayoría aislados, lo que no permitiría el desarrollo óseo a través del volumen de la pieza.

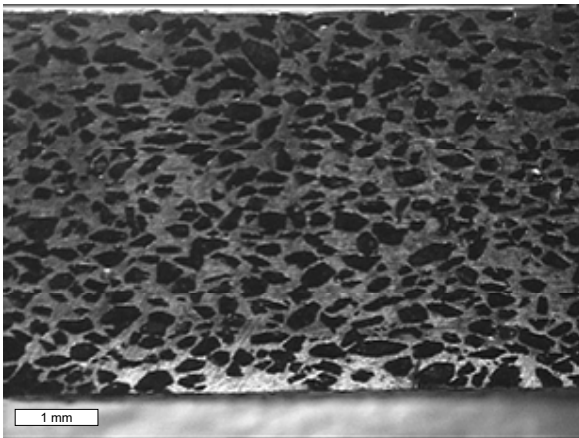

a

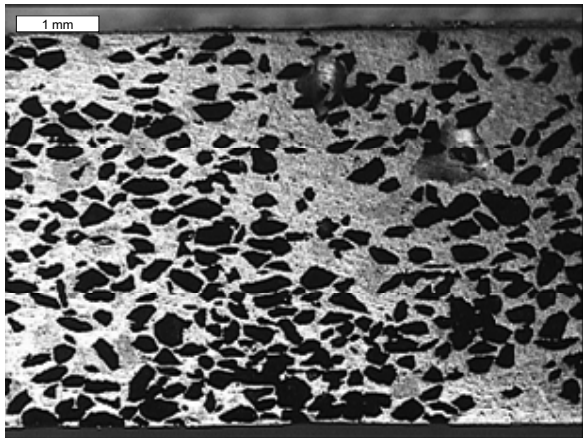

C

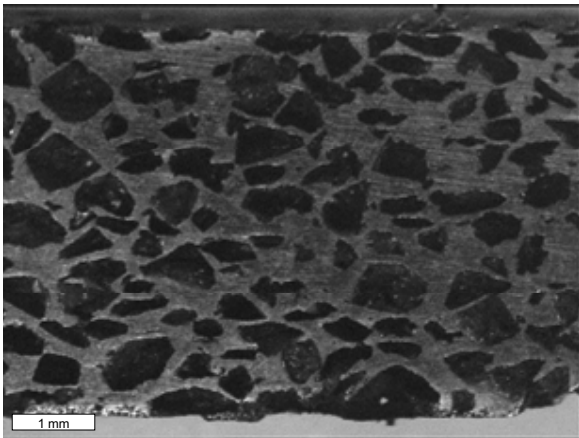

b

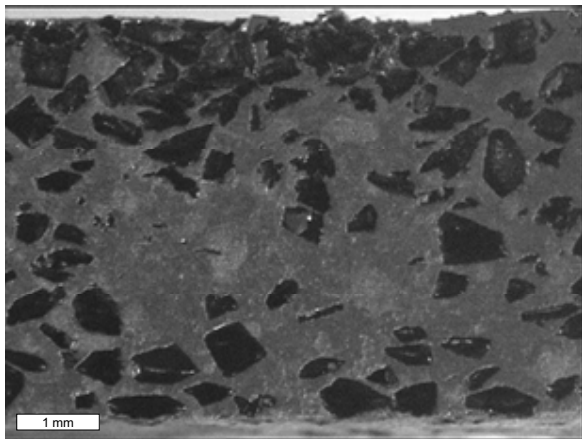

d

Fig. 5.40. Distribución de poros en piezas porosas de TiCP3: a) 30TiCP-70Bi, 250$500 \mu \mathrm{m}, 100 \mathrm{MPa}$; b) 30TiCP-70Bi, 500-1000 $\mu \mathrm{m}, 100 \mathrm{MPa}$; c); 50TiCP-50Bi, 250$500 \mu \mathrm{m}, 200 \mathrm{MPa}$ d) $50 \mathrm{TiCP}-50 \mathrm{Bi}, 500-1000 \mu \mathrm{m}, 300 \mathrm{MPa}$

En relación al nivel de porosidad obtenido, figura 5.41, como era de esperar, ésta aumenta con el contenido de bicarbonato de amonio, variando muy poco en función de la fracción granulométrica de espaciador o la presión de compactación. Por otra parte, debido a la contracción originada durante la evaporación del espaciador y sinterización de la pieza (entorno a 30\%v), la porosidad total resulta inferior a la cantidad adicionada de espaciador. Cabe destacar además que la densidad relativa $\left(\rho * \rho_{\mathrm{S}}\right)$ resulta en todos los casos superior a 0,3, figura 5.41, por lo que, de acuerdo con Ashby [Asbhy 2000], no puede hablarse propiamente de espumas, sino de piezas altamente porosas. 


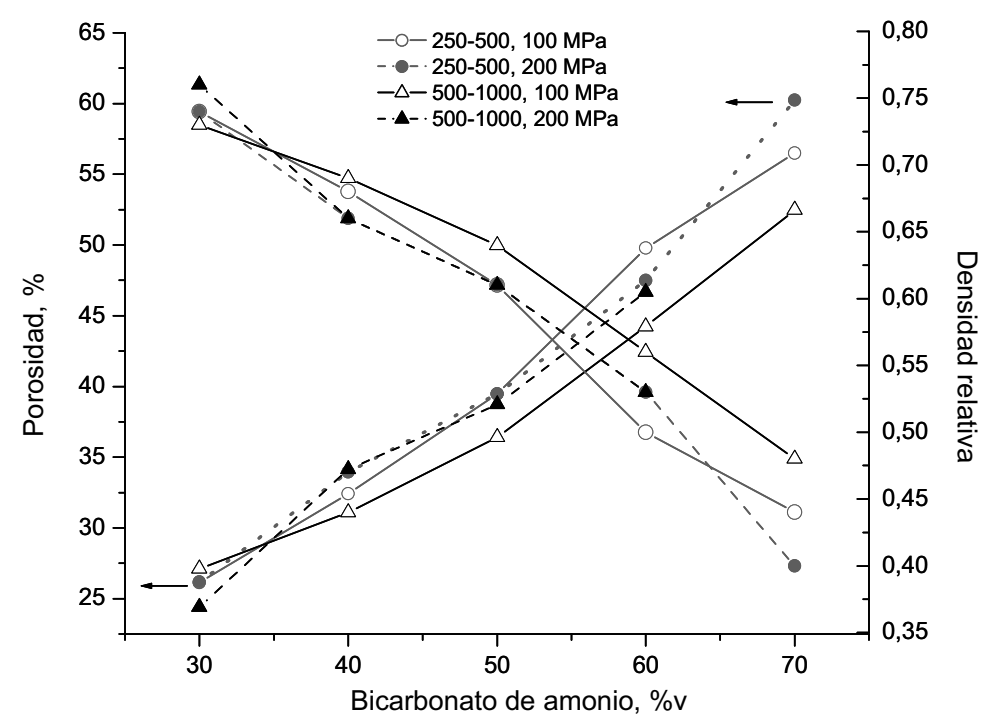

Fig. 5.41. Porosidad total y densidad relativa de piezas porosas de TiCP3 obtenidas con diferentes contenidos de bicarbonato de amonio y compactadas a 100 y 200 $\mathrm{MPa}$.

5.2.2.2 Resistencia a flexión y rigidez de las piezas porosas obtenidas.

Las propiedades mecánicas obtenidas en las pruebas previas fueron suficientes para permitir su uso como implante. Mientras que la resistencia a flexión resultó ser superior a los $100 \mathrm{MPa}$ en la mayoría de los casos, la rigidez descendió entre un 35 y $80 \%$, según porosidad de la pieza final, respecto a la presentada por las piezas sin espaciador, tabla 5.1. 
Tabla 5.1. Propiedades de las piezas porosas de TiCP3 realizadas por el método de espaciadores.

\begin{tabular}{|c|c|c|c|c|c|c|c|c|}
\hline Temp. & Tiempo, $\mathrm{h}$ & Frac. Espac., $\mu \mathrm{m}$ & $\mathrm{P}, \mathrm{MPa}$ & TiCP3-Bi, \%v & $P, \%$ & $\rho r$ & $\sigma_{\mathrm{YF}}, \mathrm{MPa}$ & $\mathrm{Er}$ \\
\hline \multirow{21}{*}{1300} & \multirow{21}{*}{ 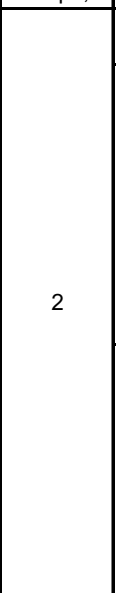 } & \multirow{2}{*}{ SIN } & 100 & \multirow{2}{*}{$100-0$} & 8,67 & 0,91 & 1317,88 & 1,00 \\
\hline & & & 200 & & 7,70 & 0,92 & 1392,10 & 1,00 \\
\hline & & \multirow{10}{*}{$250-500$} & \multirow{5}{*}{100} & $70-30$ & 26,13 & 0,74 & 489,24 & 0,62 \\
\hline & & & & $60-40$ & 32,42 & 0,68 & 347,26 & 0,60 \\
\hline & & & & $50-50$ & 39,47 & 0,61 & 320,24 & 0,54 \\
\hline & & & & $40-60$ & 49,78 & 0,50 & 223,15 & 0,35 \\
\hline & & & & $30-70$ & 56,49 & 0,44 & 148,69 & 0,23 \\
\hline & & & \multirow{5}{*}{200} & $70-30$ & 26,17 & 0,74 & 508,17 & 0,68 \\
\hline & & & & $60-40$ & 33,95 & 0,66 & 401,51 & 0,58 \\
\hline & & & & $50-50$ & 39,46 & 0,61 & 246,03 & 0,46 \\
\hline & & & & $40-60$ & 47,49 & 0,53 & 154,19 & 0,31 \\
\hline & & & & $30-70$ & 60,24 & 0,40 & 132,48 & \\
\hline & & \multirow{9}{*}{$500-1000$} & \multirow{5}{*}{100} & $70-30$ & 27,12 & 0,73 & 269,59 & 0,59 \\
\hline & & & & $60-40$ & 31,09 & 0,69 & 302,23 & 0,53 \\
\hline & & & & $50-50$ & 36,40 & 0,64 & 236,37 & 0,51 \\
\hline & & & & $40-60$ & 44,24 & 0,56 & 162,85 & 0,35 \\
\hline & & & & $30-70$ & 52,47 & 0,48 & 123,93 & 0,00 \\
\hline & & & \multirow{4}{*}{200} & $70-30$ & 24,39 & 0,76 & 352,58 & 0,58 \\
\hline & & & & $60-40$ & 34,15 & 0,66 & & \\
\hline & & & & $50-50$ & 38,74 & 0,61 & 181,06 & 0,52 \\
\hline & & & & $40-60$ & 46,68 & 0,53 & 82,50 & \\
\hline
\end{tabular}

Así, la siguiente figura representa gráficamente la variación de la resistencia a flexión de piezas porosas de TiCP3 en función de la adición de bicarbonato de amonio, figura 5.42a, y de su porosidad, figura 5.42b. Como era de esperar, la resistencia disminuye a medida que aumenta la porosidad, observándose la mayor caída entre probetas sin espaciador y con un 30\%v. De acuerdo con diversos autores [Bram 2005, Esen 2007] ello es debido a la combinación de diversos factores, como la microporosidad existente, la existencia de imperfecciones en los materiales porosos, tales como la geometría irregular y rugosidad superficial de los macroporos, así como la mayor heterogeneidad del material.

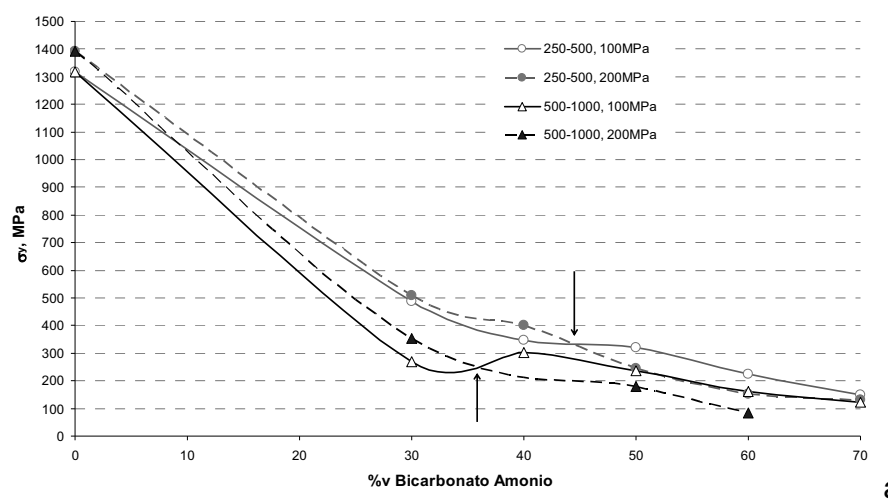




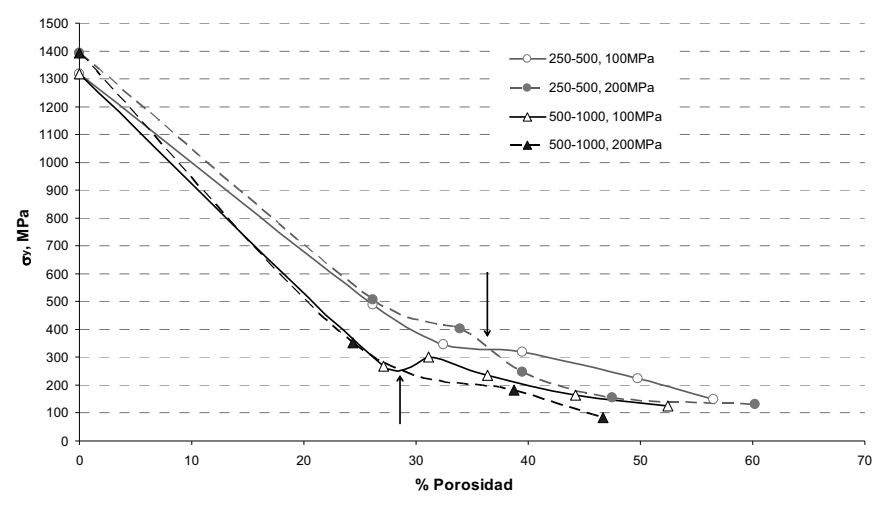

b)

Fig. 5.42. Resistencia a flexión en función de: a) Porcentaje volumétrico de bicarbonato de amonio adicionado; b) Porosidad.

Tal como se observa, para una misma presión de compactación y cantidad de espaciador, la resistencia resulta superior cuanto menor el tamaño de bicarbonato de amonio. Ello puede deberse a dos efectos relacionados pues, por una parte, partículas más pequeñas permiten una mejor distribución del titanio para conformar las paredes entre los macroporos y, por otra, las partículas más groseras son susceptibles de sufrir mayor recuperación elástica tras la compactación. Ambos efectos originan que la compresibilidad de las piezas sea menor, lo que origina una menor densidad en verde de la pieza [Uphadayaya 1997]. Cabe indicar que, pese a que tal efecto resulta poco notorio en las pruebas preliminares, resulta algo más destacable en las piezas base de la presente investigación, véase apartado 5.4 .

Por otra parte, todo ello provoca que el efecto de la presión de compactación sobre la resistencia a flexión dependa del contenido en bicarbonato. Así, con reducidas cantidades, mayor presión de compactación provoca un aumento de resistencia, debido a que aumenta la densidad en verde de la pieza, lo que favorece su sinterabilidad [Schatt 1997, German 2005]. Por el contrario, cuando la adición de espaciador supera el 35 $40 \% \mathrm{v}$, la tendencia se invierte y más presión implica menos resistencia, lo que probablemente es debido tanto a una mayor dificultad en el 
ordenamiento del polvo de Ti64, como a la mayor recuperación elástica de las partículas de espaciador a medida que aumenta la presión de compactación.

Este efecto se produce para contenidos en bicarbonato inferiores cuanto mayor el tamaño de partícula de espaciador, observándose para cantidades entorno al 35\%v para la fracción de 500 a $1000 \mu \mathrm{m}$ y entorno al $45 \%$ v para el tamaño inferior, $250-500 \mu \mathrm{m}$. Tal como se ha comentado, ello es debido a la mejor distribución del polvo de la matriz y menor recuperación elástica cuanto menor el tamaño de bicarbonato.

Por otra parte, la rigidez de estas pruebas previas se determinó mediante la pendiente de la curva tensión - deformación unitaria obtenida a flexión. Cabe indicar que en ningún caso los valores obtenidos coinciden con los valores teóricos aportados según bibliografía, en donde se indica para el TiCP un módulo elástico E = 103 GPa [Amigó 2003a], lo que podría deberse tanto a desviaciones del equipo de ensayo, como a la porosidad de las piezas obtenidas por vía pulvimetalúrgica. De acuerdo con diversos autores [Schatt 1997, Degischer 2002], los poros actúan como concentradores de tensiones, generando una distribución de éstas no homogénea a lo largo de la sección. Ello provoca la variación del módulo elástico con la tensión aplicada, por lo que la ley de Hook no resulta aplicable en materiales porosos, siendo más adecuado referirnos a rigidez de las piezas porosas obtenidas, en lugar de módulo elástico.

Por ello, y dado que se buscaba determinar la reducción de rigidez en función de la adición de bicarbonato (rigidez relativa respecto a la muestra sin espaciador), para determinar la rigidez relativa de cada muestra, $\left(E_{r}=\frac{E^{*}}{E_{S}}\right)$, se empleó como $E_{S}$ la rigidez de una muestra sin espaciador, compactada a la misma presión. En consecuencia, la rigidez relativa de las muestras sin espaciador es 1 , pese a que poseen una porosidad entorno al 
8-10\%. Finalmente, cabe indicar que en estas pruebas preliminares no se incluyeron los datos de probetas con rotura frágil.

Como era de esperar, la rigidez se reduce a medida que aumenta el contenido en bicarbonato de amonio, no observándose una tendencia concreta en relación al tamaño de espaciador. La rigidez de las piezas porosas de TiCP con un rango de porosidad entre $20-60 \%$ se reduce a un $65-20 \%$ de la presentada por la pieza sin espaciador, figura 5.43.

Al relacionar la rigidez relativa mínima obtenida $(0,22-0,30)$ con el módulo aportado en bibliografía mediante la expresión $\left(\rho^{*}=\rho_{r} \cdot \rho_{s}\right)$, se obtiene un módulo para el material poroso de TiCP entorno a 23 -31 GPa, muy próximo al del hueso cortical (12 - 27 GPa, véase apartado 2.6) [Comín 1999, Asaoka 2003, Köhl 2007], lo que resulta de vital importancia para minimizar el debilitamiento del hueso por reabsorción ósea.

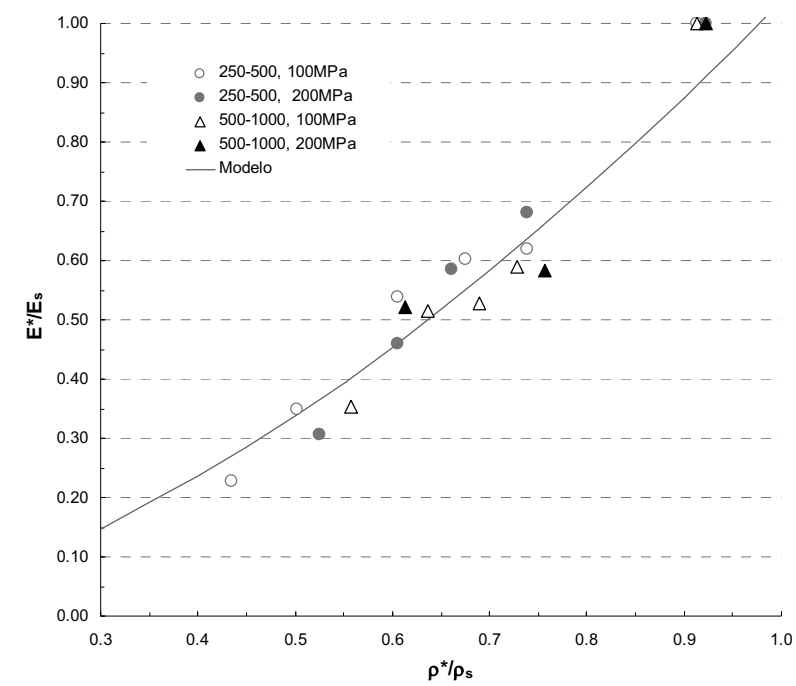

Fig. 5.43. Rigidez relativa en función de la densidad relativa. 
De acuerdo con el modelo propuesto por Gibson-Asbhy [Gibson 1999], la rigidez relativa puede relacionarse con la densidad relativa de las espumas por medio de la ecuación (5.2):

$$
\frac{E^{*}}{E_{s}}=C\left(\frac{\rho^{*}}{\rho_{s}}\right)^{n}
$$

Partiendo de nuestros datos experimentales, se obtiene un coeficiente $C$ próximo a la unidad $(1,037)$ y un exponente $n$ de 1,62 . Tal como se observa en la figura 5.43 anterior, el modelo correlaciona bien con los datos experimentales obteniéndose un $R^{2}$ de 0,86 .

La proximidad del valor $\mathrm{C}$ a la unidad es coherente, pues la ridigez de la pieza debe tender a la unidad cuando la densidad relativa se aproxima a 1. Por otra parte, las diferencias con el modelo propuesto por Gibson-Ashby [Gibson 1999], quienes obtienen un valor de 2 para el exponente, son debidas a que, si bien se han desarrollado piezas porosas, no pueden considerarse una espuma como tal, pues la densidad relativa nunca resulta inferior a 0.3 [Gibson 1999].

Por otra parte el exponente obtenido en nuestro modelo resulta bastante similar al obtenido por Bram, $n=2$ [Bram 2005], para piezas porosas de TiCP obtenidas por el mismo método pero con diferentes tamaños de espaciador y ensayando las piezas a compresión. Por el contrario, el valor resulta mucho menor en relación al aportado por Esen [Esen 2007], aunque ello es debido a que, en su trabajo, Esen empleó partículas esféricas de titanio, y eliminó el espaciador al tiempo que sinterizaba, realizando dicho proceso a $1200{ }^{\circ} \mathrm{C}$ durante 1 hora en atmósfera de $\mathrm{Ar}$, por lo que los cuellos de unión generados fueron de reducidas dimensiones, lo que provocó una mayor influencia de la densidad relativa sobre la rigidez de la pieza. 


\subsection{PIEZAS POROSAS OBTENIDAS POR SINTERIZACIÓN DE MICROESFERAS.}

Como se ha visto, existe una importante interacción con el molde empleado, lo que viene justificado por la elevada reactividad del titanio, exponencial con la temperatura [Tarín 1999, ASM N4 1994]. Los resultados expuestos a continuación son referentes a piezas sinterizadas sobre itria mayoritariamente, no obstante en determinados apartados se exponen también características de piezas sinterizadas sobre otros moldes, con el fin de comparar distintas técnicas de caracterización.

\subsubsection{CARACTERIZACIÓN MICROESTRUCTURAL.}

5.3.1.1. Microscopia óptica (MO), estereomicroscopía y Microscopia electrónica de barrido (MEB).

Independientemente de la reactividad observada con los diferentes moldes utilizados, se observa una modificación de la microestructura del material de partida en función de los parámetros temperatura y tiempo. Así, tal como se observa en la figura 5.44, la comparación entre micrografías obtenidas antes y después de la sinterización revela el paso de una estructura martensítica (producto del enfriamiento rápido de las microesferas durante su fabricación por PREP), a una estructura Widmanstätten, conformada por laminas alternadas de las fases $\alpha$ y $\beta$ [Gil 2001, Tarín 1995]. Asimismo, se observó un engrosamiento de grano proporcional al tiempo de permanencia.

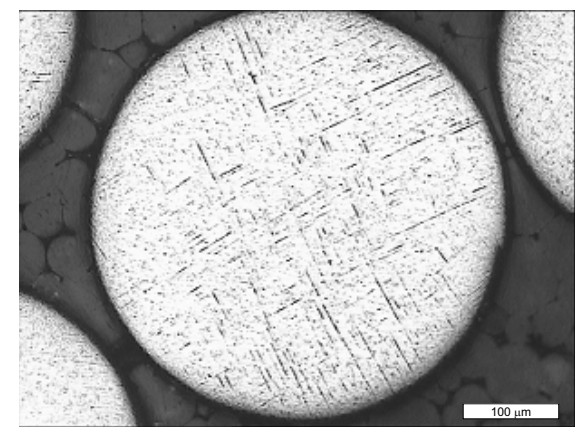

a

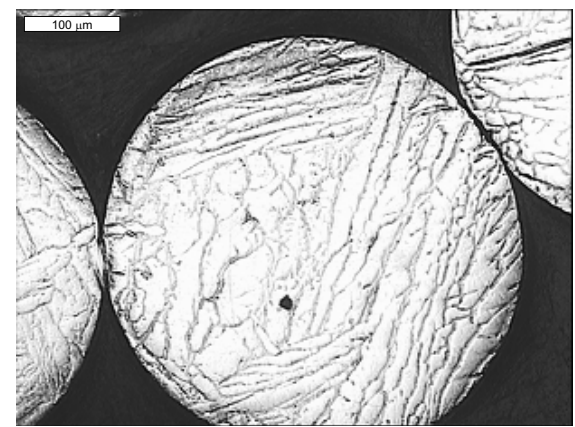

b

Fig. 5.44. MO microesferas de Ti64 GG: a) Previo a la sinterización; b) Tras sinterización en moldes de gres a $1400^{\circ} \mathrm{C}, 4$ horas. 
Del mismo modo, tal como era de esperar, para un mismo tiempo de sinterización, cuanto mayor es la temperatura, mayores resultan el engrosamiento de grano y los cuellos de unión desarrollados, figura 5.45, [German 1994, Tarín 1995, Beljavin 2004].

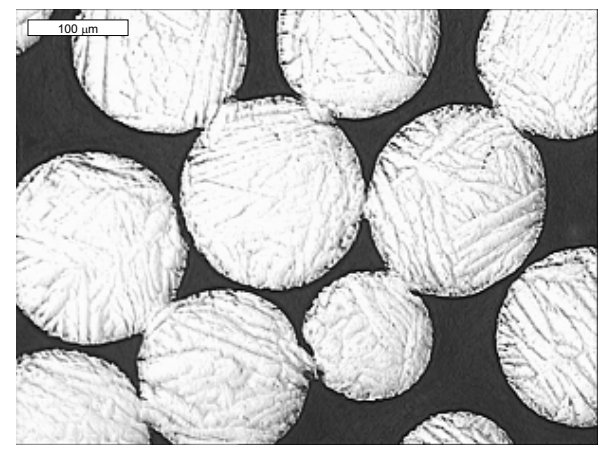

a

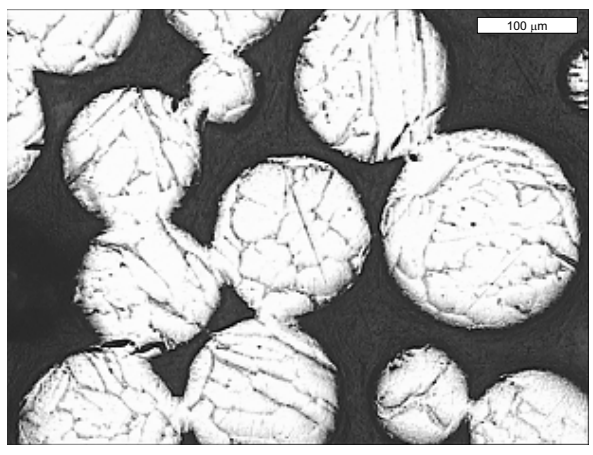

b

Fig. 5.45. MO microesferas de Ti64 GF sinterizadas durante $8 \mathrm{~h}$ a: a) $1300^{\circ} \mathrm{C}$; b) $1400^{\circ} \mathrm{C}$.

Por otra parte, a pesar del engrosamiento de grano (crecimiento de la fase $\alpha$, color claro) que se observa con la temperatura y tiempo de sinterización, el desarrollo de los cuellos de unión formados provoca que las propiedades mecánicas aumenten en ausencia de reactividad, véase apartado 5.4.4. Resulta destacable además el hecho de que los cuellos de unión siempre se forman en fase $\alpha$, interrumpiéndose las laminillas procedentes de las microesferas contiguas, (véase Anexo 1).

El estudio de la zona de rotura a flexión permitió distinguir tanto las dimensiones de los cuellos de unión generados como su forma de rotura, figura 5.46a. Así, a las temperaturas aplicadas la sinterización se produce fundamentalmente por difusión superficial y en volumen, véase apartado 5.3.3.2 [German 1994], desplazándose los átomos a las zonas de contacto con las esferas contiguas, lo que genera la evolución de las microesferas originalmente lisas y esféricas hacia morfologías poligonales, figura $5.46 \mathrm{~b}$. 


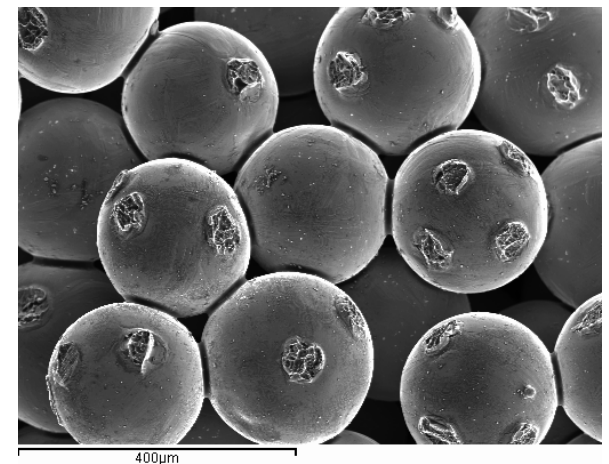

a

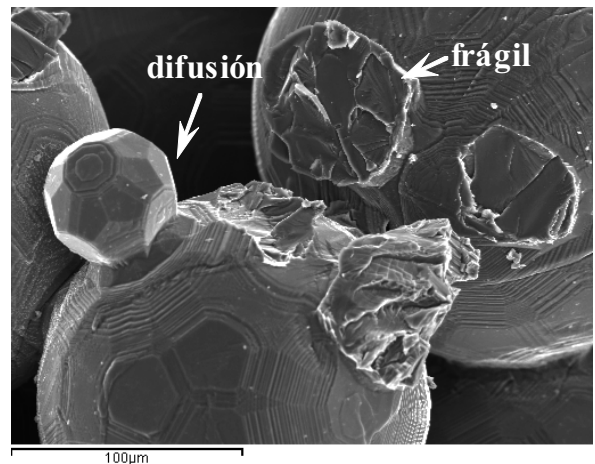

b

Fig. 5.46. Rotura a flexión de microesferas de Ti64 GF, sinterizadas a $1400^{\circ} \mathrm{C}$ : a) Sobre itria, 4 horas; b) Sobre gres, 8 horas.

Tal como se ha indicado al estudiar la reactividad, existe una diferencia notable en la forma de rotura y, por ende, la tenacidad de las piezas, en función del molde empleado, presentando las piezas sinterizadas en itria la mayor ductilidad, figura 5.47, en comparación con las sinterizadas en alúmina, figuras 5.48 , en donde se observaron las roturas más frágiles.

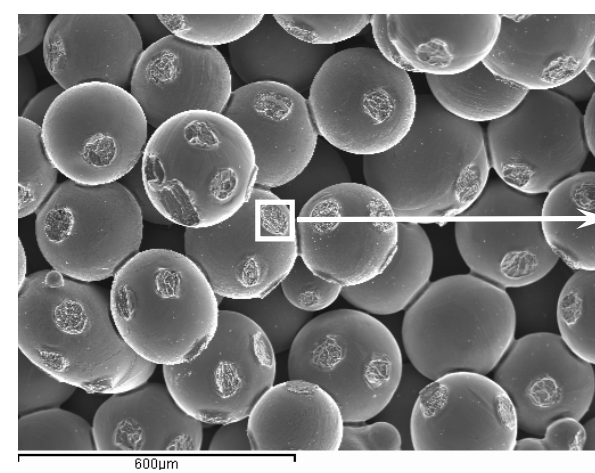

a

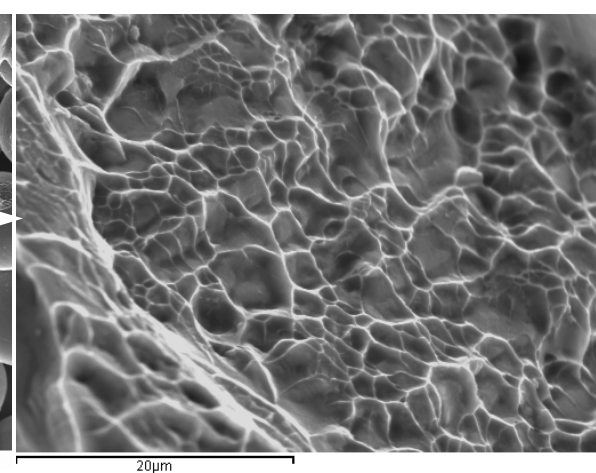

b

Fig. 5.47. Rotura a flexión de una probeta de Ti64 GM, sinterizada en moldes de $\mathrm{Y}_{2} \mathrm{O}_{3}$ a $1400{ }^{\circ} \mathrm{C}, 8 \mathrm{~h}$. 


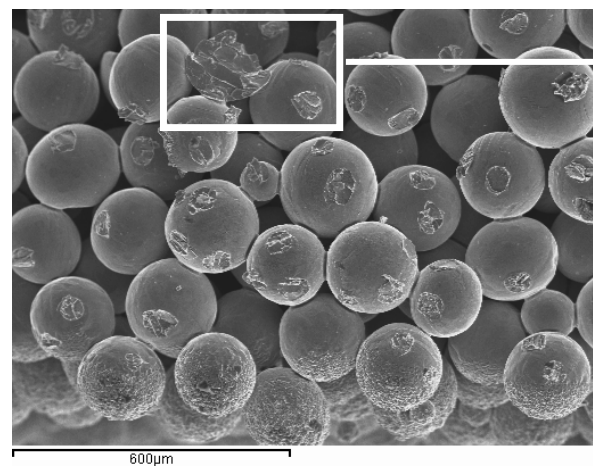

a

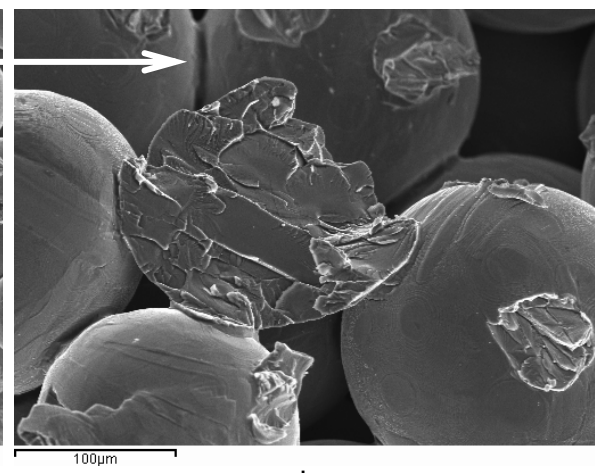

b

Fig. 5.48. Rotura a flexión de una probeta de Ti64 GM, sinterizada en moldes de $\mathrm{Al}_{2} \mathrm{O}_{3}$ a $1400^{\circ} \mathrm{C}, 8 \mathrm{~h}$.

Finalmente cabe indicar que en la mayoría de muestras sinterizadas a partir de la combinación de las granulometrías gruesa y media (50M50G) se produjo cierta segregación, figura 5.49. Ello origina una densidad no uniforme de las piezas porosas obtenidas, lo que, de acuerdo con diversos autores [Gibson 1999, Degischer 2002], provoca mayor dispersión de las propiedades obtenidas. No obstante, el mayor índice de coordinación provoca una resistencia intermedia entre ambas granulometrías, como se verá más adelante.

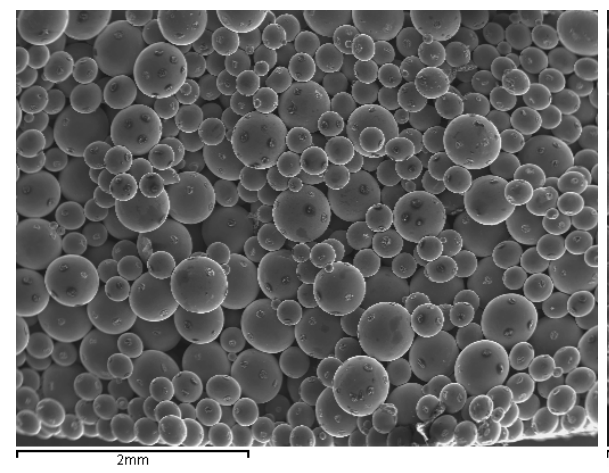

a

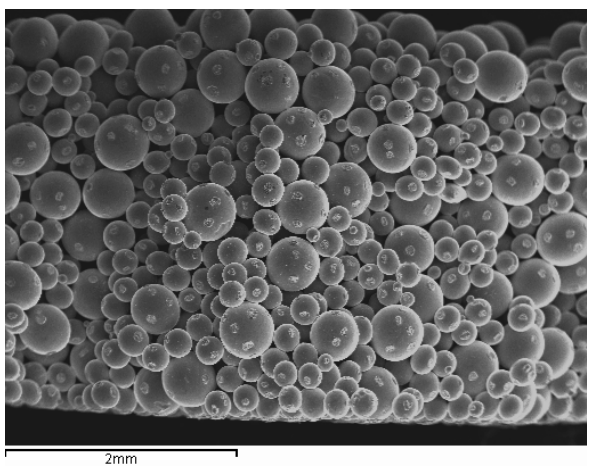

b

Fig. 5.49. Micrografía MEB de una probeta de Ti64 50M50G, sinterizada en moldes recubiertos de itria a: a) $1350^{\circ} \mathrm{C}, 3 \mathrm{~h}$; b) $1350^{\circ} \mathrm{C}, 8 \mathrm{~h}$. 


\subsubsection{DENSIDAD, POROSIDAD Y TAMAÑO DE PORO.}

De cara a una aplicación como implante óseo, resulta de gran importancia que la porosidad sea interconectada, en un porcentaje, morfología, dimensiones y distribución adecuadas para permitir el crecimiento de los tejidos óseos [Kupp 2002, Degischer 2002, Gaona 2007]. Por ello, es fundamental estudiar su variación en función tanto de la temperatura y tiempo de sinterización, como de la granulometría empleada. Además de los parámetros de interés descritos, resulta importante la porosidad total de cara a reducir la rigidez del implante [Asbhy 2000, Vallet 2000, Hollander 2006, Esen 2007].

Con el fin de comparar resultados, en las probetas sinterizadas sobre gres, la porosidad se determinó tanto según norma ASTM B328 (método de Arquímedes), como mediante análisis de imagen.

Así, la porosidad determinada por análisis de imagen resulta superior respecto a la adquirida mediante el método de Arquímedes, figura 5.50.

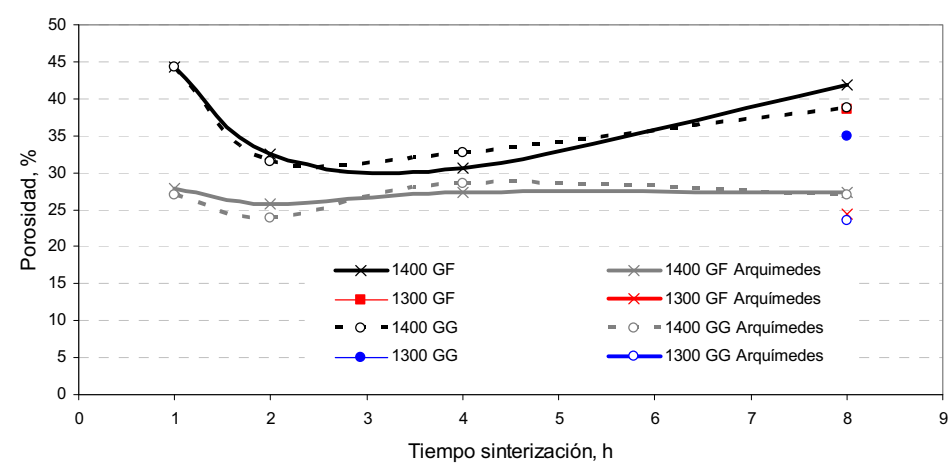

Fig. 5.50. Porosidad interconectada de probetas sinterizadas en moldes de gres. Determinación mediante análisis de imagen y según ASTM B328 (Arquímedes).

Ello viene justificado por las diferentes metodologías, pues en la preparación metalográfica, las microesferas son cortadas a diferentes alturas, que no siempre corresponden con su máxima dimensión [Shatt 1997], con lo que queda un espacio de huecos mayor. Ello es corroborado por los estudios previos realizados por Schatt y colaboradores [Shatt 1997], 
según los cuales el diámetro promedio de una esfera adquirido mediante técnicas de análisis de imagen resulta inferior a su diámetro real, pudiendo relacionarse con éste mediante la expresión:

$$
\mathrm{d}_{\mathrm{kl}} \approx 0,79 \cdot \mathrm{d}
$$

Donde:

$d_{k l}$ es el diámetro medido sobre la imagen $2 D$.

d es el diámetro aproximado que tendrá la esfera real.

Por tanto, el diámetro de la microesfera medido sobre la imagen bidimensional es menor respecto al real, resultando de ello una proporción mayor de huecos.

Por otra parte, se observa una reducida variación con el tiempo de sinterización, entre el 23 y $28 \%$, sin mostrar ninguna tendencia concreta. De igual forma, pese a que es previsible que se modifique el tamaño del poro en función de la dimensión de la microesfera de partida, ello no repercute sobre la porosidad total, pues el factor de empaquetamiento debe mantenerse [Pero-Sanz 2000], véase apartado 2.5.

En las piezas sinterizadas sobre itria, la porosidad se determinó únicamente mediante el método de Arquímedes. Tal como se observa en la figura 5.51, $y$ al igual que en las piezas sinterizadas sobre gres, la porosidad varia en un rango bastante estrecho, oscilando entre el 23 y $27 \%$ ( $\rho_{r} 0.77$ a 0.73$)$. Tal como era de esperar, la menor porosidad se obtiene al combinar fracciones granulométricas, pues los huecos dejados por las microesferas de mayor tamaño son rellenados por otras más pequeñas. 


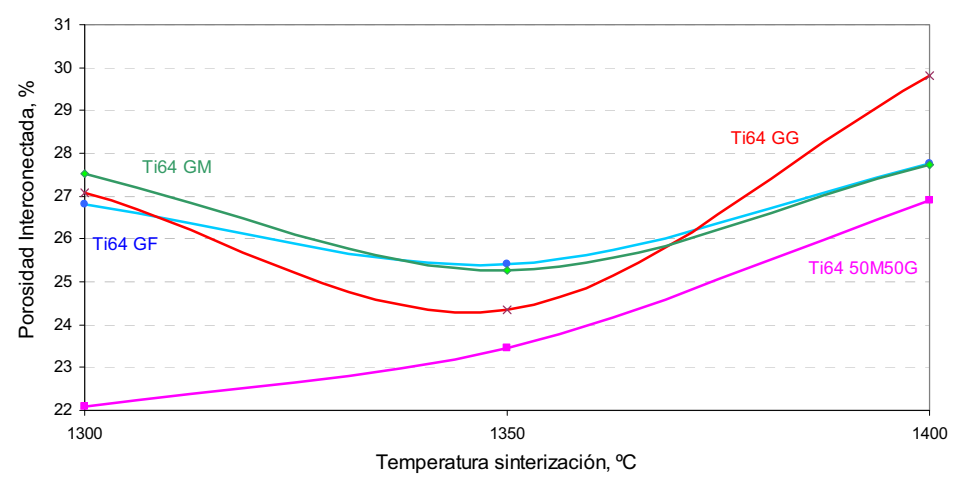

Fig. 5.51. Porosidad interconectada, calculada según norma ASTM B328, para probetas sinterizadas en moldes de itria durante $4 \mathrm{~h}$.

Pese a que en un proceso pulvimetalúrgico convencional tras el desarrollo de los cuellos de unión se iniciaría el redondeamiento de los poros y estos empezarían a aislarse, lo que provocaría la densificación del material [German 1994, Upadhyaya 1997], el tamaño de las microesferas produce que únicamente se alcancen los estados iniciales de sinterización, por lo que apenas se origina contracción y los poros mantienen su morfología. Por tanto, la variación de porosidad viene marcada más por variaciones de proceso, como diferencias en la vibración aplicada a las partículas tras su vertido en el molde, o de la propia distribución granulométrica dentro de cada probeta, que por la densificación lograda durante la sinterización.

No obstante, resulta de gran interés observar como la reducción de porosidad con el tiempo (incremento de contracción) resulta superior en las microesferas más groseras en relación con las más finas, figura 5.52, lo que tal como se verá al discutir la evolución de los cuellos de unión, apunta a distintos mecanismos de sinterización en función del tamaño de las microesferas y, por tanto, de su superficie específica. 


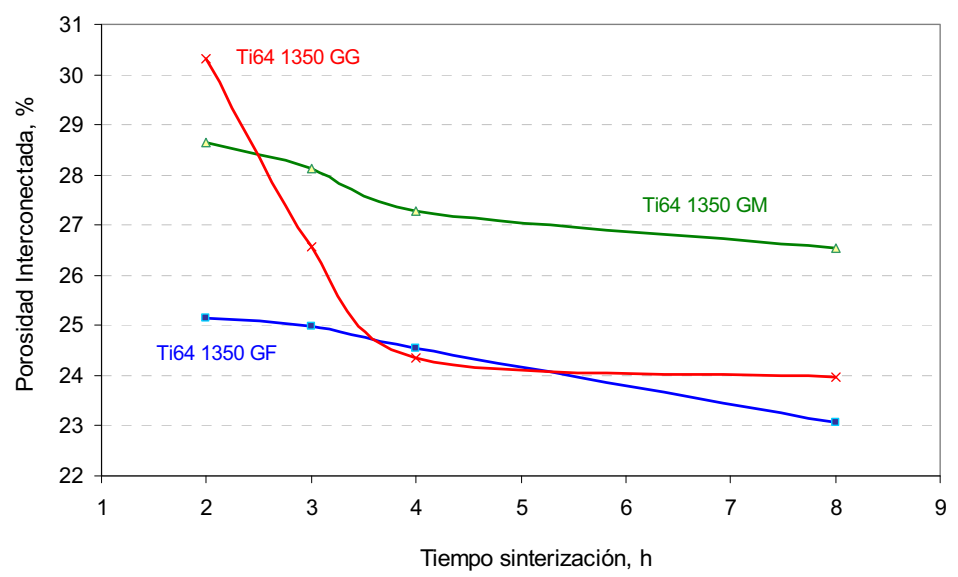

Fig. 5.52. Porosidad interconectada, calculada según norma ASTM B328, para probetas sinterizadas en moldes de itria a $1350^{\circ} \mathrm{C}$.

Tal como se observa, la porosidad (23 a $29 \%$ ) oscila entre la teórica de una ordenación cúbica centrada en caras y en cuerpo, con factores de empaquetamiento de 0,74 y 0,68 (P 26 a 32\%) respectivamente [Pero-Sanz 2000, Amigo 2001]. No obstante, dado que existe una distribución granulométrica, los huecos dejados por las más grandes son ocupados por las más pequeñas, lo que implica una mayor densificación aunque la ordenación no sea perfecta.

En definitiva, tal como se ha visto, las piezas porosas desarrolladas presentan porosidad abierta $\mathrm{y}$, dado que el proceso de sinterización se encuentra en su etapa inicial, la contracción es reducida, y la variación de porosidad es debida más a variaciones durante el propio proceso de conformado, como la distribución granulométrica de las microesferas dentro de cada pieza, diferencias en la vibración aplicada... No obstante, sí se ha observado una contracción ligeramente superior cuanto mayor el tamaño de la microesfera lo que, tal como se verá en el apartado 5.3.3.2, responde a mecanismos de sinterización ligeramente distintos. 


\subsubsection{Tamaño de poro teórico.}

Tal como se indicó en el panorama científico, en una ordenación cristalina perfecta con partículas del mismo tamaño, los huecos dejados entre ellas son producto tanto de la propia ordenación, como del tipo de hueco, tetraédrico u octaédrico [Schatt 1997, Pero-Sanz 2000, Asbhy 2005].

Por otro lado, pese a que las espumas de titanio de poro abierto producidas por metalurgia de polvos son excelentes candidatos como implantes porosos [Wen 2001, Bram 2005, Guden 2005], para permitir el crecimiento de los tejidos y el transporte de fluidos resulta indispensable tanto que la porosidad sea interconectada, como disponer de un tamaño de poro óptimo [Takemoto 2006, Li JP 2005]. Este tamaño de poro crítico oscila entre 100 y $500 \mu \mathrm{m}$ [Bram 2005, Takemoto 2006, Guden 2005, Kujala 2003], tal que permita desarrollar los conductos sanguíneos por una parte $(\approx 450 \mu \mathrm{m})$, y las células del hueso por otra $(\approx 100 \mu \mathrm{m})$ [Bram 2005].

La representación del tamaño de poro teórico para las distintas ordenaciones cristalinas, en función del tamaño medio de la esfera, véase apartado 2.5, permitía prever como, para lograr dicho espacio mínimo, las esferas deberían tener, en el mejor de los supuestos (hueco octaédrico en $\mathrm{CCC} \circ \mathrm{HC}$ ) un diámetro superior a 250 micras. Por tanto, en nuestro caso las microesferas de GF quedarían por debajo $(-250 /+180 \mu \mathrm{m})$, y las de GM $(-300 /+212 \mu \mathrm{m})$ se moverían entre el límite.

La figura 5.53 representa el tamaño de poro en función de la ordenación cristalina, para las microesferas empleadas en la presente investigación, GF, GM y GG, con un diámetro medio de 188, 220 y 468 micras respectivamente. Se han incluido además los resultados obtenidos mediante porosimetría de mercurio, para muestras sinterizadas a $1300^{\circ} \mathrm{C}$, 2h, en la Universidad Politécnica de Cataluña. 


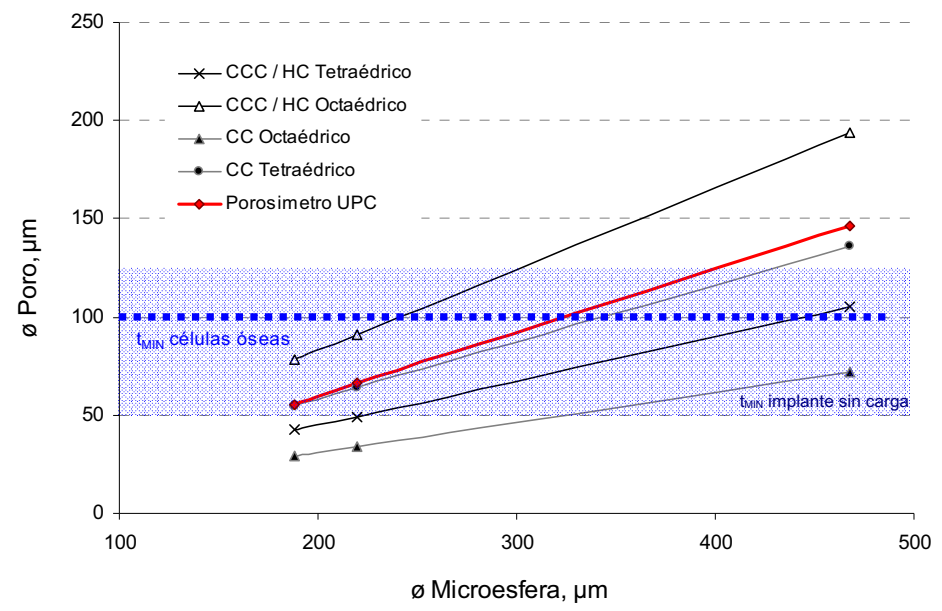

Fig. 5.53. Evolución del tamaño de poro teórico para distintas ordenaciones cristalinas en función del tamaño de la esfera de partida.

Tal como se observa, el tamaño de poro obtenido experimentalmente se asemeja al ocupado por los huecos tetraédricos en una ordenación cúbica centrada en cuerpo (CC). Pese a que se trata de un cálculo aproximado, los resultados son coherentes pues, por una parte, la ordenación CC es no compacta, lo que implica la existencia de huecos y vacantes; por otra, las microesferas siguen una distribución granulométrica, con lo que los huecos dejados por microesferas de mayor tamaño son rellenados por otras más pequeñas, reduciendo con ello la porosidad y el tamaño de hueco final.

En definitiva, de acuerdo con los resultados obtenidos, y según estudios previos realizados por diversos autores [Bram 2005, Takemoto 2006, Guden 2005, Kujala 2003], el crecimiento óseo únicamente seria factible en las piezas porosas obtenidas a partir de las microesferas más groseras. A pesar de ello, según Kujala y colaboradores [Kujala 2003], en casos donde el implante no soporta carga se ha conseguido crecimiento óseo con tamaños de poro entre 50 y 125 micras con lo que, en determinadas aplicaciones, habría cierta posibilidad de vascularización sobre las piezas porosas obtenidas a partir de las microesferas más finas. 
No obstante, cabe indicar que la relación entre este tamaño de poro mínimo y las propiedades mecánicas a obtener, podría modificarse al estrechar la distribución granulométrica y sinterizar microesferas de tamaños intermedios entre las granulometrías media y gruesa. Cabría completar además la investigación con estudios futuros para concretar la aplicación y discernir si el tamaño de poro obtenido resulta adecuado.

5.3.2.2. Conclusiones parciales de la porosidad, densidad y tamaño de poro de la pieza porosa.

En definitiva, los aspectos más destacables son, por una parte el hecho de que la porosidad obtenida es interconectada; por otra que al combinar granulometrías la porosidad se reduce, pues los huecos dejados por las microesferas más gruesas son rellenados por las de menor tamaño y, finalmente, que su variación con los parámetros de proceso (tamaño de la microesfera, temperatura y tiempo de sinterización) es reducida.

En todos los casos la porosidad obtenida oscila en un rango bastante estrecho, 23 a 29\% ( $\rho_{r}$ entre 0,71 - 0,77) dependiendo más de la amplitud de la curva granulométrica (distribución de tamaños), que del tamaño de la microesfera. Este valor se asemeja al de una ordenación cúbica centrada en cuerpo, con un factor de empaquetamiento de 0,68 , lo que implica una porosidad mínima del 32\% [Callister 2005, Ashby 2005].

En relación al tamaño de poro, según el tamaño mínimo de 100 micras propuesto por determinados autores [Bram 2005, Takemoto 2006, Guden 2005, Kujala 2003], el hueso únicamente se desarrollaría sobre las microesferas más groseras. No obstante, dado que otros autores [Kujala 2003] han demostrado crecimiento óseo en ausencia de carga con tamaños de poro de 50 a 125 micras, cabria cierta posibilidad de vascularización sobre piezas porosas desarrolladas con microesferas de granulometría media o incluso fina. 


\subsubsection{DIMENSIONES DE LOS CUELLOS DE UNIÓN.}

Al igual que en el estudio de porosidad, con el fin de comparar los resultados obtenidos mediante análisis de imagen y tomados de micrografías adquiridas en el MEB, en las piezas sinterizadas sobre gres se emplearon ambos métodos.

Al comparar los resultados obtenidos, mediante las distintas metodologías, se observó como las medidas tridimensionales siempre resultaban mayores respecto a las tomadas en la imagen 2D. Tal como se comentó en el apartado 5.3.2.1, las diferencias son debidas a que los cuellos de unión son cortados a diferentes alturas que no siempre corresponden con su máxima dimensión [Shatt 1997].

Por otra parte, a igualdad de parámetros del proceso se observa como los cuellos desarrollados por las microesferas finas siempre resultan inferiores respecto a las gruesas, lo que se debe a su menor energía para llevar a cabo el proceso de sinterización [German 1994, Schatt 1997, Cirincione 2002]. De igual modo, la mayor difusión con la temperatura y tiempo de sinterización [German 1994, Upadhayaya 1997] provocan cierto crecimiento de los cuellos con ambos parámetros. No obstante, es interesante resaltar como en moldes de gres, para tiempos superiores a 4 horas, estos se mantienen pero no aumentan, figura 5.54, lo que probablemente sea debido a la reactividad entre las microesferas y el molde. 


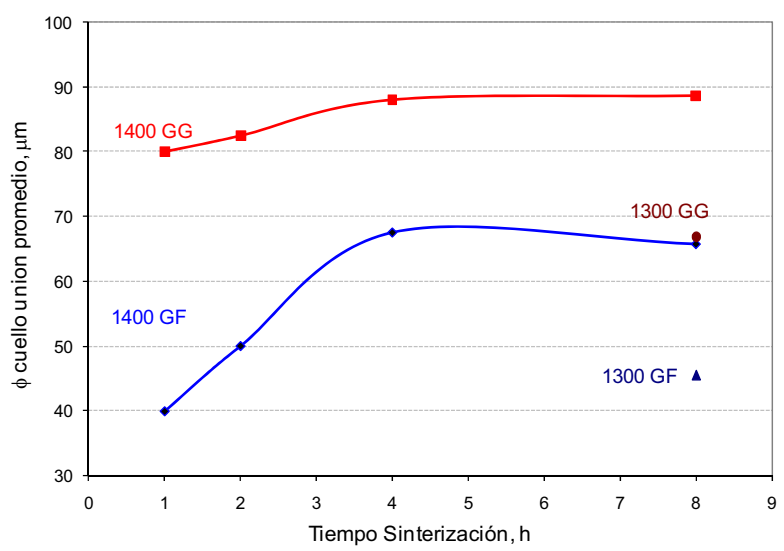

Fig. 5.54. Cuellos de unión desarrollados por microesferas de Ti64 GF y GG sinterizadas en moldes de gres a 1300 y $1400^{\circ} \mathrm{C}$, entre 1 y $8 \mathrm{~h}$.

Al igual que en las piezas sinterizadas sobre gres, para un mismo ciclo térmico los cuellos de unión desarrollados por las microesferas sinterizadas sobre itria son mayores a medida que aumenta el diámetro de la esfera, figura 5.55 .

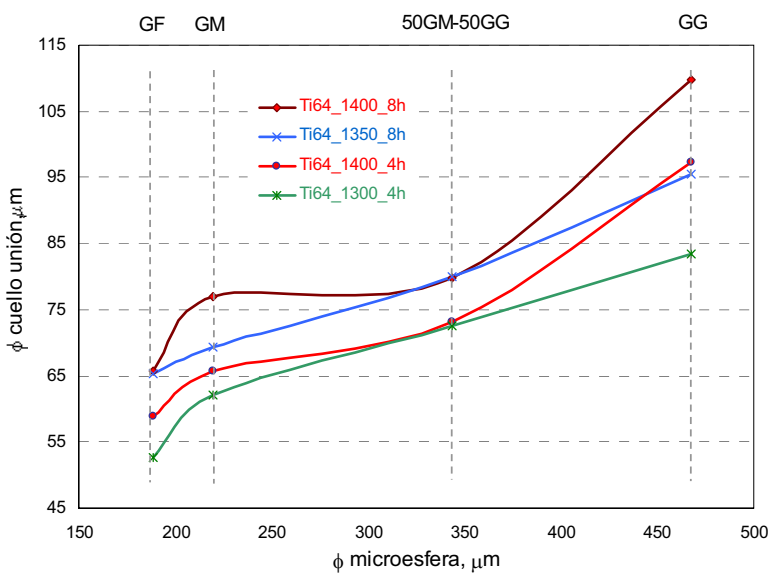

Fig. 5.55. Cuellos de unión según el diámetro de la microesfera original. Sinterización en moldes de itria a diferentes tiempos y temperaturas. 
Por otra parte, partiendo de la dimensión promedio del cuello de unión generado, se estableció una relación teórica entre la superficie de unión desarrollada y la superficie de la esfera promedio de cada granulometría $\left(\mathrm{S}_{\text {unión }} / \mathrm{S}_{\text {esfera }}\right)$.

Por el contrario, la relación teórica entre $S_{\text {unión }} / S_{\text {esfera }}$ es superior cuanto menor el tamaño de la esfera, figura 5.56. Pese a que cuanto mayor es el diámetro de una esfera, mayor es su superficie $\left(S_{\text {esfera }} 4 \cdot \pi \cdot r_{2}\right)$, la superficie específica (superficie de las partículas por un gramo de material [Callister 1995] evoluciona de forma inversa con el tamaño de las partículas, lo que implica mayor energía superficial para llevar a cabo los procesos de sinterización [Cirincione 2002]. En definitiva, menor tamaño de partícula implica mayor energía disponible en la sinterización, lo que repercute en el desarrollo de una mayor área de unión con esferas contiguas.

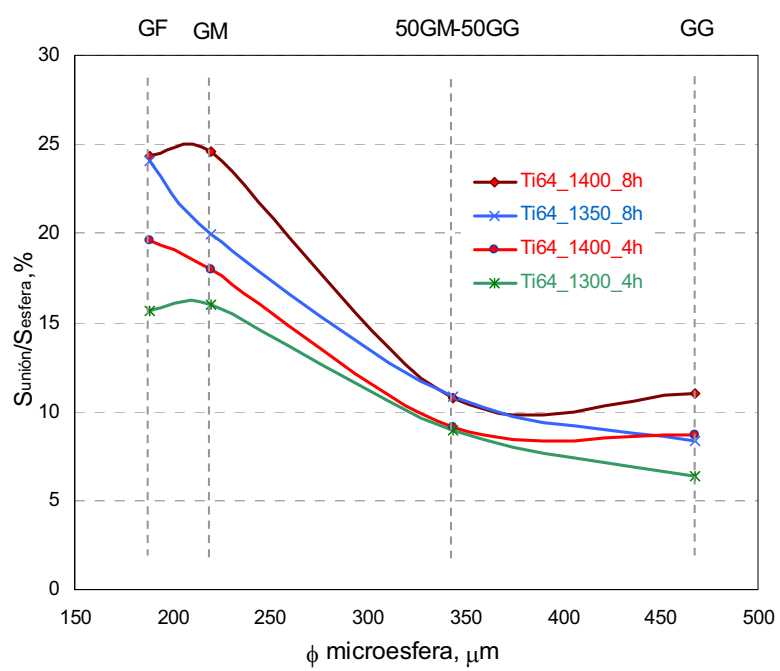

Fig. 5.56. Relación $S_{\text {unión }} / S_{\text {esfera }}$ según el diámetro de la microesfera original.

Sinterización en moldes de itria a diferentes tiempos y temperaturas.

Debido al tamaño de las microesferas, pese a que el tiempo y la temperatura empleados son elevados, en todos los casos la sinterización se encuentra los estadios iniciales, caracterizados por producirse poca contracción, véase apartado 5.3.22, y por la reducida modificación de la 
forma de los poros [German 1994]. Para esta etapa, German [German 1994] establece una relación entre el ratio del cuello de unión desarrollado respecto al tamaño de la microesfera inicial y el tiempo de sinterización (5.4), con unos exponentes $\mathrm{n}$ y $\mathrm{m}$ que hacen referencia al mecanismo de sinterización:

$$
\left(\frac{\phi_{\text {cuello }}}{\phi_{\mathrm{ME}}}\right)^{\mathrm{n}}=\left(\frac{\mathrm{B} \cdot \mathrm{t}}{\phi_{\mathrm{ME}}^{\mathrm{m}}}\right)
$$

Donde:

$\varnothing_{\text {cuello }}=$ Diámetro del cuello de unión desarrollado.

$\varnothing_{\mathrm{ME}}=$ Diámetro de la microesfera de partida.

$\mathrm{B}=$ Constante geométrica y del material.

t= tiempo de sinterización.

$\mathrm{n}$ y $\mathrm{m}=$ coeficientes dependientes del mecanismo de transporte de masa.

Tras establecer dicha relación sobre las piezas porosas desarrolladas por sinterización de microesferas, se obtiene en todos los casos un exponente $n$ próximo a 5 , siendo ligeramente superior al sinterizar microesferas más finas. De acuerdo con German [German 1994], dicho valor implica que el principal mecanismo de sinterización es la difusión por volumen y, el valor ligeramente superior obtenido para las microesferas más finas denota una mayor influencia de la difusión por superficie. Los resultados son lógicos pues, cuanto más groseras las microesferas de partida, mayor el transporte de masa desde el interior de las partículas, mientras que al aumentar la superficie específica, se facilita el transporte por superficie, llevado a cabo a través de la difusión en superficie y los fenómenos de evaporación y condensación. Por otra parte, ello explicaría el hecho de que la contracción sea mayor cuanto mayor el diámetro de la microesfera de partida, figura 5.52 , pues mientras que la difusión superficial no origina densificación, los fenómenos de difusión por volumen si provocan contracción. 
Finalmente, cabe indicar que, cuando no se produce reacción con el molde la dimensión de los cuellos de unión aumenta, en general, tanto con la temperatura como con el tiempo de sinterización, figura 5.57, lo que no ocurría en piezas sinterizadas en moldes de gres o alúmina. Cabe destacar como, en las microesferas de mayor tamaño, no se observa un crecimiento mayor de los nexos de unión a partir de 8 horas, lo que probablemente sea debido a la reactividad observada en determinadas muestras para tiempos mayores.

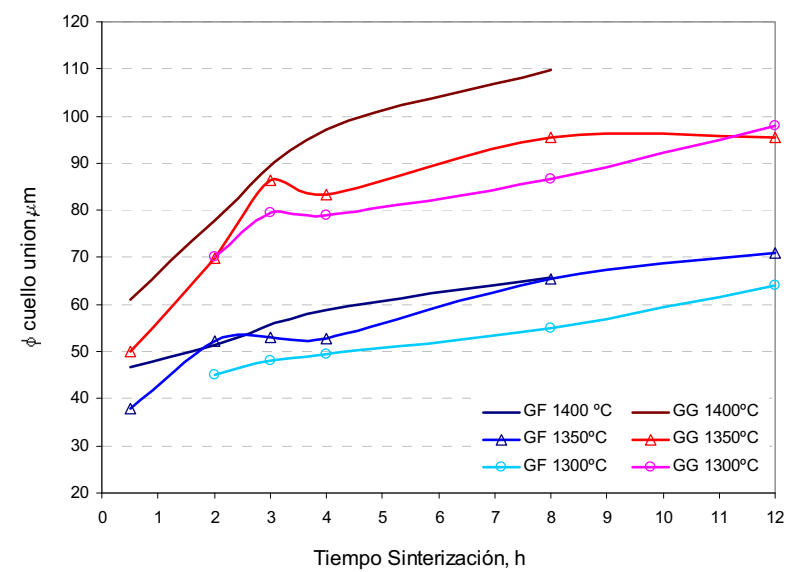

Fig. 5.57. Cuellos de unión desarrollados por microesferas GF y GG sinterizadas en moldes de itria a 1300 y $1400^{\circ} \mathrm{C}$ a diferentes tiempos.

En definitiva, la variación del tamaño del cuello de unión desarrollado se observó más claramente en las piezas sinterizadas sobre itria, pues fue en las que no se produjo reactividad. De acuerdo con la relación $S_{\text {unión }} / S_{\text {esfera }}$ observada, son de esperar mejores propiedades mecánicas cuanto mayor la temperatura o tiempo de sinterización y más finas las microesferas, lo que se debe a su mayor energía superficial. Finalmente, tal como se ha visto, la sinterización se encuentra en sus estados iniciales, por lo que presenta una contracción reducida. De acuerdo con las relaciones obtenidas, el principal mecanismo de sinterización es la difusión por volumen, presentando una mayor tendencia a la difusión por superficie cuanto más finas las microesferas, lo que origina una contracción todavía menor. 


\subsubsection{CARACTERIZACIÓN MECÁNICA.}

Los ensayos estáticos de resistencia a la flexión y rigidez permiten discernir entre la combinación óptima de variables de proceso: molde, granulometría, temperatura y tiempo de sinterización a utilizar. No obstante, de acuerdo con Bram y colaboradores [Bram 2005], éstos ensayos merecen ser completados en investigaciones futuras, mediante la realización de ensayos dinámicos (fatiga).

\subsubsection{Resistencia a Flexión.}

Como se ha visto, apartado 5.2.1, la resistencia a flexión depende fundamentalmente de la reactividad con los diferentes moldes empleados. Tal es así, que al emplear moldes de gres y alúmina no se observaba una correlación directa con la temperatura y tiempo de sinterización, como cabria esperar [Thieme 2001, Oh 2003, Asaoka 2003]. Por el contrario, el recubrimiento del molde con itria minimiza la reactividad, evitando la absorción y combinación del titanio con elementos no deseados. No obstante, puesto que el molde sigue siendo básicamente de alúmina, y la itria únicamente se aporta como mero recubrimiento, para tiempos largos y temperaturas elevadas se observó como las microesferas atravesaban la capa de itria y llegaban a reaccionar con el molde de alúmina, véase apartado 5.2.1, lo que se refleja en una importante merma de propiedades mecánicas.

Las tablas 5.2 a 5.4 recogen la resistencia y tenacidad a flexión de las muestras obtenidas por sinterización de microesferas a las temperaturas de sinterización empleadas. Los resultados corresponden a las piezas ensayadas en la situación más desfavorable (contacto con el molde en zona traccionada) y se han incluido las propiedades de las piezas sinterizadas sobre los moldes de gres, alúmina y circona para facilitar su comparación. Finalmente, cabe señalar que los resultados de las microesferas sinterizadas sobre itria que sufrieron reactividad con la alúmina del molde 
subyacente se desestimaron, corroborando posteriormente dicho fenómeno mediante microscopía óptica y electrónica de barrido.

Tabla 5.2. Resistencia a flexión y tenacidad de piezas porosas obtenidas por sinterización de microesferas sobre distintos moldes y sinterizadas a $1300^{\circ} \mathrm{C}$.

\begin{tabular}{|c|c|c|c|c|c|c|c|c|c|c|}
\hline \multirow{2}{*}{$\mathrm{T},{ }^{\circ} \mathrm{C}$} & \multirow{2}{*}{$\mathrm{t}, \mathrm{h}$} & \multirow{2}{*}{ Microesfera } & \multicolumn{2}{|c|}{ Itria } & \multicolumn{2}{|c|}{ Gres } & \multicolumn{2}{|c|}{ Alúmina } & \multicolumn{2}{|c|}{ Circona } \\
\hline & & & $\sigma_{\mathrm{YF}}, \mathrm{MPa}$ & Tenac., J & $\sigma_{\mathrm{YF}}, \mathrm{MPa}$ & Tenac., J & $\sigma_{\mathrm{YF}}, \mathrm{MPa}$ & Tenac., J & $\sigma_{\mathrm{YF}}, \mathrm{MPa}$ & Tenac., J \\
\hline \multirow{19}{*}{1300} & \multirow{3}{*}{2} & GF & 130,55 & 0,28 & & & & & 67,59 & 0,05 \\
\hline & & GM & 88,00 & 0,08 & & & & & 66,79 & 0,05 \\
\hline & & GG & 40,63 & 0,04 & & & & & 30,77 & 0,03 \\
\hline & \multirow{4}{*}{3} & GF & 134,16 & 0,27 & & & & & & \\
\hline & & GM & 103,63 & 0,15 & & & & & & \\
\hline & & GG & 34,29 & 0,05 & & & & & & \\
\hline & & 50M50G & 84,34 & 0,14 & & & & & & \\
\hline & \multirow{4}{*}{4} & GF & 169,07 & 0,30 & & & 83,14 & 0,12 & 86,66 & 0,07 \\
\hline & & GM & 113,70 & 0,12 & & & 70,59 & 0,11 & 75,42 & 0,06 \\
\hline & & GG & 53,09 & 0,07 & & & 32,31 & 0,04 & 42,76 & 0,04 \\
\hline & & 50M50G & 109,04 & 0,21 & & & 61,62 & 0,08 & & \\
\hline & \multirow{4}{*}{8} & GF & 239,42 & 0,48 & 53,85 & 0,03 & 68,14 & 0,10 & 106,70 & 0,09 \\
\hline & & GM & 170,77 & 0,32 & & & 66,89 & 0,10 & 106,74 & 0,09 \\
\hline & & GG & 73,42 & 0,08 & 21,89 & 0,05 & 32,19 & 0,05 & 59,47 & 0,05 \\
\hline & & $50 \mathrm{M} 50 \mathrm{G}$ & & & & & 61,24 & 0,09 & & \\
\hline & \multirow{4}{*}{12} & GF & 211,93 & 0,43 & & & & & & \\
\hline & & GM & 189,51 & 0,35 & & & & & & \\
\hline & & GG & 70,26 & 0,08 & & & & & & \\
\hline & & 50M50G & 161,90 & 0,23 & & & & & & \\
\hline
\end{tabular}

Tabla 5.3. Resistencia a flexión y tenacidad de piezas porosas obtenidas por sinterización de microesferas sobre distintos moldes y sinterizadas a $1350^{\circ} \mathrm{C}$.

\begin{tabular}{|c|c|c|c|c|c|c|c|c|}
\hline \multirow{2}{*}{$\mathrm{T},{ }^{\circ} \mathrm{C}$} & \multirow{2}{*}{$\mathrm{t}, \mathrm{h}$} & \multirow{2}{*}{ Microesfera } & \multicolumn{2}{|c|}{ Itria } & \multicolumn{2}{|c|}{ Alúmina } & \multicolumn{2}{|c|}{ Circona } \\
\hline & & & $\sigma_{\mathrm{YF}}, \mathrm{MPa}$ & Tenac., J & $\sigma_{\mathrm{YF}}, \mathrm{MPa}$ & Tenac. J & $\sigma_{\mathrm{YF}}, \mathrm{MPa}$ & Tenac., J \\
\hline \multirow{24}{*}{1350} & \multirow{4}{*}{0,5} & GF & 57,28 & 0,04 & & & & \\
\hline & & GM & 56,85 & 0,03 & & & & \\
\hline & & GG & 17,21 & 0,01 & & & & \\
\hline & & 50M50G & 45,27 & 0,03 & & & & \\
\hline & \multirow{4}{*}{2} & GF & 144,64 & 0,32 & 83,87 & 0,10 & 75,80 & 0,12 \\
\hline & & GM & 101,51 & 0,15 & & & 78,51 & 0,06 \\
\hline & & GG & 36,76 & 0,05 & 33,90 & 0,05 & 35,18 & 0,03 \\
\hline & & 50M50G & 80,32 & 0,13 & & & & \\
\hline & \multirow{4}{*}{3} & GF & 151,89 & 0,33 & 72,26 & 0,10 & & \\
\hline & & GM & 135,57 & 0,25 & & & & \\
\hline & & GG & 45,26 & 0,08 & 33,89 & 0,06 & & \\
\hline & & 50M50G & 114,88 & 0,22 & & & & \\
\hline & \multirow{4}{*}{4} & GF & 161,84 & 0,21 & 60,78 & 0,09 & 109,45 & 0,11 \\
\hline & & GM & 156,03 & 0,33 & & & 105,70 & 0,10 \\
\hline & & GG & 48,49 & 0,05 & 26,89 & 0,03 & 45,44 & 0,04 \\
\hline & & 50M50G & 117,62 & 0,21 & & & & \\
\hline & \multirow{4}{*}{8} & GF & 288,49 & 0,63 & 62,77 & 0,08 & 104,85 & 0,08 \\
\hline & & GM & 163,71 & 0,30 & & & 105,19 & 0,09 \\
\hline & & GG & 77,24 & 0,12 & 24,25 & 0,04 & 58,39 & 0,05 \\
\hline & & 50M50G & 142,77 & 0,24 & & & & \\
\hline & \multirow{4}{*}{12} & GF & 264,35 & 0,51 & & & & \\
\hline & & GM & 249,39 & 0,47 & & & & \\
\hline & & GG & 97,14 & 0,13 & & & & \\
\hline & & 50M50G & 216,07 & 0,54 & & & & \\
\hline
\end{tabular}


Tabla 5.4. Resistencia a flexión y tenacidad de piezas porosas obtenidas por sinterización de microesferas sobre distintos moldes y sinterizadas a $1400^{\circ} \mathrm{C}$.

\begin{tabular}{|c|c|c|c|c|c|c|c|c|c|c|}
\hline \multirow{2}{*}{$\mathrm{T},{ }^{\circ} \mathrm{C}$} & \multirow{2}{*}{$\mathrm{t}, \mathrm{h}$} & \multirow{2}{*}{ Microesfera } & \multicolumn{2}{|c|}{ Itria } & \multicolumn{2}{|c|}{ Gres } & \multicolumn{2}{|c|}{ Alúmina } & \multicolumn{2}{|c|}{ Circona } \\
\hline & & & $\sigma_{\mathrm{YF}}, \mathrm{MPa}$ & Tenac., J & $\sigma_{\mathrm{YF}}, \mathrm{MPa}$ & Tenac., J & $\sigma_{\mathrm{YF}}, \mathrm{MPa}$ & Tenac., J & $\sigma_{\mathrm{YF}}, \mathrm{MPa}$ & Tenac., J \\
\hline \multirow{18}{*}{1400} & \multirow{4}{*}{0,5} & GF & 78,36 & \begin{tabular}{|l|}
0,07 \\
\end{tabular} & & & & & & \\
\hline & & GM & 73,75 & 0,21 & & & & & & \\
\hline & & GG & 25,78 & 0,02 & & & & & & \\
\hline & & 50M50G & 61,72 & 0,05 & & & & & & \\
\hline & \multirow{2}{*}{1} & GF & & & 53,71 & 0,08 & & & & \\
\hline & & GG & & & 15,63 & 0,03 & & & & \\
\hline & \multirow{4}{*}{2} & GF & 191,67 & 0,49 & $\begin{array}{l}75,78 \\
\end{array}$ & 0,13 & 39,69 & 0,04 & 106,31 & 0,11 \\
\hline & & GM & 123,38 & 0,13 & & & & & 91,84 & 0,08 \\
\hline & & GG & 51,78 & 0,04 & 29,87 & 0,06 & 20,68 & 0,03 & 41,78 & 0,04 \\
\hline & & 50M50G & 102,19 & 0,12 & & & & & & \\
\hline & \multirow{4}{*}{4} & GF & 240,50 & 0,49 & 66,03 & 0,09 & & & 149,19 & 0,14 \\
\hline & & GM & 185,20 & 0,40 & & & & & 127,48 & 0,10 \\
\hline & & GG & 73,53 & 0,10 & 23,57 & 0,05 & & & 70,47 & 0,06 \\
\hline & & 50M50G & 121,28 & 0,18 & & & & & & \\
\hline & \multirow{4}{*}{8} & GF & 319,85 & 0,64 & 93,44 & 0,11 & & & & \\
\hline & & GM & 227,11 & 0,51 & & & & & & \\
\hline & & GG & 106,01 & 0,14 & 27,91 & 0,03 & & & & \\
\hline & & 50M50G & 201,61 & 0,46 & & & & & & \\
\hline
\end{tabular}

Tal como se observa de forma gráfica, en las figuras 5.58 y 5.59 , las propiedades mecánicas, límite elástico y tenacidad aumentan con el tiempo de sinterización y evolucionan de forma inversa con el tamaño de las microesferas de partida. Estos resultados son acordes con los obtenidos al analizar los cuellos de unión desarrollados pues, pese a que éstos crecen con la temperatura, tiempo de sinterización y tamaño de las microesferas, la $\mathrm{S}_{\text {unión }} / \mathrm{S}_{\text {esfera }}$ resultaba inversamente proporcional al diámetro de la microesfera de partida.

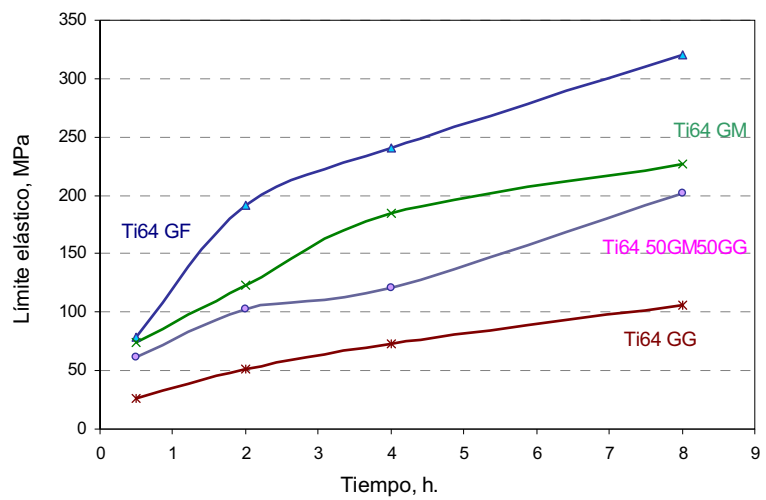

Fig. 5.58. R. Flexión de probetas sinterizadas en moldes de itria a $1400^{\circ} \mathrm{C}$ durante 0,5 a $8 \mathrm{~h}$. 


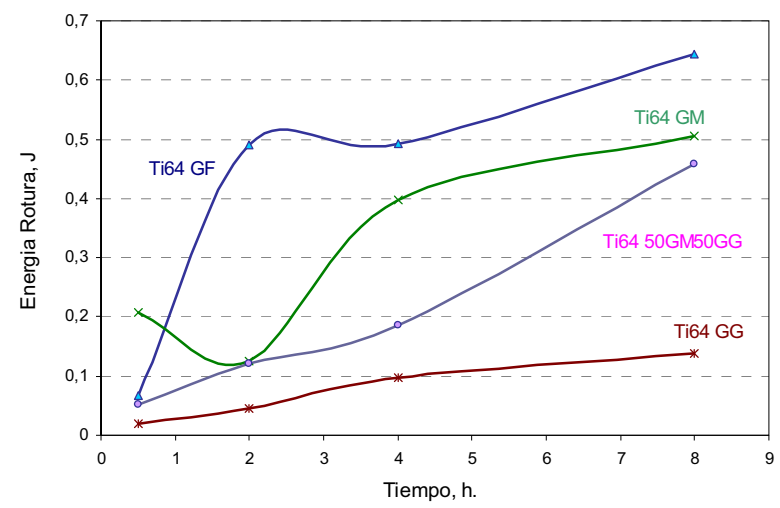

Fig. 5.59. Tenacidad de probetas sinterizadas en moldes de itria a $1400^{\circ} \mathrm{C}$ durante 0,5 a $8 \mathrm{~h}$.

Esta misma evolución en relación al tiempo y tamaño del material de partida se observó al sinterizar a 1350 y $1300^{\circ} \mathrm{C}$, véase tablas 5.2 a 5.4 .

De igual modo, la figura 5.60 refleja como, para un mismo tiempo, la resistencia a flexión aumenta con la temperatura. Como se ha comentado, la variación con la temperatura y tiempo de sinterización resulta mayor cuanto menor el tamaño de las microesferas, resultando este último parámetro el más influyente de los tres, figura 5.61.

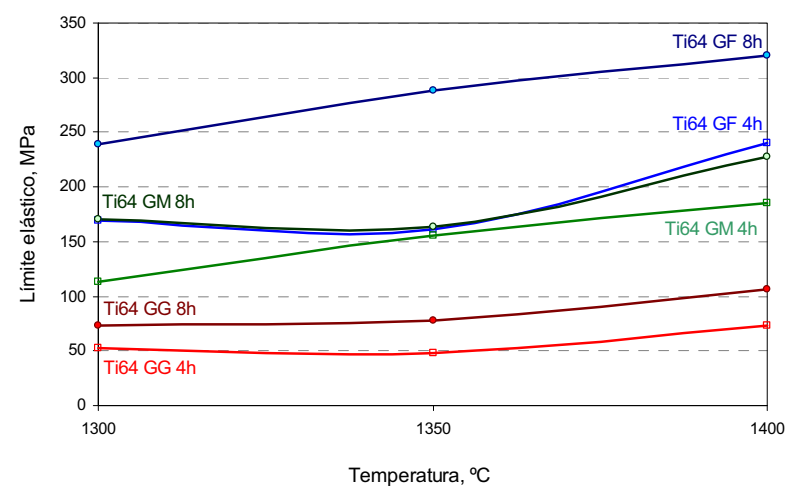

Fig. 5.60. R. Flexión de probetas sinterizadas en moldes de itria durante 4 y 8 horas a 1300,1350 y $1400^{\circ} \mathrm{C}$. 


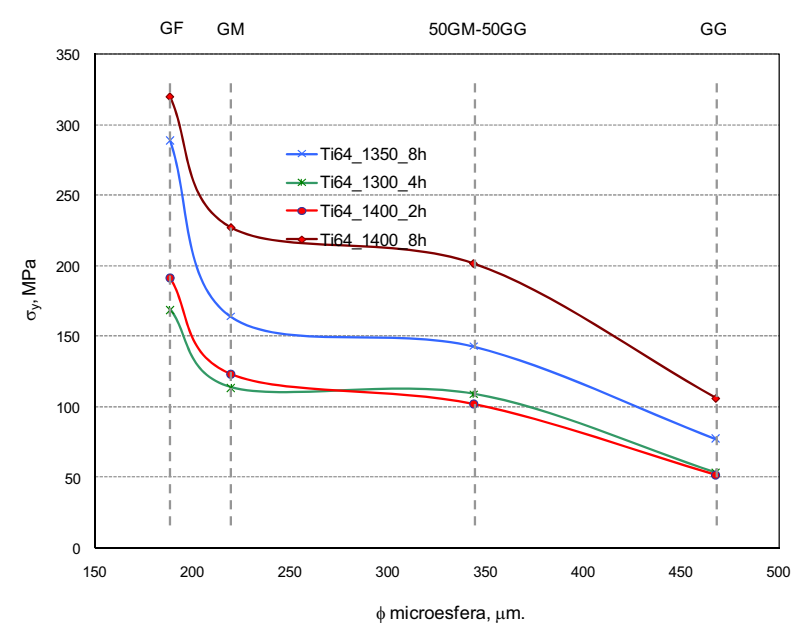

Fig. 5.61. R. Flexión de probetas sinterizadas en moldes de itria durante 2 y 4 horas a 1300,1350 y $1400{ }^{\circ} \mathrm{C}$, en función del diámetro promedio de la microesfera de partida.

Por otra parte, es de interés señalar la influencia de la reactividad en función del ciclo térmico aplicado. Así, en la figura 5.62, se observa como la curva de sinterización a $1400{ }^{\circ} \mathrm{C}$ durante 8 horas presenta ciertas anomalías en relación a la superficie de unión desarrollada.

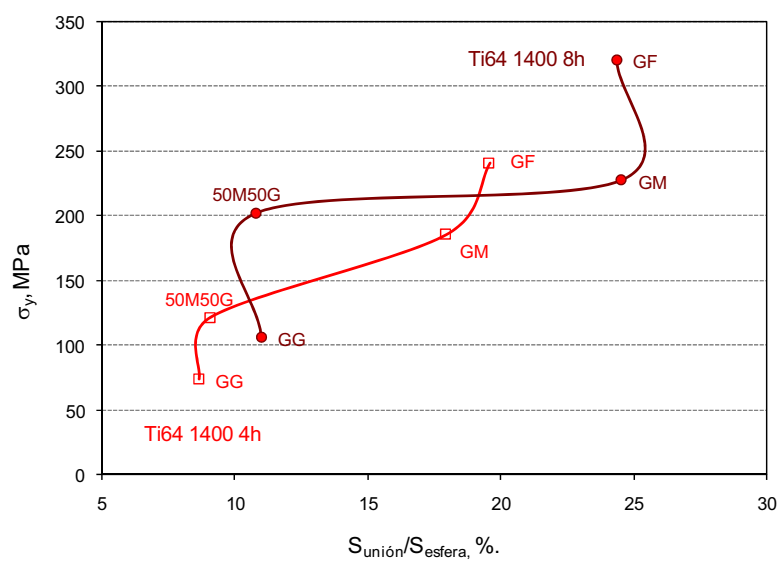

Fig. 5.62. R. Flexión de probetas sinterizadas sobre itria a $1400{ }^{\circ} \mathrm{C}$ durante 4 y 8 horas, en función de la relación $\mathrm{S}_{\text {unión }} / \mathrm{S}_{\text {esfera. }}$ 
Tal como se ha indicado, estas variaciones pueden estar originadas por la reactividad con el molde de alúmina, pese al recubrimiento de itria, a temperaturas elevadas y tiempos largos. En definitiva, aunque la reacción se produce únicamente en determinadas ocasiones, quedando en la mayoría de ellas a nivel superficial, en algunas probetas ensayadas a flexión se ha provocado una importante variación de propiedades mecánicas, reduciéndose su valor incluso hasta la mitad.

En este sentido, al comparar el límite elástico y tenacidad obtenidos en distintos moldes para un mismo tiempo, temperatura y tamaño de microesfera, se observa una resistencia muy superior cuando éstos se recubren de itria respecto a cuando se utilizan sin recubrir, tablas 5.2 a 5.4 . Además, se observa como al emplear moldes de alúmina, las propiedades mecánicas no aumentan a medida que avanza el tiempo de sinterización, acentuándose el efecto cuanto menor es el diámetro de la esfera (mayor superficie específica). Tanto es así, que en las microesferas de menor tamaño se obtiene el doble de resistencia al sinterizar en moldes recubiertos con itria respecto a moldes de alúmina sin recubrir, figura 5.63 .

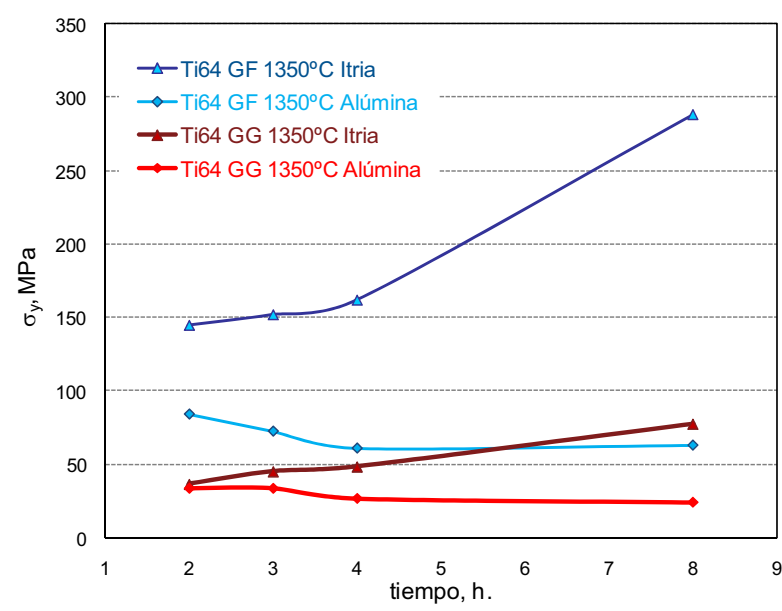

Fig. 5.63. R. Flexión de probetas sinterizadas en moldes de alúmina e itria a $1350^{\circ} \mathrm{C}$ durante diferentes tiempos. 
De igual modo, a igualdad de parámetros de proceso, las piezas sinterizadas sobre circona presentaron menor resistencia, tablas 5.2 a 5.4 . Tal como se observa, en la figuras 5.64 i 5.65, en todos los casos el límite elástico resulta inferior en las piezas sinterizadas sobre $\mathrm{ZrO}_{2}$, observándose una reducción inversamente proporcional al tamaño de la microesfera. Es decir, mientras que en las microesferas más groseras la resistencia obtenida resulta semejante, en las más finas las piezas porosas pierden la mitad de su resistencia. Ello es debido a la mayor superficie específica y, por tanto, mayor reactividad, cuanto menor el tamaño de la microesfera [Tarín 1999].

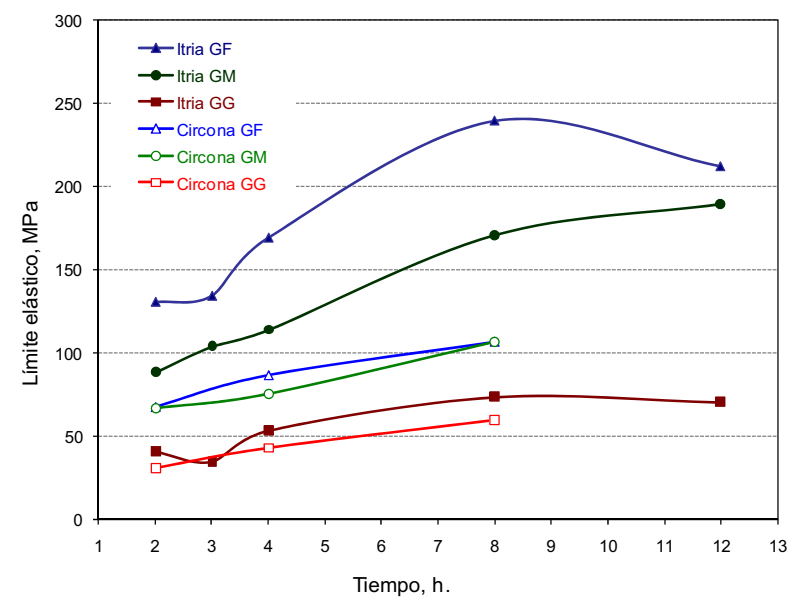

Fig. 5.64. R. Flexión de piezas porosas sinterizadas en moldes de itria y circona a $1300^{\circ} \mathrm{C}$.

Se observa además como, en el rango de temperaturas estudiado, la resistencia obtenida en las piezas sinterizadas sobre circona aumenta a 1300 y $1350{ }^{\circ} \mathrm{C}$, tablas 5.2 a 5.4 , mientras que a mayor temperatura, figura 5.65 , la resistencia no aumenta a partir de las 4 horas. Tal como se discutió en el estudio de la reactividad con el molde, ello es consecuencia de la mayor reactividad con la temperatura [Baeslack 1993, Tarín 1999]. 


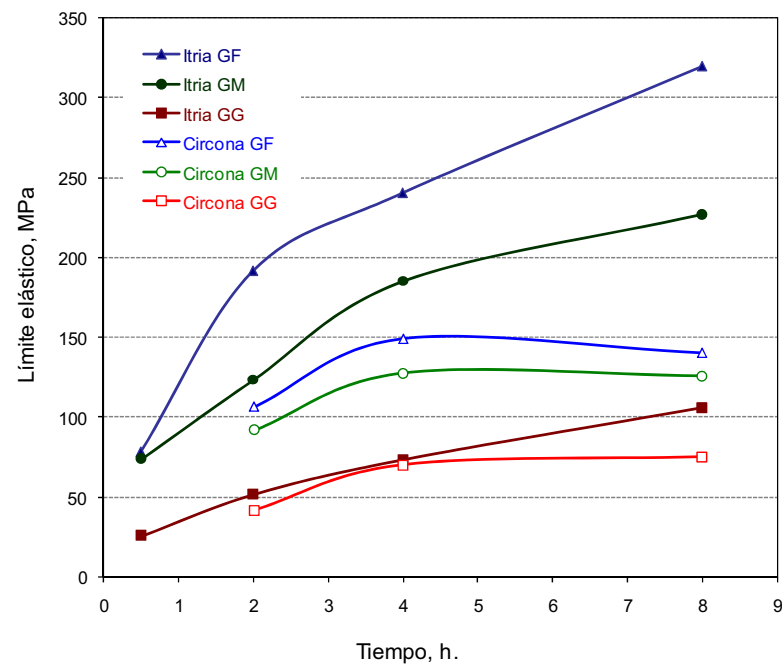

Fig. 5.65. R. Flexión de piezas porosas sinterizadas en moldes de itria y circona a $1400^{\circ} \mathrm{C}$.

En relación a la dispersión de los resultados obtenidos, la tabla 5.5 resume la desviación estándar máxima obtenida para cada granulometría a las diferentes temperaturas. Esta variación resulta mayor en materiales porosos, pues influye tanto el porcentaje y distribución de huecos, como la reproducibilidad de las condiciones de proceso [Gibson 1999, Degischer 2002]. Tal como se observa, la máxima desviación se obtiene al combinar granulometrías, pues se amplia la distribución de tamaños, lo que facilita las diferencias entre piezas, tanto en relación a la dimensión de las microesferas que rellenan el molde (que condiciona las dimensiones de los cuellos de unión), como por los huecos dejados entre ellas y el relleno de estos por otras de menor tamaño.

Por otra parte, en la fracción más gruesa los resultados son más homogéneos, lo que probablemente es debido a la menor superficie específica de las microesferas de mayor tamaño, que facilita su ordenación en el molde. 
Tabla 5.5. Desviación estándar máxima de la resistencia a flexión en función de la temperatura y tamaño de microesfera inicial.

\begin{tabular}{|c|c|c|c|c|}
\hline \multirow{2}{*}{$\begin{array}{c}\text { Temperatura, } \\
{ }^{\circ} \mathrm{C}\end{array}$} & \multicolumn{4}{|c|}{ Fracción } \\
\cline { 2 - 5 } & G.Fino & G.Medio & G.Grueso & $50 \mathrm{GM}$ - GG \\
\hline 1300 & 10,27 & 7,61 & 11,67 & 19,80 \\
\hline 1350 & 14,55 & 14,57 & 6,97 & 33,14 \\
\hline 1400 & 10,21 & 26,60 & 4,73 & 9,60 \\
\hline
\end{tabular}

Partiendo de la resistencia a flexión media obtenida para las piezas sinterizadas sobre itria, que presentaron los mejores resultados, se ha obtenido un modelo de correlación, ecuación 5.3.2, que permite estimar la resistencia a flexión (MPa) en función de las distintas variables de proceso ( $T, t, y$ tamaño de microesfera).

$\sigma_{y}=-790,178+0,4355 \cdot d i+0,353 \cdot T+44,49 \cdot \log _{10} t-0,00845 \cdot t \cdot T+\frac{3486,32 \cdot t+46,86 \cdot T}{d i}$

Donde "di" es el diámetro medio en $\mu \mathrm{m}$, "t" el tiempo de sinterización en horas y "T" la temperatura en ${ }^{\circ} \mathrm{C}$. Cabe señalar que, debido a la amplitud del estudio realizado, en el que además de los parámetros temperatura tiempo y tamaño de las microesferas de partida $\left(T, t, \emptyset_{\mathrm{ME}}\right)$, se estudió la reactividad del titanio con diferentes materiales empleados como molde, el número de muestras ensayadas a flexión resulta relativamente reducido, no suponiendo una cantidad lo suficientemente representativa. Ello, unido a la mayor dispersión de resultados en piezas metálicas porosas [Gibson 1999, Degischer 2002], provoca que el ajuste del modelo matemático no sea tan bueno como seria deseable, obteniéndose una desviación estándar del $15,64 \%$, con un coeficiente de determinación $R^{2}$ de $95,69 \%$ y una desviación máxima del 8,3\%.

Tal como se observa al representar la resistencia para las tres temperaturas de sinterización, figuras 5.66 a 5.68, la aproximación del modelo es bastante buena para las granulometrías media y gruesa. En el caso de la granulometría más fina, la máxima desviación se produce a $1400{ }^{\circ} \mathrm{C}$, 
quedando el modelo por el lado de la seguridad, pues estima una resistencia entre un 7 y $12 \%$ inferior a la realmente obtenida. Cabe destacar también la discrepancia entre el valor experimental y teórico obtenidos para la granulometría fina sinterizada a $1300^{\circ} \mathrm{C}$ durante 12 horas, figura 5.68 , aunque probablemente en este es debida a la existencia de defectos durante el desarrollo de la pieza porosa (vibración insuficiente, reactividad con el molde...), pues se produce un descenso anómalo de la resistencia con el tiempo de sinterización.

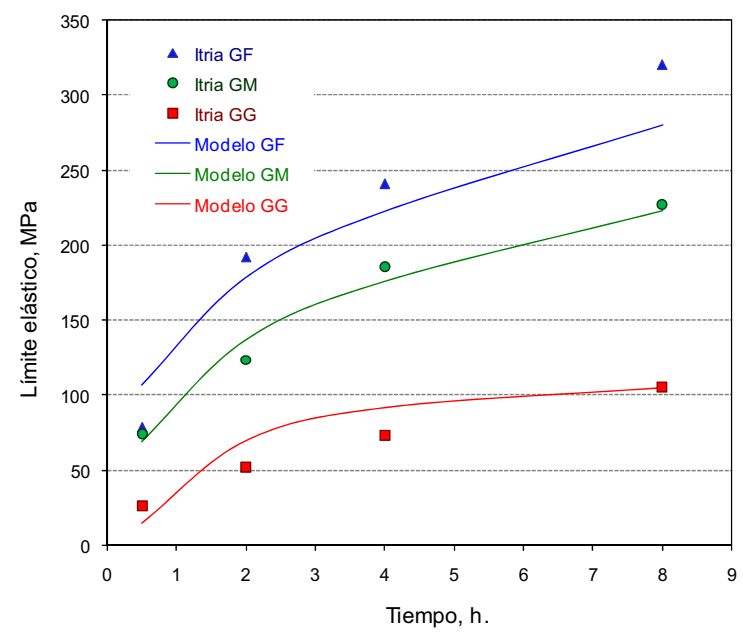

Fig. 5.66. R. Flexión de probetas sinterizadas en moldes de itria a $1400^{\circ} \mathrm{C}$ durante 0,5 a 8 h y modelo de correlación.

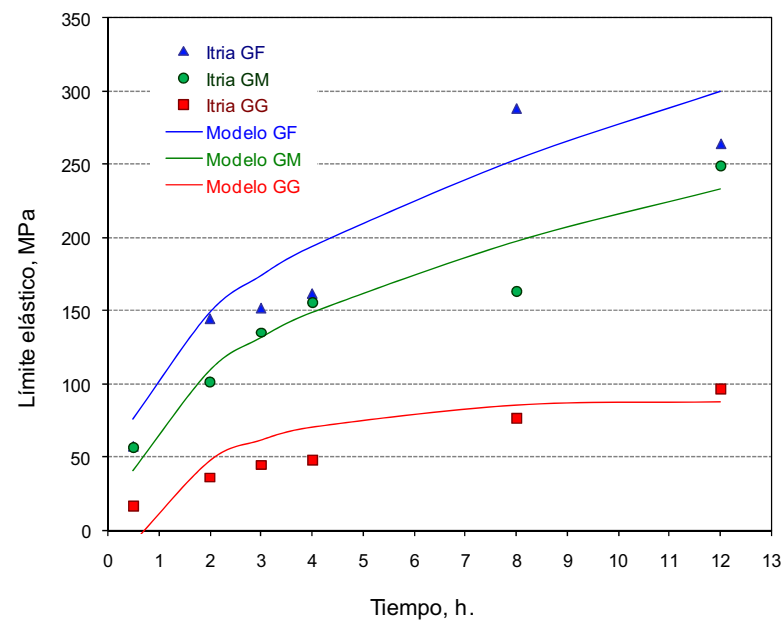

Fig. 5.67. R. Flexión de probetas sinterizadas en moldes de itria a $1350^{\circ} \mathrm{C}$ durante 0,5 a 12 h y modelo de correlación. 


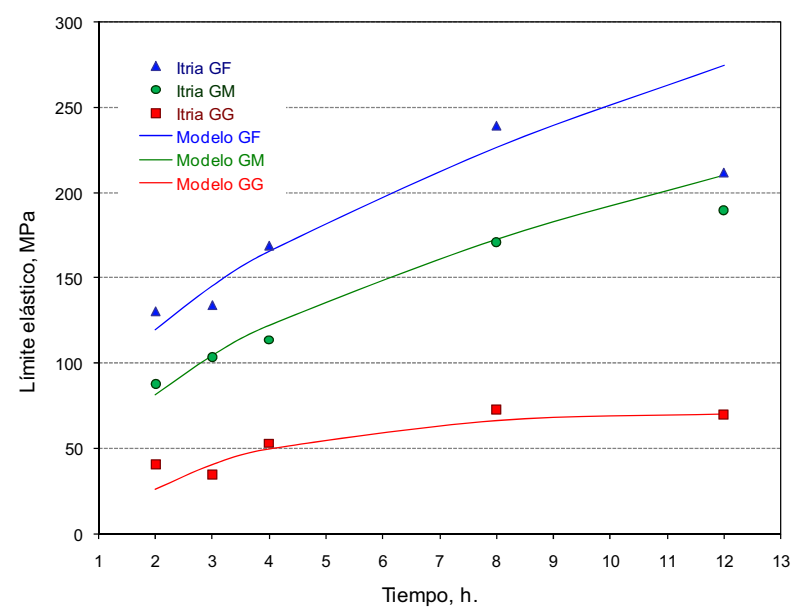

Fig. 5.68. R. Flexión de probetas sinterizadas en moldes de itria a $1300^{\circ} \mathrm{C}$ durante 2 a $12 \mathrm{~h}$ y modelo de correlación.

Finalmente, es de gran importancia resaltar que este modelo ha sido desarrollado para estimar resultados de piezas desarrolladas en moldes de itria, y se han eliminado para su obtención los resultados de aquellas piezas que presentaron reactividad con el molde subyacente de alúmina.

\subsubsection{Rigidez a flexión.}

La rigidez de las piezas porosas obtenidas por sinterización de microesferas sobre itria se determinó tanto mediante la pendiente de la curva $\sigma-\varepsilon_{0}$, como a partir de la fórmula de flexión (apartado 4.4.4.3), resultando siempre superior en este último caso.

Dado que en materiales porosos el material plastifica en el tramo aparentemente elástico, resulta más apropiado hablar de rigidez de la estructura celular, en lugar de módulo de Young [Banhart 1998, Degisher 2002]. Por ello y con el fin de comparar con la reducción de rigidez obtenida en las piezas porosas procesadas, se hablará de rigidez relativa, en lugar de establecer un valor numérico para el módulo de Young. 
Así, para determinar la rigidez relativa $\left(E_{r}=\frac{E^{*}}{E_{S}}\right)$ se tomó como rigidez del sólido $\left(E_{s}\right)$ el valor promedio de las piezas sin espaciador compactadas a las diferentes presiones de compactación $(100,200$ y $300 \mathrm{MPa})$. Concretamente, para determinar la rigidez relativa en función de la pendiente de la curva, se adoptó como rigidez del sólido $\mathrm{E}_{\mathrm{SFP}}=10.825 \mathrm{MPa}$, mientras que para determinarla a partir de la fórmula de flexión se tomó el valor $\mathrm{E}_{\mathrm{SFF}}=16.752 \mathrm{MPa}$ (véase apartado 4.4.4.3 para determinación de los valores de rigidez).

Por otra parte, como más adelante se verá, se han determinado dos modelos matemáticos de correlación entre las variables de proceso y la rigidez relativa obtenida a flexión (por aplicación de la fórmula y por determinación de la pendiente de la curva $\sigma-\varepsilon_{0}$ ). Las siguientes tablas recogen tanto la rigidez relativa obtenida por ambos métodos, como los valores obtenidos mediante el modelo de correlación.

Tabla 5.6. Rigidez relativa de piezas porosas obtenidas por sinterización de microesferas sobre distintos moldes y sinterizadas a $1300^{\circ} \mathrm{C}$.

\begin{tabular}{|c|c|c|c|c|c|c|}
\hline \multirow{2}{*}{$\mathrm{T},{ }^{\circ} \mathrm{C}$} & \multirow{2}{*}{$\mathrm{t}, \mathrm{h}$} & \multirow{2}{*}{ Microesfera } & \multicolumn{4}{|c|}{ Rigidez Relativa, Itria } \\
\hline & & & $\mathrm{E}_{\mathrm{FF}}$ & $\mathrm{E}_{\mathrm{FF} \text {, Modelo }}$ & $E_{F P}$ & $\mathrm{E}_{\mathrm{FP} \text {, Modelo }}$ \\
\hline \multirow{15}{*}{1300} & \multirow{3}{*}{2} & GF & 0,25 & 0,20 & 0,18 & 0,12 \\
\hline & & GM & 0,23 & 0,18 & 0,12 & 0,09 \\
\hline & & GG & 0,13 & 0,06 & 0,07 & 0,03 \\
\hline & \multirow{3}{*}{3} & GF & 0,21 & 0,23 & 0,12 & 0,14 \\
\hline & & GM & 0,17 & 0,21 & 0,11 & 0,11 \\
\hline & & GG & 0,08 & 0,09 & 0,05 & 0,05 \\
\hline & \multirow{3}{*}{4} & GF & 0,25 & 0,25 & 0,13 & 0,15 \\
\hline & & GM & 0,24 & 0,23 & 0,12 & 0,12 \\
\hline & & GG & 0,12 & 0,10 & 0,08 & 0,06 \\
\hline & \multirow{3}{*}{8} & GF & 0,40 & 0,31 & 0,19 & 0,20 \\
\hline & & GM & 0,33 & 0,29 & 0,18 & 0,17 \\
\hline & & GG & 0,16 & 0,15 & 0,09 & 0,08 \\
\hline & \multirow{3}{*}{12} & GF & 0,32 & 0,36 & 0,19 & 0,25 \\
\hline & & GM & 0,31 & 0,33 & 0,21 & 0,21 \\
\hline & & GG & 0,18 & 0,19 & 0,11 & 0,11 \\
\hline
\end{tabular}


Tabla 5.7. Rigidez relativa de piezas porosas obtenidas por sinterización de microesferas sobre distintos moldes y sinterizadas a $1350^{\circ} \mathrm{C}$.

\begin{tabular}{|c|c|c|c|c|c|c|}
\hline \multirow[b]{2}{*}{$\mathrm{T},{ }^{\circ} \mathrm{C}$} & \multirow[b]{2}{*}{$\mathrm{t}, \mathrm{h}$} & \multirow[b]{2}{*}{ Microesfera } & \multicolumn{4}{|c|}{ Rigidez Relativa, Itria } \\
\hline & & & $\mathrm{E}_{\mathrm{FF}}$ & $\mathrm{E}_{\mathrm{FF}, \text { Modelo }}$ & $E_{F P}$ & $\mathrm{E}_{\mathrm{FP} \text {, Modelo }}$ \\
\hline \multirow{18}{*}{1350} & \multirow{3}{*}{0,5} & GF & 0,17 & 0,17 & 0,10 & 0,11 \\
\hline & & GM & 0,15 & 0,14 & 0,10 & 0,08 \\
\hline & & GG & 0,06 & 0,03 & 0,04 & 0,03 \\
\hline & \multirow{3}{*}{2} & GF & 0,30 & 0,26 & 0,18 & 0,15 \\
\hline & & GM & 0,19 & 0,26 & 0,12 & 0,12 \\
\hline & & GG & 0,10 & 0,11 & 0,05 & 0,06 \\
\hline & \multirow{3}{*}{3} & GF & 0,30 & 0,29 & 0,18 & 0,17 \\
\hline & & GM & 0,24 & 0,26 & 0,13 & 0,14 \\
\hline & & GG & 0,09 & 0,14 & 0,06 & 0,07 \\
\hline & \multirow{3}{*}{4} & GF & 0,27 & 0,31 & 0,16 & 0,18 \\
\hline & & GM & 0,26 & 0,28 & 0,17 & 0,15 \\
\hline & & GG & 0,17 & 0,16 & 0,08 & 0,08 \\
\hline & \multirow{3}{*}{8} & GF & 0,34 & 0,37 & 0,30 & 0,24 \\
\hline & & GM & 0,27 & 0,34 & 0,15 & 0,20 \\
\hline & & GG & 0,23 & 0,21 & 0,12 & 0,11 \\
\hline & \multirow{3}{*}{12} & GF & 0,38 & 0,41 & 0,29 & 0,28 \\
\hline & & GM & 0,36 & 0,38 & 0,27 & 0,24 \\
\hline & & GG & 0,23 & 0,24 & 0,14 & 0,13 \\
\hline
\end{tabular}

Tabla 5.8. Rigidez relativa de piezas porosas obtenidas por sinterización de microesferas sobre distintos moldes y sinterizadas a $1400^{\circ} \mathrm{C}$.

\begin{tabular}{|c|c|c|c|c|c|c|}
\hline \multirow{2}{*}{$\mathrm{T},{ }^{\circ} \mathrm{C}$} & \multirow{2}{*}{$\mathrm{t}, \mathrm{h}$} & \multirow{2}{*}{ Microesfera } & \multicolumn{4}{|c|}{ Rigidez Relativa, Itria } \\
\hline & & & $\mathrm{E}_{\mathrm{FF}}$ & $\mathrm{E}_{\mathrm{FF}, \text { Modelo }}$ & $\mathrm{E}_{\mathrm{FP}}$ & $\mathrm{E}_{F \mathrm{~F}, \text { Modelo }}$ \\
\hline \multirow{12}{*}{1400} & \multirow{3}{*}{0,5} & GF & 0,22 & 0,22 & 0,14 & 0,14 \\
\hline & & GM & 0,18 & 0,20 & 0,12 & 0,12 \\
\hline & & GG & 0,08 & 0,08 & 0,05 & 0,06 \\
\hline & \multirow{3}{*}{2} & GF & 0,31 & 0,31 & 0,24 & 0,18 \\
\hline & & GM & 0,28 & 0,29 & 0,15 & 0,16 \\
\hline & & GG & 0,18 & 0,17 & 0,06 & 0,09 \\
\hline & \multirow{3}{*}{4} & GF & 0,43 & 0,36 & 0,18 & 0,22 \\
\hline & & GM & 0,35 & 0,34 & 0,18 & 0,19 \\
\hline & & GG & 0,18 & 0,21 & 0,10 & 0,11 \\
\hline & \multirow{3}{*}{8} & GF & 0,53 & 0,42 & 0,29 & 0,27 \\
\hline & & GM & 0,35 & 0,40 & 0,24 & 0,23 \\
\hline & & GG & 0,26 & 0,26 & 0,15 & 0,14 \\
\hline
\end{tabular}

Tal como se observa, a igualdad de parámetros de proceso, la rigidez obtenida por medio de la fórmula de flexión siempre resulta superior en relación a la obtenida mediante la pendiente de la curva lo que, tal como se verá, se repite en las piezas obtenidas por el método de espaciadores. Asimismo, como era de esperar, la rigidez aumenta con la temperatura y tiempo de sinterización y disminuye a medida que aumenta el tamaño de las microesferas de partida, tablas 5.6 a 5.8 y figuras 5.69 y 5.70 . Ello es debido 
al mayor desarrollo de los cuellos de unión, véase apartado 5.3.3, pues rigidizan la pieza al conferirle resistencia. Cabe destacar que en la mayoría de casos la rigidez de la pieza porosa resulta inferior al $40 \%$ de la rigidez del material sólido (en este caso, Ti64 sin espaciador).

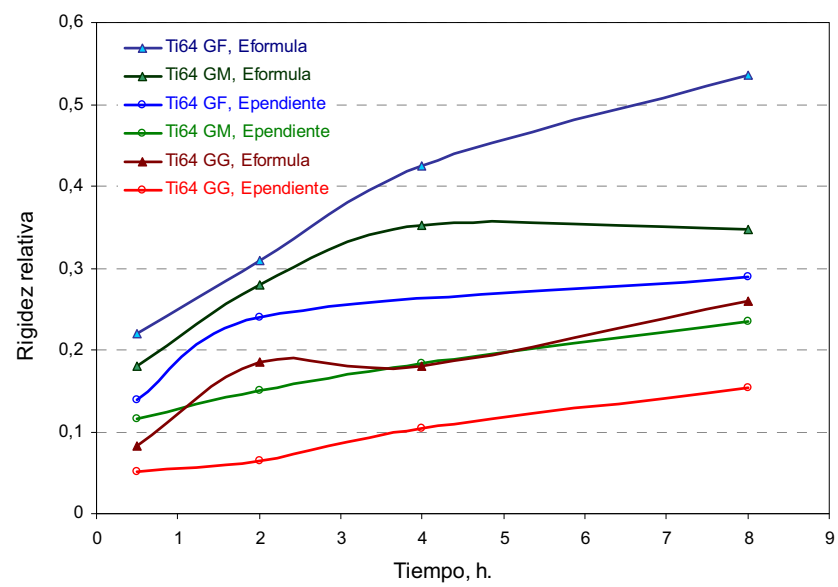

Fig. 5.69. Rigidez a flexión (según pendiente de la curva y formula de flexión) de probetas sinterizadas en moldes de itria a $1400^{\circ} \mathrm{C}$.

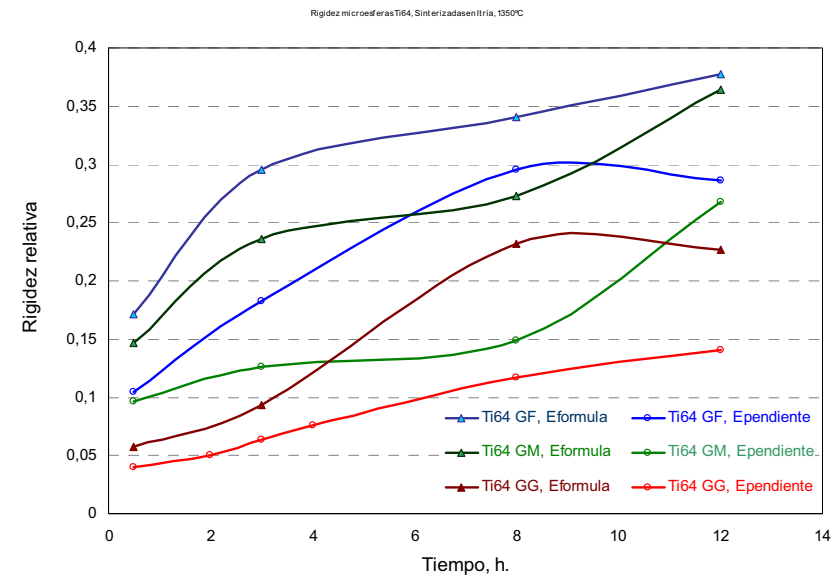

Fig. 5.70. Rigidez a flexión (según pendiente de la curva y formula de flexión) de probetas sinterizadas en moldes de itria a $1350^{\circ} \mathrm{C}$. 
La figura 5.71 refleja la reducción de rigidez a medida que aumenta el tamaño de la microesfera.

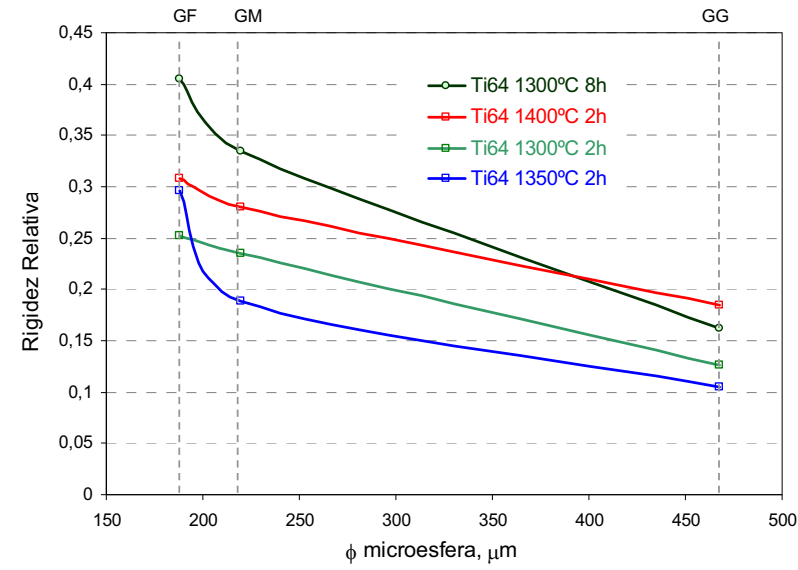

Fig. 5.71. Rigidez a flexión (según formula de flexión) en función del tamaño de la microesfera inicial para diferentes ciclos de sinterización.

Tal como se verá, en el caso de los espaciadores la rigidez relativa resulta igual independientemente del método de determinación, lo que no sucede en el caso de las microesferas, seguramente debido a los valores adoptados como $E_{S}$, para piezas de Ti64 sin espaciador, pues probablemente el mecanismo de deformación será distinto. Independientemente es de gran importancia observar como la rigidez desciende notablemente en relación a la que presenta el material sólido oscilando, en la mayoría de los casos, entre el 7,5 y $40 \%$ de ésta.

Considerando que el hueso cortical posee una rigidez entre 10 y $30 \mathrm{GPa}$ [Heimann 2002, Asaoka 2003] (véase apartado 2.6), con los valores, entorno a $0,1-0,3\left(\rho^{*}=\rho_{\mathrm{r}} \cdot \rho_{\mathrm{s}}=11\right.$ a $\left.33 \mathrm{GPa}\right)$ mejorará enormemente el comportamiento junto al hueso [Comín 1999, Wen 2002 a].

Finalmente, cabe señalar que en las piezas porosas obtenidas por sinterización de microesferas no se ha encontrado una correlación acorde con el modelo propuesto por Asbhy [Asbhy 2000], véase apartado 2.7, pues, como se ha visto, no existe una variación determinada de la densidad con las variables de proceso temperatura, tiempo y tamaño de microesfera. 
A pesar de ello, si se ha encontrado cierta correlación entre las variables de proceso y la rigidez relativa obtenida a flexión. El primer modelo obtenido correlaciona la rigidez relativa mediante la aplicación de la fórmula de flexión:

$$
E_{r-F O R}=\left(\frac{E^{*}}{E_{s}}\right)=0,0011 \cdot T+0,06 \cdot \log _{10} t-0,713 \cdot d i^{0,112}+\left(\frac{0,916 \cdot t}{d i}\right)
$$

Mientras que el segundo relaciona los parámetros del proceso con la rigidez relativa obtenida mediante la pendiente de la curva $\sigma-\varepsilon$ a flexión:

$$
E_{r-P E N D}=\left(\frac{E^{*}}{E_{S}}\right)=0,00062 \cdot T+0,023 \cdot \log _{10} t-0,396 \cdot d i^{0,113}+\left(\frac{1,43 \cdot t}{d i}\right)(5.7
$$

Donde "di" es el diámetro medio en $\mu \mathrm{m}$, "t" el tiempo de sinterización en horas y "T" la temperatura en ${ }^{\circ} \mathrm{C}$. Como se ha indicado anteriormente, dado el reducido número de muestras (5 probetas) obtenidas para cada combinación de parámetros de proceso, y puesto que la dispersión de resultados es mayor en materiales porosos [Gibson 1999, Degischer 2002], el ajuste del modelo no resulta elevado. Concretamente, para el modelo de correlación (5.6), de la rigidez obtenida según la fórmula, se obtiene una desviación estándar del 3,85\%, con un coeficiente de determinación $\mathrm{R}^{2}$ de $87,53 \%$ y una desviación máxima del $11,49 \%$. De forma similar, en el modelo de correlación (5.7), de la rigidez según pendiente de la curva, la desviación estándar es de $3,85 \%$, con un coeficiente de determinación $\mathrm{R}^{2}$ de $86,76 \%$ y una desviación máxima del $10,10 \%$. A pesar de todo, lo revelante es que los modelos establecidos permiten realizar una estimación de las propiedades descritas en función de los parámetros de proceso seleccionados.

Las figuras 5.72 y 5.73 recogen la comparación entre la rigidez obtenida de forma experimental y según el modelo matemático propuesto. La primera de ellas hace referencia a la rigidez determinada según fórmula $\left(E_{F F}\right)$ y la segunda según pendiente de la curva $\left(E_{\mathrm{FP}}\right)$. Tal como se observa, la máxima desviación se produce para las piezas de GF sinterizadas a $1400^{\circ} \mathrm{C}$ 
durante 4 y 8 horas por lo que, como se ha visto en el estudio de reactividad, la mayor rigidez podría deberse a cierta reactividad con el molde de alúmina subyacente.

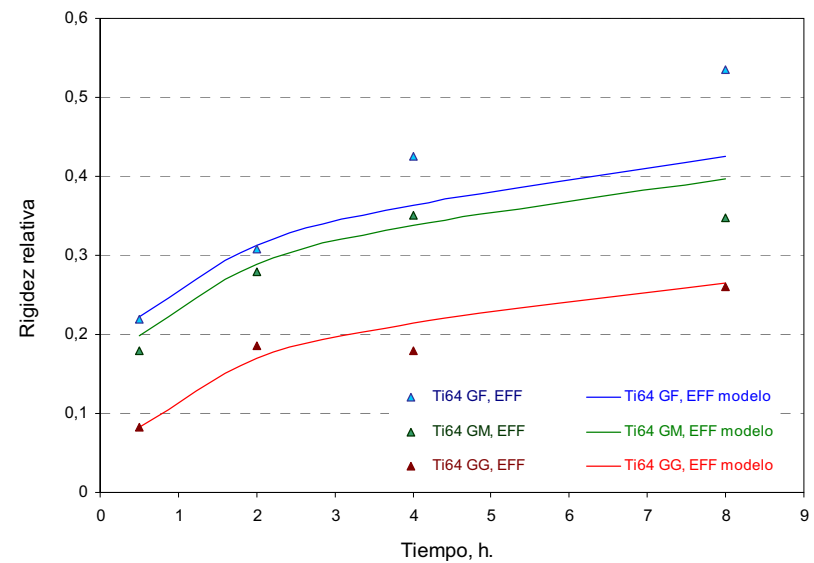

Fig. 5.72. Rigidez a flexión según formula de flexión y modelo correspondiente para probetas sinterizadas sobre itria a $1400^{\circ} \mathrm{C}$.

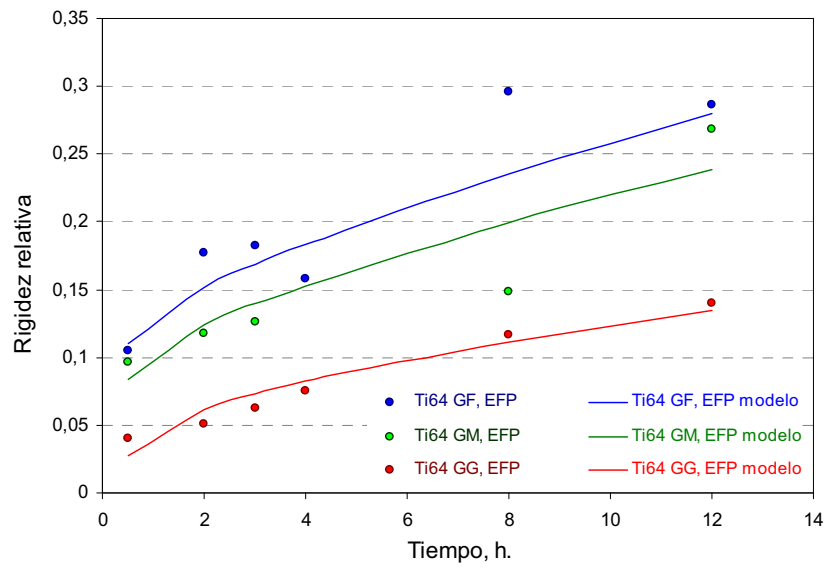

Fig. 5.73. Rigidez a flexión según pendiente de la curva de flexión y modelo correspondiente para probetas sinterizadas sobre itria a $1350^{\circ} \mathrm{C}$. 


\subsubsection{Discusión y conclusiones parciales de las propiedades} mecánicas obtenidas por sinterización de microesferas.

En definitiva, mediante sinterización de microesferas se han desarrollado piezas porosas de la aleación Ti64 con una resistencia suficiente (hasta 320 $\mathrm{MPa}$ ) y una rigidez mucho menor en relación a la presentada por el material sólido ( 7,5 a $40 \%$ de ésta).

Aunque la resistencia desarrollada sobre moldes de circona es superior a la obtenida en alúmina, las mejores propiedades mecánicas se obtienen al utilizar itria como soporte. La pérdida de resistencia entre las piezas desarrolladas en moldes de $\mathrm{ZrO}_{2}$ respecto a las de $\mathrm{Y}_{2} \mathrm{O}_{3}$ resulta mayor cuanto menor el tamaño de las microesferas utilizadas, generándose pérdidas incluso superiores al $100 \%$. Por ello, pese a que el uso de moldes de gres, alúmina o circona resulta más ventajoso desde el punto de vista industrial, pues no requiere recubrir moldes ni proceder a su limpieza tras cada ciclo de sinterización, no parece aconsejable su uso, siendo más recomendable mejorar el método de deposición de la itria con el fin de crear recubrimientos más estables y duraderos.

No obstante, dado que las mejores propiedades mecánicas se alcanzan a temperaturas elevadas y tiempos largos de sinterización, resulta necesario plantear posteriores estudios con el fin de mejorar la adhesión del recubrimiento, o incluso tratar de conformar moldes enteramente con itria.

Por otra parte, tal como se indicaba en el panorama científico, el hueso cortical humano presenta un límite elástico a compresión entre 110 y 200 MPa, siendo éste menor a tracción y a flexión [Comín 1999, Wen 2002 b, Heimann 2002, Asaoka 2003]. Por tanto, únicamente es posible alcanzar unas propiedades mecánicas, resistencia y tenacidad, adecuadas sinterizando sobre itria, donde la combinación de los parámetros del proceso temperatura, tiempo de sinterización y tamaño de las microesferas de partida ha permitido obtener un amplio abanico de propiedades 
mecánicas (25 - $320 \mathrm{MPa}$ ), con una rigidez muy inferior en relación a la presentada por el material denso.

En la siguiente tabla se resume la resistencia a flexión, $\sigma_{y}$, de las piezas porosas de Ti6Al4V desarrolladas mediante sinterización de microesferas sobre moldes de itria:

Tabla. 5.9. $\sigma_{y}$ a flexión en función de la fracción granulométrica de microesferas.

\begin{tabular}{|c|c|c|}
\hline TIPO & GRANULOMETRIA, $\mu \mathrm{m}$ & $\sigma_{\mathbf{y}}, \mathbf{M P a}$ \\
\hline GF & $-250 /+180$ & 57 a 320 \\
\hline GM & $-300 /+212$ & 57 a 250 \\
\hline GG & $-600 /+425$ & 17 a 106 \\
\hline
\end{tabular}

Cuanto menor el tamaño de las microesferas utilizadas, mejores propiedades mecánicas aunque, tal como se vió en el apartado 5.3.2.3, menor el tamaño de poro de la pieza porosa, lo que reduce la probabilidad de que se produzca el crecimiento óseo.

Tal como se observa en las figuras 5.74 a 5.76 , el rango de resistencia dentro de cada fracción granulométrica es debido a los distintos ciclos de sinterización Temperatura / tiempo. La máxima desviación respecto al modelo propuesto se obtiene para la granulometría más grosera, especialmente a las temperaturas más elevadas. Ello podría ser debido al predominio de distintos mecanismos de sinterización en función del tamaño de la microesfera, véase apartado 5.3.3.2, lo que modificaría ligeramente la relación entre las variables temperatura, tiempo y tamaño de microesfera. 


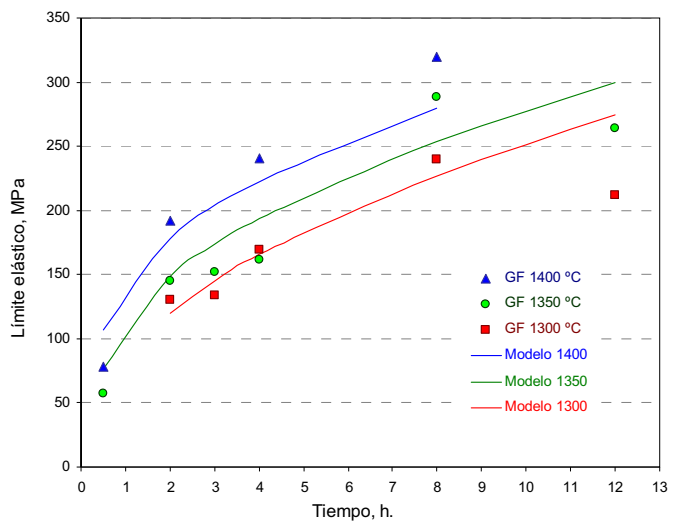

Fig. 5.74. R. Flexión de probetas de GF sinterizadas en moldes de itria entre 1300 y $1400^{\circ} \mathrm{C}$, de 0,5 a 12 horas y modelo de correlación.

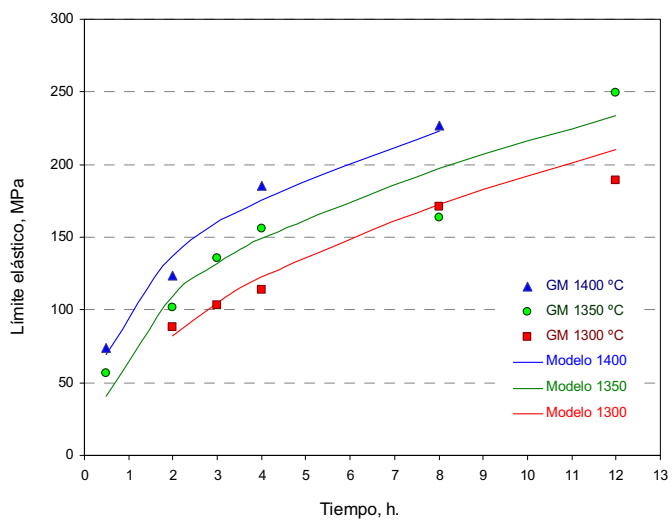

Fig. 5.75. R. Flexión de probetas de GM sinterizadas en moldes de itria entre $1300 \mathrm{y}$ $1400^{\circ} \mathrm{C}$, de 0,5 a 12 horas y modelo de correlación.

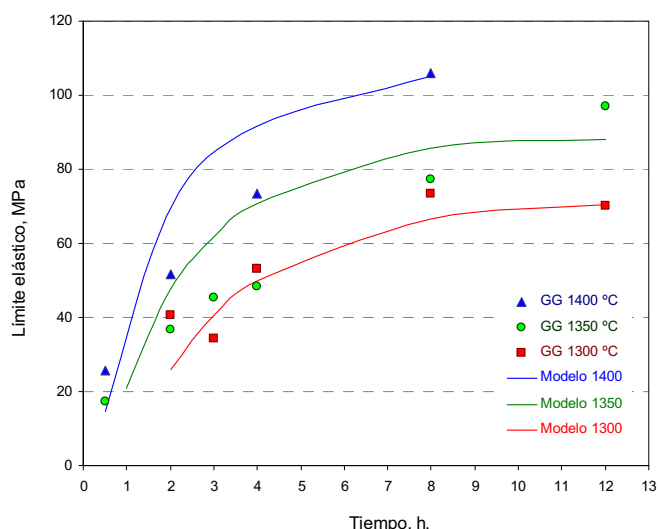

Fig. 5.76. R. Flexión de probetas de GG sinterizadas en moldes de itria entre 1300 y $1400^{\circ} \mathrm{C}$, de 0,5 a 12 horas y modelo de correlación. 
Pese a que la concreción de los parámetros de proceso vendrá determinada por la aplicación concreta a la que sea sometido el implante, en términos generales cabe indicar que se emplearán microesferas tan finas como sea posible (en función del tamaño de poro que permita la vascularización), con tiempos mínimos de 4 horas y temperaturas entre 1350 y $1400{ }^{\circ} \mathrm{C}$.

Se ha obtenido modelos de correlación que permiten estimar tanto la resistencia a flexión, como la rigidez de las piezas porosas desarrolladas por sinterización de microesferas. Pese a que se necesitaría un número mayor de probetas para que la muestra resultase representativa, suponen una herramienta para aproximar las propiedades a obtener en función del tamaño de la microesfera, temperatura y tiempo de sinterización.

\subsubsection{ANÁLISIS DE ELEMENTOS.}

Con el fin de establecer un rango de magnitud y dado que no existe un estándar para piezas porosas de Ti6Al4V, se comparan los valores obtenidos con los permitidos por las normas ASTM F1472-99, para piezas de Ti6Al4V de forja utilizables como implantes [ASTM F1472], y ASTM F1108-97a, para implantes de Ti6Al4V obtenidos por colada [ASTM F1108]. No obstante, cabe adoptar estas normas como una mera referencia, pues la mayor superficie específica de las piezas porosas desarrolladas en relación a las obtenidas por forja o colada, así como el hecho de ensayar las piezas directamente tras su sinterización, sin aplicar tratamientos químicos para eliminar posibles capas endurecidas [ASM N4 1994] probablemente originará que el contenido en intersticiales resulte superior.

\subsubsection{Análisis de carbono.}

Tal como se observa en la figura 5.77, al obtener piezas porosas de Ti64 mediante sinterización de microesferas, siempre se produce una ganancia de $\mathrm{C}$ con respecto a las microesferas de partida, siendo ésta generalmente mayor cuanto menor el tamaño de la microesfera, lo que se debe a su mayor superficie específica [German 2005]. 
Considerando que la reactividad resulta superior en el titanio poroso, pues dispone de mayor superficie específica, el contenido en carbono puede considerarse bueno pues oscila entorno a 0,08 y $0,1 \% \mathrm{Wt}$, valores límite establecidos por las normas ASTM F1472 y ASTM F1108 para piezas de forja y colada respectivamente.

Por otra parte, el incremento en carbono, C, podría deberse a la contaminación del tubo en ciclos previos, por lo que la mayor temperatura alcanzada podría ayudar a quemar las partículas existentes en el horno, originando así un descenso de $\mathrm{C}$ a medida que aumenta la temperatura.

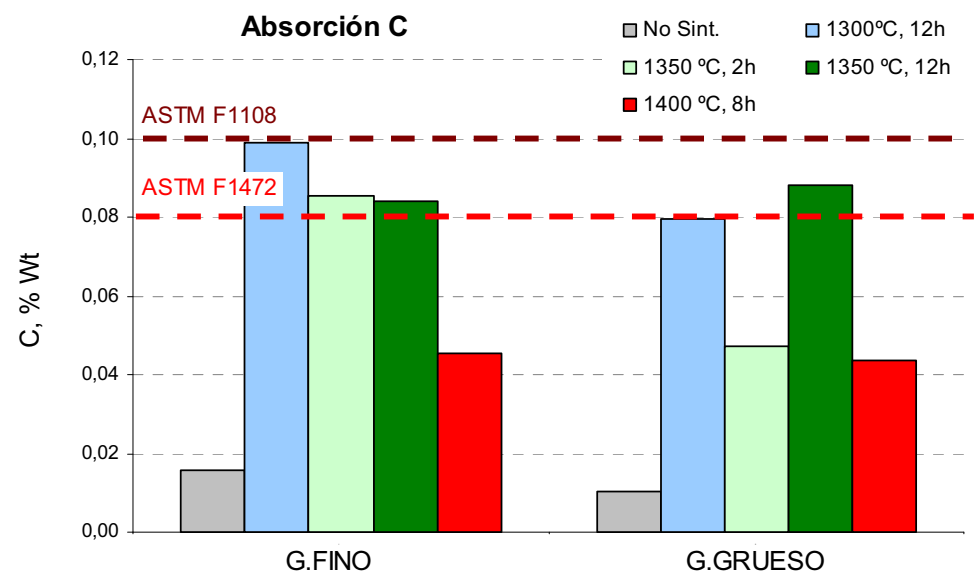

Fig. 5.77. Análisis de $C$ de piezas porosas de Ti64 obtenidas por sinterización de microesferas.

Los análisis de azufre muestran todo lo contrario, pues el contenido de azufre se reduce, resultando poco significativo y, en todos los casos, inferior a $0,004 \% W t$.

\subsubsection{Análisis de $\mathrm{N} \mathrm{y} \mathrm{O}_{2}$.}

Tal como se observa en las figuras 5.78 y 5.79 , salvo en la pieza de GG sinterizada a $1400^{\circ} \mathrm{C} 8 \mathrm{~h}$, la presencia de $\mathrm{O}_{2}$ y $\mathrm{N}$ resulta generalmente superior cuanto menor el tamaño de las microesferas. El incremento de $\mathrm{O}_{2}$ resulta excesivo únicamente en las piezas que atraviesan la capa de itria y reaccionan con el molde base de $\mathrm{Al}_{2} \mathrm{O}_{3}\left(\mathrm{GG} 1400^{\circ} \mathrm{C}\right.$ h8) pues, en general, 
se mantiene por debajo de 0,28 \%Wt, figura 5.78. Por tanto, los análisis corroboran los resultados previos obtenidos, donde se observaba como la reacción con el molde de $\mathrm{Al}_{2} \mathrm{O}_{3}$ provocaba un fuerte endurecimiento y una merma considerable de propiedades mecánicas, véase apartado 5.2.1.

Por otro lado, aumenta la presencia de $\mathrm{O}_{2}$ y $\mathrm{N}$ en relación a las microesferas de partida, manteniéndose el nivel de $\mathrm{O}_{2}$ generalmente más estable respecto al $\mathrm{N}$. En este sentido, pese a que el contenido en $\mathrm{O}_{2}$ resulta algo superior a $0,20 \% \mathrm{Wt}$, límite permitido por las normas adoptadas como referencia [ASTM F1472, ASTM F1108], podría considerarse admisible teniendo en cuenta la mayor reactividad por tratarse de un material poroso.

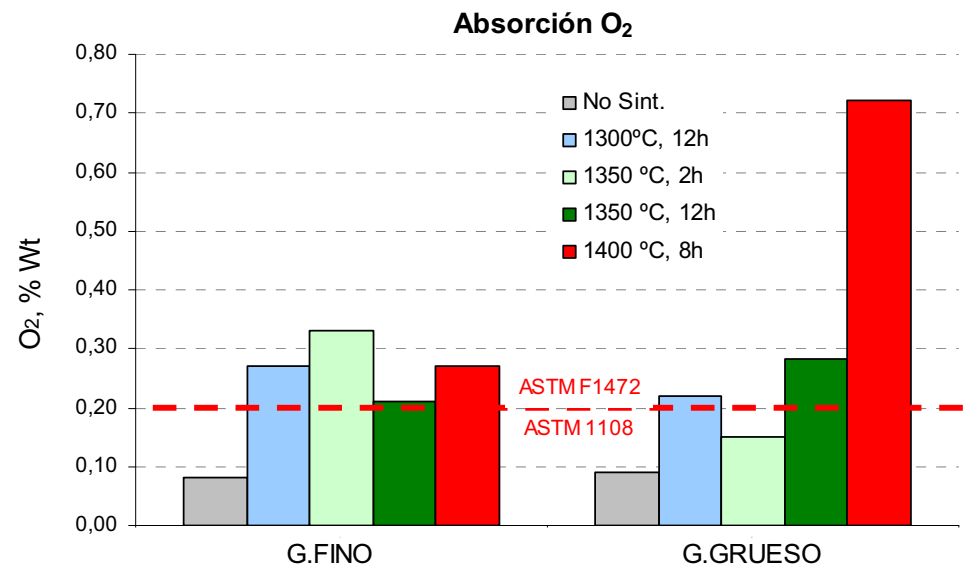

Fig. 5.78. Análisis de $\mathrm{O}_{2}$ piezas porosas de Ti64 obtenidas por sinterización de microesferas. GG, $1400^{\circ} \mathrm{C}$, 8h: restos de itria en la pieza.

Como muestra la figura 5.79, los niveles de nitrógeno siempre resultan inferiores al máximo permitido por las normas ASTM F1108 y F1472. 


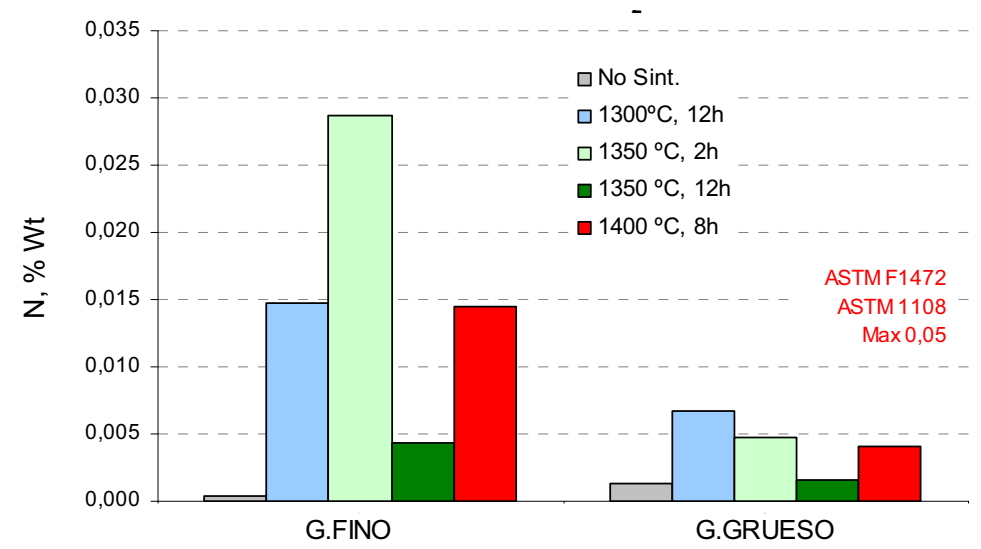

Fig. 5.79. Análisis de $\mathrm{N}$ piezas porosas de Ti64 obtenidas por sinterización de microesferas. GG, $1400^{\circ} \mathrm{C}$, 8: restos de itria en la pieza.

\subsubsection{TRATAMIENTOS TÉRMICOS.}

En la presente investigación se realizaron tratamientos térmicos con el fin de mejorar las propiedades mecánicas y, con ello, mejorar la resistencia a fatiga de las piezas porosas obtenidas, mediante la modificación de su microestructura. Tal como se ha indicado en el desarrollo experimental, los tratamientos fueron realizados tanto en dilatómetro, como en horno.

\subsubsection{Tratamientos térmicos realizados en dilatómetro.}

Se realizaron cuatro ciclos térmicos sobre un mismo tipo de pieza porosa, de granulometría media $(-300 /+212 \mu \mathrm{m})$ sinterizada a $1350{ }^{\circ} \mathrm{C}$ durante 2 horas. En todos ellos las rampas se calentamiento y enfriamiento se realizaron a $20^{\circ} \mathrm{C} / \mathrm{min}$, a excepción del enfriamiento desde la primera isoterma $\left(1027^{\circ} \mathrm{C}\right)$ hasta la segunda $\left(815^{\circ} \mathrm{C}\right)$, EF1, cuyas velocidades se indican en la tabla 5.10 . Tras una permanencia de 15 minutos a $815^{\circ} \mathrm{C}$, se alcanzaron las temperaturas y indicadas en la tabla, IS3, que fueron mantenidas 480 y 120 minutos para los tratamientos tipo B y $S$ respectivamente. 
Tabla 5.10. Tratamientos térmicos aplicados en el dilatómetro.

\begin{tabular}{|c|c|c|c|c|c|}
\hline \multirow{2}{*}{ TT } & \multirow{2}{*}{ IS $1,{ }^{\circ} \mathrm{C}$} & \multirow{2}{*}{$\begin{array}{l}\mathrm{EF} 1, \\
{ }^{\circ} \mathrm{C} / \mathrm{min}\end{array}$} & \multirow{2}{*}{ IS $2,{ }^{\circ} \mathrm{C}$} & \multicolumn{2}{|c|}{ IS3 } \\
\hline & & & & $\mathrm{T},{ }^{\circ} \mathrm{C}$ & $t, \min$ \\
\hline B & \multirow{4}{*}{1027} & 3 & \multirow{4}{*}{815} & \multirow{2}{*}{843} & \multirow{2}{*}{480} \\
\hline BT & & 50 & & & \\
\hline$S$ & & 3 & & \multirow{2}{*}{621} & \multirow{2}{*}{120} \\
\hline ST & & 50 & & & \\
\hline
\end{tabular}

Puesto que todos los ciclos presentaban la misma rampa de calentamiento inicial hasta los $1027^{\circ} \mathrm{C}$, se observa una dilatación $(\Delta \mathrm{L})$ constante hasta que, entorno a los $750{ }^{\circ} \mathrm{C}$ se inicia una transformación mediante la cual la probeta inicia su contracción, figura 5.80 .

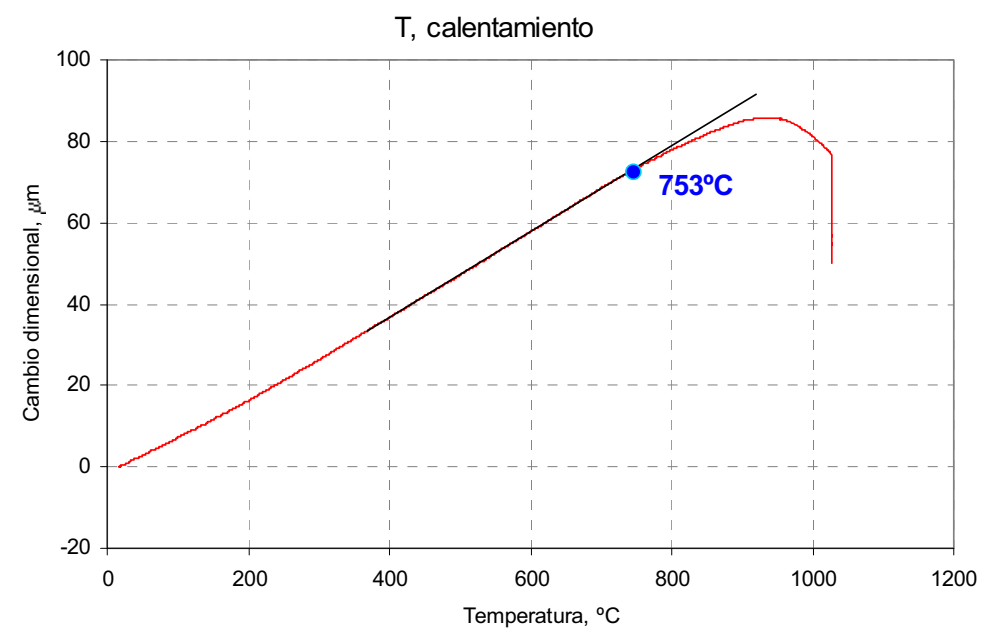

Fig. 5.80. Cambios dimensionales en el calentamiento hasta $1027^{\circ} \mathrm{C}$, ciclo S.

Pese a que, durante el calentamiento la transformación alotrópica entre las fases $\alpha$ y $\beta$ del titanio, cuando este es puro, se origina entorno a los $882^{\circ} \mathrm{C}$ [ASM N9 2004, Lütjering 2007], según autores como Tarín [Tarín 1995] para la aleación Ti64 dicha transformación iniciaría antes, desarrollándose entre los 800 y $1024^{\circ} \mathrm{C}$. No obstante, en el diagrama Ti-V, figura 5.81 , se observa 
una transformación eutectoide a los $675^{\circ} \mathrm{C}$, mediante la cual iniciaría la transformación a fase $\beta$. Dado que el Al estabiliza la fase $\alpha$, su presencia modificará ligeramente el diagrama Ti-V, ensanchando la zona de estabilidad de la fase a y, por tanto, elevando la temperatura de dicha transformación.

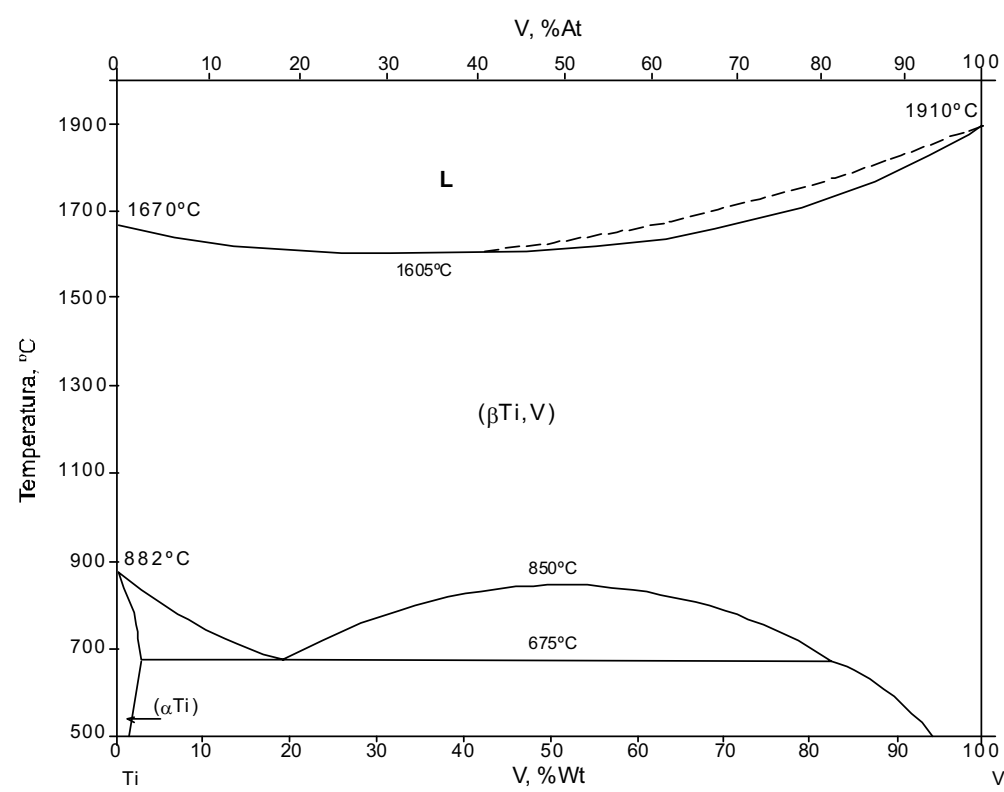

Fig. 5.81. Diagrama de fase Titanio - Vanadio [ASM N3 1997].

Por otro lado, aunque la composición de las fases, $\alpha(\mathrm{HC})$ y $\beta(\mathrm{CC})$, puede variar ligeramente en función del tratamiento térmico aplicado y del contenido en elementos intersticiales, los parámetros de red típicos de la fase $\alpha(\mathrm{HC})$ oscilan entorno a $a=0,293 \mathrm{~nm}$ y $\mathrm{c}=0,467 \mathrm{~nm}$, mientras que el de la fase $\beta$ (CC) oscila entorno $a=0,332 \mathrm{~nm}$ [Rodríguez 1999, Leyens 2003], figura 5.82, por lo que la transformación alotrópica de la fase $\alpha$ a $\beta$, implica una contracción. 


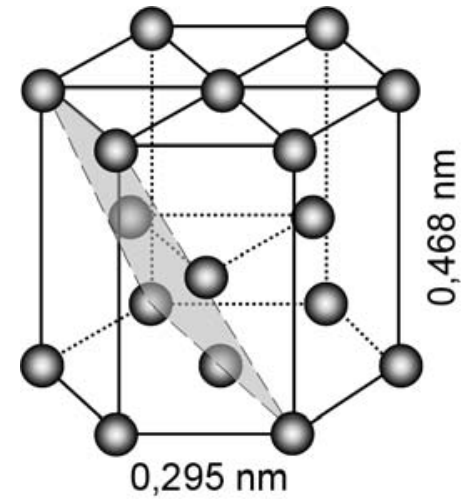

a

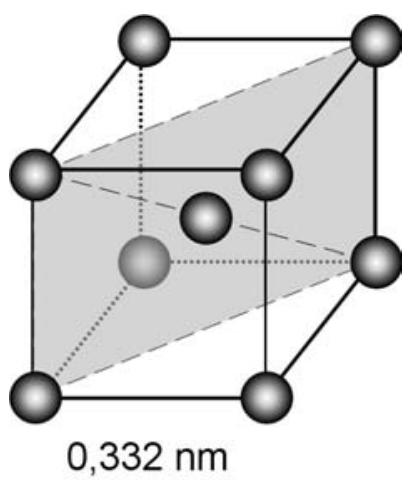

$\mathrm{b}$

Fig. 5.82. Parámetros de red típicos de las fases $\alpha(\mathrm{HC})$ y fase $\beta(\mathrm{CC})$ del titanio.

En definitiva, las observaciones realizadas apuntan a que la transformación observada en todos los ciclos térmicos aplicados cuyo inicio se produce entorno a los $750^{\circ} \mathrm{C}$, corresponde a la transformación alotrópica de la fase $\alpha$ a la fase $\beta$ de la aleación Ti6Al4V.

\subsection{Transformaciones dilatométricas en los ciclos B y} BT.

En los tratamientos denominados B y BT, tras el calentamiento hasta $1027^{\circ} \mathrm{C}$, se realizó un enfriamiento hasta temperatura de $815^{\circ} \mathrm{C}$, a velocidades de $3^{\circ} \mathrm{C} / \mathrm{min}$ y $50^{\circ} \mathrm{C} / \mathrm{min}$ respectivamente, tabla 5.10 . Únicamente se produjeron transformaciones durante el primer enfriamiento, no observándose modificaciones en el coeficiente de dilatación de las muestras durante el resto del ciclo.

Como se ha indicado, durante la isoterma de $1025^{\circ} \mathrm{C}$, la muestra contrae de forma constante, figura 5.80, lo que es debido a la transformación alotrópica de la fase $\alpha$ a fase $\beta$ del titanio. Al enfriar, se inicia una transformación entorno a los $1008{ }^{\circ} \mathrm{C}$ que provoca que la muestra empiece a dilatar en lugar de contraer, figuras 5.83 y 5.84. Cuando dicha transformación finaliza, la pendiente de la curva es distinta a la inicial, lo que indica que la microestructura se ha modificado. 


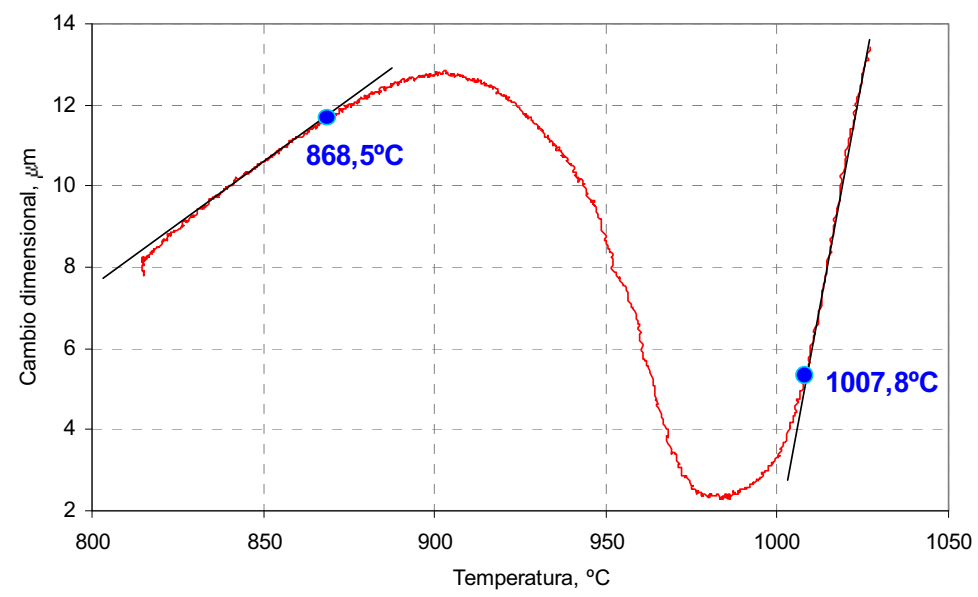

Fig. 5.83. Tratamiento $\mathrm{B}$, enfriamiento desde 1027 a $815^{\circ} \mathrm{C}$, a $3^{\circ} \mathrm{C} / \mathrm{min}$.

Cuando el enfriamiento es lento $\left(3^{\circ} \mathrm{C} / \mathrm{min}\right)$, la transformación se produce entre los 1008 y $868{ }^{\circ} \mathrm{C}$, figura 5.83 , e involucra un cambio dimensional entorno a 6 micras $\left(\varepsilon_{y} \approx 0,067 \%\right)$. Por el contrario, cuando el enfriamiento se realiza a $50^{\circ} \mathrm{C}$, el rango de temperaturas entre el que se producen las transformaciones es más estrecho (1009 a $\left.901^{\circ} \mathrm{C}\right)$, e involucra un cambio dimensional menor, entorno a 1 micra ( $\varepsilon_{y} \approx 0,011 \%$ ), figura 5.84. En consecuencia, la microestructura resultante es más fina en el segundo caso, figura 5.85, pues se invierte más energía en la nucleación, quedando menos tiempo para el crecimiento del grano [Amigó 2001, Callister 2005], (para más información véase microestructuras en Anexo 1). 


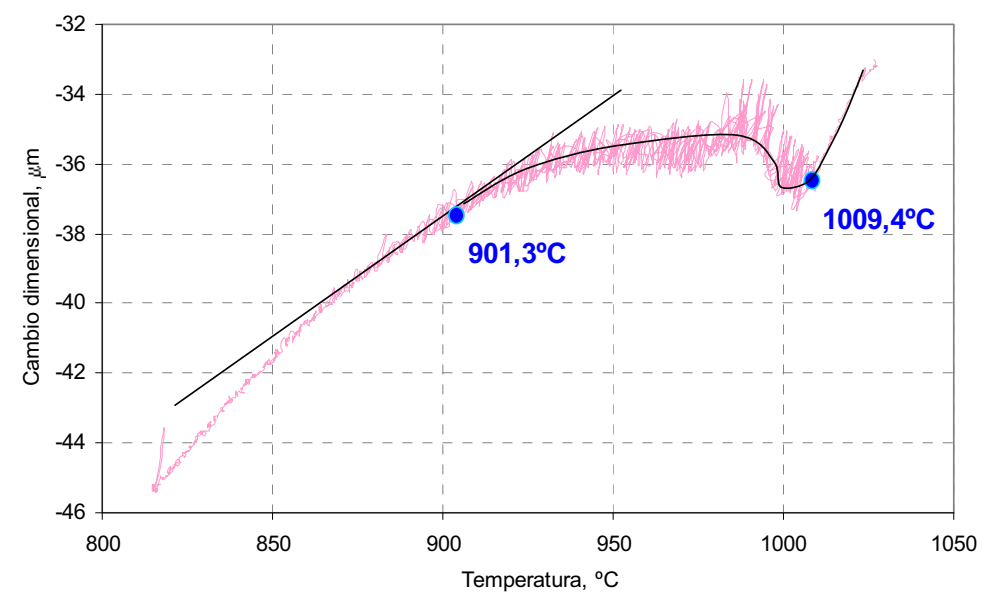

Fig. 5.84. Tratamiento BT, enfriamiento desde 1027 a $815^{\circ} \mathrm{C}$, a $50^{\circ} \mathrm{C} / \mathrm{min}$.

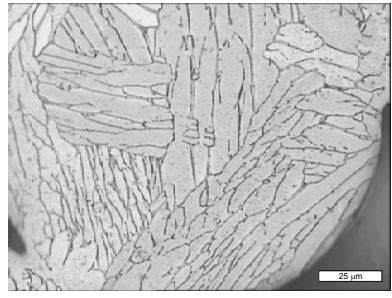

a

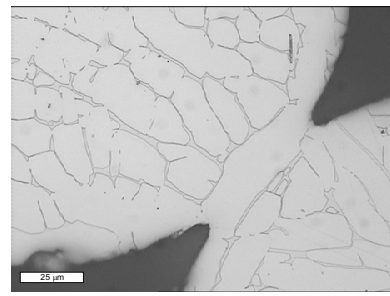

b

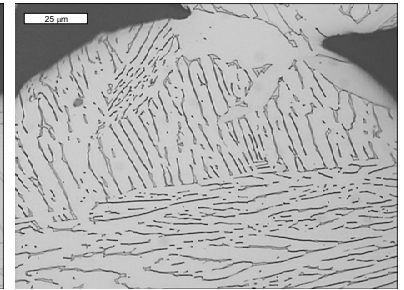

C

Fig. 5.85. Microestructura obtenida tras la sinterización y tras los tratamientos realizados en dilatómetro: a) Sin TT, sinterizada a $1350^{\circ} \mathrm{C}, 2 \mathrm{~h}$; b) TT tipo B; c) TT tipo BT.

Según el diagrama de fases aportado por Leyens [Leyens 2003] para el Ti6Al con $4 \%$ de vanadio, figura 5.86 , entorno a los $1000{ }^{\circ} \mathrm{C}$ se inicia la descomposición de la fase $\alpha$ en $\alpha+\beta$, resultando una microestructura más fina cuanto más rápido es el enfriamiento desde fase $\beta$ [Tarín 1999, Rodríguez 1999, Leyens 2003]. 


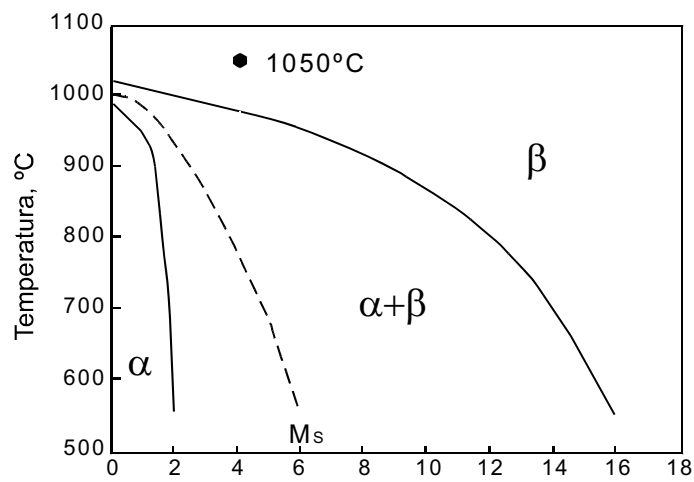

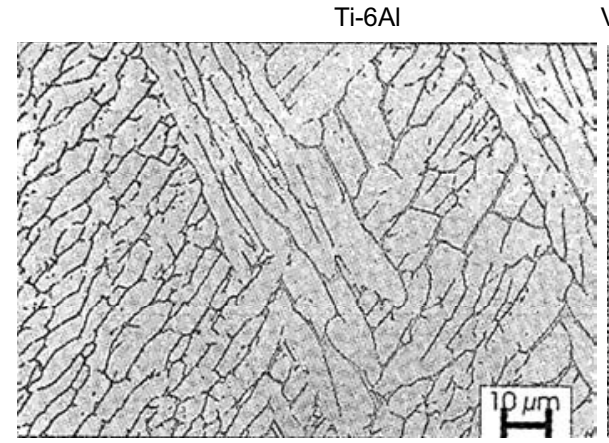

a

$\mathrm{V}, \% \mathrm{Wt}$

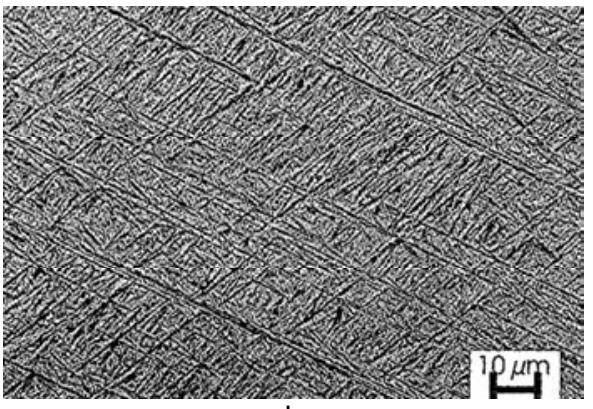

b

Fig. 5.86. Transformación desde fase $\beta$ para una aleación Ti-6Al con distintos contenidos en V. Microestructuras obtenidas al: a) Enfriar en horno; b) Templar en agua [Adaptado de Leyens 2003].

Tal como se ha observado en la figura 5.85 , al enfriar lentamente $\left(3^{\circ} \mathrm{C} / \mathrm{min}\right)$ desde fase $\beta$, se genera una microestructura laminar de placas a de Widmanstätten. La ralentización del proceso de enfriamiento permite una difusión controlada entre las fases $\alpha$ y $\beta$ cuando la temperatura desciende por debajo de la temperatura de transición (entorno a $1020^{\circ} \mathrm{C}$ para el Ti64), y la fase $\alpha$ comienza a nuclear en los bordes de grano $\beta$, creciendo en forma de láminas. La estructura laminar resultante se compone de gruesas placas de fase $\alpha$ y finas placas de fase $\beta$, unidas formando paquetes o colonias [Tarín 1999, Gil 2001, Leyens 2003].

Por el contrario, pese a que los tratamientos aplicados fueron variaciones del conocido BUS [Amigo 2003b, ASM N9 2004], véase apartado 2.8, al enfriar rápidamente desde temperaturas superiores a la de transición $\beta$, no 
se observa la rotura de las láminas existentes, sino más bien una transformación martensítica, generada por transformación sin difusión desde la fase $\beta$ [Leyens 2003, ASM N9 2004]. La martensita tipo $\alpha$ ' posee una estructura hexagonal compacta, con parámetros de red similares a los de la fase $\alpha$ y presenta una estructura finamente laminar. A diferencia de los aceros, el efecto de endurecimiento producido por la martensita es reducido, debido al gran tamaño de grano, y a la inexistencia de supersaturación por átomos intersticiales [ASM N9 2004, Rodríguez 1999, Leyens 2003].

\subsection{Transformaciones dilatométricas en los ciclos S y ST.}

En los tratamientos térmicos denominados S y ST, el primer tramo del ciclo térmico aplicado, hasta la isoterma de $815^{\circ} \mathrm{C}$, fue el mismo, por lo que las transformaciones resultan semejantes, resultando una microestructura más fina en el ST respecto al S, figura 5.87 (Anexo 1 para más información).

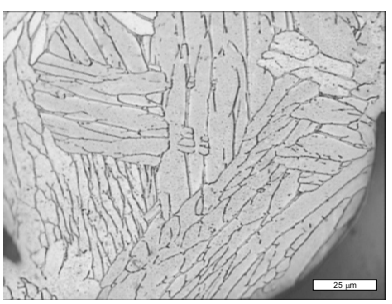

a

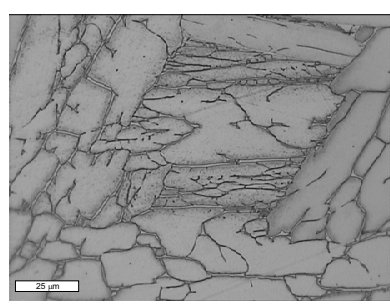

b

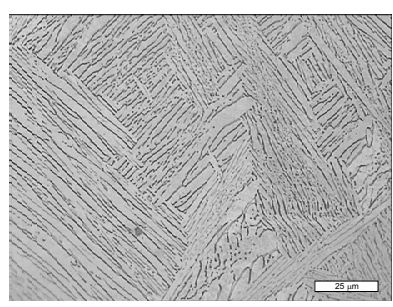

$\mathrm{C}$

Fig. 5.87. Microestructura obtenida tras la sinterización y tras los tratamientos realizados en dilatómetro: a Sin TT, sinterizada a $1350^{\circ} \mathrm{C}, 2 \mathrm{~h}$; b) TT tipo S; c) TT tipo ST.

Por otro lado, mientras que en el tratamiento $B$ no se observaban transformaciones tras la isoterma de $815^{\circ} \mathrm{C}$, en los tratamientos S y ST se producen dos saltos dilatométricos. Así, la primera transformación $\left(\approx 700^{\circ} \mathrm{C}\right)$ ocurre únicamente cuando el enfriamiento previo ha sido lento (S), mientras la segunda aparece tanto en el S como ST, ocurriendo a menor temperatura cuanto más rápido ha sido el primer enfriamiento $\left(653^{\circ} \mathrm{C}\right.$ en ST respecto a $677^{\circ} \mathrm{C}$ en S), figuras 5.88 y 5.89 . Estas diferencias son producto de la microestructura resultante de la primera etapa, siendo en el enfriamiento rápido de tipo martensítica, y de láminas relativamente groseras de las fases $\alpha$ y $\beta$ alternadas en el enfriamiento lento, figura 5.87. 


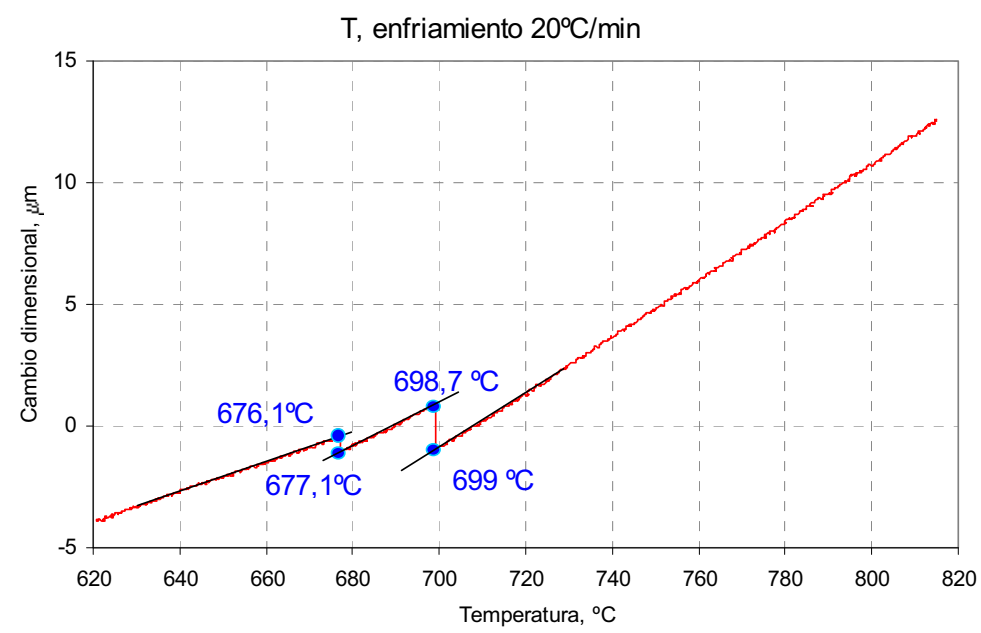

Fig. 5.88. Tratamiento $\mathrm{S}$, enfriamiento desde 815 a $621^{\circ} \mathrm{C}$, con enfriamiento anterior a $3^{\circ} \mathrm{C} / \mathrm{min}$.

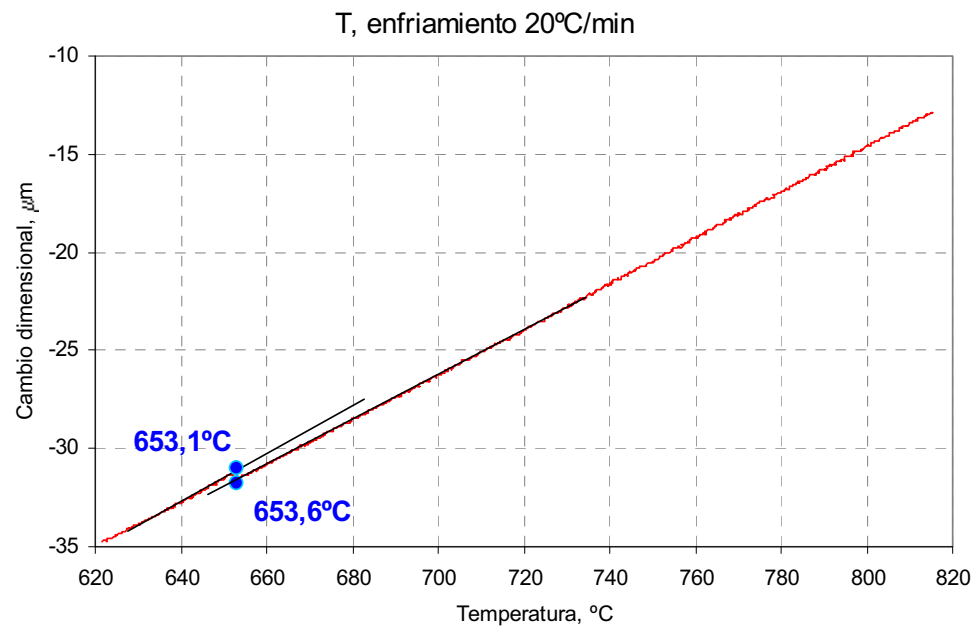

Fig. 5.89. Tratamiento ST, enfriamiento desde 815 a $621{ }^{\circ} \mathrm{C}$, con enfriamiento anterior a $50^{\circ} \mathrm{C} / \mathrm{min}$.

Por tanto, a diferencia de los tratamientos B y BT, resulta destacable que en los tratamientos $S$ y ST las modificaciones de la primera rampa de enfriamiento (hasta $815^{\circ} \mathrm{C}$ ), si influyen en el comportamiento de la muestra durante el segundo enfriamiento, hasta $621^{\circ} \mathrm{C}$. En definitiva, la diferente 
microestructura obtenida durante el primer enfriamiento, función de la velocidad, condiciona los cambios dimensionales originados tras la segunda isoterma $\left(815^{\circ} \mathrm{C}\right)$. Tal como se observa, al descender por debajo de los 815 ${ }^{\circ} \mathrm{C}$ el material va contrayendo de forma homogénea hasta sufrir una expansión brusca, tras la cual la pendiente de la curva resulta menor, lo que implica un cambio microestructural.

La microestructura resultante, figuras 5.85 y 5.87 , confirma el hecho de que las transformaciones que sufre el material son distintas pues, pese a que la velocidad de enfriamiento es la misma en los tratamientos BT y ST, la microestructura resultante del ST es más fina y posee menor espesor de fase $\alpha$ en la zona de los cuellos de unión en relación a la obtenida mediante el BT, véase Anexo 1 para más información.

\subsubsection{Tratamientos térmicos realizados en horno.}

En horno se realizaron los dos tipos distintos de tratamientos térmicos, $\mathrm{B}$ y $\mathrm{S}$, anteriormente descritos, tabla 5.10. Concretamente se realizaron cuatro ciclos térmicos, los dos primeros en tubo de acero, y los últimos en tubo de alúmina, véase apartado 4.4.6.2. Además, se fue modificando el soporte base de las piezas y la limpieza previa del tubo con el fin de tratar de evitar la reactividad observada. Así, en el primer tratamiento las muestras se depositaron sobre un lecho de itria depositado sobre una bandeja de $\mathrm{Al}_{2} \mathrm{O}_{3}$, creando una atmósfera de Ar previo al inicio del ciclo. En el segundo ciclo se empleó una chapa de Ti64 como soporte, y se estabilizó previamente el sistema a $150{ }^{\circ} \mathrm{C}$ durante 30 minutos con el fin de eliminar la posible humedad residual. En los ciclos tercero y cuarto se sustituyó el tubo de acero por otro de $\mathrm{Al}_{2} \mathrm{O}_{3}$, y se modificó la atmósfera previa al vacío en el tubo haciendo pasar una corriente de $\mathrm{H}_{2}$ en lugar de $\mathrm{Ar}$, con el objeto de crear una atmósfera reductora y evitar así la oxidación superficial. En el cuarto ciclo se envolvió la chapa de titanio con alambre de acero con el fin de facilitar el contacto de las muestras con la atmósfera del horno también por su parte inferior. 
Los tratamientos térmicos realizados se resumen en la tabla 5.11:

Tabla 5.11. Tratamientos térmicos realizados sobre microesferas.

\begin{tabular}{|c|c|c|c|c|}
\hline CICLO & TUBO & SOPORTE & TT & PURGA FINAL \\
\hline 1 & Acero & Itria & B1 & $\mathrm{Ar}$ \\
\hline 2 & Acero & Placa Ti64 & S1 & $\mathrm{Ar}$ \\
\hline 3 & $\mathrm{Al}_{2} \mathrm{O}_{3}$ & Placa Ti64 & B2 & $\mathrm{H}_{2}$ \\
\hline 4 & $\mathrm{Al}_{2} \mathrm{O}_{3}$ & Placa Ti64 & S2 & $\mathrm{H}_{2}$ \\
\hline
\end{tabular}

Tras el primer ciclo se observó una fuerte oxidación de las muestras, especialmente en la zona de contacto con la itria, figura 5.90.

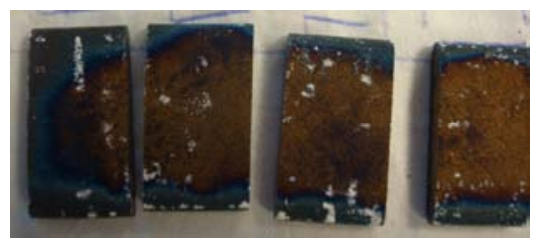

a

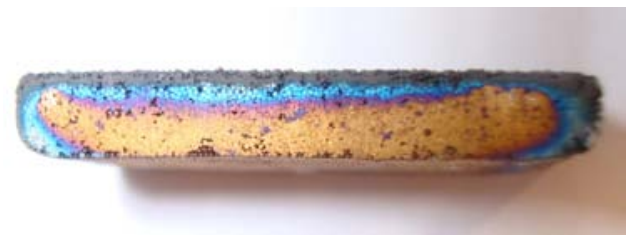

b

Fig. 5.90. Piezas tras la realización del primer ciclo térmico, B1: a) Cara en contacto con el molde; b) Vista de perfil, zona inferior en contacto con el molde.

El grosor de la capa de óxido formada crece desde la parte en contacto con la itria hasta el contacto con la atmósfera del horno con un grosor, de acuerdo con los estudios realizados por Van et al. [Van-Gils 2004], de 40 a $90 \mathrm{~nm}$ aproximadamente, tabla 5.12. El mayor espesor al contacto con la atmósfera del horno se justificaría por la mayor presencia de $\mathrm{O}_{2}$. 
Tabla 5.12. Color de los óxidos de titanio según el espesor de la capa formada [Adaptado de Van-Gils 2004].

\begin{tabular}{|c|c|}
\hline e, $\mathbf{n m}$ & Color \\
\hline 38 & Oro \\
\hline 40 & Cobre \\
\hline 46 & Azul púrpura \\
\hline 80 & Azul \\
\hline 90 & Azul claro \\
\hline 110 & Verde \\
\hline 120 & Amarillo \\
\hline 134 & Rosa \\
\hline
\end{tabular}

Tras la realización del segundo ciclo térmico las muestras también se oxidaron, aunque en menor medida, figura 5.91 .

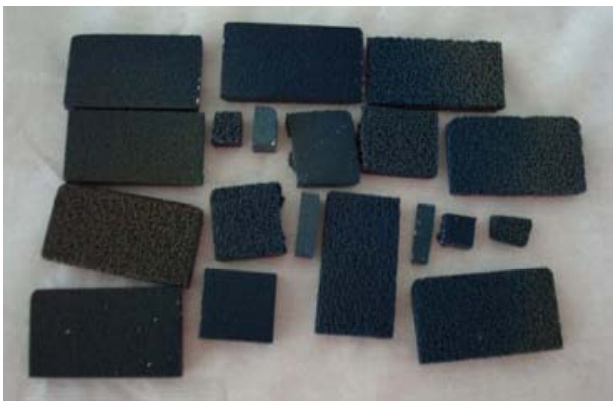

a

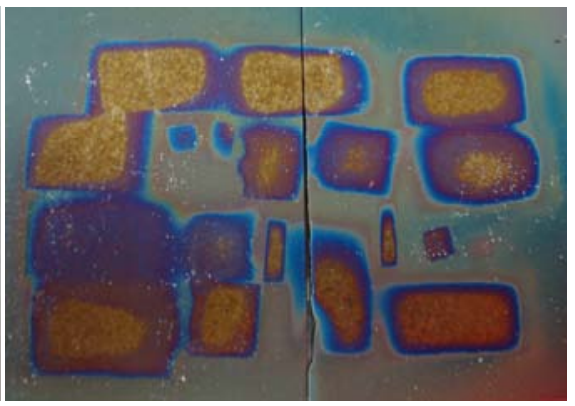

b

Fig. 5.91. Oxidación de piezas tras segundo ciclo térmico, S1. A) Contacto con atmósfera horno; b) Placa de Ti64.

Pese a que el diagrama de Ellingham de la figura 5.92 es para especies puras, y la presencia de elementos de aleación modifica ligeramente los cambios en su energía libre, se observa como los posibles óxidos de Fe y $\mathrm{Cr}$ (acero refractario) existentes en el tubo pueden ser fácilmente reducidos por el titanio para formar sus propios óxidos. 


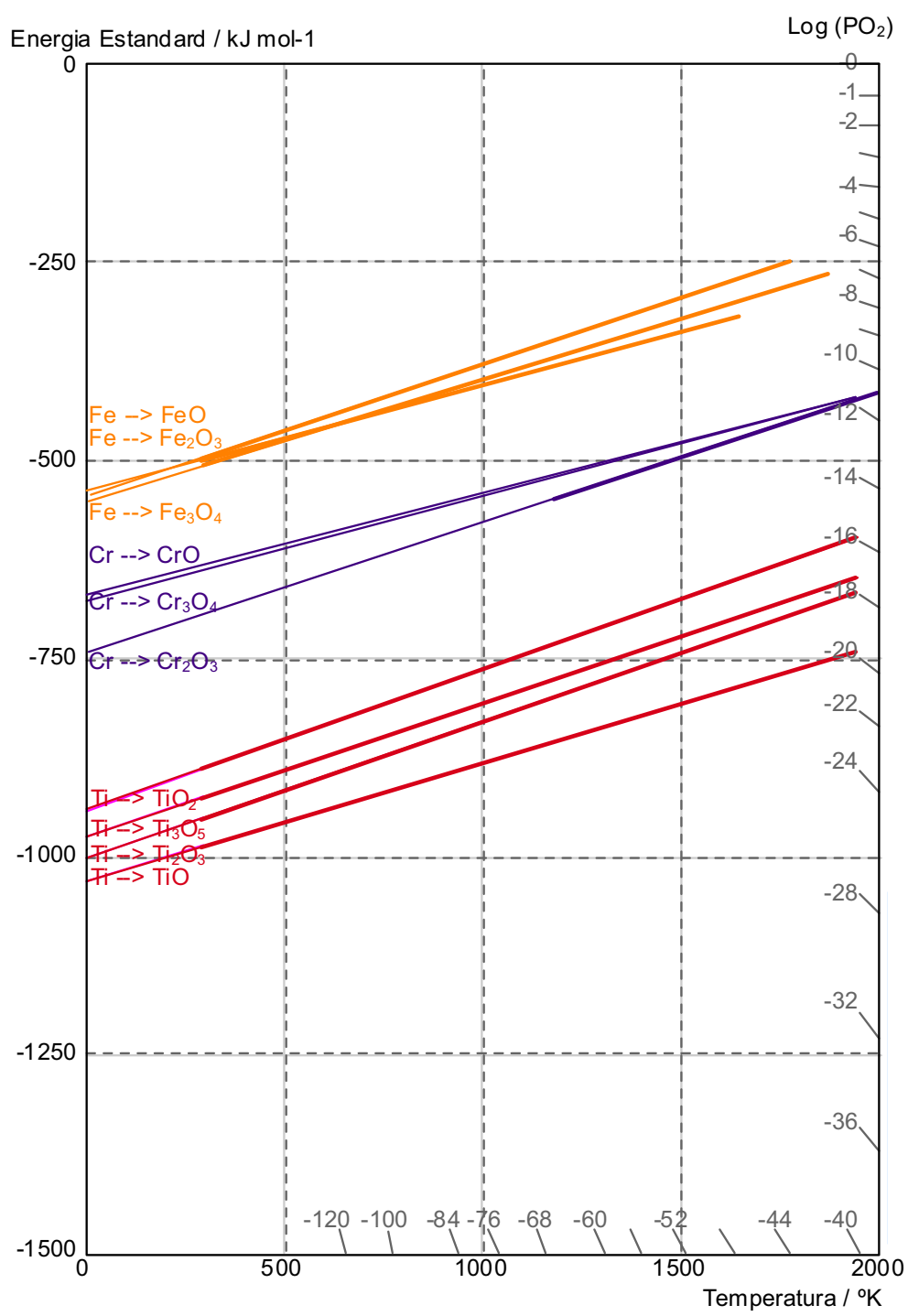

Fig. 5.92. Diagrama de Ellingham variación de la energía libre de óxidos de titanio, hierro y cromo. $\mathrm{T}\left({ }^{\circ} \mathrm{C}\right)=\mathrm{T}\left({ }^{\circ} \mathrm{K}\right)-273$. [Adaptado de "Interactive Ellingham diagram"].

Por otro lado, tras determinar la presión de disociación del óxido $\left(\log \mathrm{PO}_{2}=\right.$ $\Delta G / R T$, mediante el trazado de una línea desde $T=0, \Delta G=0$ hasta la temperatura deseada y prolongarla hasta la escala logarítmica), se observa como la oxidación del titanio se produce durante el enfriamiento, pues, por una parte, cuando disminuye la temperatura, se reduce la presión parcial de 
$\mathrm{O}_{2}$ de equilibrio, $\left(\mathrm{PO}_{2}=\operatorname{Exp} \mathrm{X}\right)$, con lo que la cantidad de oxígeno necesaria para que se formen óxidos de titanio es menor, mientras que, por otra, la energía de formación del óxido $(\Delta G)$ resulta más negativa, lo que implica mayor estabilidad del óxido de titanio y, por tanto, mayor tendencia a formarse [Muñoz 2005].

Pese a que el tercer y cuarto ciclos se realizaron en tubo de alúmina, empleando como soporte una chapa de Ti64 y realizando la última purga del tubo con hidrógeno en lugar de argón, las muestras también se oxidaron en ambos ciclos. Pese a que el nivel de oxidación resultó menor respecto a los ciclos anteriores, el proceso todavía no resulta adecuado para una aplicación como implante.

No obstante, se observó cierta oxidación de la lanza de sujeción del termopar, con una mayor reactividad en la zona donde se situaba éste, lo que podría justificar la oxidación de las muestras por las reacciones de reducción-oxidación anteriormente descritas. Por ello, previo a la realización del cuarto ciclo, se procedió a limpiar la lanza de sujeción del termopar con una lija. Ello, junto a la colocación de un alambre que evitase el contacto directo con la placa soporte, provocó una mejora sustancial del aspecto de las muestras, reduciéndose en gran medida el nivel de oxidación, figura 5.93 .

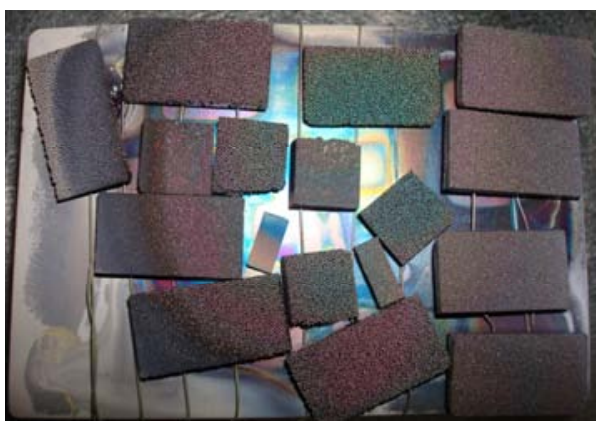

a

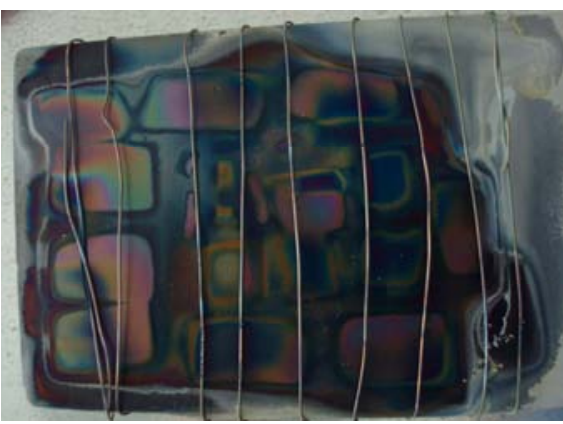

b

Fig. 5.93. Piezas tras cuarto ciclo térmico, S2. A) Contacto con atmósfera horno; b) Placa de Ti64. 
No obstante, como se desarrollará en el apartado siguiente, existe una fuerte influencia de la atmósfera residual del horno y, pese al mejor aspecto superficial de las piezas obtenidas en los ciclos 3 y 4 , con atmósfera residual de $\mathrm{H}_{2}$, las propiedades mecánicas de estas piezas resultan muy inferiores en relación a las de los ciclos 1 (B1) y 2 (S1).

5.3.6.2.1. Microestructura de las muestras tratadas térmicamente en horno.

Como se observa en la figura 5.94a (Anexo 1 para más información), en las muestras sinterizadas y sin aplicación de tratamiento térmico, se obtuvo una microestructura de tipo Windsmanstätten, conformada por finas láminas de fase $\alpha$ y $\beta$ alternadas, véase apartado 2.8. Como se ha indicado anteriormente, se trata de una microestructura generada por la difusión controlada entre las fases $\alpha$ y $\beta$ cuando se enfría desde fase $\beta$ por debajo de la temperatura de transición [Tarín 1999, Gil 2001, Leyens 2003].

A diferencia de en los tratamientos realizados en dilatómetro, la reducida velocidad de enfriamiento alcanzada en los tratamientos aplicados en horno provoca que en ningún caso se alcance un grano más fino en relación al de la pieza sinterizada, produciéndose siempre un engrosamiento de la microestructura existente durante la aplicación del tratamiento térmico, figura 5.94 b y c (véase Anexo 1). Ello, junto a la oxidación de las piezas y la formación de hidruros frágiles, justifica la pérdida de propiedades mecánicas.

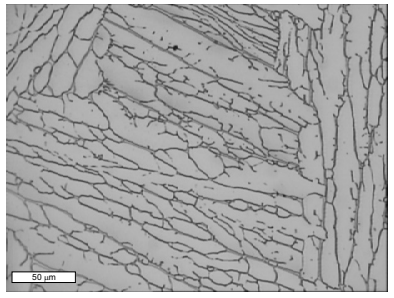

a

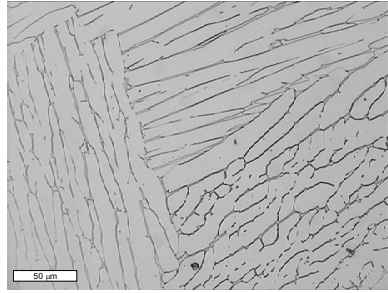

b

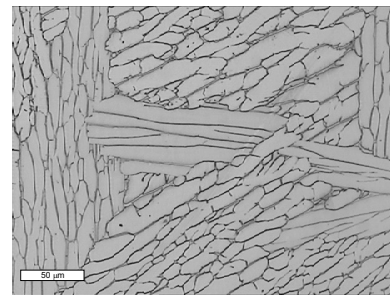

$\mathrm{C}$

Fig. 5.94. Microestructura obtenida tras la sinterización de microesferas GG sinterizadas a $1400{ }^{\circ} \mathrm{C} 8 \mathrm{~h}, \mathrm{y}$ tras los tratamientos realizados en horno: a) Pieza sinterizada; b) Tratamiento B; c) Tratamiento S. 
5.3.6.2.2. Propiedades mecánicas de las muestras tratadas térmicamente en horno.

En los siguientes gráficos, figuras 5.95 a 5.97, se observa la evolución de la resistencia a flexión en función del TT aplicado sobre probetas sinterizadas a $1350{ }^{\circ} \mathrm{C}$, durante $2 \mathrm{~h}$, de diferentes tamaños de microesfera inicial. Tal como se observa, en todos los casos se reducen drásticamente las propiedades mecánicas de la pieza obtenida, siendo tal reducción más acusada en los tratamientos tipo $B$ respecto a los tipo $S$.

Por otra parte, en los ciclos 1 (B1) y 2 (S1), donde el vacío se iniciaba desde una atmósfera residual de $\mathrm{Ar}$, se obtiene una resistencia más elevada respecto a los 3 (B2) y 4 (S2), en los que se partía de una atmósfera residual de hidrógeno. Por tanto, pese a que las probetas presentaban mejor aspecto tras los dos últimos tratamientos térmicos, la absorción de hidrógeno fragiliza enormemente el material.

Ésta reducción de resistencia podría atribuirse al engrosamiento de grano, figura 5.94, pero fundamentalmente es producto de la oxidación observada y el efecto perjudicial que ello implica [Baeslack 1993, Tarín 1999, Lütjering 2007]. La máxima reducción se produce en los ciclos 3 y 4, producto de la absorción de $\mathrm{H}_{2}$. Según diversos autores [Qazi 2003, Azevedo 2003], la solubilidad del $\mathrm{H}_{2}$ es reducida en la fase $\alpha(\mathrm{HC})$ del titanio, pero muy alta en la $\beta$ (hasta $50 \%$ ) y su presencia genera hidruros frágiles por transformación eutectoide a temperatura próxima a los $300{ }^{\circ} \mathrm{C}\left(\mathrm{Ti}-\beta \rightarrow \mathrm{Ti}-\alpha+\mathrm{TiH}_{2}-\delta\right)$. Por otra parte, la presencia de este elemento modifica la temperatura de transición $\beta$, descendiendo desde los 1000 hasta $810{ }^{\circ} \mathrm{C}$ cuando el $\mathrm{H}_{2}$ aumenta de 0 a 30\% [Qazi 2003].

En relación al tipo de tratamiento, cabe indicar que a igualdad de parámetros, los tipo $\mathrm{S}$ (Temperatura y tiempo de envejecido menor, $621^{\circ} \mathrm{C}$ $120 \mathrm{~min}$ ) generan mayor resistencia respecto a los tipo $\mathrm{B}\left(843^{\circ} \mathrm{C}, 480 \mathrm{~min}\right)$. Ello probablemente es debido al menor engrosamiento de las laminas $\alpha+\beta$ 
de la estructura original tras su rotura en el primer enfriamiento, véase Anexo 1.

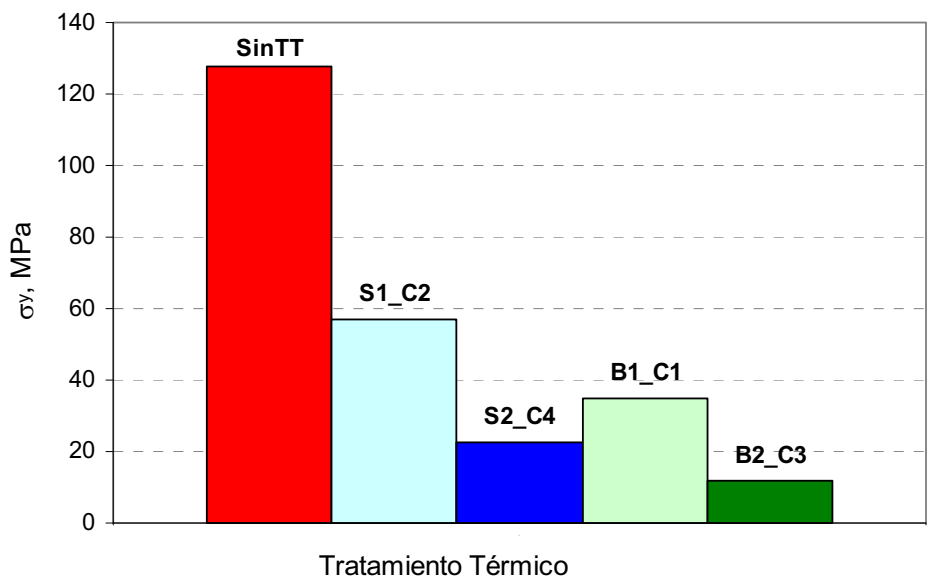

Fig. 5.95. Variación del límite elástico a flexión con el tratamiento térmico realizado. Microesferas de GF.

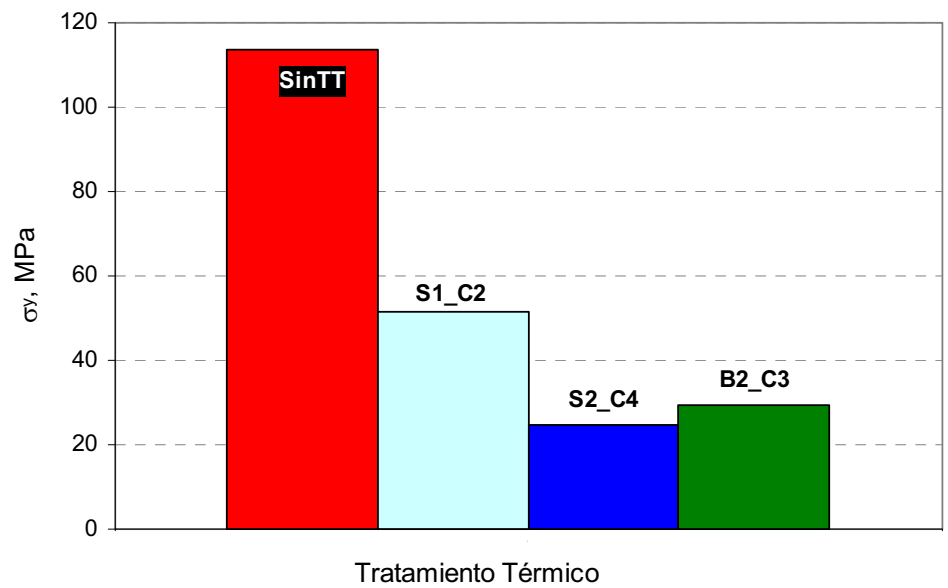

Fig. 5.96. Variación del límite elástico a flexión con el tratamiento térmico realizado. Microesferas de GM. 


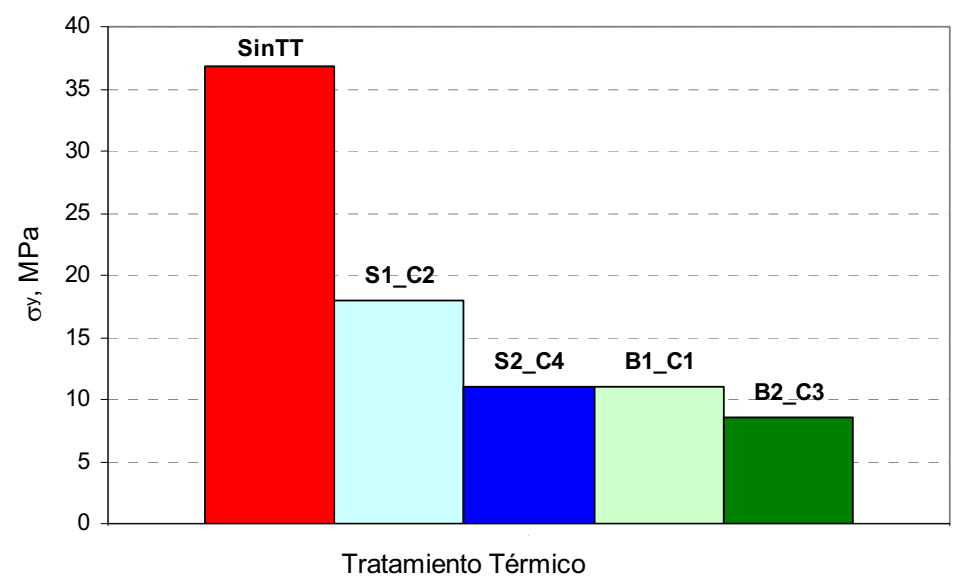

Fig. 5.97. Variación del límite elástico a flexión con el tratamiento térmico realizado. Microesferas de GG.

La comparación entre las curvas tensión - deformación de las probetas sin y con tratamiento térmico, pone de manifiesto la mayor capacidad de absorción de energía de las muestras originales, sin aplicación de tratamiento térmico, figura 5.98, lo que se debe a la fragilización de éstas provocada por la oxidación y formación de hidruros.

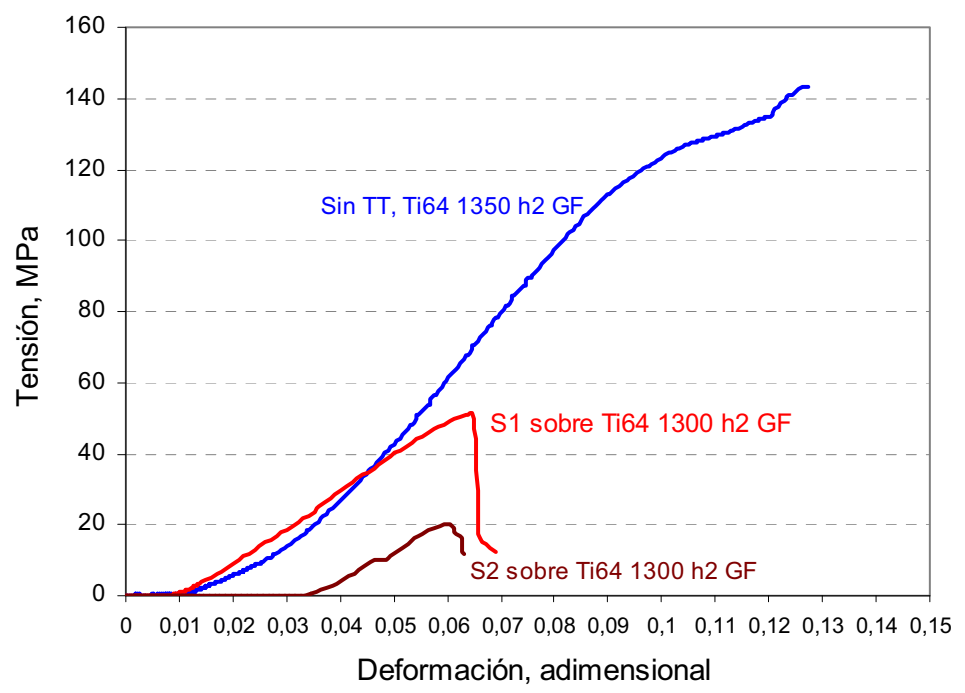

Fig. 5.98. Curvas tensión - deformación de microesferas de GF sinterizadas a $1350^{\circ} \mathrm{C}$ durante $2 \mathrm{~h}$, con y sin aplicación de $\mathrm{S} 1$ y $\mathrm{S} 2$. 
5.3.6.3. Conclusiones parciales de la aplicación de tratamientos térmicos.

Pese a que a nivel de laboratorio si es posible modificar la microestructura evitando la oxidación de las piezas porosas, al nivel industrial resulta complejo aplicar tratamientos térmicos al titanio con los medios técnicos habituales. Por un lado, la utilización de tubos de acero modifica la atmósfera del horno, mientras que el uso de tubos de alúmina limita la velocidad de enfriamiento a un máximo de $10^{\circ} \mathrm{C} / \mathrm{min}$, produciéndose la oxidación de las piezas junto con un engrosamiento de grano y pérdida de propiedades mecánicas.

Por otra parte, pese a que en los tratamientos aplicados en el dilatómetro, si se afinó la microestructura, la velocidad de enfriamiento aplicada resultó insuficiente, por lo que no se consiguió romper totalmente la microestructura resultante de la sinterización.

A pesar de todo, cabe indicar que sí existen empresas especializadas en la realización de éste tipo de tratamientos térmicos (Biovac S.A.), que logran modificar la microestructura en productos de forja evitando la oxidación de sus probetas. Estas empresas disponen de hornos de molibdeno, con la posibilidad de inyectar $\mathrm{Ar}$ a presión, con lo que obtienen velocidades de enfriamiento superiores a $150{ }^{\circ} \mathrm{C} / \mathrm{min}$, lo que permite romper las groseras láminas de la estructura Widmanstätten originadas durante la sinterización y generar microestructuras martensíticas o de tipo "Broken-Up". 


\subsection{PIEZAS POROSAS OBTENIDAS POR EL MÉTODO DE ESPACIADORES.}

\subsubsection{OBSERVACIONES AL PROCESO DE OBTENCION.}

En comparación con las pruebas previas de TiCP, que mantenían su forma incluso para un $70 \% \mathrm{v}$ de espaciador, véase apartado 5.2.2, durante el secado de las piezas base de la presente investigación se observó cómo probetas con porcentajes volumétricos de espaciador de $55 \%$ o superior compactadas a $100 \mathrm{MPa}$ tendían a desmoronarse al manipularlas una vez eliminado éste, figuras 5.99 y 5.100. Pese a que en general las probetas con $30 \circ 40 \% \mathrm{v}$ de espaciador y las compactadas a 200 y $300 \mathrm{MPa}$ mantenían su forma, se optó por secar todas las muestras directamente sobre el molde en el que posteriormente serian sinterizadas, figura 5.100. Dado que estas muestras presentaban, una vez sinterizadas, muy baja resistencia a flexión, únicamente se secaron y sinterizaron algunas.

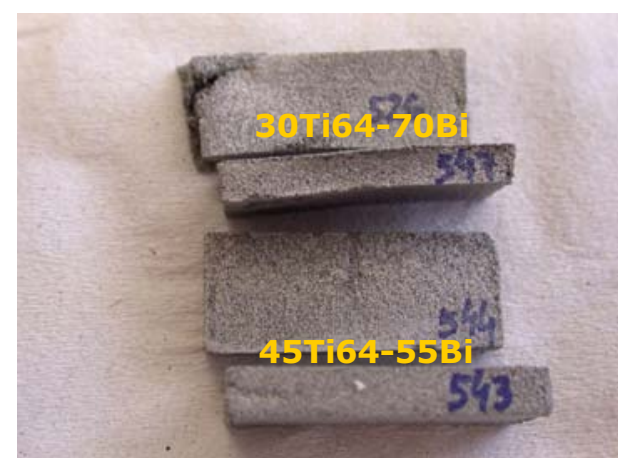

Fig. 5.99. Piezas porosas desarrolladas por el método espaciadores, con $70 \%$ y $55 \% \mathrm{v}$ de bicarbonato de amonio, compactadas a $300 \mathrm{MPa}$. 


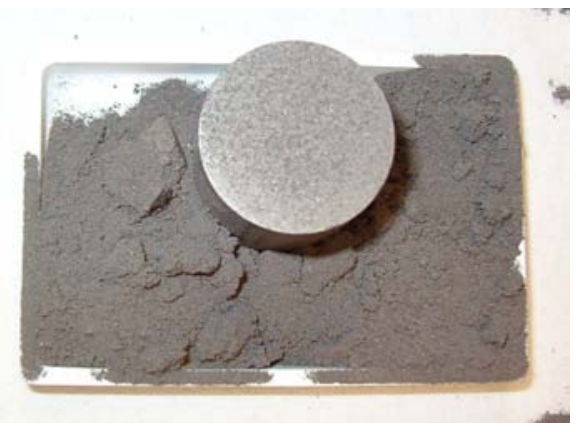

a

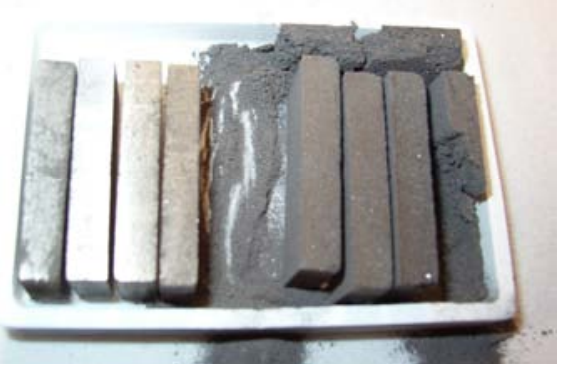

b

Fig. 5.100. Desmoronamiento durante el secado de piezas porosas desarrolladas por el método espaciadores: a) Probeta de compresión con $70 \%$ v Espaciador; b) Probetas de flexión con $70 \%$ v y $55 \%$ v de espaciador.

Dado que todas las muestras fueron compactadas en AMES y el horno de vacío tiene una capacidad limitada, las muestras se fueron secando y sinterizando progresivamente. Ello, junto a ciertos problemas en el suministro de polvo de itria y el método de deposición, provocó que parte de las muestras fueran sinterizadas dos meses después de su compactación. Dada la influencia sobre los resultados obtenidos, se ha diferenciado entre las probetas sinterizadas durante los quince días posteriores a la compactación (tanda A), y aquellas sinterizadas después de este periodo (tanda B).

Por tanto, puesto que el espaciador no fue eliminado inmediatamente tras la compactación, en determinadas muestras evaporó de forma espontánea casi en su totalidad, figura 5.101. No obstante, esto sólo ocurrió en algunas probetas, y la mayoría de ellas se pudieron manipular para su secado y posterior sinterización. 

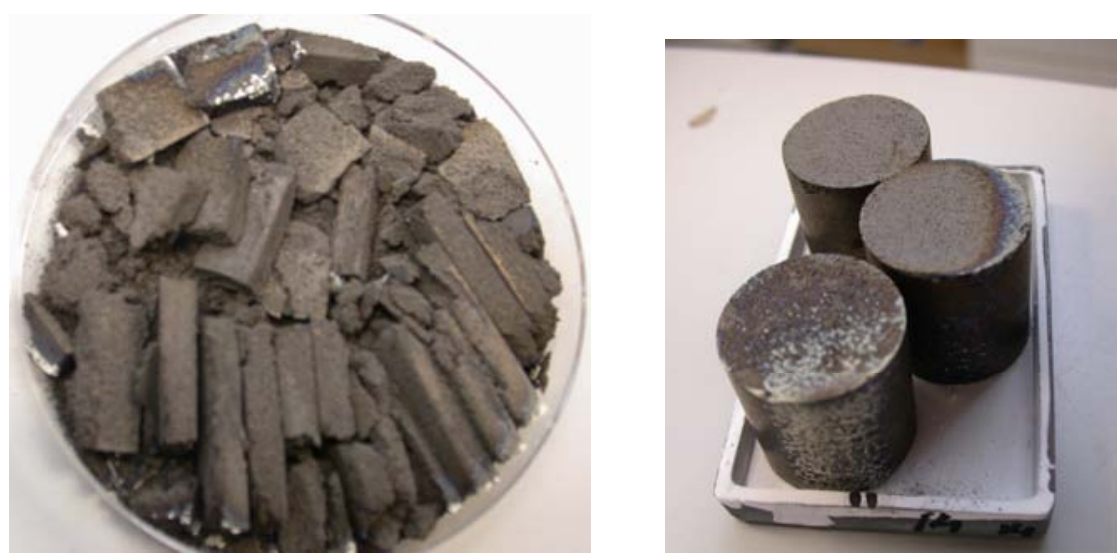

Fig. 5.101. Evaporación espontánea del bicarbonato de amonio en probetas de: a) Flexión; b) Compresión.

A pesar de todo, no se observó una relación directa entre la cantidad de bicarbonato de amonio y el tiempo transcurrido hasta su evaporación. Así, mientras que dos meses después de la compactación muestras con $40 \% \mathrm{v}$ de bicarbonato presentaban degradación, figura 5.102 a, otras con $70 \%$ de bicarbonato, contenían el espaciador sin presentar deterioro aparente a los diez meses después de su compactación, figura 5.102b.

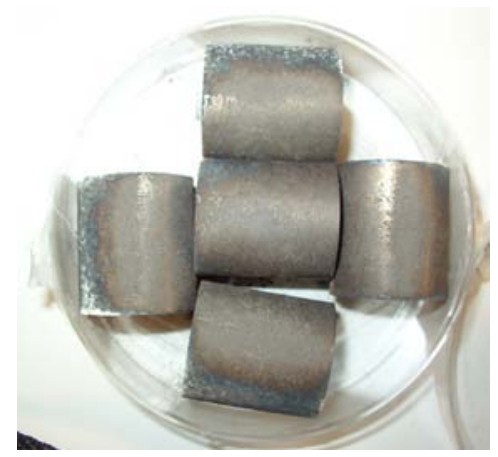

a

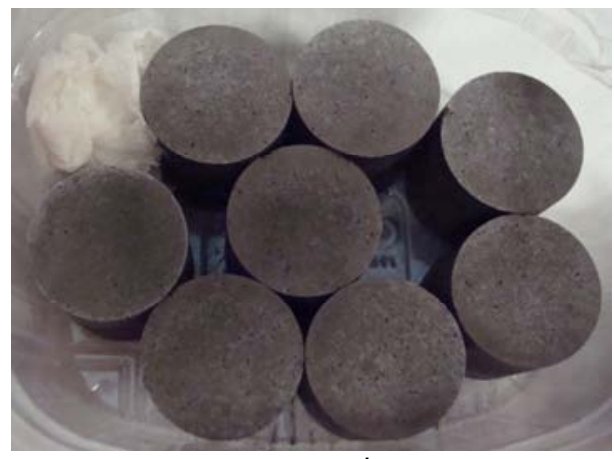

b

Fig. 5.102. Probetas con espaciador, previo a su secado: a) $40 \%$ v de bicarbonato de amonio, 2 meses después de su compactación; b) $70 \%$ de bicarbonato de amonio, 10 meses después de su compactación. 
Pese a que la influencia del secado inmediato se verá al analizar los resultados de las propiedades mecánicas y análisis químico de las muestras sinterizadas, cabe destacar la gran importancia de realizar el proceso de forma lo más continua posible.

Por otra parte, para la realización de piezas porosas empleando urea en lugar de bicarbonato de amonio (lo que se denominó "pruebas finales" en la presente investigación), las muestras fueron igualmente compactadas en AMES. Pese a que diversos autores han logrado conformar piezas porosas de titanio empleando urea como agente espaciador [Dewidar 2007, Kotan 2007], en nuestro caso la eliminación de la urea resultó mucho más compleja y, pese a que se llevó a cabo a temperaturas más elevadas (200$\left.220{ }^{\circ} \mathrm{C}\right)$ y en bajo vacío $\left(\approx 4 \cdot 10^{-1} \mathrm{mbar}\right)$, provocó grandes problemas, generando un aspecto deficiente en las probetas tras su secado, figura 5.103.

La principal diferencia entre el uso de urea y bicarbonato de amonio estriba en los productos generados en la descomposición, pues en la primera se forma un compuesto sólido que contamina el titanio, véase 4.1.1. Pese a que determinados autores han tratado de eliminar la urea mediante descomposición en agua caliente, la contaminación todavía resulta mayor [Dewidar 2005]. En general el deterioro de estas es mayor cuanta más presión de compactación o adición (\%v) de espaciador, figura 5.103.

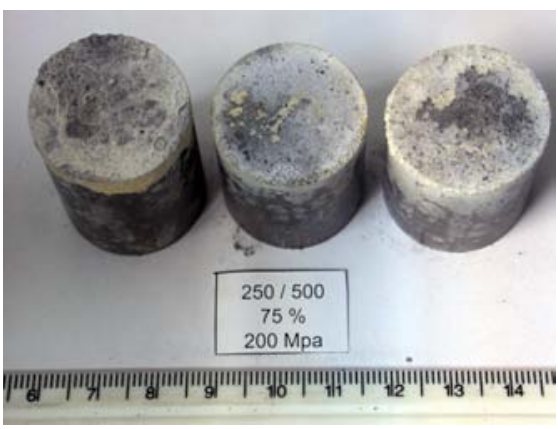

a

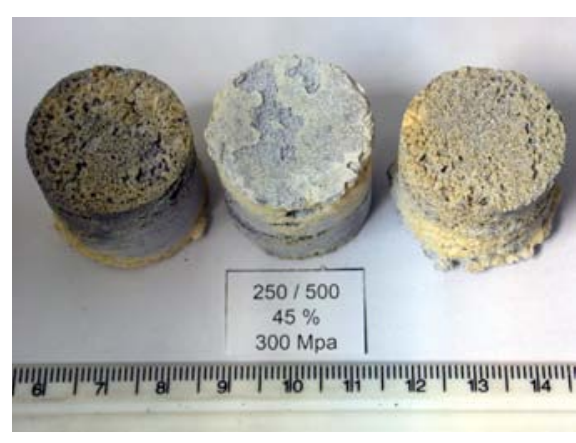

b

Fig. 5.103. Aspecto de las probetas de Ti64 con urea como espaciador tras su secado: a) 25\%v urea, $200 \mathrm{MPa}$; a) 55\%v urea, $300 \mathrm{MPa}$. 
Al no producirse su completa eliminación, los restos de urea existentes en la probeta llegaron a deteriorar la bomba rotatoria del horno de vacío. La degradación de las probetas tras la sinterización, figura 5.104, provocó que las propiedades mecánicas fuesen menores en relación a las piezas porosas obtenidas con bicarbonato, véase apartado 5.4.4.

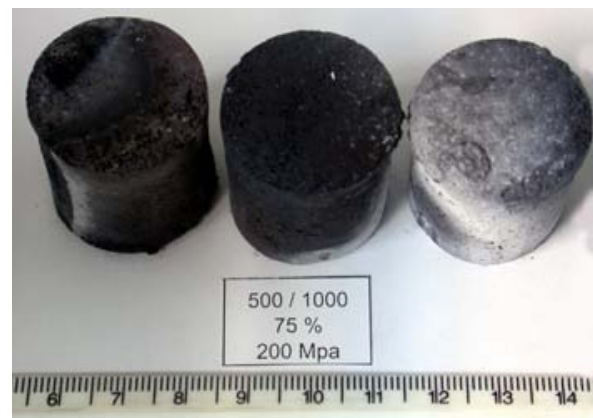

a

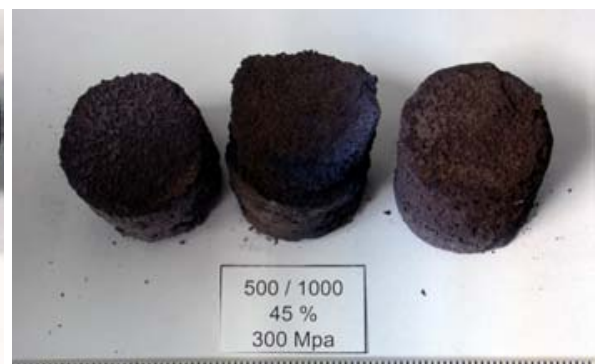

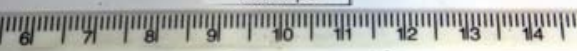

b

Fig. 5.104. Aspecto de las probetas de Ti64 con urea como espaciador tras su sinterizado: a) 25\%v urea, $200 \mathrm{MPa}$; a) 55\%v urea, $300 \mathrm{MPa}$.

\subsubsection{CARACTERIZACIÓN MICROESTRUCTURAL.}

En las muestras base de la presente investigación se observa una distribución de poros más homogénea, figura 5.105, respecto a las pruebas preliminares, véase apartado 5.2.2. No obstante, se produce cierta aglomeración de partículas de bicarbonato de amonio, creando macroporos de mayor tamaño en relación con la fracción granulométrica de espaciador adicionada.
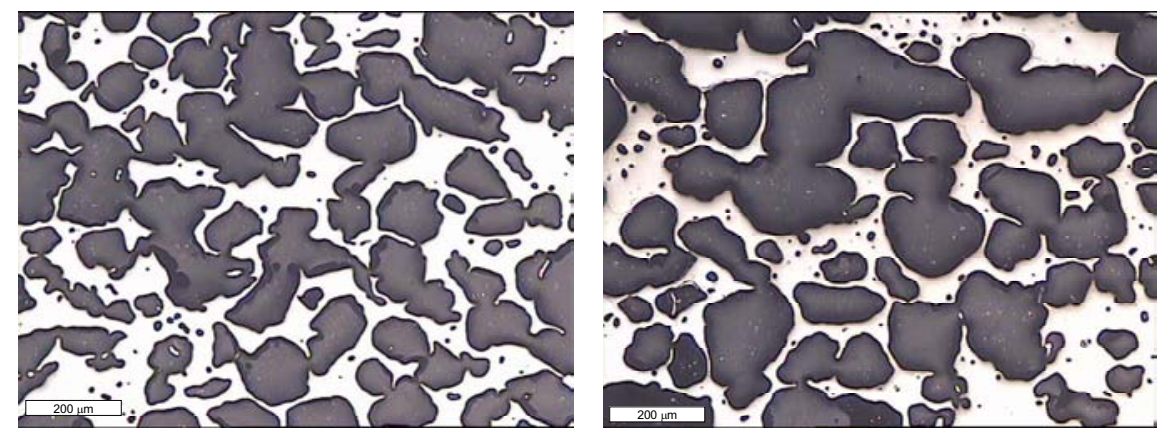

Fig. 5.105. Micrografías MO de probetas de Ti64 con 40\%v de espaciador, compactadas a $200 \mathrm{MPa}$ y sinterizadas a $1300^{\circ} \mathrm{C}$ durante $2 \mathrm{~h}$; a) Fracción $125-250$ $\mu \mathrm{m}$; b) Fracción 250-500 $\mu \mathrm{m}$. 
Pese a la mayor homogeneidad en la distribución de los macroporos, los microporos no se distribuyen de forma regular a lo largo de la probeta, figura 5.106. Ello es debido a la fricción con las paredes del molde, lo que provoca que la presión efectiva y, por tanto la densidad, sean máximas al contacto con el punzón y desciendan a medida que aumenta la distancia a éste [German 1994, Schatt 1997]. Lógicamente, cuanto mayor la presión efectiva, mayor la densidad relativa y menor el volumen de poros [Molera 1977, Upadhyaya 1997].

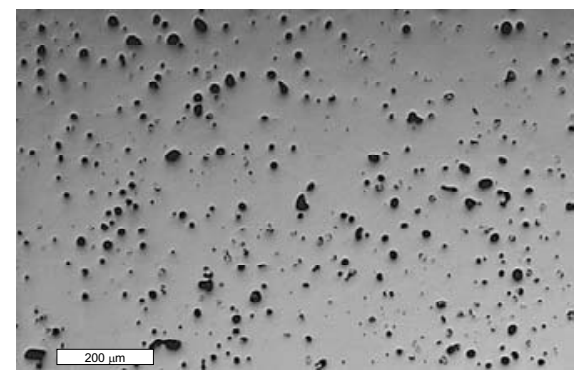

a

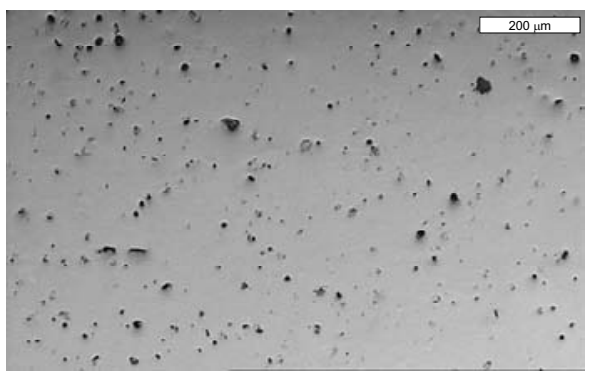

b

Fig. 5.106. Micrografías MO de dos zonas distintas de una probeta de Ti64 sin espaciador, compactada a $300 \mathrm{MPa}$ y sinterizada a $1300^{\circ} \mathrm{C}$ durante $2 \mathrm{~h}$.

La porosidad residual, figura 5.107 a, producto de las reducidas presiones de compactación aplicadas oscila, en piezas de Ti64 sin espaciador, entre 4,5 y $10 \%$, siendo mayor cuanta menor presión de compactación [Schatt 1997]. Por otra parte, al atacar la probeta, se observa como ésta presenta una microestructura del tipo Windmanstätten, producto de la difusión controlada entre las fase $\alpha$ y $\beta$ durante el enfriamiento lento en el horno de vacío [Gil 1996, Gil 2001, Leyens 2003], figura 5.107b. 


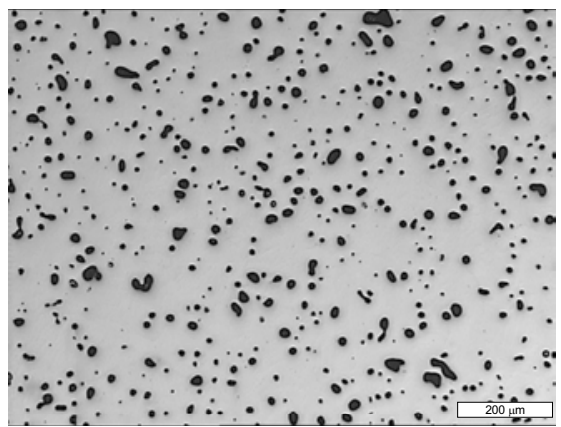

a

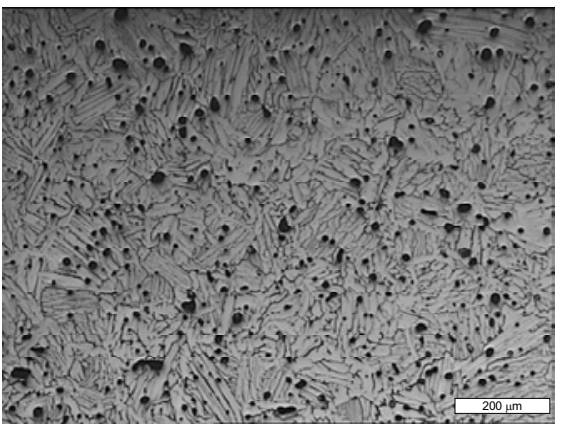

b

Fig. 5.107. Micrografía MO de una probeta de Ti64 sin espaciador, compactada a $100 \mathrm{MPa}$ y sinterizada a $1300^{\circ} \mathrm{C}, 2 \mathrm{~h}$. A) Pulido; b) Atacada con reactivo Kroll.

Las micrografías obtenidas mediante MEB denotan una rotura a flexión de las probetas bastante plana en relación con la presentada por las microesferas. En las probetas sin espaciador la rotura es más dúctil respecto a aquellas que lo contuvieron, caracterizándose las primeras por la mayor formación de microhuecos [Amigó 2001, Ferrer 2003], figura 5.108.

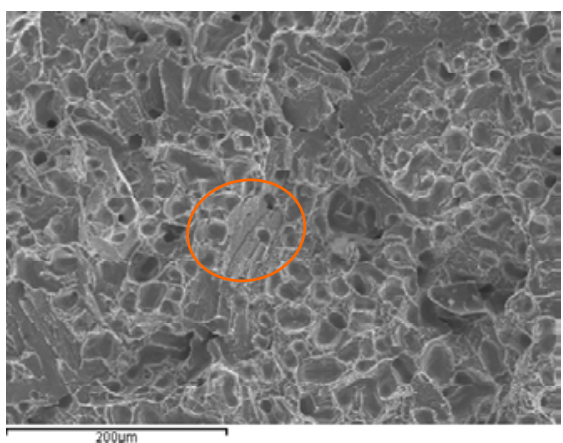

a

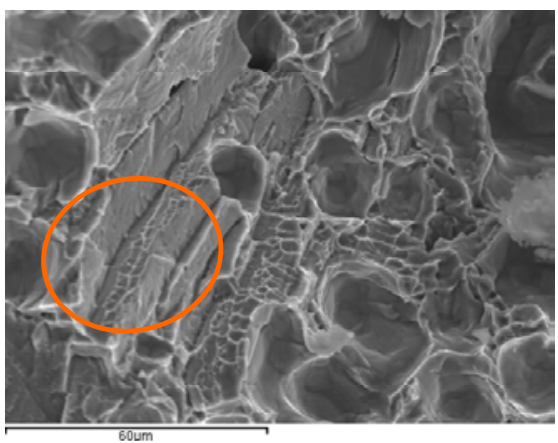

b

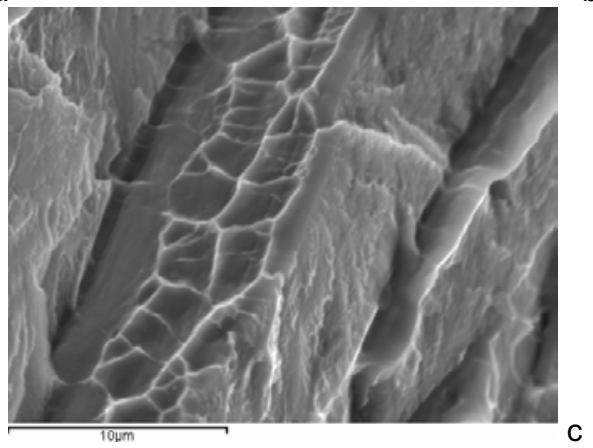

Fig. 5.108. Zona de rotura a flexión de 100Ti64-0Bi compactada a $100 \mathrm{MPa}$ y sinterizada a $1300^{\circ} \mathrm{C}$ durante $2 \mathrm{~h}$. 
Por otra parte, frente a las muestras sin espaciador, las que contuvieron bicarbonato de amonio presentan, en general, una rotura más frágil, caracterizada por la formación de zonas planas, figura 5.109, aunque se observan determinadas zonas con formación de microhuecos, figura 5.110a, especialmente para reducidos contenidos de espaciador.

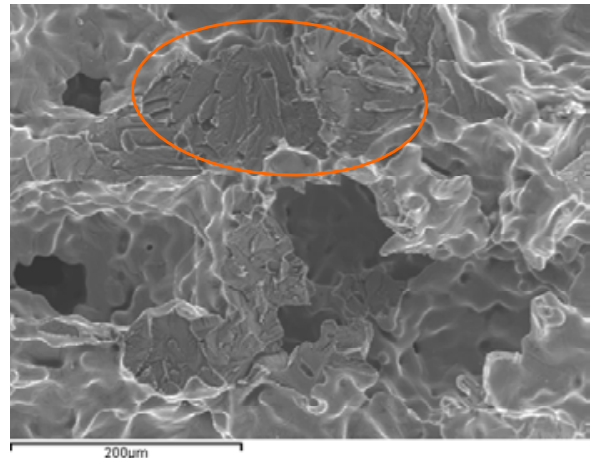

a

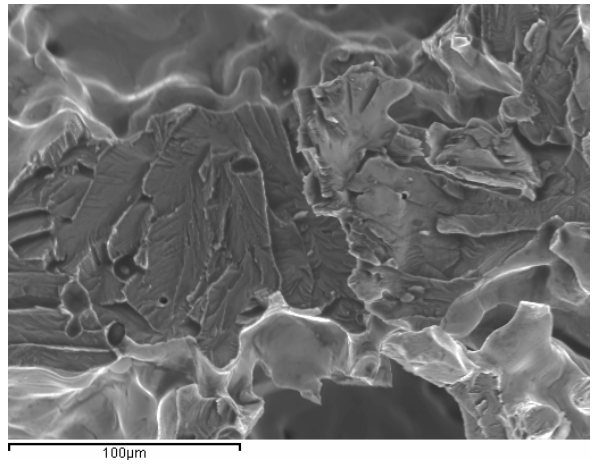

b

Fig. 5.109. Zona de rotura a flexión de 60Ti64-40Bi, fracción 250 a $500 \mu \mathrm{m}$, compactada a $200 \mathrm{MPa}$ y sinterizada a $1300^{\circ} \mathrm{C}$ durante $2 \mathrm{~h}$.

Las muestras en las que se empleó urea como espaciador presentan una rotura más frágil respecto a las realizadas con bicarbonato, figura 5.110.

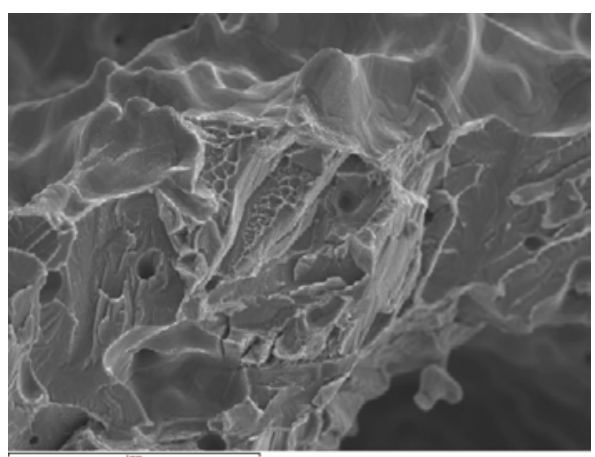

a

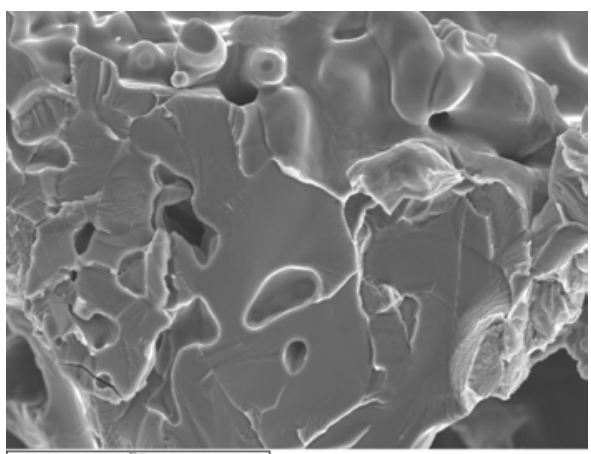

b

Fig. 5.110. Zona de rotura a flexión de probetas con $75 \%$ Ti64 y $25 \%$ de espaciador, fracción 250 a $500 \mu \mathrm{m}$, compactadas a $200 \mathrm{MPa}$ : a) Bicarbonato de amonio; b) Urea. 
Asimismo, a igualdad de parámetros del proceso (adición, tamaño de espaciador y presión de compactación) se observa menor cohesión de las paredes de los macroporos en las muestras de urea, figura 5.111, lo que origina una mayor rugosidad.

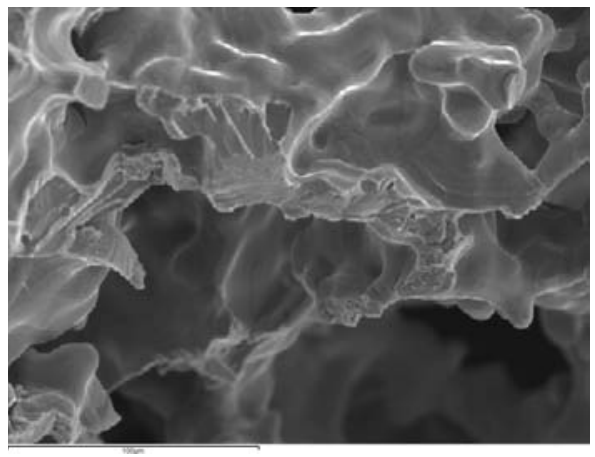

a

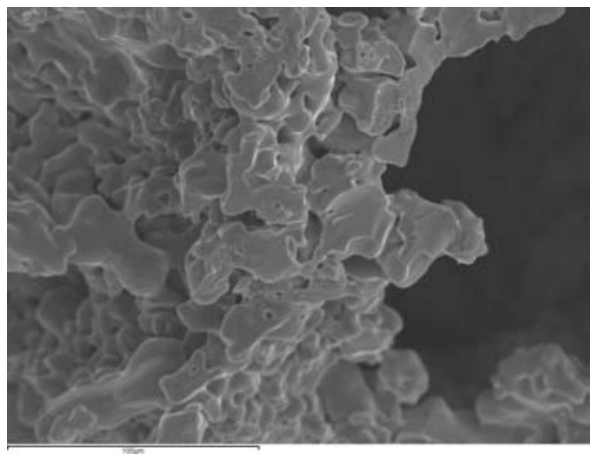

b

Fig. 5.111. Zona de rotura a flexión de probetas con $45 \%$ Ti64 y $55 \%$ de espaciador, fracción 250 a $500 \mu \mathrm{m}$, compactadas a $200 \mathrm{MPa}$ : a) Bicarbonato de amonio; b) Urea.

Por otra parte, para un mismo contenido en urea, se produce una mayor rotura de las paredes de las celdillas cuanto mayor la presión de compactación, figura 5.112, lo que probablemente es debido a la mayor dificultad en la eliminación de la urea en relación con el bicarbonato.

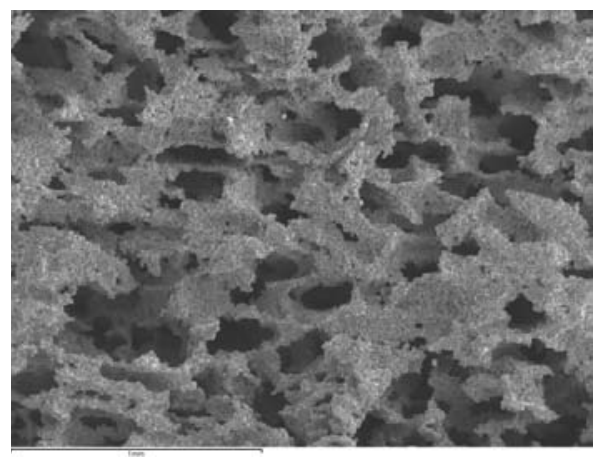

a

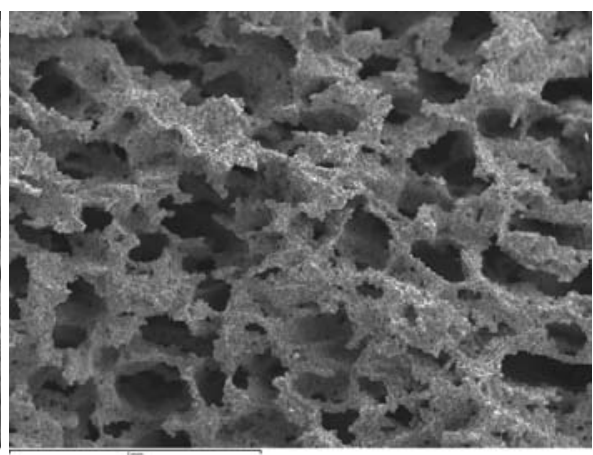

b

Fig. 5.112. Zona de rotura a flexión de probetas con $45 \%$ Ti64 y 55\% de urea espaciador, fracción 250 a $500 \mu \mathrm{m}$, compactadas a: a) $200 \mathrm{MPa}$; b) $300 \mathrm{MPa}$. 


\subsubsection{DENSIDAD, POROSIDAD Y TAMAÑO DE PORO.}

\subsubsection{Densidad, porosidad y tamaño de poro.}

La densidad del sinterizado $\left(\rho^{*}=\mathrm{m} / \mathrm{V}_{\mathrm{A}}, \mathrm{g} / \mathrm{cm}^{3}\right)$, densidad relativa $\left(\rho^{*} / \rho_{\mathrm{S}}\right)$, porosidad $\left(\mathrm{h} \cdot 100 / \rho_{A}, \%\right)$, así como contracción, radial $\left(\nabla r / r_{0} \cdot 100, \%\right)$, lineal $\left(\nabla \mathrm{l} / \mathrm{I}_{0} \cdot 100, \%\right)$ y volumétrica $\left(\nabla \mathrm{V} / \mathrm{V}_{0} \cdot 100, \%\right)$ de las probetas de compresión se determinaron a partir de sus dimensiones. La tabla 5.13 recoge los resultados obtenidos en función de la adición de espaciador, fracción granulométrica y presión de compactación, desestimando las variables temperatura y tiempo por su reducida influencia sobre las propiedades descritas.

Tabla 5.13. Densidad, porosidad y variación dimensional de las piezas porosas de Ti64 realizadas por el método de espaciadores.

\begin{tabular}{|c|c|c|c|c|c|c|c|c|}
\hline Fracción & \begin{tabular}{|c|} 
Ti64- \\
Bicarbonato, \%v \\
\end{tabular} & $\mathrm{P}, \mathrm{MPa}$ & $\rho^{*}, \mathrm{~g} / \mathrm{cm}^{3}$ & $\begin{array}{c}\rho_{\mathrm{r}}=\rho^{*} / \rho_{\mathrm{S}}, \\
\mathrm{g} / \mathrm{cm}^{3}\end{array}$ & $P, \%$ & $\Delta \mathrm{L}_{1}, \%$ & $\Delta \mathrm{L}_{\mathrm{r}}, \%$ & $\Delta \mathrm{V}, \%$ \\
\hline \multirow{3}{*}{ SIN } & \multirow{3}{*}{$100-0$} & 100 & 4,11 & 0,91 & 8,74 & 17,46 & 17,78 & 44,20 \\
\hline & & 200 & 4,14 & 0,92 & 8,04 & 12,96 & 13,81 & 35,31 \\
\hline & & 300 & 4,11 & 0,91 & 8,63 & 10,79 & 11,13 & 29,54 \\
\hline \multirow{4}{*}{$125-250$} & \multirow{2}{*}{$60-40$} & 200 & 2,05 & 0,46 & 54,38 & $\begin{array}{l}15,70 \\
\end{array}$ & 16,70 & 41,49 \\
\hline & & 300 & 2,02 & 0,45 & 55,15 & 13,53 & 15,82 & 38,70 \\
\hline & \multirow{2}{*}{$45-55$} & 200 & 1,51 & 0,34 & 66,49 & 18,58 & 18,68 & 46,11 \\
\hline & & 300 & 1,50 & 0,33 & 66,68 & 17,52 & 17,56 & 43,93 \\
\hline \multirow{6}{*}{$250-500$} & \multirow{2}{*}{$75-25$} & 100 & 2,79 & 0,62 & 38,06 & 18,44 & 18,98 & 46,45 \\
\hline & & 200 & 2,72 & 0,60 & 39,56 & 15,35 & 16,58 & 41,09 \\
\hline & \multirow{2}{*}{$60-40$} & 100 & 2,10 & 0,47 & 53,37 & 18,74 & 19,45 & 47,25 \\
\hline & & 200 & 2,06 & 0,46 & 54,29 & 16,28 & 17,10 & 42,46 \\
\hline & \multirow{2}{*}{$45-55$} & 100 & 1,57 & 0,35 & 65,12 & 21,38 & 21,01 & 50,94 \\
\hline & & 200 & 1,52 & 0,34 & 66,15 & 19,09 & 19,38 & 47,41 \\
\hline \multirow{2}{*}{$500-1000$} & $\begin{array}{l}75-25 \\
\end{array}$ & 100 & 2,71 & 0,60 & 39,77 & 17,14 & 17,75 & 43,93 \\
\hline & $60-40$ & 100 & 2,01 & 0,45 & 55,31 & 18,48 & 18,18 & 45,41 \\
\hline
\end{tabular}

Tal como se observa, se produce una gran contracción durante la evaporación del bicarbonato y sinterización de la pieza $\left(\nabla L_{r}\right.$ y $\nabla L_{l}$ el entre 11 $-21 \%$; $\nabla \mathrm{V}$ entre $30-50 \%$ ), lo que modifica en gran medida las dimensiones de las piezas porosas, figura 5.113. 


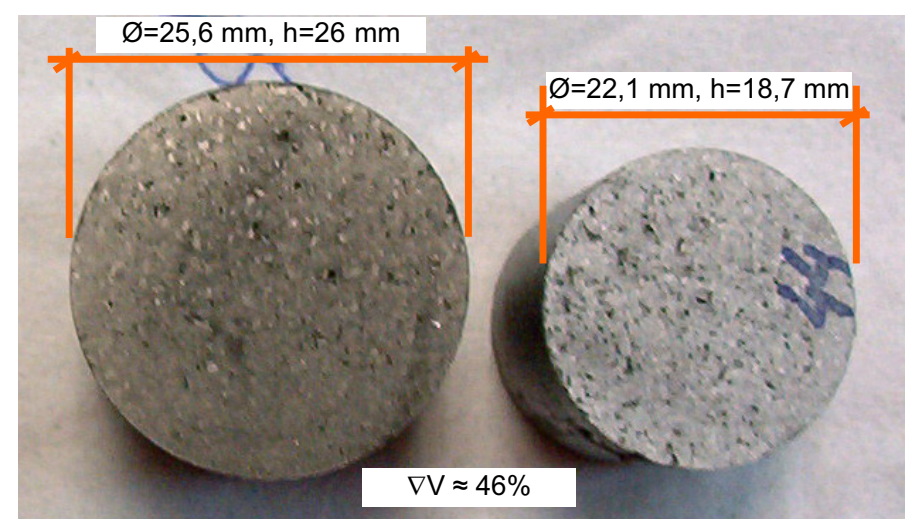

Fig. 5.113. Probetas de Ti64 con $40 \%$ v de bicarbonato de amonio, tras su compactación y tras ser secadas y sinterizadas.

Al comparar las deformaciones lineal y radial, tabla 5.13, se observan valores similares, lo que implica que la contracción es homogénea, por lo que las piezas no deben distorsionar su geometría en exceso. Por otra parte, la reducida presión de compactación aplicada provoca que la variación de dimensiones sea de gran importancia incluso para piezas sin espaciador.

La variación dimensional aumenta con el contenido en bicarbonato de amonio y, para un mismo contenido y tamaño de espaciador, disminuye al aumentar la presión de compactación, tabla 5.13 y figura 5.114. Esto es debido a que una mayor densidad en verde de la pieza (producto de mayor presión de compactación o mayor cantidad de Ti64), facilita la sinterización [German 1994, Upadhyaya 1997]. Por otra parte, para una misma presión de compactación no se observa una variación determinada con el tamaño de espaciador. 


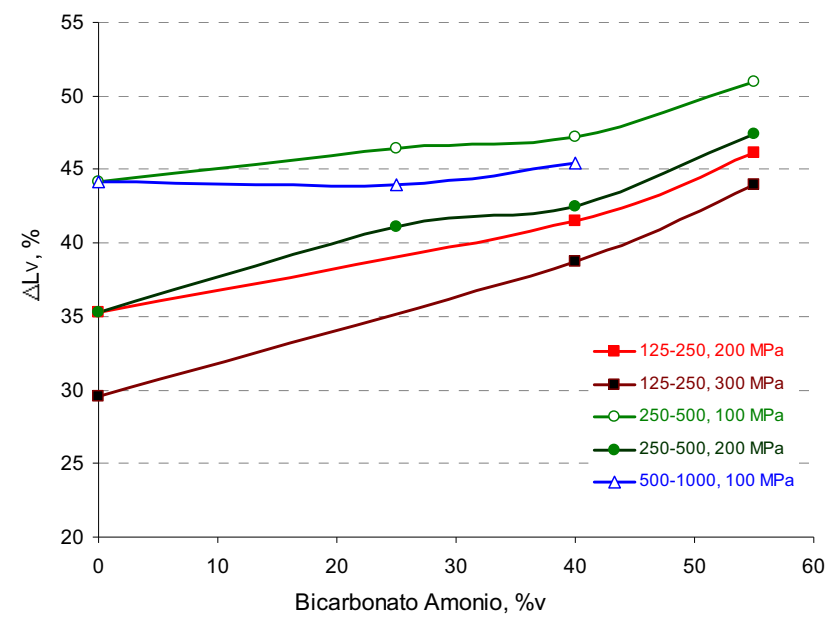

Fig. 5.114. Contracción volumétrica de probetas de Ti64 con diferentes adiciones de espaciador.

Pese a que se observa cierto incremento de densidad a medida que se reduce la presión de compactación (originado por una mayor contracción), no resulta significativo, tabla 5.13. De igual modo, para un mismo contenido en espaciador no se observa una variación considerable de la porosidad en función de la presión de compactación, temperatura y tiempo de sinterización. No obstante, a igualdad de parámetros, la porosidad resulta muy similar en las fracciones más pequeñas (menor tamaño de espaciador), y algo superior en la más grosera, lo que podría deberse a la menor compresibilidad de la mezcla cuanto mayor el tamaño del espaciador.

Por otra parte, existe una diferencia notable entre las pruebas previas realizadas, en las que se empleó una prensa manual, y éstas piezas, compactadas en AMES con una prensa automática. Así, mientras las primeras presentaban una porosidad inferior a la adición de espaciador, véase apartado 5.2.2, en las piezas base de la investigación la porosidad siempre resulta entre un 10 y $14 \%$ superior al contenido en bicarbonato, figura 5.115. Ello, unido a la mayor contracción de éstas ( $\nabla L_{V}$ entre $\left.30-50 \%\right)$ en relación a las pruebas previas realizadas en la UPV $\left(\nabla L_{V} \approx 30 \%\right)$, permite concluir que dichos efectos pueden ser producto de la mayor velocidad de 
compactación de la prensa automática $(3000$ N/s) en relación a la manual, lo que provoca una plastificación mucho menor de los polvos, con mayor recuperación elástica y, por tanto, menor densificación [Ferrer 2003]. Este efecto se ve probablemente acentuado por la presencia de partículas de espaciador, cuyo tamaño dificulta todavía más la compresibilidad de los polvos. Por otra parte, ello justifica el desmoronamiento de las piezas base de la investigación con contenidos menores de espaciador respecto a los adicionados en las pruebas previas, véase apartado 5.2.2.

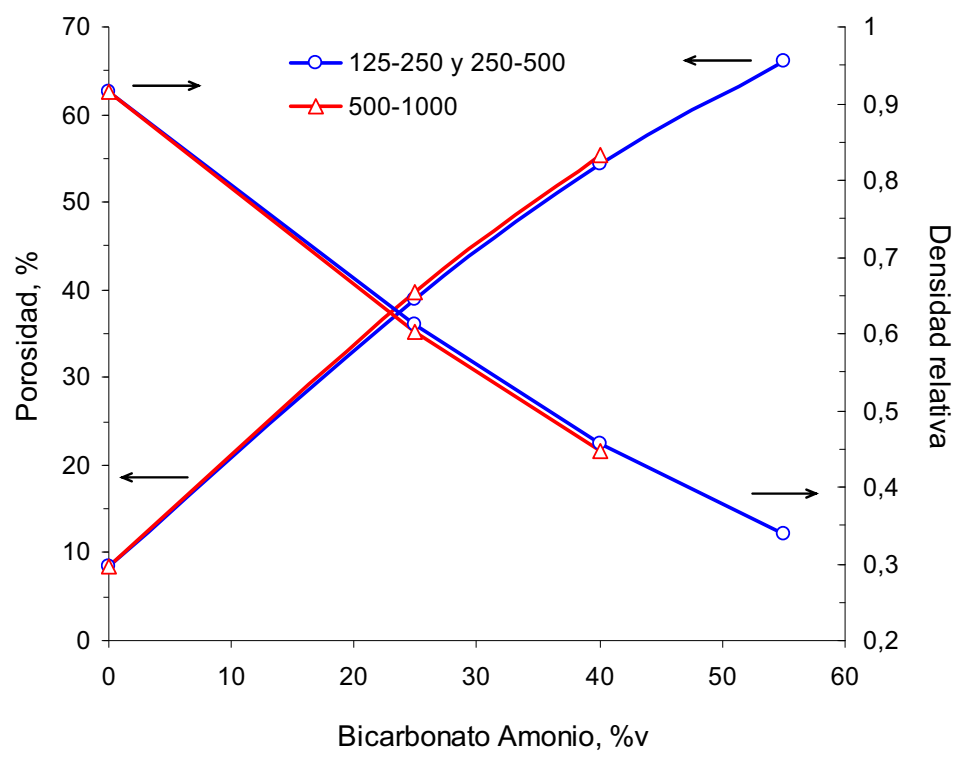

Fig. 5.115. Porosidad total y densidad relativa de piezas porosas de Ti64 con

En relación al tamaño de poro, debido tanto a la distribución granulométrica de las partículas de espaciador, como a la coalescencia entre algunas de ellas, figura 116, resulta complejo determinar un tamaño de poro concreto para cada fracción de bicarbonato de amonio. Por tanto, mientras que se ha determinado un diámetro medio para los microporos entorno a 12 micras, en el caso de los macroporos la forma y dimensiones dependen principalmente de la coalescencia entre diferentes partículas de espaciador, figura 5.116. En este sentido, cabe indicar que se esperan mejores propiedades mecánicas cuanto menor el tamaño de partícula, pues permite mayor 
homogeneidad en la distribución del material, generando con ello una densidad y desarrollo de paredes entre macroporos más uniforme.

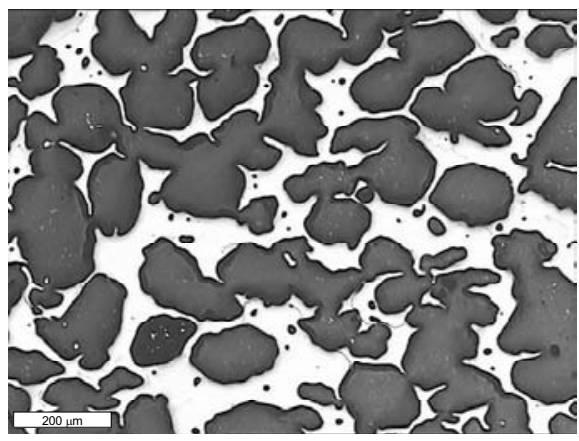

a

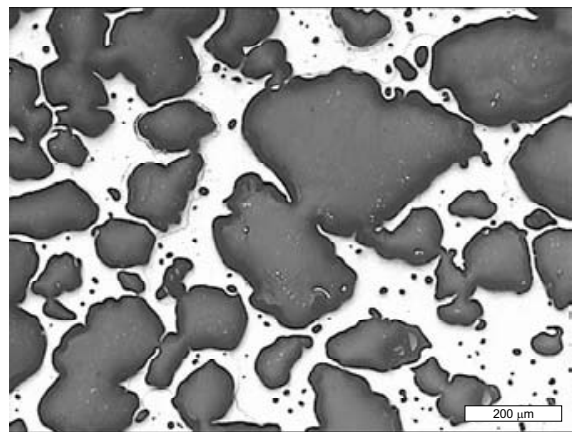

b

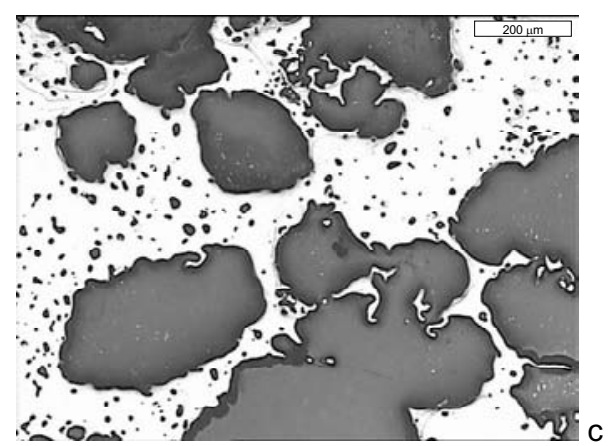

Fig. 5.116. Micrografías MO tratadas para análisis de imagen de piezas porosas de Ti64, con $40 \%$ v de espaciador, sinterizadas a $1300^{\circ} \mathrm{C}$ durante $2 \mathrm{~h}$ : a) Compactada a

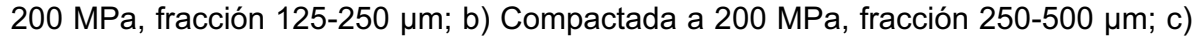
Compactada a $100 \mathrm{MPa}$, fracción 500-1000 $\mu \mathrm{m}$.

5.4.3.2. Conclusiones parciales de densidad, porosidad y tamaño de poro de las piezas porosas de Ti64 realizadas por el método de espaciadores.

Durante la evaporación del bicarbonato y sinterización se produce una contracción muy importante $\left(\nabla L_{r}\right.$ y $\nabla L_{l}$ el entre $11-21 \% ; \nabla L_{v}$ entre $\left.30-50 \%\right)$, resultando destacable incluso en piezas sin espaciador $\left(\nabla \mathrm{L}_{v} \approx 30 \% \mathrm{v}\right)$. La contracción aumenta con el contenido en espaciador y al disminuir la presión de compactación, mientras que varía poco con el tamaño de bicarbonato. 
La deformación lineal y radial presenta valores similares, lo que ocasiona una contracción homogénea.

La contracción y porosidad de las piezas de Ti6Al4V resultan superiores a las obtenidas en las pruebas previas realizadas con TiCP3; presentando las primeras un desmoronamiento para contenidos menores de espaciador. Todo ello puede ser consecuencia de la mayor velocidad de compactación de las piezas porosas de Ti6Al4V $(3000 \mathrm{~N} / \mathrm{s})$ en relación a las pruebas preliminares (prensa manual), lo que provoca una mayor recuperación elástica de los polvos, con menor plastificación y densidad en verde. Este efecto se ve previsiblemente acentuado por la presencia de partículas de espaciador, cuyo tamaño dificulta todavía más la compresibilidad de los polvos.

Finalmente, debido a la distribución granulométrica de las partículas de espaciador y a la coalescencia entre ellas, no es posible hablar de un tamaño de poro concreto. No obstante, son de esperar mejores propiedades cuanto menor el tamaño de espaciador, pues favorece una densidad más homogénea.

\subsubsection{CARACTERIZACIÓN MECÁNICA.}

Se determinó tanto la resistencia a flexión y a compresión, como la rigidez de las piezas porosas obtenidas. Se ha analizado la influencia de las variables Temperatura, tiempo y presión de compactación, comparando entre las distintas fracciones granulométricas de espaciador. La siguiente tabla 5.14 resume la resistencia, tenacidad y rigidez relativa obtenidas a flexión y a compresión (véase apartados 4.4.2 y 4.4.4 para la determinación de los parámetros). Se ha determinado los valores promedio de los ensayos realizados, y se ha marcado en rojo las propiedades mecánicas de las muestras con espaciador sinterizadas en la segunda tanda, véase 5.4.1, pues podrían presentar resultados anómalos producidos por la presencia prolongada del espaciador. Por otra parte, se ha eliminado los resultados para las muestras con $70 \%$ v de espaciador, pues no mantenían su integridad durante el procesado, véase apartado 5.4.1.1. 
Tabla 5.14. Densidad relativa y propiedades mecánicas de las piezas porosas de Ti64 realizadas por el método de espaciadores.

\begin{tabular}{|c|c|c|c|c|c|c|c|c|c|c|c|c|}
\hline \multirow{2}{*}{ FRAC., $\mu \mathrm{m}$} & \multirow{2}{*}{$\mathrm{T},{ }^{\circ} \mathrm{C}$} & \multirow{2}{*}{$\mathrm{t}, \mathrm{h}$} & \multirow{2}{*}{ P, Mpa } & \multirow{2}{*}{$\%$ Ti64 } & \multirow{2}{*}{ \%Bicarbonato } & \multirow{2}{*}{$\rho_{\text {relativa }}$} & \multicolumn{2}{|c|}{ FLEXION } & \multirow{2}{*}{$\begin{array}{c}\text { COMPRESION } \\
\sigma_{\mathrm{CY}}, \mathrm{MPa} \\
\end{array}$} & \multicolumn{3}{|c|}{ RIGIDEZ RELATIVA } \\
\hline & & & & & & & $\sigma_{\mathrm{FY}}, \mathrm{MPa}$ & Tenac., J & & $E_{\mathrm{rFF}}$ & $E_{\mathrm{rFP}}$ & $\mathrm{E}_{\mathrm{rCP}}$ \\
\hline \multirow{14}{*}{ SIN ESP. } & \multirow{2}{*}{1275} & \multirow{2}{*}{2} & 100 & \multirow{2}{*}{100} & \multirow{2}{*}{0} & 0,91 & 1917,98 & 11,06 & 1068,00 & 0,75 & 1,03 & 1,03 \\
\hline & & & 200 & & & 0,92 & 1844,71 & 18,46 & 1071,00 & 0,73 & 0,98 & 0,88 \\
\hline & \multirow{3}{*}{1275} & \multirow{3}{*}{4} & 100 & \multirow{3}{*}{100} & \multirow{3}{*}{0} & 0,93 & 1983,72 & 10,61 & 1071,00 & 1,13 & 0,78 & 1,02 \\
\hline & & & 200 & & & 0,94 & 1996,04 & 9,63 & 1115,00 & 1,13 & 1,00 & 0,95 \\
\hline & & & 300 & & & 0,94 & 2013,74 & 10,07 & & 1,02 & 0,99 & \\
\hline & \multirow{6}{*}{1300} & \multirow{3}{*}{1} & 100 & \multirow{3}{*}{100} & \multirow{3}{*}{0} & 0,90 & 1754,09 & 7,90 & 1023,50 & 1,03 & 1,06 & 1,01 \\
\hline & & & 200 & & & 0,93 & 1842,90 & 7,87 & 1055,00 & 1,07 & 0,99 & 1,05 \\
\hline & & & 300 & & & 0,93 & 1848,50 & 7,14 & 1040,00 & 1,01 & 0,98 & 0,77 \\
\hline & & \multirow{3}{*}{2} & 100 & \multirow{3}{*}{100} & \multirow{3}{*}{0} & 0,92 & 1838,61 & 7,61 & 1061,50 & 1,11 & 1,08 & 1,06 \\
\hline & & & 200 & & & 0,94 & 1765,52 & 7,16 & 1086,00 & 1,05 & 1,01 & 0,91 \\
\hline & & & 300 & & & 0,94 & 1844,27 & 7,90 & & 0,96 & 1,05 & \\
\hline & \multirow{3}{*}{1325} & \multirow{3}{*}{1} & 100 & \multirow{3}{*}{100} & \multirow{3}{*}{0} & 0,90 & 1702,26 & 11,22 & 988,00 & 0,98 & 1,05 & 0,99 \\
\hline & & & 200 & & & 0,92 & 1831,55 & 7,37 & 1050,00 & 1,02 & 1,02 & 0,88 \\
\hline & & & 300 & & & 0,93 & 1987,84 & 10,45 & & 1,00 & 0,98 & \\
\hline & & & & \multicolumn{2}{|c|}{ Promedio para $100 \mathrm{MPa}$} & 0,91 & 1839,33 & 9,68 & 1042,40 & 1,00 & 1,00 & 1,02 \\
\hline & & & & \multicolumn{2}{|c|}{ Promedio para $200 \mathrm{MPa}$} & 0,93 & 1856,14 & 10,10 & 1075,40 & 1,00 & 1,00 & 0,94 \\
\hline & & & & \multicolumn{2}{|c|}{ Promedio para $300 \mathrm{MPa}$} & 0,94 & 1923,59 & 8,89 & 1040,00 & 1,00 & 1,00 & 0,77 \\
\hline
\end{tabular}

\begin{tabular}{|c|c|c|c|c|c|c|c|c|c|c|c|c|}
\hline \multirow{2}{*}{ FRAC., $\mu \mathrm{m}$} & \multirow{2}{*}{$\mathrm{T},{ }^{\circ} \mathrm{C}$} & \multirow{2}{*}{$\mathrm{t}, \mathrm{h}$} & \multirow{2}{*}{ P, Mpa } & \multirow{2}{*}{ \%Ti64 } & \multirow{2}{*}{ \%Bicarbonato } & \multirow{2}{*}{$\rho_{\text {relativa }}$} & \multicolumn{2}{|c|}{ FLEXION } & \multirow{2}{*}{$\begin{array}{c}\text { COMPRESION } \\
\sigma_{\mathrm{CY}}, \mathrm{MPa} \\
\end{array}$} & \multicolumn{3}{|c|}{ RIGIDEZ RELATIVA } \\
\hline & & & & & & & $\sigma_{\mathrm{FY}}, \mathrm{MPa}$ & Tenac., J & & $E_{r F F}$ & $\mathrm{E}_{\mathrm{rFP}}$ & $\mathrm{E}_{\mathrm{rCP}}$ \\
\hline \multirow{14}{*}{$125-250$} & 1275 & 2 & 200 & 60 & 40 & 0,46 & 316,19 & 0,63 & 108,20 & 0,38 & 0,28 & 0,19 \\
\hline & 1275 & 4 & 300 & 45 & 55 & 0,55 & 122,38 & 0,15 & 98,34 & 0,24 & 0,16 & 0,16 \\
\hline & \multirow{8}{*}{1300} & \multirow{4}{*}{1} & \multirow{2}{*}{200} & 60 & 40 & 0,45 & 258,92 & 0,48 & 100,84 & 0,41 & 0,27 & 0,16 \\
\hline & & & & 45 & 55 & 0,35 & 117,05 & 0,16 & 87,34 & 0,21 & 0,14 & 0,17 \\
\hline & & & \multirow{2}{*}{300} & 60 & 40 & 0,43 & 255,24 & 0,49 & 95,97 & 0,52 & 0,25 & 0,15 \\
\hline & & & & 45 & 55 & 0,34 & 114,77 & 0,14 & 84,44 & 0,22 & 0,14 & 0,16 \\
\hline & & \multirow{4}{*}{2} & \multirow{2}{*}{200} & 60 & 40 & 0,47 & 251,86 & 0,47 & 110,27 & 0,35 & 0,27 & 0,18 \\
\hline & & & & 45 & 55 & 0,33 & 143,48 & 0,22 & 38,45 & 0,19 & 0,15 & 0,08 \\
\hline & & & \multirow{2}{*}{300} & 60 & 40 & 0,46 & 255,35 & 0,46 & 105,77 & 0,31 & 0,30 & 0,18 \\
\hline & & & & 45 & 55 & 0,34 & 113,62 & 0,13 & 39,49 & 0,16 & 0,15 & 0,09 \\
\hline & \multirow{4}{*}{1325} & \multirow{4}{*}{1} & \multirow{2}{*}{200} & 60 & 40 & 0,45 & 296,10 & 0,55 & 98,16 & 0,33 & 0,31 & 0,13 \\
\hline & & & & 45 & 55 & 0,32 & 120,89 & 0,18 & 40,00 & 0,17 & 0,15 & 0,07 \\
\hline & & & \multirow{2}{*}{300} & 60 & 40 & 0,45 & 248,52 & 0,46 & 102,06 & 0,29 & 0,29 & 0,16 \\
\hline & & & & 45 & 55 & 0,32 & 103,81 & 0,12 & 37,49 & 0,12 & 0,14 & 0,08 \\
\hline & & & & \multicolumn{2}{|c|}{ Promedio para $60 \mathrm{Ti} 64-40 \mathrm{Bi}, \% \mathrm{v}$} & 0,45 & 268,88 & 0,50 & 103,04 & 0,37 & 0,28 & 0,16 \\
\hline & & & & \multicolumn{2}{|c|}{ Promedio para 45Ti64-55Bi, \%v } & 0,36 & 119,43 & 0,16 & 60,79 & 0,19 & 0,15 & 0,12 \\
\hline
\end{tabular}

\begin{tabular}{|c|c|c|c|c|c|c|c|c|c|c|c|c|}
\hline \multirow{2}{*}{ FRAC., $\mu \mathrm{m}$} & \multirow{2}{*}{$\mathrm{T},{ }^{\circ} \mathrm{C}$} & \multirow{2}{*}{$\mathrm{t}, \mathrm{h}$} & \multirow{2}{*}{ P, Mpa } & \multirow{2}{*}{ \%Ti64 } & \multirow{2}{*}{ \%Bicarbonato } & \multirow{2}{*}{$\rho_{\text {relativa }}$} & \multicolumn{2}{|c|}{ FLEXION } & \multirow{2}{*}{$\begin{array}{c}\text { COMPRESION } \\
\sigma_{\mathrm{CY}}, \mathrm{MPa} \\
\end{array}$} & \multicolumn{3}{|c|}{ RIGIDEZ RELATIVA } \\
\hline & & & & & & & $\sigma_{\mathrm{FY}}, \mathrm{MPa}$ & Tenac., J & & $E_{\mathrm{rFF}}$ & $E_{r F P}$ & $\mathrm{E}_{\mathrm{rCP}}$ \\
\hline \multirow{30}{*}{$250-500$} & \multirow{12}{*}{1275} & \multirow{6}{*}{2} & \multirow{3}{*}{100} & 75 & 25 & 0,62 & 423,24 & 1,20 & 214,73 & 0,64 & 0,45 & 0,33 \\
\hline & & & & 60 & 40 & 0,48 & 230,15 & 0,65 & 122,03 & 0,32 & 0,24 & 0,20 \\
\hline & & & & 45 & 55 & 0,32 & 102,20 & 0,31 & 92,76 & 0,18 & 0,10 & 0,17 \\
\hline & & & \multirow{3}{*}{200} & 75 & 25 & 0,61 & 477,26 & 1,30 & 202,57 & 0,46 & 0,41 & 0,33 \\
\hline & & & & 60 & 40 & 0,46 & 281,79 & 0,64 & 105,45 & 0,32 & 0,22 & 0,19 \\
\hline & & & & 45 & 55 & 0,35 & 103,57 & 0,26 & 99,55 & 0,17 & 0,10 & 0,17 \\
\hline & & \multirow{6}{*}{4} & \multirow{3}{*}{100} & 75 & 25 & 0,64 & 635,00 & 1,42 & 225,00 & 0,56 & 0,46 & 0,37 \\
\hline & & & & 60 & 40 & 0,48 & 243,01 & 0,65 & 122,00 & 0,44 & 0,24 & 0,21 \\
\hline & & & & 45 & 55 & 0,36 & 96,66 & 0,27 & 100,43 & 0,22 & 0,10 & 0,20 \\
\hline & & & \multirow{3}{*}{200} & 75 & 25 & 0,62 & 643,29 & 1,66 & 211,26 & 0,59 & 0,38 & 0,32 \\
\hline & & & & 60 & 40 & 0,47 & 235,35 & 0,65 & 112,00 & 0,40 & 0,23 & 0,20 \\
\hline & & & & 45 & 55 & 0,36 & 108,11 & 0,32 & 92,39 & 0,15 & 0,11 & 0,18 \\
\hline & \multirow{12}{*}{1300} & \multirow{6}{*}{1} & \multirow{3}{*}{100} & 75 & 25 & 0,61 & 499,37 & 1,04 & 214,00 & 0,66 & 0,40 & 0,35 \\
\hline & & & & 60 & 40 & 0,44 & 208,23 & 0,59 & 91,00 & 0,30 & 0,23 & 0,11 \\
\hline & & & & 45 & 55 & 0,33 & 59,33 & 0,07 & 43,62 & 0,14 & 0,08 & 0,10 \\
\hline & & & \multirow{3}{*}{200} & 75 & 25 & 0,59 & 558,14 & 1,21 & 185,88 & 0,66 & 0,38 & 0,30 \\
\hline & & & & 60 & 40 & 0,45 & 221,71 & 0,47 & 103,00 & 0,27 & 0,19 & 0,18 \\
\hline & & & & 45 & 55 & 0,32 & 44,91 & 0,05 & 39,86 & 0,10 & 0,07 & 0,09 \\
\hline & & \multirow{6}{*}{2} & \multirow{3}{*}{100} & 75 & 25 & 0,62 & 534,28 & 1,16 & 218,43 & 0,62 & 0,43 & 0,37 \\
\hline & & & & 60 & 40 & 0,46 & 191,27 & 0,40 & 113,03 & 0,28 & 0,21 & 0,16 \\
\hline & & & & 45 & 55 & 0,32 & 80,89 & 0,10 & & 0,14 & 0,09 & \\
\hline & & & \multirow{3}{*}{200} & 75 & 25 & 0,61 & 446,83 & 0,91 & 415,07 & 0,45 & 0,35 & 0,64 \\
\hline & & & & 60 & 40 & 0,46 & 229,83 & 0,45 & 113,76 & 0,30 & 0,23 & 0,17 \\
\hline & & & & 45 & 55 & 0,34 & 63,88 & 0,08 & 40,70 & 0,09 & 0,09 & 0,10 \\
\hline & & & & 75 & 25 & 0,61 & 559,95 & 1,36 & 192,47 & 0,54 & 0,41 & 0,33 \\
\hline & & & 100 & 60 & 40 & 0,47 & 210,50 & 0,43 & 108,61 & 0,15 & 0,08 & 0,16 \\
\hline & & & & 45 & 55 & 0,34 & 110,54 & 0,22 & 45,20 & 0,20 & 0,11 & 0,09 \\
\hline & 1325 & 1 & & 75 & 25 & 0,61 & 559,70 & 1,20 & 193,23 & 0,62 & 0,39 & 0,32 \\
\hline & & & 200 & 60 & 40 & 0,46 & 179,48 & 0,38 & 107,02 & 0,30 & 0,20 & 0,19 \\
\hline & & & & 45 & 55 & 0,33 & 61,05 & 0,06 & 45,50 & 0,14 & 0,08 & 0,11 \\
\hline & & & & Promedio $\mathrm{p}$ & $75 \mathrm{Ti} 64-25 \mathrm{Bi}, \% \mathrm{v}$ & 0,61 & 533,71 & 1,25 & 227,26 & 0,58 & 0,41 & 0,37 \\
\hline & & & & Promedio $\mathrm{p}$ & 60Ti64-40Bi, \%v & 0,46 & 223,13 & 0,53 & 109,79 & 0,31 & 0,21 & 0,18 \\
\hline & & & & Promedio $p$ & 45Ti64-55Bi, \%v & 0,34 & 83,11 & 0,17 & 66,67 & 0,15 & 0,09 & 0,14 \\
\hline
\end{tabular}




\begin{tabular}{|c|c|c|c|c|c|c|c|c|c|c|c|c|}
\hline \multirow{2}{*}{ FRAC., $\mu \mathrm{m}$} & \multirow{2}{*}{$\mathrm{T},{ }^{\circ} \mathrm{C}$} & \multirow{2}{*}{$\mathrm{t}, \mathrm{h}$} & \multirow{2}{*}{ P, Mpa } & \multirow{2}{*}{$\%$ Ti64 } & \multirow{2}{*}{ \%Bicarbonato } & \multirow{2}{*}{$\rho_{\text {relativa }}$} & \multicolumn{2}{|c|}{ FLEXION } & \multirow{2}{*}{\begin{tabular}{|c|} 
COMPRESION \\
$\sigma_{\mathrm{CY}}, \mathrm{MPa}$ \\
\end{tabular}} & \multicolumn{3}{|c|}{ RIGIDEZ RELATIVA } \\
\hline & & & & & & & $\sigma_{\mathrm{FY}}, \mathrm{MPa}$ & Tenac., J & & $E_{\mathrm{rFF}}$ & $E_{r F P}$ & $E_{\mathrm{rCP}}$ \\
\hline \multirow{10}{*}{$500-1000$} & \multirow{4}{*}{1275} & \multirow{2}{*}{2} & \multirow{2}{*}{100} & 75 & 25 & 0,59 & 541,76 & 1,35 & 182,05 & 0,52 & 0,55 & 0,29 \\
\hline & & & & 60 & 40 & 0,46 & 268,27 & 0,75 & 90,12 & 0,32 & 0,34 & 0,12 \\
\hline & & \multirow{2}{*}{4} & \multirow{2}{*}{100} & 75 & 25 & 0,60 & 458,35 & 0,90 & 192,10 & 0,55 & 0,60 & 0,37 \\
\hline & & & & 60 & 40 & 0,45 & 279,80 & 0,65 & 98,00 & 0,31 & 0,32 & 0,16 \\
\hline & \multirow{4}{*}{1300} & \multirow{2}{*}{1} & \multirow{2}{*}{100} & 75 & 25 & 0,60 & 269,96 & 0,47 & 187,00 & 0,38 & 0,55 & 0,30 \\
\hline & & & & 60 & 40 & 0,44 & 130,61 & 0,18 & 97,20 & 0,27 & 0,27 & 0,10 \\
\hline & & \multirow{2}{*}{2} & \multirow{2}{*}{100} & 75 & 25 & 0,61 & 296,84 & 0,46 & 208,05 & 0,45 & 0,55 & 0,31 \\
\hline & & & & 60 & 40 & 0,45 & 155,11 & 0,29 & 102,79 & 0,28 & 0,30 & 0,13 \\
\hline & \multirow{2}{*}{1325} & \multirow{2}{*}{1} & \multirow{2}{*}{100} & 75 & 25 & 0,59 & 290,40 & 0,43 & 186,00 & 0,50 & 0,58 & 0,30 \\
\hline & & & & 60 & 40 & 0,43 & 146,15 & 0,25 & 88,78 & 0,27 & 0,29 & 0,06 \\
\hline & & & & \multicolumn{2}{|c|}{ Promedio para 75Ti64-25Bi, \%v } & 0,60 & 371,46 & 0,72 & 191,04 & 0,48 & 0,57 & 0,31 \\
\hline & & & & \multicolumn{2}{|c|}{ Promedio para $60 \mathrm{Ti} 64-40 \mathrm{Bi}, \% \mathrm{v}$} & 0,45 & 195,99 & 0,42 & 95,38 & 0,29 & 0,31 & 0,12 \\
\hline
\end{tabular}

5.4.4.1. Influencia del tiempo de espera entre la compactación y la eliminación del espaciador.

Tal como se observa en la tabla 5.14, las piezas sin espaciador y realizadas con la fracción granulométrica de espaciador más pequeña (125 a $250 \mu \mathrm{m})$ se sinterizaron en la tanda $A$, mientras que las realizadas con el resto de fracciones se sinterizaron en ambas tandas, $A$ y $B$.

Generalmente las piezas degradadas sufrían un cambio de aspecto que evidenciaba la degradación, presentando posteriormente rotura frágil en el ensayo de compresión, figura 5.117 a y b.

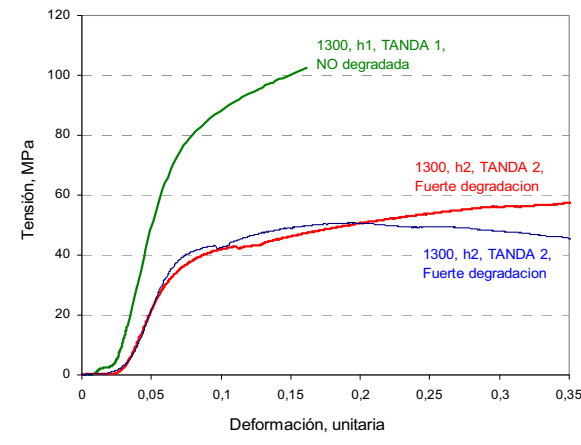

a

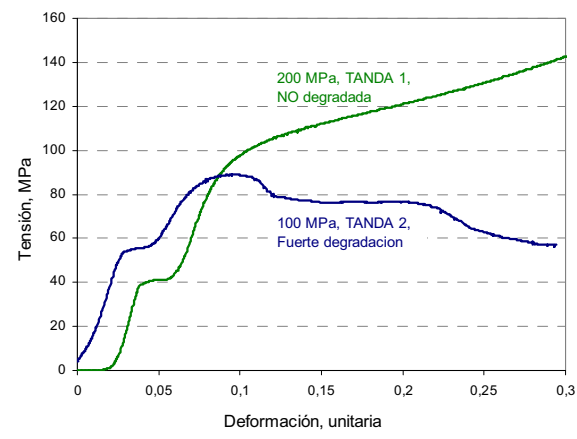

b

Fig. 5.117. Curvas Tensión - deformación a compresión para probetas con: a) 55\% espaciador, $300 \mathrm{MPa}, 125-250 \mu \mathrm{m}$; b) $40 \%$ espaciador, $1300^{\circ} \mathrm{C}, 1 \mathrm{~h}, 250-500 \mu \mathrm{m}$.

Al someter las piezas a compresión la posible reactividad con elementos intersticiales se manifiesta claramente durante la deformación, mostrando un comportamiento frágil, figura 5.118a o dúctil, figura 5.118b. 


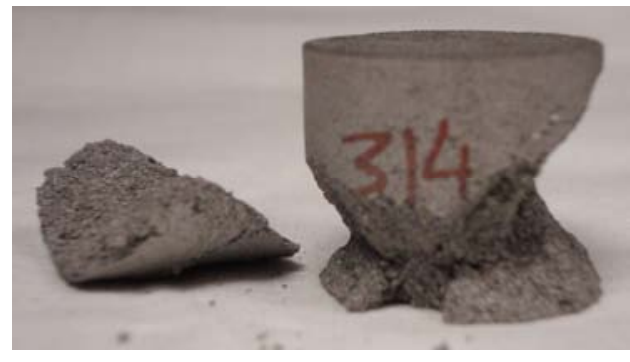

a

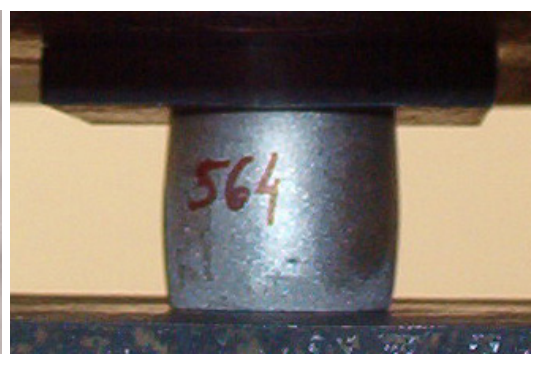

b

Fig. 5.118. Ensayo compresión de muestras con espaciador compactadas a 100 MPa y sinterizadas a $1300^{\circ} \mathrm{C}, 1 \mathrm{~h}$ : a) Frágil, probeta con $60 \%$ Ti64; b) Dúctil, probeta con $100 \%$ Ti64.

Pese a que ninguna probeta sinterizada en la primera tanda presentó rotura frágil, no todas las muestras sinterizadas en la segunda tanda presentaron fragilidad, aunque el riesgo de reacción con elementos intersticiales aumenta a medida que aumenta el contenido en bicarbonato de amonio. Tal como se observa en la tabla 5.14, en las fracciones de espaciador más reducidas ( 125 a 250 y 250 a $500 \mu \mathrm{m}$ ), las muestras con hasta $40 \%$ v de espaciador mostraron resistencias similares, tanto a flexión como a compresión, independientemente del tiempo de espera entre compactación y secado (tanda A o tanda B). No obstante, en las muestras con $55 \%$ v de bicarbonato la degradación previa a la sinterización ya se observó a simple vista, lo que posteriormente dio lugar a notables variaciones de resistencia entre los diferentes ciclos, figura 5.119 . 


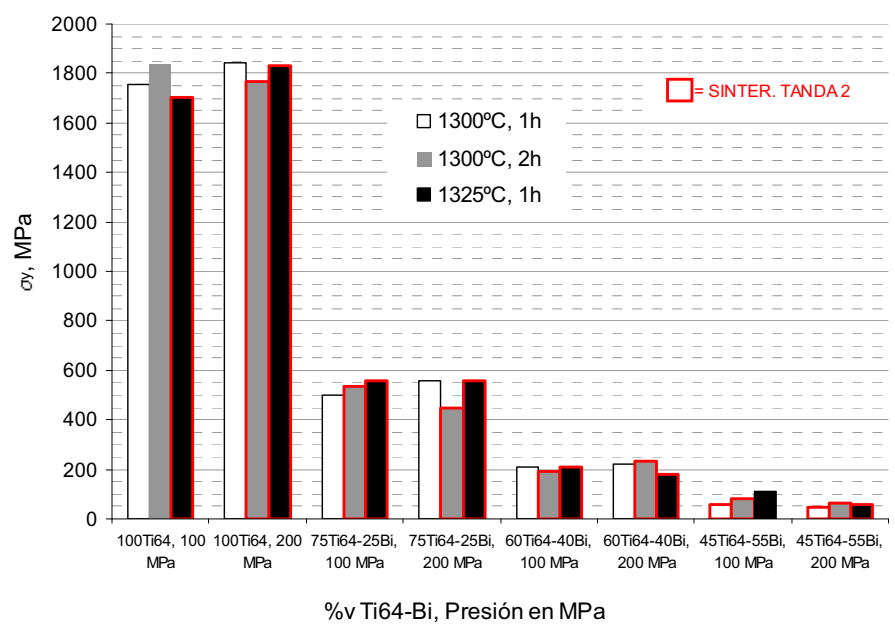

Fig. 5.119. $\sigma_{y}$ a flexión de la fracción $250-500 \mu \mathrm{m}$, variación con \%v bicarbonato, presión de compactación y ciclo de sinterización.

Por el contrario, pese que las muestras realizadas con el tamaño más grosero de bicarbonato (500 a $1000 \mu \mathrm{m})$ presentan una resistencia a compresión similar, tabla 5.14 , si se observa una notable diferencia de la resistencia a flexión, figura 5.120, en función del tiempo de permanencia del espaciador, diferencia que resulta importante incluso para contenidos de espaciador de únicamente un $25 \%$ v.

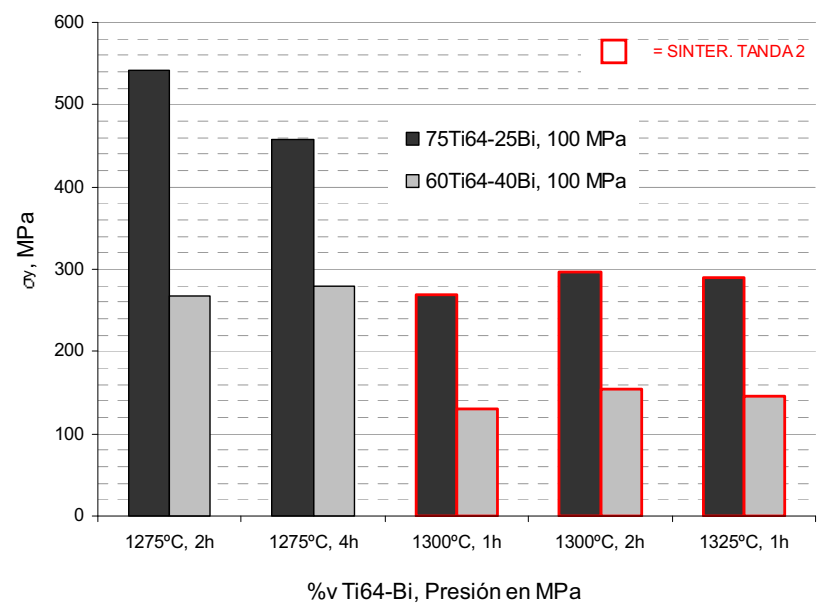

Fig. 5.120. $\sigma_{y}$ a flexión de la fracción $500-1000 \mu \mathrm{m}$, con 25 y $40 \%$ v de bicarbonato y sinterizadas a distintos ciclos. 
De las observaciones realizadas se desprende la gran influencia del tiempo de espera entre la compactación y eliminación del espaciador, siendo de gran importancia eliminar el espaciador y sinterizar tan pronto como sea posible tras la compactación tratando de evitar o minimizar la absorción de elementos intersticiales, véase también apartado 5.4.5.

Pese a que la influencia de la permanencia del espaciador durante un tiempo prolongado se ha analizado en el presente apartado, en el desarrollo de los resultados se mantendrá la diferenciación entre las probetas sinterizadas en las tandas A y B.

5.4.4.2. Resistencia a flexión de la las piezas porosas base de la investigación.

La resistencia a flexión de probetas sin espaciador oscila entre 1700 y $2000 \mathrm{MPa}$, en función de la presión de compactación y ciclo de sinterización, figura 5.121. En todos los casos las propiedades mecánicas aumentan con la presión de compactación. A pesar de que el incremento de resistencia resulta más notable cuando aumenta la temperatura de sinterización, no se observa una evolución concreta con la temperatura, lo que probablemente sea debido al reducido intervalo de variación. Finalmente, se produce cierto incremento de la resistencia con el tiempo de sinterización. 


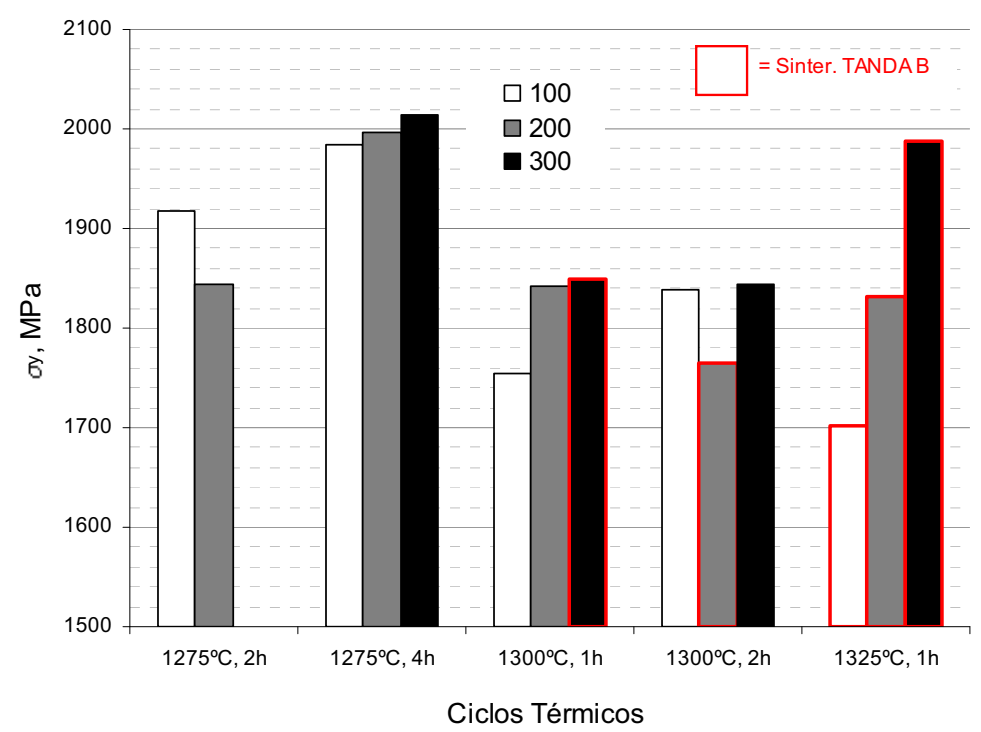

Fig. 5.121. $\sigma_{y}$ a flexión de las muestras sin espaciador, 100\% Ti64, compactadas a 100, 200 y $300 \mathrm{MPa}$. Comparación entre ciclos térmicos.

Para muestras con espaciador, la resistencia a flexión desciende, independientemente del tamaño de espaciador a medida que aumenta el contenido en bicarbonato de amonio, siendo éste el parámetro de mayor influencia, tabla 5.14 y figura 5.122 .

La máxima reducción de resistencia se origina con cantidades relativamente reducidas de espaciador $(25 \% \mathrm{v})$, figura 5.122. Ello probablemente es debido al efecto concentrador de tensiones ejercido por los poros que, por una parte, implica una distribución de tensiones no uniforme y, por otra, provoca una mayor variabilidad de los resultados, pues los poros se distribuyen de forma aleatoria [Schatt 1997, Degischer 2002]. Por otra parte, la presencia de elementos intersticiales, podría incrementar las propiedades mecánicas de la pieza porosa obtenida [Baeslack 1993, Tarín 1999]. 


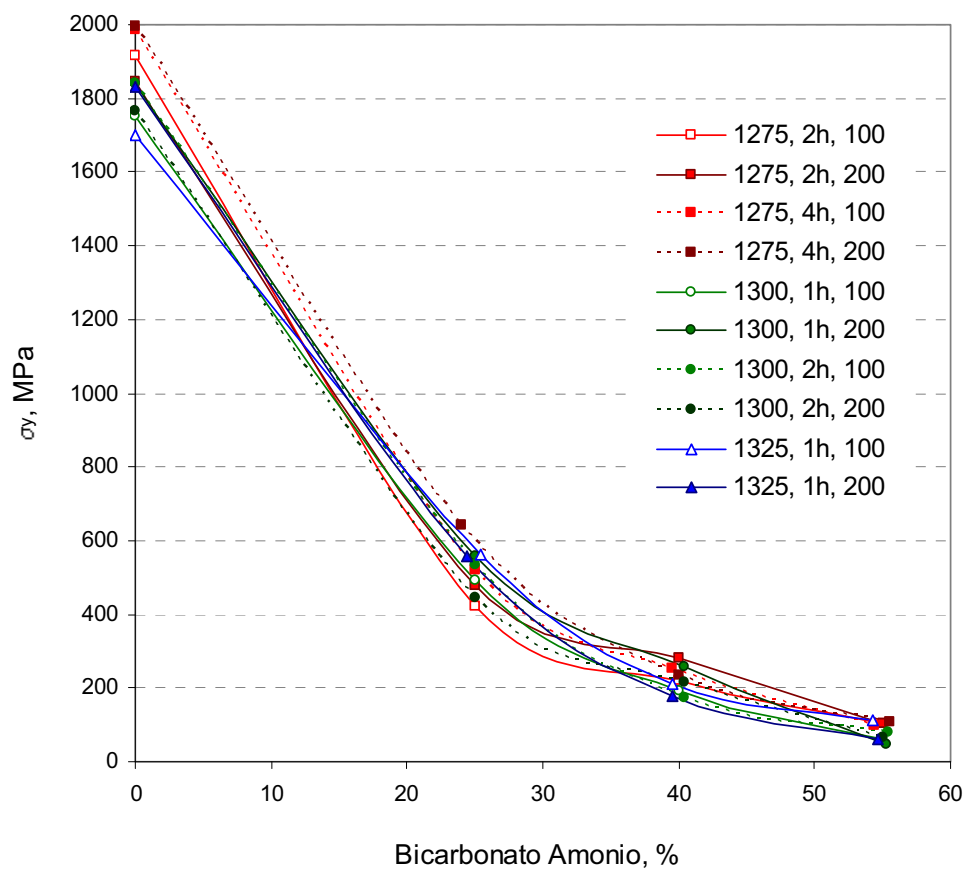

Fig. 5.122. $\sigma_{y}$ a flexión de la fracción 250-500 $\mu \mathrm{m}$, variación con ciclos de sinterización y presión de compactación. Los símbolos han sido desplazados ligeramente en horizontal para mejorar la claridad.

Tal como se observa en la figura 5.122, las líneas se entrecruzan en contenidos de bicarbonato entorno al $35 \% \mathrm{v}$, lo que implica relación entre las variables del proceso temperatura, tiempo, presión de compactación y adición de espaciador.

Así, en muestras con hasta un $25 \%$ v de espaciador, el límite elástico $\left(\sigma_{\mathrm{Y}}\right)$ en general se mantiene o aumenta con la presión de compactación, figura 5.121 y 5.123 . Por el contrario, cuando la adición de espaciador excede el $35 \% \mathrm{v}$, la resistencia desciende en general a medida que aumenta la presión de compactación. No obstante, éste efecto depende del ciclo de sinterización, de forma que, a $1275^{\circ} \mathrm{C}$, la resistencia aumenta ligeramente con la presión de compactación, figura 5.123, mientras que a $1300-1325$ ${ }^{\circ} \mathrm{C}$, la resistencia se mantiene o desciende al aumentar la presión, figura 5.124 . 


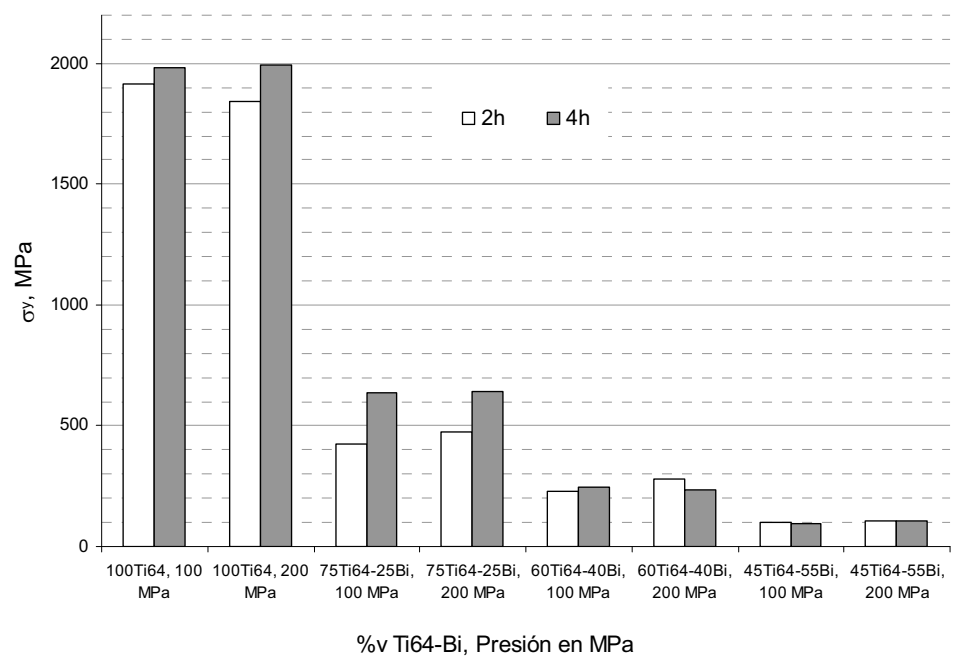

Fig. 5.123. $\sigma_{y}$ a flexión de la fracción $250-500 \mu$ m sinterizada a $1275^{\circ} \mathrm{C}$, variación con adición de bicarbonato, presión de compactación y tiempo de sinterización.

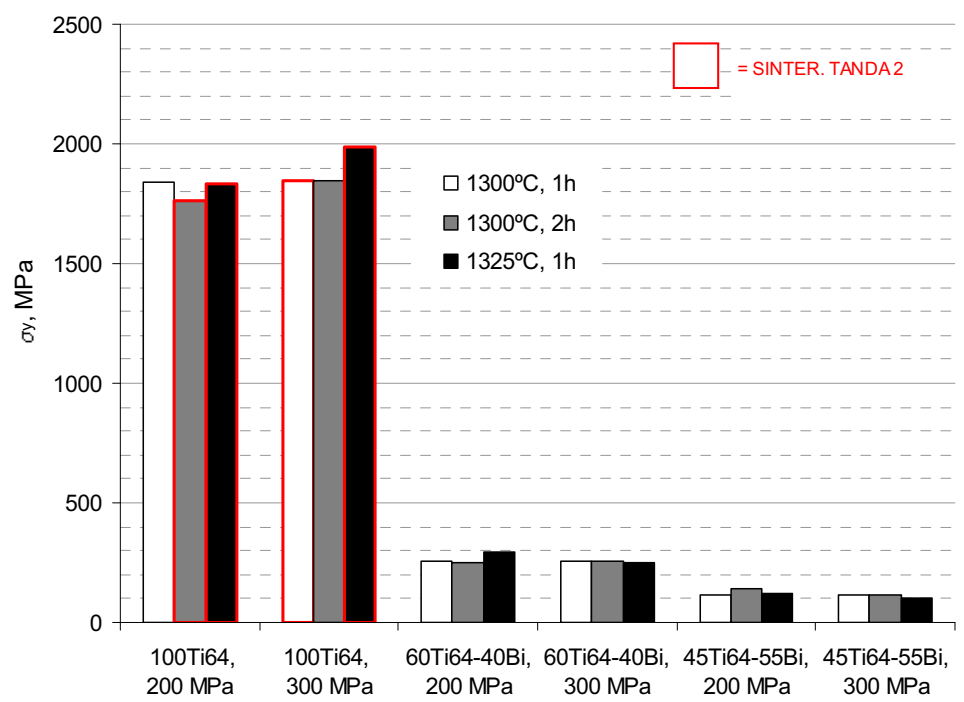

Fig. 5.124. $\sigma_{y}$ a flexión de la fracción 125-250 $\mu \mathrm{m}$, variación con presión de compactación para piezas sinterizadas a $1300^{\circ} \mathrm{C}$ durante 1 y $2 \mathrm{~h}$ y a $1325^{\circ} \mathrm{C}$ durante $1 \mathrm{~h}$. 
Tal como se ha indicado en las pruebas preliminares, la variación de propiedades con la presión de compactación puede deberse a que la presencia de espaciador en cantidades suficientes dificulta la compresibilidad del polvo de la matriz, generando a la vez mayor recuperación elástica tras la compactación, lo que reduce la densidad en verde de la pieza. Dicho efecto se ve acentuado por la mayor velocidad de compactación aplicada en las piezas base de la investigación (3000 N/s), lo que reduce su plastificación [Ferrer 2003]. A pesar de todo, cabe indicar que el efecto observado resulta de gran interés, pues se asemeja más a la práctica industrial. Además de esta tendencia general observada, cabe recordar la posible fragilización por reacción con elementos intersticiales, de mayor importancia a medida que aumenta el contenido en bicarbonato, véase apartados 5.4.4.1 y 5.4.5.

En relación al resto de variables, a igualdad de parámetros el tiempo de sinterización influye poco sobre la resistencia a flexión, figura 5.125.

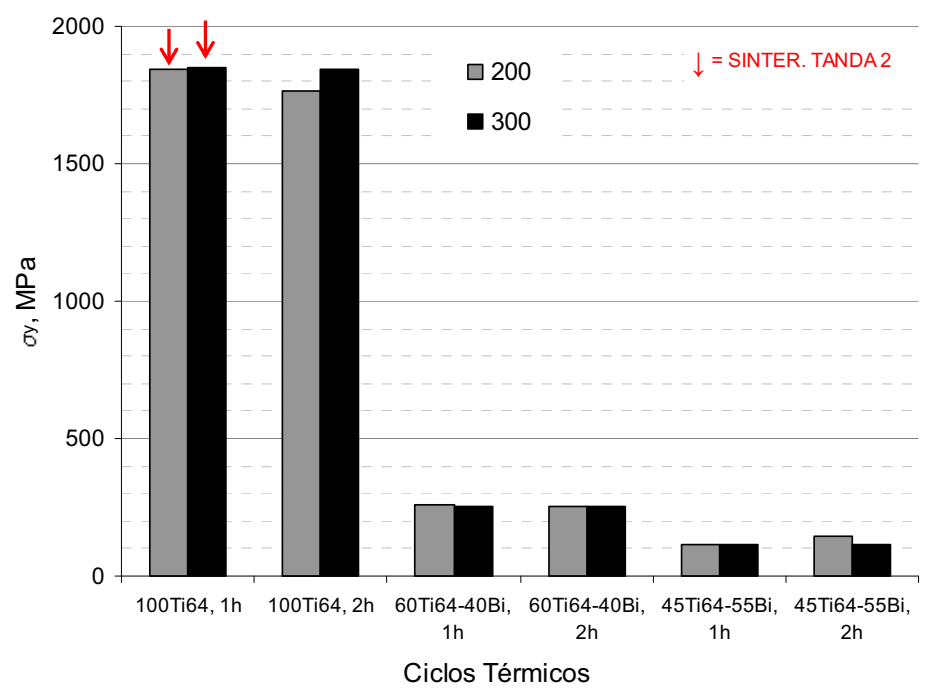

Fig. 5.125. $\sigma_{y}$ a flexión de la fracción $125-250 \mu \mathrm{m}$, sinterización a $1300{ }^{\circ} \mathrm{C}$, variación con el tiempo y presión de compactación. 
De igual modo, a presiones bajas (100 y $200 \mathrm{MPa}$ ), la temperatura y tiempo de sinterización únicamente produjeron un aumento de resistencia en probetas con hasta un $25 \%$ v de espaciador, tabla 5.14, figura 5.126. Por el contrario, para probetas con mayor cantidad de espaciador la temperatura resultó más influyente a mayor presión de compactación y, mientras que a 100 y $200 \mathrm{MPa}$ no se observa una variación concreta con los ciclos temperatura-tiempo, a $300 \mathrm{MPa}$ el límite elástico desciende ligeramente a medida que aumenta la temperatura de sinterización, figura 5.127. Ello podría deberse a una mayor reacción con elementos intersticiales para bajas presiones, aunque no se han encontrado evidencias de ello.

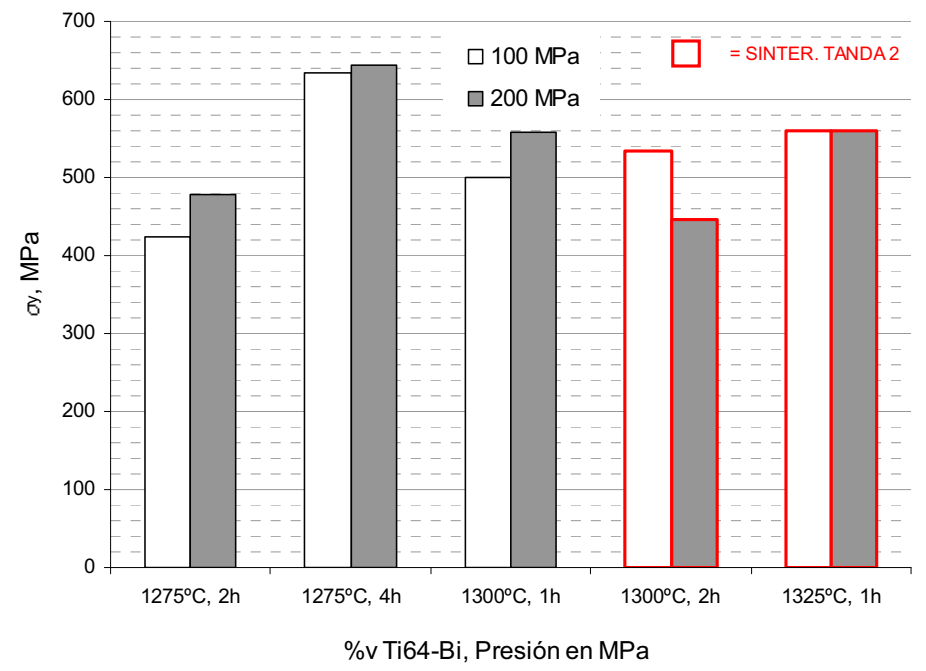

Fig. 5.126. $\sigma_{y}$ a flexión de la fracción 250-500 $\mu \mathrm{m}$, variación con el ciclo de sinterización para muestras con $75 \% \mathrm{Ti} 64-25 \% \mathrm{Bi}$ compactadas a 100 y $200 \mathrm{MPa}$. 


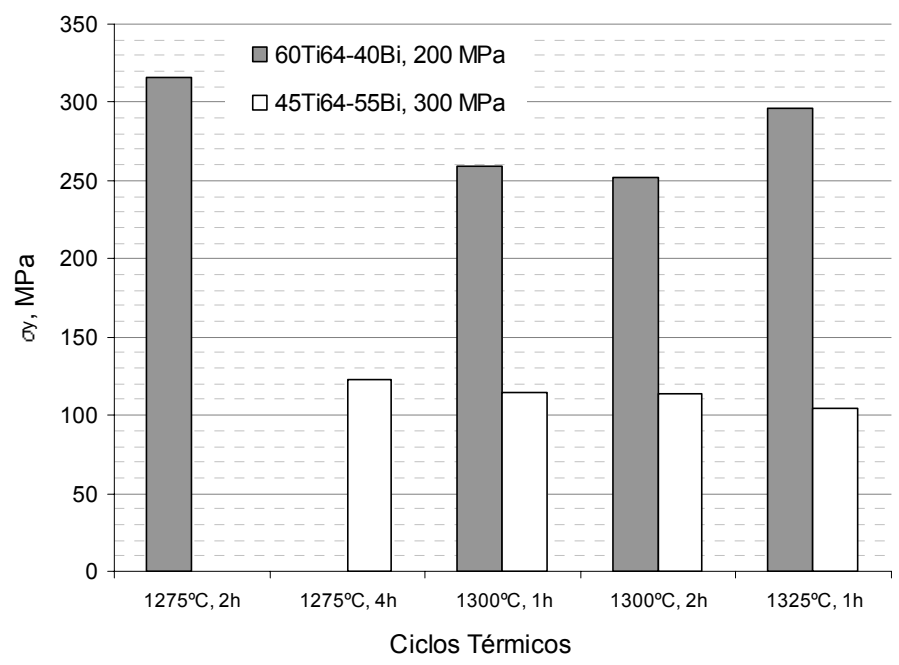

Fig. 5.127. $\sigma_{y}$ a flexión de la fracción 125-250 $\mu \mathrm{m}$, variación con el ciclo de sinterización para 60Ti64-40Bi \%v $200 \mathrm{MPa}$ y 45Ti64-55Bi $300 \mathrm{MPa}$.

Al comparar las distintas fracciones granulométricas de espaciador se observa como a la presión más baja, $100 \mathrm{MPa}$, el tamaño influye poco, y la resistencia depende del ciclo térmico, aumentando en general con el tamaño a $1275^{\circ} \mathrm{C} 2 \mathrm{~h}$, figura 5.128 , y reduciéndose en los ciclos mayores $\left(1300^{\circ} \mathrm{C} 2 \mathrm{~h}\right.$ y $\left.1325^{\circ} \mathrm{C} 1 \mathrm{~h}\right)$, tabla 5.14 , figura 5.129 . A $100 \mathrm{MPa}$ no se observa una tendencia concreta en el resto de ciclos. Por el contrario, al aumentar la presión de compactación, un mayor tamaño de bicarbonato provoca un decremento de las propiedades mecánicas, tabla 5.14 y figura 5.129 . 
5. RESULTADOS Y DISCUSION

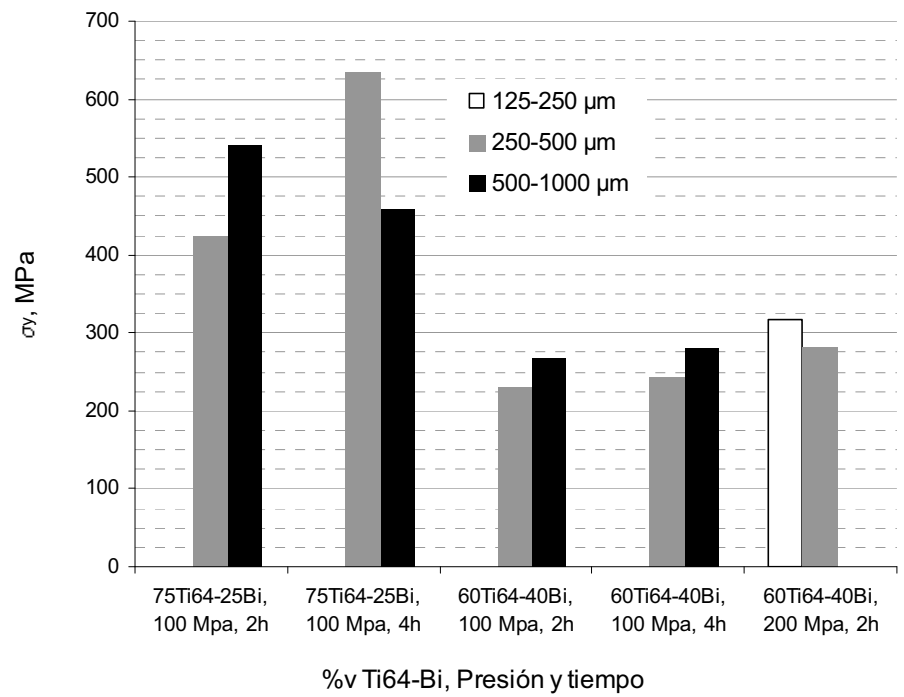

Fig. 5.128. $\sigma_{y}$ a flexión de las muestras sinterizadas a $1275^{\circ} \mathrm{C}$. Comparación entre fracciones granulométricas de espaciador.

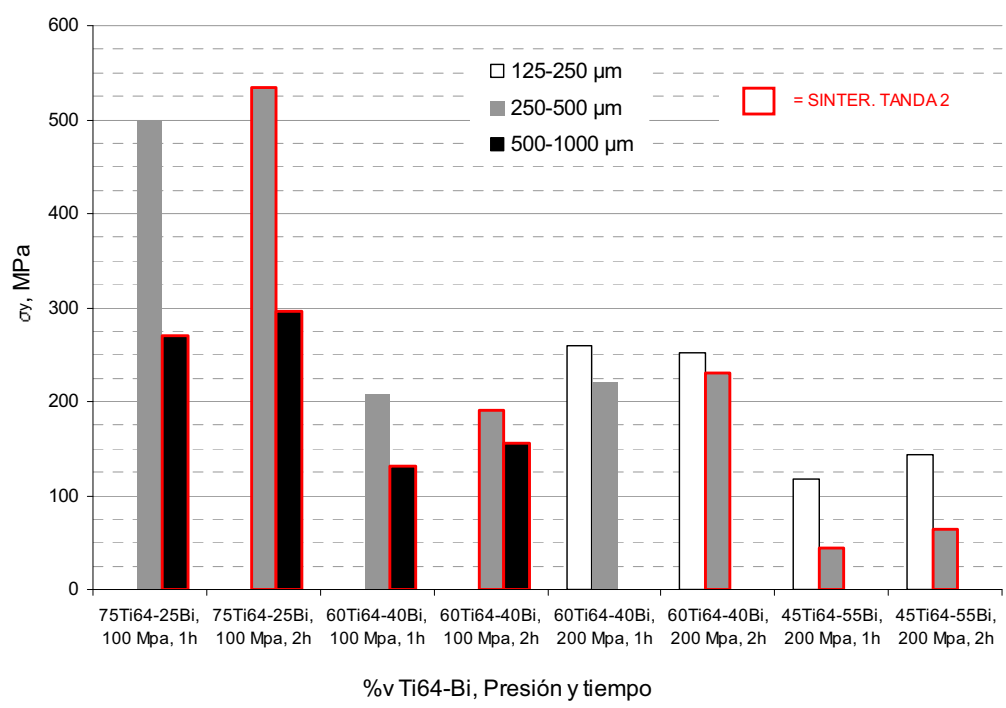

Fig. 5.129. $\sigma_{y}$ a flexión de las muestras sinterizadas a $1300^{\circ} \mathrm{C}$. Comparación entre fracciones granulométricas de espaciador. 
Finalmente en las muestras realizadas empleando urea como espaciador en sustitución del bicarbonato, debido al aspecto que presentaban una vez eliminado el espaciador, véase apartado 5.4.1.2, se decidió ensayar a flexión únicamente las muestras con mayor contenido en urea (25 y 40\%v). En todos los casos se observó como las probetas con la fracción granulométrica intermedia de espaciador (250-500 $\mu \mathrm{m})$ obtenían la máxima resistencia, siendo esta mínima para la fracción de 125 a $250 \mu \mathrm{m}$, figura 5.130. Ésta diferencia probablemente esté originada por la mayor rotura de las paredes entre macroporos durante la eliminación de la urea respecto a la originada en la eliminación del bicarbonato, figura 5.111. Por una parte, en el tamaño menor de espaciador un reducido espesor de pared entre macroporos podría ocasionar su colapso para presiones relativamente bajas, por el contrario, en un tamaño grande de urea podría resultar crítico el reducido número de paredes conformadas, no obstante no se ha encontrado evidencia de ello.

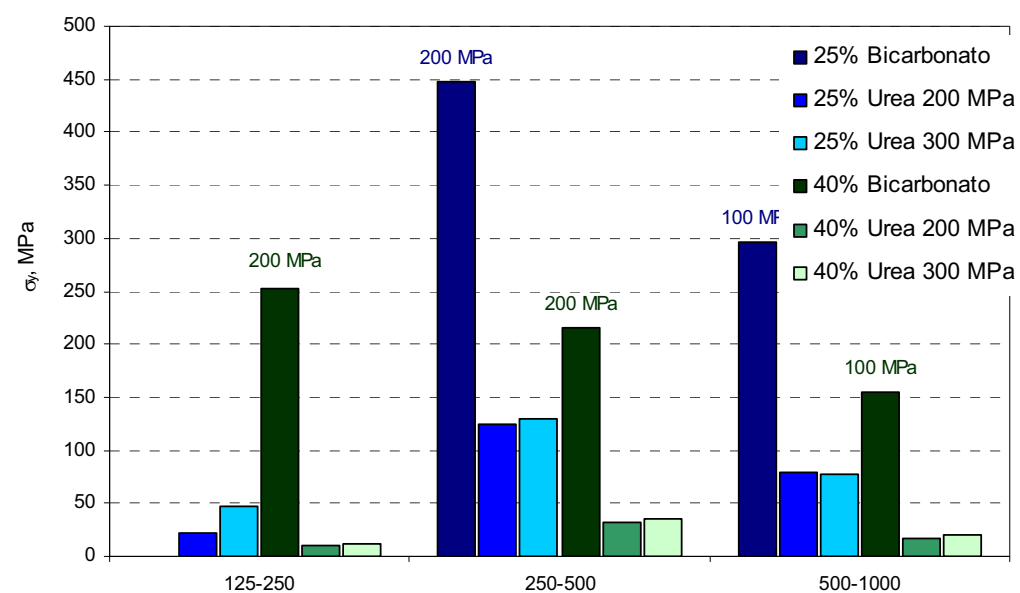

Fig. 5.130. $\sigma_{y}$ a flexión de las muestras con urea como espaciador, sinterizadas a $1300^{\circ} \mathrm{C}, 2 \mathrm{~h}$. Comparación entre fracciones granulométricas y con las obtenidas con bicarbonato para los mismos parámetros de proceso.

La significativa merma de resistencia producida en relación a las muestras en las que se empleó bicarbonato de amonio, así como el deficiente aspecto de las piezas tras la eliminación de la urea, hacen necesario profundizar en futuras investigaciones sobre la eliminación de ésta de forma completa y eficiente. 


\subsubsection{Resistencia a Compresión.}

Pese a que, también se compactaron probetas utilizando urea como espaciador, por el mal aspecto obtenido tras la evaporación de la urea y los deficientes resultados a flexión, éstas no se ensayaron.

En las piezas sin espaciador, figura 5.131, un aumento de la presión de compactación genera siempre un incremento del límite elástico a compresión de la pieza. De igual modo, para igual presión y temperatura de sinterización, un incremento del tiempo también incrementa su resistencia. Por el contrario, no se observa una evolución concreta de las propiedades mecánicas con la temperatura.

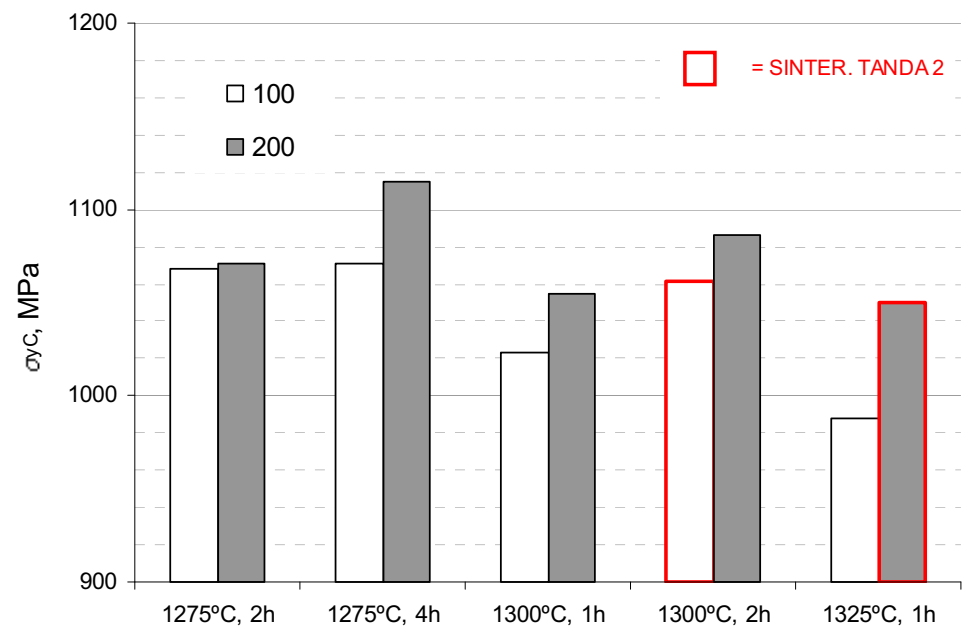

Fig. 5.131. $\sigma_{y}$ a compresión $100 \%$ Ti64 compactadas a 100 y 200 MPa y sinterizadas a distintos ciclos.

Las probetas base de la investigación, realizadas con Ti6Al4V como matriz y bicarbonato como espaciador, presentaron un comportamiento similar al observado a flexión. Así, a igualdad del resto de parámetros la resistencia a compresión resulta ligeramente superior para las dos fracciones de espaciador más pequeñas, reduciéndose para la fracción más grosera, figura 5.132. De igual modo, el límite elástico a compresión, depende fundamentalmente del porcentaje volumétrico de bicarbonato, 
produciéndose la máxima caída de resistencia entre probetas sin espaciador y con únicamente un $25 \%$ v, figura 5.132 .

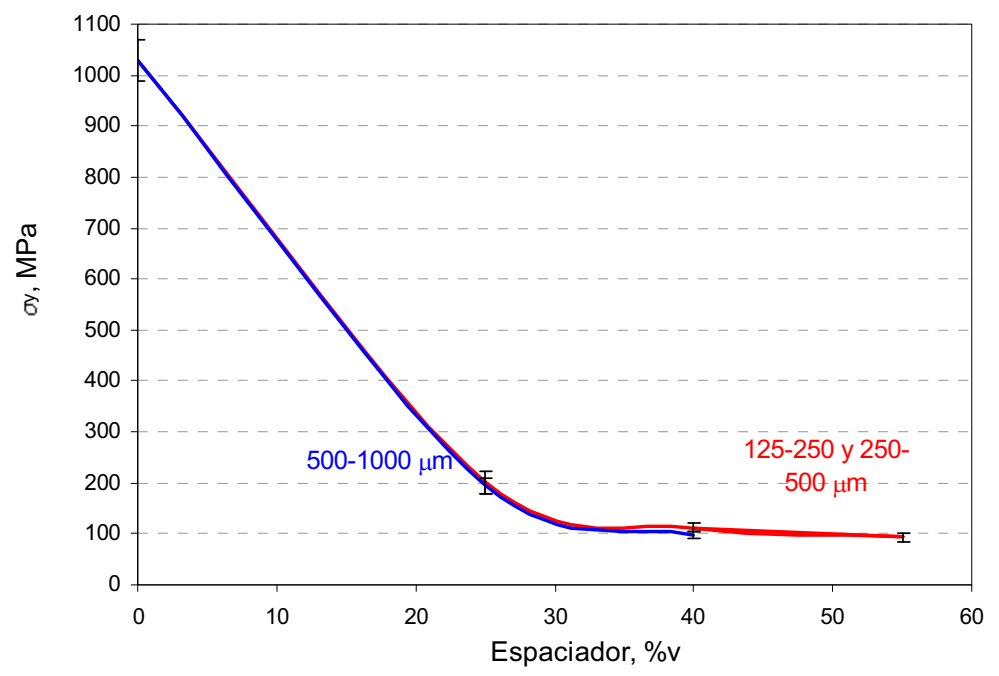

Fig. 5.132. $\sigma_{y}$ a compresión en función del \%v y fracciones granulométricas de espaciador.

Con un $25 \%$ v de bicarbonato, la resistencia a compresión se reduce entorno a un $80 \%$ (800 $\mathrm{MPa}$ ) respecto a la de la pieza sin espaciador. En cambio, al adicionar hasta un $30 \% \mathrm{v}$ más de bicarbonato la caída de resistencia es menor ( $\approx 140 \mathrm{MPa} 50 \%$ respecto a $75 \%$ Ti64). Por otra parte, cabe destacar la reducida diferencia entre el límite elástico de probetas con 40 o 55\% de espaciador. Ello implica que, para cantidades considerables de bicarbonato (a partir del $40 \%$ ), un incremento de espaciador del $15 \% \mathrm{~V}$ se corresponde aproximadamente con pérdidas de resistencia del mismo orden $(\approx 15 \mathrm{MPa}$, $\approx 15 \%$ ). Dicha caída de resistencia puede deberse a la contribución de diversas variables, como la microporosidad existente, la morfología irregular y rugosidad de los poros, la mayor heterogeneidad del material así como la menor resistencia de las partículas de espaciador, cuya deformación durante la compactación puede ocasionar una distribución heterogénea de la presión de compactación a lo largo de la pieza porosa. 
Al igual que en probetas sin espaciador, la temperatura influye poco, probablemente porque el rango de variación es estrecho. Así, para una misma temperatura y tamaño de espaciador, la resistencia aumenta cuando:

- $\quad$ Disminuye el contenido en espaciador, figura 5.132.

- $\quad$ Aumenta el tiempo de sinterización, tabla 5.14.

- Desciende la presión de compactación, figura y 5.133.

Si bien en los ensayos de flexión un aumento de presión en muestras con hasta un $25 \% \mathrm{v}$ de bicarbonato provocaba un incremento de propiedades mecánicas, a compresión únicamente mejoran el comportamiento con la presión las probetas de Ti64 sin adición de bicarbonato, reduciéndose generalmente el $\sigma_{y}$ para el resto de los casos, figura 5.133, tabla 5.14.

La variación diferente de las piezas con 75\%v de Ti64 en función de la presión de compactación según se someten a flexión o compresión podría venir ocasionada por las propias dimensiones de las piezas $\left(\approx 10.21 .5 \mathrm{~mm}^{3}\right.$ a flexión $\mathrm{y} \approx \mathrm{h} 27 \mathrm{~mm} \cdot \phi 25,5 \mathrm{~mm}$ a compresión), pues el mayor volúmen de las segundas implica menor presión efectiva sobre el polvo de Ti64 que conforma la matriz, con mayor influencia de las partículas de espaciador, que modificarán de forma más acentuada la distribución de presiones durante la compactación, lo que origina mayor hetereogeneidad de la pieza final.

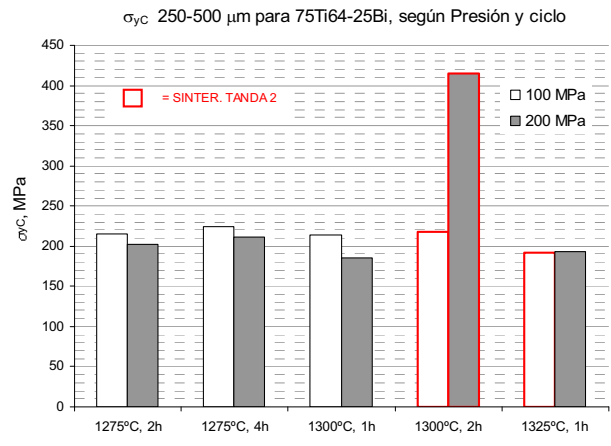

a

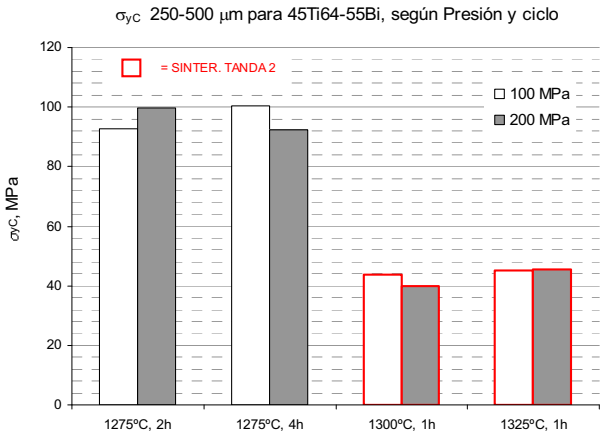

b

Fig. 5.133. $\sigma_{y}$ a compresión en función de la presión de compactación y ciclo térmico para muestras con 75 y $45 \%$ v de Ti64. Fracción 250 a $500 \mu \mathrm{m}$. 
En relación a la deformación de las muestras ensayadas a compresión, cabe señalar que la deformación plástica determinada gráficamente, GR2, resulta ligeramente superior a la determinada mediante las dimensiones de la probeta antes y después del ensayo, lo que podría deberse a la deformación inherente al propio equipo. Dado que la diferencia resultó reducida, en las probetas con espaciador la deformación plástica se determinó únicamente a partir de sus medidas.

En las probetas sin espaciador, la deformación en el límite elástico aumenta ligeramente con la presión de compactación, y varía poco con el ciclo de sinterización, oscilando en todos los casos entre $12-16 \%$ (2,7 y 3 $\mathrm{mm}$ ). Dicho efecto viene justificado por el incremento de la densidad en verde de la pieza a medida que aumenta la presión, facilitando con ello su sinterabilidad [ASM N7 1993, German 2005]. Dado que la deformación relativa es la misma en casi todas las muestras ensayadas $(7 \mathrm{~mm})$, el aumento de la región elástica viene unido a la reducción de la deformación plástica, figura 5.134 .

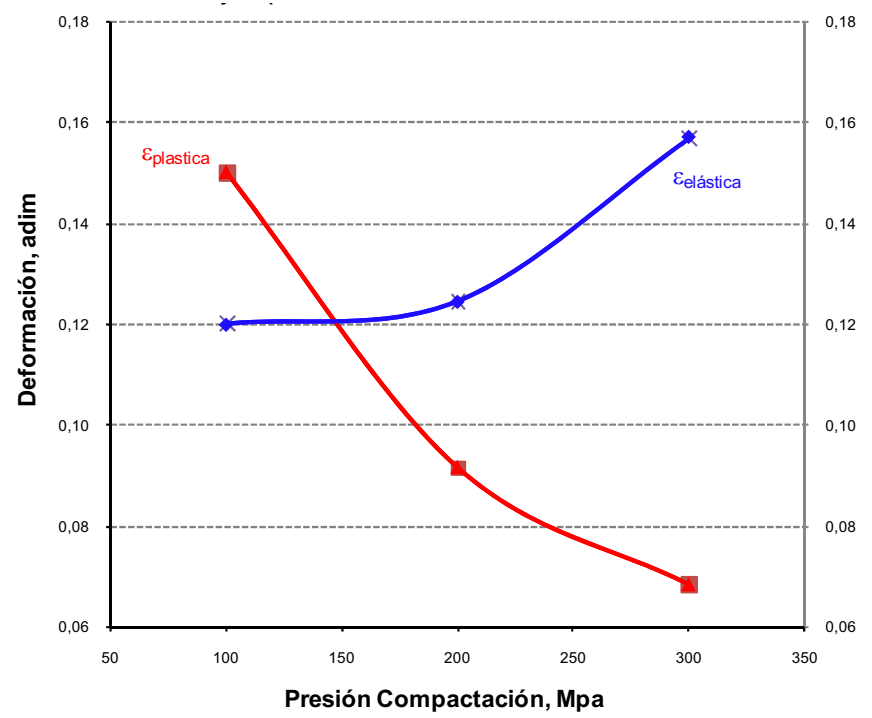

Fig. 5.134. Deformación elástica y plástica de probetas sin espaciador compactadas a $100 \mathrm{MPa}$ y sinterizadas a $1300^{\circ} \mathrm{C}, 1 \mathrm{~h}$. 
Por otra parte, la deformación elástica $\left(\varepsilon_{\mathrm{y}}\right)$ es máxima en probetas sin espaciador y se reduce a medida que aumenta el contenido en bicarbonato, figuras 5.135 y 5.137 .

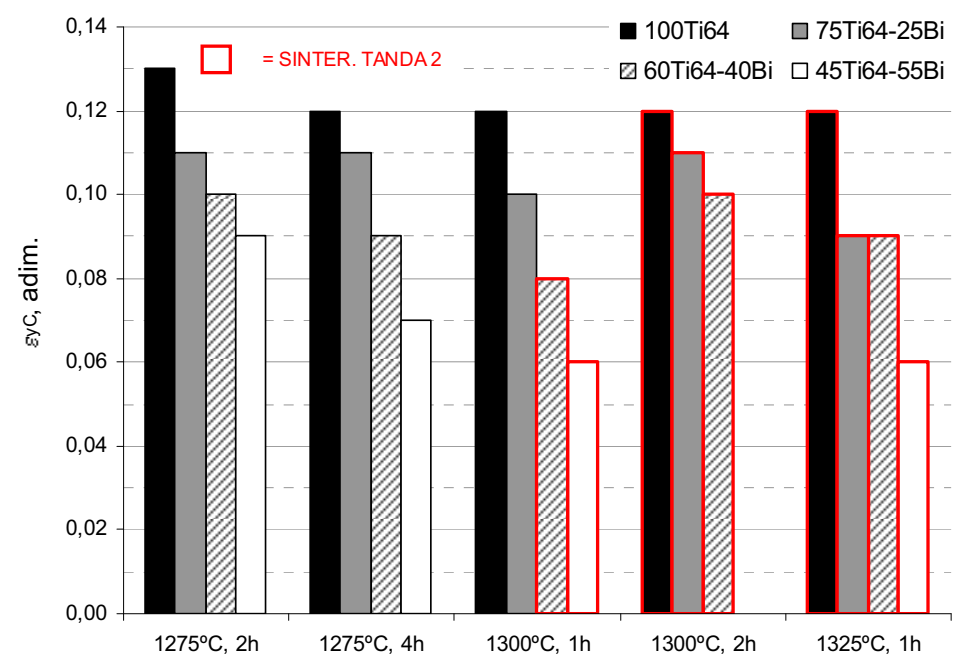

Fig. 5.135. Deformación en el $\sigma_{y}$ a compresión en función del \%v de espaciador y ciclo de sinterización. Fracción 250 a 500 m, compactadas a $100 \mathrm{MPa}$

Lógicamente, la $\varepsilon_{\text {plástica }}$ evoluciona de forma inversa, aumentando desde el $13-15 \%$ en probetas sin espaciador, hasta un máximo de $26-27 \%$ en muestras con $55 \%$ v de bicarbonato de amonio, figura 5.136. Las diferencias entre la deformación plástica de las muestras con $55 \%$ v de espaciador son debidas a que parte de ellas fueron ensayadas en la Instron A1340-1006, a una deformación relativa $7 \mathrm{~mm}$, y otras en la Instron 4204, con una deformación relativa de $3 \mathrm{~mm}$.

En general, las variaciones con el resto de parámetros del proceso $(\mathrm{P}, \mathrm{T}, \mathrm{t}$ o tamaño del espaciador) influyen poco sobre la deformación. Únicamente cabe destacar cierta reducción de la $\varepsilon_{\mathrm{y}}$ en probetas con $45 \% \mathrm{v}$ de bicarbonato, sinterizadas en la segunda tanda, lo que probablemente es debido a la fragilización de la pieza por absorción de elementos intersticiales, figura 5.137. 


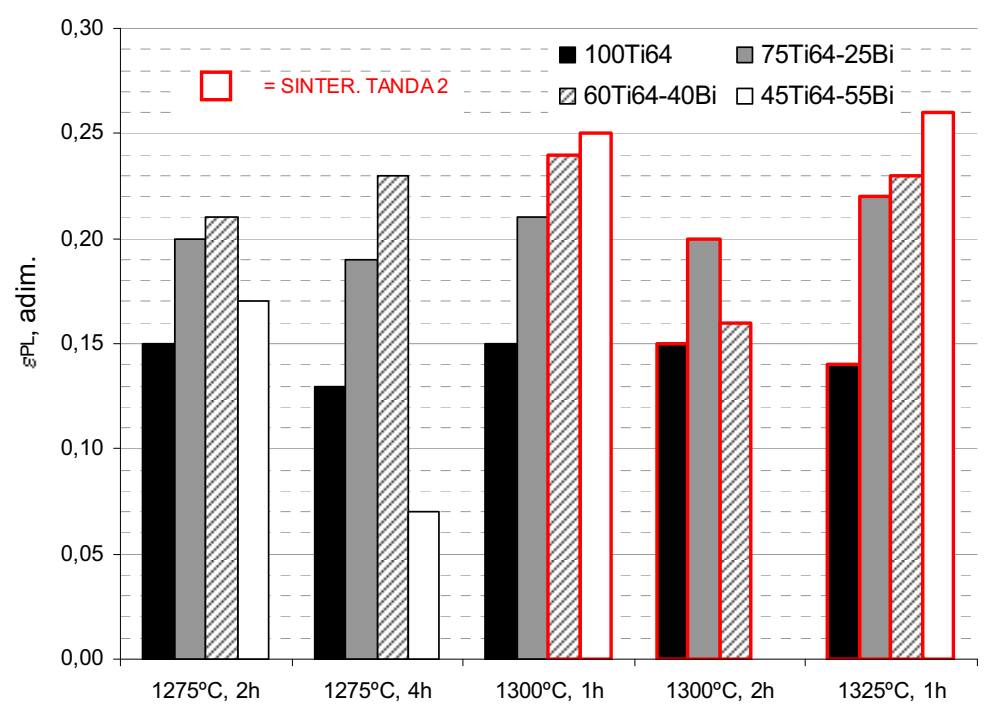

Fig. 5.136. Deformación plástica a compresión en función del \%v de espaciador y ciclo de sinterización. Fracción 250 a $500 \mu \mathrm{m}$, compactadas a $100 \mathrm{MPa}$.

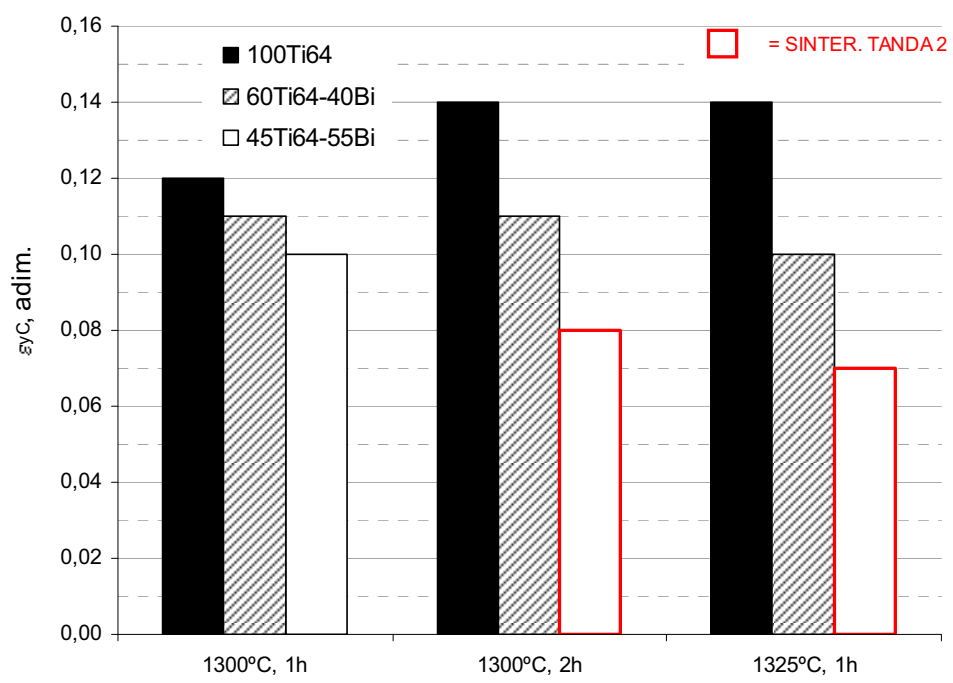

Fig. 5.137. Deformación en el $\sigma_{y}$ a compresión en función del \%v de espaciador. Fracción 125 a $250 \mu \mathrm{m}$, compactadas a $200 \mathrm{MPa}$. 
5.4.4.4. Rigidez de las piezas porosas base de la presente investigación.

La rigidez de las piezas porosas realizadas por el método de espaciadores y empleando bicarbonato de amonio como tal, se evaluó mediante la determinación de la pendiente de las curvas tensión - deformación unitaria a compresión $\left(E_{C}\right)$ y a flexión $\left(E_{F P}\right)$, así como por la fórmula que relaciona el módulo de Young con la flecha máxima a flexión $\left(\mathrm{E}_{\mathrm{FF}}\right)$.

A partir de los valores obtenidos, se determinó la rigidez relativa $\left(E_{r}=E^{*} / E_{S}\right)$, adoptando como rigidez del sólido, $E_{S}$, los valores recogidos en la tabla 5.15. Como se observa, para la rigidez relativa a flexión $\left(E_{\mathrm{rF}}\right)$ se adoptó como rigidez del sólido $\left(\mathrm{E}_{\mathrm{SF}}\right)$ el valor promedio de las piezas sin espaciador compactadas a las diferentes presiones de compactación (100, 200 y 300 $\mathrm{MPa}$ ). Por el contrario, dada la reducida variación de rigidez obtenida a compresión, en este caso se adoptó únicamente el promedio de las piezas sin espaciador compactadas a las distintas presiones.

Tabla 5.15. Rigidez promedio de piezas sin espaciador, adoptada como $E_{S}$, según los distintos métodos de determinación.

\begin{tabular}{|c|c|c|c|}
\hline $\mathrm{P}, \mathrm{MPa}$ & $\mathrm{E}_{\mathrm{SFF}}, \mathrm{MPa}$ & $\mathrm{E}_{\mathrm{SFP}}, \mathrm{MPa}$ & $\mathrm{E}_{\mathrm{SC}}, \mathrm{MPa}$ \\
\hline 100 & 15.726 & 10.521 & \\
\hline 200 & 16.840 & 10.991 & \multirow{2}{*}{12.509} \\
\hline 300 & 17.690 & 10.963 & \\
\hline
\end{tabular}

Como se observa en la tabla, la rigidez a flexión obtenida mediante la determinación de la pendiente de la curva $\left(\mathrm{E}_{\mathrm{FP}}\right)$ resulta ligeramente inferior a la determinada por aplicación de la fórmula que relaciona el módulo con la flecha máxima $\left(\mathrm{E}_{\mathrm{FF}}\right)$. No obstante, la rigidez relativa a flexión $\left(\mathrm{E}_{\mathrm{F}}{ }^{*} / \mathrm{E}_{\mathrm{SF}}\right)$ resulta semejante para ambos métodos, figura 5.138. Los modelos matemáticos de correlación entre la densidad y rigidez relativa representados serán explicados en el apartado siguiente 5.4.4.4. 


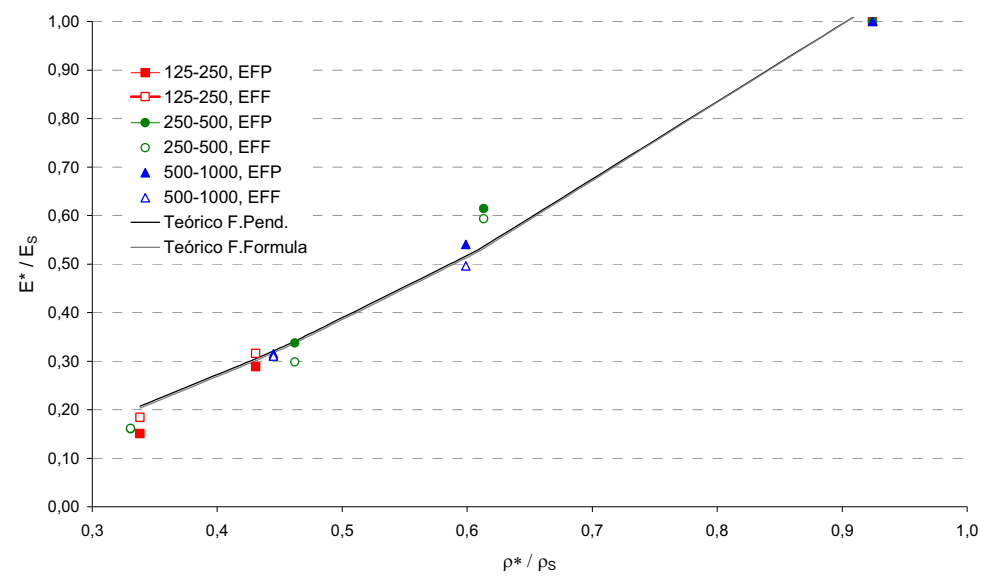

Fig. 5.138. Rigidez relativa a flexión determinada según pendiente de la curva, $E_{F P}, y$ fórmula, $E_{F F}$, para piezas porosas de Ti64 en función de su densidad relativa.

Por el contrario, al comparar la rigidez relativa obtenida mediante la determinación de la pendiente de la curva para ambos tipos de ensayos se obtienen valores superiores a flexión respecto a compresión, figura 5.139. Al igual que en las figuras anteriores, los modelos matemáticos de correlación representados se explicarán en el apartado siguiente.

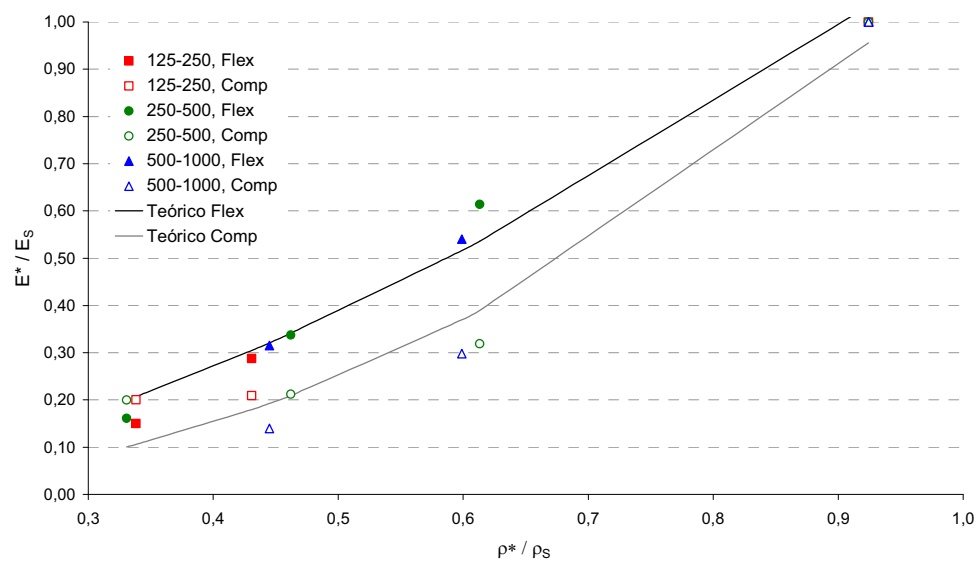

Fig. 5.139. Rigidez relativa determinada según pendiente de la curva a flexión, $E_{F P}, y$ a compresión, $\mathrm{E}_{\mathrm{C}}$, para piezas porosas de Ti64 en función de su densidad relativa.

De acuerdo con los datos recogidos en la tabla 5.14, el parámetro de mayor influencia resulta la adición de espaciador [Wen 2002a, Bram 2005]. En piezas sin espaciador o hasta un $25 \% \mathrm{v}$, la rigidez relativa a compresión 286 
desciende en general con la presión de compactación, mientras que para contenidos mayores de bicarbonato la rigidez apenas se modifica con la presión. La variación con el resto de parámetros de proceso ( $T$, t y tamaño de espaciador) resulta reducida.

Al igual que ocurría con la resistencia, la máxima reducción de rigidez se da entre probetas sin espaciador y con una adición de un $25 \% \mathrm{v}\left(\nabla \mathrm{E}_{\mathrm{C}} \approx 67-\right.$ $70 \% ; \nabla \mathrm{E}_{\mathrm{F}} \approx 40-47 \%$ respecto $\left.100 \mathrm{Ti64}\right)$, tabla 5.14 y figura 5.139 . Pese a que contenidos mayores de espaciador $(40 \% \mathrm{v}-55 \% \mathrm{v})$ reducen todavía más la rigidez, dicha variación no es proporcional a la adición de espaciador $\left(\nabla \mathrm{E}_{\mathrm{C}} \approx 80-88 \% ; \nabla \mathrm{E}_{\mathrm{F}} \approx 67-80 \%\right.$ respecto 100Ti64). Así, con adiciones de únicamente un $25 \% \mathrm{v}$ de bicarbonato ( $40 \%$ de porosidad), la rigidez de las piezas porosas desarrolladas resulta próxima a la presentada por el hueso humano cortical [Comín 1999, Asaoka 2003, Köhl 2007], lo que resulta de vital importancia de cara a facilitar el trabajo del hueso junto al implante [Park 1992, Simske 1997, Vallet 2000].

5.4.4.5. Modelos matemáticos de correlación entre la densidad relativa y las propiedades mecánicas de las piezas porosas de Ti64 obtenidas mediante el método de espaciadores.

Autores como Gibson y Asbhy [Gibson 1999] propusieron modelos matemáticos de correlación entre la porosidad y propiedades obtenidas (5.4.1) basándose en microestructuras ideales: poros esféricos, cilíndricos o cúbicos ordenados regularmente.

$$
\frac{\sigma^{*}}{\sigma_{s}}=C\left(\frac{\rho^{*}}{\rho_{s}}\right)^{n}
$$

En dichos modelos, la constante de proporcionalidad, C, y el exponente, $\mathrm{n}$, reflejan parámetros de la espuma, tales como la morfología de la celda, forma y ordenamiento [Asbhy 2000, Esen 2007]. En espumas metálicas, imperfecciones como la curvatura de la celda, concentración de material en 
determinados puntos, densidad no uniforme, pueden degradar la resistencia y rigidez de la espuma.

Pese a que los modelos propuestos no pueden extenderse directamente a materiales reales y se propusieron para materiales porosos con densidades relativas inferiores a 0,3 , en el estudio realizado, se ha encontrado una dependencia entre las propiedades mecánicas relativas obtenidas $\left(\sigma_{\mathrm{y}}{ }^{*} / \sigma_{\mathrm{s}}\right)$ y la densidad relativa $\left(\rho * / \rho_{s}\right)$, donde los parámetros "*" y " $s$ " representan la propiedad de la espuma y la del material sólido respectivamente.

Dado que la variable de mayor influencia es el contenido en espaciador, los modelos se obtuvieron tomando la resistencia promedio para piezas con una misma adición de espaciador (densidad relativa), independientemente del ciclo de sinterización, presión aplicada y tamaño de partículas de espaciador.

Por otra parte, se tomó como densidad del sólido, $\rho_{\mathrm{s}}, 4,5 \mathrm{~g} / \mathrm{cm}^{3}$ para el TiCP3 y 4,42 g/ $\mathrm{cm}^{3}$ para el Ti64 [Boyer 1994, Matweb.com]. Para el límite elástico, tanto a flexión como a compresión, se adoptó el del material sin adición de espaciador, siendo éste de $1857 \mathrm{MPa}$ a flexión ( $\sigma_{\mathrm{YFS}}$ ) y 1030 a compresión $\left(\sigma_{\mathrm{YCS}}\right)$. De forma similar, se adoptó como rigidez del sólido, $\mathrm{E}_{\mathrm{S}}$, la indicada en la tabla 5.15 anterior.

Con dichos parámetros se obtuvo, para la resistencia relativa a flexión, el modelo de correlación (5.4.2):

$$
\frac{{\sigma_{Y F}}^{*}}{\sigma_{Y F S}}=1,246\left(\frac{\rho^{*}}{\rho_{S}}\right)^{2,86}
$$

Y para la resistencia relativa a compresión, el modelo de correlación (5.4.3):

$$
\frac{\sigma_{Y C}{ }^{*}}{\sigma_{Y C S}}=1,323\left(\frac{\rho^{*}}{\rho_{S}}\right)^{3,62}
$$


Ambos modelos presentan un coeficiente de correlación $R^{2}$ de 0,99 . La figura 5.140 recoge los valores, experimentales y teóricos, de la resistencia a flexión y a compresión obtenidas.

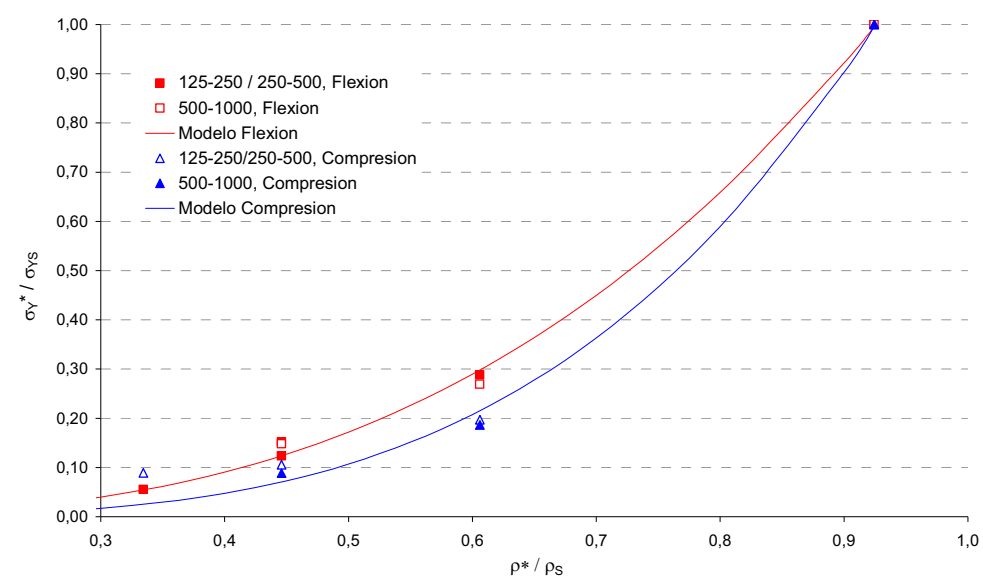

Fig. 5.140. Resistencia relativa, a flexión y a compresión, en función de la densidad relativa.

De igual modo, se obtuvieron modelos de correlación entre la densidad y rigidez relativa de las piezas desarrolladas. La tabla 5.16 recoge los coeficientes obtenidos tanto para las pruebas previas realizadas con TiCP3, como para las muestras realizadas con Ti64 y en función del método de determinación (compresión o flexión y, en éste último, mediante fórmula o pendiente de la curva). Asimismo, se recogen modelos aportados por otros autores para piezas porosas de TiCP [Bram 2005, Esen 2007].

Tal como se observa, los coeficientes $\mathrm{C}$ y $\mathrm{n}$ son coincidentes para la rigidez relativa de las piezas porosas de Ti64 obtenida a flexión, independientemente de que ésta se determine por aplicación de la fórmula o mediante la pendiente de la curva $\sigma-\varepsilon_{0}$. 
Tabla 5.16. Modelos de correlación de la rigidez relativa obtenida por diversos métodos en función de la densidad relativa.

\begin{tabular}{|c|c|c|c|c|c|}
\hline MATERIAL & ENSAYO & DETERMINACIÓN E* & $\mathrm{C}$ & $\mathrm{n}$ & $\begin{array}{c}\text { Correlación } \\
\text { modelo, } \mathrm{R}^{2}\end{array}$ \\
\hline TiCP3 & Flexión & Pendiente curva & 1,037 & 1,62 & 0,86 \\
\hline Ti6AI4V & Flexión & Pendiente curva & 1,172 & 1,60 & 0,97 \\
\hline Ti6Al4V & Flexión & Fórmula & 1,173 & 1,60 & 0,98 \\
\hline Ti6Al4V & Compresión & Pendiente curva & 1,136 & 2,19 & 0,96 \\
\hline & & Gibson-Asbhy 1999 & 1 & 2 & \\
\hline TiCP & Compresión & Bram 2005 & 0,167 & 2 & - \\
\hline TiCP & Compresión & Esen 2007 & 1,598 & 4,72 & 0,99 \\
\hline
\end{tabular}

Por otra parte, el modelo obtenido para la determinación a compresión se asemeja bastante al propuesto por Gibson y Asbhy [Gibson 1999], resultando también bastante similar al obtenido por Bram [Bram 2005], lo que se debe a la similitud tanto en el desarrollo de las piezas como en el método de determinación. Por el contrario, en su trabajo Esen [Esen 2007] utilizó partículas esféricas de titanio, por lo que las paredes entre celdillas originadas en la sinterización resultaron de reducido tamaño lo que explica que su modelo propuesto resulte más sensible a la variación de densidad relativa. Por otra parte, el valor próximo a la unidad obtenido para el coeficiente $C$ en nuestros modelos resulta coherente, pues cuando la densidad relativa es próxima a uno, también debe serlo la rigidez relativa.

Finalmente, cabe destacar la reducida diferencia del coeficiente $\mathrm{C}$ obtenido para las piezas porosas de TiCP y de Ti64. El valor más reducido para las primeras es debido a su menor rigidez, producto del menor contenido en elementos de aleación [Leyens 2003, Lütjering 2007].

En definitiva, los modelos obtenidos resultan de gran interés pues, permiten aproximar las propiedades mecánicas (resistencia a flexión, a compresión y rigidez), para una determinada adición de espaciador $o$, lo que es equivalente, para una porosidad concreta, en función del material base y método de determinación. 
5.4.4.6. Conclusiones parciales de la caracterización mecánica de las piezas porosas de Ti6Al4V desarrolladas por el método de espaciadores.

En relación al tiempo de espera entre la compactactación y la eliminación del espaciador:

- Existe una gran influencia del tiempo de espera entre la compactación y eliminación del espaciador sobre las propiedades mecánicas, siendo de gran importancia eliminar el espaciador y sinterizar tan pronto como sea posible tras la compactación.

- En el ensayo de compresión la fragilización se manifiesta en la deformación de la muestra, presentando un comportamiento dúctil o frágil. A flexión dicho comportamiento no se observa a simple vista, pero las diferencias entre la resistencia de las probetas sinterizadas en la tanda $A$ y $B$ resultaron mucho más notables.

En relación a la resistencia a flexión de las piezas porosas obtenidas por el método de espaciadores:

- La resistencia a flexión de las piezas porosas obtenidas por la técnica de espaciadores se resume en la tabla 5.17, en función del contenido y tamaño de espaciador.

Tabla. 5.17. $\sigma_{y}$ a flexión, MPa, en función del \%v y fracciones granulométricas de espaciador. * Eliminados los resultados con rotura frágil de la probeta.

\begin{tabular}{|c|c|c|c|}
\hline \multirow{2}{*}{$\begin{array}{c}\text { Ti64 - Espaciador, } \\
\mathbf{\%}\end{array}$} & \multicolumn{3}{|c|}{ FRACCIÓN GRANULOMÉTRICA, $\boldsymbol{\mu m}$} \\
\cline { 2 - 4 } & $\mathbf{1 2 5}-\mathbf{2 5 0}$ & $\mathbf{2 5 0 - 5 0 0}$ & $\mathbf{5 0 0 - 1 0 0 0}$ \\
\hline $\mathbf{1 0 0 - \mathbf { 0 }}$ & \multicolumn{3}{|c|}{$1857+/-157$} \\
\hline $\mathbf{7 5 - 2 5}$ & $\begin{array}{c}\text { No } \\
\text { probetas }\end{array}$ & $535+/-110$ & $500+/-40^{*}$ \\
\hline $\mathbf{6 0 - 4 0}$ & $283+/-33$ & $230+/-50$ & $275+/-5^{*}$ \\
\hline $\mathbf{4 5 - 5 5}$ & \multicolumn{2}{|c|}{$103+/-\mathbf{7}^{*}$} & No probetas \\
\hline
\end{tabular}


- Las variables de mayor influencia resultan la adición de espaciador y presión de compactación, influyendo en menor medida el tamaño de espaciador y ciclo térmico.

- Los efectos de la presión, adición de espaciador y ciclo térmico interaccionan entre ellos, siendo los dos primeros los más influyentes:

A medida que aumenta el contenido en espaciador, desciende $\sigma_{\mathrm{y}}$

- En probetas sinterizadas a $1275{ }^{\circ} \mathrm{C}$, $01300{ }^{\circ} \mathrm{C} 1 \mathrm{~h}$, las propiedades mecánicas varían poco con la presión de compactación, de forma que aumentan muy ligeramente o se mantienen.

- En probetas sinterizadas a $1300^{\circ} \mathrm{C} 2 \mathrm{~h}$ y $1325^{\circ} \mathrm{C} 1 \mathrm{~h}$, la influencia de la presión depende del contenido en espaciador:

- Hasta un $25 \%$ v de bicarbonato de amonio, cuanto mayor es la presión de compactación, mayores son las propiedades mecánicas obtenidas.

- En probetas con 40 o $55 \% \mathrm{v}$ de espaciador, cuanto mayor la presión de compactación, menores las propiedades mecánicas obtenidas. A $200 \mathrm{MPa}$, existe poca variación con el ciclo T-t, mientras que a $300 \mathrm{MPa}$ se produce un considerable descenso del $\sigma_{\mathrm{y}}$ a medida que aumenta la temperatura.

- En cuanto al tamaño de espaciador:

- Las propiedades mecánicas descienden en general al aumentar el tamaño de espaciador.

- Únicamente en probetas con 40 ○ $55 \% \mathrm{v}$ de espaciador, compactadas a $100 \mathrm{MPa}$ y sinterizadas a $1275^{\circ} \mathrm{C}$ durante $2 \mathrm{~h}$, cuanto mayor el tamaño de espaciador, mayor el límite elástico. 
En relación a la resistencia a compresión de las piezas porosas obtenidas por el método de espaciadores:

- La resistencia a compresión de las piezas porosas obtenidas por la técnica de espaciadores se resume en la tabla 5.18 , en función del contenido y tamaño de espaciador:

Tabla. 5.18. $\sigma_{y}$ a compresión, MPa, en función del \% $\mathrm{v}$ y fracciones granulométricas de espaciador. *Eliminados los resultados de rotura frágil.

\begin{tabular}{|c|c|c|c|}
\hline \multirow{2}{*}{ Ti64 - Espaciador, \%V } & \multicolumn{3}{|c|}{ FRACCIÓN GRANULOMÉTRICA, $\boldsymbol{\mu m}$} \\
\cline { 2 - 4 } & $\mathbf{1 2 5 - \mathbf { 2 5 0 }}$ & $\mathbf{2 5 0 - 5 0 0}$ & $\mathbf{5 0 0 - 1 0 0 0}$ \\
\hline $\mathbf{1 0 0 - \mathbf { 0 }}$ & \multicolumn{3}{|c|}{$1030+/-40$} \\
\hline $\mathbf{7 5 - 2 5}$ & $\begin{array}{c}\text { No } \\
\text { probetas }\end{array}$ & $203+/-20$ & $192+/-10^{*}$ \\
\hline $\mathbf{6 0 - 4 0}$ & \multicolumn{2}{|c|}{$109+/-13$} & $91+/-10^{*}$ \\
\hline $\mathbf{4 5 - 5 5}$ & \multicolumn{2}{|c|}{$92+/-\mathbf{7}^{*}$} & No probetas \\
\hline
\end{tabular}

- Al igual que a flexión, los parámetros más influyentes resultan la adición de bicarbonato y presión de compactacion, influyendo en menor medida la temperatura y tiempo de sinterización.

- La resistencia a compresión aumenta, para todas las fracciones granulométricas, al reducir el contenido en espaciador y a diferencia del comportamiento a flexión, únicamente mejoran su resistencia al aumentar la presión las probetas sin espaciador.

- La deformación elástica $\left(\varepsilon_{y}\right)$, resulta superior en probetas sin bicarbonato de amonio (12-14\%) y se reduce a medida que aumenta el contenido en espaciador ( $7 \%$ para $55 \% \mathrm{v}$ de espaciador).

- La deformación plástica evoluciona de forma inversa, siendo mínima en probetas sin espaciador y aumentando con el contenido en bicarbonato ( $26-27 \%$ para un $55 \% \mathrm{v})$. 
En relación a la rigidez de las piezas porosas obtenidas por el método de espaciadores:

- La rigidez depende fundamentalmente de la adición de espaciador, no observándose diferencias significativas con el resto de parámetros de proceso ( $T, t, P$, tamaño espaciador).

- El valor de rigidez depende del método de determinación:

- La rigidez relativa obtenida a partir del ensayo de flexión resulta coincidente para ambos métodos de determinación (pendiente de la curva y por aplicación de la fórmula).

- La rigidez relativa es superior a flexión que a compresión.

- Para un $\mathbf{2 5 \%}$ v de espaciador la rigidez a flexión se reduce hasta el $50 \%$ de la del material sólido, asemejándose a los valores presentados por el hueso cortical humano.

En relación a los modelos matemáticos para las piezas porosas obtenidas por el método de espaciadores:

- Los modelos matemáticos de correlación entre la densidad relativa y las propiedades mecánicas permiten predecir la resistencia a flexión, a compresión y rigidez, en función de la porosidad de la pieza.

En general:

- Únicamente podrían emplearse con suficiente margen de seguridad piezas con $25 \%$ v de espaciador, pues el límite elástico a compresión para el hueso cortical oscila entre 110 y $200 \mathrm{MPa}$ [Comín 1999, Wen 2002 b, Heimann 2002, Asaoka 2003]. Éste contenido resulta inferior al delimitado por la resistencia a flexión, según la cual podrían emplearse piezas con $40 \%$ v de bicarbonato de amonio ( $\approx 103 \mathrm{MPa}$ ). 
- Las propiedades mecánicas de las piezas porosas obtenidas por el método de espaciadores podrían optimizarse:

- Realizando el proceso de forma continua, es decir, eliminar el espaciador inmediatamente tras la compactación y proceder a su inmediata sinterización, con lo que se minimizaría la contaminación de la pieza porosa.

- Aplicando presiones de compactación tan bajas como sea posible, lo que facilitará tanto una distribución más uniforme como la eliminación de las partículas de espaciador).

- Compactando a menor velocidad, lo que reducirá la recuperación elástica del material.

\subsubsection{ANALISIS DE ELEMENTOS.}

Al igual que en el análisis de los resultados obtenidos en las piezas porosas obtenidas por sinterización de microesferas, con el fin de establecer un rango de magnitud y dado que no existe un estándar para piezas porosas de Ti6Al4V, se comparan los valores obtenidos con los permitidos por las normas ASTM F1472-99, para piezas de Ti6Al4V de forja utilizables como implantes [ASTM F1472], y ASTM F1108-97a, para implantes de Ti6AI4V obtenidos por colada [ASTM F1108]. No obstante, cabe adoptar estas normas como una mera referencia, pues la mayor superficie específica de las piezas porosas desarrolladas en relación a las obtenidas por forja o colada, así como el hecho de ensayar las piezas directamente tras su sinterización, sin aplicar tratamientos químicos para eliminar posibles capas endurecidas [ASM N4 1994] probablemente originará que el contenido en intersticiales resulte superior. 


\subsubsection{Análisis de carbono.}

La mayor parte de los análisis se han realizado sobre probetas sin espaciador, con la finalidad de observar si se producía ganancia de intersticiales por el hecho de sinterizar junto a otras muestras que hubiesen contenido bicarbonato de amonio previamente.

Tal como se observa en la figura 5.141, el contenido en Carbono de las pruebas preliminares (TiCP3) es inferior respecto al que presentan las muestras de Ti64. Dicho efecto podría deberse a los diferentes moldes empleados, pues mientras que en los moldes de gres utilizados para sinterizar piezas de TiCP existen elementos susceptibles de combinar con el carbono, en los de $\mathrm{Al}_{2} \mathrm{O}_{3} \mathrm{o}$ itria esto es menos probable, con lo que el posible $\mathrm{C}$ existente en el horno (por sinterización de otros materiales,...) podría reaccionar con el titanio.

El contenido en azufre se reduce, resultando poco significativo y, en todos los casos, inferior a 0,003 \%Wt.

No obstante, el aspecto más destacable resulta ser el incremento de carbono que se produce entre muestras sin y con espaciador, siendo este más elevado cuanto mayor el contenido en bicarbonato de amonio, independientemente del tiempo de espera entre prensado y eliminación de espaciador. En general los valores obtenidos para probetas sin espaciador oscilan entorno al 0,025 \%Wt, mientras que al adicionar $40 \%$ de bicarbonato ascienden a 0,05 \%Wt y, con 55\% de espaciador ya resultan del orden de los obtenidos para las microesferas (entorno 0,08 \%Wt). Cabe señalar además, que el contenido en $\mathrm{C}$ es mayor en la superficie de la muestra $(0,0849 \% \mathrm{Wt})$ que en su interior $(0,0604 \% \mathrm{Wt})$. 


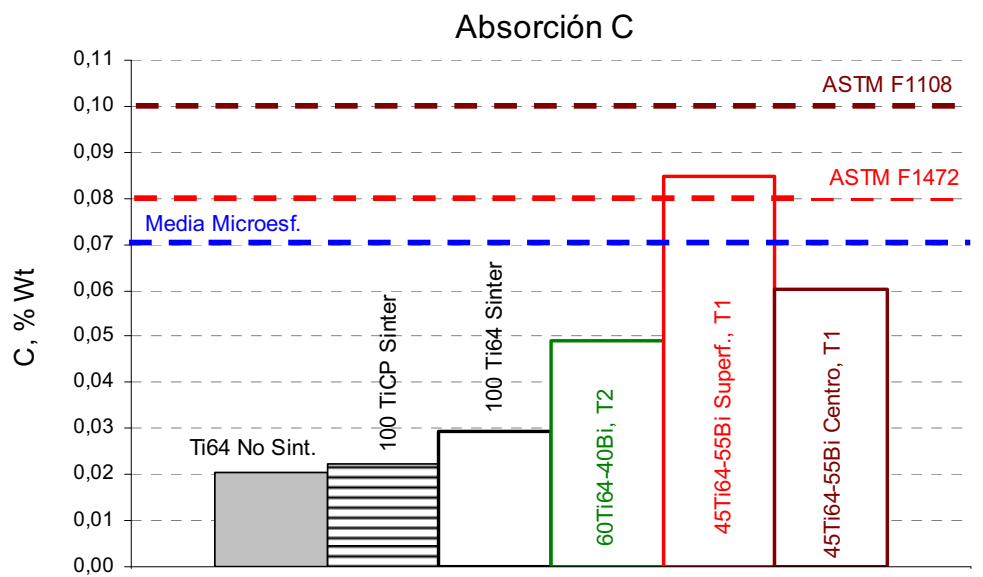

Fig. 5.141. Análisis de $C$ de piezas porosas de Ti64 obtenidas por el método de espaciadores.

De los resultados obtenidos se desprende que el contenido en carbono cumpliría con las normas de referencia, resultando en general inferior al obtenido en las piezas desarrolladas por sinterización de microesferas. Dado que únicamente resulta superior en superficie, probablemente seria necesario mecanizar la pieza para eliminar la capa superficial endurecida.

\subsubsection{Análisis de $\mathrm{N}$ y $\mathrm{O}_{2}$.}

El contenido en $\mathrm{O}_{2}$ de las muestras obtenidas por el método de espaciadores resulta elevado (entorno a 0,6 \%Wt), siendo superior tanto al obtenido en las piezas desarrolladas por sinterización de microesferas, como al máximo permitido por la norma adoptada como referencia. A pesar de ello, conviene destacar que la ganancia de $\mathrm{O}_{2}$ de probetas sin espaciador respecto al polvo de partida resulta reducida $(<0,65 \% \mathrm{Wt})$ pues, de acuerdo con los ensayos realizados, éste ya presentaba cerca de un $0,55 \% \mathrm{Wt}$.

Por otra parte, si se observa un notable incremento del $\% \mathrm{O}_{2}$ en probetas que contuvieron mayor tiempo el espaciador $\mathrm{y}$, al igual que ocurría con el $\mathrm{C}$, se detecta más $\mathrm{O}_{2}$ en superficie $(0,7410 \% \mathrm{Wt})$ respecto al interior de la muestra $(0,6757 \% \mathrm{Wt})$, figura 5.142 . 


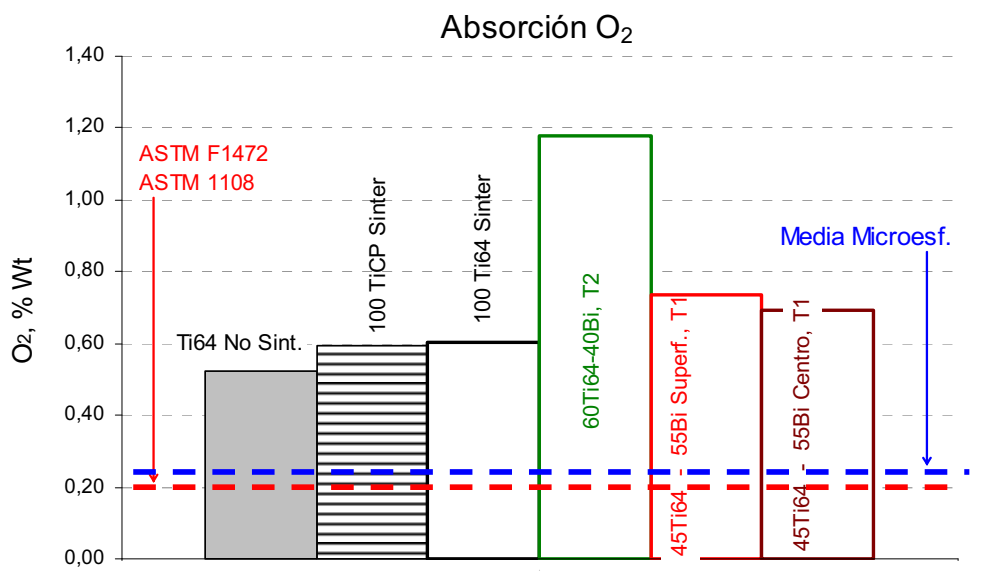

Fig. 5.142. Análisis de $\mathrm{O}_{2}$ de piezas porosas de Ti64 obtenidas por método espaciadores.

Tal como se observa en la figura 5.143, la presencia de $\mathrm{N}$ decae notablemente en relación con el polvo de partida, quedando en unos niveles por debajo tanto de las piezas obtenidas por sinterización de microesferas, como del nivel exigido por la normativa de referencia. Probablemente dicha reducción es debida al arrastre de átomos de nitrógeno para formar moléculas de $\mathrm{N}_{2}$ durante la eliminación del bicarbonato de amonio.

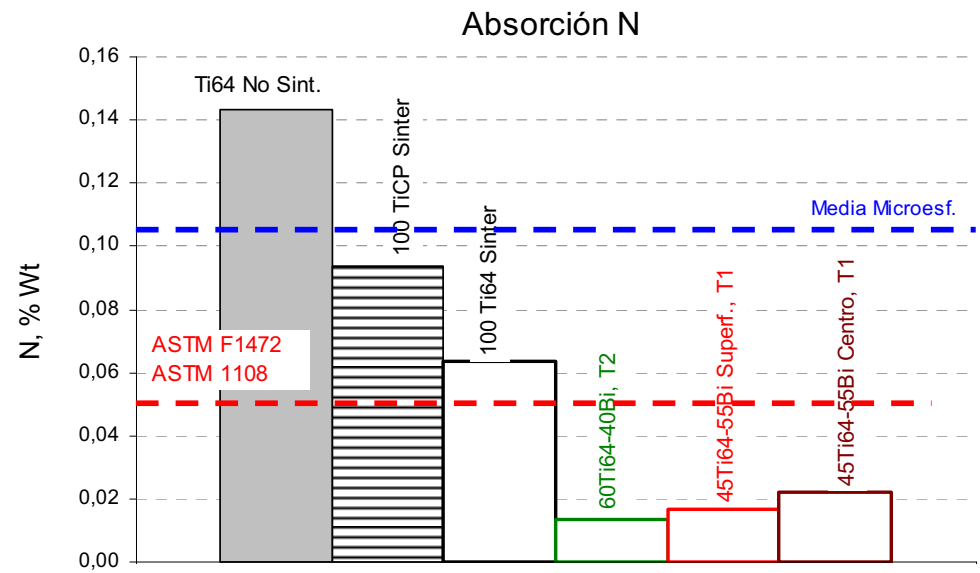

Fig. 5.143. Análisis de $\mathrm{N}$ de piezas porosas de Ti64 obtenidas por método espaciadores. 
Pese a que el nivel de $\mathbf{O}_{2}$ es superior al establecido por las normas ASTM F1472 y ASTM F1108 para piezas de Ti6Al4V de forja y colada utilizables como implantes, resulta semejante al del polvo de partida. A pesar de que el contenido en $\mathrm{O}_{2}$ ya resultaba elevado en relación al establecido por la norma ASTM F1580, para polvos de Ti64 empleados en el recubrimiento de implantes, la ganancia de este elemento no resulta significativa cuando el espaciador es eliminado en un periodo de tiempo relativamente reducido. Dado que no existe una norma de referencia para piezas de Ti6Al4V desarrolladas por pulvimetalúrgia y utilizables como implante, podría considerarse aceptable el contenido en $\mathrm{O}_{2}$ de las piezas porosas desarrolladas por el método de espaciador, y analizar en futuras investigaciones su comportamiento a fatiga.

No obstante, el nivel de $\mathrm{O}_{2}$ resultaría inaceptable en aquellas muestras que presentaron comportamiento frágil en el ensayo de compresión $\left(\mathrm{O}_{2}\right.$ $1.27 \% \mathrm{Wt}$ ). Ello corrobora la gran influencia del tiempo transcurrido entre la compactación y el secado, resultando incluso más influyente que la propia adición de bicarbonato, por lo que es necesario realizar el proceso de forma continua, eliminando el espaciador inmediatamente tras la compactación.

\subsubsection{CORROSION.}

Todo este interés resulta complementario a la determinación de la resistencia frente a la corrosión, estudiada en colaboración con el Instituto Tecnológico y de Estudios Superiores de Monterrey, en su sede de Querétano, bajo la supervisión del Doctor José Luís Ortiz Rosales.

No obstante, en estos ensayos sólo se ha contemplado el comportamiento de algunas unidades y no todas ellas. Concretamente, se ha trabajado con piezas porosas de Ti6Al4V, con un $55 \% \mathrm{v}$ de bicarbonato de amonio, compactadas a 100 y $200 \mathrm{MPa}$ y sinterizadas tanto a $1275^{\circ} \mathrm{C}$ durante 2 y 4 horas, como a $1325^{\circ} \mathrm{C}$ durante $1 \mathrm{~h}$. Se tomó además una muestra de forja como patrón de comparación. 


\subsubsection{Resultados de corrosión y discusión.}

En primer lugar, cabe hacer referencia a la dificultad de determinar la intensidad de corrosión sobre muestras porosas pues, por una parte, no se conoce exactamente el área sometida a corrosión, mientras que, por otra, en los casos en los que no se logre un sellado totalmente estanco, el electrolito podrá infiltrar entre los poros, actuando sobre una mayor superficie de corrosión. Por ello, en las pruebas potenciodinámicas, en lugar de determinar las densidades de corriente $i_{\text {corr, }}$ se midieron directamente las corrientes de corrosión $I_{\text {corr }}$ La tabla 5.19 recoge los resultados obtenidos.

Tabla 5.19. Corrientes y potenciales de corrosión de curvas potenciodinámicas.

\begin{tabular}{|c|c|c|c|c|c|}
\hline \multicolumn{4}{|c|}{ Muestra } & \multirow{2}{*}{$E_{\text {corr }}(V)$} & \multirow{2}{*}{$I_{\text {corr }}(A)$} \\
\hline Ti64-Bi, \%v & $\mathrm{P}, \mathrm{MPa}$ & $\mathrm{T},{ }^{\circ} \mathrm{C}$ & $t, h$ & & \\
\hline $100-0$ & 100 & 1275 & 2 & 1,428E-01 & $4,12300 \mathrm{E}-06$ \\
\hline $45-55$ & 100 & 1275 & 2 & 1,397E-01 & $1,52200 \mathrm{E}-05$ \\
\hline $100-0$ & 200 & 1275 & 2 & 1,804E-01 & 2,81333E-06 \\
\hline $45-55$ & 200 & 1275 & 2 & 2,342E-01 & 3,07567E-06 \\
\hline $100-0$ & 100 & 1275 & 4 & 2,151E-01 & 1,95333E-06 \\
\hline $45-55$ & 100 & 1275 & 4 & $2,669 \mathrm{E}-01$ & 2,94867E-06 \\
\hline $100-0$ & 200 & 1275 & 4 & 2,007E-01 & 1,79367E-06 \\
\hline $45-55$ & 200 & 1275 & 4 & 1,452E-01 & 3,71767E-06 \\
\hline $100-0$ & 100 & 1325 & 1 & 1,951E-01 & 1,93367E-06 \\
\hline $45-55$ & 100 & 1325 & 1 & 2,293E-01 & 6,71400E-06 \\
\hline $100-0$ & 200 & 1325 & 1 & $2,280 \mathrm{E}-01$ & 1,50133E-06 \\
\hline $45-55$ & 200 & 1325 & 1 & 1,663E-01 & $2,03900 \mathrm{E}-06$ \\
\hline \multicolumn{4}{|c|}{ Forja } & 2,486E-01 & $6,32267 \mathrm{E}-07$ \\
\hline
\end{tabular}

Tal como se observa en la tabla 5.19 y figura 5.144, la muestra obtenida por forja presenta una $I_{\text {corr }}$ menor y un potencial $E_{\text {corr }}$ mayor respecto a las muestras obtenidas por metalurgia de polvos, por lo que presenta mayor resistencia a la corrosión. No obstante, por la magnitud de las $I_{\text {corr }}$ de las 
otras dos probetas, se puede inferir un comportamiento a la corrosión aceptable de un material que forma una capa pasiva.

Se observó como la corriente de corrosión aumentaba ligeramente al incrementar la cantidad de espaciador, lo que podría deberse a que la solución del electrolito puede acceder a algunos resquicios de los poros que no fueron sellados completamente por la parafina, es decir, poros internos no comunicados inicialmente con la superficie, y por lo tanto inaccesibles a la parafina pero expuestos a la superficie después del desbaste.

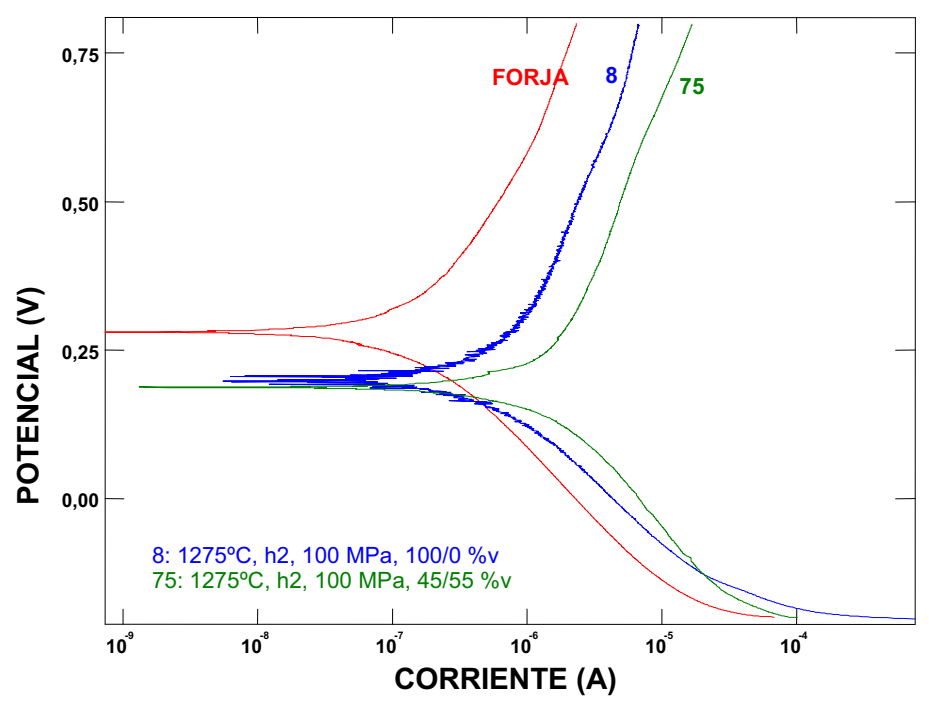

Fig. 5.144. Curvas de polarización de 3 muestras representativas.

Por otra parte, como se ha indicado en el desarrollo experimental, los espectros de impedancia resultantes fueron evaluados, ajustando los puntos a la respuesta del circuito eléctrico equivalente, donde $R_{\text {sol, refleja la }}$ resistencia del electrolito, $C_{d l l}$, la capacitancia de doble capa y $R_{c t}$, la resistencia a la transferencia de carga, siendo esta última inversamente proporcional a la velocidad de corrosión. 
Tabla 5.20. Parámetros de circuitos equivalentes para las pruebas de EIS.

\begin{tabular}{|c|c|c|c|c|c|}
\hline \multicolumn{4}{|c|}{ Muestra } & \multirow{2}{*}{$R_{\text {sol }}(\Omega)$} & \multirow{2}{*}{$\boldsymbol{R}_{c t}(\Omega)$} \\
\hline Ti64-Bi, \%v & $\mathrm{P}, \mathrm{MPa}$ & $\mathrm{T},{ }^{\circ} \mathrm{C}$ & $\mathbf{t}, \mathbf{h}$ & & \\
\hline $100-0$ & 100 & 1275 & 2 & 316,76 & $1,0630 E+05$ \\
\hline $45-55$ & 100 & 1275 & 2 & 226,06 & $4,0445 E+04$ \\
\hline $100-0$ & 200 & 1275 & 2 & 167,27 & $1,9830 E+05$ \\
\hline $45-55$ & 200 & 1275 & 2 & 107,31 & $2,5489 E+04$ \\
\hline $100-0$ & 100 & 1275 & 4 & 328,21 & $3,3445 E+05$ \\
\hline $45-55$ & 100 & 1275 & 4 & 108,00 & $2,2515 E+05$ \\
\hline $100-0$ & 200 & 1275 & 4 & 146,61 & $1,6044 E+05$ \\
\hline $45-55$ & 200 & 1275 & 4 & 181,56 & $6,8080 E+04$ \\
\hline $100-0$ & 100 & 1325 & 1 & 172,62 & $2,4498 E+05$ \\
\hline $45-55$ & 100 & 1325 & 1 & 233,65 & $1,1623 E+05$ \\
\hline $100-0$ & 200 & 1325 & 1 & 168,85 & $6,2034 E+05$ \\
\hline $45-55$ & 200 & 1325 & 1 & 204,64 & $6,3034 E+04$ \\
\hline \multicolumn{4}{|c|}{ Forja } & 186,42 & $3,2402 E+05$ \\
\hline
\end{tabular}

De los resultados obtenidos se desprende que las muestras obtenidas por metalurgia de polvos tienen un comportamiento similar o más resistente a la transferencia de carga que la muestra de forja. Por otra parte, dicha resistencia disminuye en muestras con espaciador, lo que es coherente con los resultados obtenidos de las voltamperometrías, por lo que la menor resistencia a la corrosión puede deberse al incremento de área que se produce después de desbastar la muestras.

La resistencia de la solución (entre 100 y $300 \Omega$ ) se encontró que era reducida en comparación con la resistencia del sustrato, con una resistencia a la transferencia de carga del orden de $10^{5} \Omega$, figura 5.145 , lo cual indica una alta resistencia a la corrosión en este medio. 


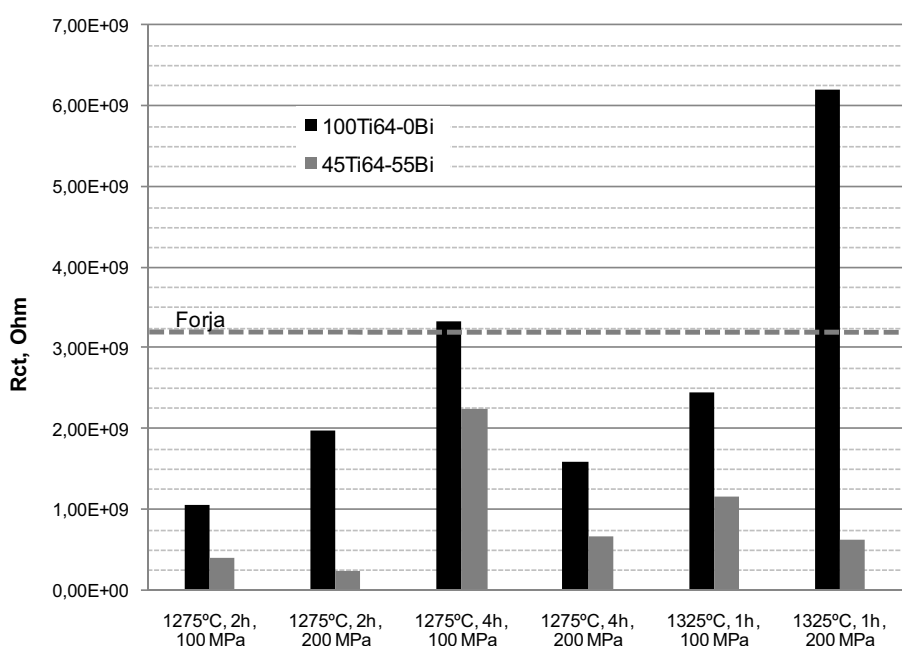

Fig. 5.145. Resistencia a la transferencia de carga variando porcentaje de espaciador.

Por tanto, los resultados de EIS permitieron concluir que la adición de espaciador disminuía la resistencia a la corrosión.

En relación al ensayo de ruido electroquímico, cabe indicar que la muestra que presentó menores fluctuaciones fue la de forja, figura 5.146a, mientras que las variaciones máximas se produjeron en la muestra con $55 \% \mathrm{v}$ espaciador compactada a $200 \mathrm{MPa}$ y sinterizada a $1275^{\circ} \mathrm{C}$ durante 2 horas, figura 5.146b.
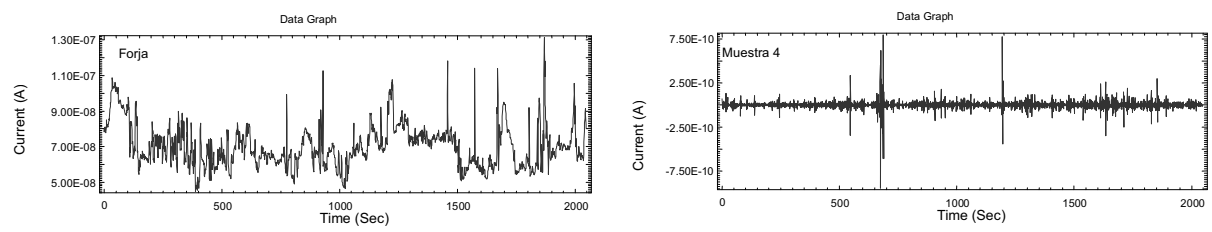

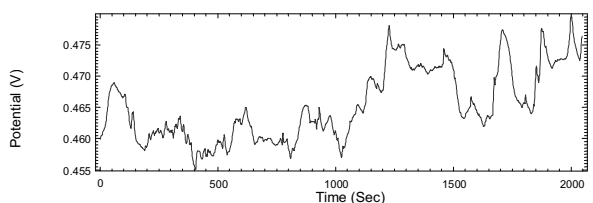

a

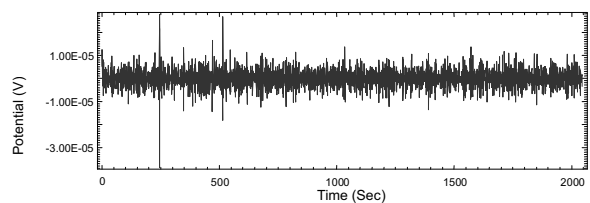

$b$

Fig. 5.146. Ruido electroquímico en: a) muestra de forja; b) 100Ti64-0Bi \%v, compactada a $200 \mathrm{MPa}$ y sinterizada a $1275^{\circ} \mathrm{C}$ durante $2 \mathrm{~h}$. Espectro tratado para eliminar las fluctuaciones de corriente y voltaje. 
En relación a la resistencia al ruido $R_{n}$, cuando se tienen dos electrodos idénticos de trabajo, ésta resulta muy similar a la resistencia a la transferencia de carga $R_{c t}$. No obstante, para este caso se presentan ciertas diferencias entre los electrodos de trabajo como: el área expuesta al electrolito, rugosidad superficial, entre otras, por lo que no se obtendrán valores de $R_{n}$ muy cercanos a la $R_{c t}$, pero si comparables, [Mansfeld 1994] diferenciados por algún orden de magnitud. Por tanto, la resistencia al ruido electroquímico, $R n$, resulta inversamente proporcional a velocidad de corrosión. Así, tal como se observa en la tabla 5.21, y al igual que en el resto de pruebas, la presencia de espaciador redujo la resistencia al ruido electroquímico, aumentando por tanto la velocidad de corrosión de las muestras más porosas. No obstante, la muestra de forja presentó menor resistencia al ruido respecto a algunas muestras que no incluían espaciador (100\% Ti64), aunque las diferencias fueron reducidas, por to que en términos prácticos se puede afirmar que las probetas de Ti6Al4V sin espaciador desarrolladas por pulvimetalurgia tienen un comportamiento ante la corrosión similar a la de la muestra de forja.

Tabla 5.21. Resistencia al ruido electroquímico en muestras experimentales.

\begin{tabular}{|c|c|c|c|c|}
\hline \multicolumn{4}{|c|}{ Muestra } & \multirow{2}{*}{$R_{n}(\Omega)$} \\
\hline Ti64-Bi, \%v & $\mathrm{P}, \mathrm{MPa}$ & $\mathrm{T},{ }^{\circ} \mathrm{C}$ & $t, h$ & \\
\hline $100-0$ & 100 & 1275 & 2 & 23.813 \\
\hline $45-55$ & 100 & 1275 & 2 & 40.849 \\
\hline $100-0$ & 200 & 1275 & 2 & 70.186 \\
\hline $45-55$ & 200 & 1275 & 2 & 55.351 \\
\hline $100-0$ & 100 & 1275 & 4 & 17.440 \\
\hline $45-55$ & 100 & 1275 & 4 & 16.365 \\
\hline $100-0$ & 200 & 1275 & 4 & 38.248 \\
\hline $45-55$ & 200 & 1275 & 4 & 27.555 \\
\hline $100-0$ & 100 & 1325 & 1 & 81.947 \\
\hline $45-55$ & 100 & 1325 & 1 & 60.645 \\
\hline $100-0$ & 200 & 1325 & 1 & 79.922 \\
\hline $45-55$ & 200 & 1325 & 1 & 56.467 \\
\hline \multicolumn{4}{|c|}{ Forja } & 62.278 \\
\hline
\end{tabular}


Finalmente, cabe indicar que mediante esta técnica se observó cierta reducción de la resistencia a la corrosión con el tiempo de sinterización, figura 5.147. Por una parte, este efecto podría deberse a la evolución de los poros durante la sinterización, pues a medida que avanza el proceso los poros adquieren morfologías más esféricas, de mayor tamaño, siendo absorbidos los poros más pequeños por los más grandes. Por tanto, en el caso de que un poro inicialmente cerrado quede expuesto al electrolito tras el desbaste, la superficie de exposición será mayor. No obstante, un incremento de temperatura debería ocasionar el mismo efecto.

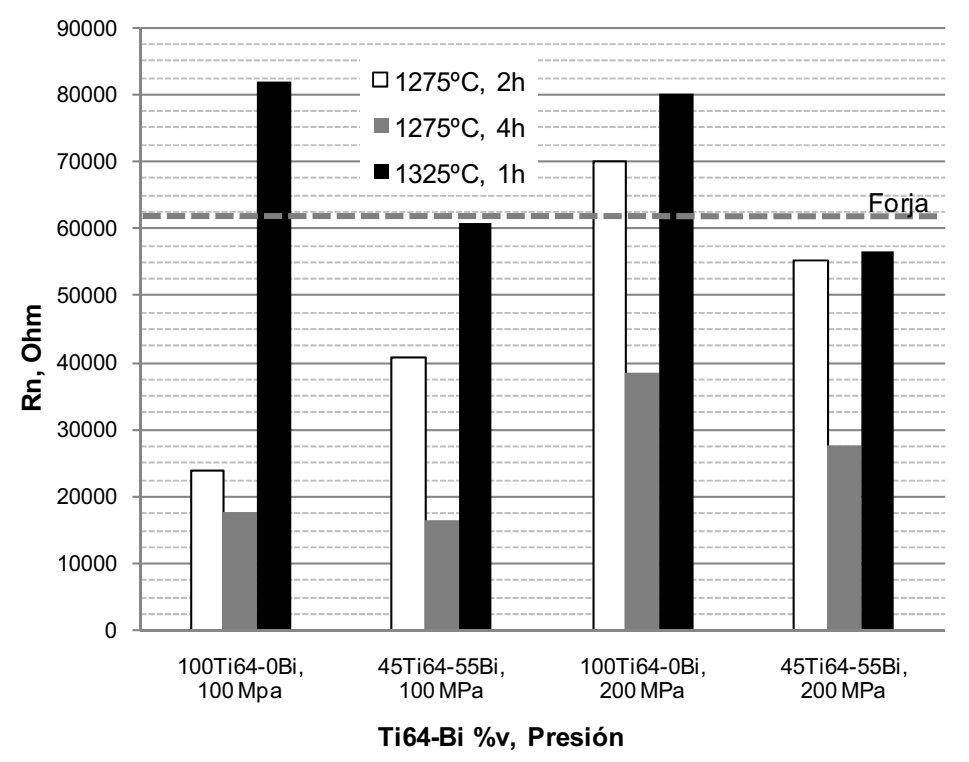

Fig. 5.147. Resistencia al ruido electroquímico según adición de bicarbonato, presión de compactación y tiempo de sinterización.

Por todo ello cabe concluir que, pese a que se ha puesto a punto una metodología para determinar la resistencia a la corrosión de piezas porosas de titanio, su estudio resulta complejo debido a la difícil determinación del área realmente expuesta. Por otra parte, es necesario ampliar el estudio en futuras investigaciones, con el fin de comprender el efecto de las variables temperatura y tiempo sobre el comportamiento a la corrosión. 
5.4.6.2. Conclusiones parciales de la corrosión en piezas obtenidas por el método de espaciadores.

- Se ha puesto a punto una metodología para la determinación de la resistencia a la corrosión de piezas porosas de titanio, aunque su estudio resulta complejo debido a la difícil determinación del área realmente expuesta.

- El porcentaje de espaciador provoca la mayor modificación en la velocidad de corrosión. A mayor adición de bicarbonato, más porosidad, lo que pude incrementar la superficie de contacto de las muestras, a pesar del sellado previo con parafina. No obstante, la variación de la corrosión parece deberse a aspectos meramente geométricos (superficie expuesta al electrolito) y no a cambios químicos en el material.

- El proceso de producción no es relevante ante la corrosión de aleaciones Ti-6Al-4V, pues no se observan diferencias significativas entre el comportamiento a la corrosión de las muestras fabricadas por Pulvimetalúrgia y la muestra de forja analizada.

En definitiva, la velocidad de corrosión se ve afectada más por aspectos geométricos que por cambios en la composición producidos durante el proceso de fabricación, por lo que aumenta fundamentalmente cuando se incrementa la adición de espaciador, debido a la mayor superficie expuesta.

De los resultados obtenidos se desprende el interés de desarrollar piezas con una piel superficial densificada, lo que reducirá la superficie expuesta, y con porosidad interior, que permita reducir la rigidez del implante y facilitar así la adecuación al hueso humano. Sobre dichas piezas se deberían aplicar tratamientos superficiales, pudiendo combinar un anodizado, para desarrollar una película superficial protectora de $\mathrm{TiO}_{2}$ (pasivado) con un recubrimiento posterior de un material bioactivo como la $\mathrm{HA}$, que facilitaría el desarrollo de las células óseas. No obstante, todo ello debe ser objeto de investigaciones posteriores. 
6

CONCLUSIONES 



\section{CONCLUSIONES.}

Como conclusión general, cabe indicar que se han desarrollado piezas porosas de titanio menos rígidas, con aptitud para la osteointegración y con unas propiedades mecánicas que permiten su uso como implante. Estas piezas han sido desarrolladas por vía pulvimetalúrgica, empleando para ello dos técnicas distintas como son la sinterización de microesferas y el método de espaciadores.

En relación a la reactividad del titanio con los moldes:

- La reactividad fue mínima al sinterizar sobre itria, y resultó máxima sobre gres y alúmina. Así, mientras que en los primeros se mantuvo la morfología y composición química, sobre gres y alúmina se produjo absorción de elementos y se modificó la morfología de las microesferas, lo que redujo sus propiedades mecánicas.

- Los moldes de circona podrían emplearse únicamente para sinterizar microesferas gruesas (diámetro medio $>450$ micras), pues su menor superficie específica produce una menor contaminación, obteniéndose unas propiedades mecánicas semejantes a las desarrolladas al sinterizar sobre itria.

- Es necesario mejorar la estabilidad y durabilidad del recubrimiento de itria sobre el molde soporte, pues en determinadas probetas sinterizadas a tiempos largos o temperaturas elevadas, en los que se alcanzan las mejores propiedades mecánicas, se produjo reactividad con el molde de alúmina subyacente.

En relación a las piezas porosas de titanio obtenidas por sinterización de microesferas:

- Se han desarrollado piezas porosas de la aleación Ti6Al4V por sinterización de microesferas, con porosidad abierta e interconectada, una rigidez inferior al $40 \%$ de la presentada por el 
material sólido, y una resistencia a flexión suficiente (hasta $320 \mathrm{MPa}$ ) para permitir su uso como implante.

- La porosidad oscila entre el 23 y $29 \%$ y varía poco con el tamaño de la microesfera, temperatura y tiempo de sinterización, dependiendo más de otros parámetros como la amplitud de la curva granulométrica. Ello es debido al relativamente gran tamaño de las microesferas de partida, pues provoca que la sinterización se desarrolle únicamente en su etapa inicial, dando lugar a una reducida contracción.

- Pese a que la porosidad es abierta e interconectada, en condiciones de carga únicamente permitirán el desarrollo óseo las piezas obtenidas por sinterización de microesferas gruesas (+425/-600 $\mu \mathrm{m})$.

- En ausencia de carga cabría la posibilidad de vascularización sobre piezas porosas desarrolladas con microesferas de granulometría media $(+212 /-300 \mu \mathrm{m})$ e incluso fina $(+180 /-250 \mu \mathrm{m})$.

- Las propiedades mecánicas, rigidez, resistencia y tenacidad a flexión, aumentan con la temperatura y tiempo de sinterización, y evolucionan de forma inversa con el tamaño de las microesferas de partida, siendo éste último parámetro el de mayor influencia. Ello es debido a la mayor superficie específica cuanto menor el diámetro de las microesferas, lo que provoca además que la variación con la temperatura y tiempo de sinterización sea mayor cuanto más pequeñas las microesferas.

- Los modelos de correlación entre la resistencia a flexión y rigidez con los parámetros de proceso, permiten estimar las propiedades mecánicas a obtener en función del tamaño de la microesfera, temperatura y tiempo de sinterización.

- En general, se emplearán microesferas tan finas como sea posible (según aplicación y tamaño de poro necesario para la vascularización), con tiempos mínimos de 4 horas y temperaturas entre 1350 y $1400{ }^{\circ} \mathrm{C}$, aunque los parámetros de proceso concretos dependerán de la aplicación 
a la que se someta el implante. Ello es debido a las mejores propiedades mecánicas alcanzadas cuanto menor el tamaño de las microesferas, y mayor la temperatura y tiempo de sinterización, aunque un menor tamaño de microesfera implica menor tamaño de poro, lo que va en detrimento de las posibilidades de osteointegración.

- En las piezas sinterizadas sobre itria puede considerarse aceptable la presencia de elementos intersticiales $\left(\mathrm{C}, \mathrm{O}_{2}, \mathrm{~N}\right)$ en relación a los niveles establecidos por las normas para implantes desarrollados por colada y forja.

- La microestructura resultante tras la sinterización y tratamientos térmicos realizados con enfriamiento lento es de tipo Widmanstätten, conformada por láminas alternadas de las fases $\alpha$ y $\beta$. El engrosamiento es mayor cuanto mayor la temperatura y/o tiempo de sinterización

- Resulta complejo mejorar la resistencia a fatiga y propiedades mecánicas mediante la aplicación de tratamientos térmicos. Por una parte, la reducida velocidad de enfriamiento alcanzada provoca que únicamente se afine la microestructura en los tratamientos realizados en dilatómetro, aunque debería aplicarse una velocidad de enfriamiento todavía mayor. Por otra, el uso de tubos de acero y la atmósfera residual del horno provoca la oxidación de las piezas en unos casos y la formación de hidruros en otros.

En relación a piezas porosas desarrolladas por el método de espaciadores:

- Se han desarrollado piezas porosas de TiCP y de la aleación Ti6Al4V empleando bicarbonato de amonio como espaciador, con una rigidez inferior respecto a la del material sólido, y una resistencia a flexión y a compresión suficiente para permitir su uso como implante.

- Las piezas porosas desarrolladas empleando urea como espaciador presentan una fuerte contaminación y reducidas propiedades mecánicas, lo que es debido a la dificultad en la eliminación de la urea. 
- Las piezas porosas de TiCP y Ti64 obtenidas por el método de espaciadores, presentan una porosidad cerrada y no conectada, por lo que no permiten el desarrollo óseo. Éstas, a diferencia de las desarrolladas por sinterización de microesferas, presentan una piel exterior densificada, con formación de paredes de titanio alrededor de las partículas de espaciador.

- La rigidez de las piezas porosas de TiCP se ha reducido de un 20 a 65\% (porosidad entre el 20 y $60 \%$ ), en relación a la del material sólido, mejorando el trabajo junto al hueso cortical.

- Durante la evaporación del bicarbonato y sinterización se produce una contracción muy importante $\left(\nabla L_{v}\right.$ entre $\left.30-50 \%\right)$, destacable incluso en piezas sin espaciador $\left(\nabla \mathrm{L}_{v} \approx 30 \% \mathrm{v}\right)$, lo que se debe tanto a la evaporación del espaciador, como a la reducida presión aplicada.

- La contracción aumenta con el contenido en espaciador y al disminuir la presión de compactación y varía poco con el tamaño de bicarbonato. Esto es debido a que mayor cantidad de espaciador o menor presión de compactación, reducen la densidad en verde de la pieza, dificultando con ello la sinterización.

- La deformación lineal y radial presenta valores similares $\left(\nabla L_{r}\right.$ y $\nabla L_{l}$ el entre $11-21 \%$ ), lo que ocasiona una contracción homogénea.

- Para una misma adición de espaciador, a mayor velocidad de compactación, mayor porosidad y contracción, lo que es consecuencia de una mayor recuperación elástica de los polvos, efecto que se ve acentuado por la presencia de partículas de espaciador.

- No se puede concretar un tamaño de poro, pues las partículas de espaciador poseen una distribución granulométrica y se produce coalescencia o contacto entre ellas. Esto dificulta la homogeneidad y reproducibilidad de las propiedades. 
- Las propiedades mecánicas dependen principalmente del contenido en bicarbonato, presión de compactación y tiempo de espera entre compactación y secado, mientras que la variación con la temperatura y tiempo resulta poco significativa.

- La probabilidad de degradación por un tiempo prolongado entre la compactación y evaporación del espaciador es mayor cuanto mayor el contenido de bicarbonato.

- En general, la resistencia a flexión evoluciona de forma inversa con el tamaño de espaciador. Ello se debe a diversas causas, como la formación de una mayor número de pilares entre las partículas de espaciador, la mayor facilidad de eliminación del espaciador, la mayor homogeneidad tanto en la distribución de presiones como del polvo que conforma la matriz, así como a una menor recuperación elástica originada en la compactación.

- El efecto de la presión de compactación sobre las propiedades mecánicas depende fundamentalmente del contenido en espaciador. Así, a flexión, probetas con $75 \%$ v de Ti64 o superior incrementan generalmente su resistencia con la presión de compactación, mientras que a compresión ello sólo sucede con muestras sin espaciador. El efecto para probetas con mayor adición de bicarbonato depende del ciclo térmico. Dicha evolución se atribuye a diferentes causas, como una distribución no uniforme de la presión de compactación y menor compresibilidad a medida que aumenta el contenido de espaciador; la velocidad de compactación aplicada, pues incrementa la recuperación elástica del material; así como otros efectos como la microporosidad existente, la geometría irregular y la rugosidad superficial de los macroporos.

- Según las propiedades mecánicas obtenidas, únicamente podrían emplearse con seguridad piezas con $\mathbf{2 5 \%}$ v de bicarbonato, pues en cantidades superiores la resistencia a compresión resulta insuficiente. 
- Las propiedades mecánicas de las piezas porosas obtenidas podrían optimizarse aplicando presiones de compactación tan bajas como sea posible, compactando a menor velocidad y eliminando el espaciador inmediatamente tras la compactación. Por una parte, compactar a menor velocidad reducirá la recuperación elástica del material, lo que permitirá emplear presiones de compactación más reducidas, facilitando con ello la eliminación de las partículas de espaciador así como una distribución más uniforme de éstas. Por otra parte, es necesario realizar el proceso de forma continua para minimizar la contaminación de la pieza porosa.

- La rigidez depende fundamentalmente de la adición de espaciador, no observándose diferencias significativas con la temperatura, tiempo, presión y tamaño espaciador.

- Mediante la adición de espaciador, se ha reducido la rigidez a compresión de las piezas hasta un $\mathbf{8 8 \%}$ en relación a la del material sólido.

- El mayor descenso de rigidez se produce entre muestras sin espaciador y con un $\mathbf{2 5 \%} \mathrm{v}$, con una rigidez a flexión de hasta el $\mathbf{5 0} \%$ de la presentada por el material sólido.

- Los modelos matemáticos obtenidos permiten estimar la resistencia a flexión, a compresión y rigidez, en función de la densidad relativa (porosidad) de la pieza.

- Los niveles de $\mathbf{C}$ y $\mathbf{N}$ cumplen con los niveles establecidos por las normas ASTM para piezas de Ti64 de forja y colada utilizables como implantes, mientras que el nivel de $\mathbf{O}_{2}$ resulta superior al admisible por estas normas.

- A pesar de que el nivel de $\mathrm{O}_{2}$ excede el admisible por las normas de referencia, cuando no existe comportamiento frágil, el contenido en $\mathrm{O}_{2}$ de las piezas porosas desarrolladas por el método de espaciadores puede considerarse aceptable, pues no aumenta de forma significativa 
respecto al polvo de partida, aunque su efecto debería analizarse en futuras investigaciones mediante la realización de ensayos dinámicos.

- El nivel de $\mathrm{O}_{2}$ resulta inaceptable en aquellas muestras que presentaron comportamiento frágil en el ensayo de compresión.

- Resulta complejo determinar con exactitud la velocidad de corrosión, pues la porosidad existente y la posible infiltración de electrolito entre el material de sellado y los poros impiden conocer el área real expuesta.

- Sin embargo, no se observa una diferencia significativa entre la resistencia a la corrosión de las piezas desarrolladas por pulvimetalúrgia y una pieza de forja.

- El incremento de la velocidad de corrosión con la adición de espaciador parece deberse más al aumento de la superficie de contacto que a modificaciones originadas durante el desarrollo de la pieza. 

7 INVESTIGACIONES FUTURAS 



\section{INVESTIGACIONES FUTURAS.}

Pese a que se han alcanzado los objetivos propuestos, desarrollando piezas de titanio en ausencia de reactividad, menos rígidas, con aptitud para la osteointegración y propiedades mecánicas suficientes para permitir su empleo en el cuerpo humano, existen determinadas líneas de la investigación en las que es necesario profundizar. Así, además de los necesarios estudios de adecuación al cuerpo humano (biocompatibilidad, resistencia a fatiga, liberación de iones...), se proponen como líneas futuras de investigación:

- Optimizar el recubrimiento de itria de los moldes, dotándolo de mayor estabilidad con el fin de evitar tanto la contaminación con el molde subyacente, como la necesidad de eliminar y reaplicar el recubrimiento tras cada ciclo.

- En las piezas porosas desarrolladas por sinterización de microesferas, sinterizar microesferas de tamaños intermedios entre las granulometrías denominadas media y gruesa en la presente tesis, con una distribución granulométrica más acotada.

- Analizar las propiedades de piezas desarrolladas por el método de espaciadores en continuo, eliminando el espaciador inmediatamente tras la compactación y procediendo a su sinterización.

- Investigar sobre la presión de compactación mínima a emplear, en función de la velocidad de compactación, de forma que permita tanto mantener la consistencia durante el proceso de consolidación, como generar una distribución de presiones más uniforme y facilitar la eliminación del espaciador.

- Analizar las propiedades obtenidas al emplear como matriz aleaciones tipo $\beta$ como la Ti30Nb o la Ti35Nb7Zr5Ta con una rigidez de tan sólo 42 y $55 \mathrm{GPa}$ respectivamente. Dado que en la sinterización de microesferas deberá tratarse de polvos prealeados su empleo vendrá condicionado por la disponibilidad en el mercado de microesferas de este tipo de aleaciones desarrolladas por PREP. Por otra parte, en la técnica de espaciadores podría emplearse mezcla elemental de polvos, y realizar pruebas preliminares sin adición de espaciador y con pequeñas cantidades para determinar tanto la homogeneidad de la 
aleación, como la posibilidad de eliminar el espaciador con una reactividad mínima o inexistente.

- En la técnica de espaciadores, estudiar el uso de otros materiales que permitan generar macroporos sin contaminar el titanio en su eliminación, evitando así su fragilización por reacción con elementos intersticiales.

- Mejorar la resistencia a fatiga y propiedades mecánicas de las piezas obtenidas mediante la realización de tratamientos térmicos, de forma eficiente y sin contaminar la pieza obtenida. El estudio se iniciaría a nivel de laboratorio, analizando tanto el comportamiento dilatométrico con la temperatura y tiempo, como los cambios microestructurales y evolución de microdureza. Posteriormente la investigación podría ampliarse en colaboración con empresas de aplicación de tratamientos térmicos sobre titanio, estudiando el efecto de un mismo tratamiento a nivel industrial y sobre piezas de dimensiones mayores.

- Aplicar tratamientos superficiales para incrementar la resistencia al desgaste y a la corrosión sobre las piezas porosas desarrolladas por sinterización de microesferas. El estudio podría realizarse sobre diferentes tratamientos aplicados de forma industrial, entre ellos de deposición física (implantación iónica evaporación...), termoquímicos (de nitruración, carburación...) o de conversión química (anodizado). Se analizaría tanto la modificación microestructural, como la resistencia al rozamiento y a la corrosión de las piezas tratadas.

- Aplicar tratamientos superficiales sobre las piezas desarrolladas por la técnica de espaciadores, con el fin de mejorar tanto la resistencia a la corrosión, como la aptitud al desarrollo de células óseas. Por una parte, podría realizarse un primer estudio en el que se evaluara la aplicabilidad de los tratamientos anteriormente propuestos para las piezas desarrolladas por sinterización de microesferas, analizando tanto la adherencia sobre la pieza base y las modificaciones microestructurales derivadas del tratamiento, como la resistencia a la corrosión. Sobre éste, podría aplicarse otro con el fin de 
incrementar la aptitud al desarrollo óseo de las piezas porosas desarrolladas. Para ello, podría establecerse colaboraciones con empresas especializadas, lo que permitiría estudiar la mejora de propiedades originada al desarrollar sobre la pieza base estructuras porosas comercializadas como el "Trabecular Metal" (tántalo), "Regenerex", "Tritanium" o "Biofoam Titanium" (de titanio), así como otras centradas en materiales bioactivos como la hidroxiapatita o el bioglass. 

8

BIBLIOGRAFIA 



\subsection{BIBLIOGRAFÍA.}

[Amigó 2001] Amigó V.; Ferrer C. (2001) Curso de fundamentos de ciencia de materiales. UPV.

[Amigó 2003 a] Amigó V.; Escuder A.V. (2003) Materials per al disseny industrial. Aliatges metàl.lics.

[Amigó 2003 b] Amigó V.; Salvador M.D.; Romero F.; Solves C.; Moreno J.F. (2003) Microstructural evolution of Ti-6Al-4V during the sintering of microspheres of $\mathrm{Ti}$ for orthopedic implants. Journal of Materials Processing Technology, 141, pp. 117122.

[Amigó 2007] Amigó V.; Romero F.; Busquets D.; Salvador M.D. (2007) Matrix-reinforcement reactivity in $\mathrm{P} / \mathrm{M}$ titanium matrix composites (Reactividad matriz-refuerzo en compuestos de matriz de titanio pulvimetalúrgico), Revista de Metalurgia, 43 (6), pp. 434-447.

[Aparicio 2003] Aparicio C.; Javier Gil F.; Fonseca C.; Barbosa M.; Planell J. A. (2003). Corrosion behaviour of commercially pure titanium shot blasted with different materials and sizes of shot particles for dental implant applications. Biomaterials, 24 (2), pp. 263-273.

[Ashby 2000] Ashby M.F.; Evans A.G.; Fleck N.A.; Gibson L.J.; Hutchinson J.W.; Wadley H.N.G. (2000). Metal Foams: A Design Guide. Butterworth-Heinemann.

[Asbhy 2005] Ashby M. F.; Johnson K. (2005). Materials and Design: The Art and Science of Material Selection in Product Design: Butterworth-Heinemann.

[Asaoka 2003] Asaoka K.; Kon M. (2003). Sintered porous titanium and titanium alloys as advanced biomaterials. THERMEC'2003, PTS 1-5, 426-4, pp. 3079-3084.

[ASM N2 1990] ASM International (1990). Metals Handbook. Properties and selection: Non ferrous alloys and special purpose materials. (Vol. 2).

[ASM N3 1997] ASM International. (1997). ASM Handbook: Alloy Phase Diagrams (Vol. 3).

[ASM N4 1994] ASM International. (1994). Heat treating. (Vol. 4).

[ASM N7 1993] ASM International. (1993). Powder metallurgy (Vol. 7).

[ASM N9 2004] ASM International. (2004). ASM Handbook. Metallography and Microstructures. (Vol. 9).

[ASM N13 1992] ASM International. (1992). Corrosion. (Vol. 13).

[ASTM B213] ASTM B213-03 Standard Test Method for Flow Rate of Metal Powders. 
[ASTM B214]

[ASTM B328]

[ASTM B417]

[ASTM E290]

[ASTM E9]

[ASTM F1108]

[ASTM F1472]

[ASTM F1580]

[ASTM F67]

[Azevedo 2003]

[Baeslack 1993]

[Banhart 1998]

[Banhart 2001]

[Bansiddhi 2008]

[Barrabés 2008]
ASTM B214 - 07 Standard Test Method for Sieve Analysis of Metal Powders.

ASTM B328-96e1 Standard Test Method for Density, Oil Content, and Interconnected Porosity of Sintered Metal Structural Parts and Oil-Impregnated Bearings (ISO 2738:1999).

ASTM B417 - 00e1 Standard Test Method for Apparent Density of Non-Free-Flowing Metal Powders Using the Carney Funnel.

ASTM E290 - 09 Standard Test Methods for Bend Testing of Material for Ductility (ISO 3325:2000).

ASTM E9-89a Standard Test Methods of Compression Testing of Metallic Materials at Room Temperature.

ASTM F1108 - 04 Standard Specification for Titanium6Aluminum-4Vanadium Alloy Castings for Surgical Implants.

ASTM F1472 - 08e1 Standard Specification for Wrought Titanium-6Aluminum-4Vanadium Alloy for Surgical Implant Applications.

ASTM F1580 - 07. Standard Specification for Titanium and Titanium-6 Aluminum-4 Vanadium Alloy Powders for Coatings of Surgical Implants. ASTM.

ASTM F67 - 06. Standard Specification for Unalloyed Titanium, for Surgical Implant Applications.

Azevedo C.R.F.; Rodrigues D.; Beneduce Neto F. (2003). Ti-Al-V powder metallurgy (PM) via the hydrogenation dehydrogenation (HDH) process. Journal of Alloys and Compounds, 353, pp. 217-227.

Baeslack W. A. (1993) Weld solidification and HAZ liquation in a metastable-beta titanium alloy-beta-21S. Materials Characterization, 30 (2), pp. 147-154.

J.; Baumeister J. (1998). Deformation characteristics of metal foams. Journal of Materials Science, 33, pp. 14311440.

Banhart J. (2001). Manufacture, characterisation and application of cellular metals and metal foams. Progress in Materials Science, 46 (6), pp. 559-632.

Bansiddhi A.; Sargeant T.D.; Stupp S.I.; Dunand D.C. (2008). Porous NiTi for bone implants: A review. Acta Biomaterialia, 4, pp. 773-782.

Barrabés M.; Sevilla P.; Planell J. A.; Gil F. J. (2008). Mechanical properties of nickel-titanium foams for reconstructive orthopaedics. Materials Science and Engineering: C, 28 (1), pp. 23-27. 
[Beljavin 2004] Beljavin K.E.; Sheleg V.K.; Minko D.V. (2004). The application of porous products of spherical titanium powder in implant surgery, in Powder Metallurgy World Congress \& amp. (PM2004), Vienna, Austria, p.7.

[Blackwood 2000] Blackwood D.J., (2000). Corrosion behaviour of porous titanium-graphite composites designed for surgical implants. Corrosion Science, 42, pp. 481-503.

[Bram 2000] Bram M.;Stiller C.;Buchkremer H. P.;Stöver C.; Baur H. (2000) High-Porosity Titanium, Stainless Steel, and Superalloy Parts Advanced Engineering Materials, 2 (4), pp. 196-199.

[Bram 2005] Bram M.; Schiefer H.; Bogdanski; Koller M.; Buchkremer H.P.; Stover D. (2005). Evaluation of Mechanical and Biological properties of highly porous Titanium parts. Euro PM2005. PM Applications, pp. 517-522.

[Bram 2006] Bram M.; Köller M.; Stöver D.; Schiefer H.; Buchkremer H.P.; Bogdanski D. (2006) Implant surgery: How bone bonds to PM titanium, Metal Powder Report, 61 (2), pp. 26-31.

[Breme 1995] Breme J.; Zhou Y.; Groh L. (1995). Development of a titanium alloy suitable for an optimized coating with hydroxyapatite. Biomaterials, 16, pp. 239-244.

[Bolelli 2006] Bolelli G.; Cannillo V.; Lusvarghi L.; Manfredini T. (2006) Wear behaviour of thermally sprayed ceramic oxide coatings. Wear, pp. 1-18.

[Boyer 1994] Boyer R.; Collings E.W.; Welsch G. (1994). Materials properties handbook: titanium alloys.

[Callister 2005] Callister W. D.; Rethwisch D. G. (2005). Fundamentals of Materials Science and Engineering: An Integrated Approach. (2nd ed.) John Wiley \& Sons, Inc..

[Cirincione 2002] Cirincione R.; Anderson R.; Zhou J.; Mumm D.; Soboyejo W. O. (2002). An investigation of the effects of sintering duration and powder sizes on the porosity and compression strength of porous Ti-6al-4V. In A. Ghosh \& T. H. Sanders \& T. D. Claar (Eds.), Processsing And Properties Of Lightweight Cellular Metals And Structures (pp. 189-198).

[Comín 1999] Comín M.; Peris J.L.; Prat J.M.; Decoz J.R.; Vera P.M.; Hoyos J.V. (1999). Biomecánica de la fractura ósea y técnicas de reparación. Valencia: IBV.

[Dahotre 1999] Dahotre N.B.; Sudarshan T.S. (1999). Intermetallic and ceramic coatings: Marcel Dekker.

[Degischer 2002] Degischer H. P.; Kriszt B. (2002). Handbook of Cellular Metals: Production, Processing, Applications: Wiley-VCH. 
[Delplancke 1982] Delplancke J.L.; Degrez M.; Fontana A.; Winand R. (1982). Self-Colour Anodizing Of Titanium. Surface technology, 16 (2), pp. 153-162.

[Dewidar 2005] Dewidar M. M.; Seo D. W.; Lim J. K. (2005). Processing of high porosity Ti-6Al-4V by powder sintering process for biomedical applications. Multiscale damage related to environment assisted cracking, pp. 177-183.

[Dewidar 2007] Dewidar M.M.; In K.M.; Lim J.K. (2007) Processing and Mechanical Properties of solid core and porous surface Ti$6 \mathrm{Al}-4 \mathrm{~V}$ implants fabricated by powder-metallurgy. Key engineering materials, 345-346, pp. 1209-1212.

[Eisenbarth 2004] Eisenbarth E.; Velten D.; Müller M.; Thull R.; Breme J. (2004). Biocompatibility of $\beta$-stabilizing elements of titanium alloys. Biomaterials, 25, pp. 5705-5713.

[Ellingsen 2006] Ellingsen J. E.; Thomsen P.; Lyngstadaas S. P. (2006). Advances in dental implant materials and tissue regeneration. Periodontology, 41 (1).

[Esen 2007] Esen Z.; Bor S. (2007). Processing of titanium foams using magnesium spacer particles. Scripta Materialia, 56 (5), pp. 341-344.

[Es-Souni 2002] Es-Souni M.; Fischer-Brandies H. (2002). On the properties of two binary NiTi shape memory alloys. Effects of surface finish on the corrosion behaviour and in vitro biocompatibility. Biomaterials, 23 (14), pp. 2887-2894.

[Esteban 2008] Esteban P. G.; Ruiz-Navas E. M.; Bolzoni L.; Gordo E. (2008) Low-cost titanium alloys? Iron may hold the answers. Metal Powder Report, 63 (4), pp. 24-27.

[Fernandez 2005] Fernandez J.; Guilemany J.M.; Gaona M. (2005), La proyección térmica en la obtención de recubrimientos biocompatibles: ventajas de la proyección termica por alta velocidad (HVOF) sobre la proyección térmica por plasma atmosférico (APS), Biomecánica, 13 (1), pp. 16-39.

[Ferrer 2003] Ferrer C.; Amigo V. (2003) Tecnología de materiales. UPV.

[Flautre 2001] Flautre B.; Descamps M.; Delecourt C.; Blary M.C. (2001) Porous HA ceramic for bone replacement: Role of the pores and interconnections - experimental study in the rabbit. Journal of Materials Science: Materials in Medicine, 12, pp. 679-682.

[Frenkel 2004] Frenkel S. R.; Jaffe W. L.;Dimaano F.;lesaka K.;Hua T. (2004). Bone response to a novel highly porous surface in a canine implantable chamber. Journal of Biomedical Materials Research Part B: Applied Biomaterials, 71B (2), pp. 387-391. 
[Freese 2008] Freese H.L.; Volas M.G.; Wood J.R.; Textor M. (2008). Titanium and its alloys in biomedical engineering., in Encyclopedia of materials: Science and technology. (pp. 9374-9380): Pergamon.

[Froes 1990] Froes F.H.; Eylon D.; Suryanarayana C. (1990). Thermochemical Processing of Titanium alloys. Journal of the minerals metals \& materials society, 42 (3), pp. 26-29.

[Gaona 2007] Gaona Latorre M. (2007). Recubrimientos biocompatibles obtenidos por Proyección Térmica y estudio in vitro de la función osteoblastica, in Departament de Ciència dels Materials i Enginyeria Metal.lúrgica, Universitat de Barcelona, Barcelona.

[García 2003] García-Alonso M. C.; Saldaña L.; Vallés G.; GonzálezCarrasco J. L.; González-Cabrero J.; Martínez M.; Gil-Garay E.; Munuera L. (2003). In vitro corrosion behaviour and osteoblast response of thermally oxidised Ti6Al4V alloy. Biomaterials, 24 (1), pp. 19-26.

[Garcia 2006] Garcia P. C.; Adabo G. L.; Faria R.; Soares S. (2006). The effect of mold temperature on castability of CPTi and Ti-6Al$4 \mathrm{~V}$ castings into phosphate bonded investment materials. Dental Materials, 22 (12), pp. 1098-1102.

[German 1994] German R.M. (1994). Powder Metallurgy Science (2nd ed.): Metal Powder Industries Federation.

[German 2005] German R.M. (2005). Powder metallurgy and particulate materials processing: the processes, materials, products, properties and applications. Metal Powder Industries Federation.

[Gibson 1999] Gibson L.J.; Ashby M.F. (1999). Cellular Solids: Structure and Properties: Cambridge University Press.

[Gil 1996] Gil Mur F. X.; Rodríguez D.; Planell J. A. (1996). Influence of tempering temperature and time on the [alpha]'-Ti-6Al-4V martensite. Journal of Alloys and Compounds, 234 (2), pp. 287-289.

[Gil 2001] Gil F. J.; Ginebra M. P.; Manero J. M.; Planell J. A. (2001). Formation of [alpha]-Widmanstätten structure: effects of grain size and cooling rate on the Widmanstätten morphologies and on the mechanical properties in Ti6Al4V alloy. Journal of Alloys and Compounds, 329 (1-2), pp. 142152.

[Gil 2002] Gil F. J. (2002). Surface hardening by anodizing and heat treatments of Ti6Al4V alloys for articular prostheses. BioMedical Materials And Engineering, 12 (3), pp. 271-281. 
[Gil 2007 a]

[Gil 2007 b]

[González 1999]

[Guden 2005]
Gil F.J.; Planell J.A.; Padrós A.; Aparicio C. (2007 a). The effect of shot blasting and heat treatment on the fatigue behavior of titanium for dental implant applications. Dental Materials, 23 (4), pp. 486-491.

Gil F. J. (2007). Comparison of the mechanical properties between tantalum and nickel-titanium foams implant materials for bone ingrowth applications. Journal of Alloys and Compounds, 439 (1-2), pp. 67-73.

González J.E.; Mirza J.C. (1999). Study of corrosion behavior of titanium and some of its alloys for biomedical and dental implant applications. Journal of Electroanalytical Chemistry, 471, pp. 109-115.

Guden M.; Celik E.;Akar E.;Cetiner, S. (2005) Compression testing of a sintered Ti6Al4V powder compact for biomedical applications. Materials Characterization, 54 (4-5), pp. 399408.

[Guehennec 2008] Guehennec A.L.; Lopez-Heredia M.A.; Enkel B.; Weiss P.; Amouriq Y.; Layrolle P. (2008) Osteoblastic cell behaviour on different titanium implant surfaces. Acta Biomaterialia, 4, pp. 535-543.

[Hagiwara 1998] Hagiwara M. (1998). BE PM synthesis of Ti6Al1'7Fe0'1Si alloy with improved high cycle fatigue strength. . Scripta Materialia, 39, pp.1185-1190.

[Hardie 1999] Hardie D.; Ouyang S. (1999). Effect of microstructure and heat treatment on fracture behaviour of smooth and precracked tensile specimens od Ti6AI4V. Materials Science and Technology, 15, pp. $1049-1057$.

[Herrmann 2002] Herrmann H.R. (2002). Granular Matter. Physica A, 313, pp. 188-210.

[Heimann 2002] Heimann R.B. (2002). Materials Science of Crystaline Bioceramics: A Review of Basic Properties and Applications. CMU. Journal, 1, pp. 23-46.

[Hollander 2006] Hollander D.A.; Walter M.V.; Wirtz T.; Sellei R. (2006). Structural, mechanical and in vitro characterization of individually structured $\mathrm{Ti}-6 \mathrm{Al}-4 \mathrm{~V}$ produced by direct laser forming. Biomaterials, 27, pp. 955-963.

[Hu 1988] Hu Y.; Dai D.; Dong Y. (1988) The ion nitriding of titanium materials and its applications, In the 6th World Conference on Titanium, Cannes, France.

[lbris 2002]
Ibris N.; Mirza Rosca J.C. (2002). EIS study of Ti and its alloys in biological media. Journal of Electroanalytical Chemistry, 526, pp. 53-62. 
[Inoue 1984]

[Isonishi 1989]

[Jia Ping 2006]

[Kamachi 2003]

[Keating 2001]

[Kim 2002]

[Köhl 2007]

[Kostov 2006]

[Kotan 2007]

[Kujala 2003]

[Kujala 2004]

[Kuphasuk 2001]
Inoue A; Chen Hs; Krause Jt; Masumoto T. (1984 ). Young Modulus Sound-Velocity And Young Modulus Of Ti-Based, $\mathrm{Zr}$-Based And Hf-Based Amorphous-Alloys. Journal of noncrystalline solids, 68 (1), pp. 63-73.

Isonishi Kazuo; Kobayashi Masahiko; Tokizane Masaharu. (1989) Production of Ti-6Al-4V alloy powders by plasma rotating electrode process. Tetsu-To-Hagane/Journal of the Iron and Steel Institute of Japan, 75 (10), pp. 1913-1920.

Jia Ping L.; de Wijn J.R.; Van Blitterswijk C.A.; de Groot K. (2006). Porous Ti6AI4V scaffold directly fabricating by rapid prototyping: Preparation and in vitro experiment. Biomaterials, 27 (8), pp. 1223-1235.

Kamachi Mudali U.; Sridhar T.M.; Raj B. (2003). Corrosion of bio implants. Sadhana, 28 (3-4), pp. 601-637.

Keating J.F.; McQueen M. M.. (2001). Substitutes for autologous bone graft in orthopaedic trauma. The journal of bond \& joint surgery (Br), 83-B (1), pp. 3-8.

Kim M. G.; Kim S. K.; Kim Y. J. (2002) Effect of mold material and binder on metal-mold interfacial reaction for investment castings of titanium alloys. Materials Transactions, 43 (4), pp. 745-750.

Köhl M.; Bram M.; Buckremer H.P.; Stöver D. (2007). Highly porous $\mathrm{NiTi}$ components Produced by Metal Injection Moulding in Combination with the Space Holder Method. Euro PM2007, pp. 129-134.

Kostov Ana; Friedrich Bernd. (2006). Predicting thermodynamic stability of crucible oxides in molten titanium and titanium alloys. Computational Materials Science, 38 (2), pp. 374-385.

Kotan G.; Bor A. S. (2007). Production and characterization of high porosity Ti-6Al-4V foam by space holder technique in powder metallurgy, 3.

Kujala S.; Ryhanen J.; Danilov A.; Tuukkanen J. (2003). Effect of porosity on the osteointegration and bone ingrowth of a weight-bearing nickel-titanium bone graft substitute. Biomaterials, 24 (25), pp. 4691-4697.

Kujala S.; Pajala A.; Kallioinen M.; Pramila A.; Tuukkanen J.; Ryhanen J. (2004). Biocompatibility and strength properties of nitinol shape memory alloy suture in rabbit tendon. Biomaterials, 25 (2), pp. 353-358.

Kuphasuk C.; Oshida Y.; Andres C.J.; Hovijitra S.T.; Barco M.T.; Brown D.T. (2001) Electrochemical Corrosion of Titanium and Titanium based Alloys. The Journal of Prosthetic Dentistry, 85, pp. 195-202. 
[Kupp 2002] Kupp D.; Claar D.; Flemmig K.; Waag U.; Goehler H. (2002, February 17-21). Processing of controlled porosity titaniumbased materials. In Processing and properties of lightweight cellular metals and structures, Seattle, Washington, pp. 6171.

[Kuroda 1998] Kuroda D.; Niinomi M.; Morinaga M.; Kato Y.; Yashiro T. (1998). Design and mechanical properties of new $\beta$ type titanium alloys for implant materials. Materials Science and Engineering A, 243, pp. 244-249.

[Kuroda 2005] Kuroda D.; Kawasaki H.; Yamamoto A.; Hiromoto S.; Hanawa T. (2005). Mechanical properties and microstructures of new Ti-Fe-Ta and Ti-Fe-Ta-Zr system alloys. Materials science \& engineering, 25 (3), pp. 312 320.

[Laptev 2004] Laptev A.; Bram M.; Buchkremer H. P.; Stover D. (2004). Study of production route for titanium parts combining very high porosity and complex shape. Powder Metallurgy, 47 (1), pp. 85-92.

[Laptev 2005] Laptev A.; Vyal O.; Bram M.; Buchkremer H. P.; Stover D. (2005). Green strength of powder compacts provided for production of highly porous titanium parts, Powder Metallurgy, 48 (4), p. 358-364.

[Levine 2006] Levine B.R.; Sporeras S.; Poggie R.A.; Della Valle C.J.; Jacobs J.J. (2006). Experimental and clinical performance of porous tantalum in orthopedic surgery. Biomaterials, $27, \mathrm{pp}$. 4671-4681.

[Levine 2008] Levine B. (2008) A New Era in PorousMetals: Applications in Orthopaedics. Advanced Engineering Materials, 10 (9), pp. 788-792.

[Leyens 2003] Leyens C.; Peters M. (2003). Titanium and titanium alloys, fundamentals and applications.

[Li C.F. 2005] Li C.F.; Zhu Z.G.;Liu T. (2005). Microhardness of pore walls in porous titanium prepared with novel powder metallurgy. Powder Metallurgy, 48 (3), pp. 237-240.

[Li H. 2005] Li H.; Fan H.; Zhang X. (2005). Fabrication of porous titanium with biomechanical compatibility. Key engineering materials, 288-289, pp. 611-614.

[Li J.P. 2004] Li J. P.; Li S. H.; Van Blitterswijk C. A.; Groot K. (2004). A novel porous Ti6Al4V: Characterization and cell attachment. www.interscience.wiley.com, pp. 223-233.

[Li J.P. 2006] Li J.P.; Li S.H.; Van Blitterswijk C.A.; De Groot K., \& (2006). Cancellous bone from porous TI6AI4V by multiple coating technique. Journal of Materials Science: Materials in Medicine, 17 (2), pp. 179-185. 
[Liu 2004]

[Lombardi 2007]

[Lopez 2006]

[Mändl 2000]

[Molera 1977]

[Muñoz 2005]

[Murray 2003]

[Niinomi 2008]

[Nomura 2005]

[Oh I.H. 2002]
Liu X.; Chu P.K.; Ding C. (2004) Surface modification of titanium, titanium alloys, and related materials for biomedical applications. Materials Science and Engineering R, 47, pp. 49-121.

Lombardi A.V.; Facs M.D.; Berasi C.C; Berend K.R. (2007). Evolution of Tibial Fixation in Total Knee Arthroplasty. The Journal of Arthroplasty, 22 (4), pp. 25-29.

Lopez-Heredia M.A.; Goyenvalle E.; Aguado E.; Leroux C.; Dorget M.; Layrolle P. (2006). Bone Growth in Porous Titanium implants Made by Rapid Prorotyping. Key engineering materials., 309-311, pp. 1099-1102.

[Lütjering 2007] Lütjering G.; Williams J.C. (2007). Titanium (2nd ed.).

[Magnissalis 2003] Magnissalis E. A.; Zinelis S.; Hartofilakidis G.; Karachalios Th., (2003) Failure Analysis of Two Ti-Alloy Total Hip Arthroplasty Femoral Stems Fractured In Vivo, Journal of Biomedical Materials Research - Part B Applied Biomaterials, 66 (1), pp. 299-305.

Mändl S.; Thorwarth G.; Schreck M.; Strirzker B.; Rauschenbach B. (2000) Raman Study of titanium oxide layers produced with plasma immersion ion implantation. Surface and Coatings Technology, 125, pp. 84-88.

Molera P. (1977) Introducción a la pulvimetalúrgia.: Bellaterra.

Muñoz M.J. (2005). Principios de obtención de materiales. UPV.

Murray N.G.D.; Dunand D.C. (2003). Microstructure evolution during solid-state foaming of titanium. Composites Science and Technology, 63, pp. 2311-2316.

Niinomi M. (2008). Mechanical biocompatibilities of titanium alloys for biomedical applications. Journal of the Mechanical Behavior of Biomedical Materials, 1 (1), pp. 30-42.

Nomura N.; Kohama T.; Oh I. H.; Hanada S.; Chiba A.; Kanehira M.; Sasaki K. (2005). Mechanical properties of porous Ti-15Mo-5Zr-3Al compacts prepared by powder sintering. Materials Science and Engineering: C, 25 (3), pp. 330-335.

Oh I. H.; Nomura N.; Hanada S. (2002). Microstructures and mechanical properties of porous titanium compacts prepared by powder sintering. Materials Transactions, 43 (3), pp. 443446. 
[Oh I.H. 2003 a] Oh I.-H.; Nomura N.; Masahashi N.; Hanada S. (2003). Mechanical properties of porous titanium compacts prepared by powder sintering. Scripta Materialia, 49 (12), pp. 11971202.

[Oh I.H. 2003 b] Oh I. H.; Segawa H.; Nomura N.; Hanada S. (2003b). Microstructures and mechanical properties of porositygraded pure titanium compacts. Materials Transactions, 44 (4), pp. 657-660.

[Oh I.H. 2007] Oh I. H.; Son H. T.; Kang C. S.; Lee J. S. (2007). Mechanical properties and biocompatibility of porous titanium prepared by powder sintering. THERMEC 2006, PTS 1-5, 539-543, pp. $635-640$.

[Olmedo 2005] Olmedo D.G.; Deborah R.; Tasat M. B.; Guglielmotti R.; Cabrini L. (2005) Effect of titanium dioxide on the oxidative metabolism of alveolar macrophages: An experimental study in rats, Journal of Biomedical Materials Research Part A, 73A (2), pp. 142-149.

[Panakkal 1997] Panakkal J.P. (December 1997). Longitudinal Ultrasonic Velocity as a Predictor of Young's Modulus in Porous Materials. Materials Evaluation, pp. $1367-1371$.

[Paunovic 2006] Paunovic M.; Schlesinger M. (2006) Fundamentals of Electrochemical Deposition: John Wile \& Sons.

[Pero-Sanz 2000] Pero-Sanz J.A. (2000). Ciencia e ingenieria de materiales. Estructura, transformacions, propiedades y selección. $\left(4^{a}\right.$ ed.).

[Pilliar 1998] Pilliar R.M. (1998) P/M processinf of Surgical Implants: Sintered Porous Surfaces for Tissue to Implant Fixation. International Journal of Powder Metallurgy, 34, pp. 33-45.

[Popa 2005] Popa C., S. V., Vida-Smiti I., Candea V., Simon S. (2005) Titanium hydroxyapatite porous structures for endosseous applications, Journal Of Materials Science: Materials In Medicine, 16, pp. 1165-1171.

[Qazi 2003] Qazi J. I.; Senkov O. N.; Rahim J.; Froes F. H. (2003). Kinetics of martensite decomposition in Ti-6Al-4V-xH alloys. Materials Science and Engineering A, 359 (1-2), pp.137-149.

[Rack 2006] Rack H. J.; Qazi J. I. (2006). Titanium alloys for biomedical applications. Materials Science and Engineering: C, 26 (8), pp. 1269-1277.

[Rak 2006] Rak Z. S.; Walter J. (2006). Porous titanium foil by tape casting technique. Journal Of Materials Processing Technology, 175 (1-3), pp. 358-363. 
[Ratner 1996] Ratner B.D.; Hoffman A.S.; Schoen F.J.; Lemons J.E. (1996). Biomaterials Science., An introduction to materials in medicine, Academic Press.

[Reig 2005] Reig Cerdá L. (2005). Analisis de la viabilidad tecnologica del titanio pulvimetalurgico, TFC en UPV.

[Rembges 1993] Rembges W.; Oppel W. (1993) Process control of plasma nitriding and plasma nitrocarburizing in industry. Surface and Coatings Technology, 59, pp. 129-134.

[Rodriguez 1999] Rodriguez Rius D. (1999). Obtención de capas de nitruro de titanio mediante tratamiento termoquímico en titanio y Ti6Al4V y caracterización de sus propiedades para aplicaciones biomédicas, U. Politècnica de Catalunya, Barcelona.

[Rodriguez 2001] Rodriguez D.; Manero J.M.; Gil F.J.; Planell J.A. (2001). Low cycle fatigue behaviour of Ti6AI4V thermochemically nitrided for its use in hip prostheses.

[Rondelli 1996] Rondelli G. (1996). Corrosion resistance tests on NiTi shape memory alloy. Biomaterials, 17 (20), pp. 2003-2008.

[Ryan 2006] Ryan G.; Pandit A.; Apatsidis D. P. (2006). Fabrication methods of porous metals for use in orthopaedic applications. Biomaterials, 27 (13), pp. 2651-2670.

[Ryan 2008] Ryan Garrett E.; Pandit Abhay S.; Apatsidis Dimitrios P. (2008). Porous titanium scaffolds fabricated using a rapid prototyping and powder metallurgy technique. Biomaterials, 29 (27), pp. 3625-3635.

[Sakamoto 2006] Sakamoto Y.; Asaoka K.; Kon M.; Matsubara T.; Yoshida K. (2006). Chemical surface modification of high-strength porous Ti compacts by spark plasma sintering. Bio-Medical Materials And Engineering, 16 (2), pp. 83-91.

[Schatt 1997] Schatt W.; Wieters K.P. (1997). Powder Metallurgy. Processing and Materials.

[Schuh 2007] Schuh A. ; Bigoney J. ; Hönle W.;Zeiler G.;Holzwarth U.;Forst R. (2007). Second generation (low modulus) titanium alloys in total hip arthroplasty. Materialwissenschaft und Werkstofftechnik, 38 (12), pp. 1003-1007.

[Sevilla 2007] Sevilla P.; Aparicio C.; Planell J. A.; Gil F. J. (2007). Comparison of the mechanical properties between tantalum and nickel-titanium foams implant materials for bone ingrowth applications. Journal of Alloys and Compounds, 439 (1-2), pp. 67-73. 
[Simmons 1998] Simmons C.A.; Valiquette S.; Carter S.; Pilliar R.M. (1998). Porous coated implants provide better initial tissue integration and stability compared with plasma sprayed implants, in Transactions of the Orthopaedic Research Society, New Orleans.

[Simon 2005] Simon M.; Lagneau C.; Moreno J.; Lissac M.; Dalard F. (2005). Corrosion resistance and biocompatibility of a new porous surface for titanium implants. European journal of oral sciences 113 (6), pp. 537-545.

[Simske 1997] Simske S. J.; Ayers R. A.; Bateman T. A. (1997). Porous materials for bone engineering. Materials Science Forum, 250, pp. 151-182.

[Smallmann 1999] Smallman R. E.; Bishop R.J., Modern Physical Metallurgy and Materials Engineering (Butterworth-Heinemann 1999, $6^{\text {th }}$ Ed.).

[Smeacetto 2006] Smeacetto F.; Salvo M.; Ferraris M. (2006). Ceramic crucible coating for high quality titanium casting: scientific and industrial approach. Italy.: Materials Science and Chemical Engineering Department. Politecnico di Torino.

[Spoerke 2005] Spoerke E. D., M. N. G., Li H., Brinson L. C., Dunand D. C., Stupp S. I. (2005). A bioactive titanium foam scaffold for bone repair. Acta Biomaterialia, 1 (5), pp. 523-533.

[Stern 1996] Stern K.H. (1996). Metallurgical and Ceramic Protective Coatings. London: Chapman \& Hall.

[Takemoto 2006] Takemoto M.; Fujibayashi S.; Otsuki B.; Matsushita T.; Kokubo T.; Nakamura T. (2006). 3-D analysis of pore structure of porous biomaterials using micro focus X-ray computed tomography. Key-Engineering-Materials, pp. 1095-1098.

[Tarín 1995] Tarin P. (1995). Structural transformations in Ti-6Al-4V alloy. Journal de Physique IV (Colloque), 5 (C2), pp. 317-324.

[Tarín 1999] Tarín P. (Febrero 1999). El titanio y sus aleaciones. ETSIA Madrid.

[Thieme 2001] Thieme M.; Wieters K. P.; Bergner F.; Scharnweber D.; Worch H.; Ndop J.; Kim T. J.; Grill W. (2001). Titanium powder sintering for preparation of a porous functionally graded material destined for orthopaedic implants. Journal of Materials Science: Materials in Medicine, 12 (3), pp. 225231.

[Tsui 1998] Tsui Y.C., Clyne T.W. (1998). Plasma sprayed hydroxyapatite coatings on titanium substrates. Part 2: Optimisation of coatings properties. Biomaterials, 19, pp. 2031-2043. 
[UNE-EN ISO 14602] UNE-EN ISO 14602:1999. Implantes quirúrgicos no activos. Implantes para osteosíntesis. Requisitos particulares. AENOR.

[UNE-EN ISO 14630] UNE-EN ISO 14630:1998. Implantes quirúrgicos no activos. Requisitos generales. AENOR.

[UNE-EN ISO 21534] UNE-EN ISO 21534:2008. Implantes quirúrgicos no activos. Implantes de sustitución articulares. Requisitos particulares. AENOR.

[Upadhyaya 1997] Upadhyaya G.S. (1997). Powder metallurgy technology, Cambridge International Science Publishing.

[Valiente 2005] Valiente J.M.; Arilla E. (2005). Materiales de Construcción: pétreos artificiales, cerámicos y vidrios. UPV.

[Vallet 2000] Vallet Regí M.; Munuera L. (2000). Biomateriales, aquí y ahora, p. 267.

[Van-Gils 2004] Van Gils S.; Mast P.; Stijns E.; Terryn H. (2004). Colour properties of barrier anodic oxide films on aluminium and titanium studied with total reflectance and spectroscopic ellipsometry. Surface and Coatings Technology, 185 (2-3), pp. 303-310.

[Venugopalan 2000] Venugopalan R.; Weimer J.; George M. A.; Lucas L.C. (2000). The effect of nitrogen diffusion hardening on the surface chemistry and scratch resistance of Ti-6Al-4V alloy. Biomaterials, 21 (16), pp. 1669-1677.

[Wang 1998] Wang R.R.; Welsch G.E.; Castro-Cedeno M. (1998). Interfacial Reactions of Cast Titanium with Mold Materials. The international journal of prosthodontics, 11 (1).

[Wehmöller 2004] Wehmöller M.; Weihe S.; Rasche C.; Scherer P.; Eufinger H. (2004). CAD/CAM-prefabricated titanium implants for large skull defects-clinical experience with 166 patients from 1994 to 2000, International Congress series, 1268, pp. 667-672.

[Wen 2001] Wen C. E.; Mabuchi M.; Yamada Y.; Shimojima K.; Chino Y.; Asahina T. (2001). Processing of biocompatible porous Ti and Mg. Scripta Materialia, 45 (10), pp. 1147-1153.

[Wen 2002 a] Wen C.E.; Yamada Y.; Shimojima K.; Chino Y.; Asahina T.; Mabuchi M. (2002) Processing and mechanical properties of autogenous titanium implant materials. Journal of Materials Science: Materials in Medicine, 13, pp. 397-401.

[Wen 2002 b] Wen C. E.; Yamada Y.; Shimojima K.; Chino Y.; Hosokawa H.; Mabuchi M., (2002) Novel titanium foam for bone tissue engineering. Journal of Materials Research, 17 (10), pp. $2633-2639$. 
[Wosche 1995] Wosche E.; Feldhaus S.; Gamm T. (1995). Rapid solidification of steel droplets in the Plasma-RotatingElectrode-Process. ISIJ International, 35 (6), p. 76477.

[Xuanyong 2004] Xuanyong L.; Chub P.K.; Dinga C., (2004) Surface modification of titanium, titanium alloys, and related materials for biomedical applications, Materials Science and Engineering R, 47, pp. 49-121.

[Yokoyama 2002] Yokoyama K.; Ichikawa T.; Murakami H.; Miyamoto Y. (2002). Fracture mechanisms of retrieved titanium screw thread in dental implant. Biomaterials, 23 (12), pp. 24592465.

[Ysander 2001] Ysander M. (2001). Intramedullary osseointegration: Development of a rodent model and study of histology and neuropeptide changes around titanium implants, Journal of Rehabilitation Research and Development, 38 (2), pp. 183190.

[Zardiackas 2001] Zardiackas L.D.; Parsell D.E.; Dillon L.D.; Mitchell D.W.; Nunnery L.A.; PoggieR. (2001). Structure, metallurgy, and mechanical properties of a porous tantalum foam. Journal of Biomedical Materials Research, 58 (2), pp. 180-187.

[Zhang 2009] Zhang E. (2009). Porous titanium and silicon-substituted hydroxyapatite biomodification prepared by a biomimetic process: Characterization and in vivo evaluation. Acta Biomaterialia, 5 (5), p. 1732.

[Zhu 2007] Zhu K.; Li C.; Zhu Z.; Liu C. (2007). Measurement of the dynamic Young's modulus of porous titanium and Ti6Al4V. Journal of Materials Science, 42 (17), pp. 7348-7353. 


\subsection{WEBS CONSULTADAS.}

- Zimmer: www.Zimmer.com, Marzo 2009

- Biomet: www.biomet.co.uk, www.biomet.es, Marzo 2009

- Stryker stryker: www.stryker.com, www.iberica.stryker, Abril 2009

- Wright Medical Technology: www.wmt.com, Abril 2009

- Online Materials Information Resource: Matweb.com Febrero 2009

- Titanium Metal Corporation: Timet. Com, Febrero 2009

- LAFITT S.A. : lafitt.es, Abril 2009

- Diagrama de Ellingham interactivo de la Universidad de Cambridge, consulta

27 Marzo 2009: www.doitpoms.ac.uk/tlplib/ellingham diagrams/interactive.php. 



\section{ANEXO 1}

Microestructura de las piezas porosas desarrolladas por sinterización de microesferas y tras los tratamientos térmicos realizados. 

Las siguientes tablas muestran la microestructura, tanto de microesferas sinterizadas sin aplicación de tratamiento térmico, como de las muestras sobre las que se aplicaron los tratamientos B1, B2, BT, S1, S2 y ST.

Pese a que los diferentes comentarios se han realizado tanto al discutir las micrografías de las piezas porosas obtenidas por sinterización de microesferas, como en los resultados obtenidos en el dilatómetro y aplicación de tratamientos térmicos, se resumen a continuación los aspectos más destacables. Así:

- La microestructura resultante en todos los procesos de enfriamiento lento, es decir, tras la sinterización y en todos los tratamientos realizados a excepción de los del dilatómetro con enfriamiento rápido, es de tipo Widmanstätten. Esta estructura se compone de gruesas placas de fase $\alpha$ y finas placas de fase $\beta$, unidas formando paquetes o colonias.

- La microestructura obtenida en los tratamientos realizados en el dilatómetro con enfriamiento rápido es de tipo martensítica, generada por transformación sin difusión desde la fase $\beta$.

- En la microestructura de las piezas sinterizadas, sin aplicación de tratamiento térmico, se produce un engrosamiento de grano con la temperatura y/o tiempo e sinterización.

- Los cuellos de unión siempre se forman en fase a (clara).

- En los tratamientos realizados con enfriamiento lento siempre se origina un engrosamiento de grano en relación al de la pieza sinterizada. 


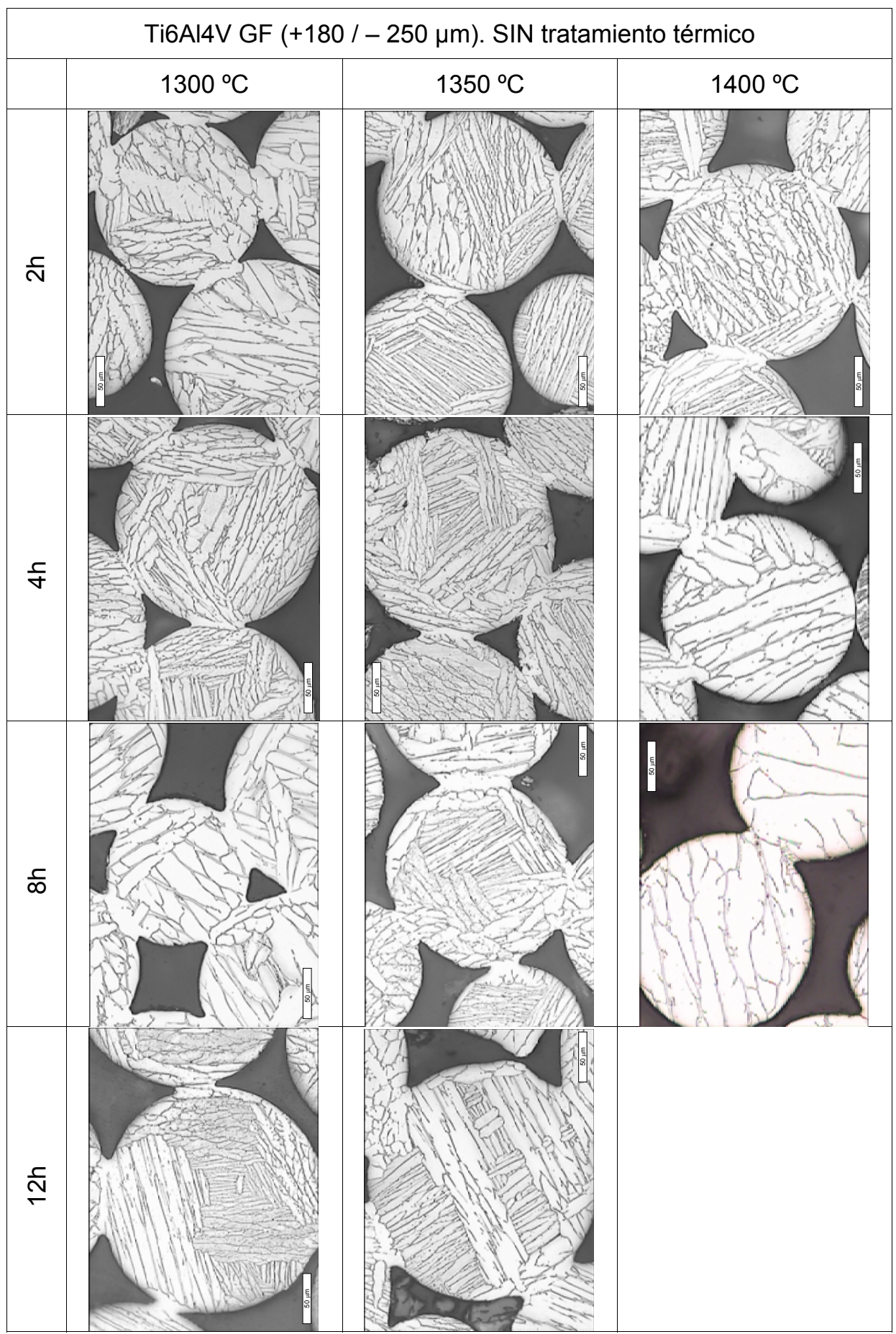




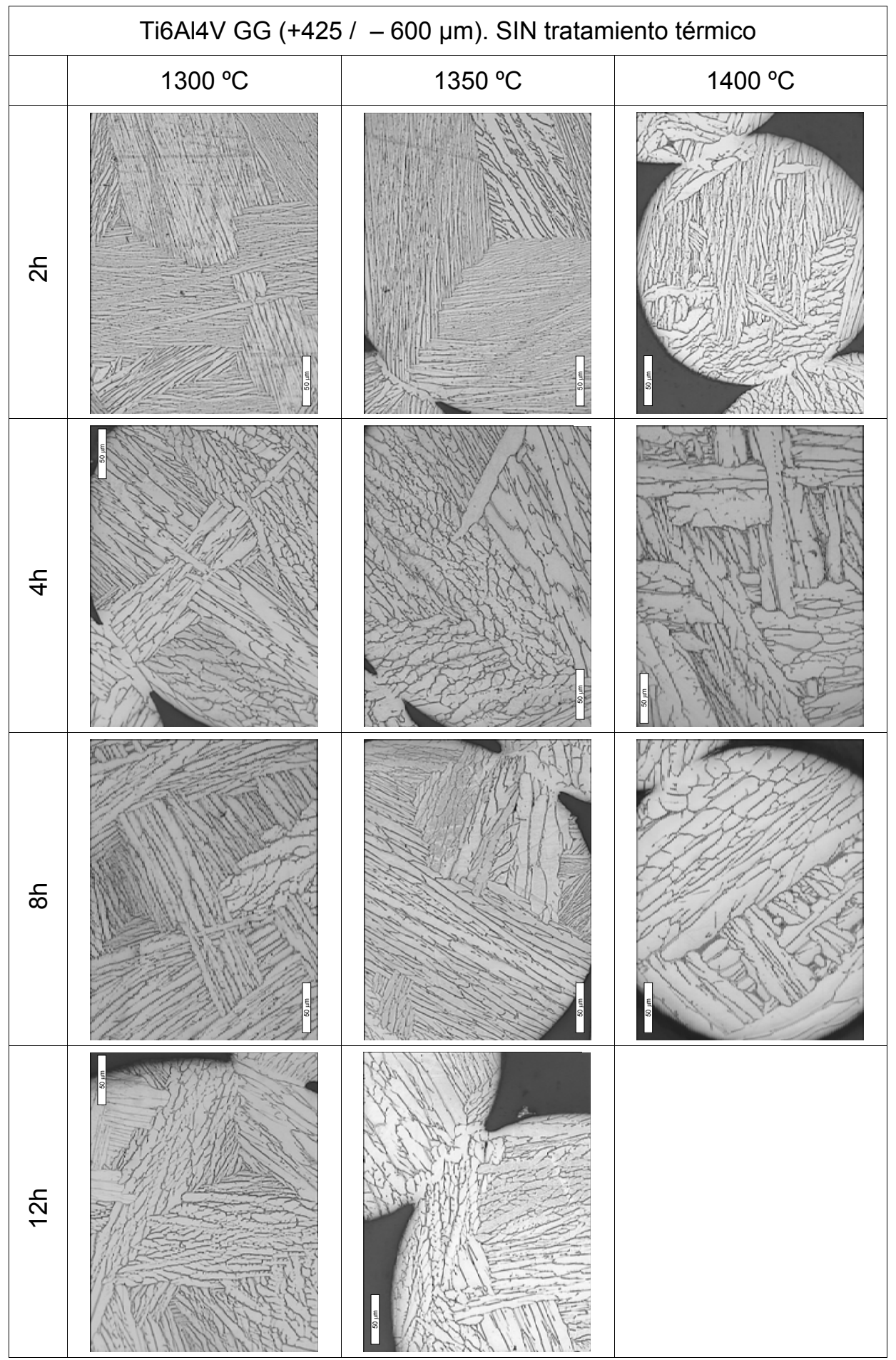




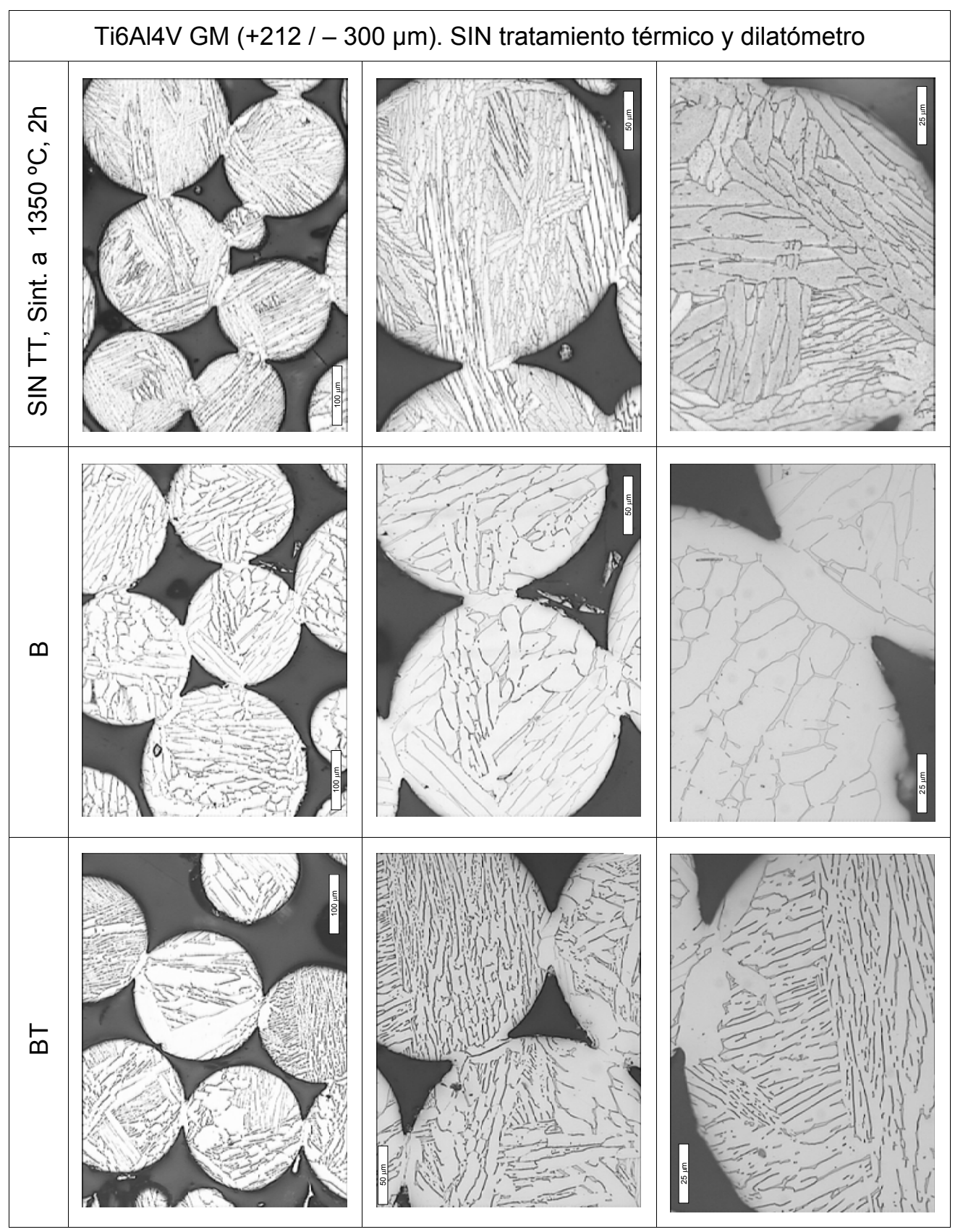




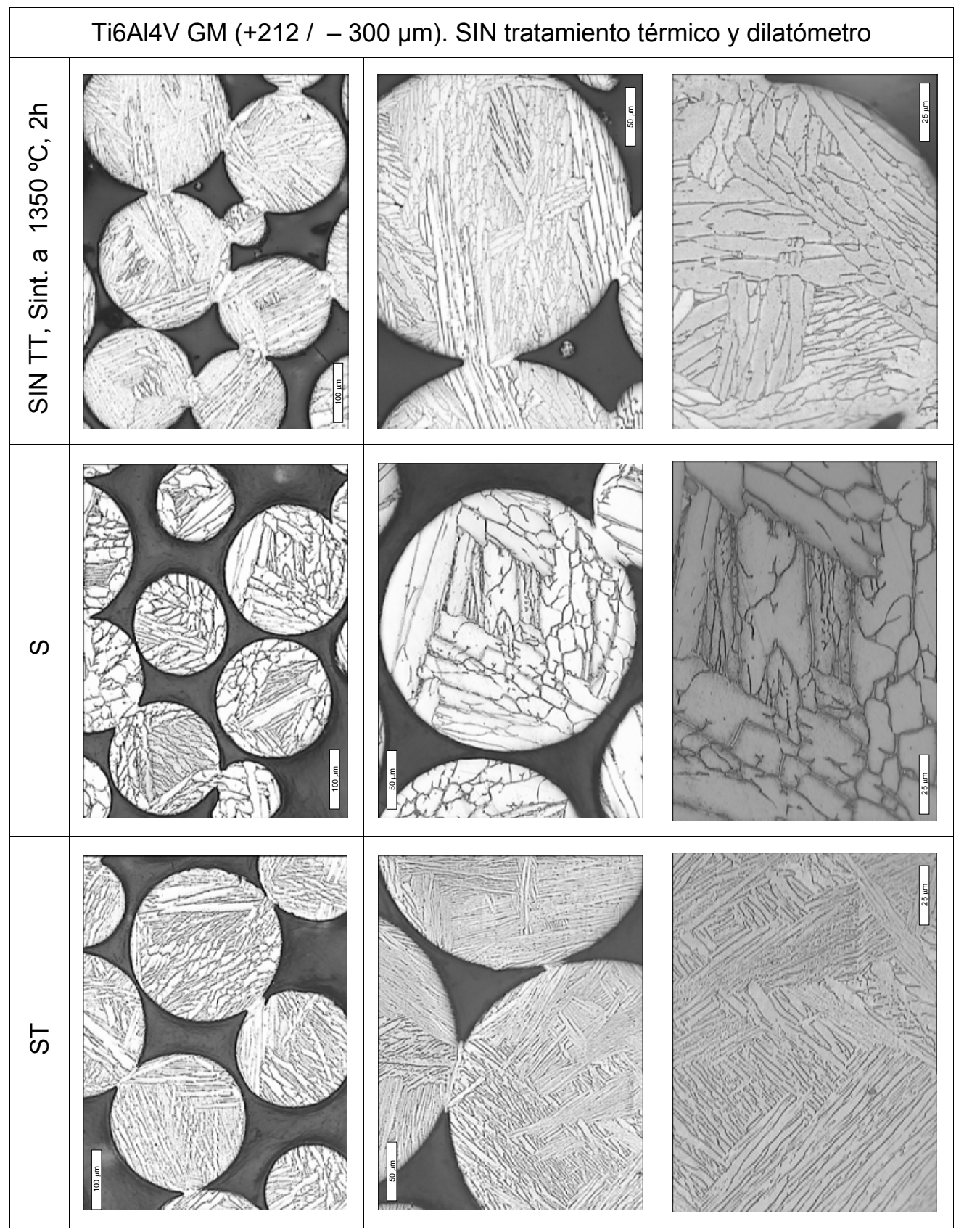




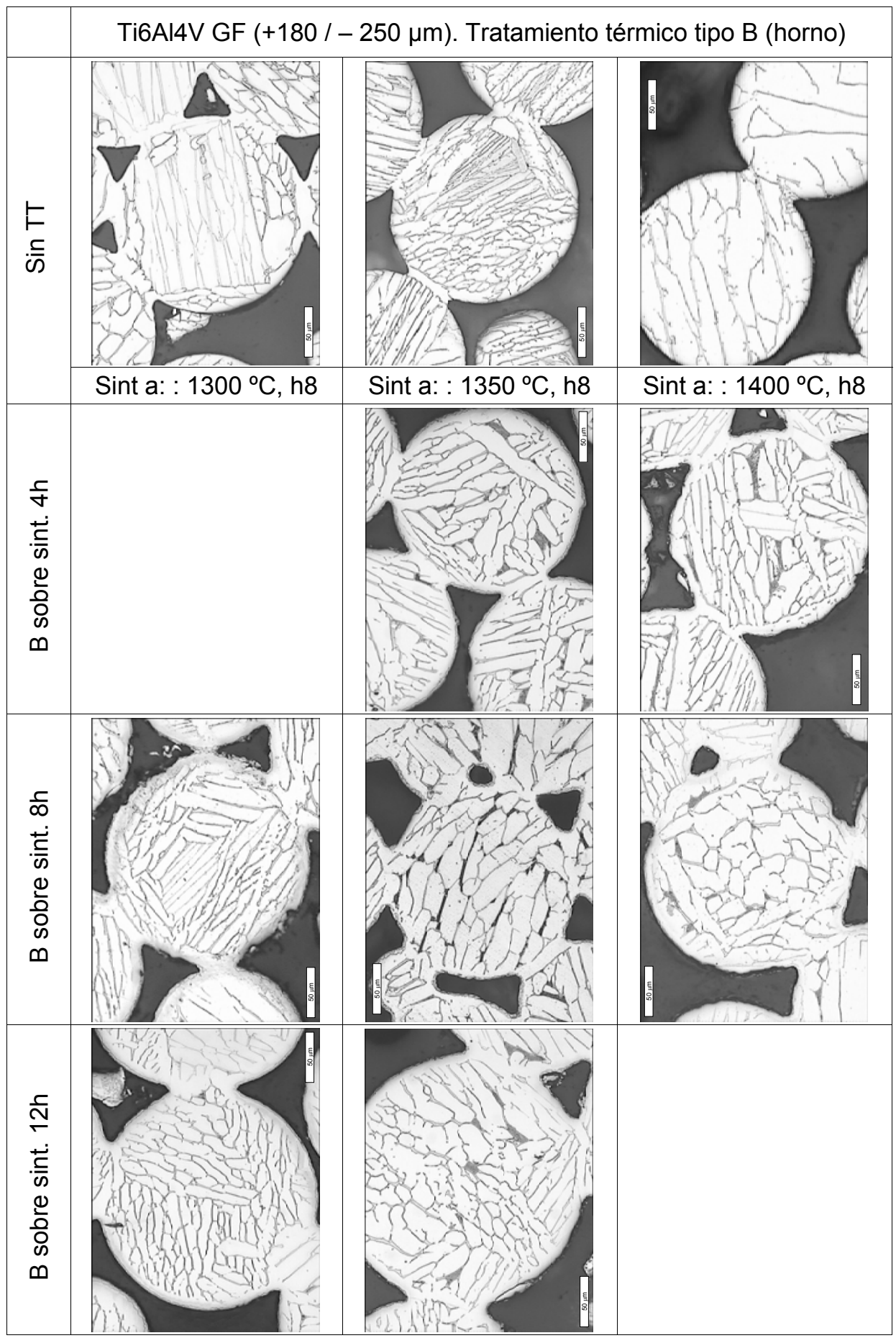




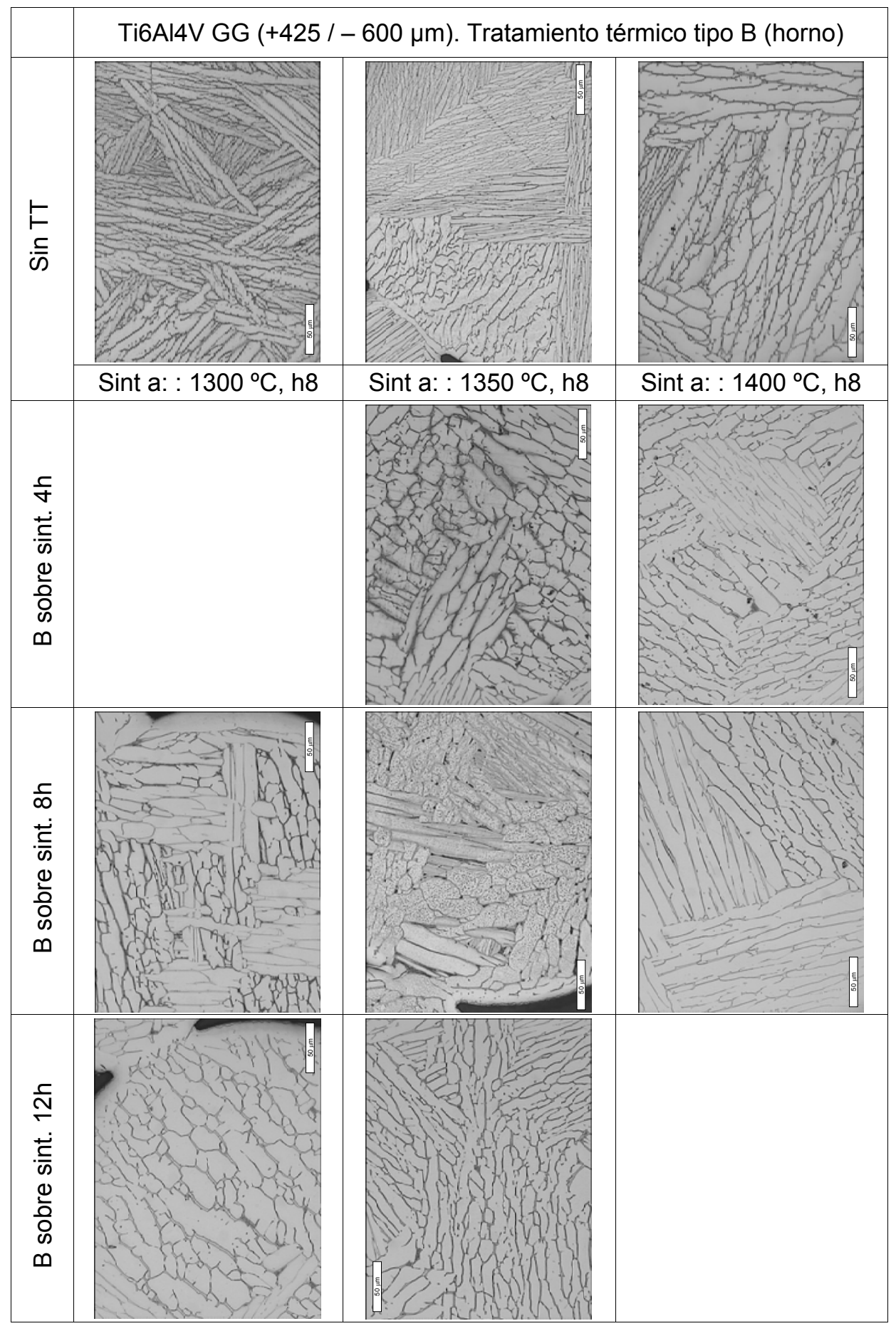




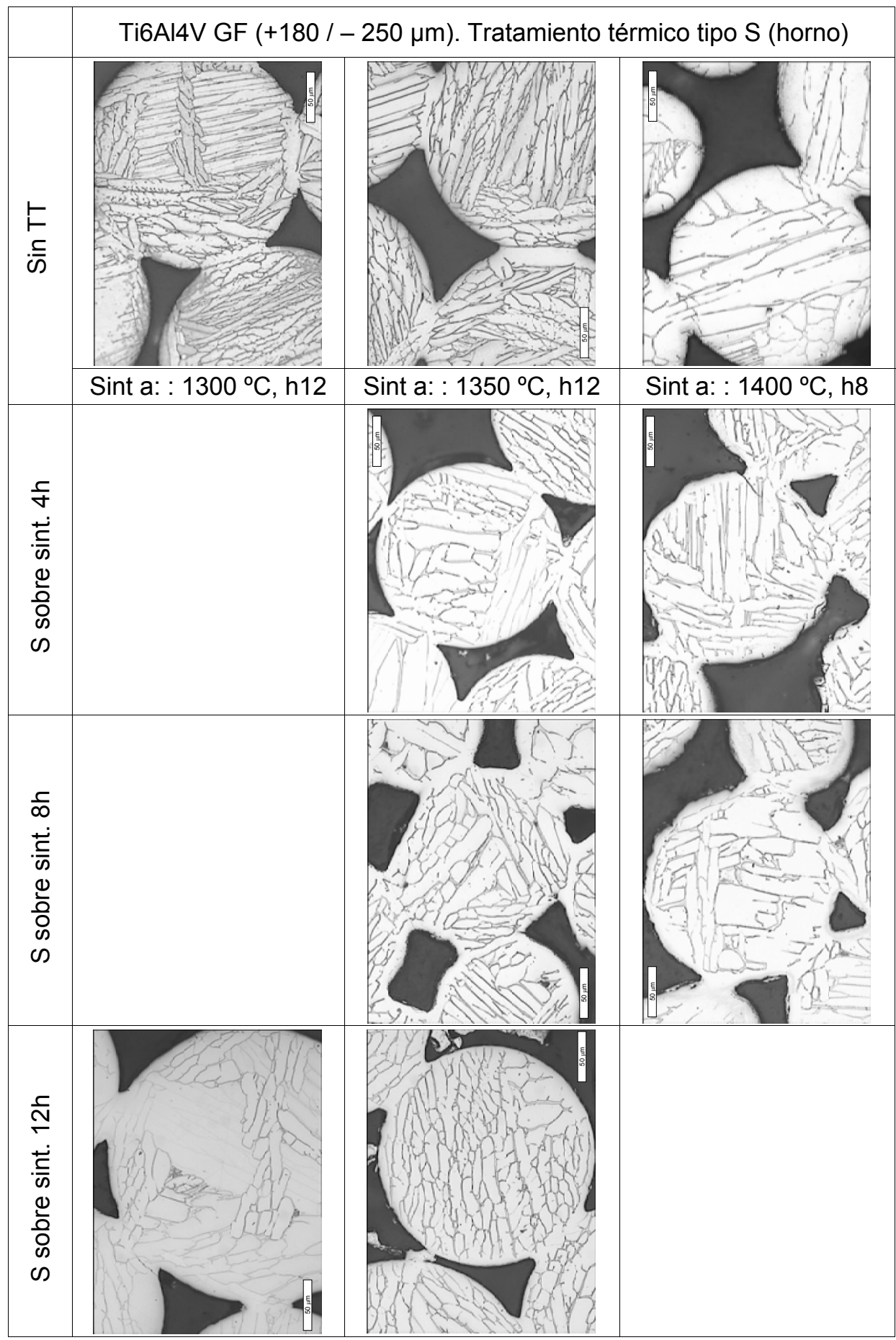




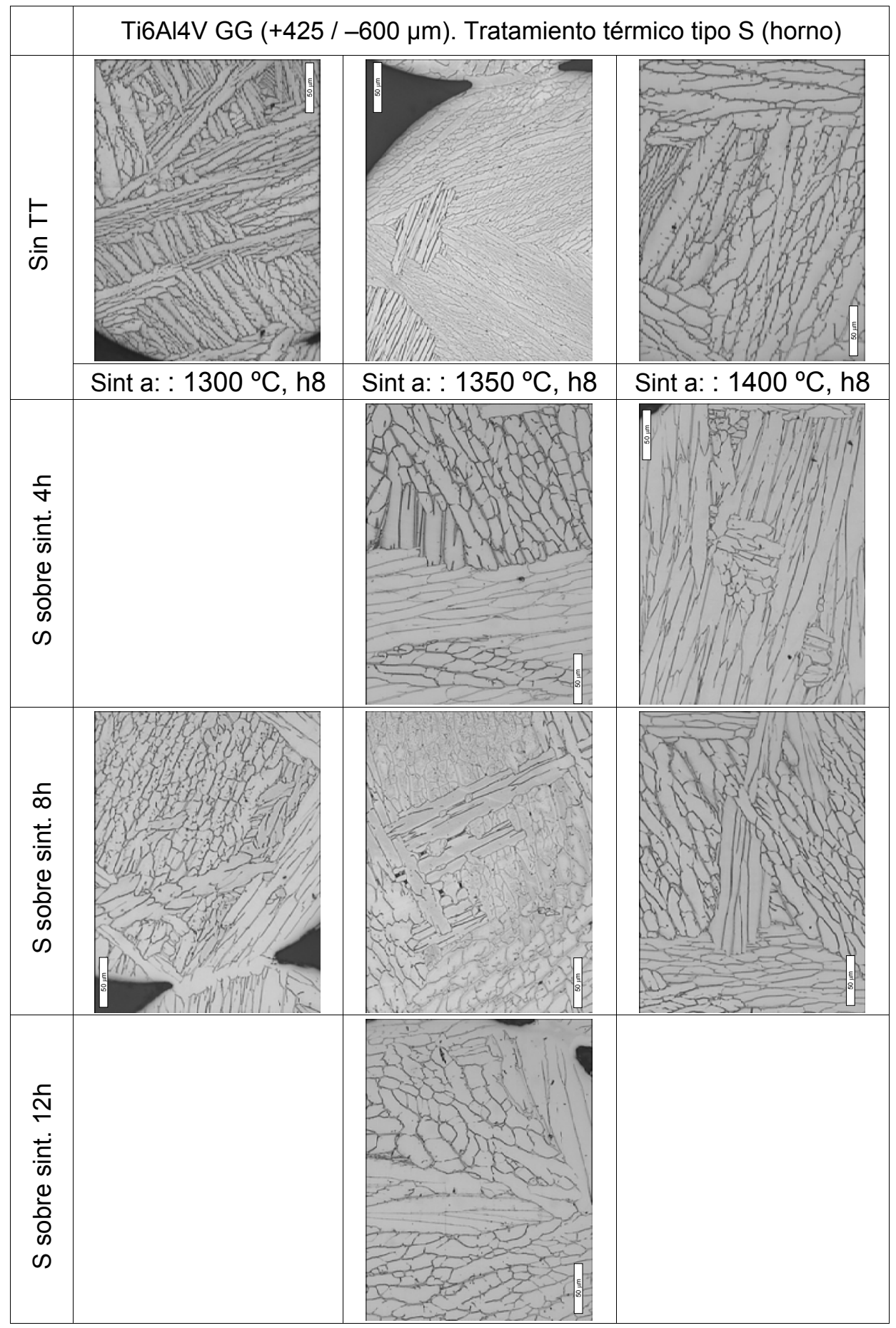





\section{ANEXO 2}

Publicaciones derivadas de la presente tesis 

Se muestra a continuación el listado de publicaciones derivadas de la presente tesis, diferenciando entre publicaciones en revista y contribuciones a congresos:

\section{PUBLICACIONES EN REVISTA}

Autores: V. Amigó, L. Reig, D. J. Busquets, J. L. Ortiz and J. A. Calero

Título: "Analysis of bending strength of porous titanium processed by space holder method".

Revista : Aceptado para publicación en "Powder Metallurgy"

ISSN impreso: 0032-5899;

ISSN on-line: 1743-2901

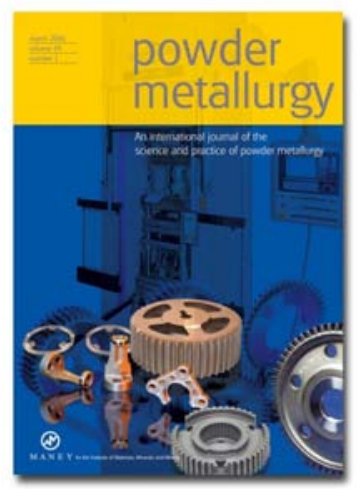

\section{ABSTRACT}

"Porous titanium specimens have been produced by means of the Space Holder Method. Titanium grade 3 (TiCP3) has been used as material and ammonium bicarbonate as spacer. Process parameters (compaction pressure, metal grain size range and spacer volume) influence on porosity morphology and distribution and bending strength has been analysed. The results denote an important loss of strength when comparing samples sintered without and with spacer. On the other hand, a higher bending strength was observed in the porous samples with a smaller size of ammonium bicarbonate particles. Finally, the evolution of bending strength with the compaction pressure depends on the spacer volume, having a direct dependency for reduced amounts and inverse for higher contents". 
Autores: Felton R.; Imgrund Ph.; Petzoldt F.; Friederici V.; Busquets-Mataix D.; Reig L.; Amigó V.; Calero J.A.,

Título: "PM companies eye a new future of taking medicine".

Revista : Metal Powder Report

ISSN: 0026-0657

Volumen: $64, N^{\circ} 3 . \quad$ Páginas, inicial:12 Final:17

Fecha: 2009

Publicación: ELSEVIER

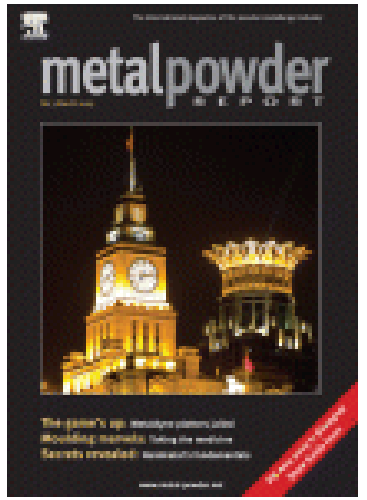

\section{THE AUTHORS}

"The research-related elements of this feature were drawn from two papers given at Euro PM2008 in Mannheim, Germany. The first was Micro-MIM for Medical Applications, by Ph Imgrund, F Petzoldt, and V Friederici, from the Fraunhofer Institute for Manufacturing and Advanced Material (IFAM) in Germany. The second was Fabrication of Ti-6Al-4V porous scaffolds by sintering of spherical powder beads, by D Busquets-Mataix, L Reig, V Amigó, and J A Calero". 


\title{
CONTRIBUCIONES A CONGRESOS
}

Ponencia en el "EURO PM 2009"

Autores: L Reig, D. Busquets-Mataix, V. Amigó, J.A. Calero

Título: "Ti6Al4V porous scaffolds by sintering of spherical powder beads: influence of porosity on stiffness".

Publicación: EURO PM 2009 Proceedings (v. 2), European Powder Metallurgy Association

ISBN10: 1899072071 ISBN13: 978-1899072071, Fecha Publicación: Oct 2009 Lugar celebración: Bella Center (Copenague), Dinamarca

Fecha: 12 - 14 Octubre 2009

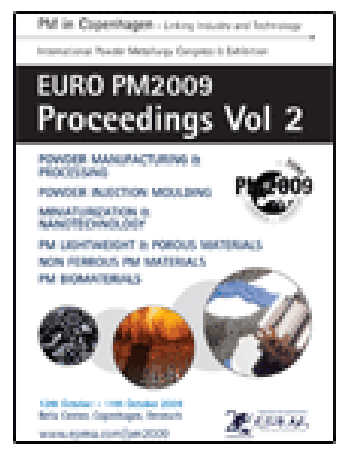

\begin{abstract}
"Porous materials are used biomedics for bone integration and replacement. In reason of this application, pore size, shape and connectivity modified in order to enhance tissue in-growth. Also, porosity influences mechanical strength and stiffness, this last parameter being also critical to avoid the so called "stress shielding" effect on the bone due to too stiff implants, leading to bone resorption. In this work, different Ti-6Al-4V porous scaffolds have been produced by vacuum sintering from spherical powders of selected size. The influence of porosity on stiffness of the implant has been analysed".
\end{abstract}


Ponencia en el "International Conference on Sintering 2008"

Autores: L Reig, V. Amigó, D. Busquets, M.D. Salvador, J.A. Calero

Título: "Analysis of sintering of titanium porous material processed by the space holder method".

Publicación: Aceptado para publicación en el ACerS International Conference on Sintering 2008.

Lugar celebración: La Jolla (San Diego), California

Fecha: 16 - 20 Noviembre 2008

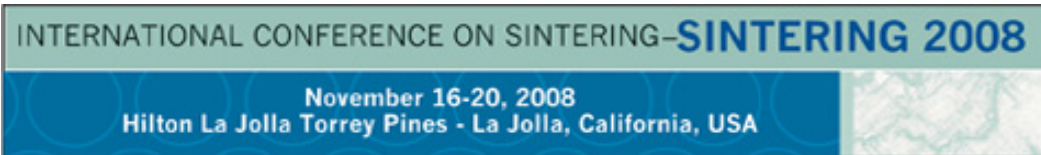

\begin{abstract}
"In this work the sintering behaviour of Ti-6Al-4V titanium alloy porous materials prepared by the space holder (SH) method have been analysed in terms of mechanical properties and microstructural characterisation. The porous materials were processed under vacuum and different sintering cycles were analysed. Other variables studied were space holder size fraction and content, and compaction pressure. The influence of these factors on bending strength was analysed. Microstructural observation was carried out by means of optical and electron microscopy in order to correlate microstructure to the observed mechanical behaviour. Results showed that different processing conditions were to be used for different $\mathrm{SH}$ content to obtain better properties. Furthermore, minimising the contact time between alloy powders and space holder resulted to be a critical point in the processing of these materials".
\end{abstract}


Ponencia en el "EURO PM 2008"

Autores: D. Busquets-Mataix, L. Reig, V. Amigó, J.A. Calero

Título: "Fabrication of Ti-6Al-4V porous scaffolds by sintering of spherical powder beads".

Publicación: EURO PM 2008 Proceedings (v. 2), European Powder Metallurgy Association

ISBN10: 1899072047 ISBN13: 9781899072040, Fecha Publicación: 24 Sep 2008

Lugar celebración: Mannheim, Alemania

Fecha: 29 Septiembre - 1 Octubre 2008

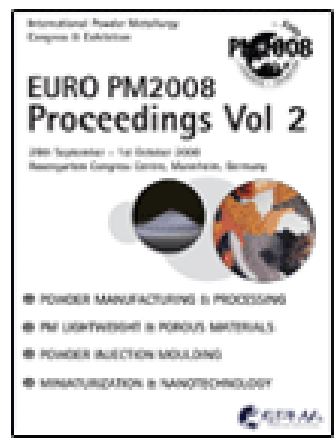

\section{ABSTRACT}

"One of the most important application areas of porous materials is bioengineering. For this application, together with the appropriate material, the fabrication of a scaffold with defined and controlled pore size, shape and connectivity is of paramount importance for the proper tissue in-growth and development, for instance in bone replacement. In this work, different Ti-6Al-4V porous scaffolds have been produced by vacuum sintering departing from spherical powders of selected size. Microstructural features found have been correlated to mechanical properties in order to analyse the suitability of such materials in biomedical applications. The best combination of powder beads and sintering parameters has been determined". 
Ponencia en el "XVII internacional Material Research Congress".

Autores: Ortiz Rosales J.L., Ruiz Avilés J.J., Zaragoza Ayala A.E., Amigó Borras V., Reig Cerdá L.

Título: "Comportamiento a la corrosión de aleaciones Ti-6Al-4V".

Lugar celebración: Cancún, México Fecha: 17-21 Agosto 2008

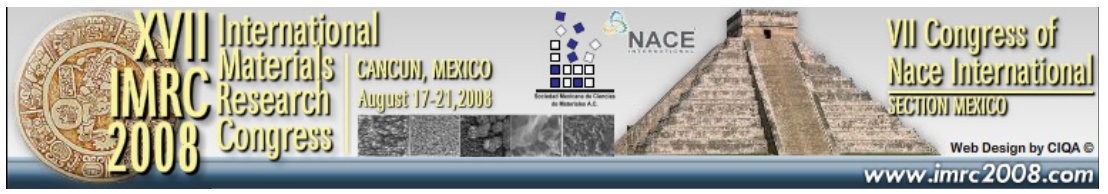

\section{ABSTRACT}

"The corrosion behavior of Ti-6Al-4V alloys manufactured by powder metallurgy with different degrees of porosity and manufacture variables were studied in Ringer's solution at $37^{\circ} \mathrm{C}$ by electrochemical techniques. Potentiodynamic and potentiostatic tests showed that corrosion rate increases as the porosity increases. However not found localized corrosion in any alloy.

Ponencia en el "Il Congreso Nacional de PM".

Autores: V. Amigó, Reig L., Busquets D., Calero J.A.

Título: "Propiedades Mecánicas de Piezas Porosas de Ti6Al4V obtenidas mediante sinterización de microesferas".

Lugar celebración: San Sebastián $\quad$ Fecha: 13-15 Julio 2008

\section{RESUMEN}

"Debido a sus propiedades, las aleaciones de titanio han sido ampliamente utilizadas en el campo de la biomedicina, empleándose en aplicaciones tan diversas como sistemas de fijación y osteosíntesis, prótesis ortopédicas, implantes dentales, marcapasos o implantes craneales.

Entre los diferentes materiales metálicos utilizados como implantes, las aleaciones de titanio ofrecen una mejor combinación de propiedades: resistencia mecánica, tenacidad, módulo de Young y resistencia a la corrosión. A pesar de ello, su rigidez resulta elevada en comparación con la del hueso humano, lo que puede conllevar problemas de debilitación ósea. A lo largo de los últimos años, se han desarrollado diversos métodos con el objetivo de resolver la problemática, entre ellos, la sinterización de microesferas, el método de espaciadores, sinterización por láser, etc. 
En el presente trabajo se han fabricado piezas porosas de la aleación Ti6Al4V mediante sinterización de microesferas, evaluando la influencia de los parámetros del proceso (tiempo, temperatura de sinterización y molde empleado), sobre las propiedades mecánicas de las piezas obtenidas. Los resultados denotan una fuerte influencia del tipo de molde utilizado, observándose únicamente una evolución directa de la resistencia flexión con la temperatura y tiempo de sinterización al sinterizar en moldes de ytria".

Póster en el "Euromat 2007".

Autores: V. Amigó, Reig L., Busquets D., Calero J.A.

Título: "Mold Contamination Influence in Titanium Porous Materials".

Lugar de celebración: Nuremberg, Alemania

Fecha: Septiembre 2007

\section{ABSTRACT}

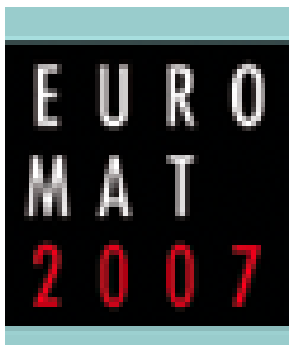

"Titanium and its alloys have expanded their applications in biomaterials field in the last years. In fact, they are used in a wide number of applications, like fixation and osteosynthesis systems, orthopaedic prostheses, dental implants, and other components like pacemaker cases or cranial implants.

Among the different metallic materials used as implants, titanium alloys are the most used because of the combination of some of their properties, i.e. mechanical resistence, toughness, young modulus and corrosion resistance. Despite of all this, their stiffness remains relatively high, creating in most cases a great mismatch between that of the implant and the human bone. One way of reducing the stiffness in the implants and also favouring the osteointegration is the fabrication of porous components by different methods as by sinterization of microspheres, the use of space holders or foaming. These subjects have been important object of research nowadays and because so, the objective of this study.

In the present work mechanical properties of sintered Ti-6Al-4V microspheres have been studied. Samples have been sintered at different temperatures and times, using different mold materials. Sintering temperatures and times have been optimized for the different titanium beads used. Also, a significant influence of the type of mold on the final properties of the components has been observed, due to interactions with titanium at the sintering temperatures used. Best results have been obtained with Yttrium oxide molds". 

